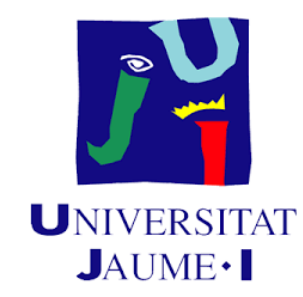

Programa de doctorado en Tecnologías Industriales, Materiales y edificación

Departamento de Ingeniería Química

\title{
Curvaturas diferidas en piezas de gres porcelánico
}

TESIS DOCTORAL

EMILIE BANNIER

Directores:

Vicent Cantavella Soler y Francisco Javier García Ten

Castellón de la Plana, junio de 2017 

Pour Juan, Marc y Estel.

Pour mes parents.

Pour ma famille.

Je vous aime. 



\section{Agradecimientos}

La realización de esta tesis doctoral hubiese sido imposible sin el apoyo de las instituciones y personas que se mencionan a continuación.

- A las empresas cerámicas y personas que han participado en este trabajo:

- a Arcilla Blanca, S.A. y a Don Francisco Segarra,

- a Azuliber, S.A. y Don Manuel Pintor,

- a Azuvi, S.A. y a Don Cándido Crespo y Francisco Peris,

- a Cerámicas Saloni, S.A y a Don Javier Barberá,

- a Nuevos Productos Cerámicos, S.A. y a Doña Amparo Peris y Don Francisco Sánchez,

- a S.A. Minero Catalana Aragonesa - SAMCA y a Don Daniel Silvestre,

- a Taulell, S.L. y a Don Jaime Sánchez, D. Carles Soler y Don Juan Sales,

- a Zirconio, S.A. y a Don José Antonio Cerisuelo y Don Óscar Climent,

a todas ellas, muchas gracias.

- Al Instituto de Tecnología Cerámica, a la Asociación de Investigación de las Industrias Cerámicas y a la Universitat Jaime I, gracias por poner los medios necesarios para la realización de esta tesis doctoral.

- A todo el personal del ITC que me ha ayudado y apoyado en todo momento. Muchas gracias.

- A Javier Castellano, por los "quenchings" y muchísimo más... mil gracias.

- A mis directores de tesis Vicente Cantavella Soler y Francisco Javier García Ten, gracias por vuestro tiempo, vuestros consejos y vuestro apoyo incondicional. Este trabajo es tanto vuestro con mío. 


\section{Agradecimientos}




\section{Resumen}

Las baldosas cerámicas, independientemente de su porosidad, pueden sufrir "curvaturas diferidas". Este fenómeno consiste en el cambio de curvatura de las baldosas después de su salida del horno durante un periodo de tiempo variable (desde pocas horas hasta varios meses).

La presencia de curvaturas diferidas origina problemas durante la fase de clasificación y sobre la calidad del producto final. Por lo tanto, es esencial entender el origen de este fenómeno para minimizar su impacto a nivel industrial.

En el caso del gres porcelánico, tanto esmaltado como no esmaltado, la curvatura de las baldosas suele mostrar una evolución en un sentido (habitualmente cóncavo) inmediatamente después de su salida del horno para, después de cierto tiempo, invertir esta tendencia. El cambio en la evolución de la curvatura, unido a la muy baja porosidad de las baldosas de gres porcelánico, indica que la causa de este comportamiento es compleja.

En esta tesis doctoral se establecen las causas de las curvaturas en diferido en gres porcelánico. Para ello, se caracterizó el comportamiento de 14 modelos de gres porcelánico industriales frente a las curvaturas diferidas y se estudió la influencia de las variables del proceso sobre las mismas. Asimismo, se propuso un modelo matemático que explica el fenómeno de las curvaturas diferidas.

Los resultados experimentales obtenidos permitieron validar el modelo propuesto para explicar las curvaturas en diferido en baldosas de gres porcelánico. Además, se aportó una solución industrial a este problema al permitir, por una parte, establecer las condiciones de proceso que evitan o reducen las curvaturas diferidas y, por otra parte, adoptar medidas de control efectivas en un entorno industrial. 


\begin{abstract}
Ceramic tiles can suffer changes in their curvature after firing during variable periods of time (from some hours up to several months). This process is known as "delayed curvature" and is observed in most type of tiles independently of their porosity.
\end{abstract}

At industrial level, the existence of delayed curvature lead to problems during the classification step and to a lower product quality. Thus, it is fundamental to understand the origin of this phenomenon with the aim to minimize its impact.

In the case of porcelain tiles, both glazed and unglazed, the curvature initially evolves in a direction (habitually towards concavity) and, after a certain time, this tendency is inverted. This change in the evolution of the curvature, together with the very low porosity of the porcelain stoneware, indicate that the causes of the delayed curvatures are quite complex in this material.

This PhD study establishes the causes of the delayed curvature in porcelain tiles. To achieve this goal, the behavior of 14 industrial models of porcelain stoneware regarding delayed curvature is characterized. Moreover, the influence of the process variables on this phenomenon is studied. Finally, a mathematical model is established, which explains the phenomenon.

The experimental results permit to validate the model which is proposed to explain the delayed curvature in porcelain tiles. Moreover, an industrial solution to the problem is defined as the results allow, from the one hand, to establish process conditions which avoid or reduce the delayed curvature and, for the other hand, to adopt effective control actions in industrial environment. 


\section{Índice}

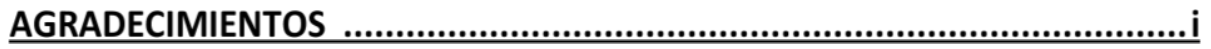

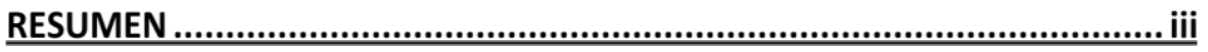

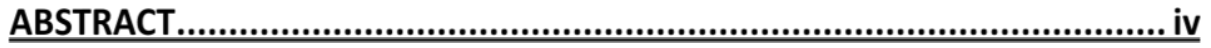

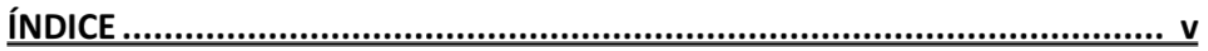

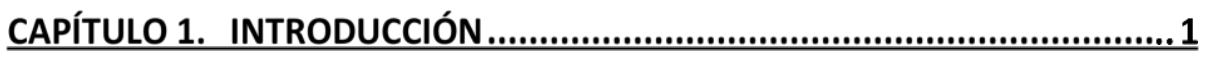

1.1. BALDOSAS CERÁMICAS

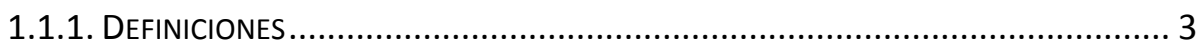

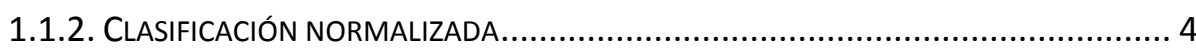

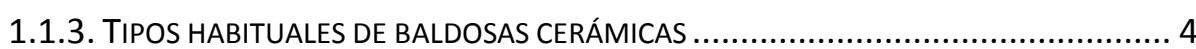

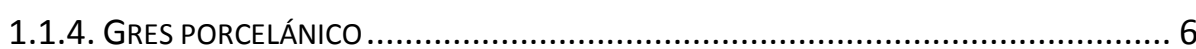

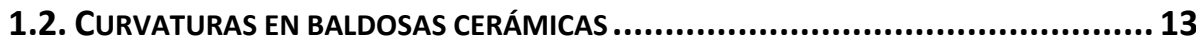

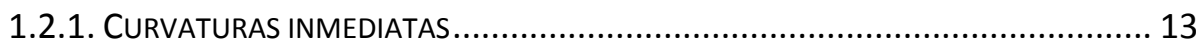

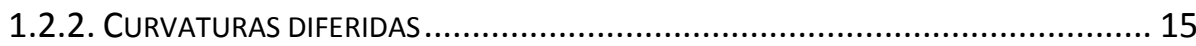

1.3. TENSIONES RESIDUALES EN BALDOSAS CERÁMICAS ...................................16

1.3.1. TENSIONES RESIDUALES DE ORIGEN TÉRMICO .......................................... 16

1.3.2. TENSIONES RESIDUALES POR ACOPLAMIENTO ESMALTE-SOPORTE ................... 18

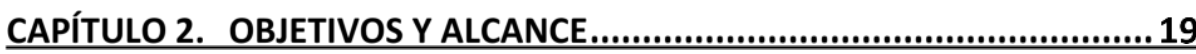

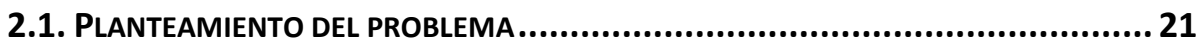

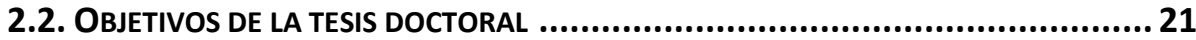

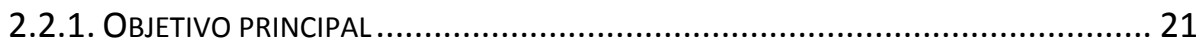

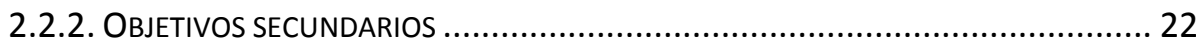


CAPÍTULO 3. MATERIALES, APARATOS Y TÉCNICAS EXPERIMENTALES....23

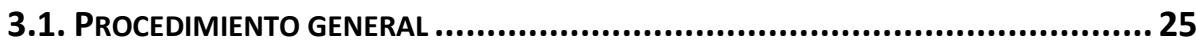

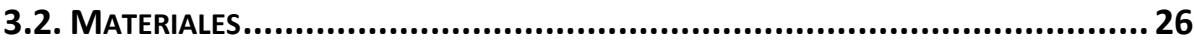

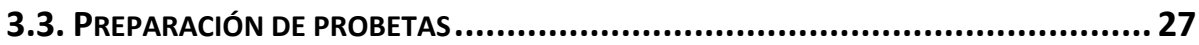

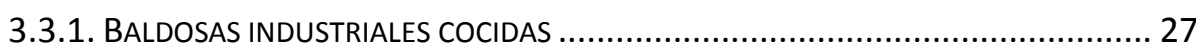

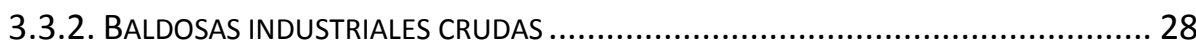

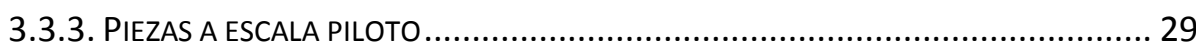

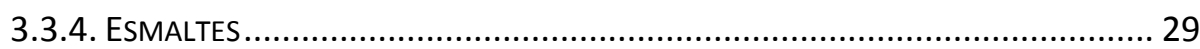

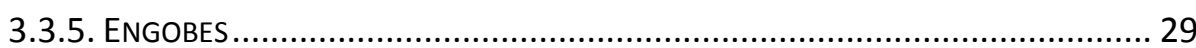

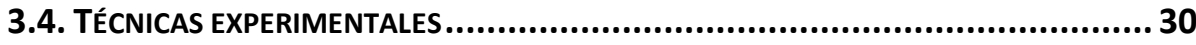

3.4.1. MEDIDA DE LA DENSIDAD APARENTE

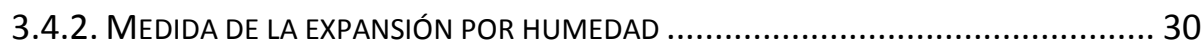

3.4.3. EXPANSIÓN TÉRMICA (CURVAS DILATOMÉTRICAS) ............................................ 31

3.4.4. MEDIDA DE LA RESISTENCIA MECÁNICA Y MÓDULO DE ELASTICIDAD ................... 31

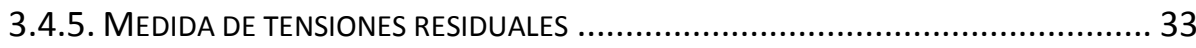

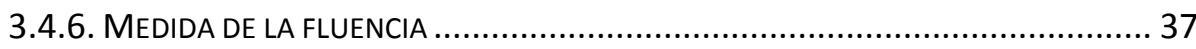

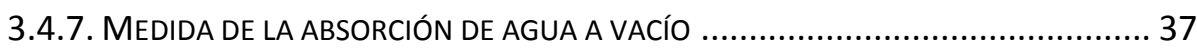

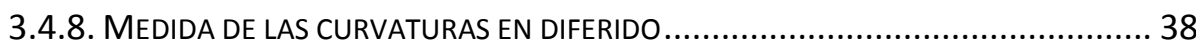

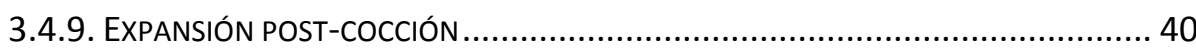

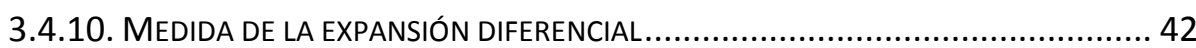

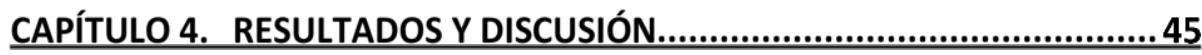

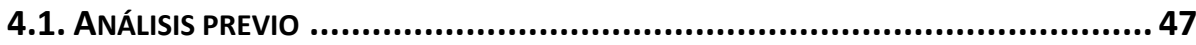

4.1.1. MEDIDA INDUSTRIAL DE LAS CURVATURAS EN DIFERIDO ................................. 47

4.1.2. FACTORES QUE PUEDEN INFLUIR EN LAS CURVATURAS EN DIFERIDO.................... 49

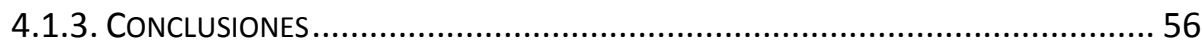

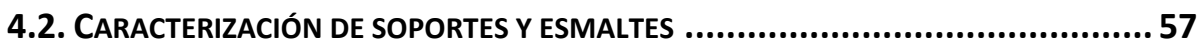

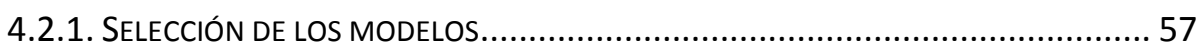

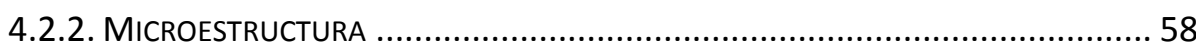

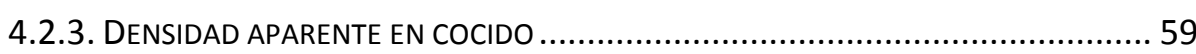

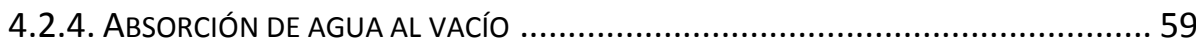

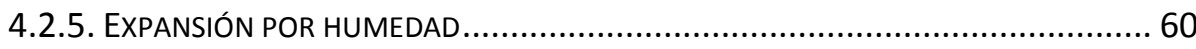

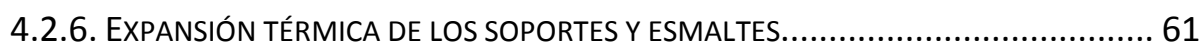

4.2.7. EXPANSIÓN POST-COCCIÓN DE LOS SOPORTES A TEMPERATURA AMBIENTE .........63

4.2.8. COMPORTAMIENTO ELÁSTICO DE LOS SOPORTES Y ESMALTES...........................67

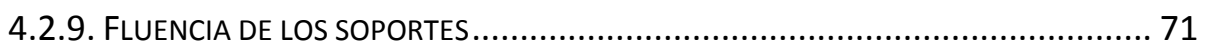

vi 


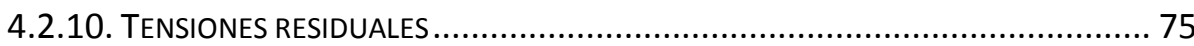

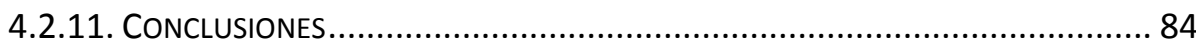

4.3. INFLUENCIA DE VARIABLES SOBRE LAS CURVATURAS EN DIFERIDO_..................86

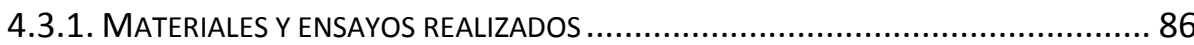

4.3.2. INFLUENCIA DE LA TEMPERATURA MÁXIMA DE COCCIÓN ................................. 86

4.3.3. INFLUENCIA DEL TAMAÑO DE PARTÍCULA (GRADO DE MOLIENDA) .................... 91

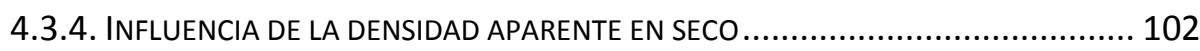

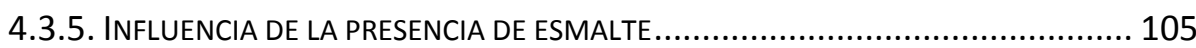

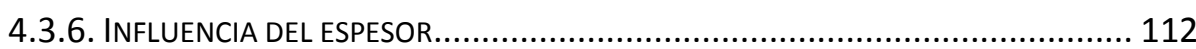

4.3.7. INFLUENCIA DEL TIEMPO DE PERMANENCIA A TEMPERATURA MÁXIMA ............. 120

4.3.8. INFLUENCIA DE LA VELOCIDAD DE ENFRIAMIENTO ...................................... 123

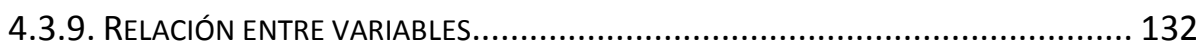

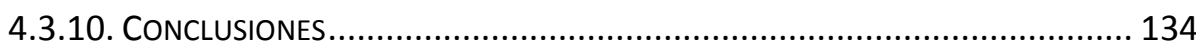

4.4. ModelizaCIÓN DE LAS CURVATURAS EN DIfERIDO .................................... 136

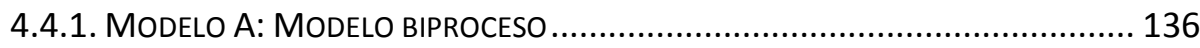

4.4.2. MODELO B: EXPANSIÓN DIFERENCIAL DISCONTINUA ................................... 138

4.4.3. MODELO C: EXPANSIÓN DIFERENCIAL ASOCIADA A UN PROCESO DIFUSIONAL ... 141

4.4.4. MODELO D: EXPANSIÓN DIFERENCIAL CON DIFUSIVIDAD VARIABLE .................. 145

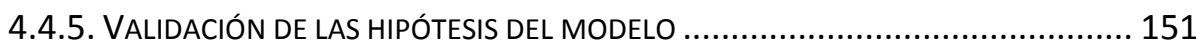

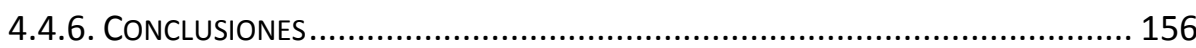

4.5. PROPUESTA DE ENSAYOS DE CONTROL INDUSTRIAL..................................... 158

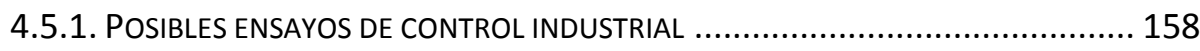

4.5.2. VALIDACIÓN DE LOS ENSAYOS DE CONTROL INDUSTRIAL PROPUESTOS............... 159

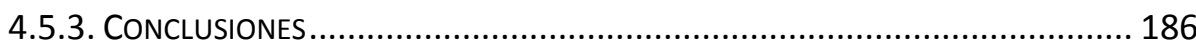

CAPÍTULO 5. CONCLUSIONES Y RECOMENDACIONES ...................... 187

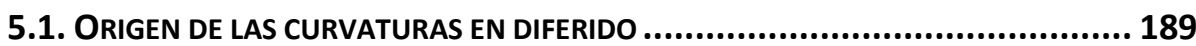

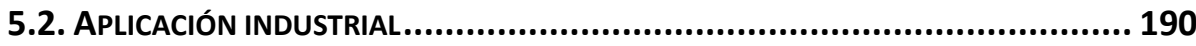

5.2.1. MEDIDAS PARA PREVENIR LAS CURVATURAS EN DIFERIDO.............................. 190

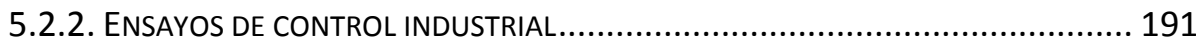

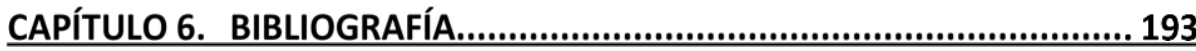

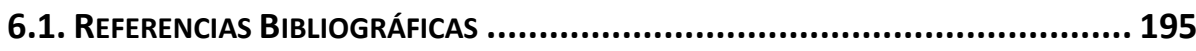

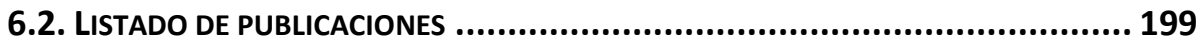

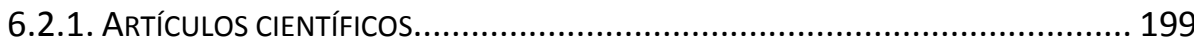

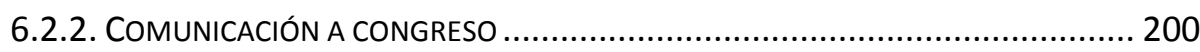


ANEXOS …

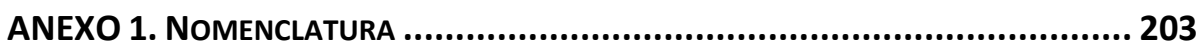

ANEXO 2. MEDIDA DE LAS TENSIONES RESIDUALES DE ACOPLAMIENTO

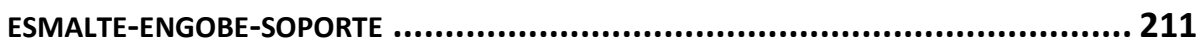

ANEXO 3. MEDIDA DE LAS TENSIONES RESIDUALES POR EL MÉTODO DE RELAJACIÓN DE LA DEFORMACIÓN POR CORTE INCREMENTAL................................................. 217

ANEXO 4. RESOLUCIÓN DE LA ECUACIÓN DE DIFUSIÓN CON COEFICIENTE DE

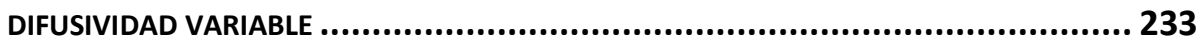

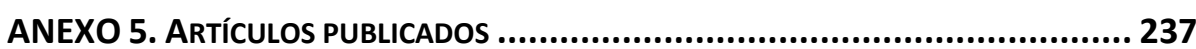




\section{Capítulo 1. Introducción}

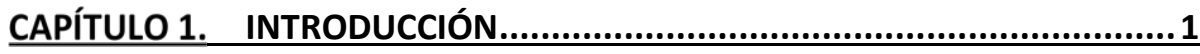

1.1. BALDOSAS CERÁMICAS ........................................................ 3

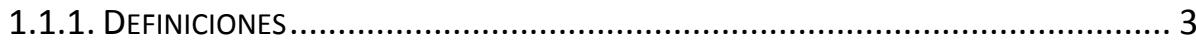

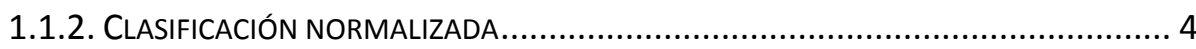

1.1.3. TIPOS HABITUALES DE BALDOSAS CERÁMICAS .......................................... 4

1.1.4. GRES PORCELÁNICO ................................................................. 6

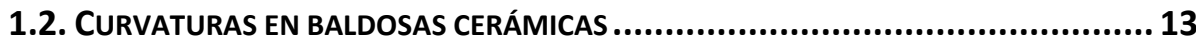

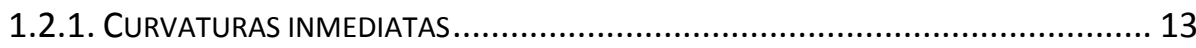

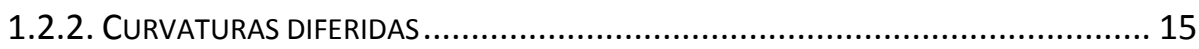

1.3. TENSIONES RESIDUALES EN BALDOSAS CERÁMICAS ............................ 16

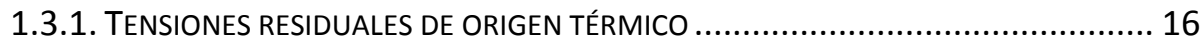

1.3.2. TENSIONES RESIDUALES POR ACOPLAMIENTO ESMALTE-SOPORTE .................... 18 
1. Introducción 


\subsection{BALDOSAS CERÁMICAS}

\subsubsection{Definiciones}

Según las normas [UNE-EN 1441 - ISO 13006], las baldosas cerámicas se definen como placas de poco grosor fabricadas a partir de composiciones de arcillas y otras materias primas inorgánicas.

Las baldosas suelen moldearse por extrusión o por prensado en seco a temperatura ambiente, y seguidamente son secadas y cocidas a temperatura suficiente para adquirir las propiedades requeridas para su uso; es decir el revestimiento de suelos y paredes tanto interiores como exteriores (figura 1.1).

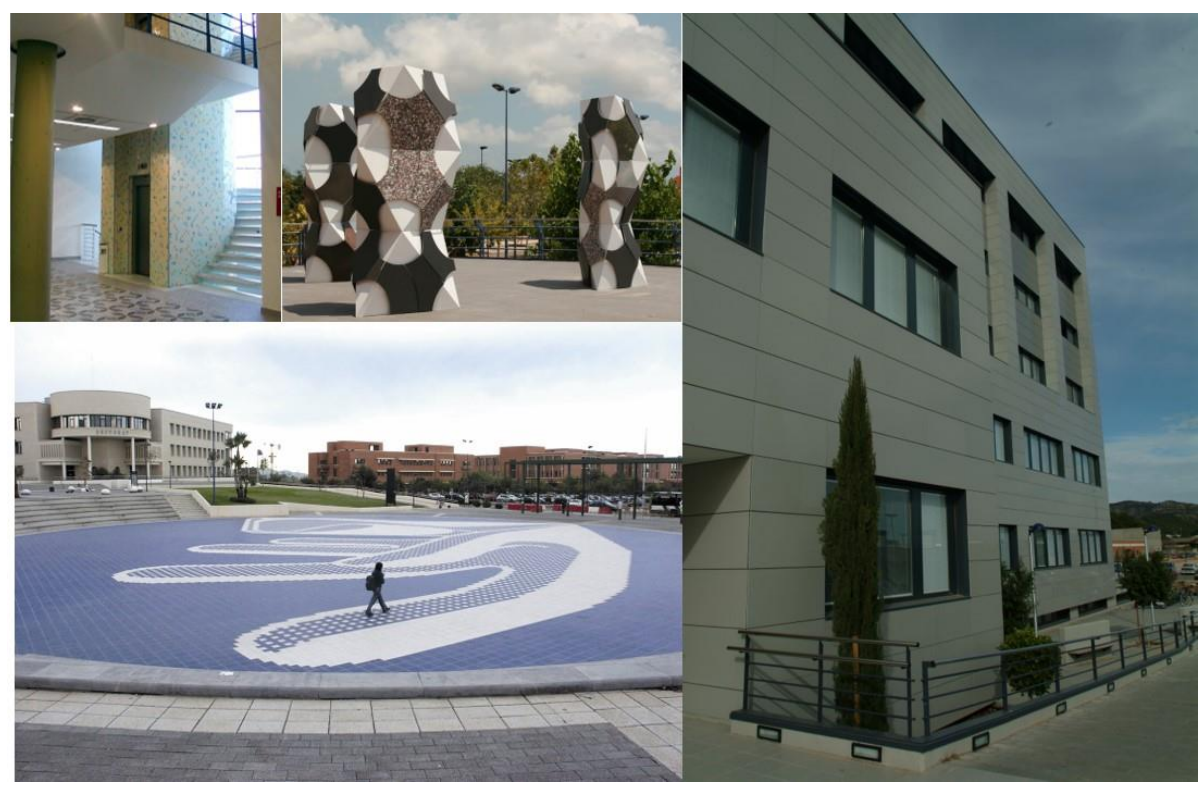

Figura 1.1. Ejemplos de uso de baldosas cerámicas en el campus de Universitat Jaume I de Castellón.

Las baldosas cerámicas pueden ser esmaltadas (GL) o no esmaltadas (UGL) definiéndose el esmalte como "una cubierta vitrificada situada sobre las baldosas cerámicas". También, se puede aplicar una capa de engobe sobre la superficie de la baldosa. El engobe "es una cubierta a base de arcilla con un acabado mate, que puede ser permeable o impermeable". Conviene destacar que una baldosa cuya superficie está recubierta por un engobe se considera "no esmaltada".

Finalmente, la norma UNE EN 14411 define el gres porcelánico como una "baldosa cerámica totalmente vitrificada con absorción de agua igual o menor del $0,5 \% "$. 


\subsubsection{Clasificación normalizada}

La clasificación normalizada de las baldosas cerámicas según las normas anteriores tiene en cuenta principalmente dos criterios (el método de moldeo y el nivel de absorción de agua):

- Grupos de baldosas por el método de moldeo

Las baldosas pueden ser conformadas por extrusión o por prensado en seco. Las baldosas extrudidas forman el grupo A de las normas y las prensadas en seco el grupo B.

- Grupos de baldosas clasificados según la absorción de agua

La absorción de agua es "el porcentaje (en masa) de agua que absorbe una baldosa cerámica", medido según un ensayo normalizado. La absorción de agua está relacionada con la porosidad abierta de la pieza y por lo tanto con algunas propiedades de las baldosas cerámicas.

Un valor de absorción de agua de hasta el $3 \%$ se considera bajo (grupo I) y como muy bajo por debajo del $0,5 \%$ (grupo la). Entre 3\% y $6 \%$, la absorción de agua es media-baja (grupo lla) y media-alta entre $6 \%$ y $10 \%$ (grupo Ilb). Finalmente, la absorción se considera alta por encima del 10\% (grupo III).

La aplicación de los criterios anteriores conduce a la creación de distintos grupos normalizados de baldosas cerámicas, tal y como se detalla en la tabla 1.1.

Tabla 1.1. Grupos normalizados de baldosas cerámicas [UNE-EN 1441].

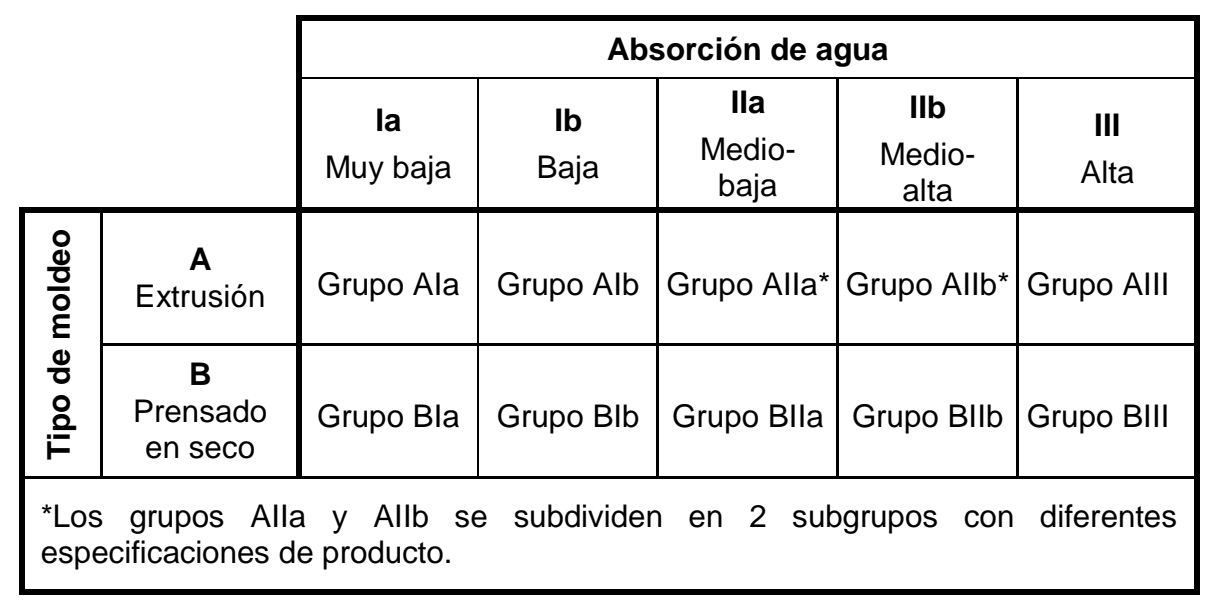

\subsubsection{Tipos habituales de baldosas cerámicas}

Más allá de la utilización de la tipología normalizada, existen unas denominaciones más extendidas de los tipos de baldosas cerámicas basadas principalmente en criterios técnicos y comerciales. Esta tipología viene resumida en la tabla 1.2 [IVE, 2011]. 
Tabla 1.2. Tipos de baldosas cerámicas usuales en España [IVE, 2011].

\begin{tabular}{|l|c|c|c|c|c|}
\hline Tipo & Moldeo & Soporte & Esmalte & $\begin{array}{c}\text { Medidas } \\
\text { habituales (cm) }\end{array}$ & $\begin{array}{c}\text { Grupo } \\
\text { UNE EN } \\
\mathbf{1 4 4 1 1}\end{array}$ \\
\hline Azulejo & Prensado & Poroso & Sí & $10 \times 10$ a $45 \times 60$ & BIII \\
\hline $\begin{array}{l}\text { Gres } \\
\text { esmaltado }\end{array}$ & Prensado & No poroso & Sí & $10 \times 10$ a $60 \times 60$ & Blb-Blla \\
\hline $\begin{array}{l}\text { Gres } \\
\text { Porcelánico }\end{array}$ & $\begin{array}{l}\text { Prensado } \\
\text { Extrudido }\end{array}$ & No poroso & Sí/No & $15 \times 15$ a $60 \times 120$ & Bla-Ala \\
\hline $\begin{array}{l}\text { Baldosín } \\
\text { catalán }\end{array}$ & Extrudido & $\begin{array}{c}\text { Poroso o } \\
\text { ligeramente } \\
\text { poroso }\end{array}$ & No & $13 \times 13$ a $24 \times 40$ & Allb-Alll \\
\hline Gres rústico & Extrudido & No poroso & Sí/No & $11,5 \times 11,5$ a 45x45 & Alb-Alla \\
\hline Barro cocido & Extrudido & Poroso & No & Gran variedad & Allb-Alll \\
\hline
\end{tabular}

- Azulejo

Es el nombre tradicionalmente dado a las baldosas cerámicas con absorción de agua alta, conformadas por prensado en seco y esmaltadas. Debido a sus características, los azulejos se utilizan para revestir paredes interiores.

\section{- Pavimento de gres esmaltado}

Son baldosas cerámicas de absorción de agua baja o media-baja, prensadas en seco y esmaltadas.

Las baldosas de gres esmaltado son adecuadas para su uso en suelos interiores en locales residenciales o comerciales. Asimismo, aquellos pavimentos de gres que reúnen las características pertinentes (resistencia a la helada y alta resistencia a la abrasión, entre otras) pueden ser utilizados para revestir suelos exteriores o fachadas.

- Gres porcelánico

Es la denominación habitual de las baldosas cerámicas con muy baja absorción de agua. Las características de las baldosas de gres porcelánico las hace adecuadas para múltiples usos como: suelos interiores en edificación residencial, comercial e incluso industrial, revestimientos de paredes interiores y uso en suelos exteriores y fachadas. Al ser el objeto de esta tesis doctoral, sus características se detallan en el apartado 1.1.4.

\section{- Baldosín catalán}

Esta denominación corresponde a baldosas con absorción de agua desde media-alta a alta (o incluso muy alta), extrudidas y generalmente no 
esmaltadas. Su uso es limitado a terrazas, balcones y porches de viviendas.

\section{- Gres rústico}

Es el nombre dado a las baldosas cerámicas con absorción de agua baja o media-baja y conformadas por extrusión. Suelen ser no esmaltadas.

El gres rústico es especialmente adecuado para revestimientos exteriores (fachadas y suelos) y para suelos de locales públicos y suelos industriales.

\section{- Barro cocido}

Es la denominación común de una gran variedad de baldosas que presentan una alta absorción de agua. Las baldosas de barro cocido suelen fabricarse de forma artesanal conduciendo a una apariencia rústica con un color térreo no uniforme que depende de las arcillas utilizadas y de la cocción. Sus características las hacen especial y casi exclusivamente adecuadas para edificios de ambiente rural.

\subsubsection{Gres porcelánico}

La aparición del gres porcelánico a finales de los años 70 permitió la fabricación de baldosas cerámicas con altas prestaciones técnicas y una apariencia muy parecida a la piedra natural. Este material se caracteriza por una muy baja porosidad y una elevada proporción de fase vítrea, que le confieren excelentes propiedades tanto mecánicas como químicas [Sánchez et al., 2010].

\section{A. Características principales}

Las propiedades del gres porcelánico lo diferencian de otros tipos de baldosas cerámicas y permiten su utilización en aplicaciones donde otros productos cerámicos no son adecuados o no ofrecen tantas posibilidades estéticas. Algunas de estas características singulares vienen detalladas a continuación:

\section{- Permeabilidad}

Por definición, las baldosas de gres porcelánico presentan una muy baja absorción de agua y por lo tanto son altamente impermeables. Asimismo, no presentan prácticamente porosidad abierta en su superficie sean esmaltadas o no. Estas características son el origen de muchas de las propiedades destacables de este producto.

\section{- Resistencia mecánica}

Según las normas, la resistencia mecánica de una baldosa cerámica viene dada por su carga de rotura a flexión. Esta característica es esencial para el uso de baldosas como pavimento, ya que deben soportar cargas gravimétricas.

Según los requisitos de la norma EN UNE 14411, las baldosas del grupo Bla (correspondientes al gres porcelánico conformado por prensado), son las que deben cumplir con los valores más altos de fuerza de rotura (a 
espesor equivalente) y resistencia mecánica. Estas altas prestaciones mecánicas son una consecuencia de la baja porosidad de este material y de su composición [Tenorio Cavalcante et al., 2004].

Debido a esta alta resistencia mecánica, el gres porcelánico es adecuado para su uso en pavimentos, incluso en lugares donde el suelo debe soportar cargas importantes (como por ejemplo almacenes, laboratorios o talleres).

\section{- Resistencia a la helada}

Las baldosas utilizadas en fachadas y suelos exteriores pueden ser expuestas a la formación de hielo. En este caso, una baja resistencia a la helada conduce a la aparición de desprendimientos, exfoliaciones o roturas, como consecuencia de la presión producida por el aumento de volumen del agua contenida en el interior de la pieza al pasar del estado líquido al estado sólido [Flórez et al., 2009].

El gres porcelánico es muy resistente a la helada debido a su baja absorción de agua que dificulta la entrada de agua en su interior. Esta característica permite su uso en zonas geográficas con heladas frecuentes, donde otras tipologías de baldosas cerámicas no presentan suficientes garantías de durabilidad.

\section{- Dimensiones}

En lo referente a sus dimensiones, cabe destacar que predominan los formatos medianos y grandes (piezas con superficies superiores a $1 \mathrm{~m}^{2}$ ) con forma cuadrada o rectangular y espesores superiores a $8 \mathrm{~mm}$ [IVE, 2011]. Sin embargo, en los últimos años, se han desarrollado nuevas tecnologías que permiten la producción de láminas de gres porcelánico de hasta $3600 \times 1200 \mathrm{~mm}$ y desde $2 \mathrm{~mm}$ de espesor [Raimondo et al., 2010].

Además, el gres porcelánico ofrece un gran abanico de posibilidades de decoración (coloreado en seco, prensado con relieves, etc.) [Amorós et al., 2007] y admite una gran variedad de procesos de post-producción como el pulido, el rectificado o el corte hidráulico [IVE, 2011].

Todo esto permite su uso en múltiples aplicaciones tanto interiores como exteriores y explica la popularidad de este producto que se ha convertido en el de mayor incremento de producción y venta frente a otros productos cerámicos de construcción [Martín-Márquez et al., 2008].

\section{B. Proceso de fabricación}

Las principales etapas que constituyen el proceso de fabricación de baldosas cerámicas son: la preparación de la composición del soporte (selección y mezcla de las materias primas, homogenización, dosificación, molienda y atomización), el conformado de la pieza, el secado, el esmaltado (opcional) y la cocción [ITC, 2002]. 
Esta tesis doctoral aplica a baldosas de gres porcelánico conformadas por prensado. Estas baldosas se fabrican mediante monococción, siguiendo el proceso de fabricación ilustrado en la figura 1.2.

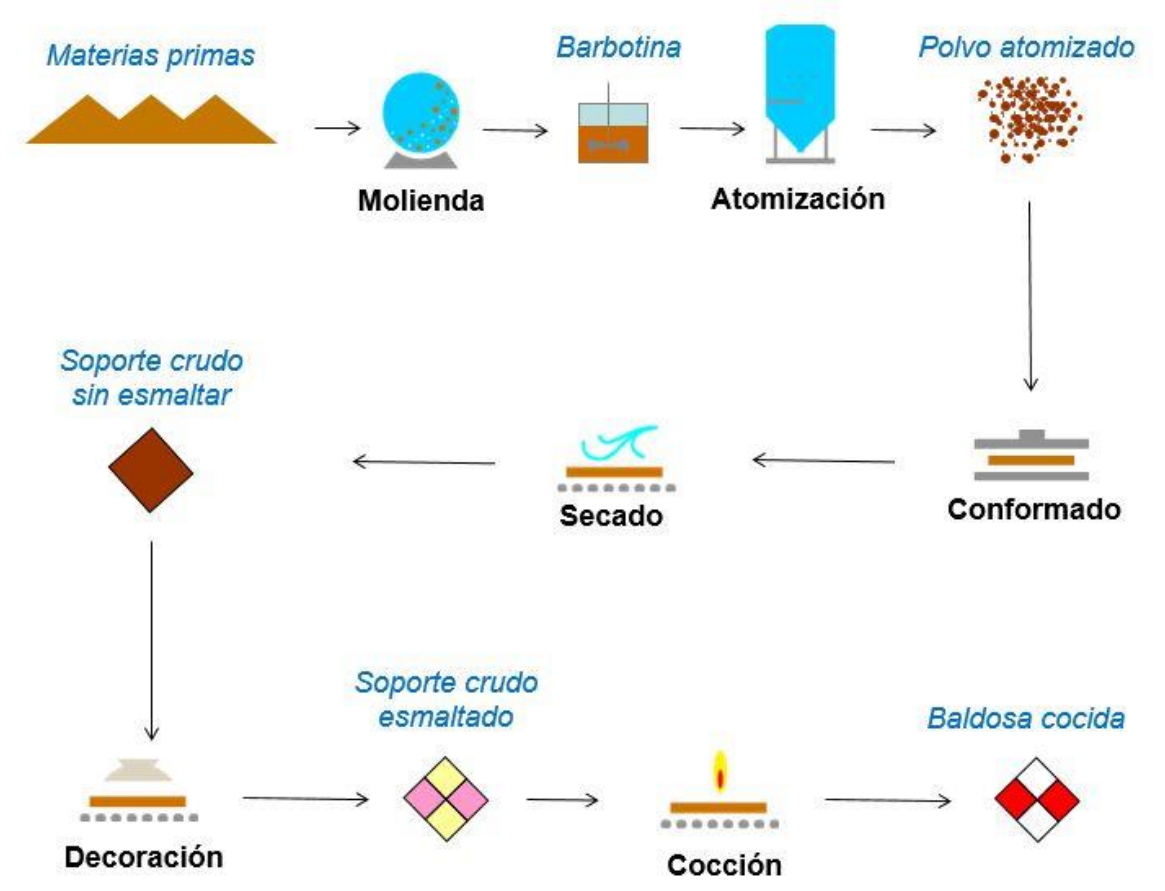

Figura 1.2. Esquema simplificado del proceso de fabricación de baldosas de gres porcelánico.

\section{- Preparación de la composición del soporte}

Cualquier proceso de fabricación cerámico empieza por la selección de las materias primas que entran a formar parte de la composición cerámica e incluyen principalmente arcillas, feldespatos, cuarzos, carbonatos y caolines.

En el caso del gres porcelánico, tanto esmaltado como no esmaltado, las materias primas básicas utilizadas suelen incluir $30-60 \%$ de arcillas, $30-$ $50 \%$ de feldespato, $0-20 \%$ de cuarzo y $0-20 \%$ de caolines [Sánchez et al., 2006]. Además de estas materias primas básicas, se suelen añadir otros compuestos en pequeñas cantidades con el objeto de modificar las características físicas o estéticas del producto final (pigmentos, wollastonitas, dolomitas, etc.) [Dondi, 2014].

Durante la molienda por vía húmeda, la mezcla de materias primas se moltura con agua en un molino de bolas resultando en una suspensión llamada barbotina (figura 1.3). La reducción del tamaño de partícula favorece la sinterización durante la cocción al aumentar la superficie específica de las partículas y, por lo tanto, su reactividad. 


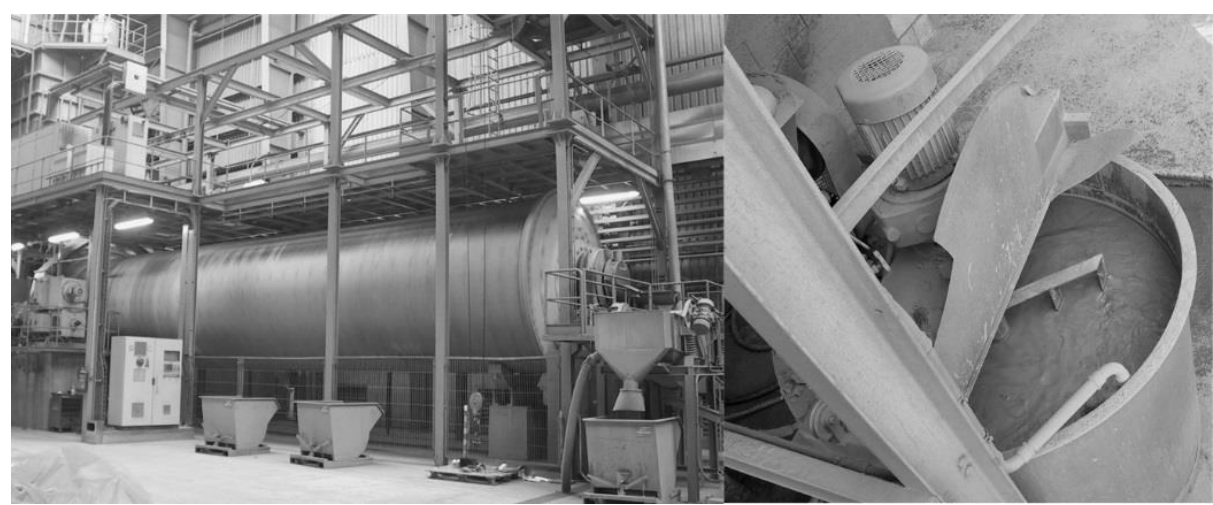

Figura 1.3. Molino industrial y barbotina (fuente: ITC).

En el caso del gres porcelánico, es especialmente necesario alcanzar un tamaño de partícula muy pequeño para favorecer la formación de fase vítrea durante la cocción y, por lo tanto, un alto grado de gresificación del producto final [Manfredi et al., 1996]. Asimismo, la eliminación de las partículas de mayor tamaño permite la obtención de piezas crudas con una microstructura formada por poros pequeños, lo que facilita la densificación de la pieza durante la cocción [Amorós et al., 2007].

La etapa de molienda viene seguida por un tamizado para separar las partículas más gruesas e impurezas.

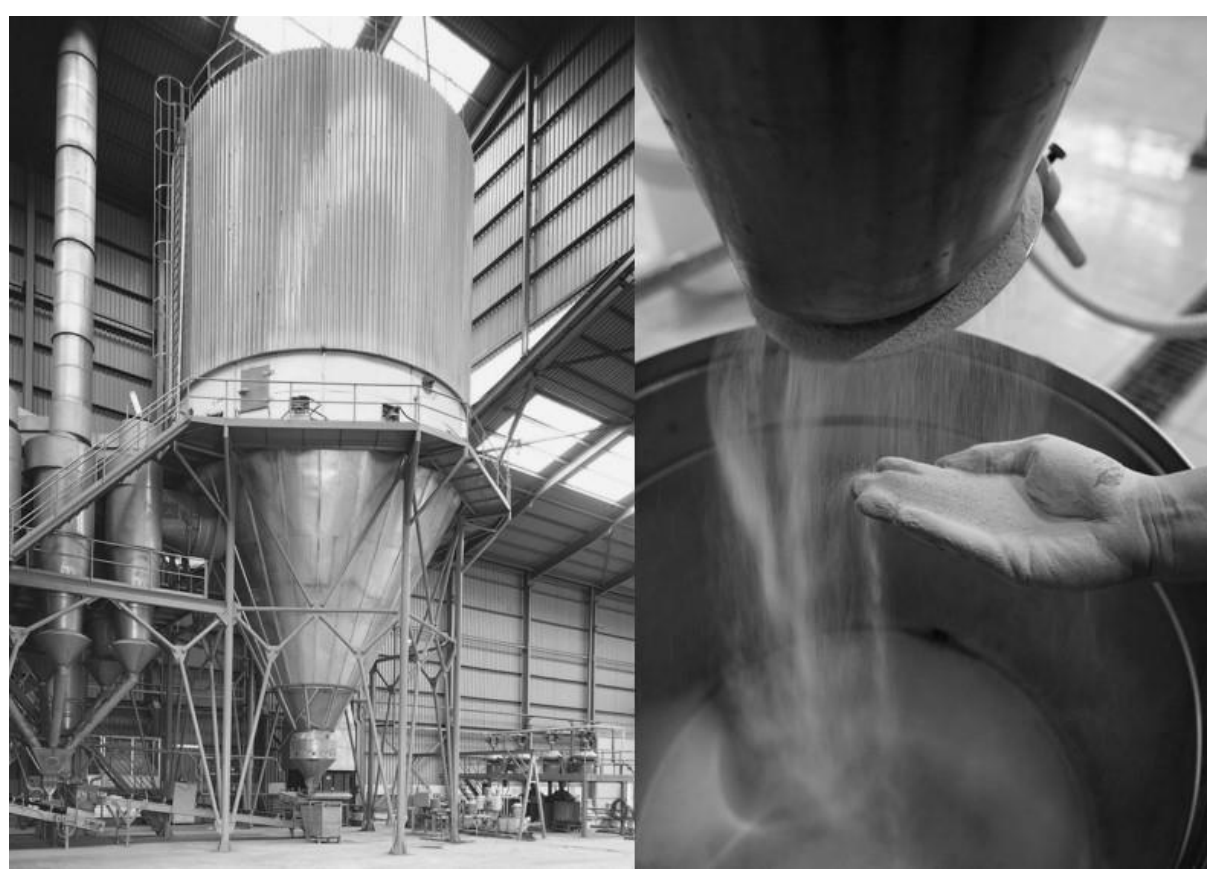

Figura 1.4. Atomizador industrial y polvo atomizado (fuente: ITC). 
A continuación, la barbotina se seca por atomización para obtener un polvo atomizado (figura 1.4). Este polvo está formado por unos gránulos esféricos, huecos en su interior y muy uniformes, por lo que presenta una alta fluidez que facilita el llenado de los moldes durante el prensado.

\section{- Conformado}

Las baldosas se conforman por prensado en seco, usando prensas hidráulicas (figura 1.5). El prensado del gres porcelánico se realiza a presiones altas (habitualmente $350-400 \mathrm{kgf} / \mathrm{cm}^{2}$ ) con el objetivo de alcanzar la máxima densidad del producto crudo [Manfredi et al., 1996].

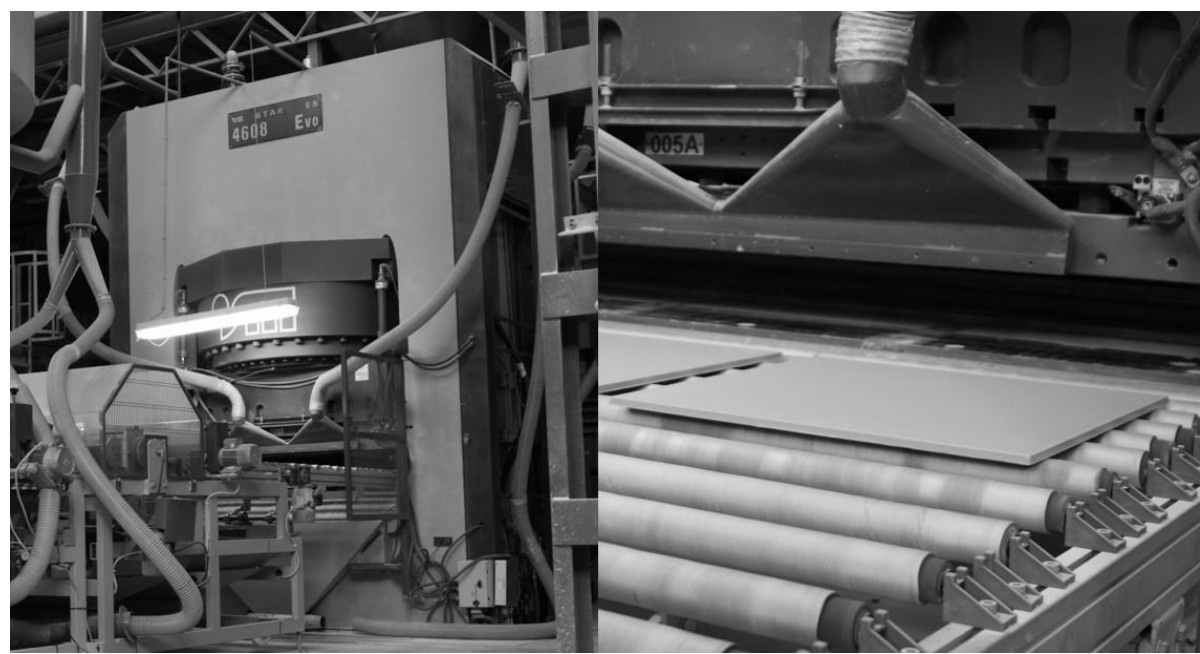

Figura 1.5. Prensa industrial y soporte crudo (fuente: ITC).

\section{- Secado}

Las piezas recién prensadas contienen entre el 5 y el $7 \%$ de humedad, por lo que se someten a una etapa de secado, con el objetivo de reducir esta humedad y aumentar su resistencia mecánica. El secado es una etapa esencial para evitar la formación de defectos y las roturas debidas a una excesiva humedad de la pieza durante las siguientes etapas del proceso.

\section{- Esmaltado y decoración.}

En su caso, se recubre el soporte crudo con una o varias capas de engobe y/o esmalte (figura 1.6). El recubrimiento se aplica de forma continua mediante las técnicas de esmaltado en cortina o mediante pulverización.

La aplicación del esmalte confiere a la superficie de la baldosa cerámica una serie de características técnicas (resistencia química, resistencia a la abrasión, impermeabilidad, fácil limpieza...) y estéticas (color, brillo, textura...) requeridas para su uso. 


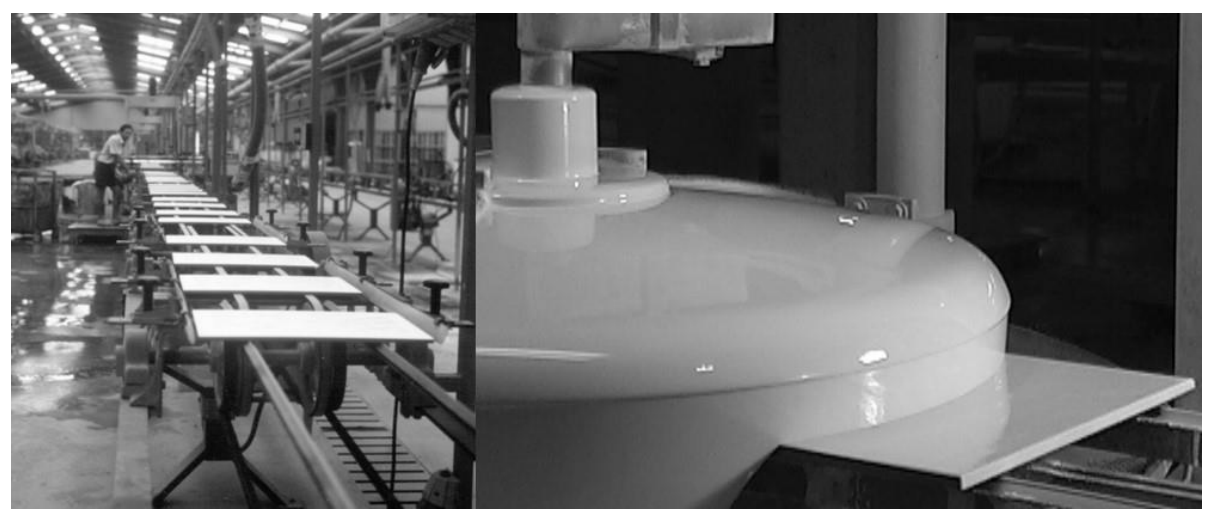

Figura 1.6. Línea de esmaltado industrial y detalle de una campana para la aplicación de esmalte a cortina (fuente: ITC).

Además, para conseguir el efecto estético deseado, se pueden utilizar técnicas complementarias de decoración, como por ejemplo la serigrafía, el huecograbado o la impresión por chorro de tinta (figura 1.7) [CTL, 2009].

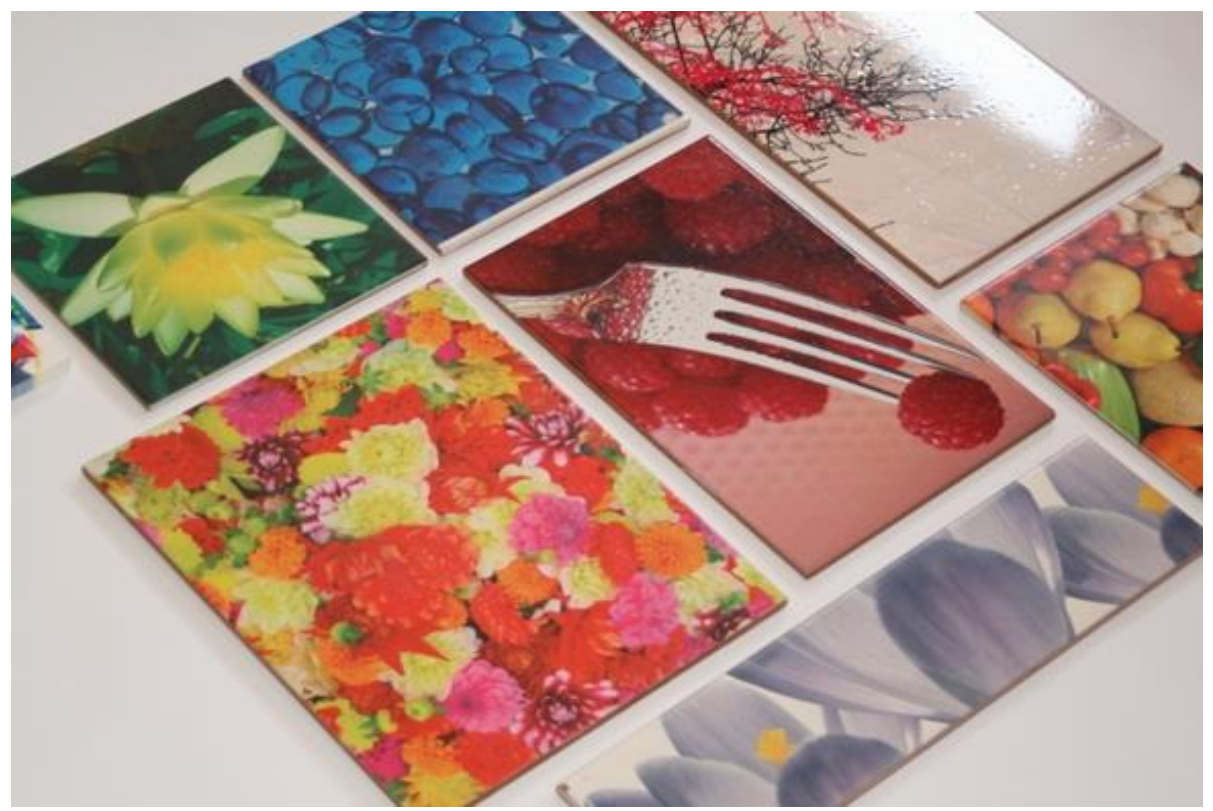

Figura 1.7. Baldosas decoradas por impresión por chorro de tinta (fuente: ITC).

- Cocción.

Finalmente, se procede a la cocción de las baldosas. Durante esta etapa, se produce una serie de cambios físico-químicos que confieren al producto final sus características técnicas y estéticas.

Las composiciones de gres porcelánico sufren varias transformaciones complejas durante su cocción. En particular, la descomposición de los 
minerales arcillosos conduce a la formación de componentes amorfos que dan lugar, a partir de $1000 \stackrel{\circ}{ } \mathrm{C}$ a la aparición de mullita y/o fases viscosas. Además, a partir de aproximadamente a $1050{ }^{\circ} \mathrm{C}$, se forma una gran cantidad de fase vítrea por la fusión de los feldespatos. Finalmente, el cuarzo se disuelve progresivamente en la fase vítrea [Gualtieri, 2007].

Como consecuencia de este proceso, el producto final queda constituido principalmente por una matriz vítrea con partículas de cuarzo, mullita y feldespatos [Zanelli, 2011].

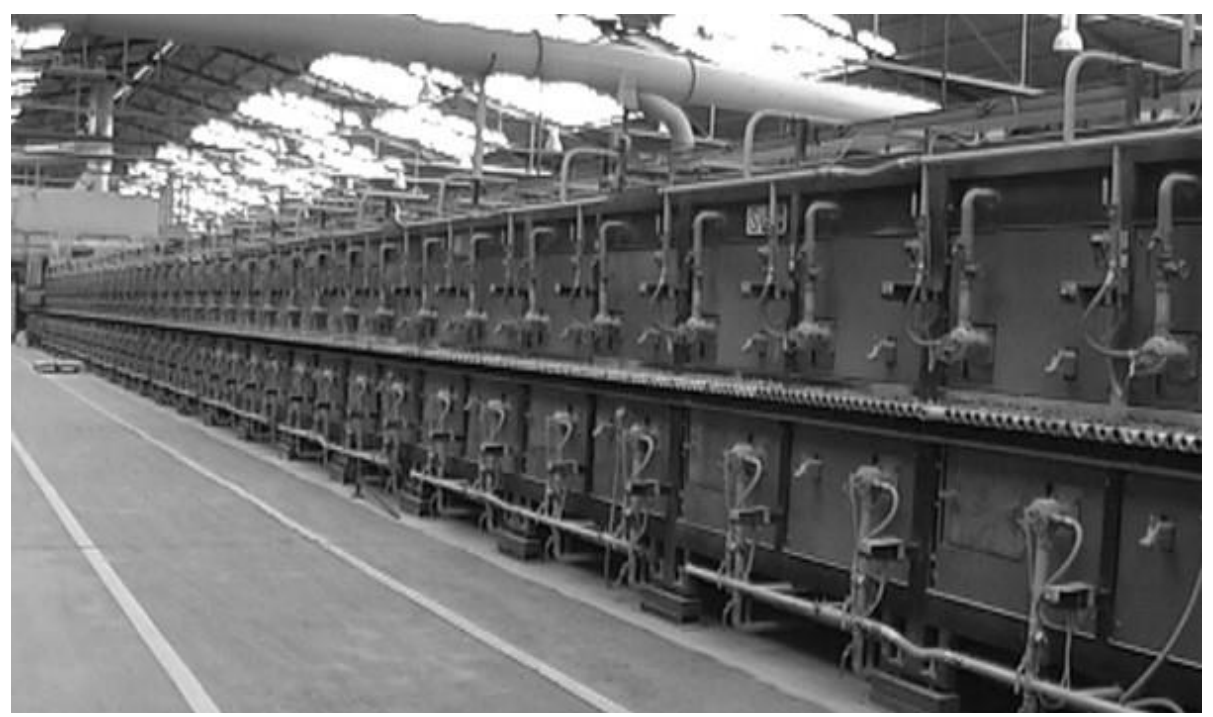

Figura 1.8. Horno de rodillos industrial para la cocción de baldosas cerámicas (fuente: ITC).

La cocción se realiza en hornos continuos de rodillos (figura 1.8) siguiendo un ciclo térmico que determina el tiempo y la temperatura de cocción, y depende del producto.

Para alcanzar la máxima vitrificación del material, los ciclos de cocción del gres porcelánico deben estar optimizados en duración y temperatura, y suelen durar 45-75 minutos con temperaturas máximas de cocción en torno a $1200 \stackrel{\circ}{\circ} \mathrm{C}$, dependiendo de la composición y del tamaño de las piezas [Dondi, 2014].

Un adecuado control tanto de los parámetros del proceso como de las composiciones químicas y mineralógicas de las composiciones cerámicas es esencial para obtener las propiedades requeridas por las baldosas de gres porcelánico (en particular su muy baja porosidad y alto grado de vitrificación) y, al igual que para otros productos cerámicos, evitar la aparición de defectos.

Entre los defectos más habituales en baldosas cerámicas, se encuentran las curvaturas tal y como se describe en el apartado siguiente. 


\subsection{Curvaturas en baldosas Cerámicas}

\subsubsection{Curvaturas inmediatas}

Las baldosas cerámicas pueden presentar curvaturas tanto convexas como cóncavas a su salida del horno. Estos defectos de planaridad tienen 3 causas principales [ITC, 1991]:

- la existencia de gradientes de temperaturas en el interior de la baldosa durante su cocción,

- la falta de acoplamiento entre el esmalte y el soporte,

- la deformación piroplástica.

\section{A. Curvaturas por gradientes de temperatura}

Durante la cocción de baldosas cerámicas se produce una expansión y posterior contracción del material. Este fenómeno es fuertemente dependiente de la temperatura y se muestra de forma cuantitativa en los diagramas de expansión-contracción, que son una representación de la dilatacióncontracción que sufre un material en función de la temperatura.

En estos diagramas se representan los cambios dimensionales que sufre una probeta al ser sometida a un tratamiento térmico, sin que actúe sobre ella ningún tipo de fuerza. Estos cambios dimensionales se conocen como "deformación libre". Cabe mencionar que los diagramas de expansióncontracción dependen de la velocidad de calentamiento y enfriamiento a la que se realiza el ensayo de forma que, al aumentar esta velocidad, el diagrama se desplaza hasta temperaturas superiores [Cantavella, 1998].

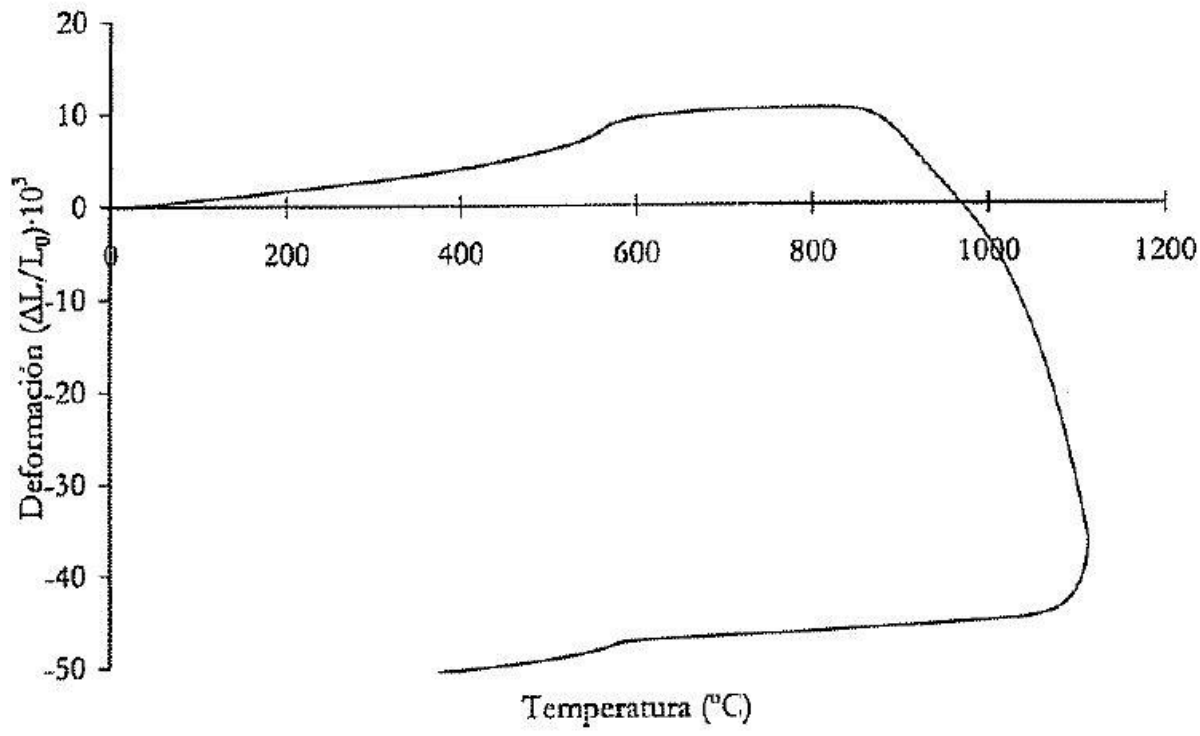

Figura 1.9. Diagrama de expansión-contracción típico de gres [Cantavella, 1998]. 
A modo de ejemplo, la figura 1.9 representa el diagrama de expansióncontracción típico de un soporte de gres.

Durante la cocción de una baldosa cerámica, cualquier diferencia de aporte de calor entre la parte superior e inferior del plano de rodillos conduce a la aparición de un gradiente de temperatura entre la cara superior e inferior o entre las superficies y el interior de la pieza.

De acuerdo con los diagramas de expansión-contracción, esta diferencia de temperatura provoca una variación de la contracción lineal entre las dos superficies de la pieza, que tiende a curvarla [ITC, 1991].

\section{B. Curvaturas por falta de acople esmalte-soporte}

La falta de ajuste entre las curvas de dilatación térmica del esmalte y del soporte ocasiona curvaturas cóncavas o convexas en las piezas cocidas (figura 1.10).

a)

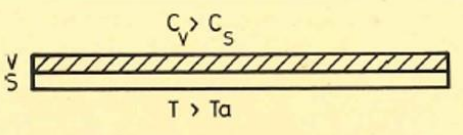

b)

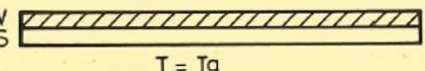

c)

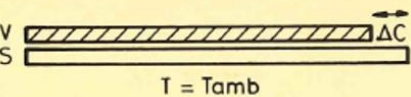

d)

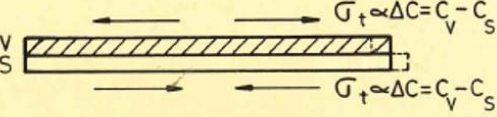

e)

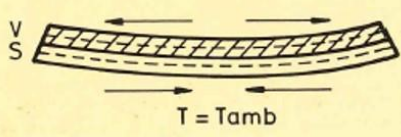

a)

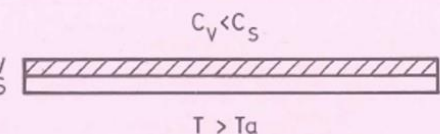

b)

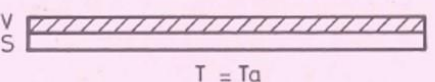

c)

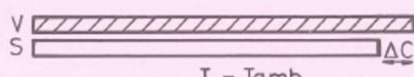

d)

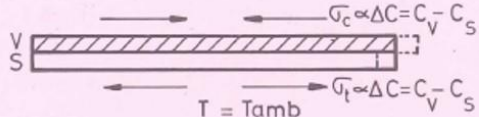

e)

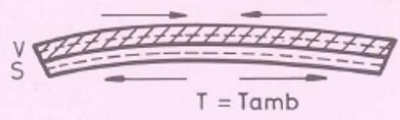

Figura 1.10. Evolución de la curvatura y de la tensión esmalte-soporte durante el enfriamiento de la pieza en el horno. Izquierda: la contracción del soporte $\left(C_{s}\right)$ es menor que la del esmalte ( $\left.C_{v}\right)$. Derecha: la contracción del soporte $\left(C_{s}\right)$ es mayor que la del esmalte $\left(C_{v}\right)$ [ITC, 1991].

En efecto, a la temperatura máxima de cocción, los dos componentes que forman una baldosa esmaltada (esmalte y soporte) tienen las mismas dimensiones, ya que el esmalte se acomoda a cualquier cambio de tamaño que experimente el soporte, puesto que el primero está en un estado viscoso. A medida que se va enfriando la pieza, el esmalte aumenta su viscosidad hasta convertirse en un material rígido que está íntimamente adherido al soporte. La temperatura a la que ocurre este fenómeno se conoce como temperatura de acoplamiento efectivo del esmalte $\left(T_{a}\right)$. 
A partir de esta temperatura, si se sigue enfriando, el esmalte y el soporte pueden experimentar contracciones térmicas diferentes, lo que originará tensiones entre ambos materiales y curvaturas en las piezas [Amorós et al., 1989].

\section{Curvaturas por deformación piroplástica}

Durante la etapa de cocción, a alta temperatura, se desarrolla una fase líquida viscosa responsable de la vitrificación. Por lo tanto, el material deja de comportarse como un sólido rígido y la aplicación de cualquier tensión produce una deformación permanente, conocida como "deformación piroplástica".

Mientras la baldosa se desplaza en un horno de rodillos, se produce un esfuerzo de flexión sobre la pieza causado por la gravedad. Como consecuencia, puede haber curvaturas cóncavas en el producto final [ITC, 1991].

Debido a su relación con la viscosidad, la deformación piroplástica solo se produce a temperaturas elevadas. Su magnitud depende de la cantidad de fase líquida, de su viscosidad y de la tensión aplicada [Escardino et al., 1985]. Este fenómeno se produce más fácilmente en la cocción de productos altamente vitrificados (como el gres porcelánico), al formarse una cantidad más elevada de fase líquida [Bernardin et al., 2006]. Sin embargo, con las composiciones y temperaturas utilizadas industrialmente, y con el plano de rodillos en buen estado, no suelen producirse deformaciones piroplásticas.

\subsubsection{Curvaturas diferidas}

Los tres defectos de planaridad descritos en los apartados anteriores corresponden a curvaturas inmediatas, es decir, son las que se observan en la pieza a su salida del horno. En algunos casos la curvatura de las baldosas evoluciona después de su salida del horno. Este fenómeno se conoce en la industria cerámica como "curvaturas diferidas" o "curvaturas en diferido" y es el objeto de esta tesis doctoral.

En efecto, no se ha encontrado ninguna publicación anterior a las de esta tesis doctoral (véase el apartado 6.2) que estudie las curvaturas diferidas en baldosas de ges porcelánico. En los pocos trabajos que mencionen este fenómeno en otros tipos de baldosas cerámicas, se suele apuntar a la relajación de tensiones residuales como una posible causa de la curvatura diferida [Cantavella et al., 2009]. 


\subsection{TENSIONES RESIDUALES EN BALDOSAS CERÁMICAS}

Las tensiones residuales son aquellas que se desarrollan en el interior de un material debido a cambios bruscos de temperatura, a deformaciones viscosas u otras causas, y permanecen después de desaparecer las fuerzas externas.

Las tensiones residuales en las baldosas cerámicas se generan durante el enfriamiento industrial de las mismas y son principalmente de dos tipos [Cantavella, 2009 - Quereda et al., 2012]:

- las tensiones de origen térmico provocadas por gradientes térmicos dentro de las piezas durante el enfriamiento industrial,

- las tensiones causadas por la falta de acople entre el esmalte y el soporte.

\subsubsection{Tensiones residuales de origen térmico}

El enfriamiento industrial de las baldosas cerámicas consta de tres fases [De Noni et al., 2011]:

1. Enfriamiento rápido inicial desde la temperatura máxima de cocción hasta $650^{\circ} \mathrm{C}$

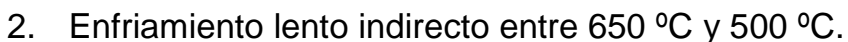

En esta fase, la velocidad de enfriamiento se reduce para evitar roturas de las piezas como consecuencia de la transformación alotrópica $\beta$ - $\alpha$ del cuarzo que ocurre a $573^{\circ} \mathrm{C}$, que tiene asociada una disminución de volumen.

3. Enfriamiento rápido final hasta temperatura ambiente.

Durante el primer tramo de enfriamiento rápido, las elevadas velocidades de enfriamiento y la baja conductividad térmica del material conducen a diferencias importantes de temperatura entre la superficie y el centro de la pieza, y por lo tanto al desarrollo de tensiones residuales en el material.

Para entender este fenómeno, es interesante asemejarlo al templado que se usa de forma habitual en la industria vidriera para aumentar la resistencia mecánica del vidrio.

Durante el templado, el vidrio se somete a un enfriamiento rápido. Su superficie se vuelve rígida inmediatamente, contrayéndose, mientras que su interior se mantiene a alta temperatura y en estado fluido, dada la baja conductividad del material.

A medida que la pieza sigue enfriándose, su interior tiende a contraerse, pero dicha contracción se ve impedida porque sus superficies exteriores ya están rígidas. Como consecuencia, se desarrollan fuertes tensiones de compresión en la superficie, contrabalanceadas por esfuerzos internos de tracción.

Al alcanzar la temperatura ambiente, el material presenta un perfil de tensiones residuales con una distribución parabólica a lo largo del espesor, como la que se muestra en la figura 1.11 [Mari, 1982]. 


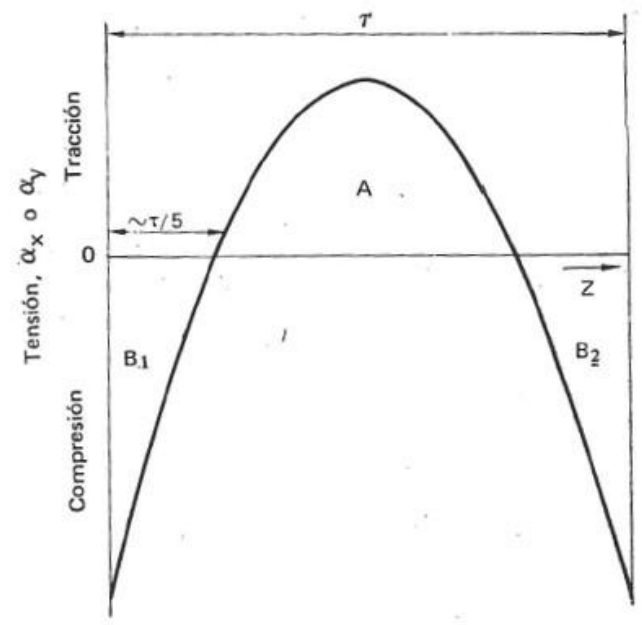

Figura 1.11. Distribución de las tensiones en el espesor de un vidrio plano templado térmicamente [Mari, 1982].

De forma similar, las baldosas cerámicas, suelen presentar esfuerzos de compresión en su superficie como resultado del enfriamiento industrial [De Noni et al., 2011]. La forma de la curva y los valores máximos de la compresión y de la tracción dependen principalmente del salto de temperatura, de la velocidad de enfriamiento y de las propiedades térmicas del material.

A modo de ejemplo, en la figura 1.12 se muestra el efecto de la velocidad de enfriamiento sobre las tensiones residuales de origen térmico en baldosas cerámicas porosas [Cantavella et al, 2009].

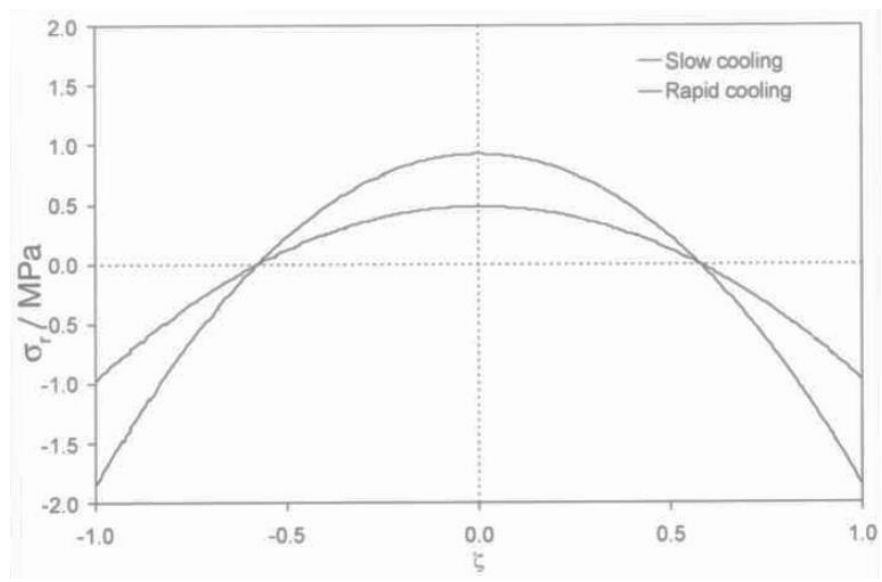

Figura 1.12. Perfil de tensiones residuales en una baldosa cerámica para 2 velocidades de enfriamiento [Cantavella et al, 2009]. 


\subsubsection{Tensiones residuales por acoplamiento esmalte- soporte}

La falta de ajuste entre las curvas de dilatación del esmalte y del soporte no sólo origina curvaturas en las baldosas (véase el apartado 1.2.1.B), también provoca tensiones entre ambas capas [ITC, 1992].

Estas tensiones residuales se desarrollan durante el enfriamiento de la baldosa esmaltada en el horno, cuando el esmalte y el soporte ya son rígidos y sufren contracciones térmicas distintas. Debido a la fuerte unión entre ambas capas, la dimensión del esmalte y del soporte debe ser la misma en su interface (figura 1.10), conduciendo a la aparición de tensiones residuales.

En el caso de que el soporte contraiga más que el esmalte, el primero ejerce un esfuerzo de compresión sobre el segundo. Por lo tanto, existen tensiones de tracción en el soporte y de compresión en el esmalte.

Por el contrario, si el esmalte contrae más que el soporte, el soporte estará sometido a un esfuerzo de compresión y el esmalte a un esfuerzo de tracción.

La magnitud de las tensiones esmalte-soporte depende de varios factores incluyendo [Amorós, 1989]:

- la diferencia de expansión térmica entre el soporte y el esmalte,

los módulos de elasticidad de ambos materiales,

los espesores relativos esmalte-soporte,

- la temperatura de acoplamiento efectivo del esmalte, $T_{a}$ (véase el apartado 1.2.1.B). 


\section{Capítulo 2. Objetivos y Alcance}

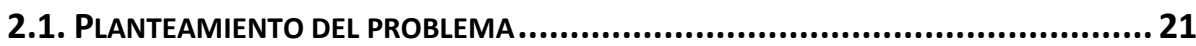

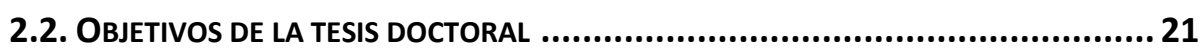

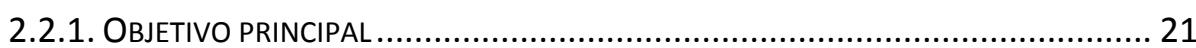

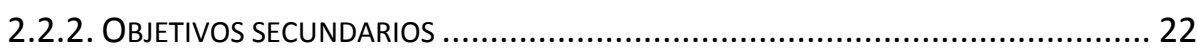


2. Objetivos y alcance 


\subsection{Planteamiento del PROBlema}

Un significativo porcentaje de baldosas cerámicas, independientemente de su porosidad, presentan el fenómeno conocido como "curvaturas diferidas" o "curvaturas en diferido". Éste consiste en el cambio de curvatura de las piezas después de su salida del horno durante un periodo de tiempo que puede llegar a alcanzar varias semanas e incluso meses.

Aunque las curvaturas diferidas no son desconocidas en el sector cerámico, en la actualidad, debido al aumento del tamaño de las baldosas que se fabrican, pueden suponer un serio problema de fabricación. Así, la presencia de curvaturas diferidas origina problemas durante la fase de clasificación y sobre la calidad del producto final, por lo que es necesario conocer la curvatura final que alcanzará la baldosa al objeto de establecer con qué curvatura deben de salir del horno, así como los criterios para su clasificación.

Las curvaturas diferidas en las baldosas porosas o azulejos presentan una tendencia a la concavidad con el tiempo, posiblemente como consecuencia de la expansión que presentan los soportes debido a su elevada porosidad (que los hace accesibles por el agua) y a la presencia de fases que expanden al hidratarse.

En gres porcelánico, tanto esmaltado como no esmaltado, este comportamiento es particularmente extraño, ya que la curvatura suele mostrar una evolución en un sentido (habitualmente hacia el sentido cóncavo) para, después de transcurrido cierto tiempo, invertir esta tendencia. El cambio en la evolución de la curvatura, unido a la muy baja porosidad de las baldosas de gres porcelánico (con absorciones de agua inferiores al $0,5 \%$ ) y a la baja proporción de fases hidratables presentes en las piezas cocidas indican que la causa de este comportamiento es mucho más compleja. Por lo tanto, es necesario establecer las causas de las curvaturas en diferido en gres porcelánico con el fin de entender este fenómeno y de aportar una solución industrial al problema.

\subsection{OBJETIVOS DE LA TESIS DOCTORAL}

\subsubsection{Objetivo principal}

En esta tesis, se pretende determinar las variables que influyen en las curvaturas en diferido en baldosas de gres porcelánico esmaltado y no esmaltado. Estas variables están relacionadas con las propiedades de los materiales, con el proceso y/o con las condiciones ambientales.

Se determinaron las causas y los mecanismos por los cuales se producen las curvaturas en diferido y se estudió la influencia de las variables de proceso sobre las mismas para permitir modificar las variables del proceso industrial con el objetivo final de reducir o controlar las curvaturas en diferido. 


\subsubsection{Objetivos secundarios}

Alcanzar este objetivo conlleva una serie de objetivos secundarios como se indica a continuación:

\section{Analizar el alcance industrial de las curvaturas en diferido}

Para tener una visión global de la situación inicial del problema, se recopiló información de diferentes empresas cerámicas sobre el problema de las curvaturas en diferido.

Además, se seleccionaron varios modelos industriales y se procedió a la medida en continuo de la evolución de la curvatura a lo largo del tiempo. Estos ensayos tenían como objetivo cuantificar el problema de curvaturas en diferido.

Finalmente, se determinaron algunas propiedades claves de las baldosas de gres porcelánico (módulo de elasticidad, expansión térmica, tensiones residuales, microestructura, etc.) para identificar cuales estaban relacionadas con las curvaturas en diferido.

\section{Estudiar la influencia de las variables de proceso sobre las curvaturas en diferido}

Se llevó a cabo un estudio sistemático, en condiciones de laboratorio, de las variables que pueden influir en las curvaturas en diferido (densidad aparente, grado de molienda, temperatura máxima de cocción, velocidad de enfriamiento...) con el fin de conocer su influencia sobre este fenómeno.

Para ello fue necesario poner a punto un procedimiento experimental que permitiera reproducir el fenómeno de las curvaturas en diferido a escala de laboratorio.

\section{Desarrollar un modelo matemático que permita explicar las curvaturas en diferido}

Se pretendía desarrollar un modelo, lo más simple posible, que permitiera justificar la evolución de las curvaturas en diferido, estableciendo la relación entre las propiedades de los materiales y las mismas.

El modelo debía permitir establecer tanto el papel que juega cada variable en las curvaturas en diferido como las condiciones en que se minimizan.

\section{Proponer ensayos de control industrial}

Con el conocimiento inicial del problema de las curvaturas en diferido no era posible asegurar que fuese posible eliminarlas por completo, en todos los materiales; lo que sí debía ser posible era establecer los factores que influyen sobre ellas y proponer ensayos de control en fábrica que permitan predecir la evolución de la curvatura en diferido en la pieza que se está procesando. 


\section{Capítulo 3. Materiales, Aparatos y Técnicas Experimentales}

\section{CAPÍTULO 3. MATERIALES, APARATOS Y TÉCNICAS EXPERIMENTALES...23}

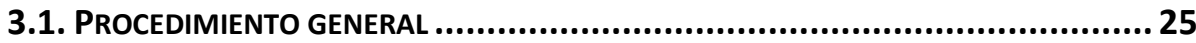

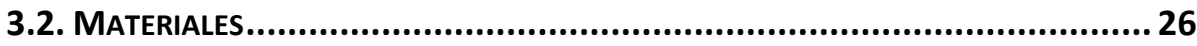

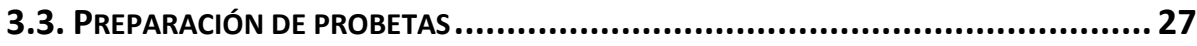

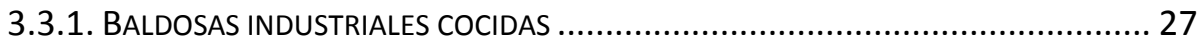

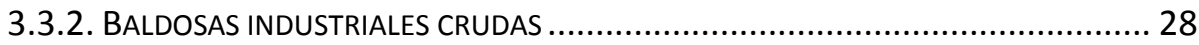

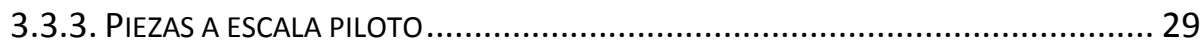

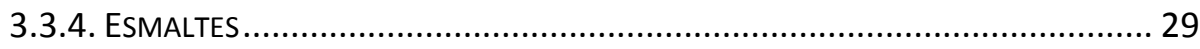

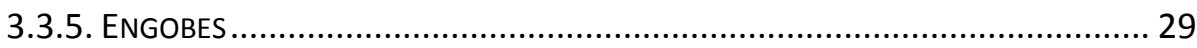

3.4. TÉCNICAS EXPERIMENTALES ....................................................... 30

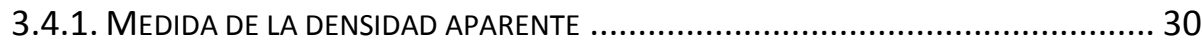

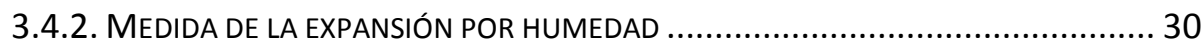

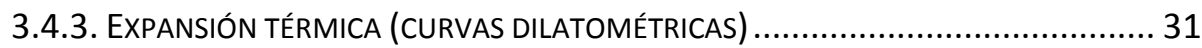

3.4.4. MEDIDA DE LA RESISTENCIA MECÁNICA Y MÓDULO DE ELASTICIDAD .................. 31

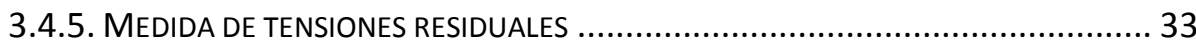

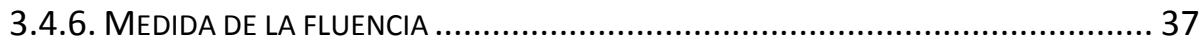

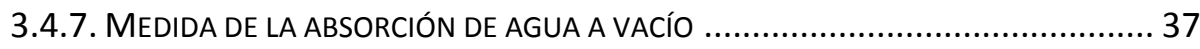

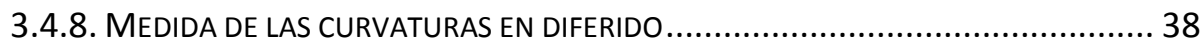

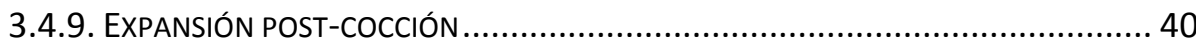

3.4.10. MEDIDA DE LA EXPANSIÓN DIFERENCIAL............................................ 42 
3. Materiales, aparatos y técnicas experimentales 


\subsection{Procedimiento general}

El objeto de la investigación era determinar el origen de las curvaturas en diferido en baldosas de gres porcelánico con el fin de proponer una solución industrial a este problema.

Para ello, el trabajo experimental constó de los siguientes pasos:

1. Análisis previo del problema

En la primera parte de esta tesis doctoral se cuantificó la magnitud de las curvaturas en diferido realizando medidas sobre distintas baldosas industriales de gres de porcelánico. En esta primera fase, se ensayaron un total de 6 baldosas suministradas por 6 empresas distintas.

Además, se analizaron cuáles eran los factores que pudieran influir sobre las curvaturas en diferido con el objetivo de determinar los ensayos a realizar en las siguientes etapas del trabajo.

2. Caracterización de soportes y esmaltes

Las baldosas de gres porcelánico suelen estar formadas por 3 capas: el soporte, el engobe y el esmalte. En esta fase del estudio se caracterizaron individualmente estas capas para 4 modelos de baldosas de gres porcelánico industriales: 2 con curvatura en diferido tras el proceso de cocción industrial y otros 2 sin curvatura diferida.

3. Determinación de la influencia de las distintas variables del proceso sobre las curvaturas en diferido

En esta etapa de la investigación se puso a punto un ensayo para reproducir las curvaturas en diferido a escala de laboratorio y evaluar el efecto de diferentes variables del proceso sobre las mismas, incluyendo el grado de molienda, la densidad aparente en seco, la presencia de esmalte, el espesor del soporte, el espesor relativo esmalte/soporte, la temperatura máxima de cocción, el tiempo de permanencia a temperatura máxima y la velocidad de enfriamiento.

Los ensayos se realizaron sobre probetas obtenidas a partir de baldosas industriales crudas y de piezas prensadas a escala piloto.

4. Planteamiento y validación del modelo

En esta parte del trabajo se desarrolló un modelo que permitía justificar la evolución de la curvatura determinada en el punto anterior. Asimismo, se realizaron una serie de ensayos sobre baldosas crudas con el fin de validar las hipótesis planteadas.

5. Propuesta y validación de ensayos de control industriales

Finalmente, se utilizaron los resultados obtenidos para proponer ensayos de control en fábrica que permitían predecir si las baldosas que se estaban procesando sufrirían o no curvaturas en diferido tras su cocción. Los ensayos propuestos se validaron a nivel de laboratorio realizando ensayos 
sobre probetas obtenidas a partir de baldosas industriales crudas de 14 modelos suministrados por distintas empresas.

\subsection{MATERIALES}

Para analizar y entender el fenómeno de las curvaturas en diferido se estudiaron 14 modelos industriales de baldosas de gres porcelánico suministradas por 8 empresas distintas, algunos de ellos presentaban curvaturas en diferido y otros no (tabla 3.1).

Como se indica en la tabla 3.1, durante el desarrollo de la investigación, se utilizaron distintos tipos de muestras como baldosas industriales cocidas y crudas, piezas obtenidas a escala piloto, engobes y esmaltes. Las baldosas crudas y las piezas a escala piloto se cocieron en un horno de laboratorio antes de realizar los ensayos, tal y como se indica a continuación en el aparatado 3.3. La tabla 3.2 indica los materiales de partida suministrados por las empresas para cada tipo de muestra y los ensayos realizados sobre cada una de ellas.

Tabla 3.1. Modelos industriales de gres porcelánico utilizados en el estudio.

\begin{tabular}{|c|c|c|c|c|}
\hline Modelo & Empresa & Esmaltado & $\begin{array}{l}\text { Curvatura } \\
\text { diferida }\end{array}$ & Tipo de muestras \\
\hline 1 & $A$ & Sí & Sí & Baldosas crudas y cocidas \\
\hline 2 & B & Sí & Sí & Baldosas crudas y cocidas \\
\hline 3 & $\mathrm{C}$ & Sí & No & Baldosas crudas y cocidas \\
\hline 4 & $\mathrm{D}$ & Sí & Sí & $\begin{array}{l}\text { Baldosas crudas y cocidas } \\
\text { Engobes y esmaltes } \\
\text { Piezas a escala piloto }\end{array}$ \\
\hline 5 & $E$ & Sí & Sí & Baldosas crudas y cocidas \\
\hline 6 & $\mathrm{~F}$ & Sí & Sí & Baldosas crudas y cocidas \\
\hline 7 & A & No & No & $\begin{array}{l}\text { Baldosas crudas y cocidas } \\
\text { Piezas a escala piloto }\end{array}$ \\
\hline 8 & B & Sí & Sí & $\begin{array}{l}\text { Baldosas crudas y cocidas } \\
\text { Engobes y esmaltes }\end{array}$ \\
\hline 9 & $\mathrm{~F}$ & Sí & No & $\begin{array}{l}\text { Baldosas crudas y cocidas } \\
\text { Engobes y esmaltes }\end{array}$ \\
\hline 10 & $A$ & Sí & No & Baldosas crudas y cocidas \\
\hline 11 & C & Sí & Sí & Baldosas crudas y cocidas \\
\hline 12 & G & Sí & No & Baldosas crudas \\
\hline 13 & $\mathrm{G}$ & Sí & Sí & Baldosas crudas \\
\hline 14 & $\mathrm{H}$ & Sí & Sí & Baldosas crudas \\
\hline
\end{tabular}


Tabla 3.2. Tipo de muestras utilizadas.

\begin{tabular}{|c|c|c|}
\hline Muestra & Material de partida & Ensayos realizados \\
\hline $\begin{array}{l}\text { Baldosas } \\
\text { industriales } \\
\text { cocidas }\end{array}$ & $\begin{array}{l}\text { - Baldosas cocidas sin esmaltar } \\
\text { (soportes cocidos) } \\
\text { - Baldosas cocidas esmaltadas }\end{array}$ & $\begin{array}{l}\text { - Curvatura en diferido } \\
\text { - Expansión post-cocción } \\
\text { - Expansión por humedad } \\
\text { - Expansión térmica } \\
\text { - Densidad aparente } \\
\text { - Absorción de agua } \\
\text { - Resistencia mecánica } \\
\text { - Módulo de elasticidad } \\
\text { - Fluencia } \\
\text { - Tensiones residuales } \\
\text { - Microestructura }\end{array}$ \\
\hline $\begin{array}{l}\text { Baldosas } \\
\text { industriales } \\
\text { crudas }\end{array}$ & $\begin{array}{l}\text { - Baldosas industriales crudas sin } \\
\text { esmaltar (soportes crudos) } \\
\text { - Baldosas industriales crudas } \\
\text { esmaltadas }\end{array}$ & $\begin{array}{l}\text { - Curvatura en diferido } \\
\text { - Expansión post-cocción } \\
\text { - Densidad aparente } \\
\text { - Absorción de agua } \\
\text { - Tensiones residuales } \\
\text { - Expansión diferencial }\end{array}$ \\
\hline $\begin{array}{l}\text { Piezas a } \\
\text { escala } \\
\text { piloto }\end{array}$ & $\begin{array}{l}\text { - Suspensión industrial de soporte } \\
\text { (barbotina) }\end{array}$ & $\begin{array}{l}\text { - Curvatura en diferido } \\
\text { - Expansión post-cocción } \\
\text { - Densidad aparente } \\
\text { - Absorción de agua }\end{array}$ \\
\hline Esmaltes & - Suspensión industrial & - Expansión térmica \\
\hline Engobes & - Suspensión industrial & - Expansión térmica \\
\hline
\end{tabular}

Para cada tipo de muestra, se utilizó un procedimiento específico para la obtención de las probetas utilizadas en los distintos ensayos, tal y como se detalla en el apartado siguiente.

\subsection{Preparación de probetas}

\subsubsection{Baldosas industriales cocidas}

En este primer caso, se utilizaron baldosas de gres porcelánico prensadas y cocidas industrialmente. Para cada modelo industrial, se disponía de baldosas esmaltadas y de soportes cocidos.

Primero se determinó la evolución de la curvatura y de la expansión postcocción sobre las baldosas esmaltadas enteras. Luego, las distintas baldosas tanto esmaltadas como sin esmaltar (soportes) se cortaron obteniéndose probetas con las medidas requeridas para los distintos ensayos a realizar (véase el apartado 3.4). 


\subsubsection{Baldosas industriales crudas}

En este caso, se partió de baldosas de gres porcelánico prensadas industrialmente y suministradas en crudo por distintas empresas. Cabe destacar que se disponía de baldosas crudas esmaltadas y sin esmaltar (soportes crudos).

A partir de las piezas anteriores, se cortaron probetas prismáticas de $150 \mathrm{~mm}$ de longitud y $30 \mathrm{~mm}$ de anchura a las que se les eliminó la costilla (relieve presente en la superficie inferior de las baldosas) mediante lijado manual. Las probetas fueron cocidas en un horno eléctrico de laboratorio (Pirometrol) con una velocidad de calentamiento de $25^{\circ} \mathrm{C} / \mathrm{min}$ y un tiempo de permanencia de 6 minutos a máxima temperatura.

Puesto que con un enfriamiento convencional dentro del horno de laboratorio no se alcanzan velocidades de enfriamiento tan altas como en el horno industrial, el enfriamiento tuvo lugar fuera del horno. Para ello, las probetas se extrajeron del horno justo después de finalizar el tiempo de permanencia a máxima temperatura y se enfriaron al ambiente en posición vertical. A ambos lados de la pieza se situaron aislantes al objeto de que el enfriamiento no fuera excesivamente rápido (figura 3.1), evitando las roturas de las probetas al llegar a la temperatura de transformación del cuarzo. Asimismo, un termopar en contacto con la pieza permitía conocer su temperatura superficial.
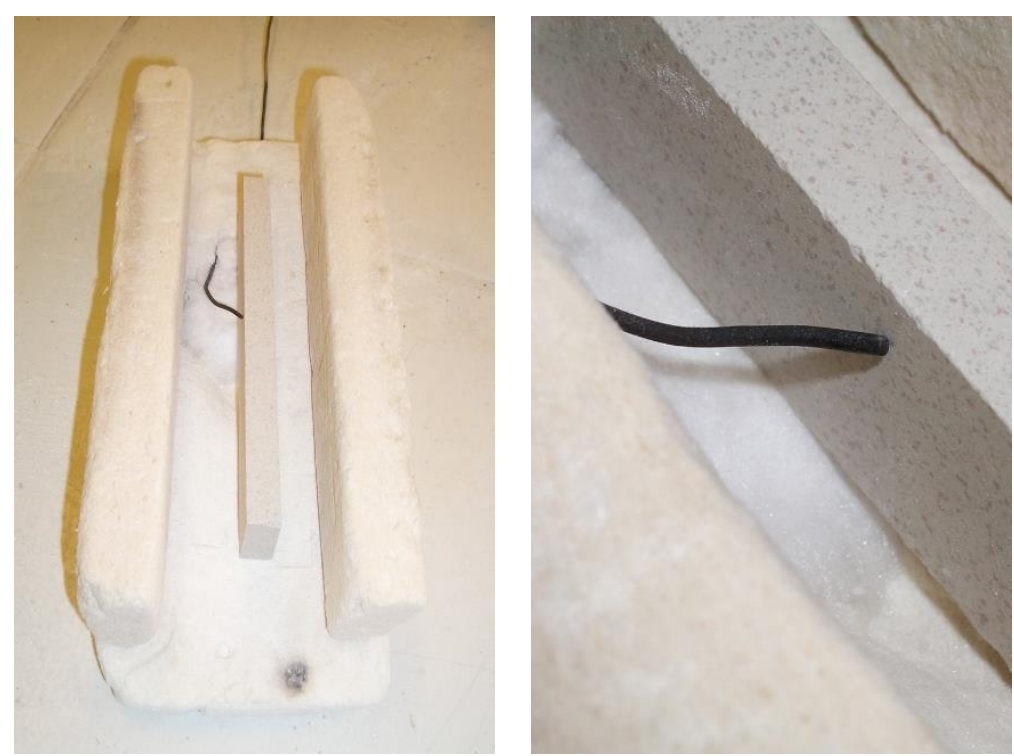

Figura 3.1. Posición de las probetas durante el enfriamiento rápido fuera del horno y detalle del termopar en contacto con la superficie.

Cabe destacar que, en estas condiciones, se consigue una velocidad de enfriamiento alta sin una diferencia térmica apreciable entre ambas superficies de la probeta. 


\subsubsection{Piezas a escala piloto}

Para estudiar el efecto de la densidad aparente en seco y del grado de molienda, fue necesario preparar piezas a escala piloto.

Para ello, se partió de suspensiones molturadas industrialmente a distintos tamaños de partícula y secadas por atomización a escala piloto. El secado por atomización se llevó a cabo en un atomizador Newtech. Este atomizador, con un poder máximo de evaporación de $30 \mathrm{~kg}$ agua/hora (mediante quemador de gas), permite obtener polvos atomizados de características muy similares a los obtenidos industrialmente.

A continuación, el conformado de las piezas se llevó a cabo en una prensa semi-industrial MAER de 120 toneladas obteniendo un tamaño de pieza de $150 \times 150 \mathrm{~mm}$. Esta prensa de molde tipo penetrante permite reproducir ciclos industriales de prensado gracias al control automático de variables como: velocidad de carro, número de primeras prensadas, tiempos de desaireación, tiempos de prensado, velocidad de extracción, etc.

Para realizar los ensayos se cortaron probetas de $150 \times 30 \mathrm{~mm}$ que se cocieron en un horno de laboratorio, siguiendo la metodología descrita en el apartado anterior.

\subsubsection{Esmaltes}

Los esmaltes se recibieron en forma de suspensiones (barbotinas). Para obtener las probetas necesarias para medir la expansión térmica, dichas suspensiones se secaron bajo una lámpara de infrarrojos antes de desleír la barbotina seca en un molino de bolas con acetona. Tras un segundo secado bajo lámparas de infrarrojo se obtuvo un polvo seco que se tamizó y humectó antes de prensar las probetas en una prensa hidráulica de laboratorio.

Las probetas obtenidas, de dimensiones $30 \mathrm{~mm}$ de largo por $7 \mathrm{~mm}$ de ancho $x 7$ alto, se secaron en estufa y cocieron en un horno eléctrico de laboratorio (Pirometrol) usando el siguiente ciclo térmico:

- Calentamiento a $25^{\circ} \mathrm{C} / \mathrm{min}$ hasta sinterización.

- Enfriamiento rápido excepto en el intervalo de la temperatura de transformación del cuarzo $(600-400 \stackrel{\circ}{\circ})$ ) donde se usó una velocidad de enfriamiento de $5 \stackrel{\circ}{\circ} / \mathrm{min}$.

Finalmente se lijaron los extremos de la probeta para que fueran planos y paralelos entre sí.

\subsubsection{Engobes}

Al igual que los esmaltes, los engobes se recibieron en forma de suspensiones. Dichas suspensiones se secaron para obtener un polvo seco siguiendo el mismo procedimiento que en el caso de los esmaltes. 
Dicho polvo se prensó obteniéndose probetas paralelepipédicas de $30 \times 7 \times 7$ $\mathrm{mm}$ aproximadamente cuyos extremos se lijaron hasta que sean planos $y$ paralelos entre sí.

Finalmente, se procedió a cocer las probetas obtenidas en un horno eléctrico de laboratorio (Pirometrol) siguiendo el siguiente ciclo térmico:

- Calentamiento a $25^{\circ} \mathrm{C} / \mathrm{min}$ hasta una temperatura máxima de $1100 \stackrel{\circ}{\circ}$.

- Permanencia a la máxima temperatura durante 6 minutos.

- Enfriamiento rápido excepto en el intervalo 590-540 ํ (temperatura del cambio alotrópico del cuarzo), para el cual se utilizó una velocidad de enfriamiento de $5 \stackrel{\circ}{\circ} / \mathrm{min}$.

\subsection{TÉCNICAS EXPERIMENTALES}

\subsubsection{Medida de la densidad aparente}

La densidad aparente se determinó por inmersión en mercurio. Las probetas se secaron a $110^{\circ} \mathrm{C}$ en una estufa eléctrica de laboratorio, con recirculación de aire. Posteriormente se pesaron y se determinó su densidad aparente por el método de inmersión en mercurio [Ashworth, 1969 - Stringer et al., 1970], usando la ecuación siguiente:

\section{Ecuación 3.1}

$$
\rho=\frac{m}{E} \cdot \rho_{H g}
$$

donde:

$\rho$ : densidad aparente de la probeta $\left(\mathrm{g} / \mathrm{cm}^{3}\right)$

$m$ : masa de la probeta $(\mathrm{g})$

E: empuje de la probeta medido por el método de inmersión en mercurio $(\mathrm{g})$

$\rho_{\text {Hg: }}$ densidad del mercurio $\left(13,53 \mathrm{~g} / \mathrm{cm}^{3}\right)$

\subsubsection{Medida de la expansión por humedad}

La expansión por humedad se realizó siguiendo el método descrito en la norma ASTM C 370-88 "Standard test method for moisture expansion of fired whiteware products", que consiste en determinar la variación de longitud de las probetas ensayadas, después de un tratamiento en autoclave a una presión de $10,5 \mathrm{kgf} / \mathrm{cm}^{2}$ durante 5 horas.

Previamente al tratamiento en el autoclave, se realizó un recocido a $550^{\circ} \mathrm{C}$ siguiendo el método descrito en la norma UNE EN ISO 10545-10: 1997 "Baldosas Cerámicas - Parte 10: Determinación de la dilatación por humedad". 


\subsubsection{Expansión térmica (curvas dilatométricas)}

En el caso de los soportes cocidos (baldosas sin esmaltar), se cortaron probetas de $35 \times 6 \mathrm{~mm}$ que se secaron en estufa a $110^{\circ} \mathrm{C}$. Luego se lijaron sus extremos para que fueran planos y paralelos entre sí. En el caso de los esmaltes y engobes, las probetas se obtuvieron siguiendo los procedimientos descritos en el apartado 3.3.

El equipo utilizado para la determinación de la expansión térmica fue un dilatómetro absoluto Netzsch, modelo EP-402, calibrado con un patrón de zafiro. El ciclo térmico empleado fue un calentamiento a $5^{\circ} \mathrm{C} / \mathrm{min}$ hasta una temperatura máxima de $800 \stackrel{\circ}{ } \mathrm{C}$ para los soportes y engobes, y hasta la temperatura de reblandecimiento para los esmaltes.

\subsubsection{Medida de la resistencia mecánica y módulo de elasticidad}

\section{A. Soportes}

A partir de los soportes industriales cocidos (baldosas sin esmaltar), se cortaron probetas prismáticas de $150 \mathrm{~mm}$ de longitud y $20 \mathrm{~mm}$ de anchura, y se determinaron su resistencia mecánica y su módulo de elasticidad mediante flexión por tres puntos de apoyo. Estos ensayos se realizaron con la cara vista hacia arriba y hacia abajo al objeto de conocer si existía un perfil de tensiones asimétrico a través del espesor de la pieza.

Los ensayos se llevaron a cabo en una máquina de ensayos mecánicos (Instron 4501) con un dispositivo de flexión mediante tres puntos de apoyo que consta de dos bordes de apoyo inferiores cilíndricos (soportes), sobre los que se sitúa la probeta, y un apoyo superior, también cilíndrico, mediante el cual se aplica la carga (figura 3.2). La velocidad de desplazamiento fue $1 \mathrm{~mm} / \mathrm{min}$.

La resistencia mecánica en flexión se calculó mediante la ecuación:

Ecuación 3.2

$$
\sigma_{\mathrm{R}}=\frac{3}{2} \frac{\mathrm{S}}{\mathrm{bh}^{2}} \mathrm{~F}_{\mathrm{R}}
$$

siendo:

$\sigma_{R}: \quad$ resistencia mecánica en flexión $(\mathrm{Pa})$

$F_{R}: \quad$ carga de rotura $(\mathrm{N})$

S: $\quad$ separación entre apoyos $(\mathrm{m})$

b: anchura de la probeta $(\mathrm{m})$

h: $\quad$ espesor de la probeta $(m)$ 


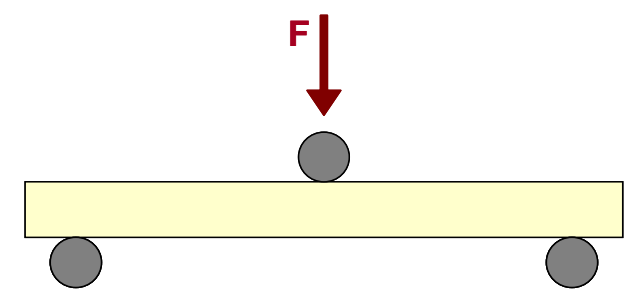

Figura 3.2. Esquema general del montaje de flexión 3 puntos.

El módulo de elasticidad se calculó a partir de la recta de desplazamiento del punto de aplicación de la carga $\left(\delta_{c}\right)$ en función de la fuerza aplicada $(F)$ utilizando la expresión:

\section{Ecuación 3.3}

$$
\delta_{\mathrm{c}}=\frac{\mathrm{FS}^{3}}{4 \mathrm{bEh}}
$$

siendo:

F: $\quad$ fuerza aplicada $(\mathrm{N})$

$\delta_{c}: \quad$ desplazamiento $(\mathrm{m})$

$\mathrm{E}$ : módulo de elasticidad $(\mathrm{Pa})$

Se realizaron ensayos con la cara vista hacia arriba y hacia abajo, con 10 probetas para cada condición.

\section{B. Esmaltes y engobes}

En el caso de los esmaltes y engobes, resulta imposible conformar probetas que permitan determinar su módulo de elasticidad mediante flexión 3 puntos usando la misma metodología que en el caso de los soportes. Para ello, se consideraron 2 métodos alternativos, tal y como se indica a continuación.

\section{a) Determinación del módulo de elasticidad por flexión 3 puntos}

Se prepararon baldosas industriales cocidas con diferente espesor de capa de engobe y esmalte (tabla 3.3). En concreto, se prepararon soportes sin esmaltar (s), soportes con una capa de engobe estándar $(\mathrm{s}+\mathrm{g})$, soportes con una capa doble de engobe $(\mathrm{s}+2 \mathrm{~g})$, soportes con una capa de engobe y una capa de esmalte estándares $(s+g+v)$ y soportes con una capa de engobe estándar y una capa doble de esmalte $(s+g+2 v)$.

A partir de las piezas anteriores, se cortaron probetas prismáticas de $150 \mathrm{~mm}$ de longitud y $20 \mathrm{~mm}$ de anchura y se determinaron su resistencia mecánica y su módulo de elasticidad efectivo mediante flexión por tres puntos de apoyo, de forma análoga a lo explicado en el apartado anterior. El módulo de elasticidad efectivo $\left(E_{\text {ef }}\right)$ es aquél que tendría una pieza homogénea con las mismas dimensiones que la probeta analizada, y que presentara la misma curva carga-desplazamiento. 
Tabla 3.3. Espesores de las distintas capas que forman las probetas utilizadas para la medida del módulo de elasticidad.

\begin{tabular}{|c|c|c|c|}
\hline Referencia & Espesor soporte & Espesor engobe & Espesor esmalte \\
\hline$s$ & simple & - & - \\
\hline$s+g$ & simple & simple & - \\
\hline$s+2 g$ & simple & doble & - \\
\hline$s+g+v$ & simple & simple & simple \\
\hline$s+g+2 v$ & simple & simple & doble \\
\hline
\end{tabular}

Los ensayos se realizaron con la cara vista hacia arriba y hacia abajo con 10 probetas para cada condición, lo que supone un total de 100 probetas por modelo estudiado.

A partir de estos ensayos, se obtuvo el módulo de elasticidad efectivo de cada tipo de probeta, permitiendo el cálculo del módulo de elasticidad de las distintas capas utilizando las ecuaciones desarrolladas en el anexo 2.

\section{b) Determinación del módulo de elasticidad por nanoindentación}

Asimismo, el módulo de elasticidad de los engobes y los esmaltes se determinó por ensayos de indentación, utilizando una punta de geometría Berkovich (pirámide triangular) y un equipo Nanotest de Micromaterials. Se efectuaron series de 20 indentaciones a una carga máxima de $1000 \mathrm{mN}$ y una velocidad de aplicación de $100 \mathrm{mN} / \mathrm{s}$, en intervalos de distancia constantes de $500 \mu \mathrm{m}$. El módulo de elasticidad se calculó a partir de la pendiente de la recta formada por los primeros puntos registrados al inicio del ciclo de descarga, momento en que tiene lugar la recuperación elástica del material.

\subsubsection{Medida de tensiones residuales}

\section{A. Tensiones de origen térmico}

Para cuantificar las tensiones residuales se prepararon probetas de $150 \times 30$ $\mathrm{mm}$, obtenidas a partir de las baldosas industriales cocidas sin esmaltar. Se utilizó el método de relajación de deformaciones por corte incremental (strain relaxation slotting method) [Prime, 1999]. Una representación esquemática del método se adjunta en la figura 3.3.

El ensayo consiste en pegar una galga extensiométrica en la parte inferior de la probeta (figura 3.4) y a continuación realizar cortes de profundidad creciente en la superficie superior mediante un disco de diamante (figura 3.5). La deformación medida con la galga $\left(\varepsilon_{g i}\right)$, como consecuencia del curvado de la probeta, es función de la profundidad de la entalla $\left(a_{i}\right)$ y se relaciona con las tensiones residuales. 


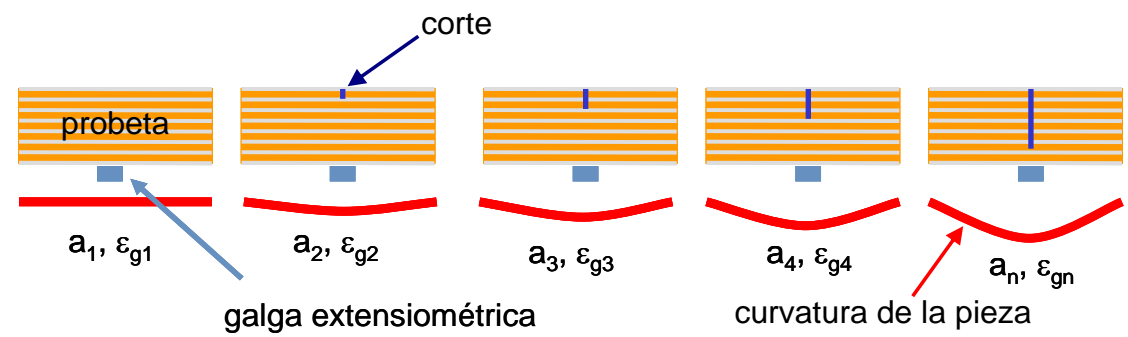

Figura 3.3. Representación esquemática del fundamento del método.

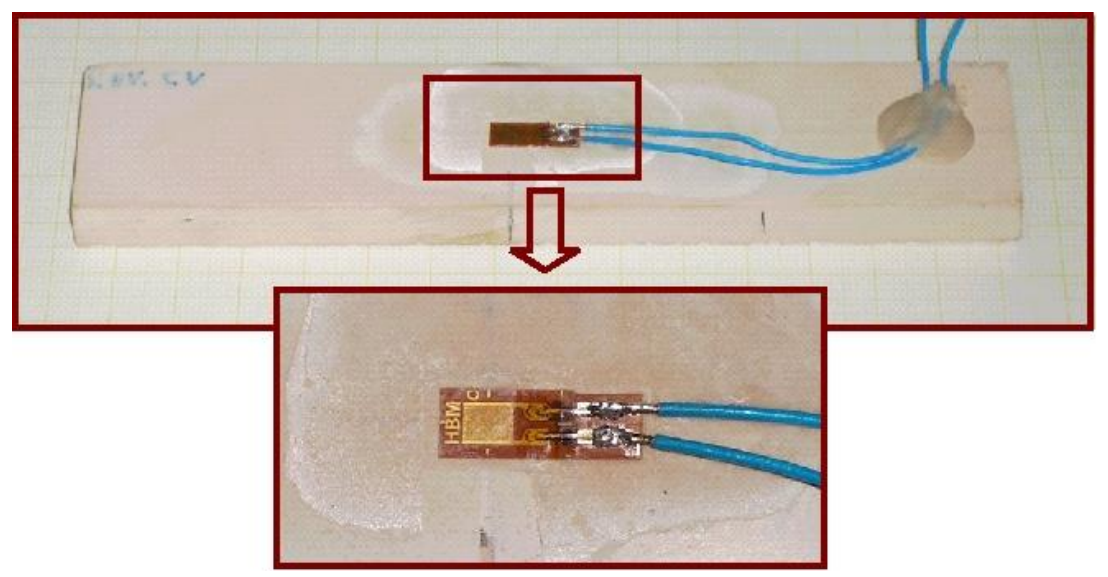

Figura 3.4. Detalle de la galga extensiométrica colocada sobre la superficie de la probeta.

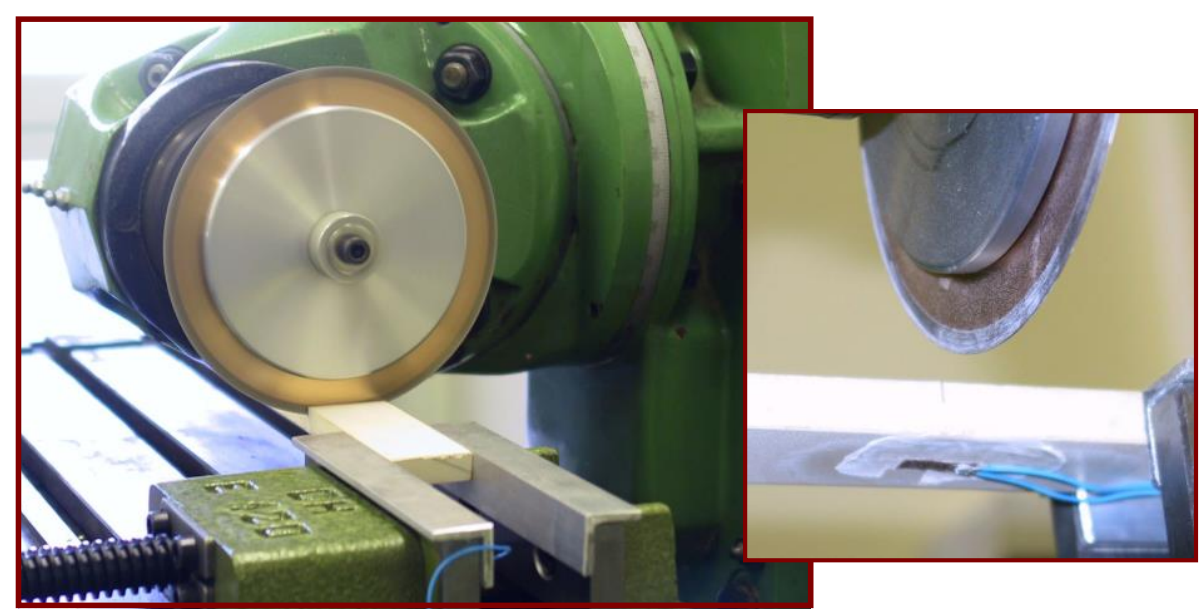

Figura 3.5. Realización de un corte para el ensayo de medida de las tensiones residuales de origen térmico. 
Para poder calcular el perfil de tensiones residuales es necesario conocer la relación entre $\varepsilon_{g}\left(a_{i}\right)$ y la tensión en cada punto del interior de la pieza. Las tensiones pueden expresarse como un desarrollo en serie de polinomios de Legendre:

\section{Ecuación 3.4}

$$
\frac{\sigma_{\mathrm{r}}}{E}=-\sum_{\mathrm{k}=2}^{n} \lambda_{k} P_{k}(\zeta)
$$

Donde:

$\sigma_{r}$ : tensión $(\mathrm{Pa})$

$\mathrm{E}: \quad$ módulo de elasticidad $(\mathrm{Pa})$

$\lambda_{k}$ : coeficiente del polinomio de Legendre de grado $k$ (adimensional)

$P_{\mathrm{k}}$ : polinomio de Legendre de grado $\mathrm{k}$

$\zeta: \quad C o o r d e n a d a$ adimensional de posición (costilla: $\zeta=-1$; cara vista: $\zeta=+1$ )

Los coeficientes $\lambda_{k}$ se calculan a partir de la deformación de la galga $\left(\varepsilon_{\mathrm{gi}}\right)$ y unos factores de calibrado $\gamma_{\mathrm{ij}}$ que se obtienen teóricamente para cada geometría mediante un método numérico (método de los elementos finitos). La expresión que permite calcular estos coeficientes es:

$$
\text { Ecuación 3.5 } \quad \lambda=\left(\gamma^{T} \gamma\right)^{-1} \gamma^{T} \varepsilon_{g}
$$

Donde $\lambda$ es el vector de valores de $\lambda_{k}$ y $\gamma$ es la matriz $\gamma_{i j}$.

Se usó el mismo método para determinar las tensiones residuales en piezas esmaltadas. En este caso, se prepararon probetas de $150 \times 30 \mathrm{~mm}$ a partir de baldosas industriales crudas esmaltadas. Para medir las tensiones tanto en la capa de esmalte como en el soporte, el corte se realizó por la superficie inferior (costilla) de la probeta y se usaron dos galgas, la primera pegada sobre la cara vista (en el centro de la probeta) y la segunda situada sobre la costilla (al lado de la zona de corte). Al igual que en el caso anterior, se usó un desarrollo en polinomios de Legendre para determinar las tensiones residuales.

El desarrollo completo de las ecuaciones para calcular las tensiones residuales de origen térmico viene detallado en el anexo 3 para sistemas homogéneos y laminados.

\section{B. Tensiones de acople esmalte-soporte}

Las tensiones de acoplamiento se calcularon a partir de las propiedades mecánicas de baldosas sin esmaltar (soportes cocidos), baldosas engobadas y baldosas esmaltadas, todas ellas industriales y cocidas. Estas propiedades se determinaron mediante flexión por tres puntos, siguiendo el procedimiento descrito en el apartado 3.4.4.

El fundamento de la medida de las tensiones de acoplamiento reside en la variación de resistencia mecánica existente entre un soporte, un soporte 
engobado y un soporte con engobe y esmalte. La figura 3.6 esquematiza lo que ocurre durante un ensayo de resistencia mecánica por flexión en tres puntos de apoyo para una probeta sin tensiones residuales y una con tensiones.

Cuando se aplica una carga $F_{1}$ sobre una probeta sin tensiones, aparece un esfuerzo de compresión sobre la superficie en contacto con el apoyo central (superficie superior) y un esfuerzo de tracción sobre la superficie apoyada sobre los dos soportes cilíndricos (superficie inferior). La fractura se produce desde la superficie en tracción cuando la carga alcanza un valor umbral $F_{2}$.

Sin embargo, cuando la probeta presenta tensiones internas, la rotura se produce a un valor de carga diferente. En efecto, si la superficie inferior presenta tensiones de compresión, la fuerza aplicada en primer lugar debe vencer el esfuerzo de compresión $\left(F_{1}\right)$, momento a partir del cual aparece un esfuerzo de tracción que finalmente conduce a la rotura de la pieza a un valor de carga $F_{3}$ mayor que $F_{2}$. Si la superficie inferior se encuentra en tracción ocurre lo contrario, de forma que la carga a la cual se inicia la fractura es menor.

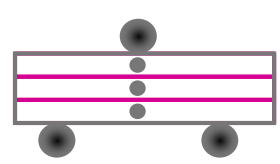

sin tensiones

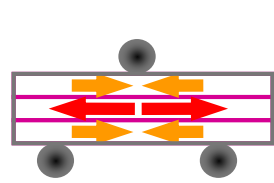

con tensiones
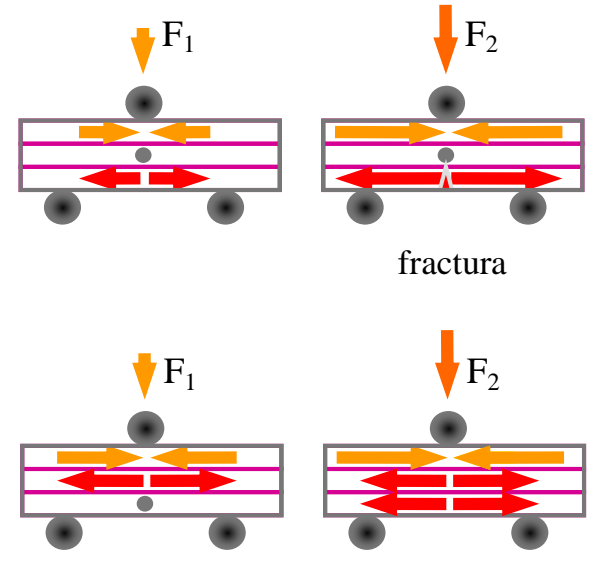

fractura

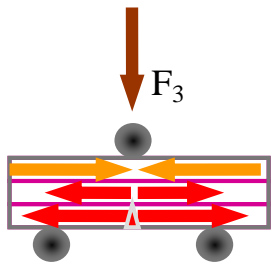

fractura

Figura 3.6. Variación de la resistencia mecánica por efecto de las tensiones $\left(F_{2}<F_{3}\right)$.

Utilizando las ecuaciones de la elasticidad y conocidos los valores de la resistencia mecánica efectiva (determinada experimentalmente) de la pieza ensayada con la cara vista hacia arriba y el módulo de elasticidad de soporte, engobe y esmalte, es posible calcular las tensiones en cada una de estas capas. Para ello se realizó un desarrollo teórico que condujo a las ecuaciones utilizadas en el cálculo de las tensiones residuales en las diferentes capas debidas al acoplamiento (anexo 2). 


\subsubsection{Medida de la fluencia}

Para medir la fluencia se utilizó el equipo mostrado en la figura 3.7. En este equipo la pieza se somete a un ensayo de flexión en tres puntos con una carga inferior a la de rotura, y se registra el desplazamiento a lo largo del tiempo mediante un transformador diferencial lineal variable (LVDT, Solartron Metrology).

Las probetas usadas, de dimensiones $220 \times 20 \mathrm{~mm}$, se obtuvieron a partir de soportes industriales cocidos y se ensayaron aplicando una carga correspondiente al $50 \%$ de la carga de rotura. La distancia entre apoyos fue $18 \mathrm{~cm}$.

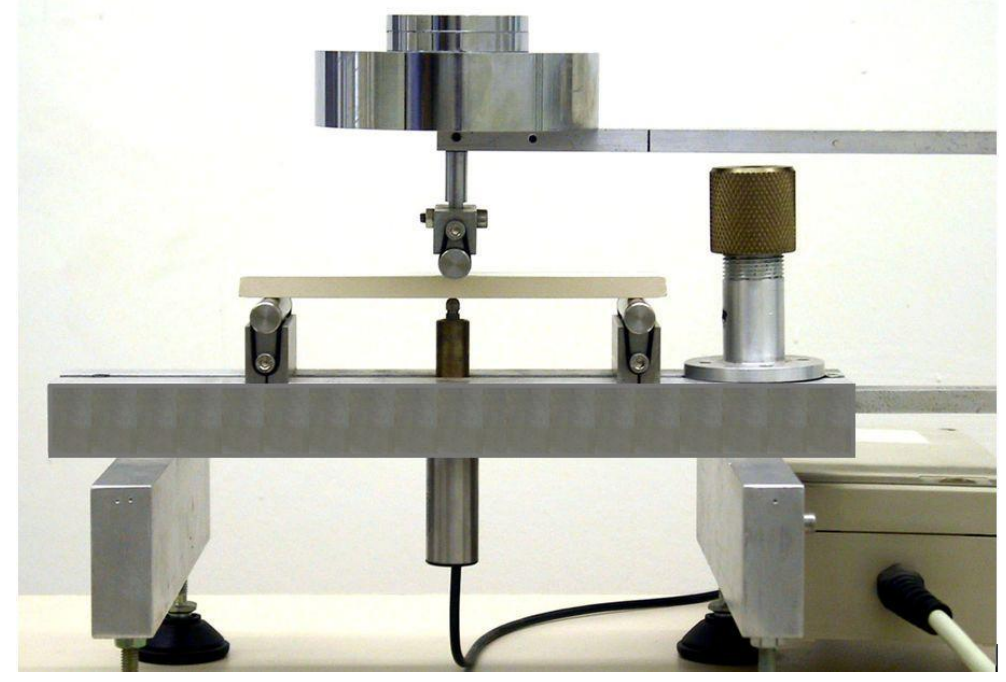

Figura 3.7. Equipo utilizado para los ensayos de fluencia.

\subsubsection{Medida de la absorción de agua a vacío}

La medida de la absorción de agua a vacío se midió según la norma UNE ISO 10545-3: 1997.

Este método consiste en introducir las probetas en un recipiente hermético, realizar un vacío de forma que la presión que se alcance en el interior sea de 100 mbar (la presión atmosférica es aproximadamente de 1000 mbar). Las probetas permanecen 30 minutos en estas condiciones. A continuación, comienza el proceso de impregnación con agua, que tiene una duración de 30 minutos (se tardan unos 30 minutos en que el nivel del agua cubra totalmente la pieza).

La pieza permanece sumergida durante 15 minutos. Posteriormente se elimina el vacío, se extraen las piezas, se secan superficialmente y se pesan. Una vez pesadas se vuelven a sumergir en agua (esta vez a presión 
atmosférica) y se extraen transcurridos 1,5 y 7 días, se secan superficialmente y se pesan.

Posteriormente se calcula la absorción de agua (AA) usando la siguiente ecuación:

\section{Ecuación 3.6}

$$
A A=\frac{m_{a}}{m_{s}}
$$

Donde:

$\mathrm{ma}_{\mathrm{a}}$ : masa de agua absorbida por la probeta $(\mathrm{kg})$

$\mathrm{m}_{\mathrm{s}}$ : masa de la probeta seca $(\mathrm{kg})$

Al objeto de conocer si el aumento de la absorción de agua con el tiempo se debía a la penetración progresiva de agua en el interior de la pieza y, en caso afirmativo, por qué superficie penetraba el agua, se realizaron también ensayos de absorción de agua a vacío añadiendo azul de metileno al agua utilizada. Una vez finalizado el ensayo (transcurridos los 7 días de permanencia en el baño) se cortaron las probetas y se observó su sección con el objetivo de determinar la penetración del azul de metileno (figura 3.8).

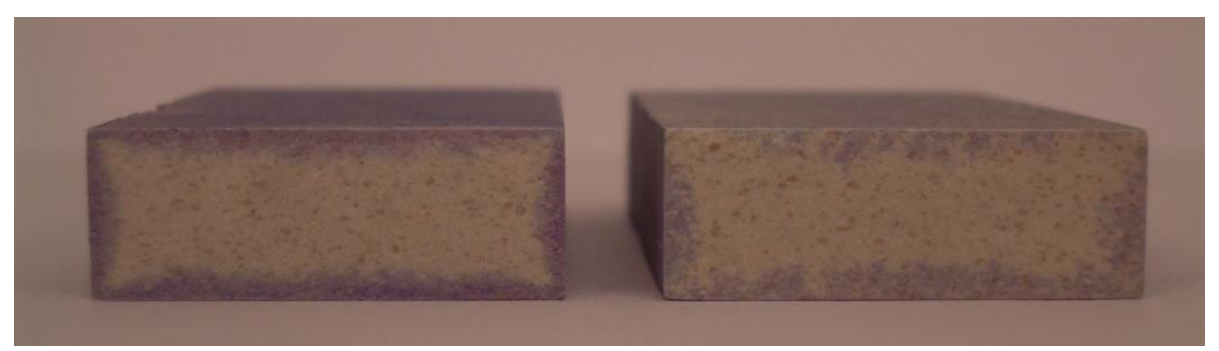

Figura 3.8. Ejemplo de penetración del azul de metileno.

\subsubsection{Medida de las curvaturas en diferido}

\section{A. Medida de curvatura sobre piezas industriales}

La curvatura diferida es un fenómeno que comienza inmediatamente tras la salida de las piezas del horno (probablemente incluso comience en el interior de este, en las últimas fases del enfriamiento) y puede prolongarse durante varias semanas. Por ello, para cada uno de los modelos ensayados, se realizaron dos tipos de medidas:

- Medida en continuo durante 24 horas tras la salida de las piezas del horno.

- Medida en discontinuo durante un periodo de 2 meses. 


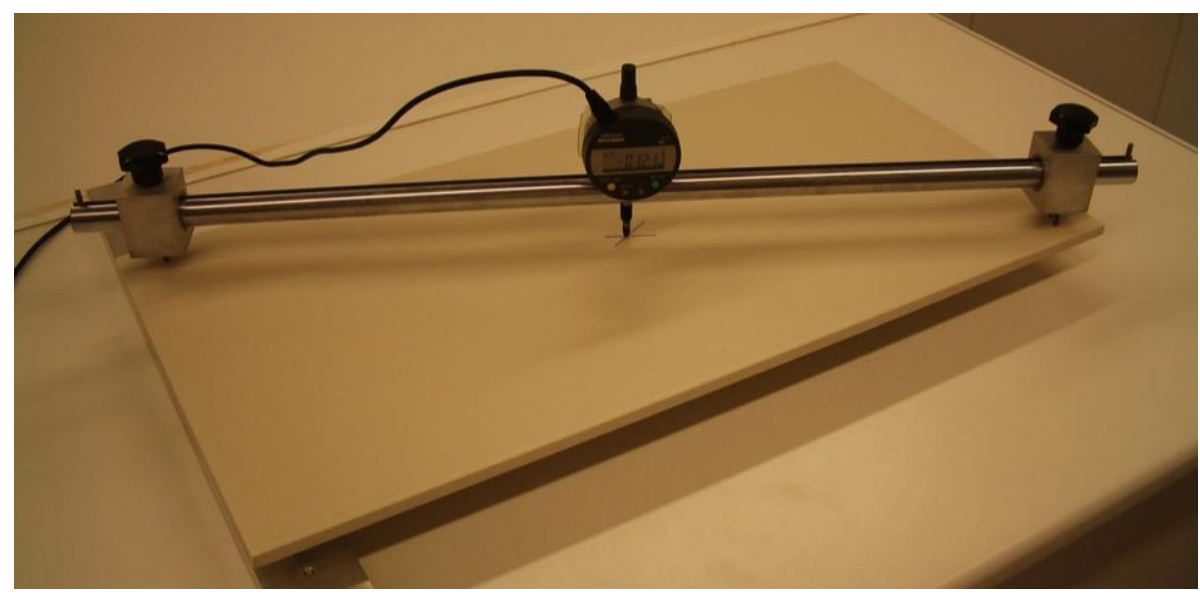

Figura 3.9. Dispositivo utilizado para medir la flecha de las piezas industriales.

Para realizar la medida en continuo en las primeras 24 horas se utilizó un reloj comparador (Mitutoyo, ID-C112PB/543-257B) colocado sobre un soporte con tres apoyos tal y como se muestra en la figura 3.9.

Con este equipo se midió la flecha central $(\delta c)$ en una de las diagonales de la pieza. Dado que el cambio de curvatura puede ser rápido en los primeros instantes, se realizaron medidas cada 60 segundos, para lo cual se conectó el reloj comparador a un ordenador industrial que disponía de un programa de adquisición de datos.

Posteriormente, mediante un equipo idéntico al mostrado, se realizó el seguimiento de la flecha con el tiempo con 5 baldosas que se habían cocido junto con la baldosa utilizada en la medida en continuo.

\section{B. Medida de la curvatura sobre probetas de laboratorio}

La evolución de la curvatura se midió en continuo durante las 24 horas siguientes a la cocción. Los ensayos comenzaron transcurridos 15 minutos desde que la temperatura superficial de la pieza alcanzara $200 \stackrel{\circ}{ } \mathrm{C}$. Para ello se utilizó el dispositivo de la figura 3.10, el cual permite determinar la flecha central $\left(\delta_{c}\right)$ con una precisión inferior al micrómetro mediante interferometría láser.

Las mediciones se realizaron cada 60 segundos, para lo cual se conectó el equipo (Mitituyo, Laser Hologage LGH-1010) a un ordenador que disponía de un programa de adquisición de datos. La distancia entre apoyos fue $130 \mathrm{~mm}$. 


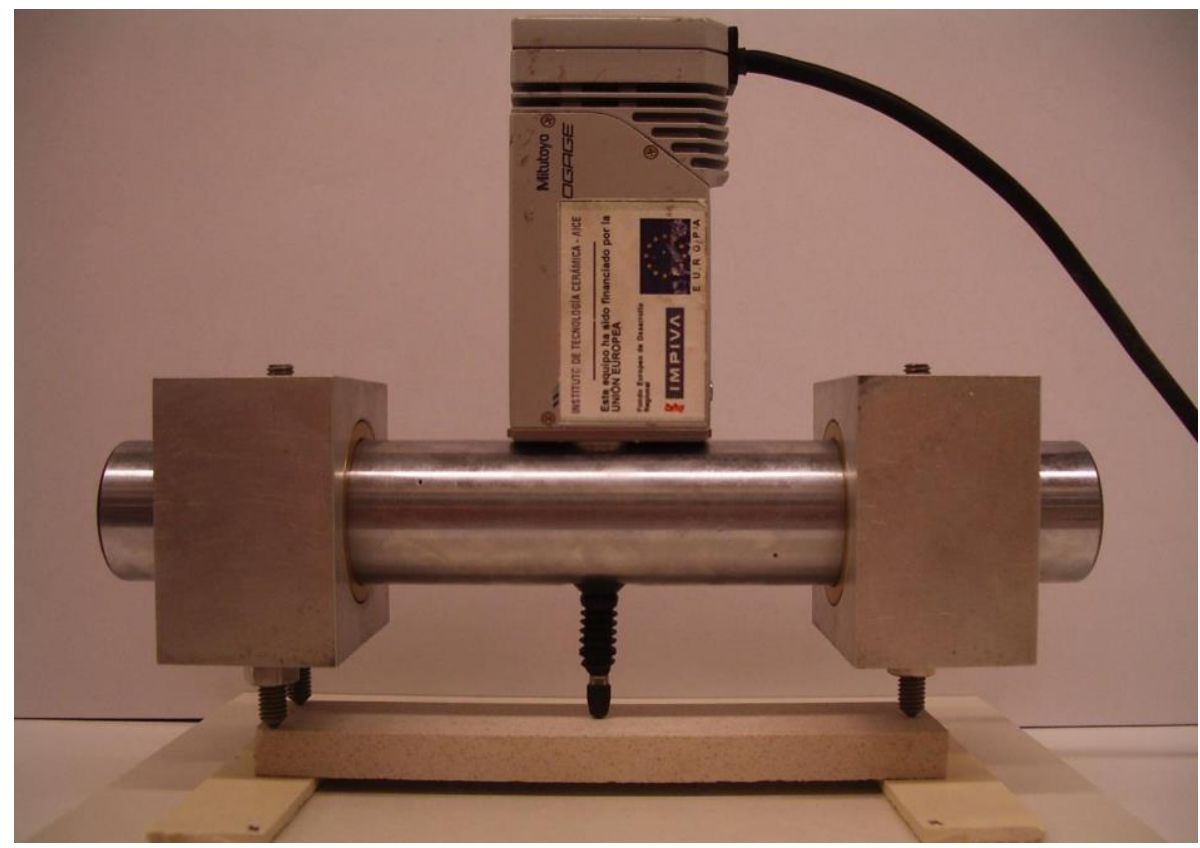

Figura 3.10. Dispositivo utilizado para medir la flecha de las probetas.

\subsubsection{Expansión post-cocción}

\section{A. Medida de expansión sobre piezas industriales}

La expansión post-cocción de baldosas industriales se midió con el equipo mostrado en la figura 3.11. Se trata de un dispositivo formado por una serie de barras de titanio y acero alternadas en una configuración tal que le permite ser muy poco sensible a los cambios térmicos. El desplazamiento se medía con un reloj comparador (Mitutoyo, ID-C112PB/543-257B) situado en uno de sus extremos.

Las medidas se realizaron sobre baldosas industriales no esmaltadas (soportes) inmediatamente a la salida del horno, registrando valores cada 60 segundos durante 24 horas. Para ello, se conectó el reloj comparador a un ordenador industrial que disponía de un programa de adquisición de datos.

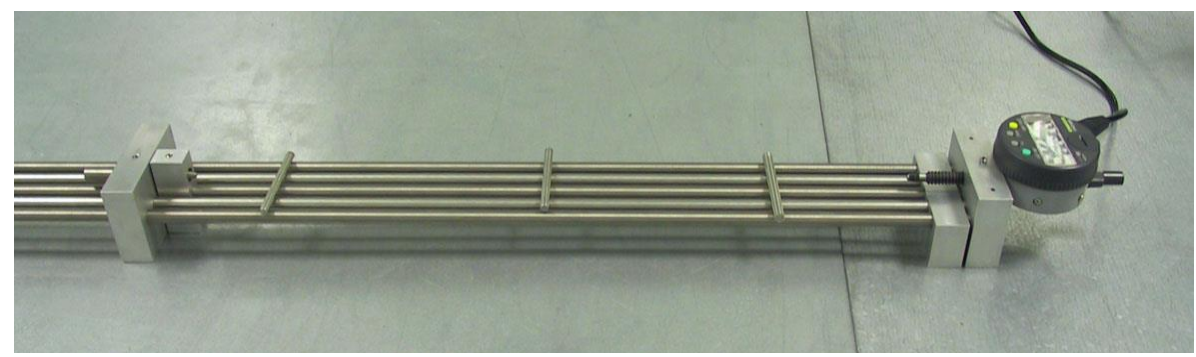

Figura 3.11. Equipo utilizado para los ensayos de expansión. 


\section{B. Medida simultánea de expansión y curvatura sobre probetas de laboratorio}

A fin de clarificar la relación entre curvatura y expansión, se decidió medir de forma simultánea la curvatura y la expansión tras la cocción en el caso de las probetas cocidas en laboratorio. Para ello se desarrolló el dispositivo mostrado en la figura 3.12 .

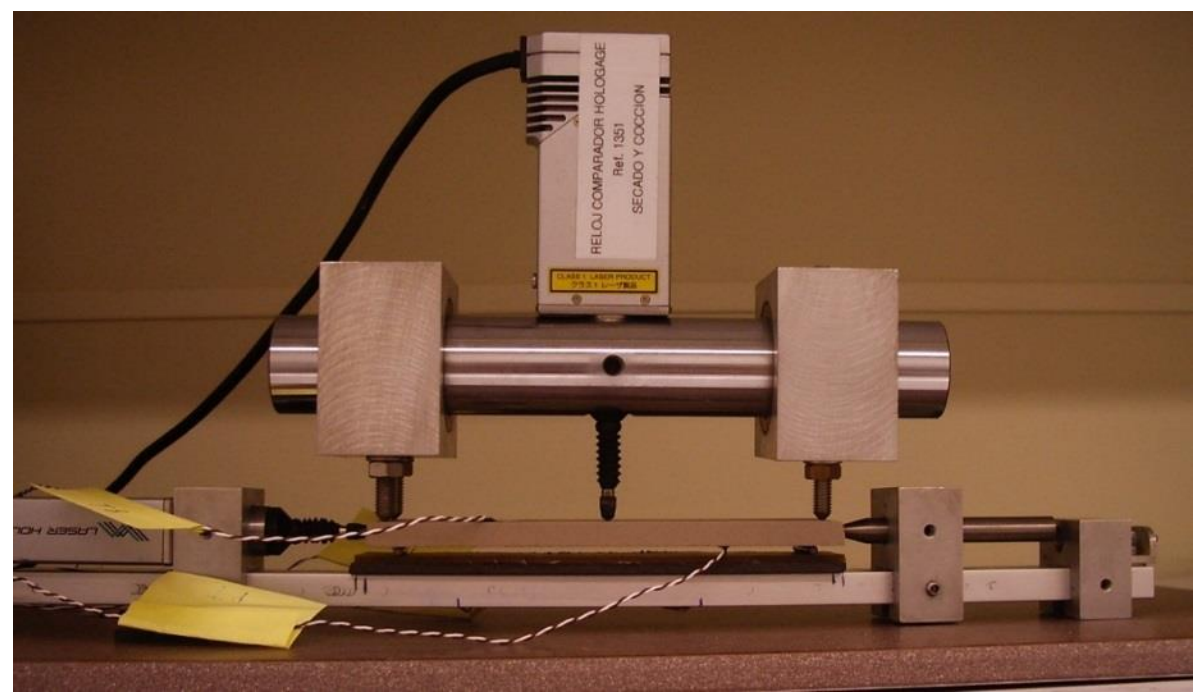

Figura 3.12. Dispositivo de medida simultánea de la flecha y de la expansión.

Este dispositivo consta de 2 relojes comparadores capaces de detectar cambios dimensionales con precisión inferior a $0,1 \mu \mathrm{m}$ mediante interferometría láser (Mitutoyo, Laser Hologage LGH-1010). Con uno de los relojes se determina la flecha central $\left(\delta_{c}\right)$, con una separación entre apoyos de $130 \mathrm{~mm}$ (con el mismo dispositivo que en el apartado 3.4.8), mientras que el otro se emplea para medir la expansión. Los equipos se conectan a ordenadores para registrar, con programas de adquisición de datos, la evolución de las propiedades con el tiempo.

Las mediciones se realizaron en continúo registrando valores cada 60 segundos durante las 24 horas posteriores a la cocción, comenzando una vez transcurridos 15 minutos desde que la temperatura superficial de la pieza alcanzase $200^{\circ} \mathrm{C}$.

En el caso de la medida de la expansión, hay que destacar que la probeta está aún caliente al inicio del ensayo y pueden existir pequeñas perturbaciones de temperatura durante el desarrollo del mismo. Por lo tanto, es necesario tener en consideración los cambios dimensionales de origen térmico que se producen en la barra de aluminio sobre la que se sitúa la pieza y los de la propia probeta. Dichos cambios se corrigen en base a los coeficientes de dilatación del aluminio y del material cerámico, y a las diferencias de temperatura determinadas con unos termopares de contacto. 


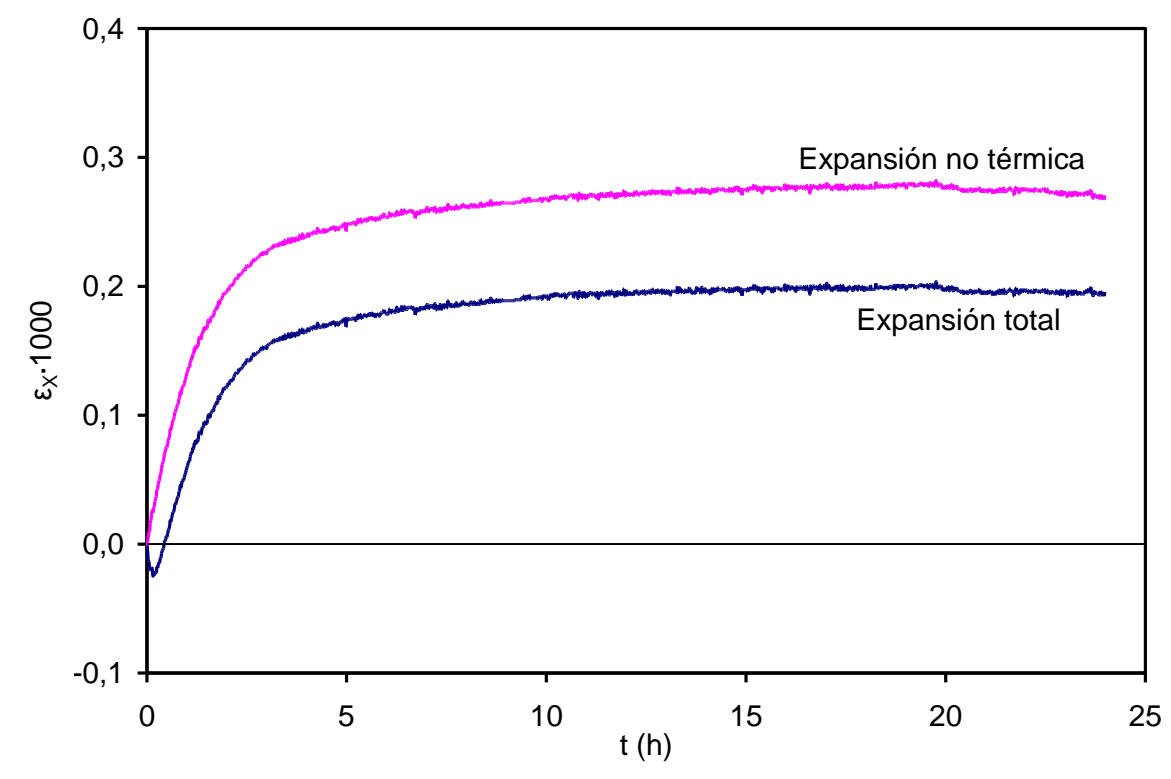

Figura 3.13. Expansión total y expansión de origen no térmico de una probeta.

A modo de ejemplo, la figura 3.13 muestra la expansión total de una probeta (en la que se aprecia una contracción inicial de origen térmico) y la expansión debida a procesos no térmicos (una vez aplicada la corrección).

\subsubsection{Medida de la expansión diferencial}

Uno de los factores que suelen considerarse como posible causante de las curvaturas en diferido es la existencia de una expansión no homogénea en las piezas (gradiente de expansión entre la parte inferior y superior).

Con el objetivo de verificar la existencia de estas diferencias, se puso a punto un ensayo para medir la expansión diferencial a escala de laboratorio, que viene esquematizado en la figura 3.14.

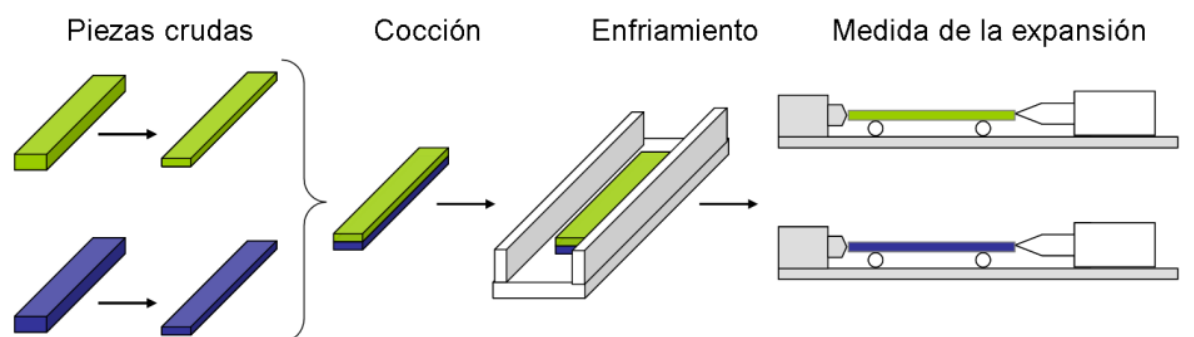

Figura 3.14. Representación esquemática del ensayo de medida de la expansión diferencial. 
Para realizar este ensayo es necesario partir de dos probetas crudas de 150 $\mathrm{mm} \times 30 \mathrm{~mm}$ y reducir su espesor a la mitad lijándolas y quedándose con la mitad superior (cara vista) de una de las probetas y con la mitad inferior (costilla) de la otra. Luego se procede a cocer juntas las dos mitades, apilándolas y colocando una fina capa de polvo de alúmina entre las mismas para poder separarlas tras el enfriamiento.

La cocción se realizó según el procedimiento descrito en el apartado 3.3.2. Sin embargo, no fue posible realizar el enfriamiento rápido en posición vertical al tener 2 probetas apiladas. En consecuencia, las probetas se enfriaron en posición horizontal, es decir con la superficie inferior en contacto con el aislante y la superficie superior al aire, tal y como se puede observar en la figura 3.14 .

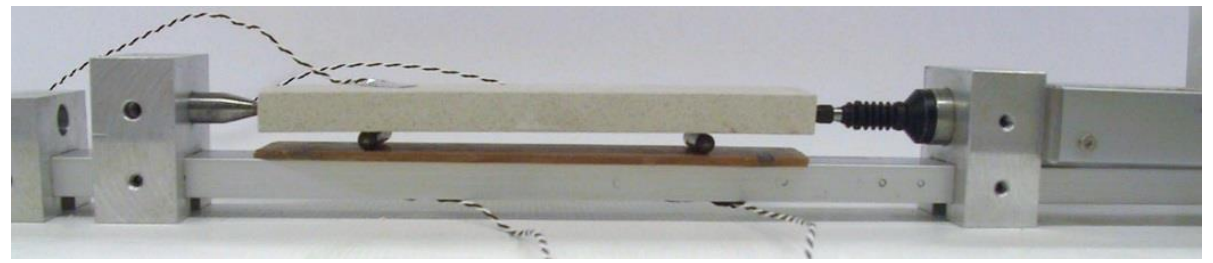

Figura 3.15. Equipo de medida de la expansión post-cocción.

Finalmente se mide por separado, y en paralelo, la expansión post-cocción de cada mitad, usando montajes similares al que se usó para medir la expansión en el apartado anterior (figura 3.15). 
3. Materiales, aparatos y técnicas experimentales 


\section{Capítulo 4. Resultados y discusión}

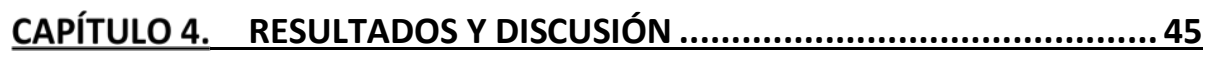

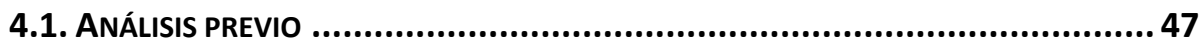

4.1.1. MEDIDA INDUSTRIAL DE LAS CURVATURAS EN DIFERIDO ....................................47

4.1.2. FACTORES QUE PUEDEN INFLUIR EN LAS CURVATURAS EN DIFERIDO................... 49

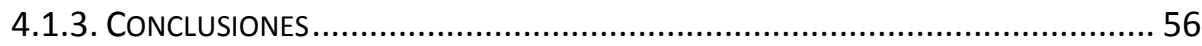

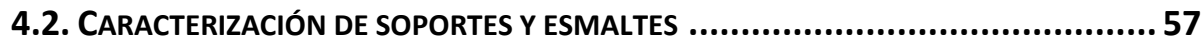

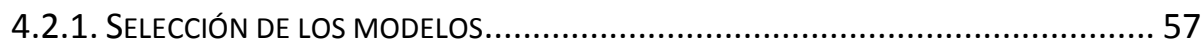

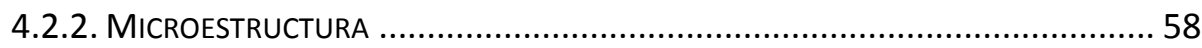

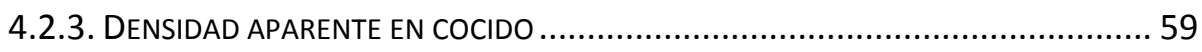

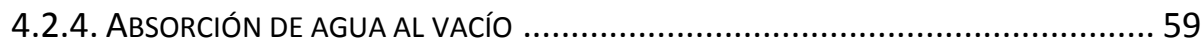

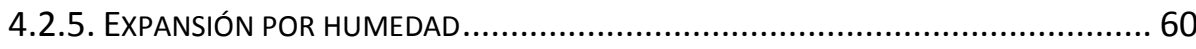

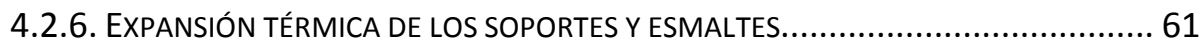

4.2.7. EXPANSIÓN POST-COCCIÓN DE LOS SOPORTES A TEMPERATURA AMBIENTE ........63

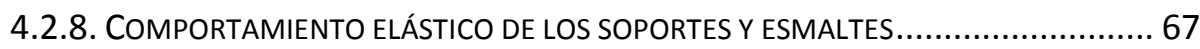

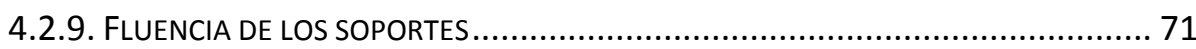

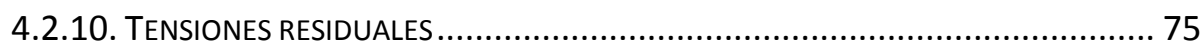

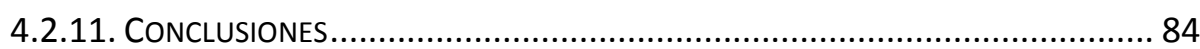

4.3. INFLUENCIA DE VARIABLES SOBRE LAS CURVATURAS EN DIFERIDO.....................86

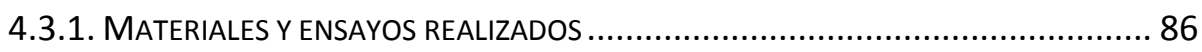

4.3.2. INFLUENCIA DE LA TEMPERATURA MÁXIMA DE COCCIÓN .................................. 86

4.3.3. INFLUENCIA DEL TAMAÑO DE PARTÍCULA (GRADO DE MOLIENDA) ..................... 91

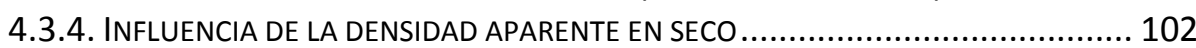

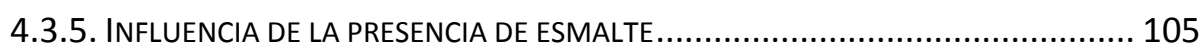

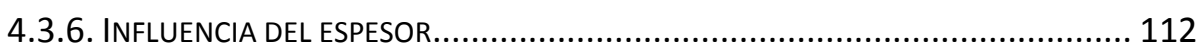

4.3.7. INFLUENCIA DEL TIEMPO DE PERMANENCIA A TEMPERATURA MÁXIMA ............ 120

4.3.8. INFLUENCIA DE LA VELOCIDAD DE ENFRIAMIENTO ...................................... 123 


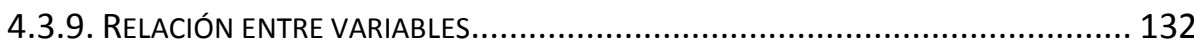

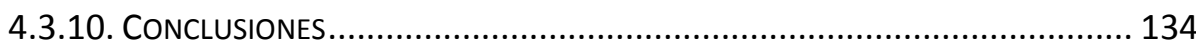

4.4. Modelización de LAS CURVATURAS EN DIFERIDO ............................... 136

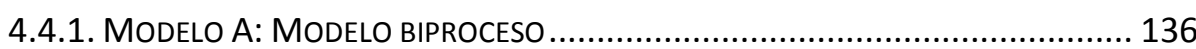

4.4.2. MODELO B: EXPANSIÓN DIFERENCIAL DISCONTINUA ................................... 138

4.4.3. MODELO C: EXPANSIÓN DIFERENCIAL ASOCIADA A UN PROCESO DIFUSIONAL ... 141

4.4.4. MODELO D: EXPANSIÓN DIFERENCIAL CON DIFUSIVIDAD VARIABLE ................ 145

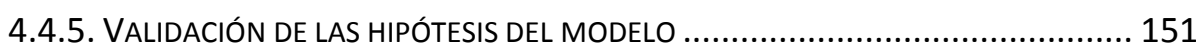

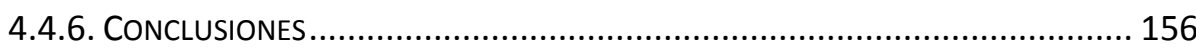

4.5. PROPUESTA DE ENSAYOS DE CONTROL INDUSTRIAL.............................. 158

4.5.1. POSIBLES ENSAYOS DE CONTROL INDUSTRIAL ...................................... 158

4.5.2. VALIDACIÓN DE LOS ENSAYOS DE CONTROL INDUSTRIAL PROPUESTOS.............. 159

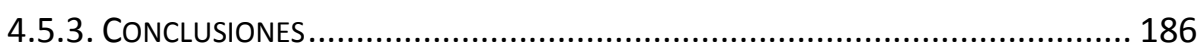




\subsection{ANÁLISIS PREVIO}

El primer paso en el estudio de las curvaturas diferidas en baldosas de gres porcelánico fue la cuantificación de la magnitud y la cinética de las curvaturas diferidas, y el análisis de los factores que podían intervenir en su aparición y desarrollo. Para ello se seleccionaron seis modelos industriales de varias empresas (tabla 4.1). Estos ensayos permitieron cuantificar el problema de curvaturas en diferido.

Tabla 4.1. Características de los modelos estudiados.

\begin{tabular}{|c|c|c|c|c|c|c|}
\hline Modelo & 1 & 2 & 3 & 4 & 5 & 6 \\
\hline Dimensiones (cm) & $45 \times 45$ & $30 \times 60$ & $33 \times 67$ & $45 \times 45$ & $30 \times 60$ & $45 \times 45$ \\
\hline Esmaltado & Sí & Sí & Sí & Sí & Sí & Sí \\
\hline
\end{tabular}

\subsubsection{Medida industrial de las curvaturas en diferido}

Tal y como se indica en el apartado 3.4.8, para cada uno de los modelos se realizaron dos tipos de medidas con el fin de caracterizar su comportamiento frente a las curvaturas en diferido:

- Medida en continuo de la flecha durante 24 horas tras la salida de las piezas del horno. Estas medidas se realizaron en planta para obtener datos desde la salida del horno.

- Medida en discontinuo de la flecha durante un periodo de 2 meses.

En la figura 4.1 y figura 4.2 se muestra la variación de la flecha $\left(\delta_{c}\right)$ con el tiempo $(\mathrm{t})$ para los modelos ensayados. Para cada modelo se muestran dos gráficas, la primera (izquierda) corresponde a la medida en continuo realizada durante las primeras 24 horas desde la salida de la pieza del horno, y la segunda (derecha) muestra los valores de flecha medidos de forma discontinua durante un periodo de 60 días.

De la observación de estas figuras se desprende lo siguiente:

- La totalidad de modelos ensayados presentan curvatura diferida, a excepción del modelo 3.

- La variación de la curvatura con el tiempo sigue la misma tendencia en todos los modelos. Consiste en una disminución inicial de la flecha para, transcurrido cierto tiempo, invertir esta tendencia.

- El proceso de disminución de la flecha es más rápido que el de aumento de la flecha.

- Existen diferencias importantes en la velocidad a la cual cambia la flecha o curvatura de las piezas. Así, los modelos 1 y 5 presentan una variación rápida de la curvatura con el tiempo, mientras que en los modelos 2 y 4 este cambio es mucho más lento.

- La curvatura tarda entre 5 y 10 días en estabilizarse. 


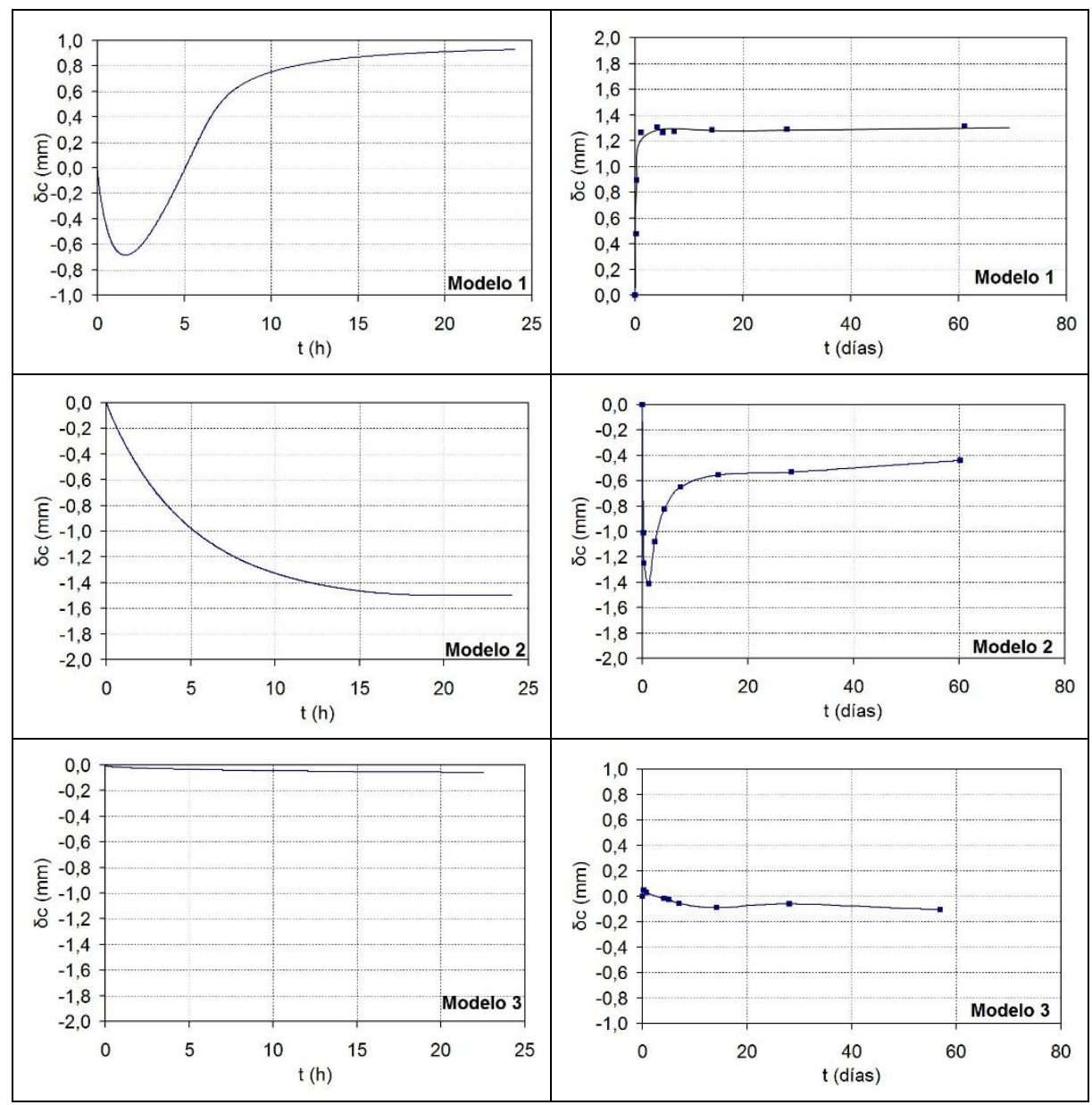

Figura 4.1. Evolución de la curvatura con el tiempo para diferentes modelos industriales de gres porcelánico. 


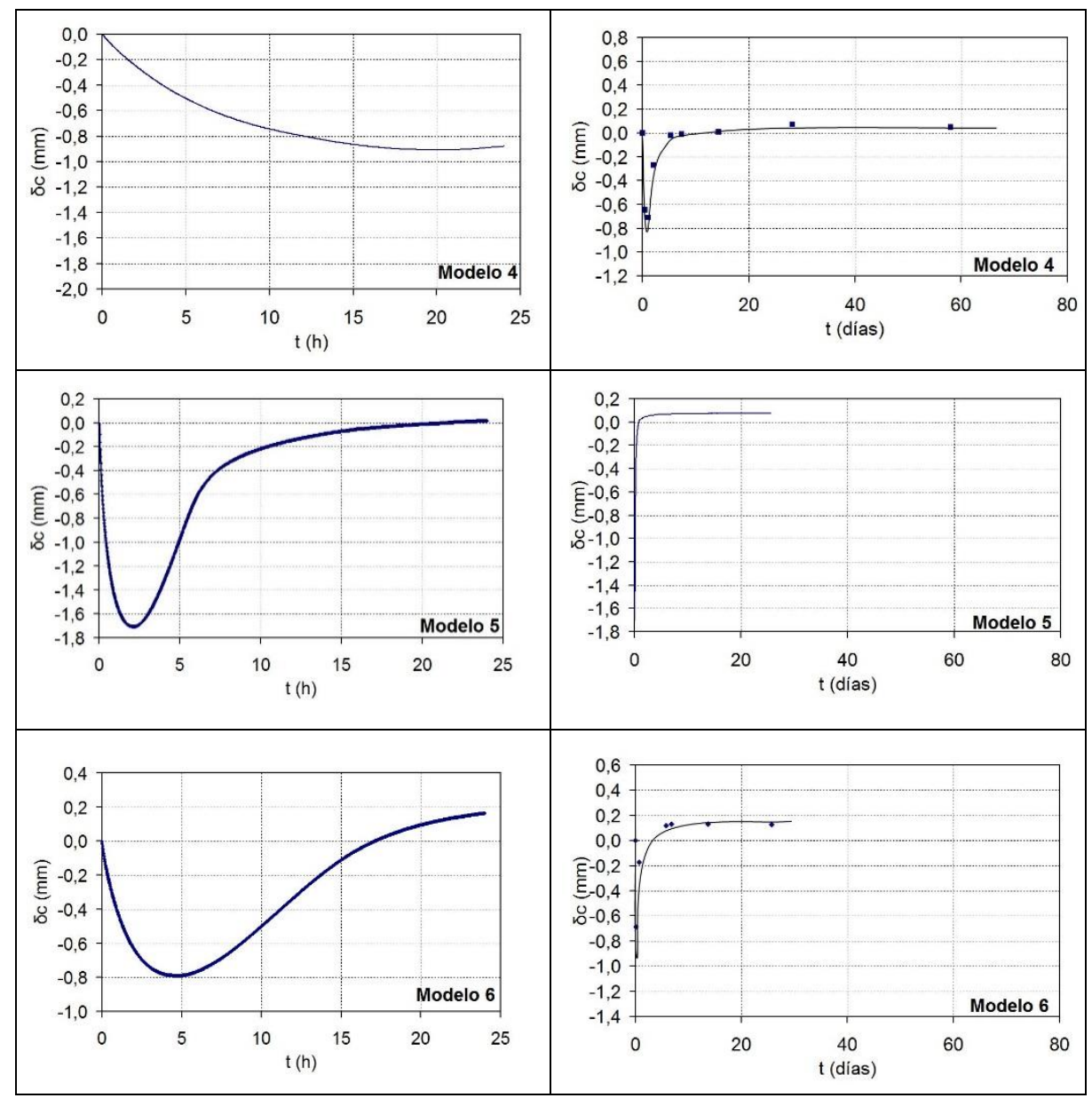

Figura 4.2. Evolución de la curvatura con el tiempo para diferentes modelos industriales de gres porcelánico.

Además de cuantificar la magnitud de las curvaturas diferidas en baldosas industriales, se identificaron los factores que podían influir sobre este fenómeno y vienen detallados en el apartado siguiente.

\subsubsection{Factores que pueden influir en las curvaturas en diferido}

En general, los factores que influyen sobre las curvaturas en diferido de las baldosas pueden agruparse en directos e indirectos. Los primeros se caracterizan por ser los causantes últimos de las curvaturas diferidas; los segundos pueden influir en las curvaturas en diferido bien porque actúen sobre algún factor directo, o bien porque modifiquen la evolución de la curvatura diferida (pero no la generan). 


\section{A. Factores directos}

Para que una baldosa cocida modifique su curvatura con el tiempo es necesario que exista un cambio en las dimensiones de alguna de sus capas respecto a otras, como podría ser el caso de la expansión del soporte de una pieza esmaltada, o que cambie la fuerza ejercida sobre ella. Este último caso puede ocurrir cuando existe una relajación de las tensiones residuales presentes en la baldosa.

De este modo, básicamente existen dos factores directos que pueden causar las curvaturas diferidas: la expansión de los soportes y la relajación de las tensiones residuales. El resto de factores son indirectos.

\section{a) Expansión de los soportes}

En una pieza esmaltada, la expansión del soporte puede conducir a la aparición de curvaturas diferidas, tal como se muestra en la figura 4.3. El mecanismo es muy similar al cambio de curvatura que se produce durante el enfriamiento dentro del horno debido al acoplamiento entre las capas de esmalte y soporte como consecuencia de la diferencia de contracción entre ambas capas [Smith, 1955]. En este caso la expansión del soporte conducirá a una curvatura cóncava, suponiendo que la pieza inicialmente es plana y que el esmalte prácticamente no expande.

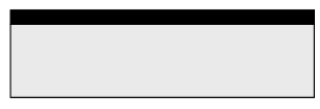

$t=0$

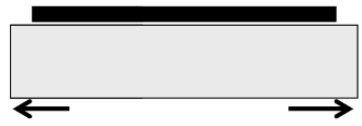

$t=t$

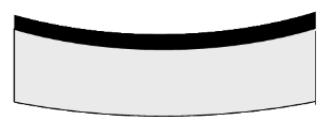

$t=t$

Figura 4.3. Representación esquemática de la curvatura diferida originada por la expansión del soporte.

Una vez identificado uno de los factores que puede causar la curvatura diferida, es necesario verificar si los soportes de gres porcelánico expanden. Aunque es bien conocido que los soportes de los azulejos presentan una expansión por humedad apreciable, que puede llegar a producir problemas de cuarteo del esmalte en condiciones límite, esta propiedad no suele medirse en los soportes de gres porcelánico, debido a la inexistencia de defectos de cuarteo en estos productos y a su reducida porosidad abierta.

En la figura 4.4 se muestra la evolución de la expansión $\left(\varepsilon_{x}\right)$ de un soporte de gres porcelánico a la salida del horno industrial. Se observa que en los instantes iniciales la expansión es muy rápida, estabilizándose a partir de las 96 horas en un valor en torno a 0,18 \%o. Este resultado depende de la composición utilizada y de la temperatura máxima de cocción; sin embargo, se puede considerar representativo de este tipo de soportes. Con fines comparativos, cabe indicar que la expansión de los soportes de azulejo de cocción blanca suele estar alrededor de $0,60 \%$, lo cual difiere sólo en un factor 3 respecto al valor que presenta el gres porcelánico. 
La expansión de los soportes, por sí sola, es insuficiente para explicar las curvaturas en diferido. Como se ha indicado anteriormente, es necesaria la presencia de otra capa que no se deforme. Este papel podría jugarlo la capa de esmalte en los productos esmaltados; sin embargo, hay baldosas de gres porcelánico no esmaltado que también presentan el problema de curvaturas diferidas.

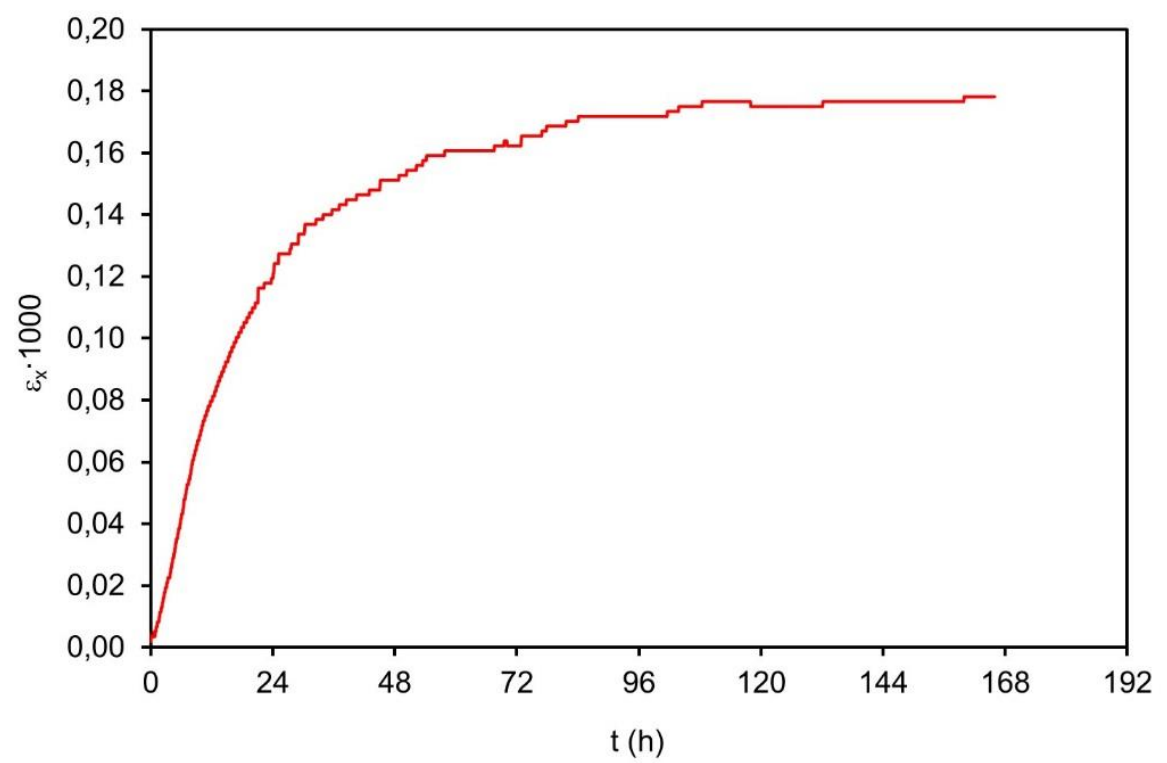

Figura 4.4. Evolución de la expansión de un soporte de gres porcelánico en función del tiempo.

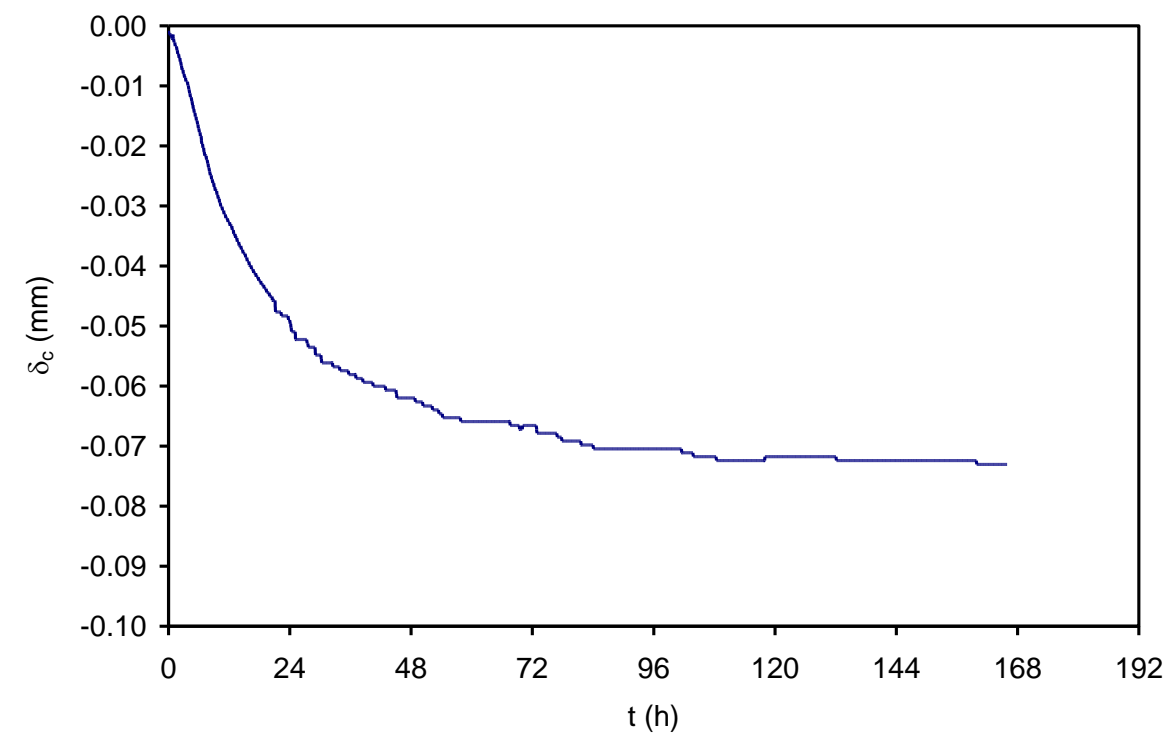

Figura 4.5. Curvatura diferida provocada por la expansión del soporte. 
En la figura 4.5 se muestra el valor de la flecha de curvatura que presentará una baldosa de $41 \times 41 \mathrm{~cm}$ calculada a partir de la expansión típica de un soporte de gres porcelánico, y considerando el acoplamiento con el esmalte. Como puede observarse, la expansión del soporte no es suficiente, en general, para explicar las curvaturas diferidas; aunque en algunos casos pueda jugar un cierto papel.

En el cálculo anterior, se ha considerado que la expansión del soporte es homogénea en todo su espesor. Sin embargo, si existiera una diferencia en la expansión del soporte entre la cara vista y la cara posterior, se podría justificar parte de la curvatura diferida, tanto en productos esmaltados como no esmaltados. No sólo eso, aun cuando la expansión total de ambas caras fuera la misma, una diferencia en la cinética de la expansión podría provocar cambios en el sentido de la curvatura similares a los observados en baldosas industriales.

\section{b) Relajación de tensiones residuales}

Otra de las hipótesis utilizadas para explicar las curvaturas en diferido es la presencia de tensiones residuales en las baldosas. Si estas tensiones se relajan por algún mecanismo, como la fluencia, pueden conducir a variaciones en la curvatura de las piezas.

La existencia de tensiones residuales en las baldosas cerámicas puede deberse a dos causas: el enfriamiento rápido de la pieza dentro del horno industrial (tensiones asociadas a los gradientes térmicos dentro de la pieza), y el acoplamiento entre el soporte y el esmalte.

Sin embargo, la existencia de un perfil de tensiones residuales no es suficiente para provocar curvaturas en diferido. Es necesario, además, que este perfil sea asimétrico y que exista fluencia. Respecto a la asimetría del perfil, cabe indicar que un perfil simétrico significa grosso modo que la tensión es la misma en la cara vista que en la cara posterior; por tanto, la pieza no tendrá tendencia a curvar hacia ninguno de los dos lados.

Asimismo, las tensiones residuales, por sí solas, no provocan curvaturas diferidas, aunque sean altamente asimétricas. Es necesario que exista un mecanismo por el que la pieza pueda liberar estas tensiones. Este mecanismo se conoce como fluencia y, al igual que en el caso de las tensiones residuales, es necesario verificar si las piezas de gres porcelánico presentan este comportamiento.

\section{B. Factores indirectos}

Las características de los materiales empleados en la fabricación de las baldosas de gres porcelánico (polvos atomizados, esmaltes, etc.) junto con las variables de proceso utilizadas, definen las características finales de las baldosas cerámicas, como se observa en el esquema de la figura 4.6. Estos factores, aunque no son los responsables directos de las curvaturas diferidas, podrían influir significativamente sobre ellas. 


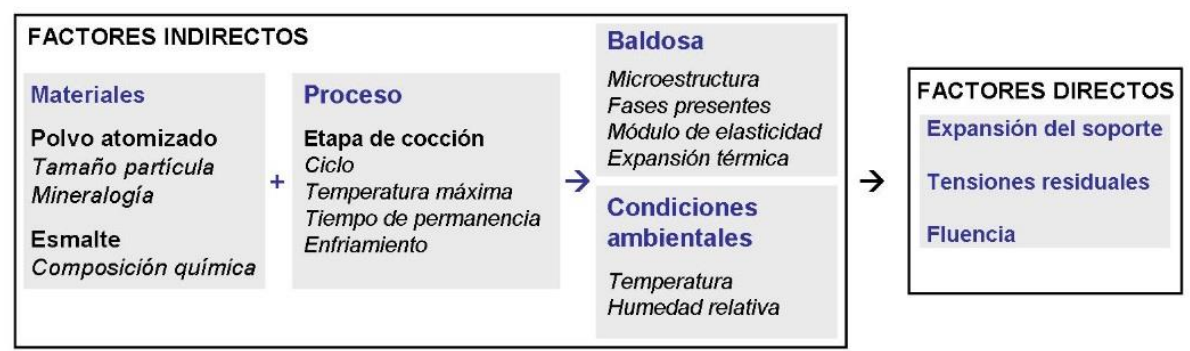

Figura 4.6. Factores que podrían influir sobre las curvaturas diferidas.

\section{a) Factores que afectan a la expansión del soporte}

La expansión por acción de la humedad de los soportes cerámicos es una característica conocida, existiendo en la normativa vigente (norma UNE EN ISO 10545-3) procedimientos para su medida. Habitualmente, los valores de expansión por acción de la humedad en autoclave, con ciclos de presión de vapor de 5 horas a 10 bares, suelen oscilar entre el 0,6 y el 1,0\% para los soportes de azulejo, reduciéndose hasta valores inferiores al 0,3\% para baldosas de baja absorción de agua como el gres porcelánico.

La expansión por humedad de los productos cerámicos porosos (loza y azulejo) ha sido ampliamente estudiada por su relación con los defectos de cuarteo del vidriado. Para estos productos el origen de la expansión por humedad de los soportes cerámicos es la adsorción química y física de moléculas de agua sobre las valencias libres existentes en las fases hidratables presentes en las piezas cocidas (fases vítreas y, en especial, fases amorfas provenientes de la deshidroxilación de los minerales arcillosos) [Smith, 1955]. Por ello, la expansión depende principalmente de la estructura porosa de la pieza (que define la mayor o menor accesibilidad por parte del agua) [Vasic, 1992] y de la naturaleza y contenido de fases presentes en la pieza cocida [Segadaes et al., 2003]. Estas características están muy influenciadas por la composición mineralógica de la composición utilizada, su tamaño de partícula y la cocción realizada [Schurecht et al., 1929]. Así, a medida que aumenta la fundencia de la composición del soporte y la temperatura de cocción o el tiempo de permanencia, disminuye la expansión por humedad de estos soportes debido a la reducción de su porosidad y de su contenido en fases hidratables [Harrison et al., 1964].

En el caso de los soportes de muy baja porosidad, como el gres porcelánico, no se han encontrado trabajos que aborden este tema, debido probablemente a la menor expansión y a la ausencia de defectos de cuarteo en estos productos. No obstante, es probable que los factores que influyen sobre la expansión por humedad en soportes porosos también lo hagan en el caso de los soportes de gres porcelánico. 


\section{b) Factores que afectan a las tensiones residuales}

Al alcanzar la temperatura máxima de cocción, las baldosas de gres porcelánico están formadas por una gran cantidad de fase líquida, cuarzo y albita residual y, en ocasiones, mullita [Sánchez et al., 2001]. En este estado, la pieza es capaz de relajar cualquier tensión que se ejerza sobre ella, ya que presenta una elevada deformabilidad viscosa. Es durante la fase de enfriamiento cuando se originan las tensiones residuales en las baldosas, ya sea por desajustes en el acoplamiento entre las capas de soporte y esmalte o por las contracciones diferenciales que surgen como consecuencia de la mayor velocidad de enfriamiento existente entre la superficie y el centro de la pieza. Así, puede decirse que los factores que determinan las tensiones residuales en las piezas de gres porcelánico son la expansión térmica y el módulo de elasticidad del soporte y esmalte, sus espesores relativos y la velocidad de enfriamiento de la pieza.

Se ha observado que el aumento en el desajuste de la expansión térmica de ambas capas, así como el aumento en el espesor del esmalte, incrementan las tensiones residuales en el soporte. Asimismo, a medida que el enfriamiento es más rápido, aumenta el gradiente de temperatura en el interior de la baldosa [Cantavella et al., 2006], lo que conduce a diferencias en la velocidad de contracción a lo largo de su sección. Ello causa un perfil de tensiones en el interior de la pieza que es más acusado a medida que aumenta la velocidad de enfriamiento [De Noni et al., 2007]. Además, cuando la velocidad de enfriamiento no es igual por ambas superficies de las baldosas (situación habitual en los hornos de rodillos) el perfil de tensiones que se establece puede ser asimétrico.

\section{c) Factores que afectan a la fluencia}

Los factores que influyen sobre la fluencia del gres porcelánico deben de asociarse a su microestructura. En la figura 4.7 se muestra la sección de una pieza de gres porcelánico observada por microscopía electrónica de barrido. Está formada por una matriz vítrea en la que existen numerosos poros y microgrietas. Los poros presentes suelen presentar formas redondeadas y proceden de la descomposición de ciertas impurezas, así como de la porosidad de elevado tamaño presente en la pieza cruda [Amorós et al., 2007]. El origen de las microgrietas es variado, destacando los desajustes existentes entre las partículas de cuarzo residual y la matriz vítrea [De Noni et al., 2007] y las zonas de unión entre los gránulos del polvo atomizado que no se han deformado en su totalidad durante el prensado [García-Ten et al., 2004]. 


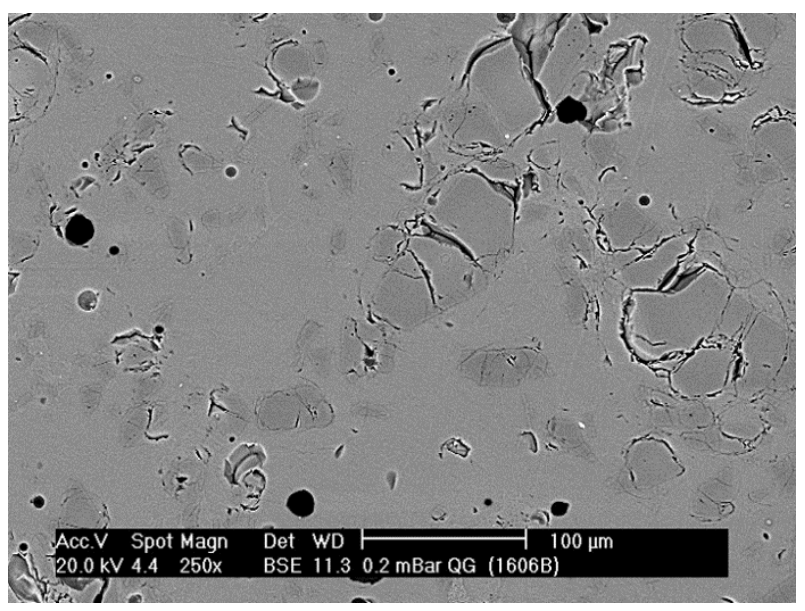

Figura 4.7. Sección transversal de una pieza de gres porcelánico.

La fluencia en piezas de gres porcelánico está causada muy probablemente por el crecimiento de las microgrietas existentes en la pieza cuando ésta se encuentra sometida a un esfuerzo de tracción. Se ha comprobado que un aumento en el contenido de cuarzo, así como de su tamaño de partícula origina una microestructura con una mayor cantidad de microgrietas, lo que probablemente aumentará la fluencia de las piezas. Esto mismo también puede suceder cuando el grado de molienda es insuficiente.

\section{d) Influencia del esmalte sobre la curvatura diferida}

En la figura 4.8 se muestra la evolución de la flecha con el tiempo para baldosas de gres porcelánico esmaltado, de $300 \times 600 \mathrm{~mm}$, con y sin esmalte. Puede observarse que mientras que la baldosa con esmalte presenta una evolución de la curvatura cualitativamente similar a la mostrada en el apartado 4.1.1., el soporte sin esmalte sigue la evolución opuesta. Es interesante destacar que el tiempo para el que se observa la curvatura mínima en la pieza con esmalte $(24 \mathrm{~h}, 0,37 \mathrm{~mm})$ prácticamente coincide con el tiempo para en que se detecta la máxima curvatura en la pieza sin esmaltar (23 h, 1,02 mm).

Este comportamiento en las piezas sin esmalte puede deberse a la existencia de velocidades de expansión diferentes entre la cara vista y la superficie posterior, dado que las baldosas se han cocido con el mismo ciclo y, por tanto, las tensiones residuales debidas al enfriamiento deben ser similares.

La figura permite también concluir que el esmalte tiene una influencia significativa sobre la evolución de la curvatura con el tiempo. 


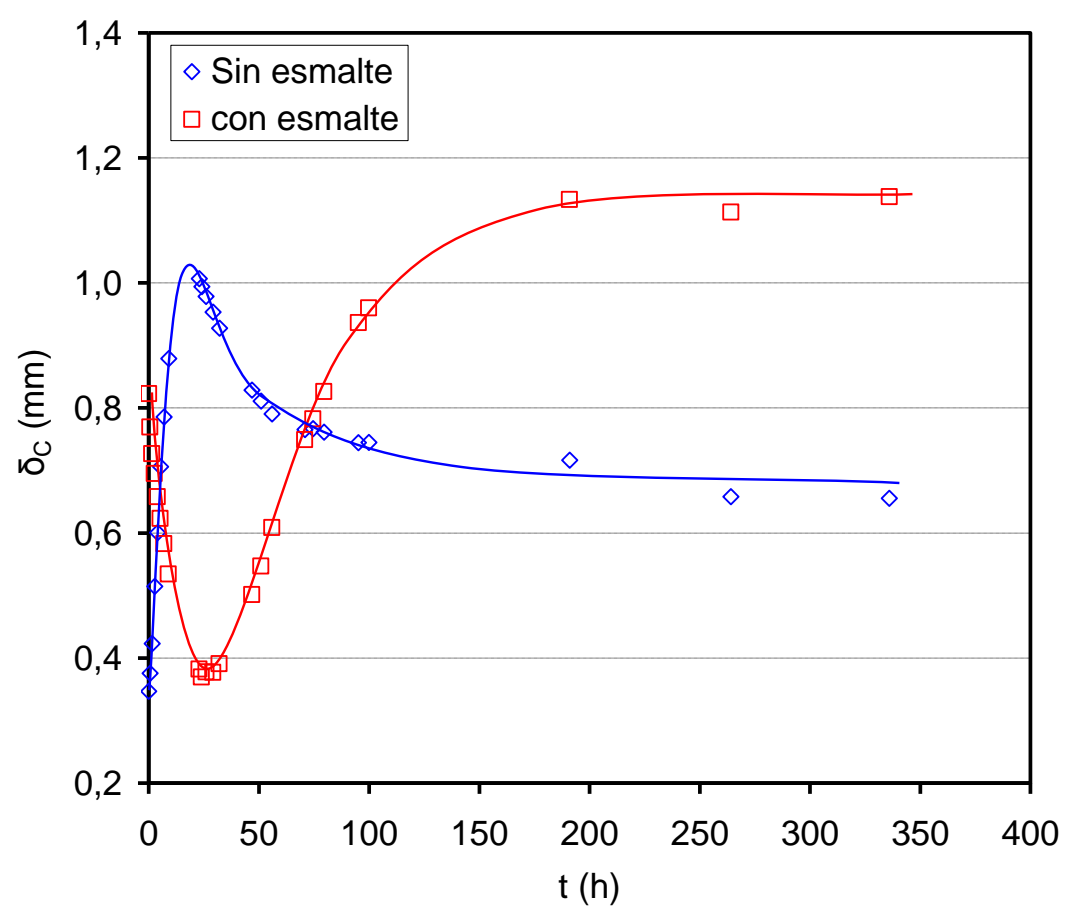

Figura 4.8. Evolución de la fecha de baldosas con y sin esmalte.

\subsubsection{Conclusiones}

Se ha cuantificado la variación de la curvatura con el tiempo en piezas industriales observando que existe un cambio en su tendencia (cóncavaconvexa). Ello implica que existen dos mecanismos, simultáneos y antagónicos, con cinéticas diferentes, que influyen sobre el proceso.

Los análisis teóricos indican que sólo existen dos factores que pueden producir las curvaturas diferidas: la expansión de los soportes y las tensiones residuales. En ambos casos es necesario que se den circunstancias adicionales para que aparezcan las curvaturas en diferido; así, es necesario que la expansión sea diferente por la cara vista y por la cara posterior, una expansión uniforme provocaría un ligero cambio dimensional, pero no una curvatura en diferido significativa. En el caso de las tensiones residuales, el perfil de tensiones debe de ser asimétrico y tiene que existir un mecanismo que permita su relajación (fluencia). 


\subsection{CaRACTERIZACión De SOPORTES Y ESMALTES}

\subsubsection{Selección de los modelos}

Para estudiar el fenómeno de curvaturas en diferido en baldosas de gres porcelánico, se seleccionaron cuatro modelos industriales que presentaban un comportamiento distinto desde el punto de vista de las curvaturas en diferido (tabla 4.2).

Tabla 4.2. Características de los modelos estudiados.

\begin{tabular}{|c|c|c|}
\hline Referencia & Esmaltado & Curvatura diferida \\
\hline Modelo 4 & Sí & Sí \\
\hline Modelo 7 & No & No \\
\hline Modelo 8 & Sí & Si \\
\hline Modelo 9 & Sí & No \\
\hline
\end{tabular}

De los 4 modelos elegidos para este estudio, solo se había medido la evolución de la curvatura en diferido de uno de ellos (modelo 4) durante el análisis previo (apartado 4.1.1). Los modelos 7 y 9 se añadieron al estudio debido a la necesidad de incorporar dos modelos que no presentaran curvaturas en diferido. En efecto, de los 6 modelos estudiados en el análisis previo, el único que no presentaba curvaturas en diferido era el 3 y la empresa fabricante no podía proporcionar muestras en el momento del estudio ya que este modelo no estaba en producción. Por otra parte, cabe destacar que el modelo 8 solo difiere del 2 (caracterizado en el apartado 4.1.1) por el tono del esmalte por lo que ambos modelos presentan un comportamiento parecido frente a las curvaturas en diferido.

Para cada uno de los modelos seleccionados, se determinaron las propiedades siguientes:

- microestructura,

- densidad aparente en cocido,

- absorción de agua a vacío (norma UNE EN ISO 10545-3),

- expansión por humedad (norma UNE EN ISO 10545-3),

- expansión térmica,

- evolución de la expansión post-cocción,

- resistencia mecánica,

- módulo de elasticidad,

- fluencia,

- tensiones residuales. 
Para poder completar la caracterización (tensiones residuales de acoplamiento) se prepararon piezas industriales con distintos espesores de engobe y esmalte, tal y como se indica en el apartado 3.4.

El modelo 8 no poseía engobe, pero presentaba dos esmaltes distintos, por lo que se preparó la misma cantidad de piezas, pero en este caso la letra g se refiere a la primera capa de esmalte en vez de al engobe.

\subsubsection{Microestructura}

Se ha observado la microestructura de los cuatro modelos seleccionados por microscopía óptica. En la figura 4.9 se muestra el aspecto de la sección de las distintas probetas.

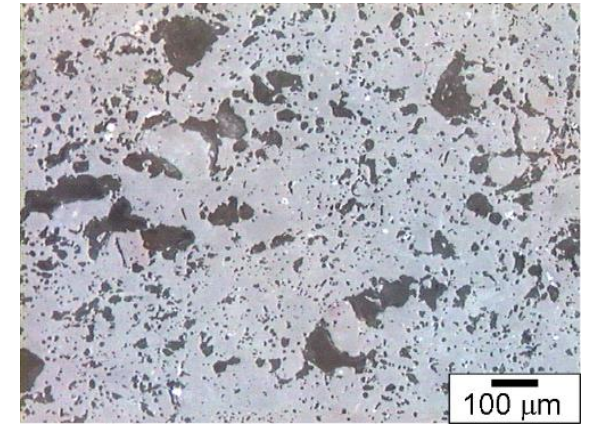

Modelo 4 (con curvatura diferida)

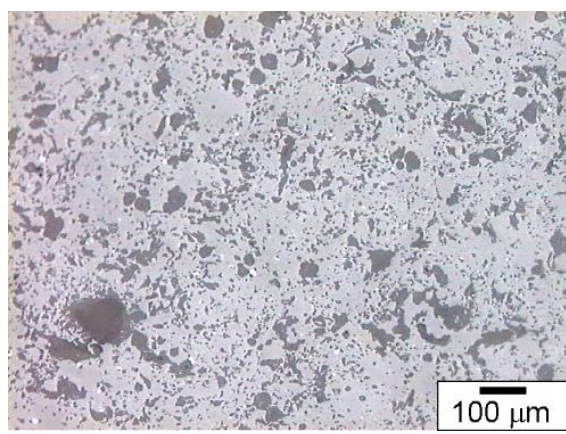

Modelo 8 (con curvatura diferida)

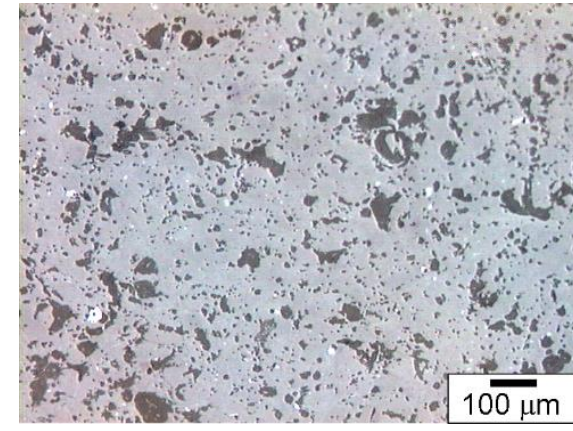

Modelo 7 (sin curvatura diferida)

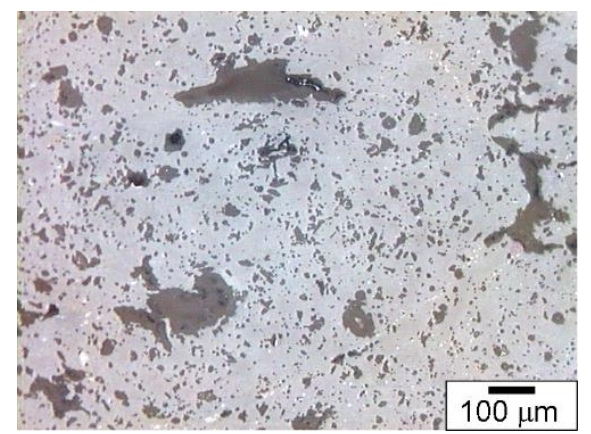

Modelo 9 (sin curvatura diferida)

Figura 4.9. Micrografías ópticas de los soportes de los modelos estudiados.

Se aprecia que el modelo 4 presenta poros de mayor tamaño, con formas más irregulares e interconectados, lo que indica que su grado de cocción ha sido inferior al modelo 7 , que muestra una microestructura formada por poros más redondeados, aislados y sin poros de elevado tamaño.

Por otra parte, el modelo 8 , con curvatura diferida, presenta una microestructura formada por una multitud de poros de pequeño tamaño lo que indica que no se ha alcanzado un suficiente grado de cocción. 
En cambio, el modelo 9 se encuentra más densificado, presenta una menor proporción de poros pequeños y algunos poros grandes que provienen, probablemente, del hueco central del granulado atomizado utilizado.

Las microestructuras observadas parecen indicar que los modelos con curvatura diferida presentan un grado de cocción inferior a aquellos que no presentan curvatura diferida.

\subsubsection{Densidad aparente en cocido}

En la tabla 4.3 se muestran los valores de la densidad aparente de los soportes (s), soportes con engobe $(\mathrm{s}+\mathrm{g})$ y soportes con engobe y esmalte $(s+g+v)$ de los cuatro modelos estudiados, medida mediante inmersión en mercurio.

Tabla 4.3. Densidades aparentes de los modelos estudiados $\left(\mathrm{en} \mathrm{kg} / \mathrm{m}^{3}\right)$.

\begin{tabular}{|c|c|c|c|c|}
\cline { 2 - 5 } \multicolumn{1}{c|}{} & $\mathbf{s}$ & $\mathbf{s + g}$ & $\mathbf{s + g + v}$ & Curvatura diferida \\
\hline Modelo 4 & $2301 \pm 1$ & $2306 \pm 1$ & $2308 \pm 2$ & Sí \\
\hline Modelo 7 & $2417 \pm 2$ & - & - & No \\
\hline Modelo 8 & $2333 \pm 1$ & $2331 \pm 1$ & $2333 \pm 3$ & Sí \\
\hline Modelo 9 & $2364 \pm 1$ & $2360 \pm 1$ & $2361 \pm 1$ & No \\
\hline
\end{tabular}

Se observa lo siguiente:

- La presencia de engobe y esmalte no modifica significativamente la densidad aparente.

- Los modelos que presentan los valores más bajos de la densidad aparente son también los que muestran curvatura diferida.

\subsubsection{Absorción de agua al vacío}

Se ha medido la absorción de agua a vacío de los soportes siguiendo el método descrito en la norma UNE EN ISO 10545-3: 1997 y ampliando el tiempo de permanencia a siete días. Los valores obtenidos se detallan en la tabla 4.4.

Tabla 4.4. Absorción de agua de los modelos seleccionados.

\begin{tabular}{|c|c|c|c|}
\cline { 2 - 4 } \multicolumn{1}{c|}{} & AA (\%) & AA7 días (\%) & Curvatura diferida \\
\hline Modelo 4 & 0,8 & 2,3 & Sí \\
\hline Modelo 7 & 0,1 & 0,1 & No \\
\hline Modelo 8 & 0,5 & 2,1 & Sí \\
\hline Modelo 9 & 0,1 & 0,1 & No \\
\hline
\end{tabular}


Puede apreciarse lo siguiente:

- La absorción de agua de los soportes cocidos industrialmente es bastante diferente, existiendo valores muy bajos $(0,1 \%)$ y valores algo más elevados $(0,5$ y $0,8 \%)$.

- Los modelos que presentan valores de absorción de agua del $0,1 \%$ no muestran un aumento de la absorción de agua al permanecer sumergidos durante 7 días. Por el contrario, aquellos modelos con valores mayores de la absorción de agua experimentan un aumento con el tiempo.

- Los modelos con soportes de muy baja absorción de agua, la cual, además, no aumenta con el tiempo, no presentan curvatura diferida.

Estos resultados parecen indicar que existe cierta relación entre la curvatura diferida, la densidad en cocido, y la absorción de agua, de tal forma que aquellos modelos que presentan un mayor grado de cocción no muestran el fenómeno de curvatura diferida.

\subsubsection{Expansión por humedad}

Se ha medido la expansión por humedad de los 4 modelos, siguiendo el método descrito en la norma ASTM C 370-88. Dicha expansión podría ser otro de los factores causantes de la curvatura diferida. En todo caso, si la expansión del soporte fuera homogénea, esta produciría un aumento en las dimensiones de la pieza, pero no un cambio de curvatura. Para que la expansión provoque curvaturas en diferido es necesario que sea no homogénea (expansión diferente entre la cara vista y la cara de la costilla).

Los resultados obtenidos vienen recogidos en la tabla 4.5.

Tabla 4.5. Expansión por humedad de los modelos seleccionados.

\begin{tabular}{|l|c|c|}
\cline { 2 - 3 } \multicolumn{1}{c|}{} & Expansión por humedad (\%) & Curvatura diferida \\
\hline Modelo 4 & 0.2 & $\mathrm{Si}$ \\
\hline Modelo 7 & $<0.1$ & $\mathrm{No}$ \\
\hline Modelo 8 & 0.2 & $\mathrm{Si}$ \\
\hline Modelo 9 & 0.1 & $\mathrm{No}$ \\
\hline
\end{tabular}

Se observa que los modelos 4 y 8 , con curvatura diferida, tienen valores de expansión por humedad más elevada que los modelos 7 y 9 , que no presentan curvatura diferida.

Estos resultados parecen indicar que existe cierta relación entre la curvatura diferida y la expansión por humedad, de tal forma que aquellos modelos que presentan una menor expansión no muestran curvaturas diferidas. 


\subsubsection{Expansión térmica de los soportes y esmaltes}

\section{A. Análisis dilatométrico de los soportes}

Los coeficientes de dilatación de los modelos seleccionados se muestran en la tabla 4.6, mientras que las curvas dilatométricas se presentan en la figura 4.10.

No existen diferencias apreciables en los coeficientes de dilatación ni en las curvas dilatométricas de los diferentes modelos, por lo que no se puede establecer ninguna relación con las curvaturas diferidas.

Tabla 4.6. Coeficientes de dilatación de los soportes.

\begin{tabular}{|l|c|c|c|}
\cline { 2 - 4 } \multicolumn{1}{c|}{} & $\begin{array}{c}\mathbf{\alpha}_{50-300 \cdot 10^{7}} \\
{ }^{\circ} \boldsymbol{C}^{-1}\end{array}$ & $\begin{array}{c}\boldsymbol{\alpha}_{300-500 \cdot 10^{7}} \\
{ }^{-5} \boldsymbol{C}^{-1}\end{array}$ & $\begin{array}{c}\mathbf{\alpha}_{500-650 \cdot 10^{7}} \\
{ }^{o} C^{-1}\end{array}$ \\
\hline Modelo 4 & 63 & 81 & 97 \\
\hline Modelo 7 & 67 & 85 & 98 \\
\hline Modelo 8 & 65 & 83 & 97 \\
\hline Modelo 9 & 66 & 84 & 97 \\
\hline
\end{tabular}

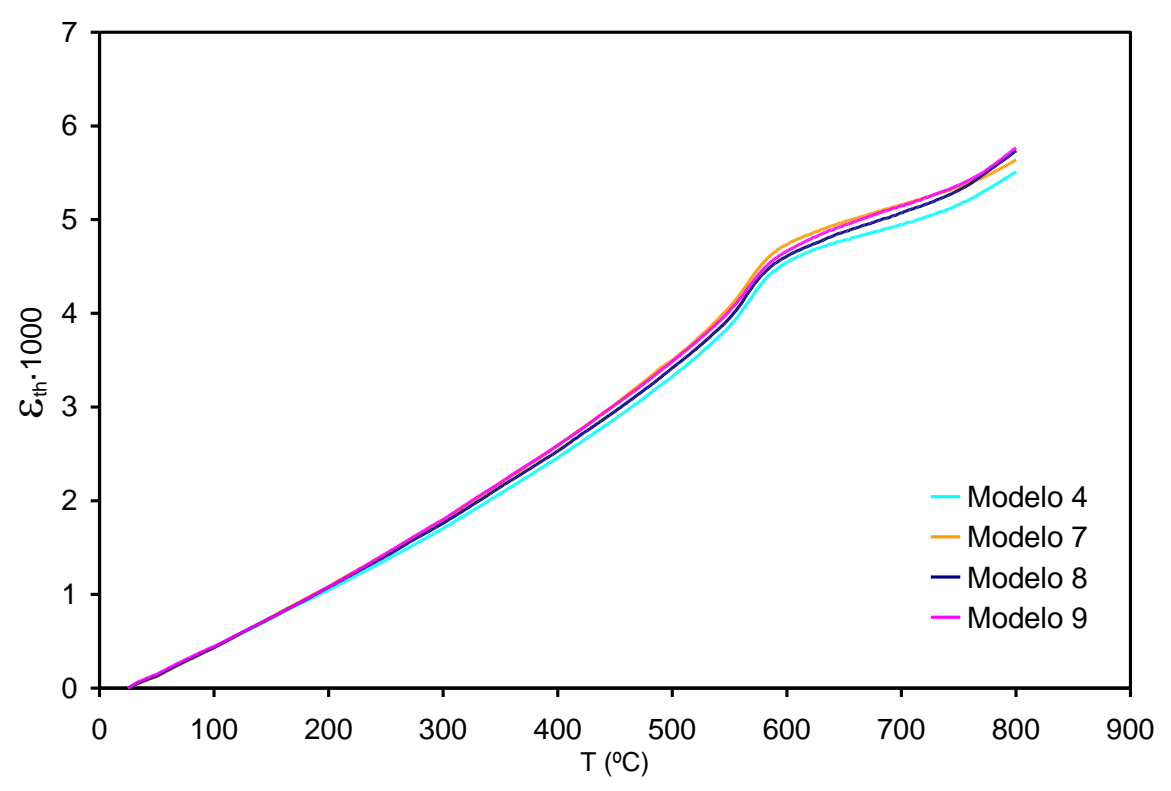

Figura 4.10. Curvas dilatométricas de los soportes. 


\section{B. Análisis dilatométrico de los esmaltes y engobes}

En la figura 4.11 se comparan las curvas dilatométricas de los modelos 4 y 8 con curvatura diferida, y del modelo 9 , sin curvatura diferida. Por su parte, las tablas 4.7 y 4.8 muestran los coeficientes de dilatación de los engobes y esmaltes, junto con la temperatura de reblandecimiento de estos últimos.
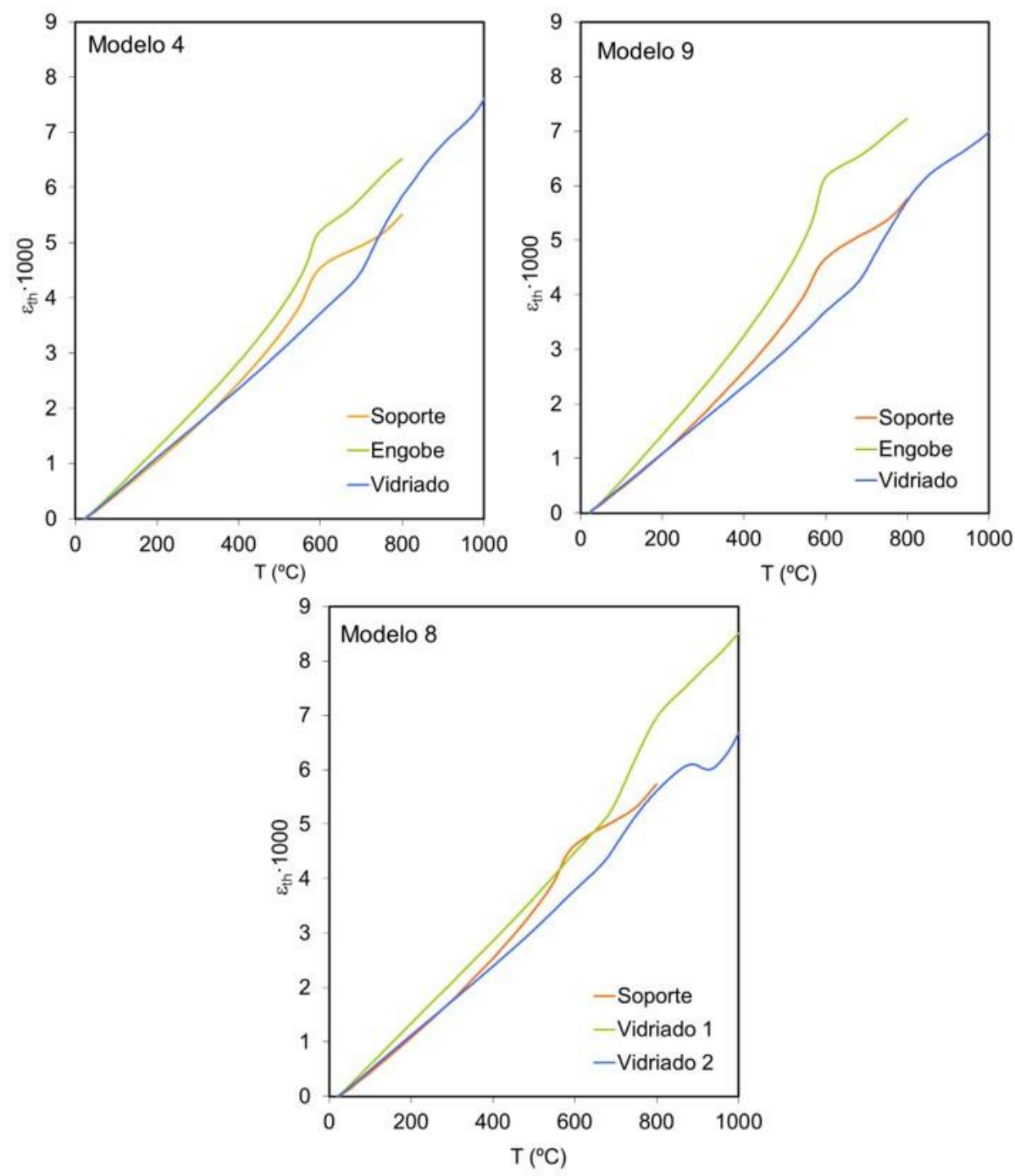

Figura 4.11. Curvas dilatométricas de los modelos 4 (con curvatura diferida), 8 (con curvatura diferida) y 9 (sin curvatura diferida).

En este caso se observa que los dos engobes presentan valores de los coeficientes de dilatación diferentes entre sí y mayores que los coeficientes de los soportes, en particular para el engobe del modelo 9. Ello se debe a la presencia de un mayor contenido en cuarzo como se deduce de la elevada 
expansión que presentan los engobes a $573^{\circ} \mathrm{C}$, coincidiendo con el cambio alotrópico $\alpha-\beta$ del cuarzo (figura 4.11). Los esmaltes presentan valores de los coeficientes de dilatación similares entre sí, con la excepción del esmalte 1 del modelo 8, que muestra valores más elevados. Respecto a los soportes, los coeficientes de dilatación de los esmaltes son más bajos, generando un esfuerzo de compresión en el esmalte que le proporciona una elevada resistencia al cuarteo.

Tabla 4.7. Coeficientes de dilatación de los engobes.

\begin{tabular}{|l|c|c|c|}
\cline { 2 - 4 } \multicolumn{1}{c|}{} & $\begin{array}{c}\boldsymbol{\alpha}_{50-300 \cdot 10^{7}} \\
{ }^{\circ} C^{-1}\end{array}$ & $\begin{array}{c}\boldsymbol{\alpha}_{300-500 \cdot 10^{7}} \\
{ }^{\circ} C^{-1}\end{array}$ & $\begin{array}{c}\boldsymbol{\alpha}_{500-650 \cdot 10^{7}} \\
{ }^{\circ} C^{-1}\end{array}$ \\
\hline Modelo 4 & 74 & 87 & 114 \\
\hline Modelo 9 & 84 & 103 & 137 \\
\hline
\end{tabular}

Tabla 4.8. Coeficientes de dilatación ( $\alpha$ ) y temperatura de reblandecimiento de los esmaltes $\left(\mathrm{T}_{\mathrm{R}}\right)$.

\begin{tabular}{|c|c|c|c|}
\hline & $\begin{array}{c}\alpha_{50-300 \cdot 10^{7}} \\
{ }^{o} C^{-1}\end{array}$ & $\begin{array}{c}\alpha_{300-500 \cdot 10^{7}}{ }^{0} C^{-1} \\
-1\end{array}$ & $\begin{array}{l}T_{R} \\
\text { oC }\end{array}$ \\
\hline Modelo 4 & 63 & 65 & 1080 \\
\hline Modelo 8 (esmalte 1) & 76 & 77 & 1072 \\
\hline Modelo 8 (esmalte 2) & 63 & 63 & 1063 \\
\hline Modelo 9 & 61 & 63 & 1090 \\
\hline
\end{tabular}

A la vista de los resultados no parece que exista una relación evidente entre el desajuste de los coeficientes de dilatación de soporte, engobe y esmalte y las curvaturas diferidas, lo que parece indicar que las tensiones residuales originadas tras el acoplamiento del esmalte con el soporte durante la fase de enfriamiento no juegan un papel decisivo sobre la curvatura diferida.

\subsubsection{Expansión post-cocción de los soportes a temperatura ambiente}

Habitualmente, la expansión de los soportes cerámicos se determina tras su permanencia en autoclave tras ciclos de vapor a presión de varias horas de duración, tal y como se ha medido en el apartado 4.2.5. Sin embargo, debido a que la curvatura diferida se detecta inmediatamente tras la cocción, también es necesario medir la expansión post-cocción de los soportes de gres porcelánico mientras se están curvando al objeto de relacionar ambas características.

Estas medidas se realizaron sobre los soportes industriales inmediatamente a la salida del horno, registrando valores cada 60 segundos durante 24 horas. 
A priori se podría pensar que los cambios dimensionales (expansión) registrados con el equipo de medida podrían verse afectados por la curvatura diferida. Efectivamente, cuando una lámina curva, la distancia entre sus extremos se modifica según se observa en la figura 4.12 .
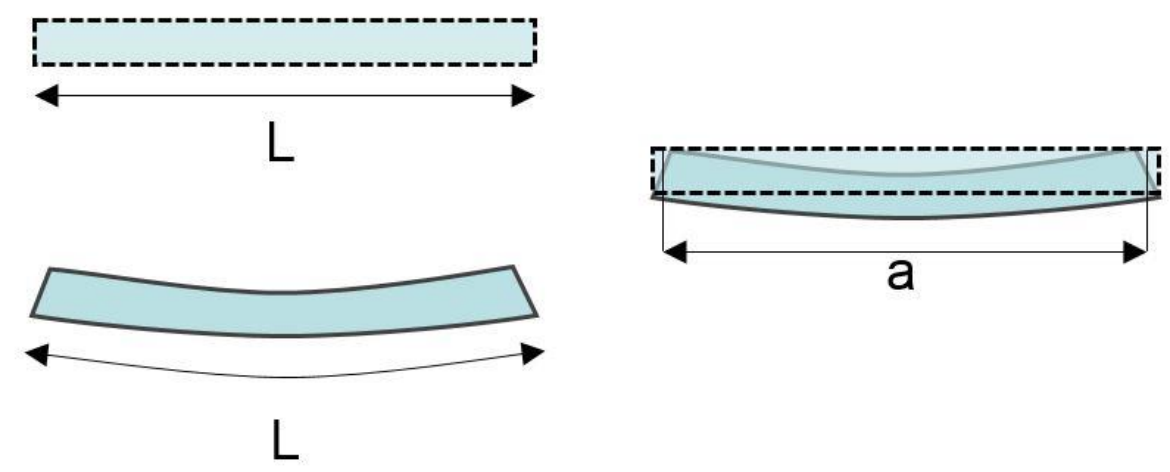

Figura 4.12. Efecto geométrico de la curvatura sobre la expansión.

La expansión debida a la curvatura $\left(\varepsilon_{c}\right)$ se puede calcular en función de la flecha $\left(\delta_{c}\right)$ mediante la ecuación aproximada siguiente:

Ecuación 4.1

$$
\varepsilon_{\mathrm{c}}=\frac{\mathrm{a}-\mathrm{L}}{\mathrm{L}}=\frac{-2}{3}\left(\frac{\delta_{\mathrm{c}}}{\mathrm{a}}\right)^{2}
$$

Para el caso de una pieza de $450 \mathrm{~mm}$ con una flecha de $1 \mathrm{~mm}$ se obtendría una contracción (expansión negativa) de 0,01\%, lo que supone un cambio dimensional insignificante.

Por ello puede afirmarse que la expansión medida se debe únicamente a dos contribuciones:

- expansión térmica, detectada como una contracción inicial al empezar el ensayo debido a que la pieza aún está caliente y se está enfriando,

- expansión no térmica, debida a la humedad u otros factores.

La contracción térmica inicial $\left(\varepsilon_{\text {tho }}\right)$ es proporcional a la diferencia entre la temperatura del soporte al inicio del ensayo $\left(\sim 40^{\circ} \mathrm{C}\right)$ y la temperatura ambiente $(\sim 20 \stackrel{\circ}{\circ})$. Un cambio de temperatura de $20 \stackrel{\circ}{ } \mathrm{C}$ en una pieza con un coeficiente de dilatación de $60 \cdot 10^{-7}{ }^{\circ} C^{-1}$ conduciría a una contracción de 0,12 $\%$, valor que no es despreciable. 
El enfriamiento de las piezas una vez han salido del horno es muy rápido (inferior a 15 minutos) y la variación de la temperatura con el tiempo puede escribirse como:

\section{Ecuación 4.2}

$$
\frac{d T}{d t}=-b \cdot\left(T-T_{a m b}\right)
$$

Donde $b$ es una constante (relacionada con el coeficiente de intercambio de calor pieza-aire), $\mathrm{T}$ la temperatura de la pieza y $\mathrm{T}_{\mathrm{amb}}$ la temperatura ambiente. Resolviendo la ecuación anterior, y admitiendo que el coeficiente de dilatación es constante se llega a:

$$
\text { Ecuación } 4.3 \quad \varepsilon_{\mathrm{th}}=\varepsilon_{\mathrm{th} 0}\left(1-\mathrm{e}^{-\mathrm{t} / \tau_{\mathrm{th}}}\right)
$$

La expansión no térmica $\left(\varepsilon_{\mathrm{X}}\right)$ responde a una expresión empírica de la forma:

$$
\text { Ecuación } 4.4 \quad \varepsilon_{\mathrm{x}}=-\varepsilon_{\mathrm{x} 0}^{0}+\mathrm{a}_{\mathrm{x}}\left(1-\mathrm{e}^{-\mathrm{t} / \tau_{\mathrm{x}}}\right)+\mathrm{b}_{\mathrm{x}} \ln \left(1+\mathrm{t} / \tau_{\mathrm{x}}\right)
$$

En la figura 4.13 se muestran las expansiones medidas para los cuatro soportes (térmicas y no térmicas) junto con el resultado de los ajustes utilizando las ecuaciones 4.3 y 4.4 (es decir sumando $\varepsilon_{\mathrm{X}}$ y $\varepsilon_{\mathrm{th}}$ ), mientras que en la figura 4.14 se representan únicamente los valores de la expansión no térmica ajustada. Los parámetros utilizados se recogen en la tabla 4.9, pero sólo para los modelos 4 y 8 ya que la expansión no térmica de los modelos 7 y 9 es muy pequeña.

\section{Tabla 4.9. Parámetros de la ecuación de la expansión no térmica.}

\begin{tabular}{|c|c|c|}
\hline Parámetro & Modelo 4 & Modelo 8 \\
\hline $\mathrm{ax} \cdot 10^{3}$ & 0,134 & 0,124 \\
\hline $\mathrm{b} \times 10^{3}$ & 0,015 & 0,026 \\
\hline$\tau \times(\mathrm{h})$ & 1,018 & 0,406 \\
\hline
\end{tabular}

Los resultados obtenidos ponen de manifiesto que existe una relación entre la curvatura en diferido y la expansión de origen no térmico, pues únicamente los modelos con curvatura diferida muestran una expansión apreciable. 
4. Resultados y discusión

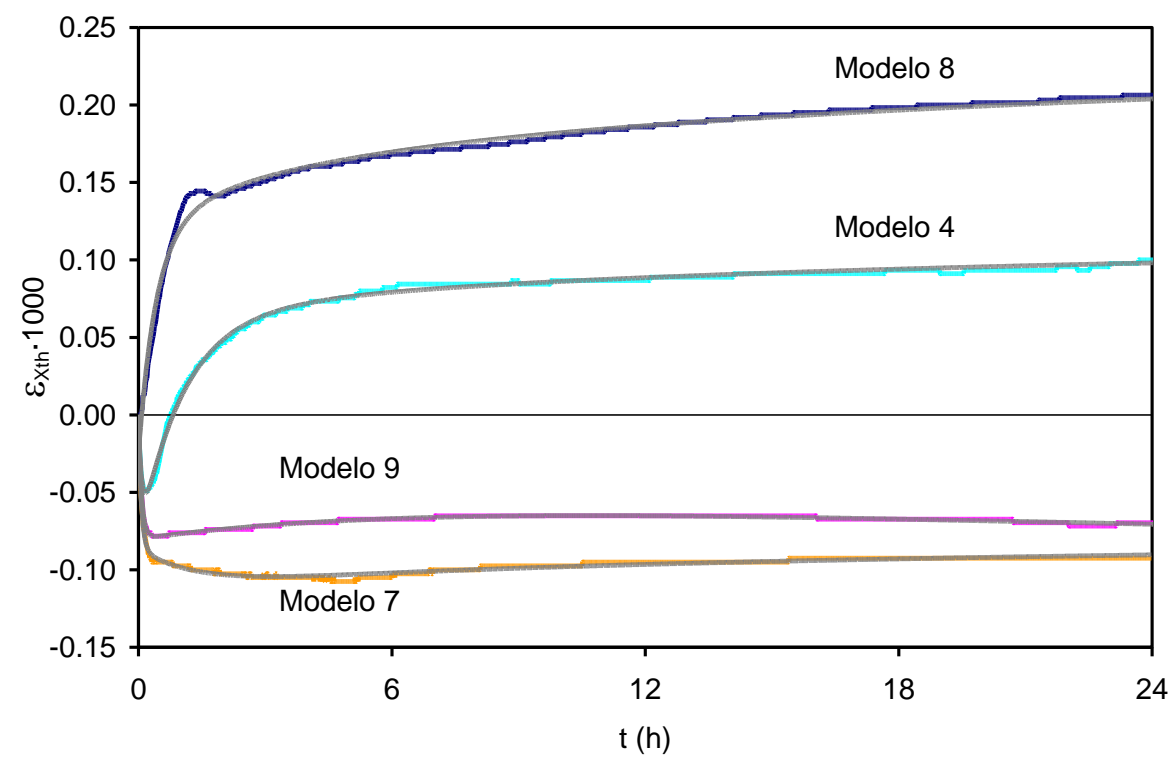

Figura 4.13. Expansión total (térmica + no térmica) de los soportes.

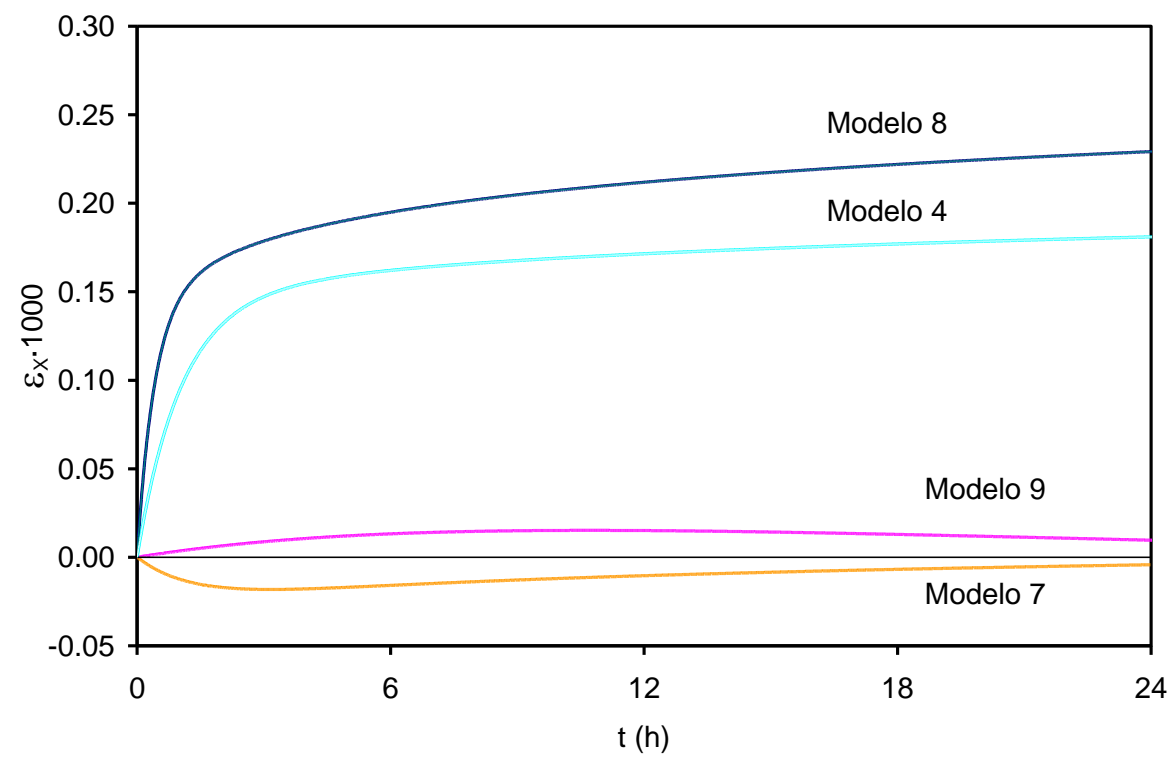

Figura 4.14. Expansión no térmica de los soportes. 


\subsubsection{Comportamiento elástico de los soportes y esmaltes}

\section{A. Resistencia mecánica y módulo de elasticidad de los soportes}

Se han determinado la resistencia mecánica y el módulo de elasticidad (ambos por flexión en tres puntos) de los soportes de los 4 modelos estudiados, realizando ensayos con la cara vista hacia arriba y hacia abajo, con 10 probetas para cada condición.

En la tabla 4.10 se presentan los resultados correspondientes a la resistencia mecánica y al módulo de elasticidad, según se trate de ensayos realizados con la cara vista hacia arriba o hacia abajo (CV $\uparrow$ o $\mathrm{CV} \downarrow$ respectivamente). El modelo 8 no se ensayó con la cara vista hacia arriba al poseer una costilla demasiado marcada, lo que podía falsear los resultados.

Se observa que apenas existen diferencias en la resistencia mecánica en función del sentido de realización del ensayo. Ello puede ser debido a que no existan tensiones residuales (hecho poco probable) o a que éstas presenten un perfil simétrico (que es la situación más habitual en este tipo de soportes).

Tabla 4.10. Resistencia mecánica y módulo de elasticidad de los soportes.

\begin{tabular}{|c|c|c|c|c|c|}
\hline & \multicolumn{2}{|c|}{$\sigma_{\mathrm{R}}(\mathrm{MPa})$} & \multicolumn{2}{|c|}{$E_{S}(G P a)$} & \multirow{2}{*}{$\begin{array}{c}\text { Curvatura } \\
\text { diferida }\end{array}$} \\
\hline & $\mathrm{CV}_{\uparrow}$ & $C V_{\downarrow}$ & $\mathrm{CV}_{\uparrow}$ & $C V_{\downarrow}$ & \\
\hline Modelo 4 & $43 \pm 1$ & $45 \pm 1$ & $34 \pm 1$ & $34 \pm 1$ & Sí \\
\hline Modelo 7 & $61 \pm 2$ & $65 \pm 3$ & $43 \pm 1$ & $45 \pm 1$ & No \\
\hline Modelo 8 & - & $38 \pm 2$ & - & $29 \pm 1$ & Sí \\
\hline Modelo 9 & $55 \pm 1$ & $56 \pm 1$ & $40 \pm 1$ & $41 \pm 1$ & No \\
\hline
\end{tabular}

Los valores del módulo de elasticidad tampoco varían de forma importante en función del sentido de realización del ensayo. El módulo de elasticidad efectivo, con la cara vista hacia arriba y abajo, no depende de la presencia de tensiones residuales; de hecho, incluso tensiones asimétricas conducirían al mismo módulo de elasticidad cuando las probetas se ensayaron en las condiciones $\mathrm{CV} \uparrow$ o $C V_{\downarrow}$; aunque sí podría cambiar si el grado de cocción o porosidad fueran significativamente diferentes en la cara vista y en la cara de la costilla.

Se observa la existencia de una elevada variación en los valores de la resistencia mecánica y módulo de elasticidad entre los diferentes modelos (54 $\%$ y $39 \%$ respectivamente). Si se comparan estos valores con la magnitud de las curvaturas en diferido, se advierte que los modelos con problemas de curvatura presentan una resistencia mecánica y un módulo de elasticidad más bajos. No obstante, con la información disponible no es posible establecer una correlación directa entre dichas propiedades y las curvaturas en diferido. 


\section{B. Resistencia mecánica y módulo de elasticidad de los engobes y esmaltes}

a) Determinación de la resistencia mecánica y del módulo de elasticidad mediante ensayos de flexión en tres puntos

Para determinar las propiedades elásticas de los esmaltes y engobes se prepararon piezas industriales con diferente espesor de capa de engobe y esmalte de los modelos seleccionados, tal y como se ha descrito anteriormente (apartado 3.4.4.). En concreto, se prepararon soportes sin esmaltar (s), soportes con una capa de engobe estándar $(\mathrm{s}+\mathrm{g})$, soportes con una capa doble de engobe $(\mathrm{s}+2 \mathrm{~g})$, soportes con una capa de engobe y una capa de vidriado estándares $(\mathrm{s}+\mathrm{g}+\mathrm{v})$ y soportes con una capa de engobe estándar y una capa doble de vidriado $(\mathrm{s}+\mathrm{g}+2 \mathrm{v})$.

A partir de las piezas anteriores se cortaron probetas prismáticas de $150 \mathrm{~mm}$ de longitud y $20 \mathrm{~mm}$ de anchura y se determinaron su resistencia mecánica y su módulo de elasticidad efectivos mediante flexión por tres puntos de apoyo. Los ensayos se realizaron con la cara vista hacia arriba y hacia abajo con 10 probetas para cada condición, lo que supone un total de 100 probetas por modelo.

La tabla 4.11 y la tabla 4.12 muestran la resistencia mecánica y el módulo de elasticidad efectivos de las probetas ensayadas (considerando homogénea la pieza). Cabe recordar que el modelo 7 corresponde a un gres porcelánico no esmaltado y el modelo 8 posee una costilla muy marcada que alteraría los resultados, por ello sólo se ha ensayado con la cara vista hacia abajo.

Tabla 4.11. Resistencia mecánica efectiva (en MPa).

\begin{tabular}{|l|c|c|c|c|c|c|c|c|c|c|}
\cline { 2 - 11 } \multicolumn{1}{c|}{} & \multicolumn{2}{c|}{$\mathbf{s}$} & \multicolumn{2}{c|}{$\mathbf{s + g}$} & \multicolumn{2}{c|}{$\mathbf{s + 2 g}$} & \multicolumn{2}{c|}{$\mathbf{s + g + v}$} & \multicolumn{2}{c|}{$\mathbf{s + g + 2 \boldsymbol { v }}$} \\
\cline { 2 - 11 } \multicolumn{1}{c|}{} & $\mathbf{C V} \uparrow$ & $\mathbf{C V} \downarrow$ & $\mathbf{C V} \uparrow$ & $\mathbf{C V} \downarrow$ & $\mathbf{C V} \uparrow$ & $\mathbf{C V}_{\downarrow}$ & $\mathbf{C V}_{\uparrow}$ & $\mathbf{C V}_{\downarrow}$ & $\mathbf{C V} \uparrow$ & $\mathbf{C V} \downarrow$ \\
\hline Modelo 4 & $43 \pm 1$ & $45 \pm 1$ & $44 \pm 2$ & $51 \pm 3$ & $45 \pm 1$ & $54 \pm 2$ & $49 \pm 1$ & $54 \pm 1$ & $46 \pm 2$ & $54 \pm 2$ \\
\hline Modelo 7 & $61 \pm 2$ & $65 \pm 3$ & - & - & - & - & - & - & - & - \\
\hline Modelo 8 & - & $38 \pm 2$ & - & - & - & - & - & - & - & - \\
\hline Modelo 9 & $55 \pm 1$ & $56 \pm 1$ & $57 \pm 1$ & $31 \pm 1$ & $51 \pm 2$ & $23 \pm 1$ & $53 \pm 3$ & $46 \pm 1$ & $57 \pm 1$ & $49 \pm 2$ \\
\hline
\end{tabular}

Tabla 4.12. Módulo de elasticidad efectivo (en GPa).

\begin{tabular}{|l|c|c|c|c|c|c|c|c|c|c|}
\cline { 2 - 11 } \multicolumn{1}{c|}{} & \multicolumn{2}{c|}{$\mathbf{s}$} & \multicolumn{2}{c|}{$\mathbf{s + g}$} & \multicolumn{2}{c|}{$\mathbf{s + 2 g}$} & \multicolumn{2}{c|}{$\mathbf{s + g + \mathbf { r }}$} & \multicolumn{2}{c|}{$\mathbf{s + g + 2 v}$} \\
\cline { 2 - 11 } \multicolumn{1}{c|}{} & $\mathbf{C V} \uparrow$ & $\mathbf{C V} \downarrow$ & $\mathbf{C V} \uparrow$ & $\mathbf{C V} \downarrow$ & $\mathbf{C V} \uparrow$ & $\mathbf{C V} \downarrow$ & $\mathbf{C V} \uparrow$ & $\mathbf{C V} \downarrow$ & $\mathbf{C V}_{\uparrow}$ & $\mathbf{C V} \downarrow$ \\
\hline Modelo 4 & $34 \pm 1$ & $34 \pm 1$ & $36 \pm 1$ & $36 \pm 2$ & $35 \pm 1$ & $36 \pm 1$ & $34 \pm 1$ & $35 \pm 1$ & $35 \pm 1$ & $37 \pm 1$ \\
\hline Modelo 7 & $43 \pm 1$ & $45 \pm 1$ & - & - & - & - & - & - & - & - \\
\hline Modelo 8 & - & $29 \pm 1$ & - & - & - & - & - & - & - & - \\
\hline Modelo 9 & $40 \pm 1$ & $41 \pm 1$ & $36 \pm 1$ & $39 \pm 1$ & $37 \pm 1$ & $36 \pm 1$ & $39 \pm 1$ & $40 \pm 1$ & $39 \pm 1$ & $40 \pm 1$ \\
\hline
\end{tabular}


Se observa lo siguiente:

- Los valores del módulo de elasticidad no varían de forma apreciable con la presencia de engobe y esmalte. Esto es debido a que el espesor de estas capas es pequeño comparado con el soporte.

- Los valores del módulo de elasticidad efectivo no varían de forma significativa al ensayar la pieza con la cara vista hacia arriba y hacia abajo. Este resultado era esperable teóricamente, y denota que el comportamiento elástico del soporte, engobe y esmalte es básicamente el mismo en tracción que en compresión.

- La resistencia mecánica de las piezas ensayadas con la cara vista hacia arriba no cambia significativamente con la presencia de engobe y esmalte, lo que indica que estas capas no modifican apreciablemente el estado de tensiones de la superficie inferior del soporte.

- La resistencia mecánica de las piezas esmaltadas ensayadas con la cara vista hacia abajo presentan valores de resistencia mecánica más elevadas que el soporte sin esmaltar. Este resultado es difícil de interpretar y podría deberse tanto a una mayor resistencia mecánica intrínseca del esmalte como a la presencia de tensiones de compresión en la capa de esmalte.

A partir de los valores de resistencia mecánica y módulo de elasticidad de la pieza completa es posible calcular el módulo de elasticidad del engobe y del esmalte. Para ello es necesario conocer los espesores de cada una de las capas, información que se detalla en la tabla 4.13. Para el modelo 8, el subíndice " $g$ " hace referencia al primer esmalte aplicado y el subíndice " $v$ " al segundo.

Tabla 4.13. Espesor de las capas de soporte $\left(h_{s}\right)$, engobe $\left(h_{g}\right)$ y vidriado $\left(h_{v}\right)$.

\begin{tabular}{|c|c|c|c|}
\cline { 2 - 4 } \multicolumn{1}{c|}{} & $\mathbf{h}_{\mathbf{s}}(\mathbf{m m})$ & $\mathbf{h}_{\mathbf{g}}(\mu \mathrm{m})$ & $\mathbf{h}_{\mathbf{v}}(\mu \mathrm{m})$ \\
\hline Modelo 4 & 8,35 & 90 & 130 \\
\hline Modelo 7 & 8,28 & & \\
\hline Modelo 8 & 9,57 & 150 & 40 \\
\hline Modelo 9 & 8,62 & 150 & 100 \\
\hline
\end{tabular}

A modo de ejemplo, la tabla 4.14 recoge los valores de módulos de elasticidad de las distintas capas del modelo 4, calculados a partir de los módulos de elasticidad efectivos de las probetas con distintos espesores.

Tabla 4.14. Módulo de elasticidad de engobes $\left(E_{g}\right)$ y vidriados $\left(E_{v}\right)$ del modelo 4 calculados a partir de los módulos de elasticidad efectivos.

\begin{tabular}{|c|c|c|c|}
\cline { 2 - 4 } \multicolumn{1}{c|}{} & Es $_{\text {(GPa) }}$ & $\mathrm{E}_{\mathrm{g}}$ (GPa) & $\mathrm{E}_{\mathrm{v}}$ (GPa) \\
\hline Modelo 4 & 34 & 55 & 42 \\
\hline
\end{tabular}


Por otra parte, la figura 4.15 compara los módulos de elasticidad efectivos teóricos de las distintas probetas del modelo 4 (calculados a partir de los valores anteriores) con los valores obtenidos experimentalmente.

Puede comprobarse que el cálculo del módulo de elasticidad de engobes y esmaltes a partir del módulo de elasticidad efectivo de las probetas no proporciona resultados satisfactorios debido, por una parte, al reducido espesor de las capas de engobe y esmalte y, por otra parte, a los elevados valores del módulo de elasticidad de los soportes. Por ello, el módulo de elasticidad se determinó por ensayos de indentación.

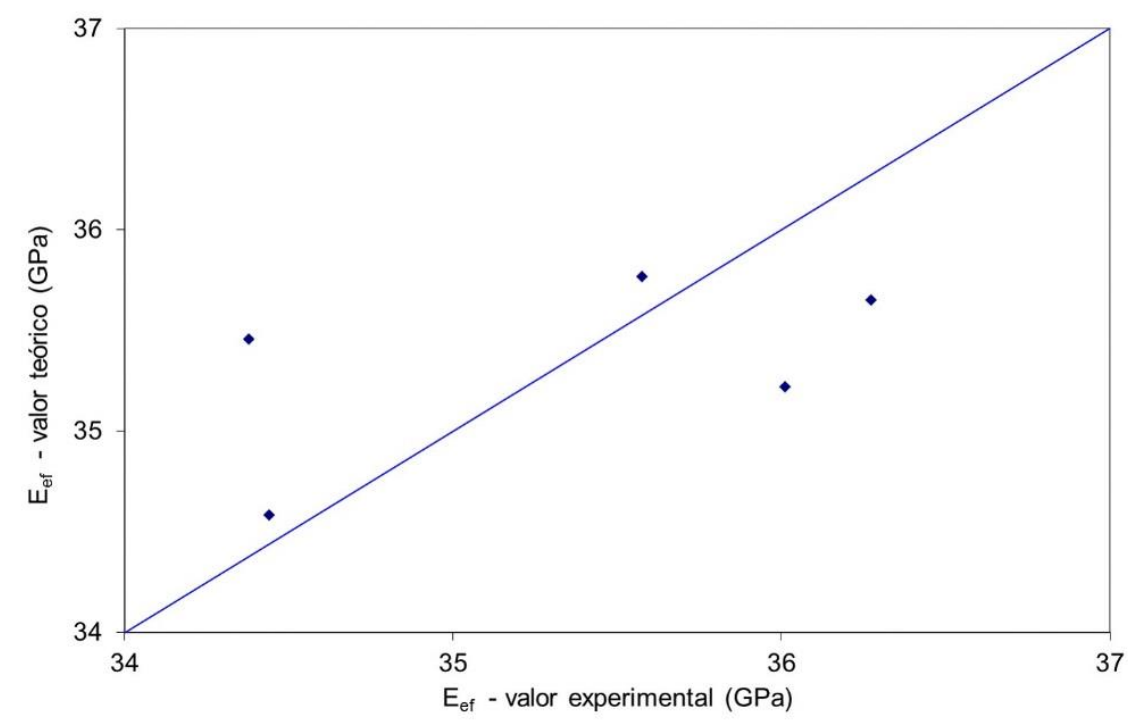

Figura 4.15. Comparación entre los valores de módulos de elasticidad efectivos teóricos y experimentales del modelo 4.

b) Determinación del módulo de elasticidad mediante ensayos de indentación

Los ensayos de indentación, aunque permiten obtener el módulo de elasticidad de las diferentes capas de engobe y esmalte, presentan una amplia dispersión, lo que hace necesario realizar un gran número de medidas. Por ello, se efectuaron series de 20 indentaciones a una carga máxima de 1000 $\mathrm{mN}$ y una velocidad de aplicación de $100 \mathrm{mN} / \mathrm{s}$, en intervalos de distancia constantes de $500 \mu \mathrm{m}$, utilizando una punta de geometría Berkovich (pirámide triangular) y un equipo Nanotest de Micromaterials.

La tabla 4.15 recoge los resultados obtenidos. Se observa que los valores de esta propiedad para el engobe no varían excesivamente, mientras que para los esmaltes la variación es más acusada. Asimismo, los valores de módulo 
de elasticidad de los esmaltes son, en general, más elevados que el de los soportes.

Tabla 4.15. Módulo de elasticidad de engobes $\left(E_{g}\right)$ y vidriados $\left(E_{v}\right)$.

\begin{tabular}{|l|c|c|c|}
\cline { 2 - 4 } \multicolumn{1}{c|}{} & $\mathrm{E}_{\mathbf{g}}(\mathrm{GPa})$ & $\mathrm{Ev}_{\mathrm{v}}(\mathrm{GPa})$ & Curvatura diferida \\
\hline Modelo 4 & $60 \pm 11$ & $75 \pm 6$ & Sí \\
\hline Modelo 8 & $57 \pm 10$ & $91 \pm 12$ & Sí \\
\hline Modelo 9 & $64 \pm 15$ & $78 \pm 8$ & No \\
\hline
\end{tabular}

\subsubsection{Fluencia de los soportes}

Uno de los factores que puede originar curvaturas diferidas son las tensiones residuales presentes en el soporte. Sin embargo, para que estas tensiones modifiquen la curvatura es necesario que exista un mecanismo que permita liberarlas, esto es, que la pieza presente un comportamiento viscoelástico cuando se le aplica una carga constante. A este comportamiento se le denomina fluencia.

En esta fase del trabajo se ha determinado si los soportes cocidos de gres porcelánico presentan fluencia. Las probetas usadas, de dimensiones $220 \mathrm{x}$ $20 \mathrm{~mm}$, se obtuvieron a partir de soportes industriales y se ensayaron aplicando una carga correspondiente al $50 \%$ de la carga de rotura.

Los materiales que presentan fluencia, cuando se someten a una tensión constante $(\sigma)$ que se mantiene con el tiempo, experimentan una deformación $(\varepsilon)$ conforme a la figura 4.16. En la gráfica se diferencian tres tramos: un primer tramo vertical (correspondiente al comportamiento elástico), un segundo tramo curvo y un tercer tramo lineal (correspondiente al comportamiento viscoso).
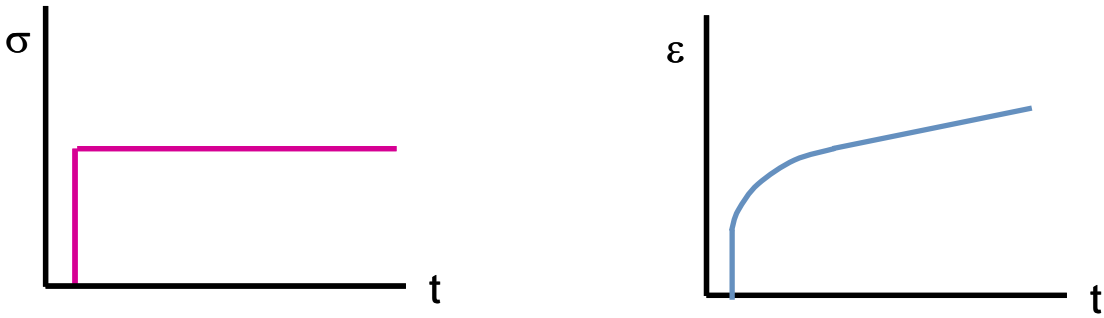

Figura 4.16. Comportamiento mecánico de los materiales con fluencia cuando se aplica una carga.

Este comportamiento puede representarse mediante la analogía mecánica de la figura 4.17 en la que se distingue entre una deformación elástica instantánea $\left(\varepsilon_{e}\right)$ representada por un muelle, una deformación elástica diferida 
$(\varepsilon D)$ representada por un muelle y un amortiguador en paralelo y una deformación viscosa $(\varepsilon v)$ representada por un amortiguador.

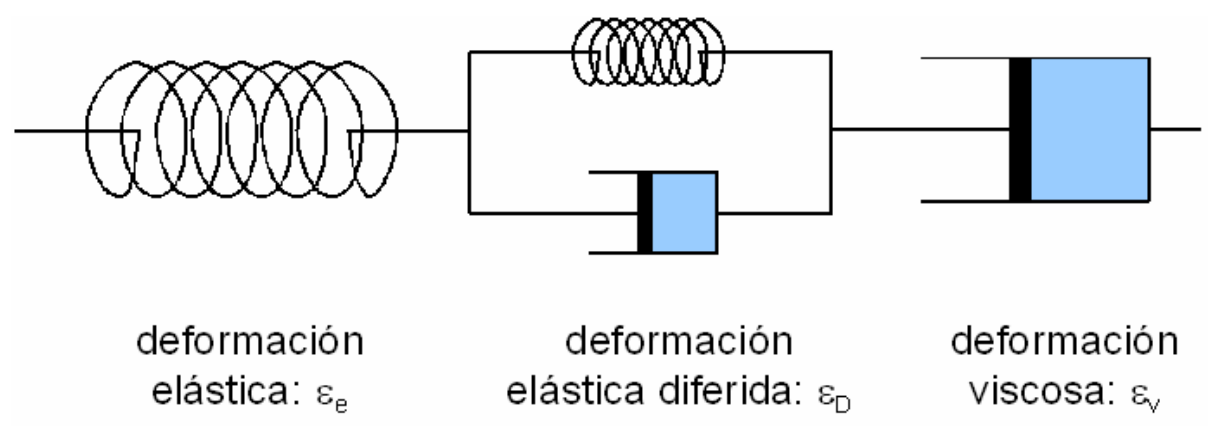

Figura 4.17. Analogía mecánica de la fluencia (modelo Burgers).

Las leyes que rigen este comportamiento vienen dadas por las ecuaciones siguientes:

- Componente elástica (instantánea)

Ecuación 4.5

$$
\varepsilon_{e}=\frac{1}{E} \sigma
$$

- Componente elástica diferida

\section{Ecuación 4.6}

$$
\frac{d \varepsilon_{D}}{d t}=\&=\frac{-1}{\tau} \varepsilon_{D}+\frac{1}{3 G_{D} \tau} \sigma
$$

- Componente viscosa

$$
\text { Ecuación } 4.7 \quad \frac{d \varepsilon_{v}}{d t}=\underset{v}{\&}=\frac{1}{3 \eta} \sigma
$$

donde:

E: módulo de elasticidad $(\mathrm{Pa})$

$\sigma: \quad$ tensión aplicada $(\mathrm{Pa})$

$\tau: \quad$ constante de tiempo (s)

GD: cizalla diferida $(\mathrm{Pa})$

$\eta: \quad$ viscosidad del material (Pa.s) 
Los ensayos de fluencia realizados ponen de manifiesto la existencia de este comportamiento viscoelástico en los soportes ensayados de gres porcelánico, tal y como se desprende de la observación de la figura 4.18 , en la que se muestra el desplazamiento (flecha, $\delta_{c}$ ) en función del tiempo durante un total de 5 días. El comportamiento puramente elástico se ha eliminado en esta figura.

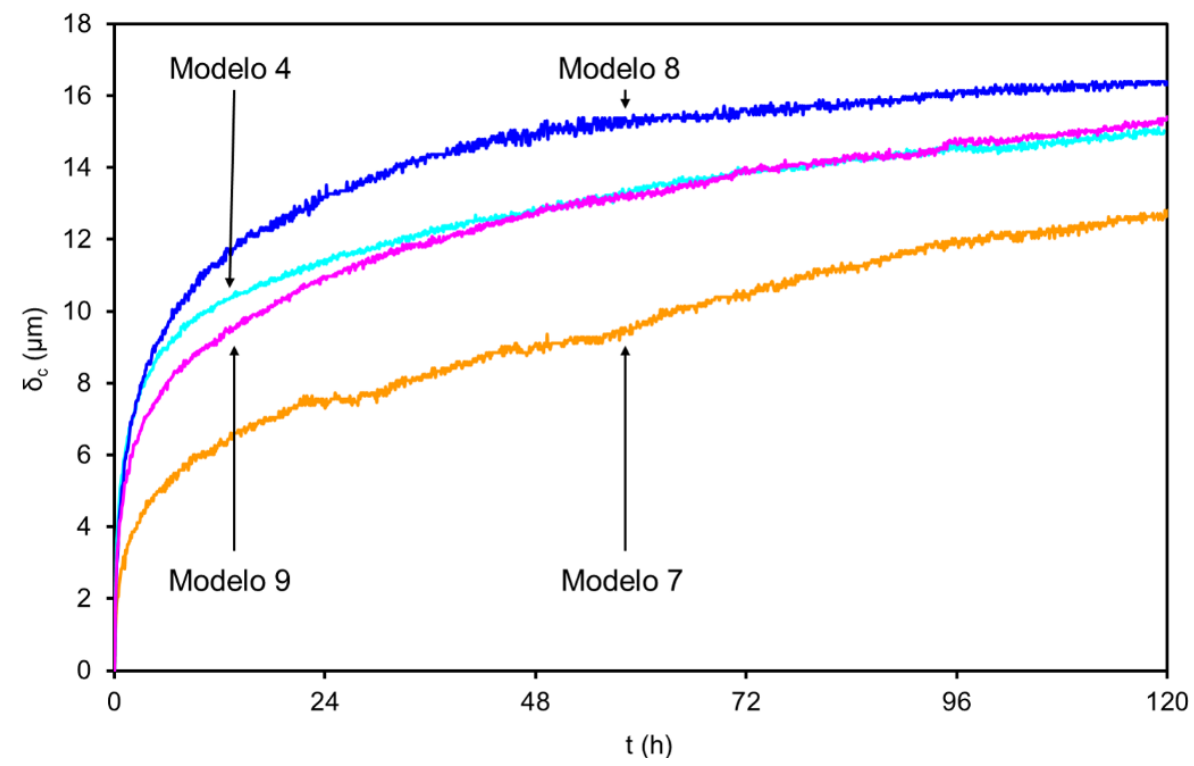

Figura 4.18. Fluencia de los soportes.

La flecha provocada por la deformación elástica diferida más la deformación viscosa $\left(\delta_{\mathrm{CDV}}\right)$ en el caso de ensayos de flexión en tres puntos se puede calcular a partir de las ecuaciones anteriores, obteniéndose:

\section{Ecuación 4.8}

$$
\delta_{c D v}=\frac{S^{2} \sigma_{m}}{18 h \eta}\left(\tau_{D}\left(1-e^{-t / \tau}\right)+t\right)
$$

siendo:

S: $\quad$ separación entre apoyos $(m)$

$\sigma_{\mathrm{m}}: \quad$ tensión máxima aplicada $(\mathrm{Pa})$

$h$ : $\quad$ espesor de la pieza $(m)$

$\eta: \quad$ viscosidad del soporte $(\mathrm{Pa} \cdot \mathrm{s})$

$\tau_{D}: \quad$ cociente entre viscosidad y cizalla diferida $(s)$

$\tau$ : $\quad$ constante de tiempo de la elasticidad diferida (s) 


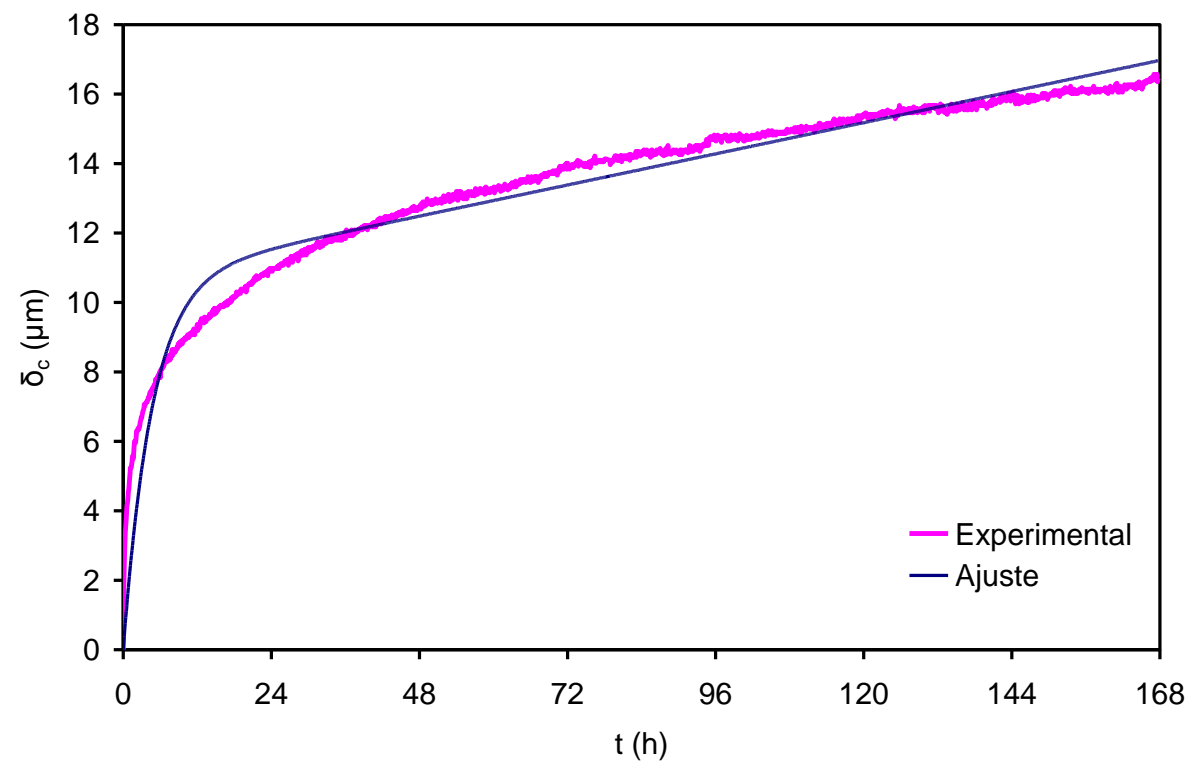

Figura 4.19. Ajuste de la fluencia del soporte del modelo 9 a la ecuación 4.8.

En la figura 4.19, se muestra el ajuste de los datos experimentales a la ecuación 4.8 para uno de los soportes. Se constata que el ajuste no es capaz de reproducir suficientemente bien los resultados experimentales. Ello puede deberse a que, en la ecuación 4.8, se ha considerado un solo término de elasticidad diferida. Si se incorpora un segundo término, la ecuación resultante es la siguiente:

$$
\text { Ecuación } 4.9 \quad \delta_{\mathrm{cDv}}=\frac{\mathrm{S}^{2} \sigma_{\mathrm{m}}}{18 \mathrm{~h} \eta}\left(\sum_{\mathrm{k}=1}^{2} \tau_{\mathrm{Dk}}\left(1-\mathrm{e}^{-\mathrm{t} / \tau_{\mathrm{k}}}\right)+\mathrm{t}\right)
$$

En la figura 4.20, se muestra el ajuste de los datos experimentales usando la ecuación 4.9 para los cuatro soportes estudiados. Los parámetros de ajuste correspondientes se detallan en la tabla 4.16. Puede observarse que el modelo reproduce adecuadamente los resultados experimentales. 
Tabla 4.16. Parámetros de la ecuación 4.9.

\begin{tabular}{|c|c|c|c|c|c|c|}
\cline { 2 - 7 } \multicolumn{1}{c|}{} & $\begin{array}{c}\tau_{\mathrm{D} 1} \\
\text { días }\end{array}$ & $\begin{array}{c}\tau_{1} \\
\text { horas }\end{array}$ & $\begin{array}{c}\tau_{\mathrm{D} 2} \\
\text { días }\end{array}$ & $\begin{array}{c}\tau_{2} \\
\text { horas }\end{array}$ & $\begin{array}{c}\eta \cdot 10^{17} \\
\text { Pa·s }\end{array}$ & $\begin{array}{c}\text { Curvatura } \\
\text { diferida }\end{array}$ \\
\hline Modelo 4 & 13,6 & 0,904 & 7,5 & 21,3 & 7,19 & Sí \\
\hline Modelo 7 & 4,2 & 0,904 & 3,6 & 21,3 & 6,37 & No \\
\hline Modelo 8 & 35,1 & 0,904 & 32,8 & 21,3 & 14,2 & Sí \\
\hline Modelo 9 & 10,4 & 0,904 & 9,3 & 21,3 & 8,24 & No \\
\hline
\end{tabular}

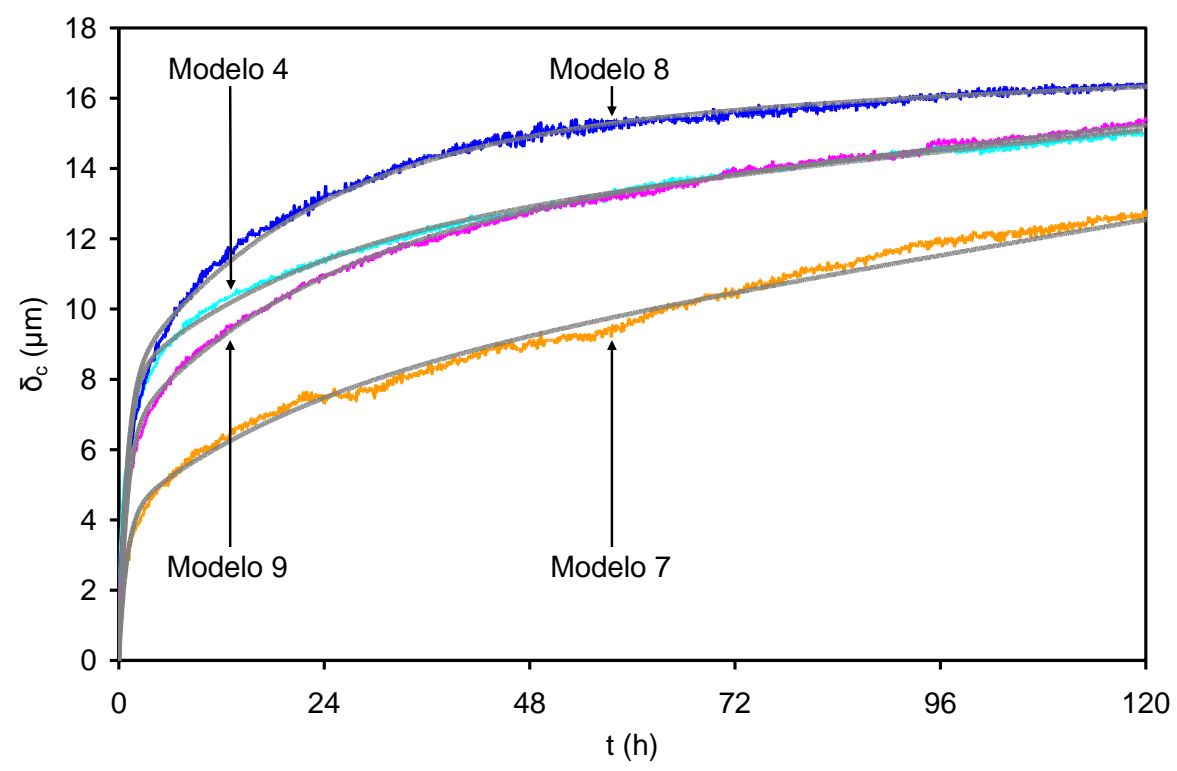

Figura 4.20. Ajuste de la fluencia de los soportes a la ecuación 4.9.

\subsubsection{Tensiones residuales}

La relajación de las tensiones por fluencia a temperatura ambiente podría ser capaz de modificar la curvatura en el transcurso del tiempo y, por tanto, contribuir al fenómeno de curvatura diferida. En el apartado anterior, se ha confirmado que todos los modelos estudiados presentan fluencia mientras que, en esta parte del trabajo, se han determinado las tensiones que se generan durante la etapa de cocción de las baldosas de gres porcelánico, las cuales reciben el nombre de tensiones residuales.

Se distinguen dos tipos de tensiones residuales: las de origen térmico y las de acoplamiento esmalte-soporte. Las tensiones de origen térmico son consecuencia de los gradientes térmicos que se producen en la pieza durante el enfriamiento. En cambio, las tensiones de acoplamiento esmalte-soporte se 
deben a diferencias en las curvas dilatométricas de soportes, engobes y esmaltes (véase el apartado 1.3).

\section{A. Tensiones de origen térmico}

Durante el enfriamiento de la pieza dentro del horno se producen gradientes térmicos significativos entre la superficie y el centro de la pieza debido a la elevada velocidad de enfriamiento que existe en la primera fase del enfriamiento industrial. Estos gradientes producen una mayor contracción en la superficie que en el interior de la pieza, lo que origina un flujo viscoso que reduce la generación de tensiones a elevada temperatura. Este proceso continúa hasta que la pieza alcanza una temperatura a la cual el flujo viscoso es prácticamente nulo. Dado que el interior de la pieza se encuentra a mayor temperatura respecto del exterior, la contracción que experimenta hasta temperatura ambiente será también mayor, lo que originará un esfuerzo de tracción en el interior y de compresión en la superficie debido a la inexistencia de flujo viscoso.

Para cuantificar las tensiones residuales se prepararon probetas de $150 \times 30$ $\mathrm{mm}$, obtenidas a partir de los soportes industriales sin esmaltar de los modelos seleccionados. Se utilizó el método de relajación de deformaciones por corte incremental ("strain relaxation slotting method"), cuyo fundamento viene detallado en el apartado 3.4.5.

Los resultados se muestran de la figura 4.21 a la figura 4.24 para los distintos modelos ensayados. En cada caso, la primera gráfica representa la evolución de la deformación medida experimentalmente por la galga $\left(\varepsilon_{g}\right)$ en función de la profundidad del corte (a). La segunda gráfica muestra el perfil de tensiones residuales calculado $\left(\sigma_{\mathrm{r}}\right)$ a lo largo de espesor de la probeta $(\mathrm{z})$.

Cabe recordar que los modelos 4 y 8 presentan curvaturas en diferido mientras que los modelos 7 y 9 no presentan el problema.

Para cada modelo se muestran dos gráficas. La primera, superior, corresponde a la deformación de la galga medida experimentalmente (valores puntuales) junto con el ajuste realizado (línea continua). La segunda, inferior, es el perfil de tensiones residuales obtenido a partir del ajuste. 
4. Resultados y discusión
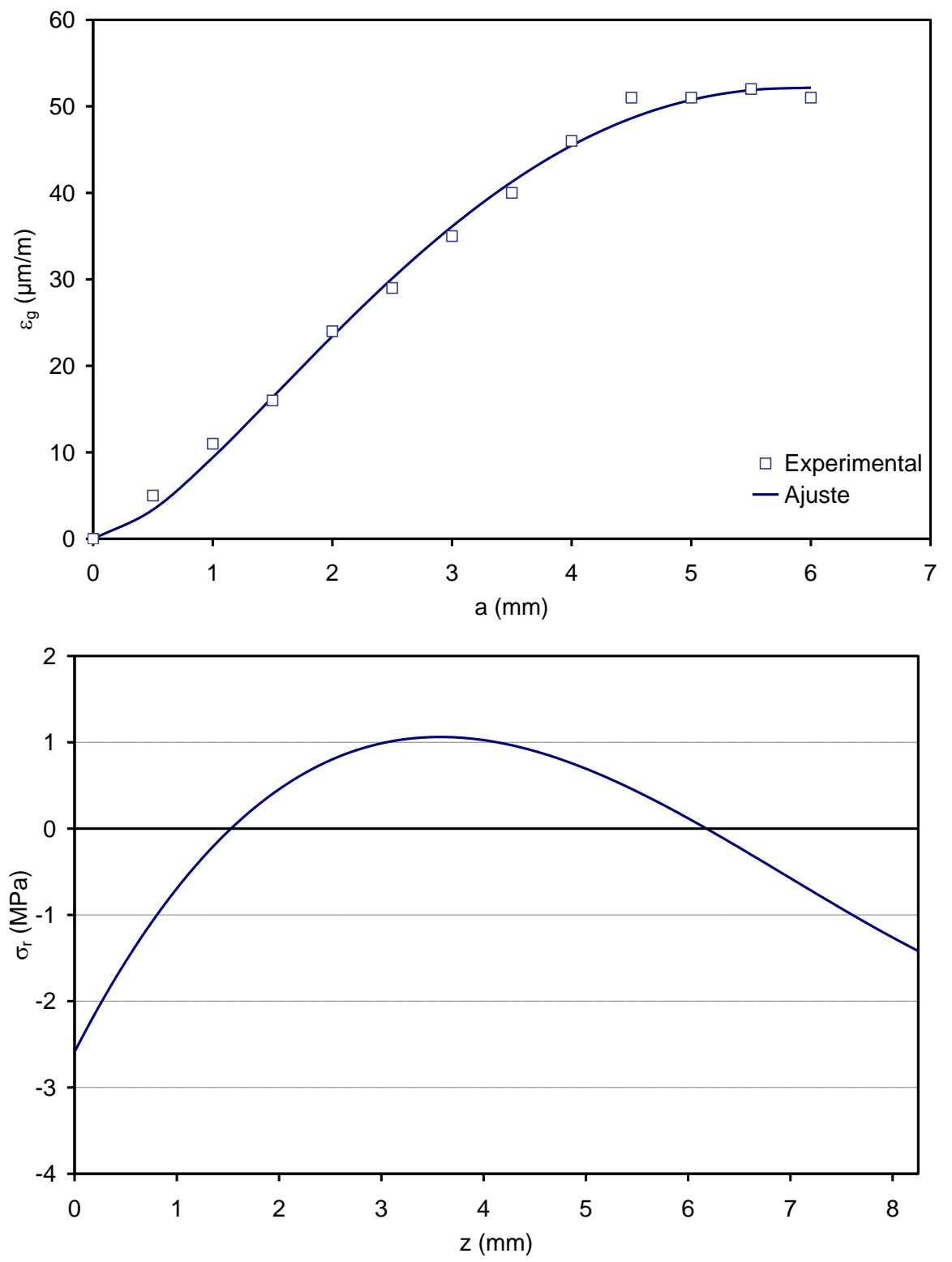

Figura 4.21. Deformación de la galga y perfil de tensiones para el modelo 4 (con curvatura diferida). 
4. Resultados y discusión
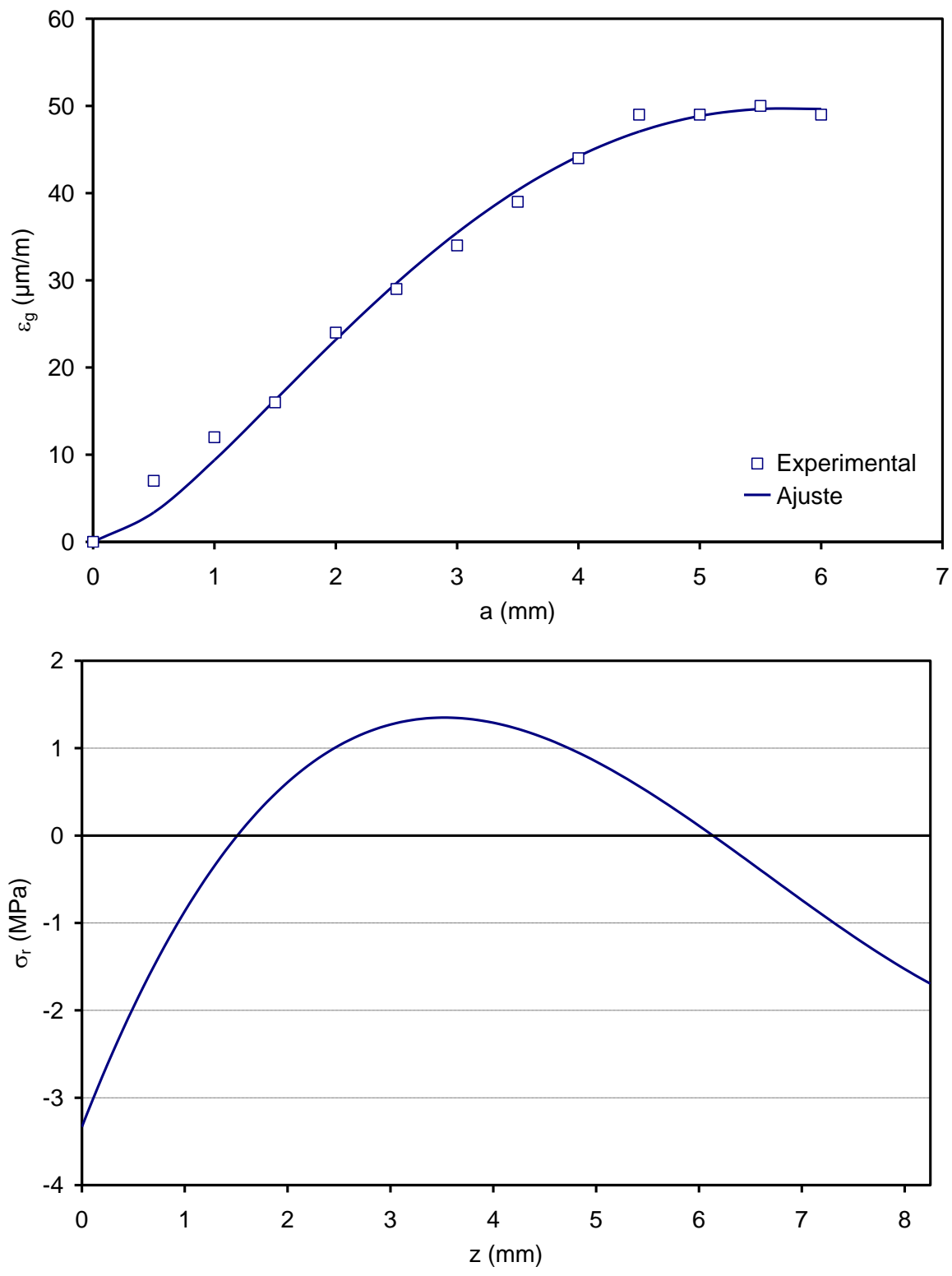

Figura 4.22. Deformación de la galga y perfil de tensiones para el modelo 7 (sin curvatura diferida). 

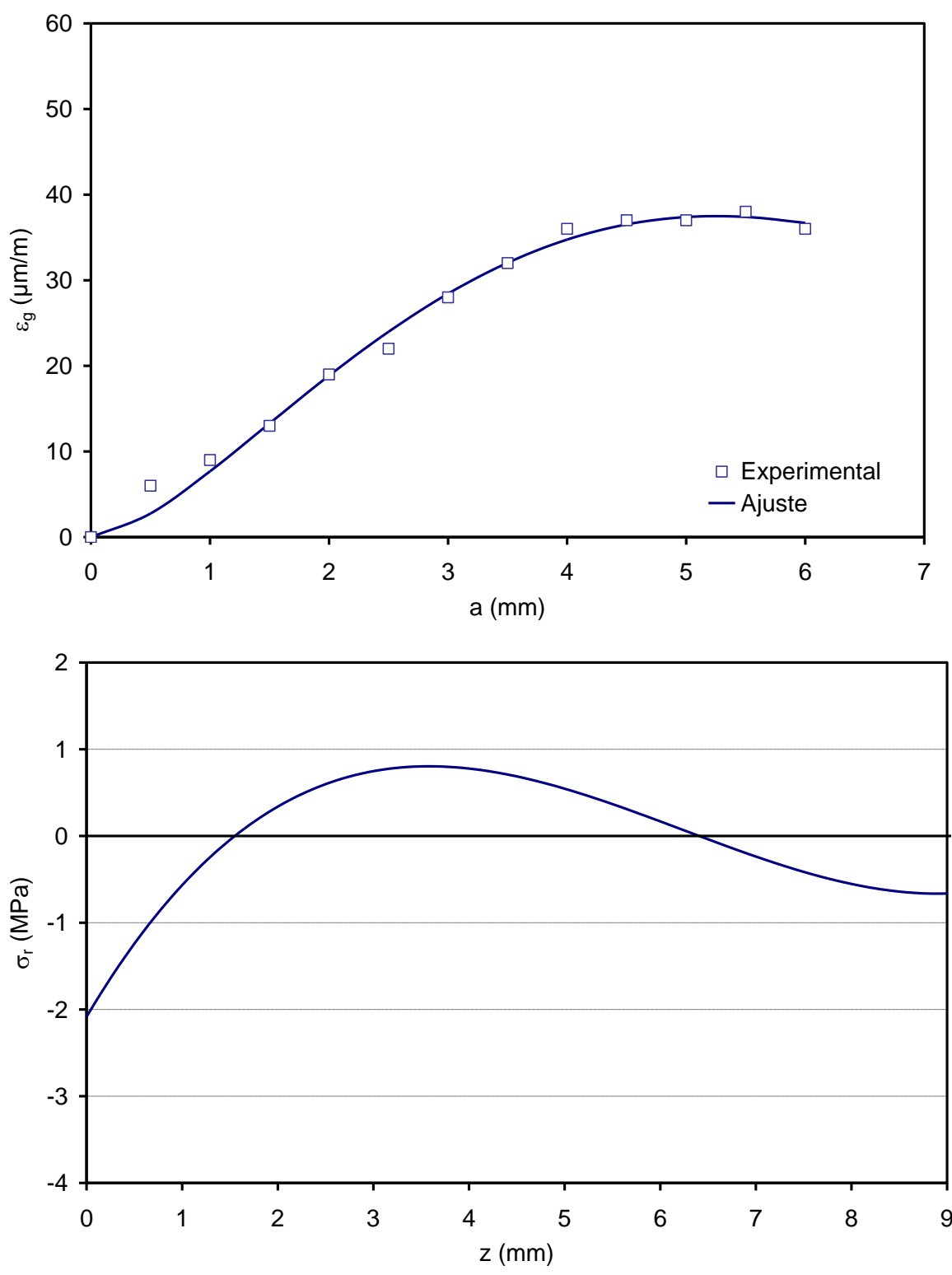

Figura 4.23. Deformación de la galga y perfil de tensiones para el modelo 8 (con curvatura diferida). 
4. Resultados y discusión
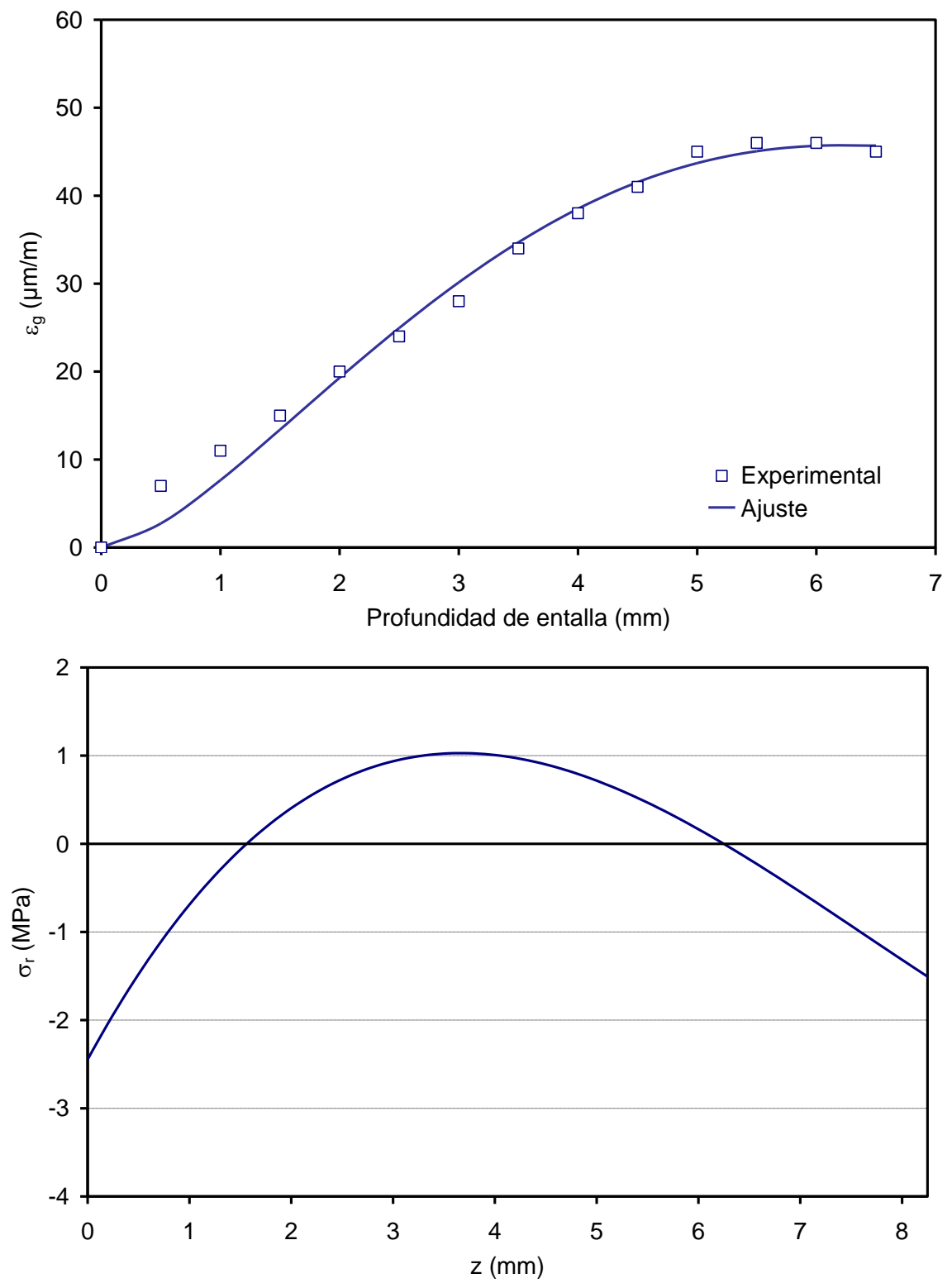

Figura 4.24. Deformación de la galga y perfil de tensiones para el modelo 9 (sin curvatura diferida). 
Los valores de los coeficientes $\lambda_{k}$ que conducen a los perfiles de tensiones mostrados se recogen en la tabla 4.17. Nótese que se obtienen ajustes con una bondad aceptable considerando únicamente los dos primeros términos del desarrollo en serie de polinomios de Legendre $\left(\lambda_{2}\right.$ y $\left.\lambda_{3}\right)$.

Tabla 4.17. Parámetros de los perfiles de tensiones residuales.

\begin{tabular}{|l|c|c|}
\cline { 2 - 3 } \multicolumn{1}{c|}{} & $\lambda_{2}(\mu \mathrm{m} / \mathrm{m})$ & $\lambda_{3}(\mu \mathrm{m} / \mathrm{m})$ \\
\hline Modelo 4 & 58,1 & $-17,0$ \\
\hline Modelo 7 & 56,8 & $-18,5$ \\
\hline Modelo 8 & 48,4 & $-24,5$ \\
\hline Modelo 9 & 48,8 & $-11,6$ \\
\hline
\end{tabular}

Analizando la información disponible se desprende lo siguiente:

- Las superficies de todas las piezas se encuentran sometidas a esfuerzos de compresión (valores negativos) mientras que la parte central aparece en tracción (valores positivos). Esta situación es la que cabe esperar en base a los gradientes térmicos que se establecen en la pieza durante el enfriamiento en el interior del horno.

- En todas las piezas se observa que la compresión en la superficie inferior (valor de $\mathrm{z}=0$ ) es superior a la de la cara vista $(\mathrm{z}=8-9 \mathrm{~mm})$.

- Las tensiones residuales en ambas superficies son pequeñas con valores máximos de compresión cercanos a $-3 \mathrm{MPa}$ en la superficie inferior. La cara vista presenta valores incluso inferiores. La zona central se encuentra sometida a esfuerzos de tracción en torno a $1 \mathrm{MPa}$ como valor máximo.

- Los perfiles de tensión residual presentan una pequeña asimetría debido a que los valores de la componente antisimétrica $\left(\lambda_{3}\right)$ no son despreciables. Esta asimetría en el perfil puede deberse a la diferencia de enfriamiento entre las caras superior e inferior de las piezas dentro del horno.

- Aunque los perfiles asimétricos podrían conducir a cambios de curvatura con el tiempo, no es posible establecer una relación directa entre las tensiones residuales obtenidas y dicho fenómeno. A modo de ejemplo, los perfiles de tensión para los modelos 4 y 9 son prácticamente iguales mientras que sólo el modelo 4 presenta curvaturas en diferido.

\section{B. Tensiones de acoplamiento esmalte-soporte}

Aun cuando no existieran diferencias de temperatura dentro de las baldosas durante el enfriamiento, las diferencias existentes entre expansión térmica del soporte, engobe y esmalte (situación habitual) pueden generar tensiones residuales en las piezas. Estas tensiones, que se añaden a las de origen térmico, son altamente no simétricas, por lo que podrían contribuir a la curvatura diferida. 
Las tensiones de acoplamiento se calcularon a partir de las propiedades mecánicas de soportes, soportes engobados y soportes esmaltados, todos ellos industriales. Los cálculos se realizaron únicamente para los modelos 4 y 9, debido a que el modelo 7 es un gres porcelánico no esmaltado y a que el modelo 8 presentaba una costilla muy marcada que impedía la correcta determinación de la resistencia mecánica.

El fundamento de la medida de las tensiones de acoplamiento reside en la variación de resistencia mecánica existente entre un soporte, un soporte con engobe y un soporte con engobe y esmalte, tal y como se describe en el apartado 3.4.5.

Los datos empleados en el cálculo se muestran en las tablas 4.18 y 4.19. Para realizar los cálculos no se han utilizado las piezas con capa simple de engobe y esmalte debido a que los valores de resistencia mecánica eran muy parecidos a los del soporte. Por ello se utilizaron los valores de resistencia mecánica efectiva de las piezas con capa doble.

En estas tablas $\mathbf{s}$ representa el soporte, $\mathbf{s}+\mathbf{2 g}$ el soporte con dos capas de engobe y $\mathbf{S}+\mathbf{g}+\mathbf{2} \mathbf{v}$ el soporte engobado con dos capas de esmalte. $\mathbf{C V} \uparrow$ indica que la probeta se ensaya con la cara vista hacia arriba y $\mathbf{C V} \downarrow$ con la cara vista hacia abajo.

Tabla 4.18. Resistencia mecánica efectiva (en MPa).

\begin{tabular}{|c|c|c|c|c|c|c|}
\cline { 2 - 7 } \multicolumn{1}{c|}{} & \multicolumn{2}{c|}{$\mathbf{s}$} & \multicolumn{2}{c|}{$\mathbf{s + 2 g}$} & \multicolumn{2}{c|}{$\mathbf{s + g + 2 v}$} \\
\cline { 2 - 7 } \multicolumn{1}{c|}{} & $\mathbf{C V} \uparrow$ & $\mathbf{C V} \downarrow$ & $\mathbf{C V} \uparrow$ & $\mathbf{C V}_{\downarrow}$ & $\mathbf{C V} \uparrow$ & $\mathbf{C V} \downarrow$ \\
\hline Modelo 4 & $43 \pm 1$ & $45 \pm 1$ & $45 \pm 1$ & $54 \pm 2$ & $46 \pm 2$ & $54 \pm 2$ \\
\hline Modelo 9 & $55 \pm 1$ & $56 \pm 1$ & $51 \pm 2$ & $23 \pm 1$ & $57 \pm 1$ & $49 \pm 2$ \\
\hline
\end{tabular}

Tabla 4.19. Módulo de elasticidad de engobes $\left(E_{g}\right)$ y vidriados $\left(E_{v}\right)$.

\begin{tabular}{|c|c|c|}
\cline { 2 - 3 } \multicolumn{1}{c|}{} & $\mathrm{E}_{\mathbf{g}}$ (GPa) & $\mathrm{Ev}_{\mathrm{v}}$ (GPa) \\
\hline Modelo 4 & $60 \pm 11$ & $75 \pm 6$ \\
\hline Modelo 9 & $64 \pm 15$ & $78 \pm 8$ \\
\hline
\end{tabular}

Se observa que ambos soportes (s) presentan valores de resistencia mecánica ligeramente superiores cuando el ensayo se realiza con la cara vista hacia abajo, lo que podría deberse en parte a la mayor tensión de compresión que presenta la superficie inferior (véase los perfiles de tensiones de origen térmica en el apartado anterior).

La aplicación de 2 capas de engobe $(\mathrm{s}+2 \mathrm{~g})$ no modifica apreciablemente los valores obtenidos al ensayar las piezas con la cara vista hacia arriba, debido a que la presencia de engobe no debe modificar significativamente el estado de tensiones de la superficie inferior de la pieza, que es por donde se inicia la 
grieta. Los mismo se observa en la serie de piezas con engobe y vidriado $(\mathrm{s}+\mathrm{g}+2 \mathrm{v})$.

Por el contrario, la presencia de engobe $(s+2 g)$ y vidriado $(s+g+2 v)$ modifica en mayor medida los valores de resistencia mecánica obtenidos al ensayar las piezas con la cara vista hacia abajo. En estas condiciones, la presencia de engobe y vidriado aumenta la resistencia mecánica para el modelo 4 y la disminuye para el modelo 9 .

La interpretación de los resultados de la resistencia mecánica con la cara vista hacia abajo es compleja porque sobre ella influyen dos factores: las tensiones residuales y la mayor resistencia mecánica intrínseca que suelen tener las capas de engobe y vidriado comparada con la del soporte. Todo ello hace que la rotura se pueda iniciar tanto en el soporte como en el engobe o en el vidriado.

A partir de los valores mostrados y las ecuaciones del anexo 2 se obtienen las tensiones residuales que se muestran en la tabla 4.20. El signo negativo indica tensiones de compresión y el positivo de tracción.

Tabla 4.20. Tensiones residuales en las diferentes capas.

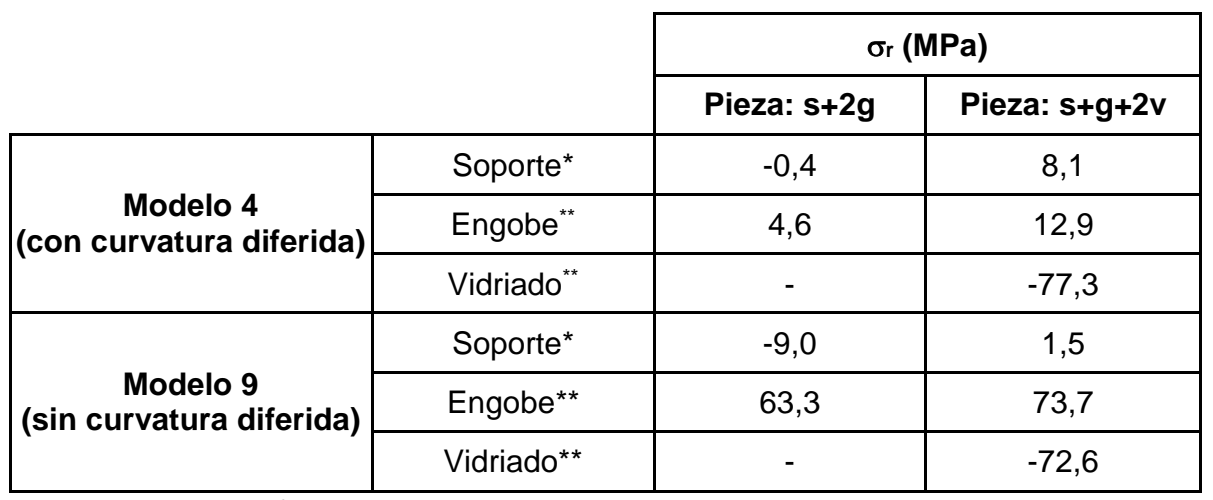

${ }^{*}$ Valor en la interfase con el engobe

** Valor promedio

Por lo tanto, los valores más altos de resistencia mecánica para el modelo 4 ensayado con la cara vista abajo se deben, posiblemente, a que el ligero esfuerzo de tracción que aparece en el engobe se ve compensado por su mayor resistencia mecánica. Sin embargo, en el modelo 9 la tensión de tracción en el engobe es muy superior, lo que hace que esta capa se rompa fácilmente, reduciendo con ello la resistencia mecánica de la pieza.

Además, se desprende lo siguiente:

- Las tensiones del soporte en la interfase con el engobe son siempre inferiores respecto a las tensiones en el engobe y en el vidriado.

- En las piezas $s+2 g$ la tensión del soporte en la interfase con el engobe es negativa (compresión), mientras que en las piezas $s+g+2 v$ es positiva (tracción). Ello indica que el vidriado tiene tendencia a traccionar la cara 
vista del soporte. Respecto a las tensiones de origen térmico, los valores de estas tensiones en el soporte son del mismo orden de magnitud, aunque de signo contrario en las piezas $\mathrm{s}+\mathrm{g}+2 \mathrm{v}$.

- El engobe de las piezas $s+2 g$ se encuentra en tracción, con tensiones mucho mayores en el modelo 9 que en el modelo 4. Esta situación es la que cabría esperar si se analizan las curvas dilatométricas determinadas en el apartado 4.2.6. En efecto, puede apreciarse que ambos engobes presentan una mayor dilatación respecto al soporte, en particular el engobe del modelo 9, que es el que se encuentra más traccionado. Este efecto es el que explica la baja resistencia mecánica efectiva que presentan las piezas $\mathrm{s}+2 \mathrm{~g}$ del modelo 9 , ensayadas con la cara vista hacia abajo.

- El vidriado de las piezas $s+g+2 v$ se encuentra tensionado en compresión, con valores que superan los $-70 \mathrm{MPa}$ para los dos modelos. El engobe en ambos modelos continúa estando en tracción, con valores superiores respecto a las piezas $\mathrm{s}+2 \mathrm{~g}$.

\subsubsection{Conclusiones}

En esta fase del proyecto se han caracterizado cuatro modelos industriales de gres porcelánico esmaltado y no esmaltado, con el objetivo de determinar una serie de características que posteriormente serán utilizadas en la resolución de un modelo matemático que permita describir el fenómeno de las curvaturas diferidas. De los resultados obtenidos se extraen las siguientes conclusiones:

- En términos generales, los modelos con curvatura diferida presentan una menor densidad aparente, una mayor absorción de agua a vacío y una mayor expansión por humedad tras su permanencia en el autoclave.

- Se ha comprobado que los dos soportes que presentan curvatura diferida también expanden tras la cocción, mientras que los que no cambian de curvatura con el tiempo no presentan expansión.

- La expansión térmica y coeficientes de dilatación de los cuatro soportes analizados es muy parecida.

- Existen diferencias entre la expansión térmica de los engobes y esmaltes utilizados en los distintos modelos. No obstante, no se ha encontrado una relación entre el desajuste dilatométrico y la existencia de curvatura diferida.

- Los soportes de los modelos que presentan curvatura diferida proporcionan menores valores de la resistencia mecánica y del módulo de elasticidad respecto a aquéllos que no cambian de curvatura con el tiempo.

- Los valores del módulo de elasticidad de los engobes ensayados son muy similares entre sí e inferiores a los de los esmaltes, que además presentan una mayor variabilidad.

- Los cuatro soportes ensayados muestran un comportamiento viscoelástico. Este comportamiento viscoelástico hace que al aplicar una carga aparezca una deformación que aumenta con el tiempo (fluencia); 
esta deformación permitiría la relajación de las tensiones residuales que pudieran existir en el soporte.

Finalmente, se han determinado las tensiones residuales que presentan los cuatro modelos estudiados, a fin de analizar su influencia sobre el fenómeno de las curvaturas diferidas. Las conclusiones que se extraen son:

\section{Tensiones de origen térmico}

- Los perfiles de tensiones de los cuatro soportes analizados son similares entre sí y presentan tensiones de compresión en ambas superficies y de tracción en la zona central. Son ligeramente asimétricos debido a que la cara vista está menos tensionada que la superficie inferior.

- Los valores de las tensiones medidos son pequeños, entre -3 y $1 \mathrm{MPa}$.

- No existe relación entre el perfil de tensiones residuales y las curvaturas en diferido para los cuatro modelos analizados, lo que indica que estas tensiones no son la causa principal de las curvaturas diferidas.

\section{Tensiones de acoplamiento esmalte-soporte}

- Las tensiones de acoplamiento, aunque pueden ser altas en engobes y vidriados, lo son bastante menos en los soportes.

- Las tensiones residuales en los soportes debidas al acoplamiento son del mismo orden de magnitud que las de origen térmico.

- Los soportes de las piezas correspondientes al modelo 4 presentan una mayor compresión que los del soporte 9 . No obstante, no es posible relacionar esta diferencia con la curvatura diferida.

Puede concluirse, por tanto, que las tensiones residuales en los soportes, tanto las de origen térmico como las de acoplamiento, no son la causa principal de las curvaturas en diferido; aunque no se puede descartar que jueguen cierto papel secundario o que influyan en las curvaturas en diferido en combinación con la expansión de los soportes o con la fluencia. Por ello, y porque pueden ser necesarias para el desarrollo del modelo matemático que describa este fenómeno, no se descarta su determinación en las siguientes fases del trabajo.

Además, los resultados obtenidos en la medida de las tensiones de origen térmico, permitirán definir el tipo de enfriamiento que debe realizarse a escala de laboratorio para reproducir las condiciones de enfriamiento industriales. Este aspecto es de vital importancia para abordar el estudio a escala de laboratorio de la influencia de las variables de proceso sobre la curvatura diferida. 


\subsection{INFLUENCIA DE VARIABLES SOBRE LAS CURVATURAS EN DIFERIDO}

Para entender el fenómeno de las curvaturas en diferido en piezas de gres porcelánico, es necesario analizar el efecto de las diferentes variables del proceso como:

- el grado de molienda,

- la densidad aparente en seco,

- la presencia del esmalte,

- el espesor del soporte y el espesor relativo esmalte/soporte,

- la temperatura máxima de cocción,

- el tiempo de permanencia a temperatura máxima,

- la velocidad de enfriamiento.

Los resultados obtenidos, además de permitir conocer la influencia de las diferentes variables, proporcionarán información acerca de los parámetros que presentan una mayor influencia sobre las curvaturas diferidas en baldosas de gres porcelánico. Esta información se utilizará posteriormente para modelizar las curvaturas en diferido.

\subsubsection{Materiales y ensayos realizados}

En esta fase del trabajo, se han estudiado dos composiciones de soporte correspondientes a los modelos 4 y 7 , que han sido caracterizados previamente en el apartado 4.2.

Para la preparación de las probetas se ha seguido el procedimiento descrito en el apartado 3.

Se midieron las propiedades siguientes:

- evolución de la curvatura con el tiempo $\left(\delta_{c}\right)$,

- evolución de la expansión post-cocción con el tiempo ( $\varepsilon x)$,

- densidad aparente en cocido $(\rho)$,

- absorción de agua (AA) y penetración de azul de metileno por la superficie inferior y superior (ZAi y ZAs),

- tensiones residuales.

\subsubsection{Influencia de la temperatura máxima de cocción}

En este apartado se estudia la influencia de la temperatura máxima de cocción utilizando soportes sin esmaltar de los modelos 4 y 7 . Las temperaturas ensayadas fueron $1190^{\circ} \mathrm{C}, 1210^{\circ} \mathrm{C}$ y $1230{ }^{\circ} \mathrm{C}$. Estas temperaturas se seleccionaron en intervalos de $20^{\circ} \mathrm{C}$ y de tal modo que para la mayor de ellas no se apreciaba curvatura diferida. 
Los resultados obtenidos se muestran en la figura 4.25 , la figura 4.26 y la tabla 4.21 para el modelo 4 , y en la figura 4.27 , la figura 4.28 y la tabla 4.22 para el modelo 7.

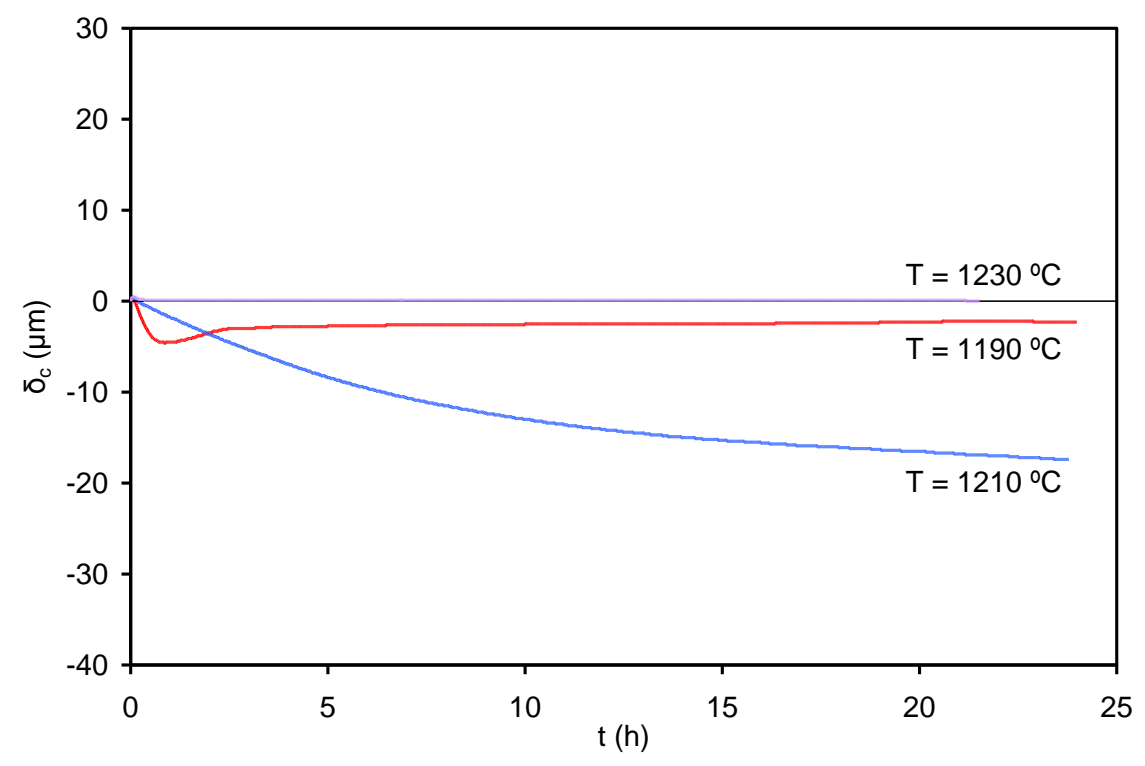

Figura 4.25. Curvatura diferida del modelo 4 cocido a diferentes temperaturas.

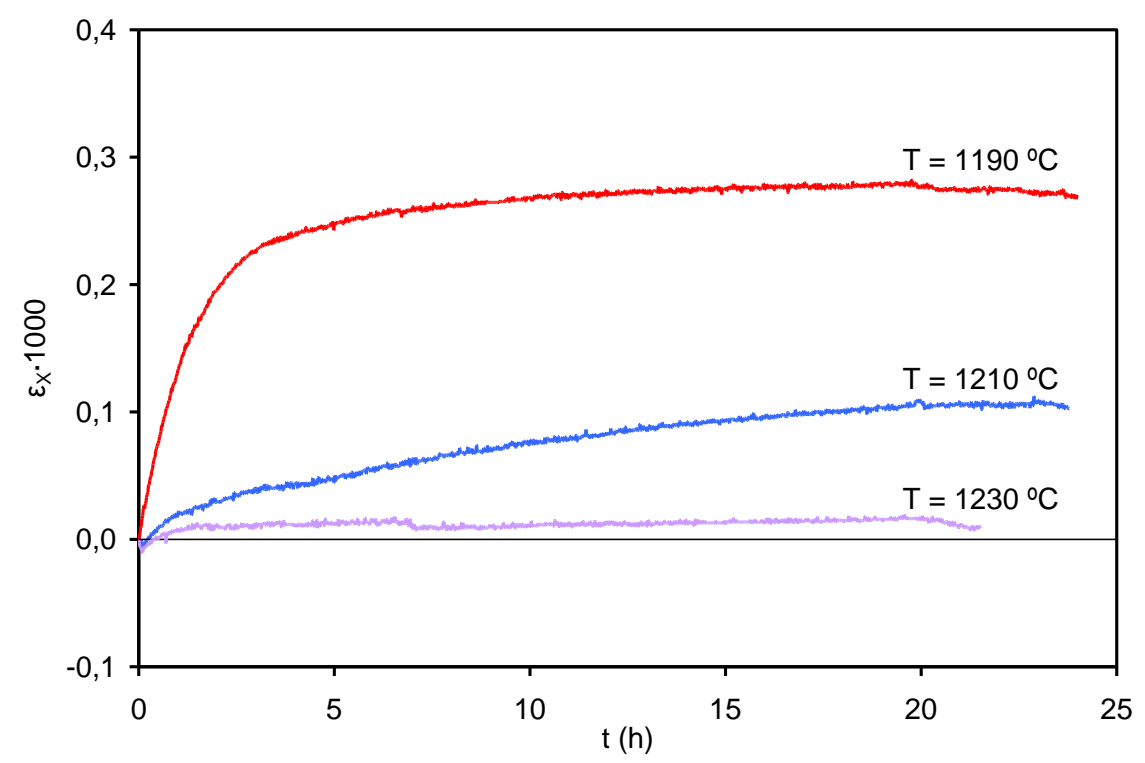

Figura 4.26. Expansión post-cocción del modelo 4 cocido a diferentes temperaturas. 


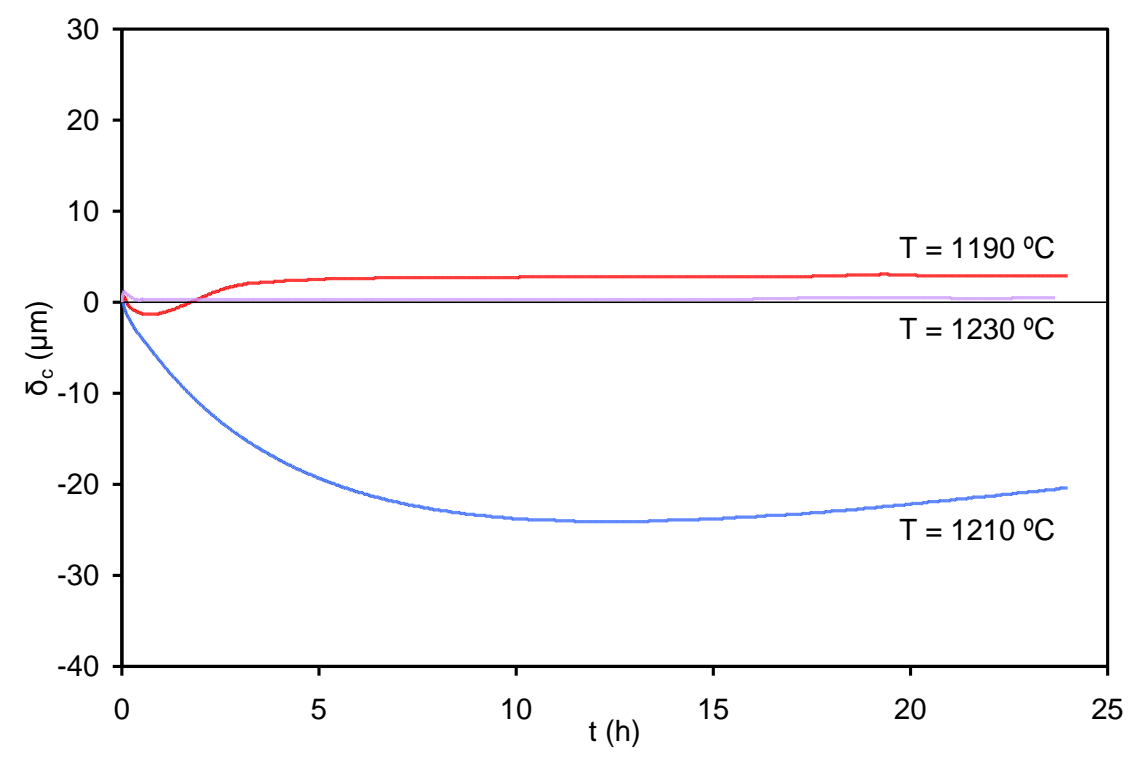

Figura 4.27. Curvatura diferida del modelo 7 cocido a diferentes temperaturas.

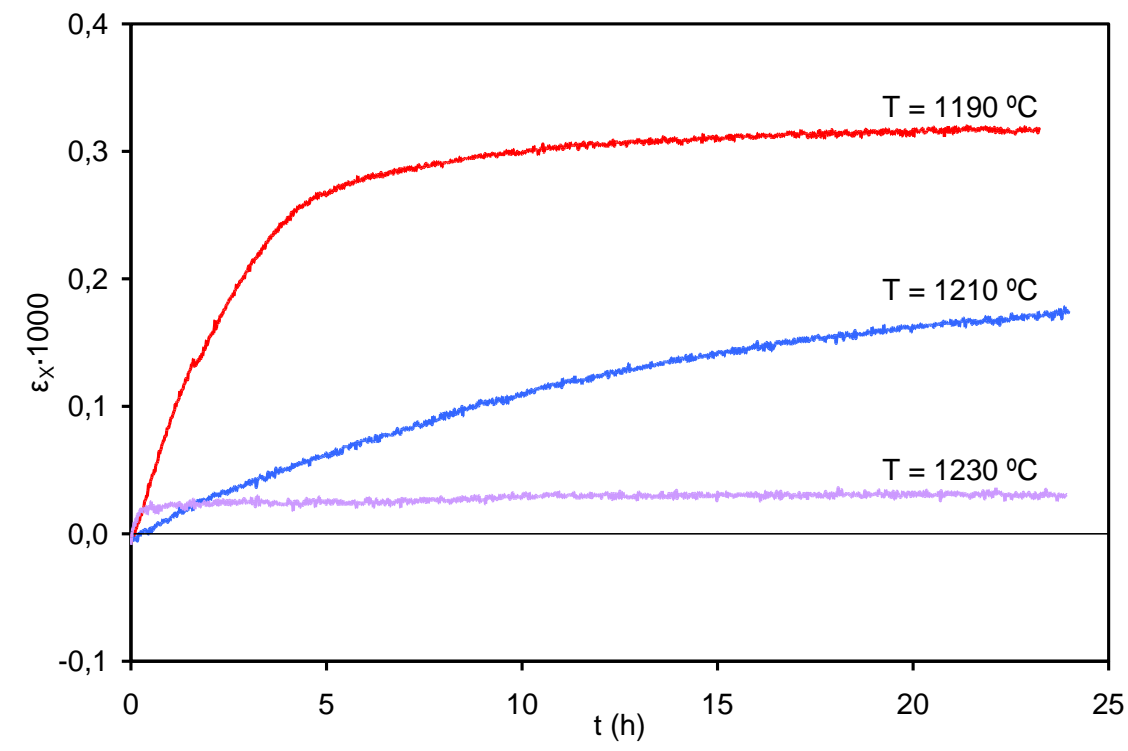

Figura 4.28. Expansión post-cocción del modelo 7 cocido a diferentes temperaturas.

88 
Tabla 4.21. Densidad aparente, absorción de agua y penetración del modelo 4 cocido a diferentes temperaturas.

\begin{tabular}{|c|c|c|c|c|}
\hline $\mathbf{T}$ & $\boldsymbol{\rho}$ & $\mathbf{A A}_{3}$ días & $\mathbf{Z}_{\mathrm{Ai}}$ & $\mathbf{Z}_{\mathrm{As}}$ \\
$(\mathbf{\circ} \mathbf{C})$ & $\left(\mathbf{k g} / \mathbf{m}^{3}\right)$ & $(\%)$ & $(\mathbf{m m})$ & $(\mathbf{m m})$ \\
\hline 1190 & 2309 & 2,2 & 2,0 & 2,2 \\
\hline 1210 & 2327 & 0,4 & 0,0 & 0,0 \\
\hline 1230 & 2316 & 0,0 & 0,0 & 0,0 \\
\hline
\end{tabular}

Tabla 4.22. Densidad aparente, absorción de agua y penetración del modelo 7 cocido a diferentes temperaturas.

\begin{tabular}{|c|c|c|c|c|}
\hline $\mathbf{T}$ & $\mathbf{\rho}$ & $\mathbf{A A}_{3}$ dias & $\mathbf{Z}_{\mathbf{A i}}$ & $\mathbf{Z}_{\mathrm{As}}$ \\
$\left({ }^{\circ} \mathbf{C}\right)$ & $\left(\mathbf{k g} / \mathbf{m}^{3}\right)$ & $(\%)$ & $(\mathbf{m m})$ & $(\mathbf{m m})$ \\
\hline 1190 & 2370 & 2,4 & 2,0 & 1,8 \\
\hline 1210 & 2412 & 0,6 & 2,1 & 0,0 \\
\hline 1230 & 2431 & 0,0 & 0,0 & 0,0 \\
\hline
\end{tabular}

Los dos modelos presentan un comportamiento cualitativamente similar, caracterizado por una evolución inicial de la curvatura hacia la concavidad (flecha negativa) hasta alcanzar un mínimo, a partir del cual la pieza evoluciona en sentido contrario. Esta evolución es la que se observa habitualmente en las piezas industriales, aunque la magnitud de las variaciones es mucho menor en las probetas de laboratorio. Esto es debido, en parte, a las menores dimensiones de estas últimas.

A medida que aumenta la temperatura, la curvatura evoluciona más lentamente con el tiempo hasta eliminarse a $1230^{\circ} \mathrm{C}$. A baja temperatura $\left(1190{ }^{\circ} \mathrm{C}\right.$ ) el cambio de curvatura es pequeño mientras que a la temperatura intermedia (1210 $\left.{ }^{\circ} \mathrm{C}\right)$, la evolución de la curvatura es tan lenta que no llega a estabilizarse a las 24 horas e incluso para el modelo 4 no se alcanza la flecha mínima (máxima concavidad).

En cuanto a la expansión post-cocción, se observa que disminuye en magnitud y es más lenta cuando aumenta la temperatura de cocción, llegando a anularse a la temperatura más alta. Asimismo, existe una relación directa entre el cambio de curvatura con el tiempo y la cinética de expansión, por lo que se desprende que ambos fenómenos podrían estar relacionados. Cuando no se observa expansión, no se produce curvatura diferida. Sin embargo, no es posible establecer relación directa entre la expansión a las 24 horas y la curvatura final.

También se puede apreciar que la absorción de agua y la penetración del azul de metileno disminuyen al aumentar la temperatura como consecuencia del avance del proceso de sinterización. Las probetas que no presentan curvaturas en diferido ni expansión poseen una absorción de agua nula.

Finalmente, se observa que la densidad aparente en cocido aumenta con la temperatura hasta que se alcanza la temperatura de máxima densificación, a partir de la cual se produce un hinchamiento de la pieza. 
Cabe destacar que los resultados obtenidos en este apartado indican que la temperatura máxima de cocción es una de las variables que en mayor medida influye sobre la curvatura diferida. De hecho, la temperatura de cocción ejerce una influencia importante sobre la curvatura diferida, pues afecta tanto a la magnitud de la curvatura como a la cinética del fenómeno.

Asimismo, se puede establecer de forma cualitativa la evolución de la curvatura de las piezas con el tiempo cuando se modifica la temperatura de cocción (figura 4.29).

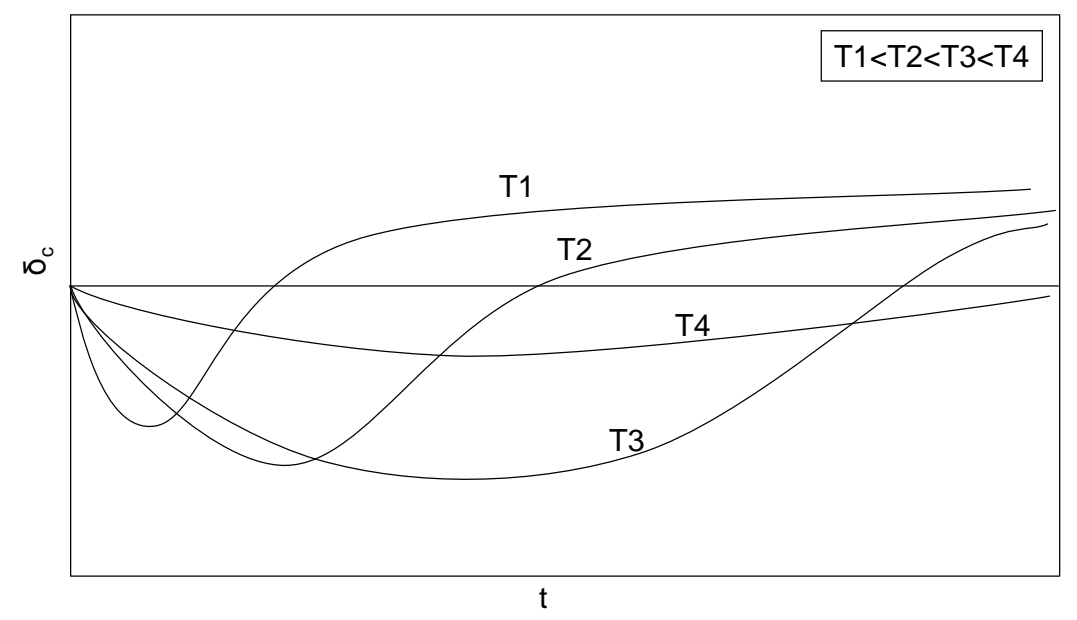

Figura 4.29. Representación esquemática de la evolución de la curvatura con el tiempo al modificar la temperatura máxima de cocción.

La evolución esperada se caracteriza por un cambio de la curvatura con el tiempo más rápido a medida que disminuye la temperatura de cocción, lo que reduce el tiempo necesario para que se estabilice la curvatura de la pieza a la salida del horno. Además, es probable que el cambio de curvatura se inicie en el interior del horno (durante el enfriamiento). Por lo tanto, una parte de la evolución de la curvatura con el tiempo no se registra, especialmente a bajas temperaturas donde la evolución es más rápida.

Para corroborar esta evolución se midió la evolución de la curvatura de probetas del modelo 7 cocidas a más temperaturas máximas de cocción (figura 4.30), confirmándose la tendencia esperada. Los resultados obtenidos también indican que pequeños cambios en la temperatura máxima de cocción (de tan solo $5 \stackrel{\circ}{\circ}$ ) pueden cambiar drásticamente tanto la cinética como la magnitud de las curvaturas en diferido. 


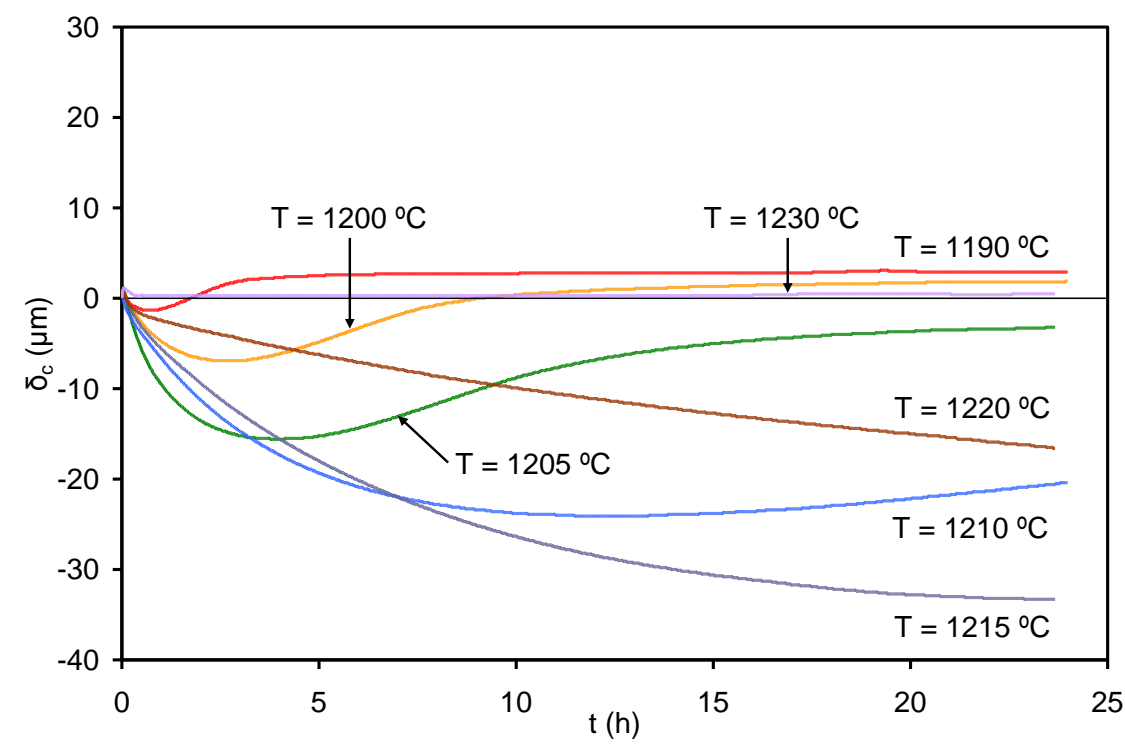

Figura 4.30. Curvatura diferida del modelo 7 cocido a siete temperaturas máximas de cocción.

A la vista de la importancia de la influencia de la temperatura máxima de cocción sobre las curvaturas en diferido, se decidió realizar el estudio del efecto de la mayoría de los otros parámetros a varias temperaturas máximas de cocción.

\subsubsection{Influencia del tamaño de partícula (grado de molienda)}

Los cambios en el tamaño de partícula de la composición modifican la microestructura en crudo de las piezas y, con ello, su comportamiento durante la cocción y sus propiedades finales. A continuación, se presentan los resultados obtenidos para cada uno de los modelos estudiados. El modelo 4 presentaba un residuo a $40 \mu \mathrm{m}(\mathrm{R})$ elevado (9\%) mientras que el modelo 7 poseía un valor del residuo bajo $(1,7 \%)$, por ello se optó por aumentar el grado de molienda para el modelo 4 y reducirlo para el modelo 7.

\section{A. Modelo 4}

De la figura 4.31 a la figura 4.36 y en la tabla 4.23 , se muestran los resultados obtenidos al disminuir el tamaño de partícula en el modelo 4 para las 3 temperaturas máximas de cocción consideradas. 
4. Resultados y discusión

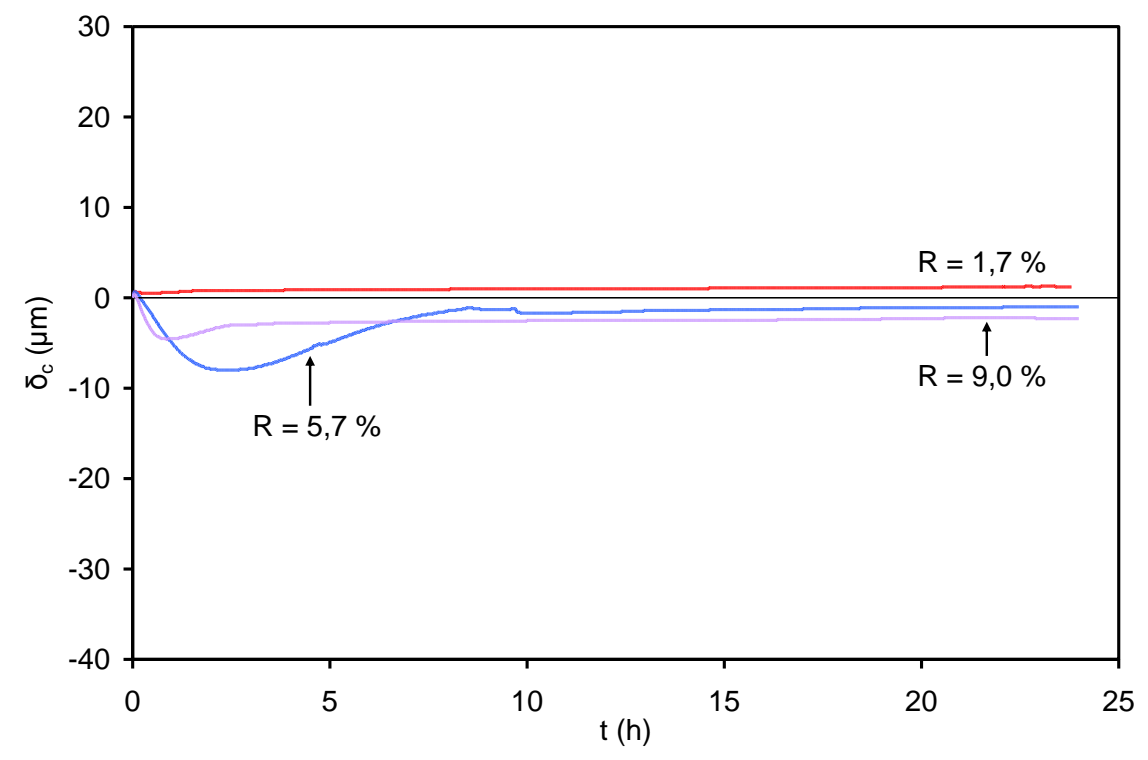

Figura 4.31. Curvatura diferida del modelo 4 con diferentes granulometrías cocido a $1190{ }^{\circ} \mathrm{C}$.

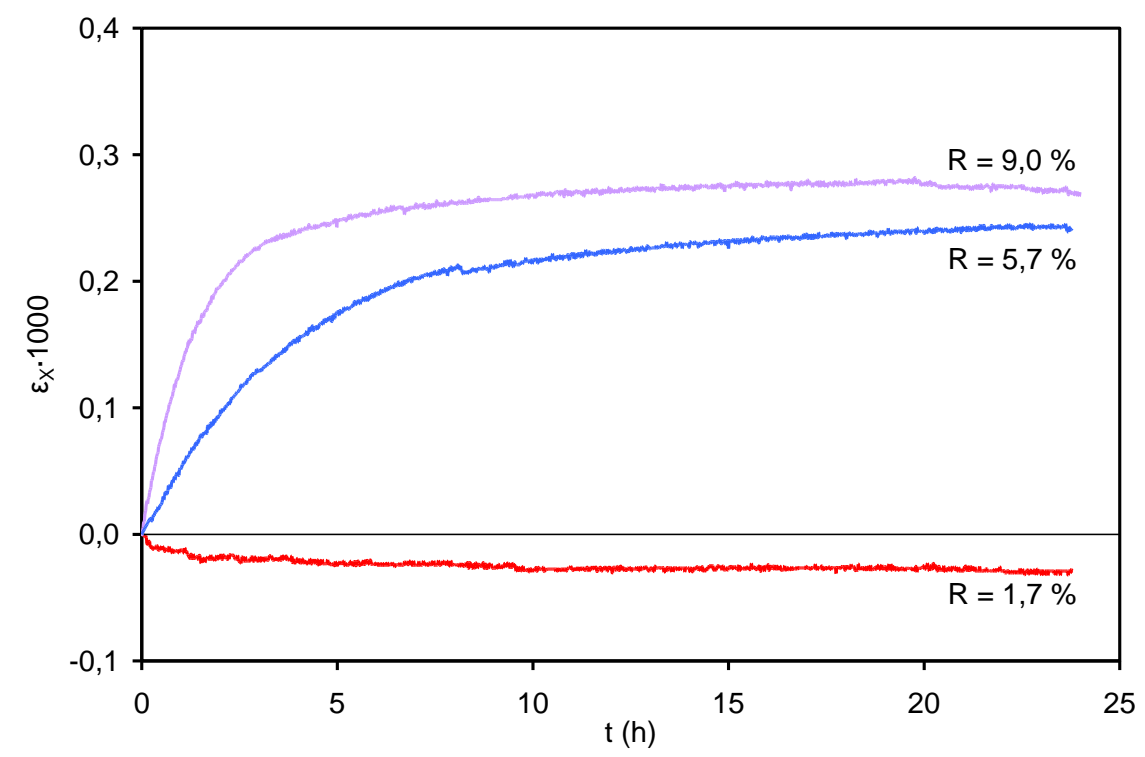

Figura 4.32. Expansión post-cocción del modelo 4 con diferentes granulometrías cocido a $1190 \stackrel{\circ}{\circ}$. 
4. Resultados y discusión

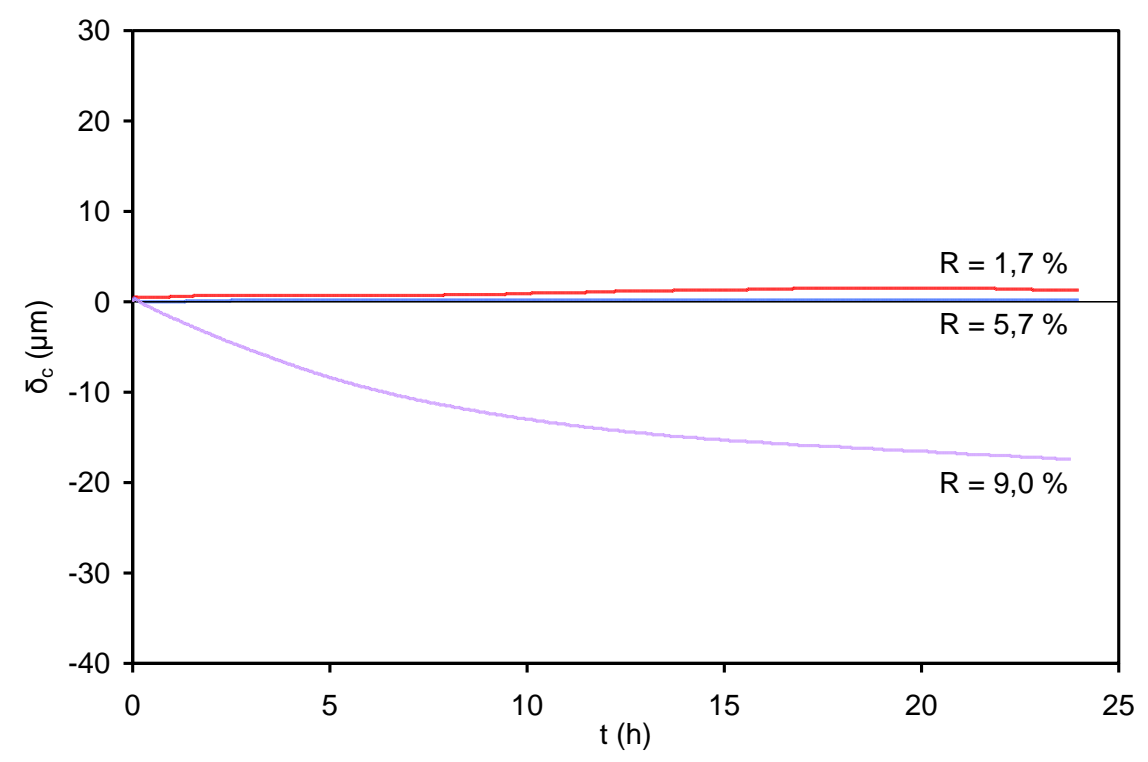

Figura 4.33. Curvatura diferida del modelo 4 con diferentes granulometrías cocido a $1210^{\circ} \mathrm{C}$.

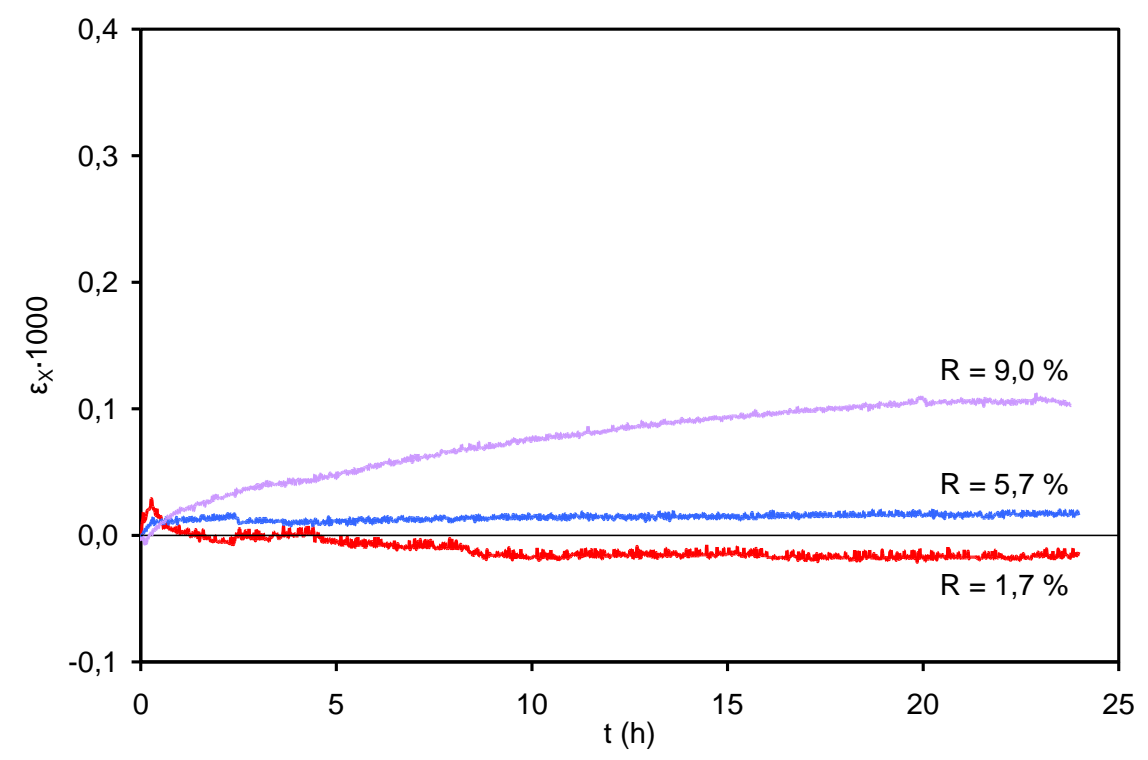

Figura 4.34. Expansión post-cocción del modelo 4 con diferentes granulometrías cocido a $1210^{\circ} \mathrm{C}$. 
4. Resultados y discusión

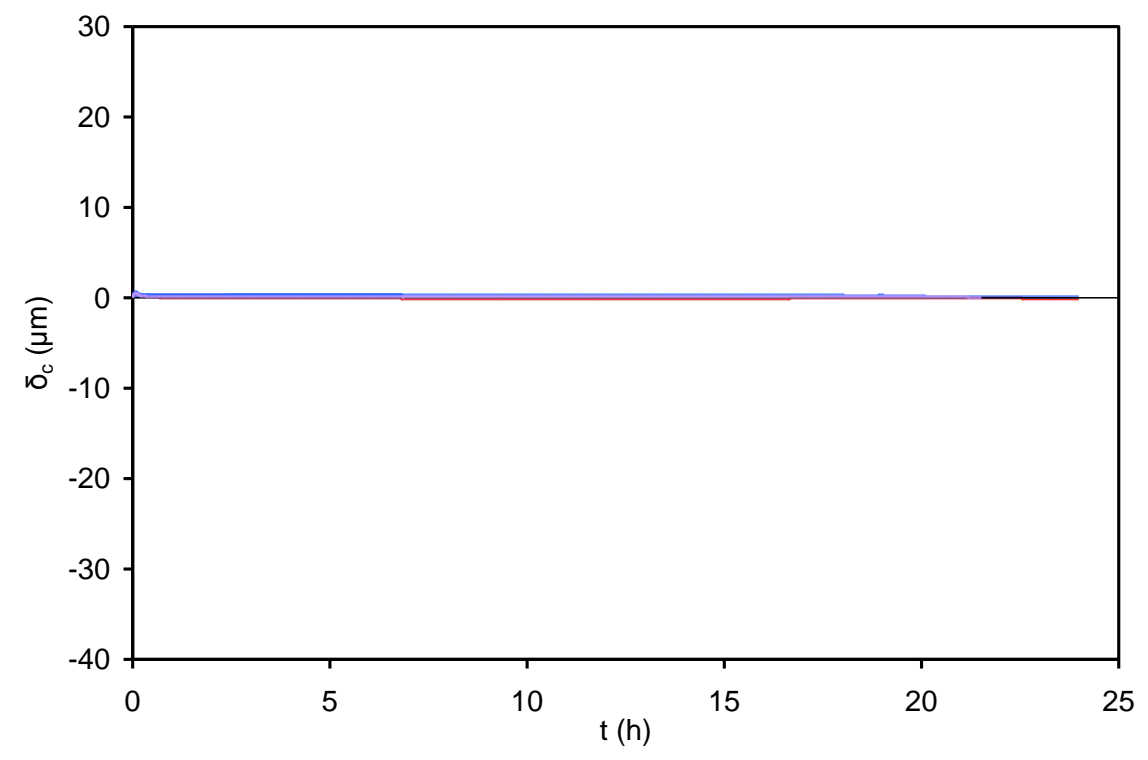

Figura 4.35. Curvatura diferida del modelo 4 con diferentes granulometrías cocido a $1230^{\circ} \mathrm{C}$.

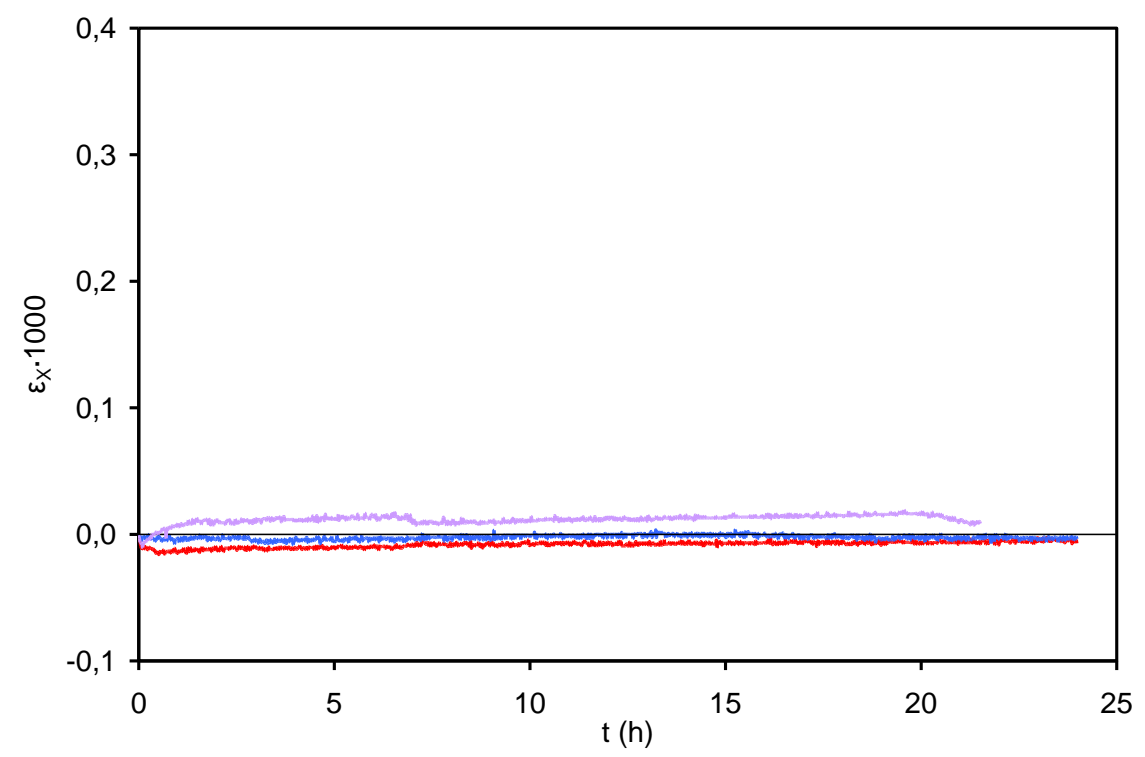

Figura 4.36. Expansión post-cocción del modelo 4 con diferentes granulometrías cocido a $1230 \stackrel{\circ}{\circ}$. 
Tabla 4.23. Densidad aparente y absorción de agua del modelo 4 con diferentes granulometrías cocido a distintas temperaturas.

\begin{tabular}{|c|c|c|c|c|c|c|c|c|c|c|c|c|}
\hline \multirow[b]{2}{*}{$\begin{array}{c}\mathbf{R} \\
(\%)\end{array}$} & \multicolumn{4}{|c|}{$1190^{\circ} \mathrm{C}$} & \multicolumn{4}{|c|}{$1210^{\circ} \mathrm{C}$} & \multicolumn{4}{|c|}{$1230^{\circ} \mathrm{C}$} \\
\hline & $\mid \begin{array}{c}\rho \\
\left(\mathbf{k g} / \mathbf{m}^{3}\right)\end{array}$ & $\begin{array}{c}\mathrm{AA}_{3 \mathrm{dias}} \\
(\%)\end{array}$ & $\begin{array}{c}\mathrm{z}_{\mathrm{Ai}} \\
(\mathrm{mm})\end{array}$ & $\begin{array}{c}\mathbf{z}_{\text {As }} \\
(\mathrm{mm})\end{array}$ & $\mid \begin{array}{c}\rho \\
\left(\mathbf{k g} / \mathbf{m}^{3}\right)\end{array}$ & $\begin{array}{c}\mathrm{AA}_{3} \text { días } \\
(\%)\end{array}$ & $\begin{array}{c}Z_{A i} \\
(m m)\end{array}$ & \begin{tabular}{|c|}
$Z_{\text {As }}$ \\
$(m m)$
\end{tabular} & $\begin{array}{c}\rho \\
\left(\mathrm{kg} / \mathrm{m}^{3}\right)\end{array}$ & $\mid \begin{array}{c}\mathrm{AA}_{3} \text { dias } \\
(\%)\end{array}$ & $=\begin{array}{c}Z_{A i} \\
(m m)\end{array}$ & $\begin{array}{l}\mathrm{Z}_{\text {As }} \\
(\mathrm{mm})\end{array}$ \\
\hline 9,0 & 2309 & 2,2 & 2,0 & 2,2 & 2327 & 0,4 & 0,0 & 0,0 & 2316 & 0,0 & 0,0 & 0,0 \\
\hline 5,7 & 2336 & 1,3 & 2,0 & 2,2 & 2348 & 0,0 & 0,0 & 0,0 & 2323 & 0,0 & 0,0 & 0,0 \\
\hline 1,7 & 2370 & 0,0 & 0,0 & 0,0 & 2374 & 0,0 & 0,0 & 0,0 & 2328 & 0,0 & 0,0 & 0,0 \\
\hline
\end{tabular}

A temperatura constante, al disminuir el residuo aumenta la densidad de las piezas y disminuye su absorción de agua debido a la obtención de una microestructura en crudo formada por poros de menor tamaño que favorecen la sinterización de las piezas.

Para cada temperatura ensayada, al disminuir el residuo disminuye la expansión, la cinética de expansión y la tendencia de las piezas a presentar curvatura diferida. Ello se debe a que la disminución del residuo aumenta el grado de cocción de las piezas. Asimismo, para cada una de las composiciones con diferente residuo, al aumentar la temperatura se observan los efectos descritos anteriormente.

La figura 4.37 muestra la densidad aparente en cocido y la absorción de agua en función de la temperatura para las diferentes granulometrías ensayadas.

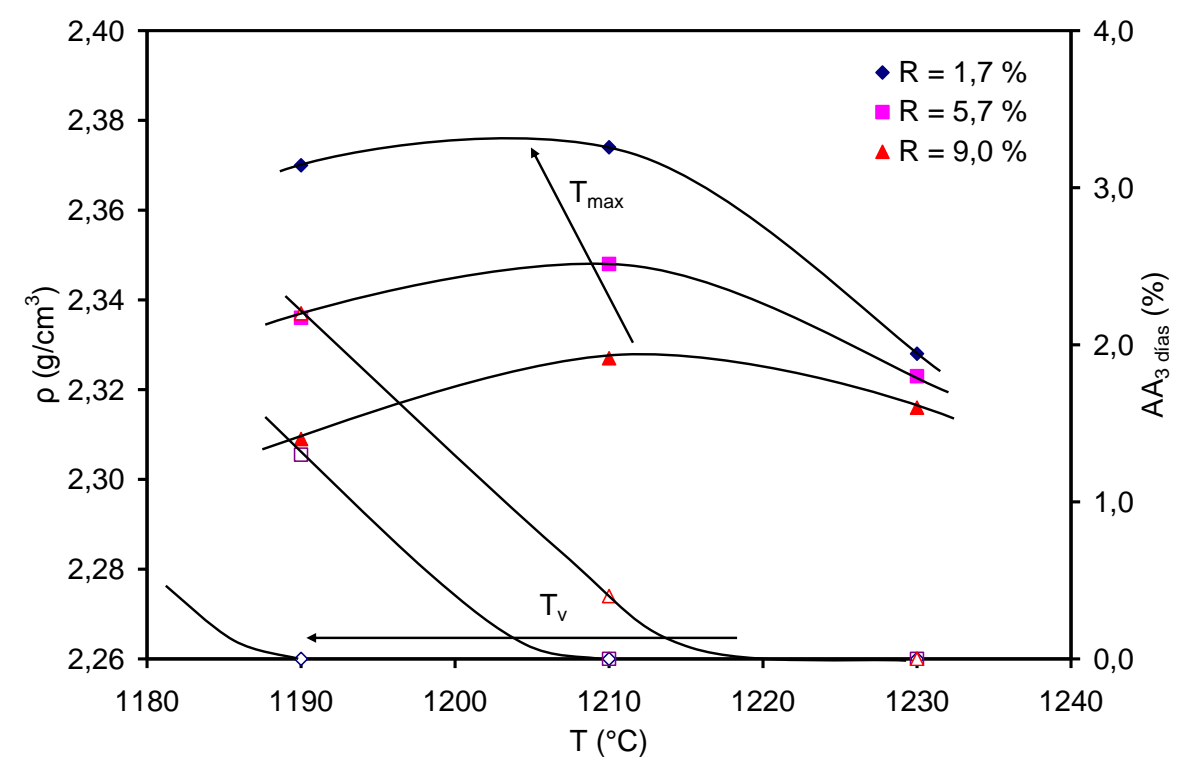

Figura 4.37. Influencia de la granulometría y la temperatura sobre la densidad aparente y la absorción. 
Se observa que al disminuir el residuo aumenta la densidad y se reduce la absorción de agua. Además, la temperatura de máxima densificación $\left(T_{\max }\right)$ y la temperatura de vitrificación ( $T_{v}$ ), a la cual la absorción de agua se anula, se desplazan hacia valores más bajos. Los valores de $T_{\max }$ y $T_{v}$ determinados a partir de la figura 4.37 se recogen en la tabla 4.24 .

Tabla 4.24. Temperatura de máxima densificación $\left(T_{\max }\right)$ y de vitrificación $\left(T_{v}\right)$ a las diferentes granulometrías.

\begin{tabular}{|c|c|c|c|}
\hline $\mathbf{R}(\%)$ & $\mathbf{T}_{\max }\left({ }^{\circ} \mathbf{C}\right)$ & $\mathbf{T}_{\mathbf{v}}\left({ }^{\circ} \mathbf{C}\right)$ & $\mathbf{T}_{\max }-\mathbf{T}_{\mathbf{v}}\left({ }^{\circ} \mathbf{C}\right)$ \\
\hline 9,0 & 1212 & 1218 & -6 \\
\hline 5,7 & 1208 & 1208 & 0 \\
\hline 1,7 & 1204 & 1190 & 14 \\
\hline
\end{tabular}

A la vista de los valores de la se observa que al disminuir el residuo aumenta la densidad y se reduce la absorción de agua. además, la temperatura de máxima densificación ( $t_{\max }$ ) y la temperatura de vitrificación ( $\left.\mathrm{t}_{\mathrm{v}}\right)$, a la cual la absorción de agua se anula, se desplazan hacia valores más bajos. los valores de $t_{\max } y t_{v}$ determinados a partir de la figura 4.37 se recogen en la tabla 4.24.

tabla 4.24, se constata que el efecto de la granulometría es mayor sobre la temperatura de vitrificación que sobre la temperatura de máxima densificación, de forma que la diferencia $T_{\max }-T_{v}$ es positiva cuando el tamaño de partícula es pequeño y negativa cuando el residuo es elevado. Ello implica que, para granulometrías finas, va a ser posible obtener piezas sin absorción de agua, expansión post-cocción y curvatura diferida a temperaturas inferiores a la de máxima densificación.

Por el contrario, cuando la granulometría es gruesa es necesario superar $T_{\max }$ para eliminar la absorción de agua, lo que implica que las piezas se encuentren en la zona de hinchamiento y muy probablemente deformen por piroplasticidad. 


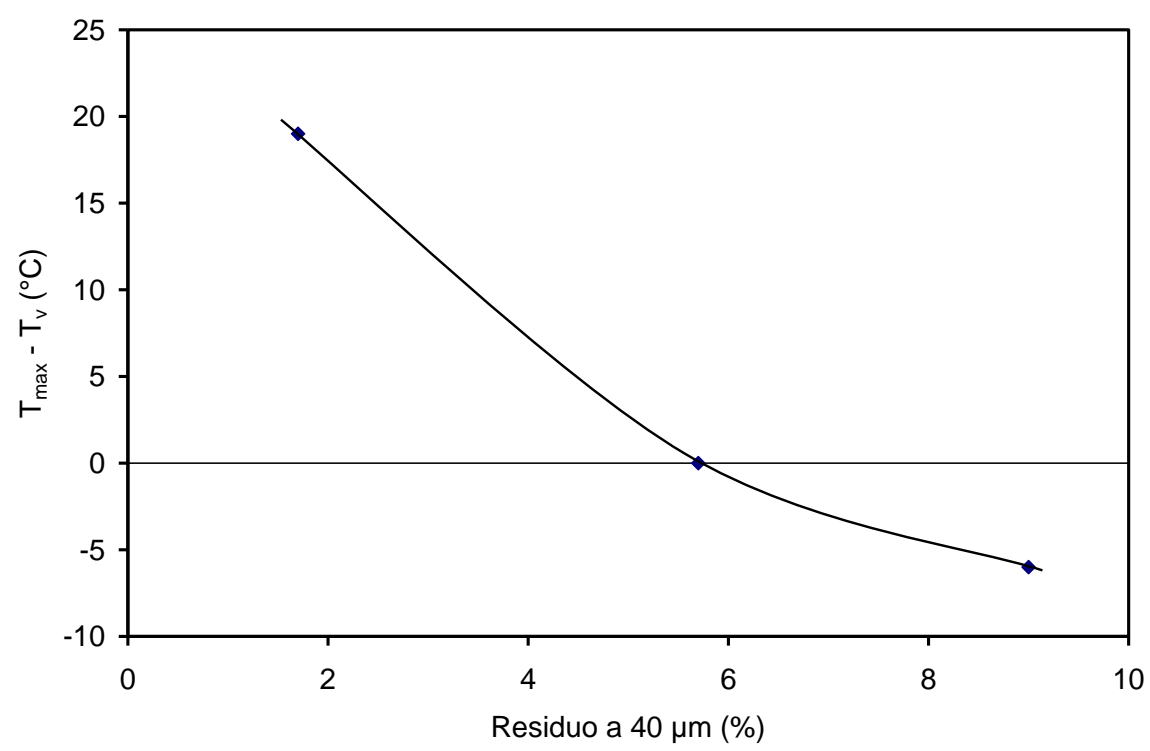

Figura 4.38. Diferencia entre $T_{\max }$ y $T_{v}$ en función del residuo a $40 \mu m$.

Los resultados obtenidos en este apartado indican que el grado de molienda ejerce un efecto importante sobre la curvatura diferida, por lo que puede ser una de las variables a modificar para evitar este comportamiento.

\section{B. Modelo 7}

De la figura 4.39 a la figura 4.44 y en la tabla 4.25 , se muestran los resultados obtenidos al aumentar el tamaño de partícula para el modelo 7 para las 3 temperaturas máximas de cocción.

Tabla 4.25. Densidad aparente y absorción de agua del modelo 7 con diferentes granulometrías cocido a distintas temperaturas.

\begin{tabular}{|c|c|c|c|c|c|c|c|c|c|c|c|c|}
\hline \multirow[b]{2}{*}{$\begin{array}{l}\mathbf{R}_{40} \\
(\%)\end{array}$} & \multicolumn{4}{|c|}{$1190^{\circ} \mathrm{C}$} & \multicolumn{4}{|c|}{$1210^{\circ} \mathrm{C}$} & \multicolumn{4}{|c|}{$1230 \stackrel{\circ}{C}$} \\
\hline & $\begin{array}{c}\rho \\
\left(\mathrm{kg} / \mathrm{m}^{3}\right.\end{array}$ & $\begin{array}{c}\mathbf{A A}_{3} \text { días } \\
(\%)\end{array}$ & $\left(\begin{array}{c}Z_{A i} \\
(m m)\end{array}\right.$ & $\begin{array}{c}Z_{\text {As }} \\
(\mathrm{mm})\end{array}$ & $\begin{array}{c}\rho \\
\left(\mathrm{kg} / \mathrm{m}^{3}\right)\end{array}$ & $\begin{array}{c}\mathrm{AA}_{3 \text { dias }} \\
(\%)\end{array}$ & $\begin{array}{c}z_{A i} \\
(m m)\end{array}$ & $\begin{array}{c}z_{\text {As }} \\
(\mathrm{mm})\end{array}$ & $\begin{array}{c}\rho \\
\left(\mathrm{kg} / \mathrm{m}^{3}\right)\end{array}$ & $\begin{array}{c}\mathrm{AA}_{3} \text { dias } \\
(\%)\end{array}$ & $\left.\begin{array}{c}\mathbf{Z}_{\mathrm{Ai}} \\
(\mathrm{mm})\end{array}\right)$ & $\begin{array}{c}Z_{\text {As }} \\
(m m)\end{array}$ \\
\hline 4,5 & 2296 & 3,8 & 1,6 & 1,6 & 2356 & 2,6 & 1,7 & 1,7 & 2404 & 1,2 & 2,6 & 1,4 \\
\hline 3,0 & 2309 & 3,8 & 1,4 & 1,4 & 2374 & 1,8 & 1,9 & 1,7 & 2407 & 0,5 & 0,0 & 0,0 \\
\hline 1,7 & 2345 & 2,5 & 1,8 & 1,7 & 2410 & 1,3 & 2,3 & 1,4 & 2427 & 0,0 & 0,0 & 0,0 \\
\hline
\end{tabular}


Se aprecia lo siguiente:

- Al aumentar el residuo disminuye la densidad aparente y aumenta la absorción de agua de las piezas como consecuencia de la presencia de poros de mayor tamaño en las piezas crudas y la menor reactividad de la composición.

- Al igual que para el modelo 4, para cada una de las muestras con diferente residuo se observan los efectos comentados en el apartado 4.3.2 al modificar la temperatura. Sin embargo, para la temperatura más baja ensayada, $1190^{\circ} \mathrm{C}$, la única pieza que presenta curvatura diferida es la de menor residuo $(1,7 \%)$, la cual muestra una tendencia hacia la convexidad (flecha positiva). Este comportamiento, en principio anómalo, podría deberse a que el cambio de curvatura comienza en el interior del horno de forma que cuando se inician las medidas una parte importante de la evolución de la curvatura con el tiempo no se registra. Ello podría justificar la ausencia de curvatura con el tiempo en otros productos con un menor grado de cocción, como el gres esmaltado.

- Al aumentar el residuo aumenta tanto la magnitud como la cinética de la expansión debido a la disminución del grado de cocción. Como excepción a este comportamiento se encuentran los experimentos con composiciones de residuo alto procesadas a baja temperatura. En estos casos, la expansión debe ser tan rápida que una parte de la misma tiene lugar con anterioridad a la realización de la medida, lo que está de acuerdo con lo comentado en el párrafo anterior. 
4. Resultados y discusión

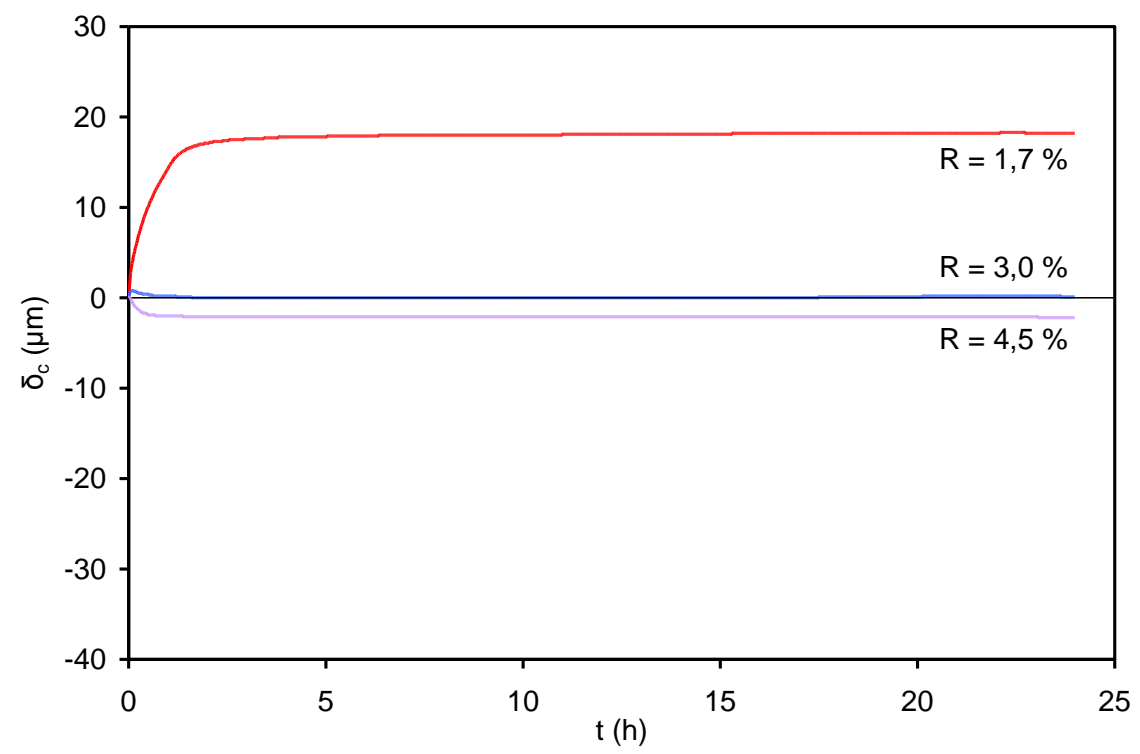

Figura 4.39. Curvatura diferida del modelo 7 con diferentes granulometrías cocido a $1190 \stackrel{\circ}{C}$.

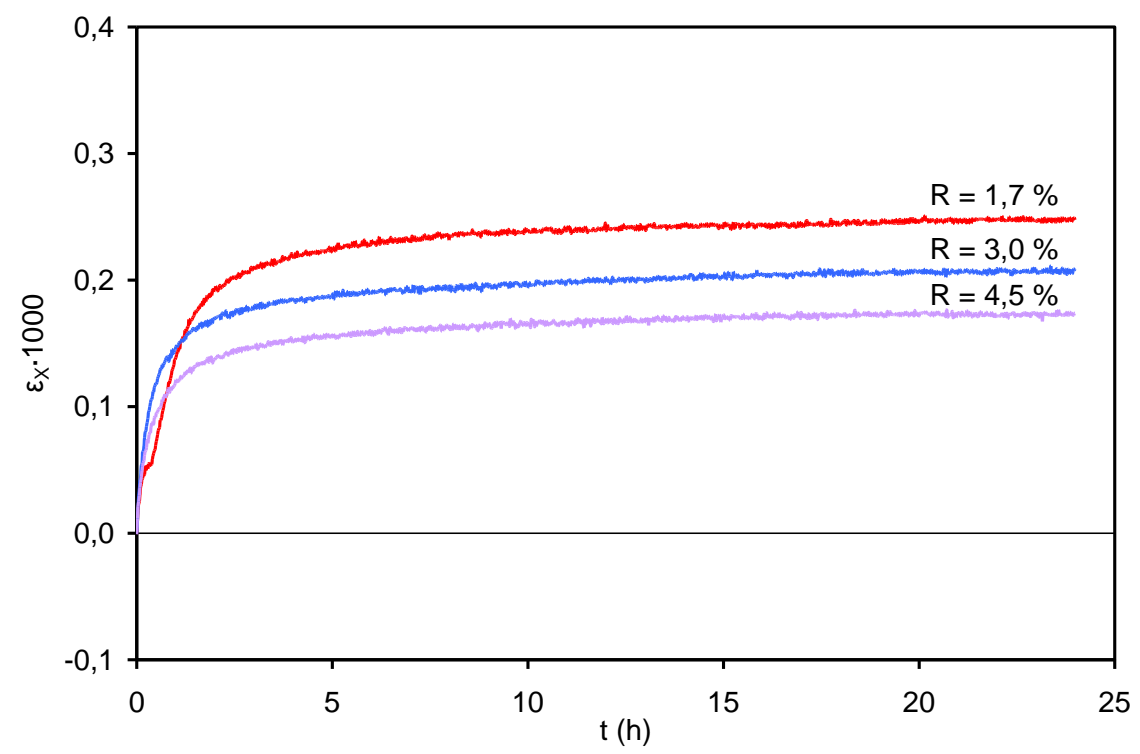

Figura 4.40. Expansión post-cocción del modelo 7 con diferentes granulometrías cocido a $1190 \stackrel{\circ}{\circ}$. 
4. Resultados y discusión

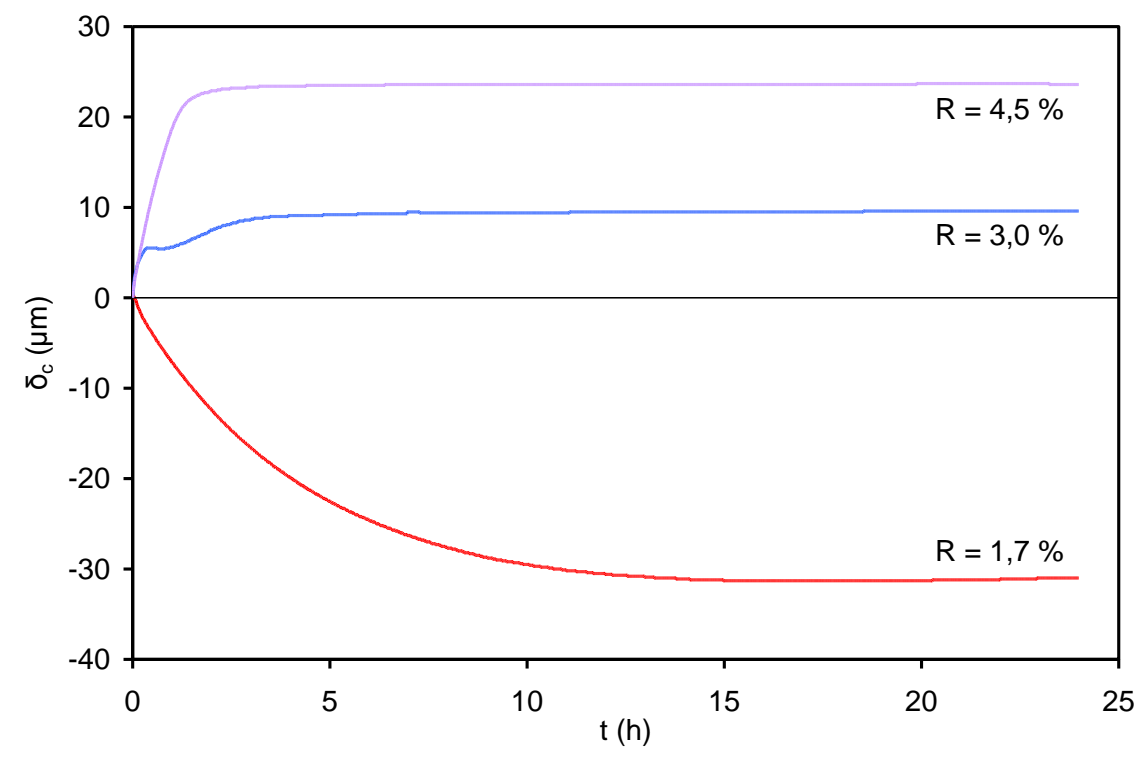

Figura 4.41. Curvatura diferida del modelo 7 con diferentes granulometrías cocido a $1210 \stackrel{\circ}{\circ}$.

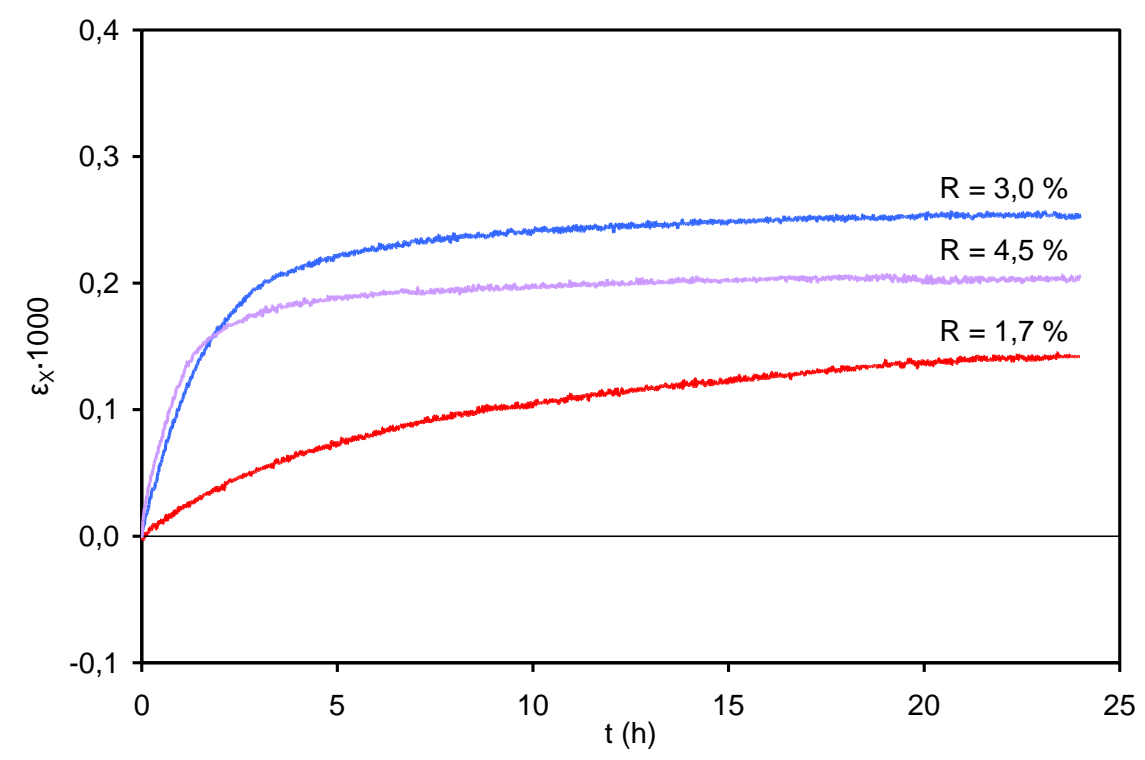

Figura 4.42. Expansión post-cocción del modelo 7 con diferentes granulometrías cocido a $1210 \stackrel{\circ}{ } \mathrm{C}$. 
4. Resultados y discusión

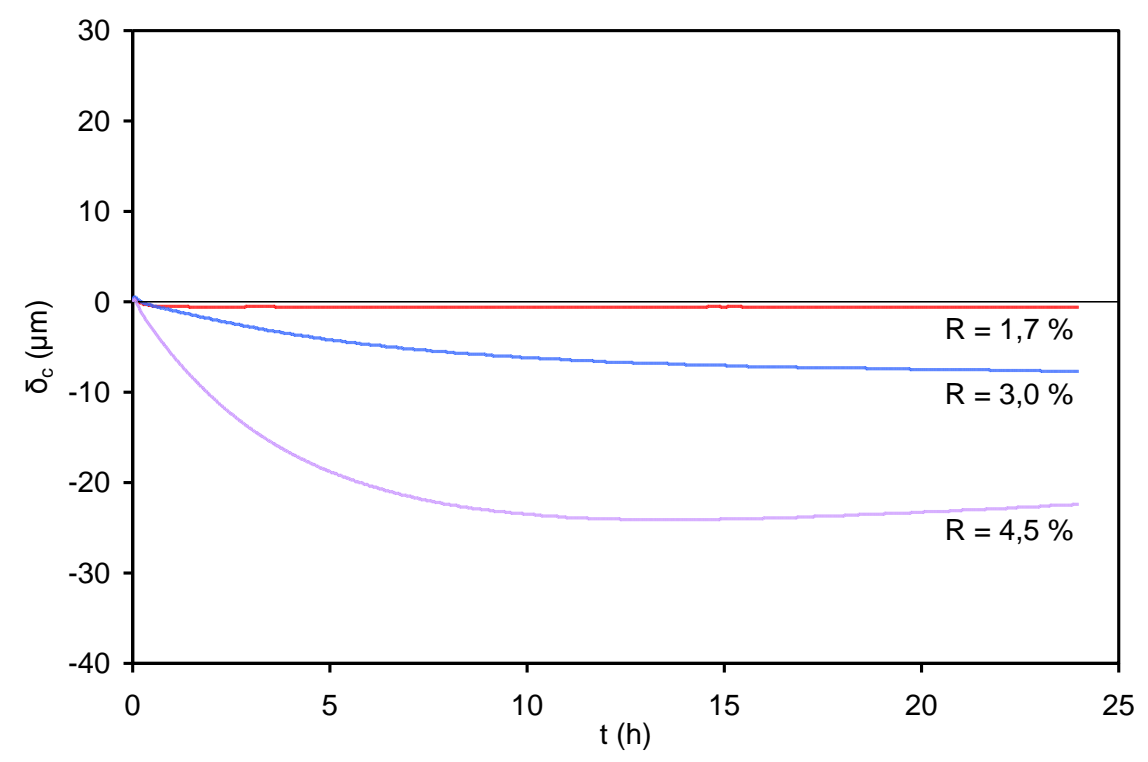

Figura 4.43. Curvatura diferida del modelo 7 con diferentes granulometrías cocido a $1230^{\circ} \mathrm{C}$.

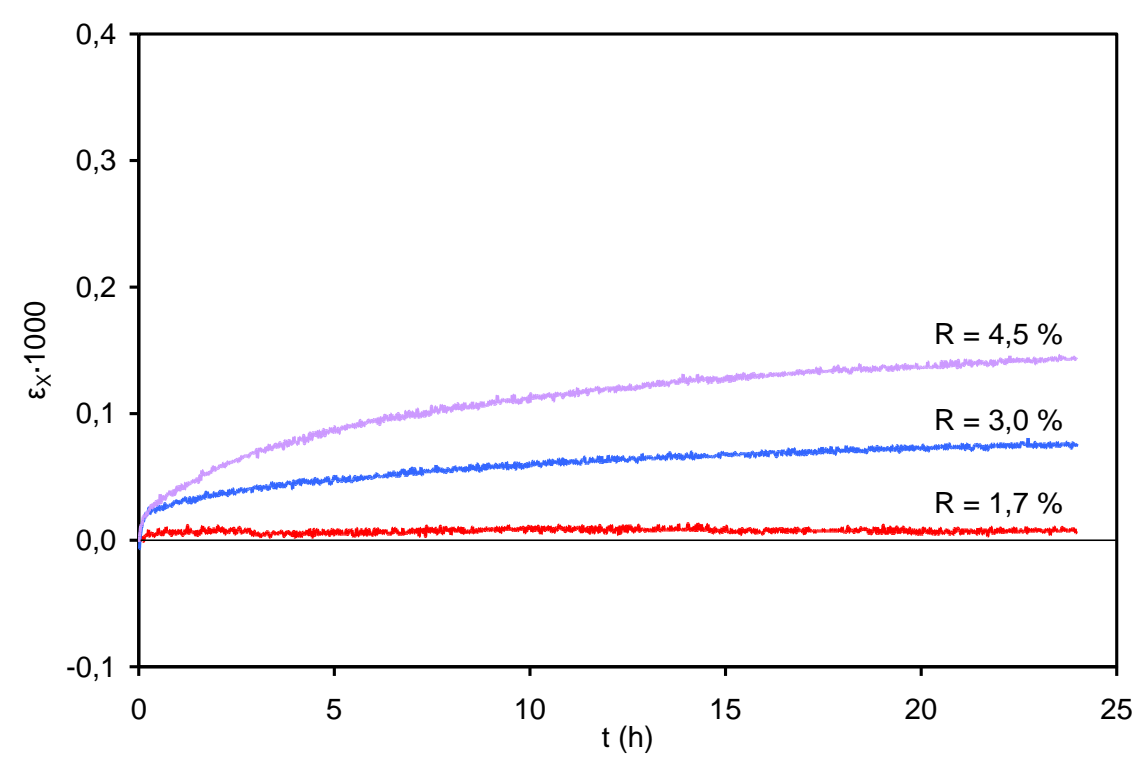

Figura 4.44. Expansión post-cocción del modelo 7 con diferentes granulometrías cocido a $1230 \stackrel{\circ}{\circ}$. 


\subsubsection{Influencia de la densidad aparente en seco}

Para abordar la influencia de la densidad aparente en seco, se conformaron piezas de cada modelo a 3 presiones diferentes, escogidas de forma que la densidad intermedia se situara en torno a $1900 \mathrm{~kg} / \mathrm{m}^{3}$ (valor habitual en la industria). En este caso, las cocciones solo se realizaron a una temperatura de cocción de $1210^{\circ} \mathrm{C}$.

Los resultados se muestran en la figura 4.45, la figura 4.46 y la tabla 4.26 para el modelo 4 , y en la figura 4.47 , la figura 4.48 y la tabla 4.27 para el modelo 7.

Tabla 4.26. Densidad aparente, absorción de agua y penetración del modelo 4 con diferentes densidades aparentes en seco cocido a $1210 \stackrel{\circ}{ } \mathrm{C}$.

\begin{tabular}{|c|c|c|c|c|}
\hline $\begin{array}{c}\mathbf{\rho}_{\text {seco }} \\
\left(\mathbf{k g} / \mathbf{m}^{3}\right)\end{array}$ & $\begin{array}{c}\boldsymbol{\rho} \\
\left(\mathbf{k g} / \mathbf{m}^{3}\right)\end{array}$ & $\begin{array}{c}\mathbf{A A}_{3 \text { dias }} \\
(\%)\end{array}$ & $\begin{array}{c}\mathbf{Z}_{\text {Ai }} \\
(\mathbf{m m})\end{array}$ & $\begin{array}{c}\mathbf{Z}_{\text {As }} \\
(\mathbf{m m})\end{array}$ \\
\hline 1860 & 2313 & 2,0 & 2,7 & 2,4 \\
\hline 1906 & 2327 & 0,4 & 0,0 & 0,0 \\
\hline 1950 & 2337 & 0,2 & 0,0 & 0,0 \\
\hline
\end{tabular}

Tabla 4.27. Densidad aparente, absorción de agua y penetración del modelo 7 con diferentes densidades aparentes en seco cocido a $1210^{\circ} \mathrm{C}$.

\begin{tabular}{|c|c|c|c|c|}
\hline $\begin{array}{c}\mathbf{\rho}_{\text {seco }} \\
\left(\mathbf{k g} / \mathbf{m}^{3}\right)\end{array}$ & $\begin{array}{c}\boldsymbol{\rho} \\
\left(\mathbf{k g} / \mathbf{m}^{3}\right)\end{array}$ & $\begin{array}{c}\mathbf{A A}_{\mathbf{3} \text { dias }} \\
(\%)\end{array}$ & $\begin{array}{c}\mathbf{Z}_{\mathbf{A i}} \\
(\mathbf{m m})\end{array}$ & $\begin{array}{c}\mathbf{Z}_{\text {As }} \\
(\mathbf{m m})\end{array}$ \\
\hline 1864 & 2375 & 1,6 & 3,0 & 2,2 \\
\hline 1904 & 2410 & 1,3 & 2,3 & 1,4 \\
\hline 1953 & 2411 & 0,1 & 0,0 & 0,0 \\
\hline
\end{tabular}

Se observa lo siguiente:

- Al aumentar la densidad aparente en seco, la velocidad de cambio de la curvatura con el tiempo disminuye. Sin embargo, no llega a anularse, por lo que, dentro del intervalo analizado, esta variable es menos efectiva que la temperatura máxima de cocción o el tamaño de partícula para eliminar la curvatura diferida.

- Por otra parte, la expansión post-cocción disminuye en magnitud y velocidad cuando aumenta la densidad aparente en seco, aunque tampoco llega a anularse. Además, la cinética de expansión está relacionada con el cambio de curvatura con el tiempo, aspecto ya observado en los apartados anteriores.

- Asimismo, el aumento de la densidad aparente en seco reduce la absorción de agua y aumenta la densidad en cocido como consecuencia de la menor porosidad en crudo y de la disminución del tamaño de poro en la pieza cruda que produce el aumento de la presión de prensado.

- Finalmente, se observa que existe cierta relación entre los valores de absorción de agua a vacío a los 3 días y la expansión a las 24 horas, lo que indica que ambas variables se encuentran relacionadas. 
4. Resultados y discusión

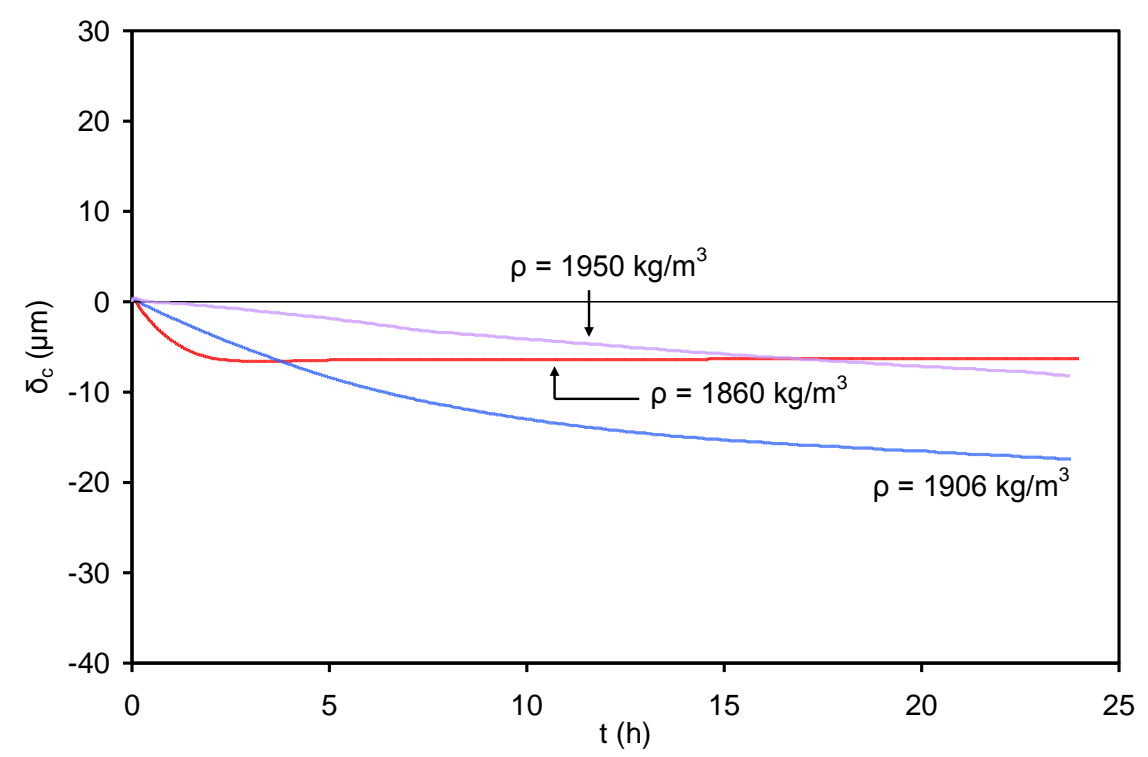

Figura 4.45. Curvatura diferida del modelo 4 con diferentes densidades aparentes en seco cocido a $1210^{\circ} \mathrm{C}$.

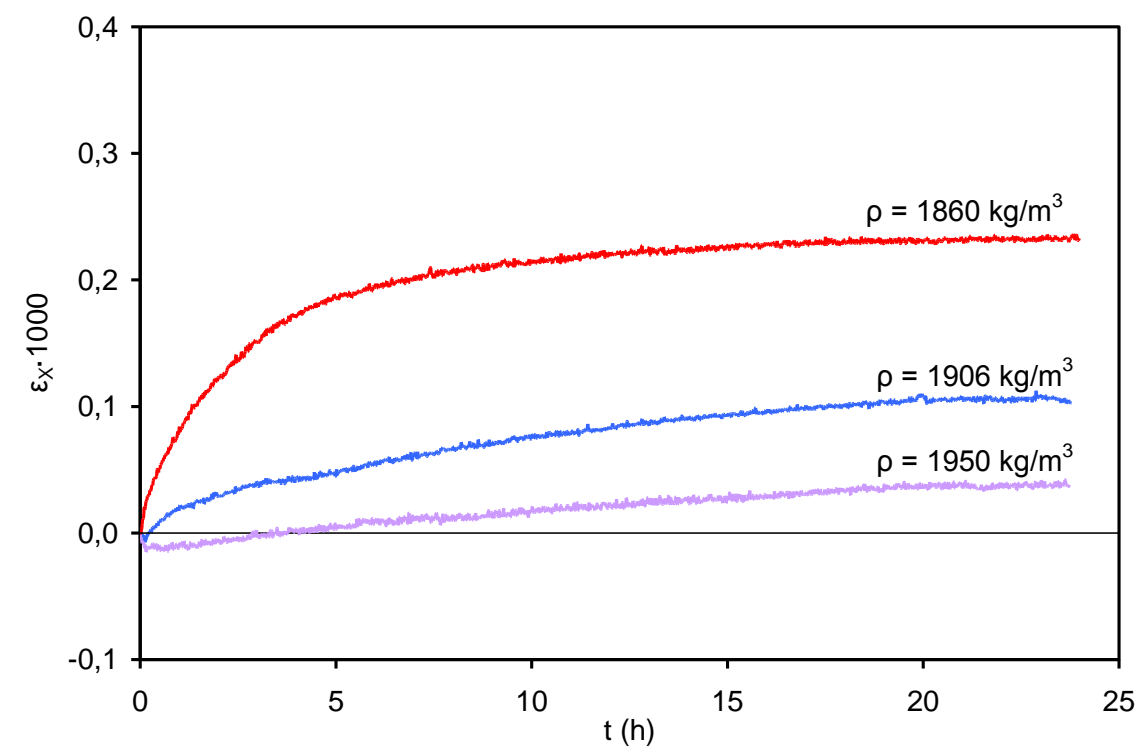

Figura 4.46. Expansión post-cocción del modelo 4 con diferentes densidades aparentes en seco cocido a $1210^{\circ} \mathrm{C}$. 
4. Resultados y discusión

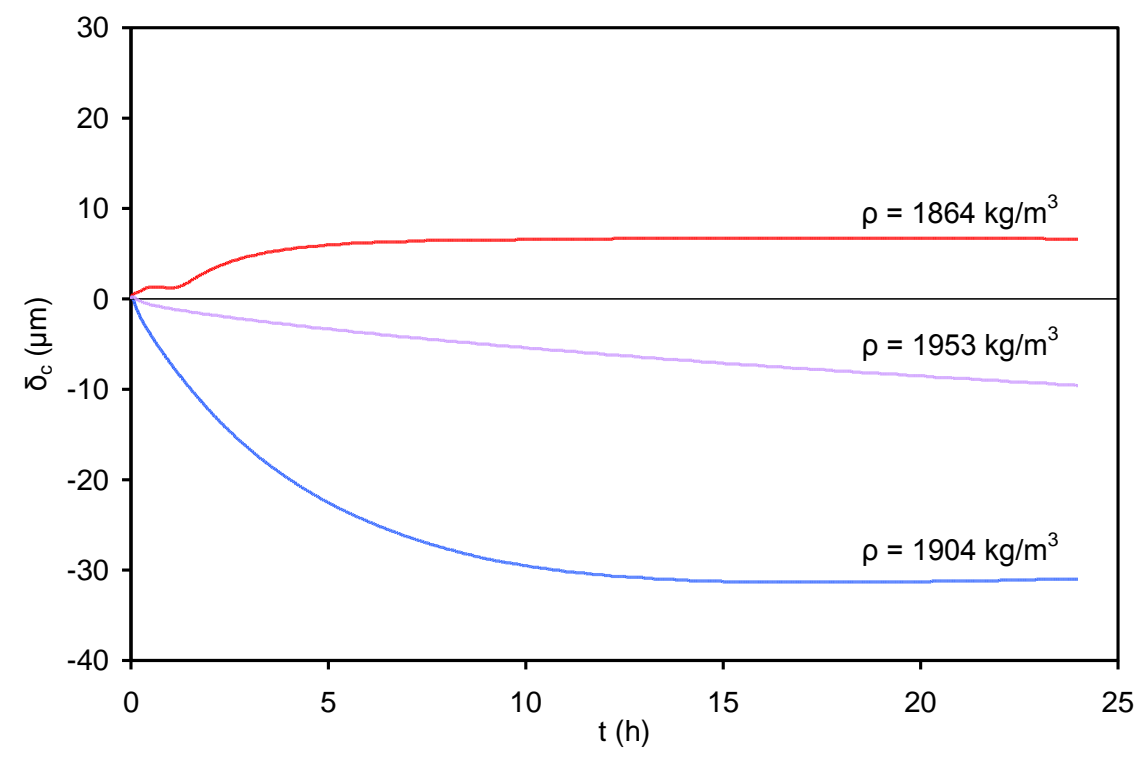

Figura 4.47. Curvatura diferida del modelo 7 con diferentes densidades aparentes en seco cocido a $1210^{\circ} \mathrm{C}$.

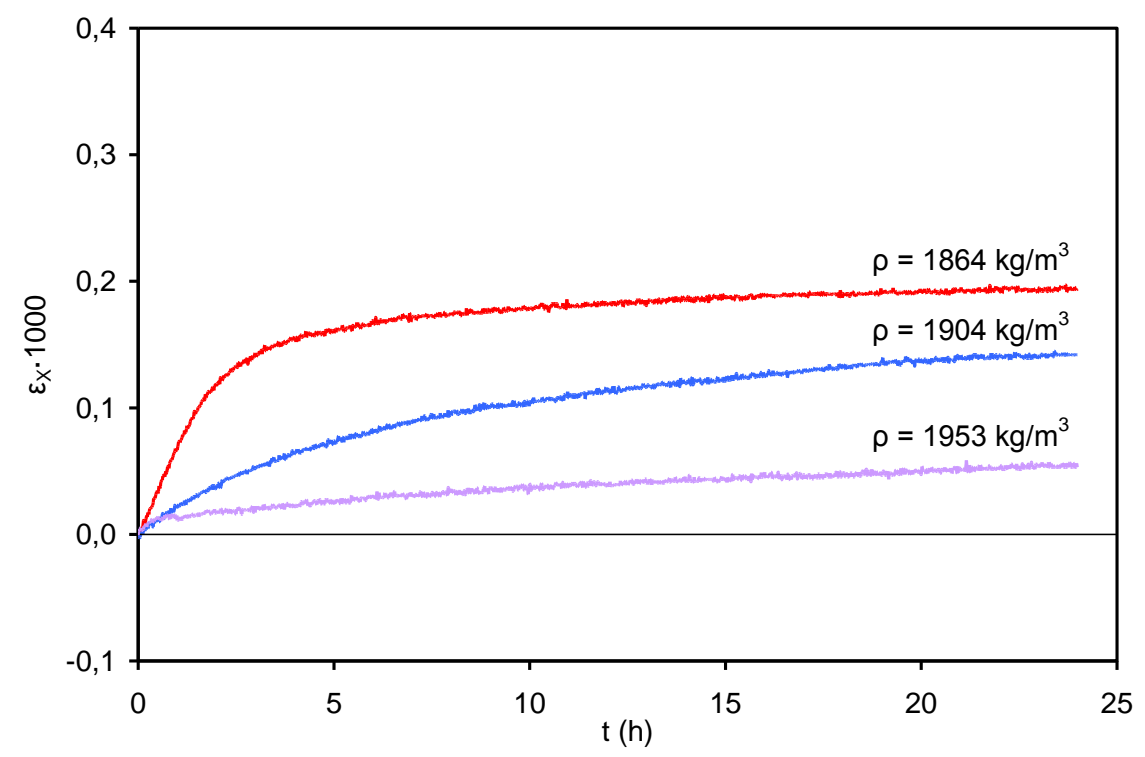

Figura 4.48. Expansión post-cocción del modelo 7 con diferentes densidades aparentes en seco cocido a $1210^{\circ} \mathrm{C}$. 


\subsubsection{Influencia de la presencia de esmalte}

En este apartado se estudia la influencia del esmalte sobre la curvatura diferida. Para ello, se aplicaron los esmaltes correspondientes sobre los soportes industriales del modelo 4 y 9 en una línea de esmaltado industrial. Al modelo 4 se le aplicó una capa de engobe y esmalte, mientras que al modelo 7 se le aplicó sólo una capa muy delgada de esmalte que tiene como objetivo disminuir la retención de suciedad de las piezas.

Se realizaron cocciones en el laboratorio a $1190^{\circ} \mathrm{C}, 1210^{\circ} \mathrm{C}$ y $1230^{\circ} \mathrm{C}$, determinando la curvatura diferida, la expansión post-cocción y las tensiones residuales de origen térmico (usando el método de relajación de deformaciones por corte incremental). Los resultados se muestran de la figura 4.49 a la figura 4.60 , en las que se incluyen las piezas sin esmaltar para poder observar las diferencias.

Del análisis de los resultados se extrae lo siguiente:

- La presencia de esmalte no influye de forma apreciable sobre la expansión global que experimentan las piezas tras la cocción. Para el modelo 7 la expansión post-cocción prácticamente no varía y para el modelo 4 se observan diferencias que podrían atribuirse al error experimental del método.

- La presencia de esmalte modifica ligeramente el perfil de tensiones del soporte en el modelo 4. La capa de engobe/vidriado aparece fuertemente tensionada en compresión, con valores próximos a $25 \mathrm{MPa}$. La tensión de compresión en la superficie inferior del soporte aumenta ligeramente, mientras que en la cara vista la tensión disminuye hasta prácticamente anularse. Aun así, las tensiones en el soporte son demasiado pequeñas para provocar cambios sustanciales de curvatura.

- El perfil de tensiones apenas se altera en el modelo 7 con la presencia de esmalte. Ello es debido a que la capa de esmalte es tan delgada que, desde un punto de vista mecánico, no influye sobre el perfil de tensiones.

- La curvatura diferida aumenta notablemente cuando la pieza está esmaltada. Este comportamiento se observa para los dos modelos, pese a que en el modelo 7 sólo hay aplicada una capa muy delgada de esmalte.

- La mayor curvatura en diferido de las piezas esmaltadas debe asociarse al efecto impermeabilizante del vidriado. De este modo, el esmalte podría modificar la expansión y la velocidad a la que expande la superficie superior de la pieza respecto a la inferior. 
4. Resultados y discusión

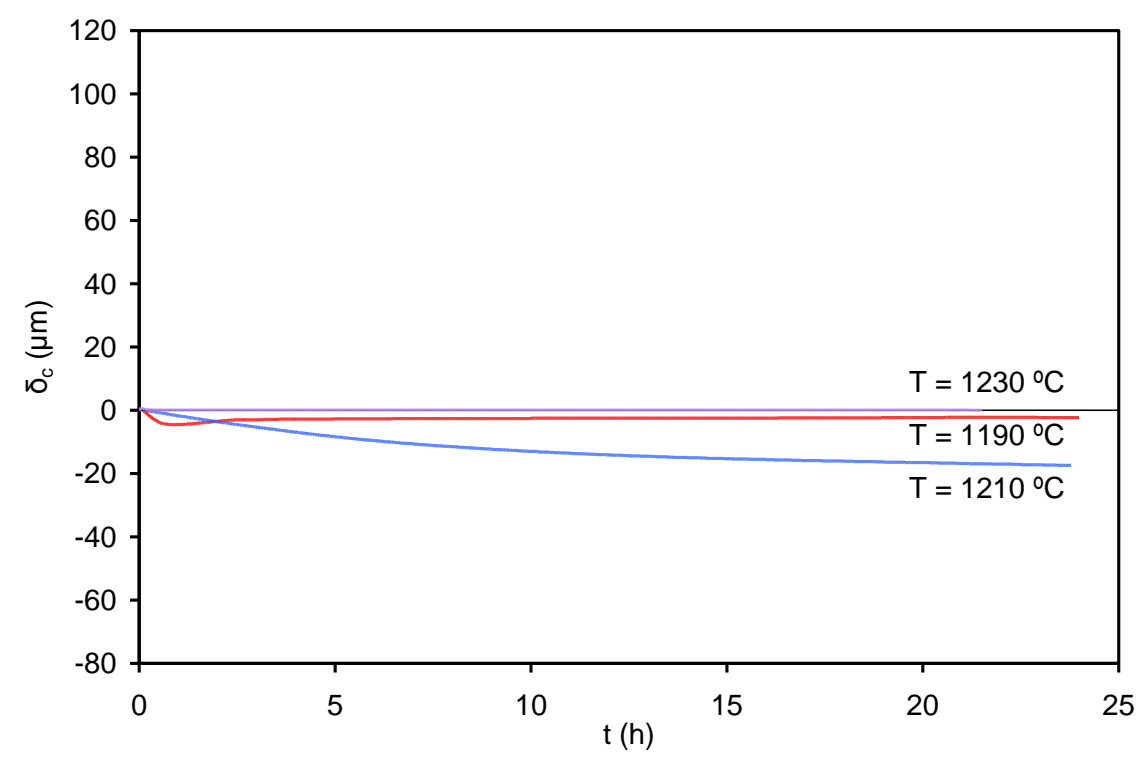

Figura 4.49. Curvatura diferida del modelo 4 sin esmalte.

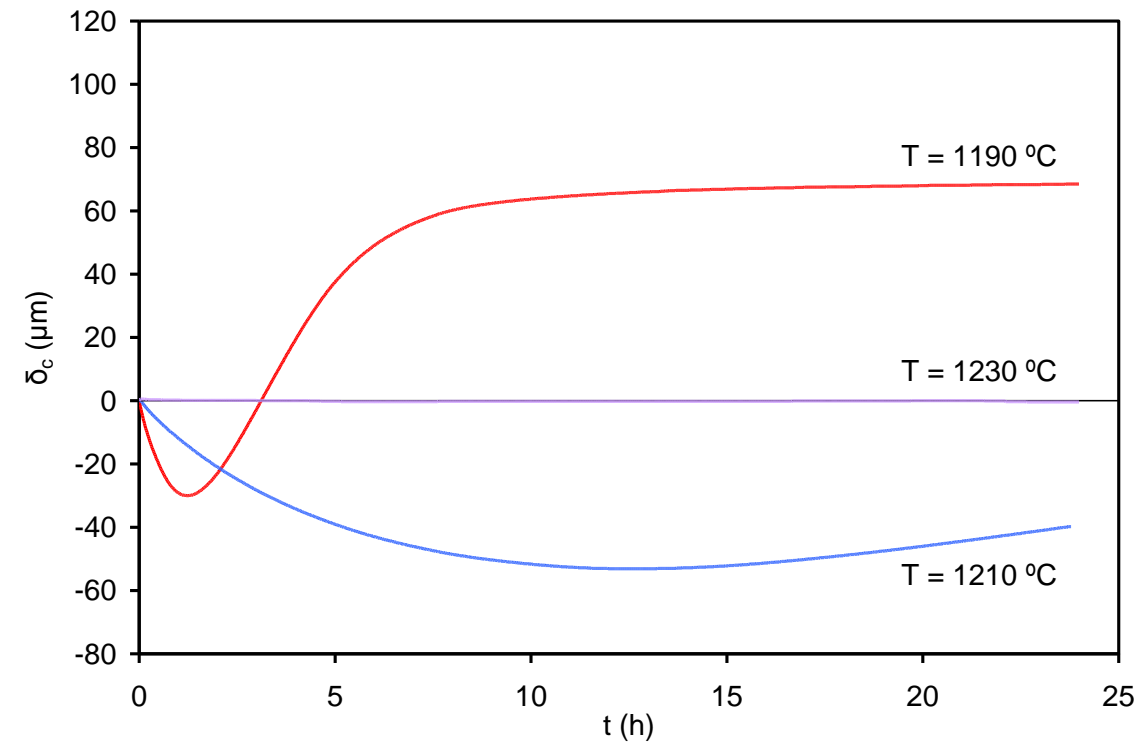

Figura 4.50. Curvatura diferida del modelo 4 con esmalte. 
4. Resultados y discusión

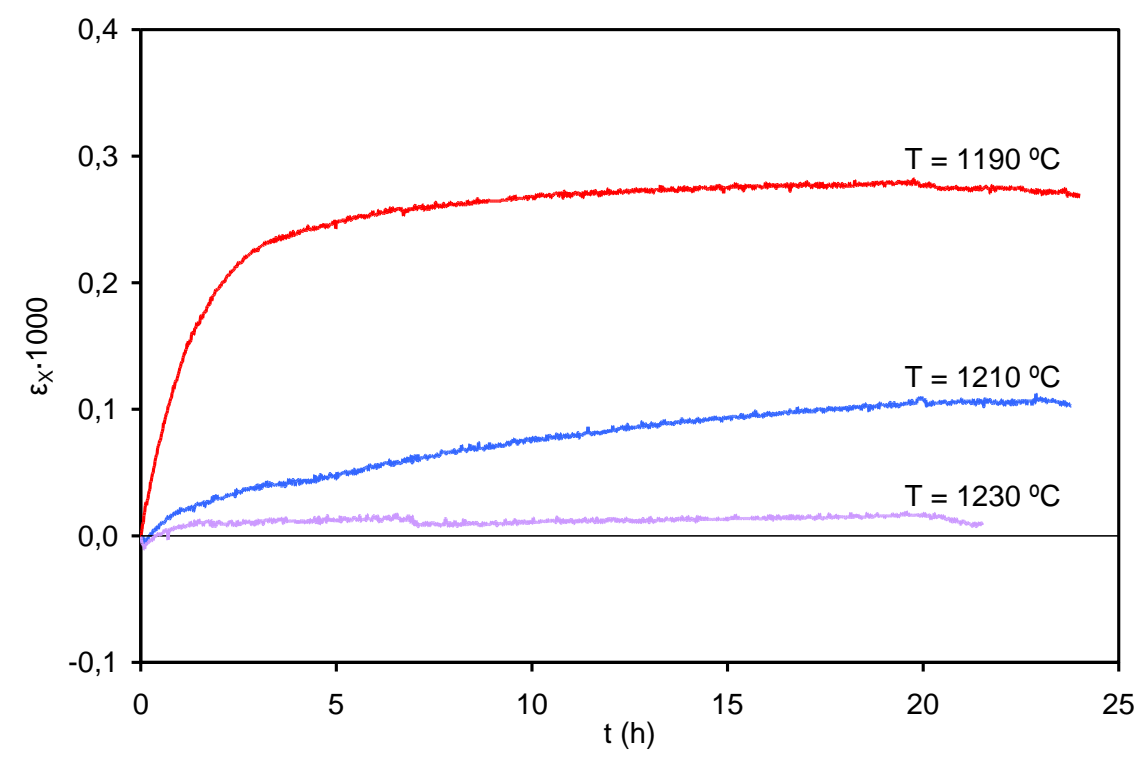

Figura 4.51. Expansión post-cocción del modelo 4 sin esmalte.

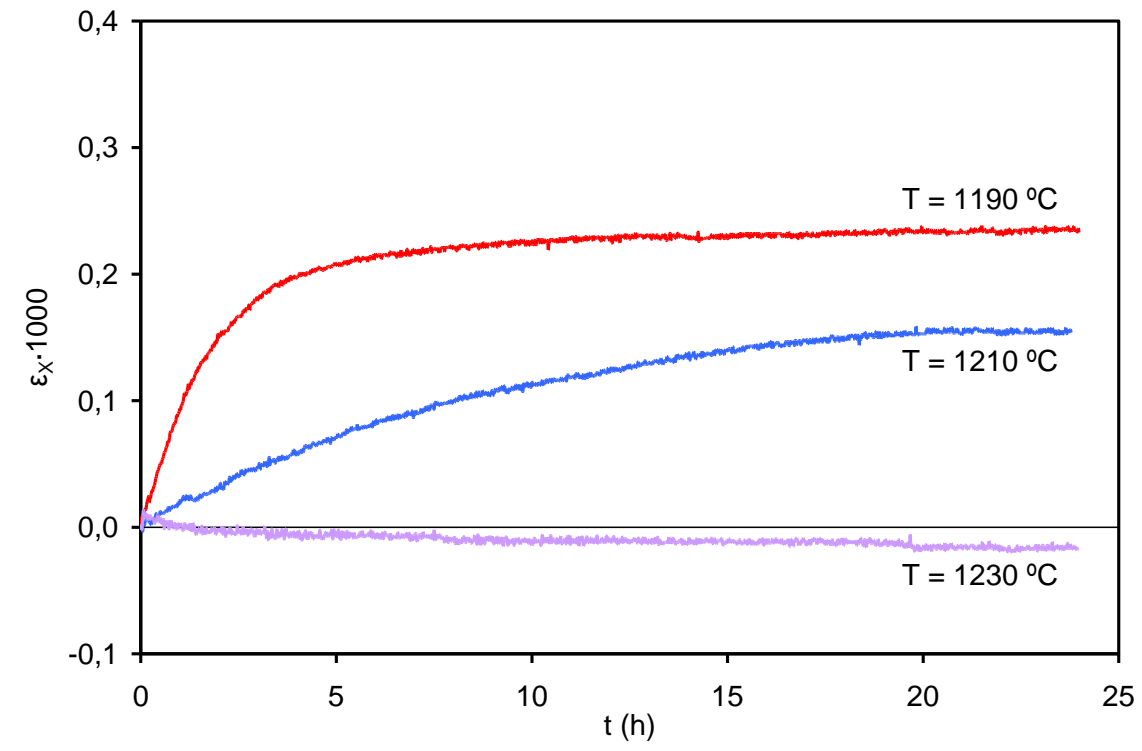

Figura 4.52. Expansión post-cocción del modelo 4 con esmalte. 
4. Resultados y discusión

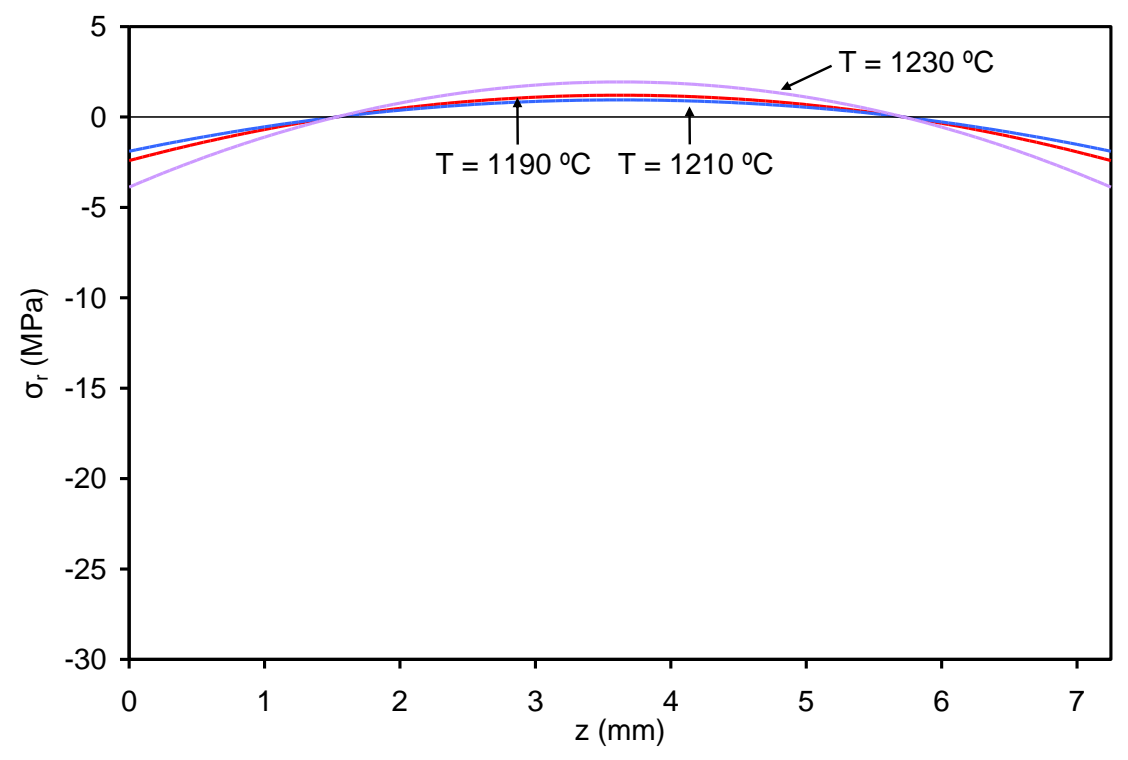

Figura 4.53. Tensiones residuales del modelo 4 sin esmalte.

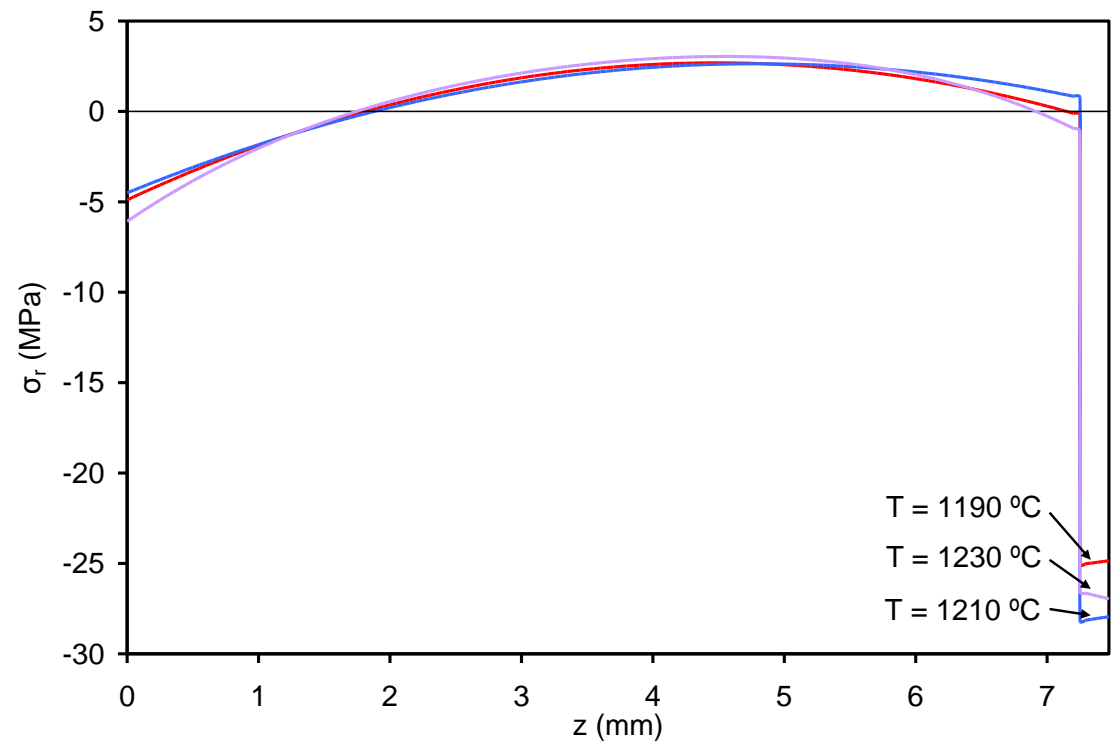

Figura 4.54. Tensiones residuales del modelo 4 con esmalte. 


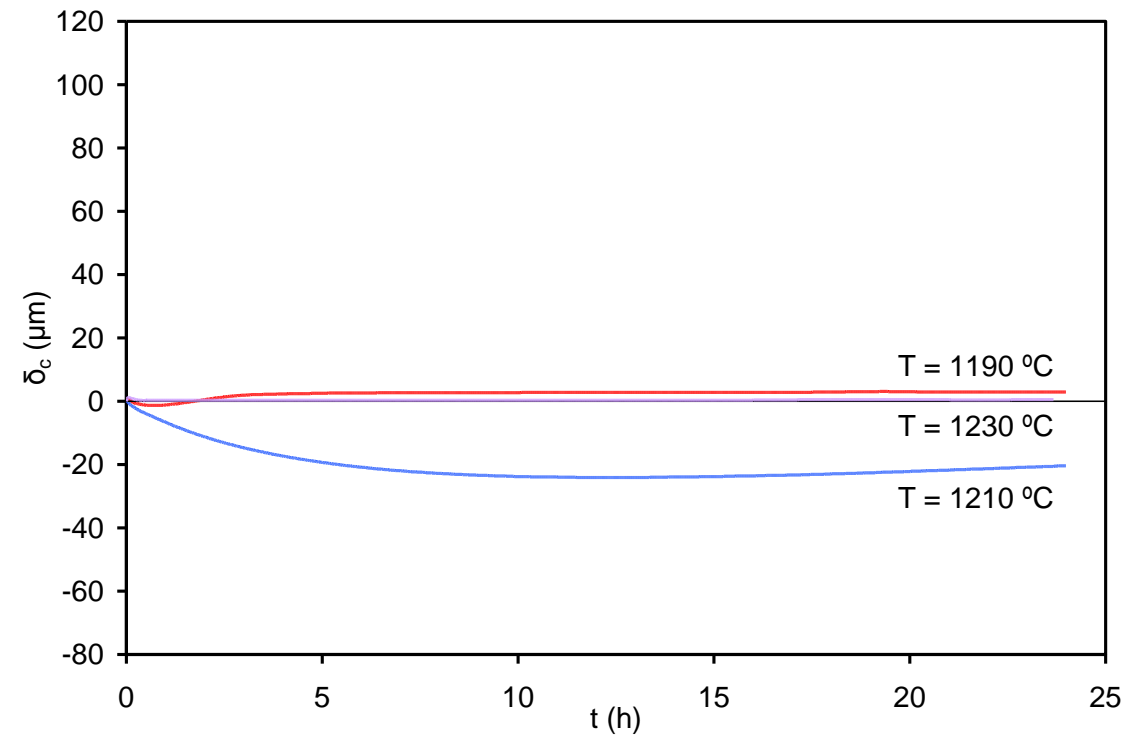

Figura 4.55. Curvatura diferida del modelo 7 sin esmalte.

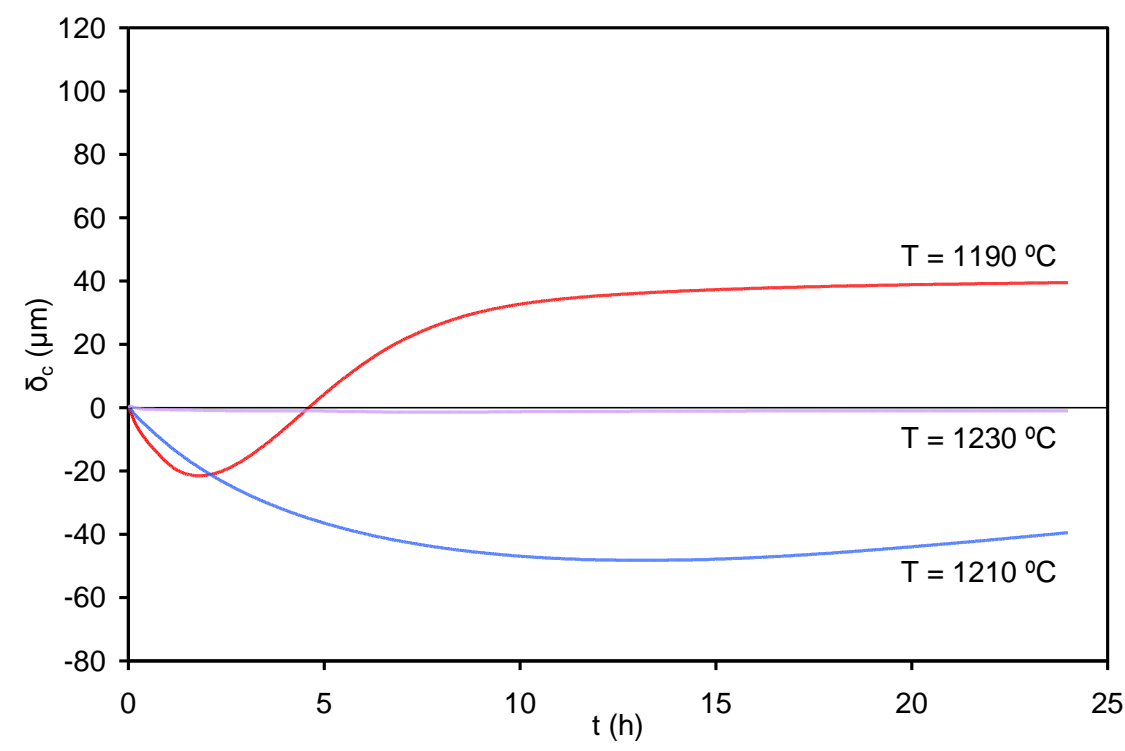

Figura 4.56. Curvatura diferida del modelo 7 con esmalte. 
4. Resultados y discusión

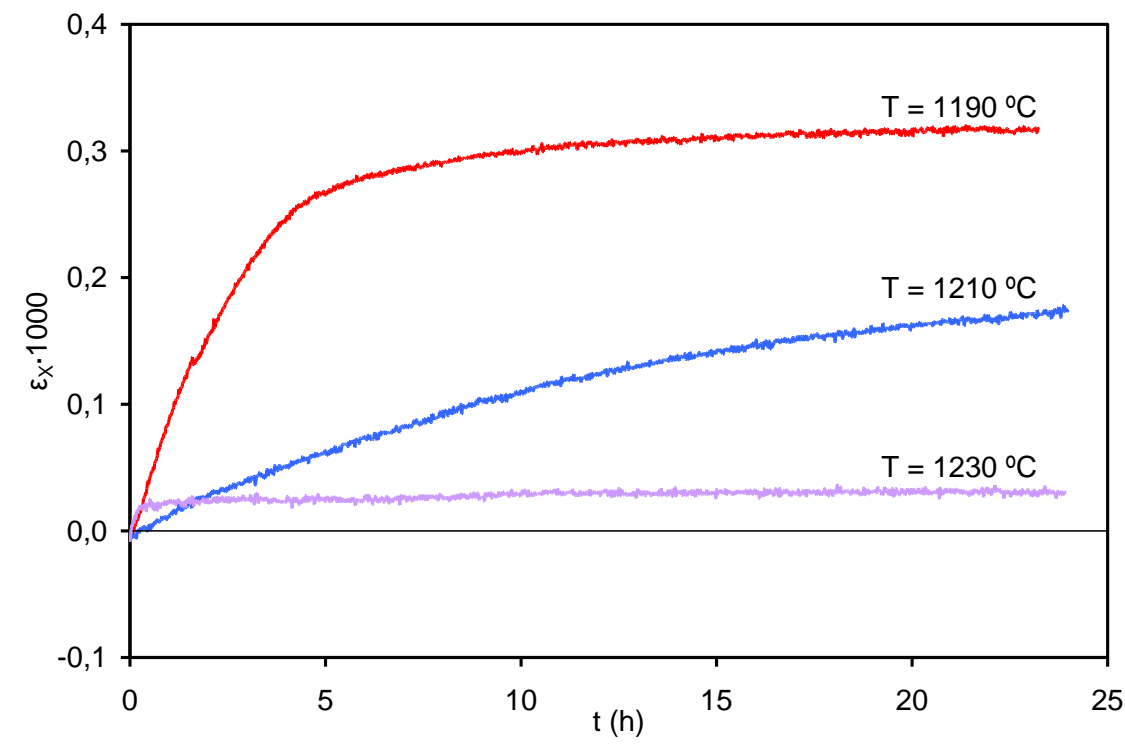

Figura 4.57. Expansión post-cocción del modelo 7 sin esmalte.

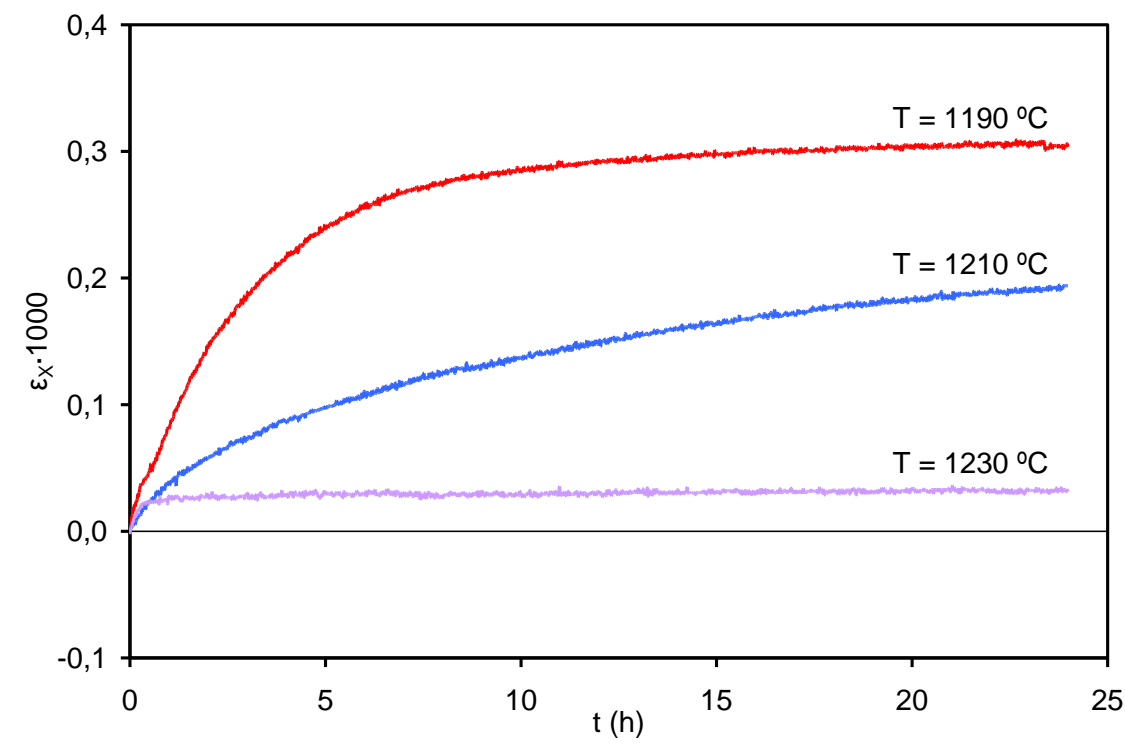

Figura 4.58. Expansión post-cocción del modelo 7 con esmalte. 


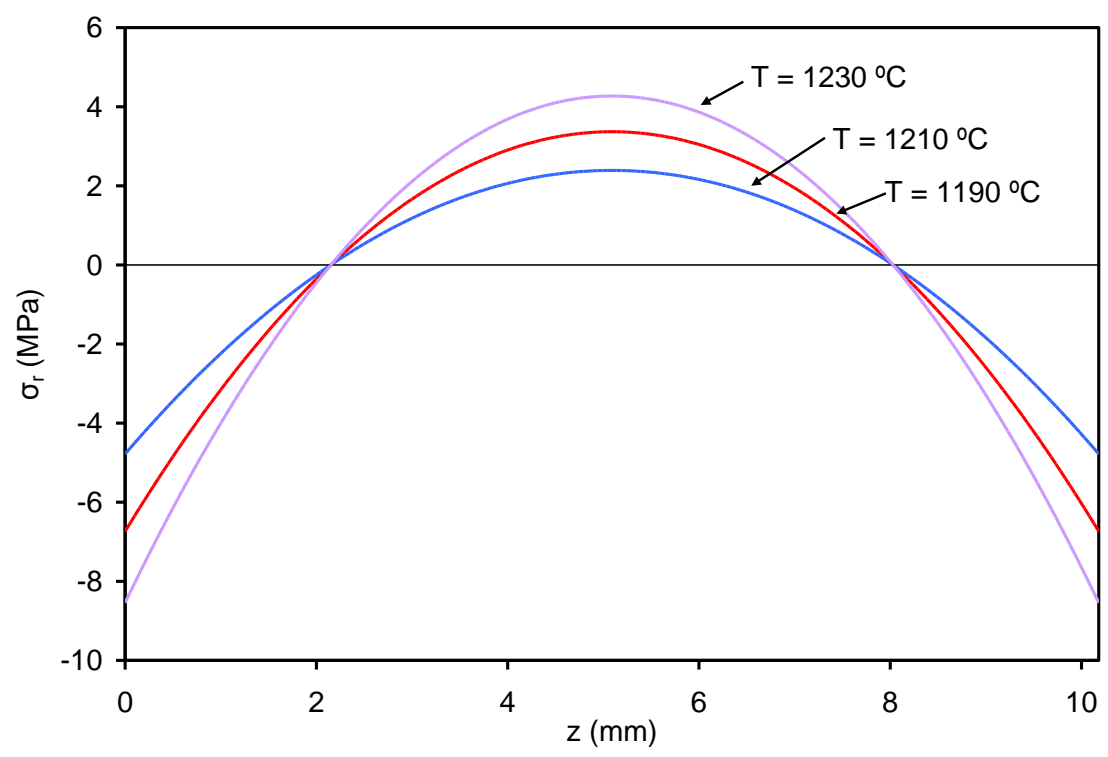

Figura 4.59. Tensiones residuales del modelo 7 sin esmalte.

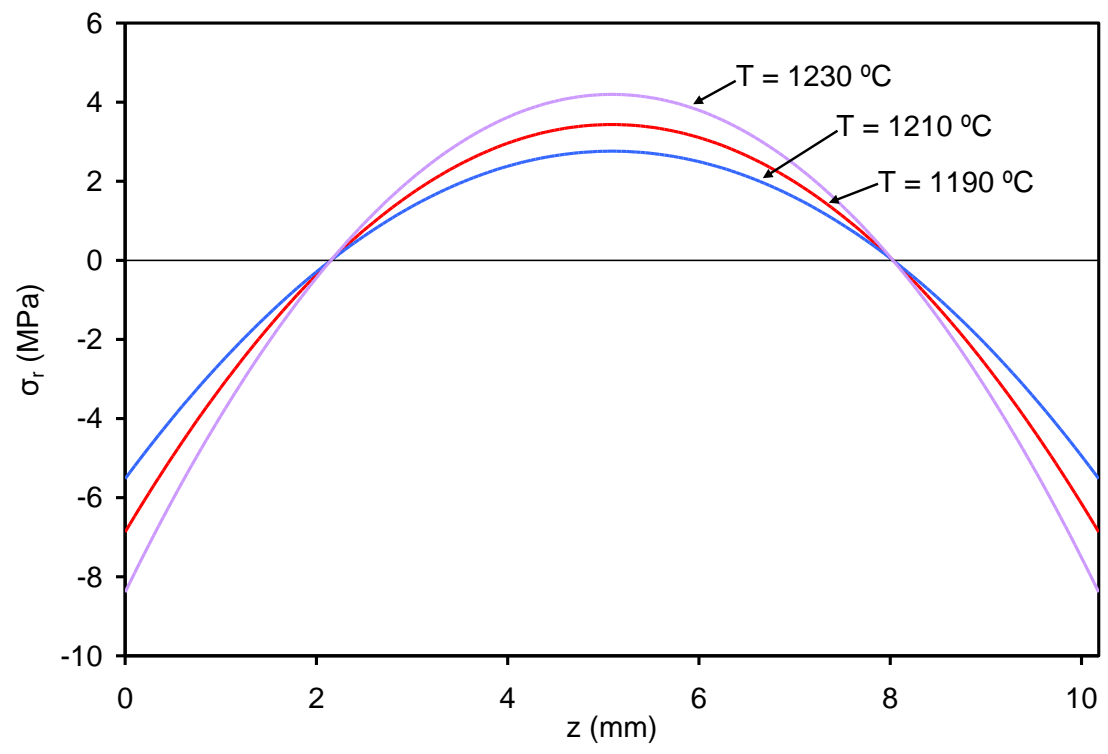

Figura 4.60. Tensiones residuales del modelo 7 con esmalte. 


\subsubsection{Influencia del espesor}

En este apartado se estudia la influencia del espesor de los soportes en piezas no esmaltadas y del espesor relativo soporte/esmalte en piezas esmaltadas. En ambos casos, se han ensayado piezas con una reducción de espesor en torno al $35 \%$, de forma que las probetas del modelo 4 pasaron de 8 a $5 \mathrm{~mm}$ y las del modelo 7 de 11 a $7 \mathrm{~mm}$.

\section{A. Influencia del espesor del soporte}

De la figura 4.61 a la figura 4.68 se muestra la curvatura diferida y la expansión post-cocción de las probetas de los dos modelos cocidos a $1190 \stackrel{\circ}{ } \mathrm{C}, 1210^{\circ} \mathrm{C}$ y $1230{ }^{\circ} \mathrm{C}$ con el espesor estándar y con el espesor reducido.

En general, la reducción del espesor produce una disminución de la expansión post-cocción debido probablemente a que mejora la transmisión de calor hacia el centro de las probetas y con ello al ligero aumento del grado de cocción. Sin embargo, no se observan cambios importantes de curvatura diferida al reducir el espesor de las piezas. Como excepción se encuentra el modelo 7 cocido a baja temperatura $\left(1190^{\circ} \mathrm{C}\right)$ para el que se observa una evolución más acusada de la curvatura hacia la convexidad.

El espesor de las piezas es una variable compleja de analizar dado que su disminución, además de afectar a aspectos puramente geométricos, influye sobre la transferencia de calor durante la cocción y sobre sus propiedades mecánicas. Así, a medida que disminuye el espesor de las piezas, el grado de cocción alcanzado es mayor y más homogéneo, la pieza es más fácilmente deformable y el enfriamiento se realiza de forma más rápida y homogénea.

No obstante, los resultados obtenidos en los ensayos indican que el espesor de piezas no esmaltadas no parece influir significativamente sobre la curvatura diferida para temperaturas próximas a la de cocción industrial del producto. 
4. Resultados y discusión

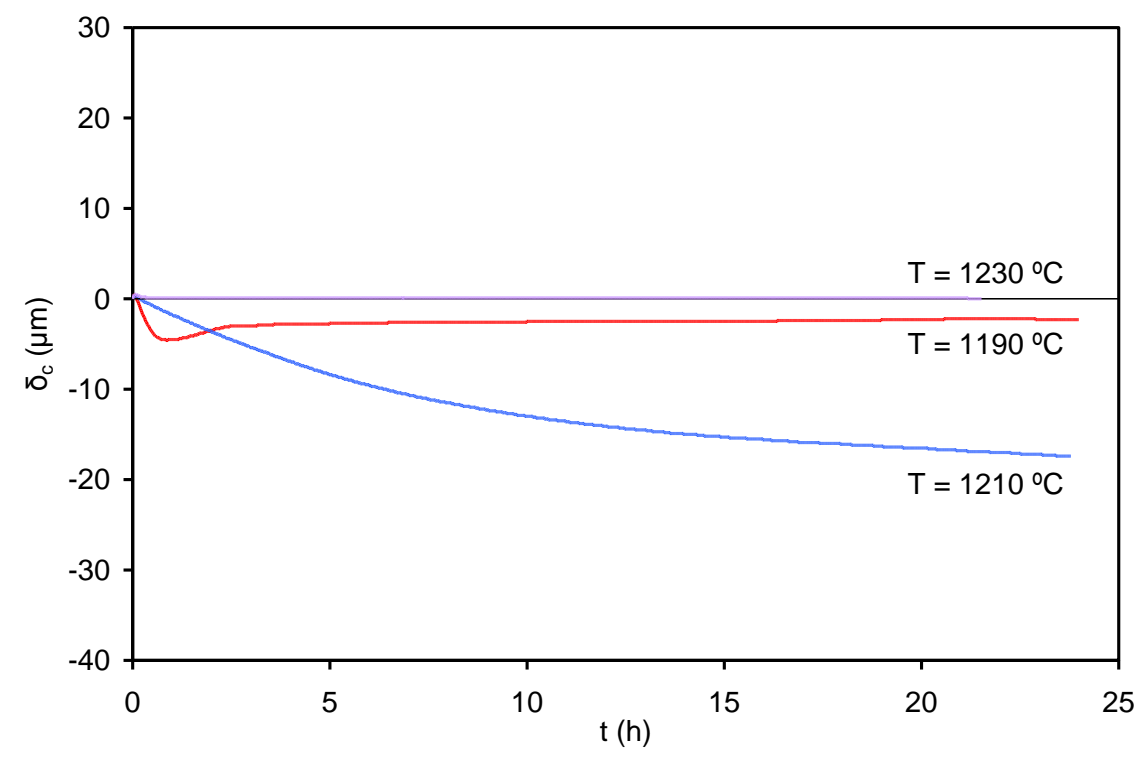

Figura 4.61. Curvatura diferida del modelo 4 sin esmaltar con espesor $8 \mathrm{~mm}$.

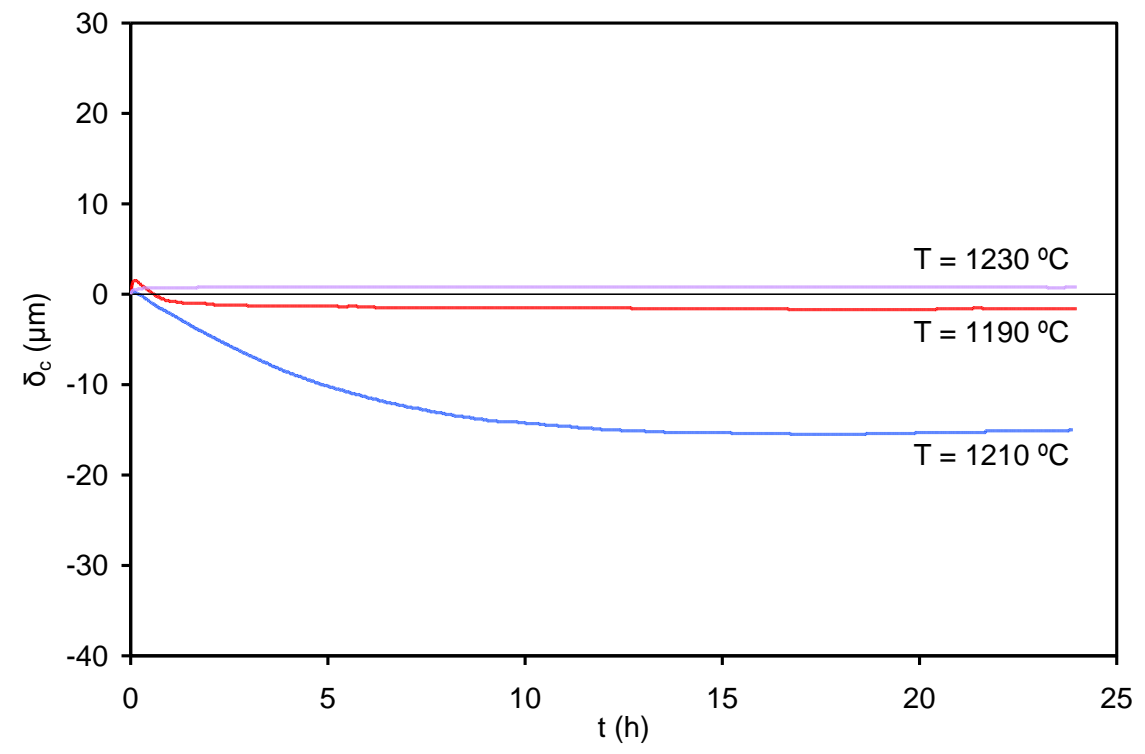

Figura 4.62. Curvatura diferida del modelo 4 sin esmaltar con espesor $5 \mathrm{~mm}$. 
4. Resultados y discusión

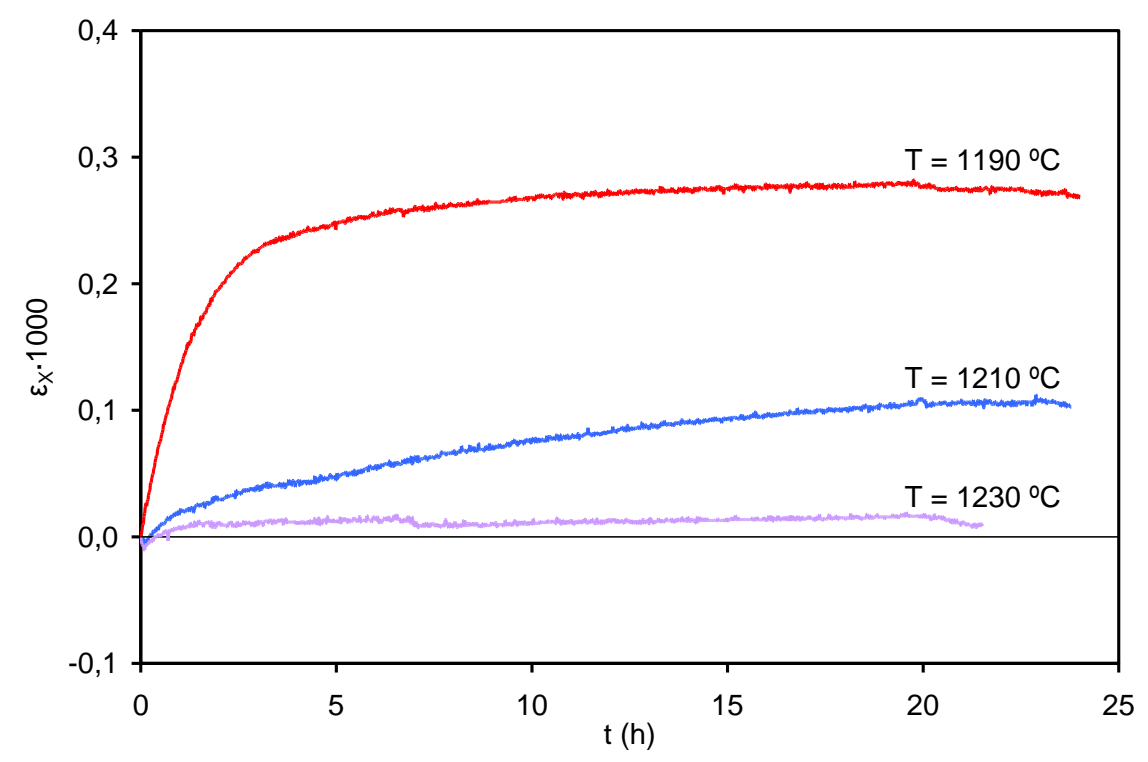

Figura 4.63. Expansión post-cocción del modelo 4 sin esmaltar y con espesor $8 \mathrm{~mm}$.

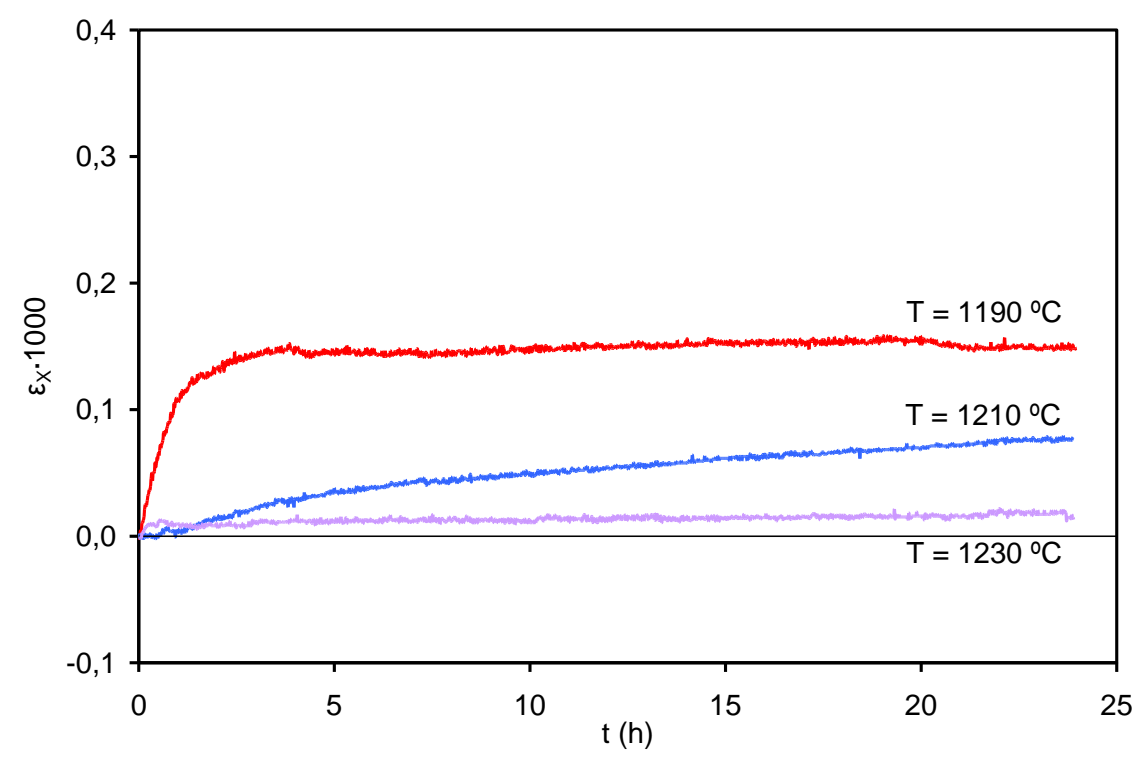

Figura 4.64. Expansión post-cocción del modelo 4 sin esmaltar y con espesor $5 \mathrm{~mm}$. 


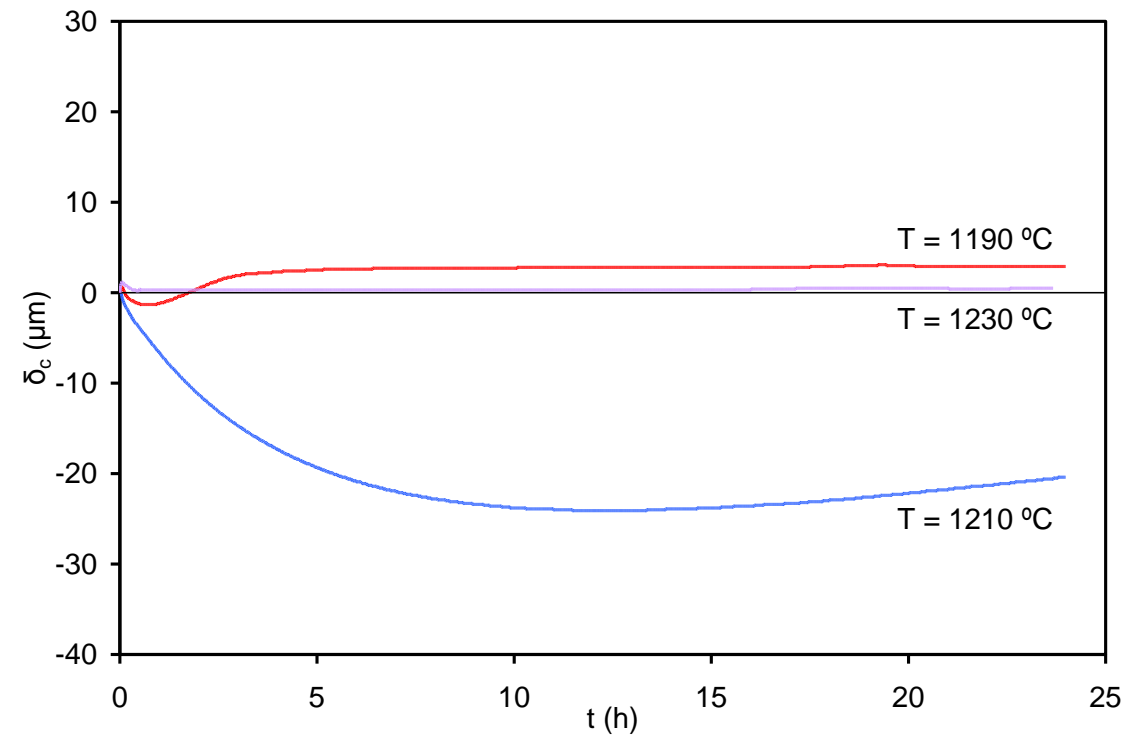

Figura 4.65. Curvatura diferida del modelo 7 sin esmaltar con espesor $11 \mathrm{~mm}$.

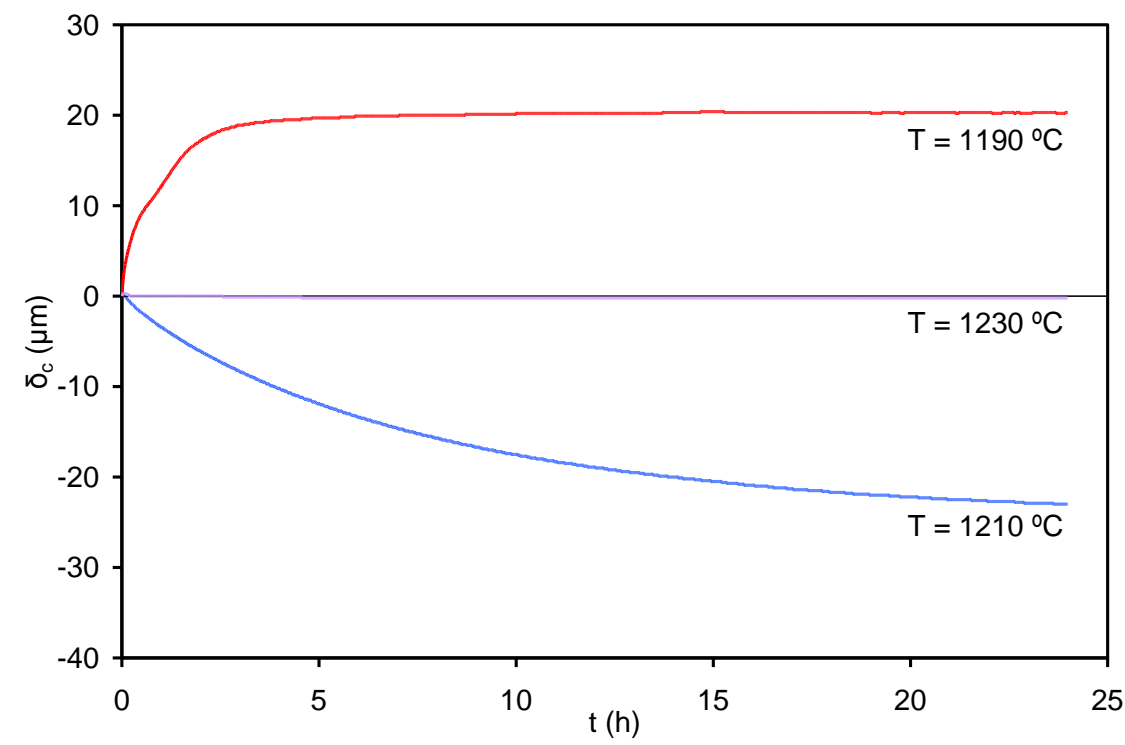

Figura 4.66. Curvatura diferida del modelo 7 sin esmaltar con espesor $7 \mathrm{~mm}$. 
4. Resultados y discusión

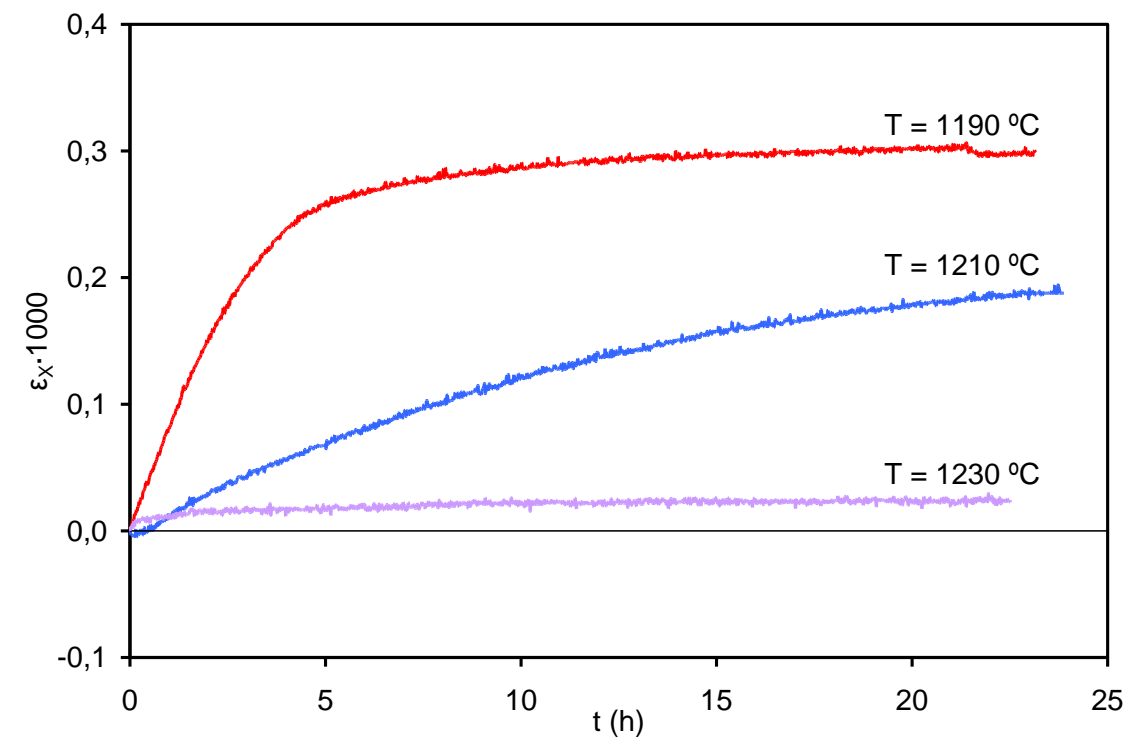

Figura 4.67. Expansión post-cocción del modelo 7 sin esmaltar con espesor 11 $\mathrm{mm}$.

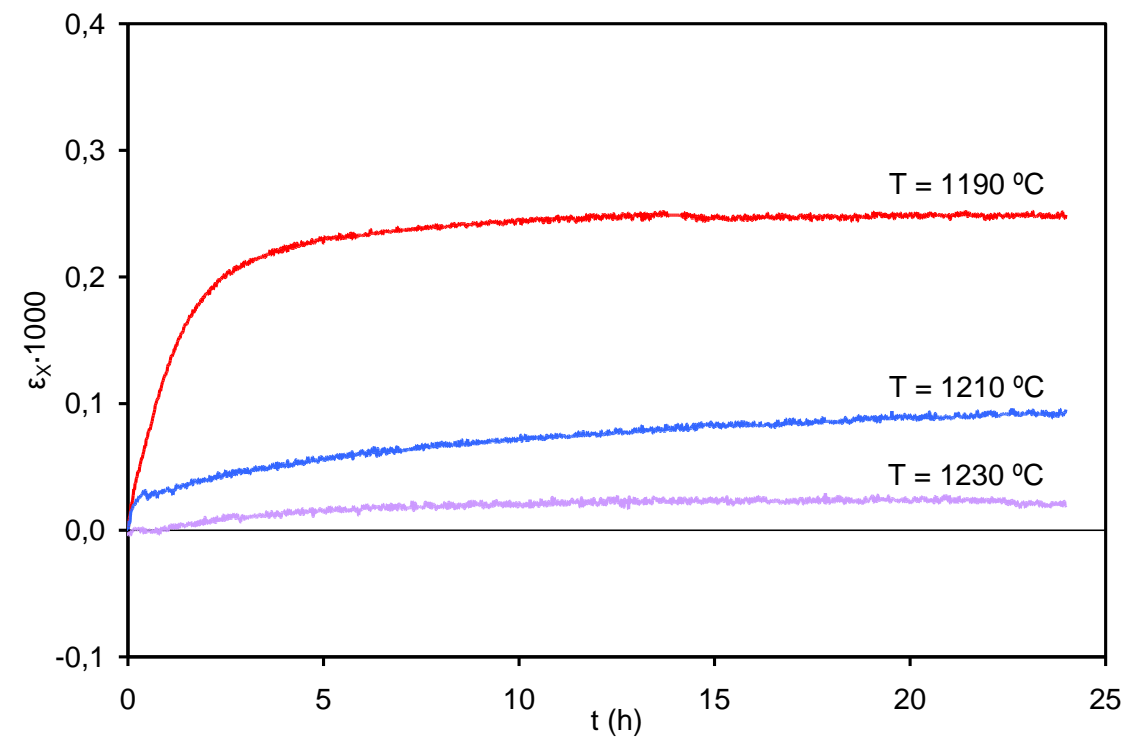

Figura 4.68. Expansión post-cocción del modelo 7 sin esmaltar con espesor 7 $\mathrm{mm}$. 


\section{B. Influencia del espesor relativo esmalte / soporte}

En este caso se han ensayado piezas esmaltadas. Los resultados se muestran de la figura 4.69 a la figura 4.72 para los dos modelos estudiados.

Se aprecia que la reducción de espesor del soporte en piezas esmaltadas disminuye la curvatura a temperaturas próximas a las de cocción industrial $\left(1210^{\circ} \mathrm{C}\right)$. A temperaturas inferiores $\left(1190^{\circ} \mathrm{C}\right)$ ) se observan valores de curvatura superiores, los cuales evolucionan hacia una mayor convexidad.

Estos resultados parecen indicar que las piezas más delgadas presentan un mayor grado de cocción, por lo que la curvatura disminuye a $1210^{\circ} \mathrm{C}$. Además, son más deformables como indica la mayor curvatura medida a $1190{ }^{\circ} \mathrm{C}$. Ninguno de estos fenómenos se han observado en el apartado anterior. 
4. Resultados y discusión

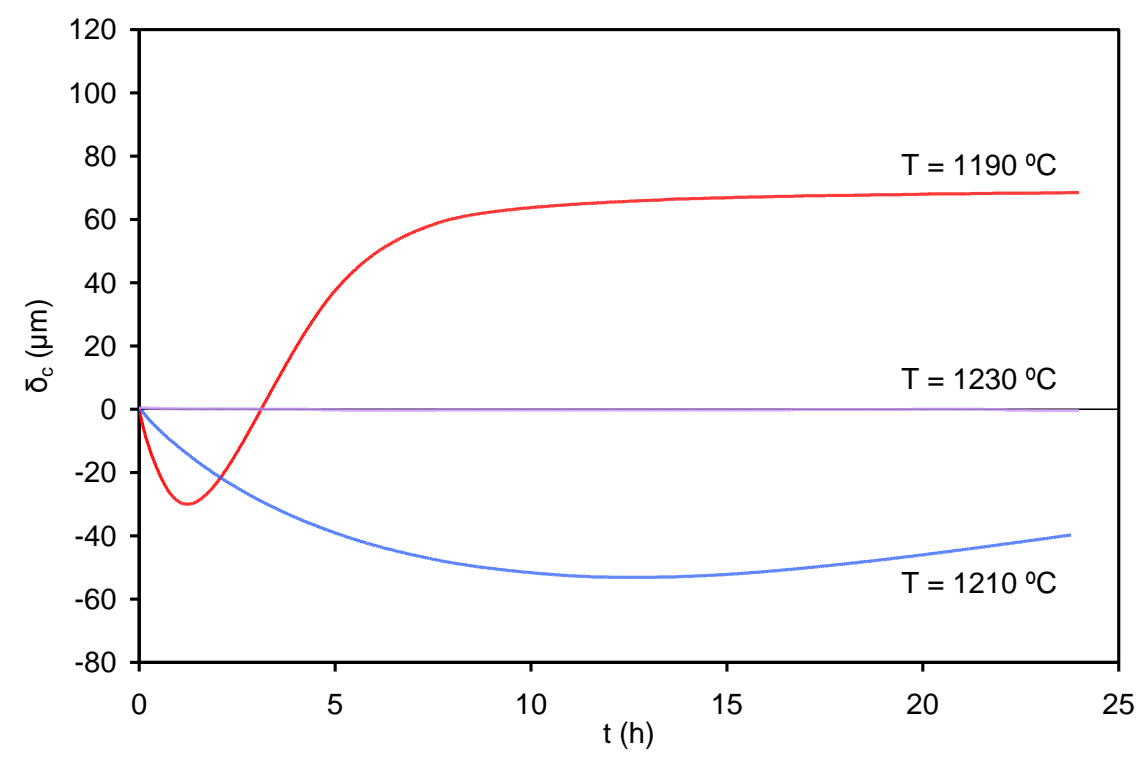

Figura 4.69. Curvatura diferida del modelo 4 esmaltado con espesor $8 \mathrm{~mm}$.

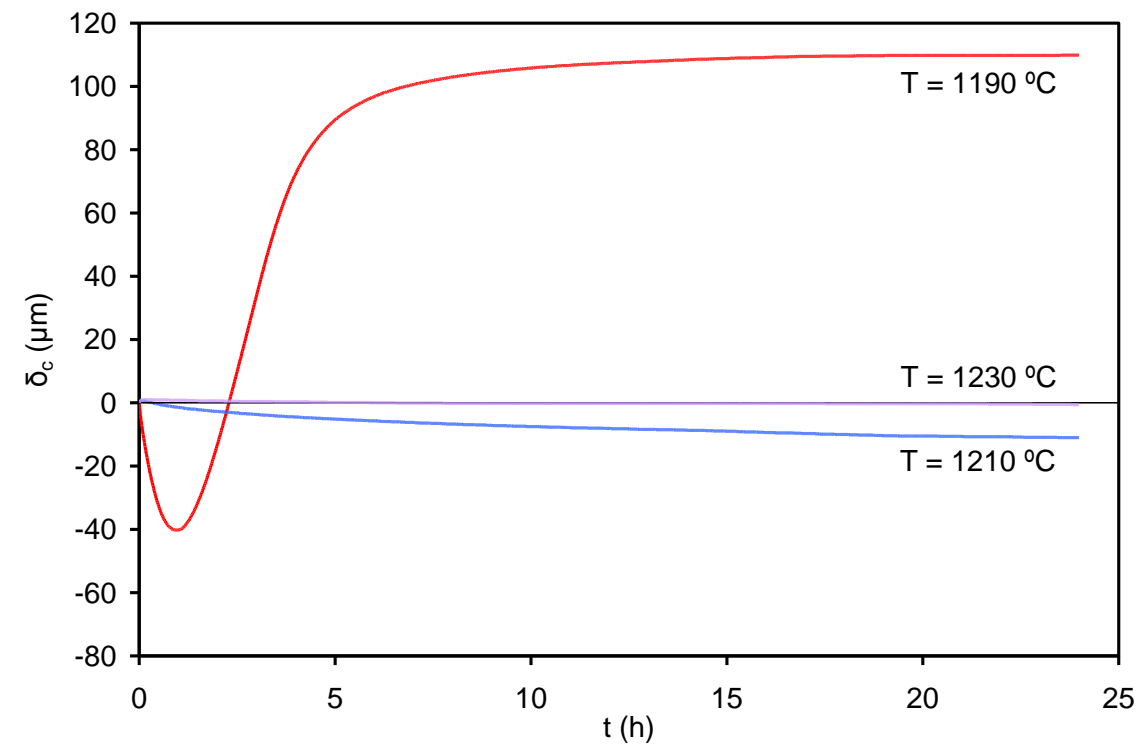

Figura 4.70. Curvatura diferida del modelo 4 esmaltado con espesor $5 \mathrm{~mm}$. 
4. Resultados y discusión

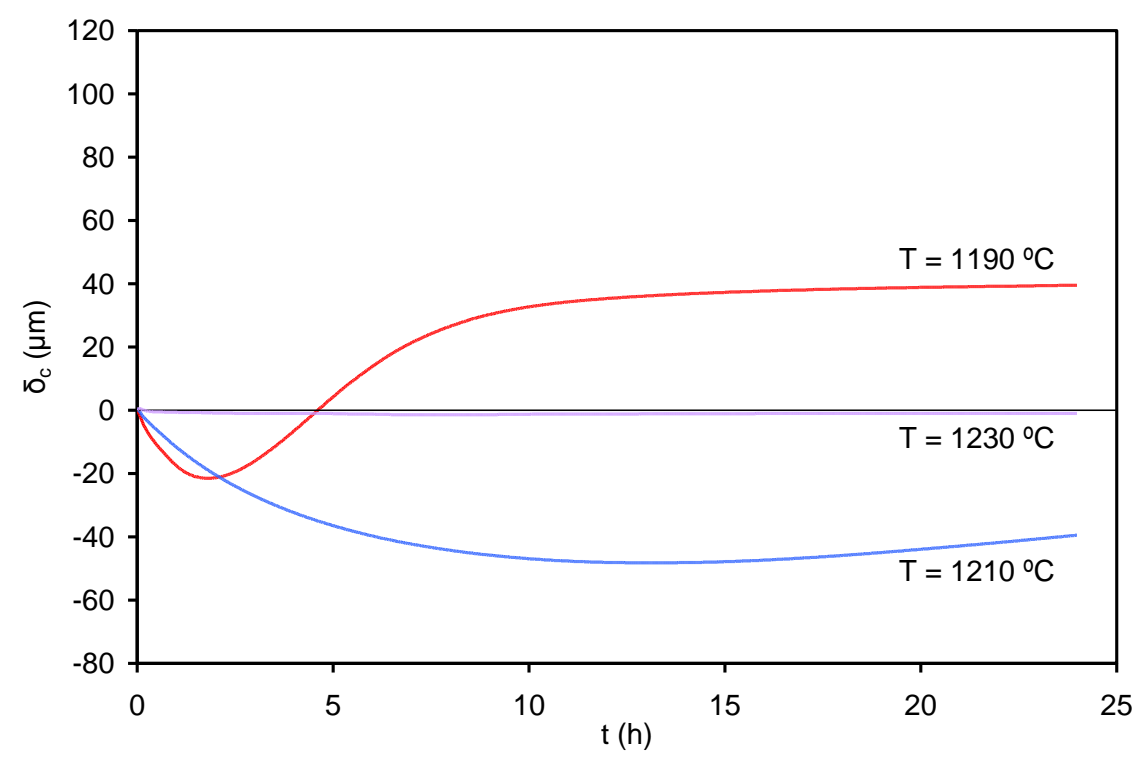

Figura 4.71. Curvatura diferida del modelo 7 esmaltado con espesor $11 \mathrm{~mm}$.

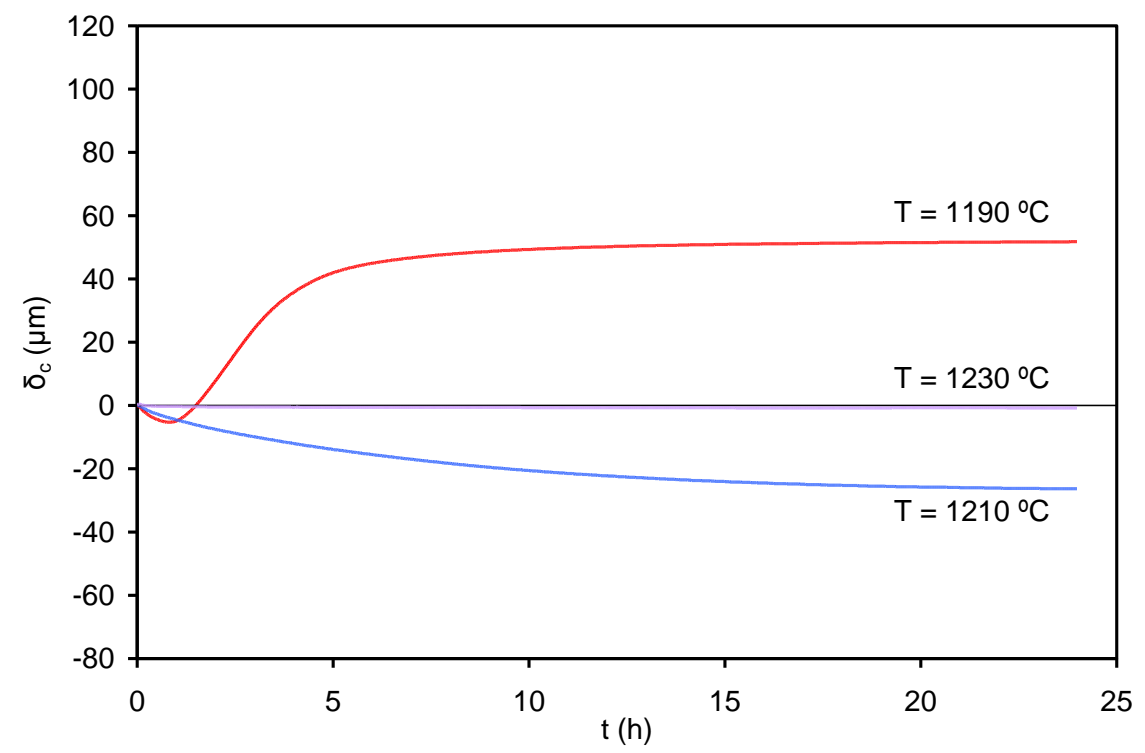

Figura 4.72. Curvatura diferida del modelo 7 esmaltado con espesor $7 \mathrm{~mm}$. 


\subsubsection{Influencia del tiempo de permanencia a temperatura máxima}

La influencia del tiempo de permanencia a temperatura máxima se evaluó realizando cocciones a $1210^{\circ} \mathrm{C}$ en las que se alteró dicha variable, aumentándola (12 minutos) y disminuyéndola (3 minutos) respecto al valor estándar (6 minutos). Los resultados obtenidos para los dos modelos se presentan de la figura 4.73 a la figura 4.76 y en la tabla 4.28 y la tabla 4.29 .

Tabla 4.28. Densidad aparente, absorción de agua del modelo 4 cocido durante diferentes tiempos de permanencia a $121{ }^{\circ} \mathrm{C}$.

\begin{tabular}{|c|c|c|c|c|}
\hline $\begin{array}{c}\mathbf{t} \\
\mathbf{m i n}\end{array}$ & $\begin{array}{c}\mathbf{\rho} \\
\mathbf{k g} / \mathbf{m}^{\mathbf{3}}\end{array}$ & $\begin{array}{c}\mathbf{A A}_{\mathbf{3} \text { días }} \\
\%\end{array}$ & $\begin{array}{c}\mathbf{z}_{\mathbf{A i}} \\
\mathbf{m m}\end{array}$ & $\begin{array}{c}\mathbf{z}_{\mathbf{A s}} \\
\mathbf{m m}\end{array}$ \\
\hline 3 & 2306 & 2,6 & 2,4 & 1,9 \\
\hline 6 & 2327 & 0,4 & 0,0 & 0,0 \\
\hline 12 & 2326 & 0,0 & 0,0 & 0,0 \\
\hline
\end{tabular}

Tabla 4.29. Densidad aparente $y$ absorción de agua del modelo 7 cocido durante diferentes tiempos de permanencia a $1210^{\circ} \mathrm{C}$.

\begin{tabular}{|c|c|c|c|c|}
\hline $\begin{array}{c}\mathbf{t} \\
\mathbf{m i n}\end{array}$ & $\begin{array}{c}\mathbf{\rho} \\
\mathbf{k g} / \mathbf{m}^{\mathbf{3}}\end{array}$ & $\begin{array}{c}\mathbf{A} \mathbf{A}_{\mathbf{3}} \text { dias } \\
\%\end{array}$ & $\begin{array}{c}\mathbf{Z}_{\mathbf{A i}} \\
\mathbf{m m}\end{array}$ & $\begin{array}{c}\mathbf{Z}_{\mathbf{A s}} \\
\mathbf{m m}\end{array}$ \\
\hline 3 & 2357 & 2,8 & 1,8 & 1,6 \\
\hline 6 & 2412 & 0,6 & 2,1 & 0,0 \\
\hline 12 & 2429 & 0,0 & 0,0 & 0,0 \\
\hline
\end{tabular}

El aumento del tiempo de permanencia tiene efectos similares sobre las propiedades analizadas al que produce un aumento de la temperatura máxima. Así, un aumento del tiempo de permanencia disminuye la velocidad del cambio de la curvatura, la expansión post-cocción, la absorción de agua y la penetración, y aumenta la densidad aparente en cocido. Por lo tanto, el tiempo de permanencia a la temperatura máxima de cocción es una variable efectiva para reducir la curvatura diferida en las condiciones ensayadas a nivel de laboratorio.

Finalmente se vuelve a comprobar que existe una relación directa entre la evolución de la curvatura con el tiempo y la cinética de expansión, y que los valores de absorción y expansión también guardan relación. 
4. Resultados y discusión

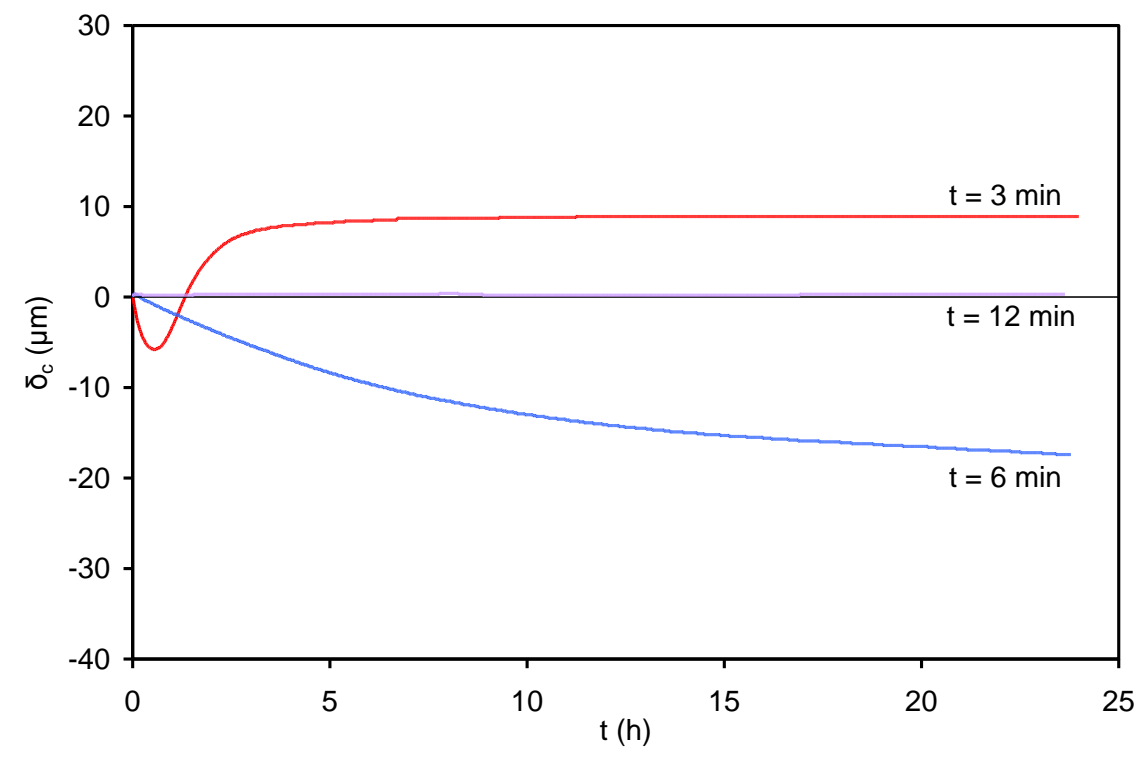

Figura 4.73. Curvatura diferida del modelo 4 cocido con diferente tiempo de permanencia a $1210^{\circ} \mathrm{C}$.

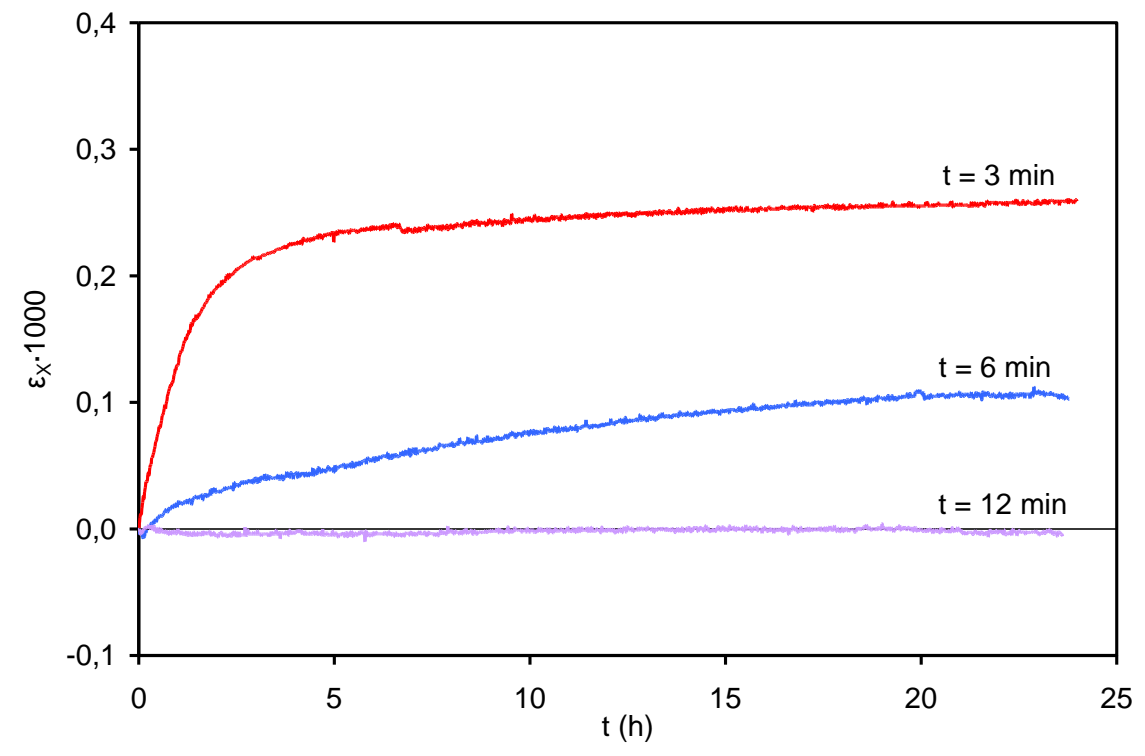

Figura 4.74. Expansión post-cocción del modelo 4 cocido con diferente tiempo de permanencia a $1210^{\circ} \mathrm{C}$. 
4. Resultados y discusión

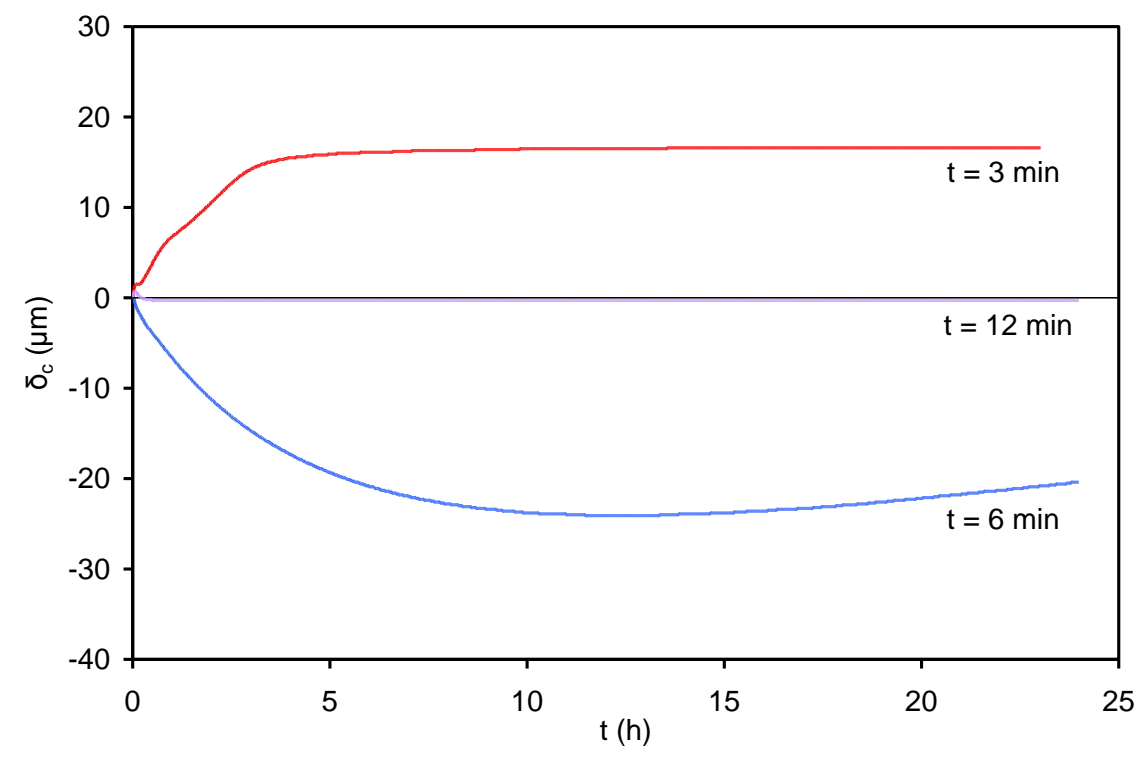

Figura 4.75. Curvatura diferida del modelo 7 cocido con diferente tiempo de permanencia a $1210^{\circ} \mathrm{C}$.

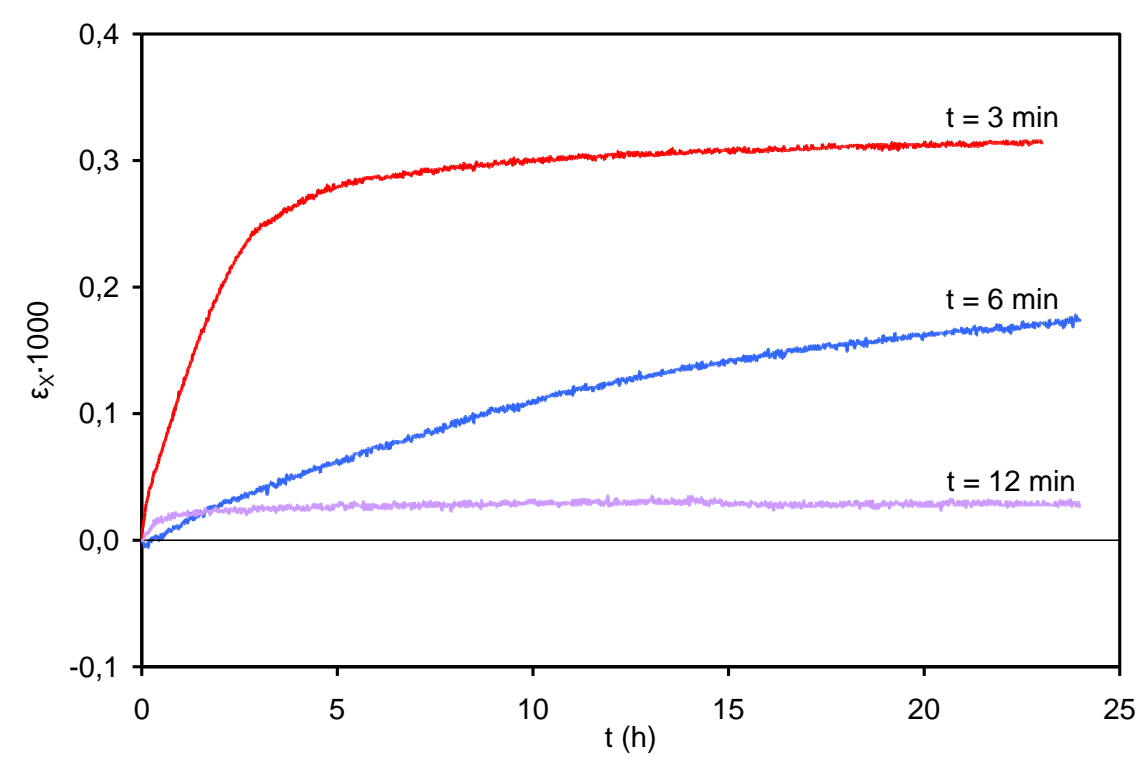

Figura 4.76. Expansión post-cocción del modelo 7 cocido con diferente tiempo de permanencia a $1210 \stackrel{\circ}{\circ}$. 


\subsubsection{Influencia de la velocidad de enfriamiento}

Para estudiar la influencia de la velocidad de enfriamiento se realizaron enfriamientos a dos velocidades diferentes, una rápida llevada a cabo fuera del horno (enfriamiento estándar) y otra lenta en el interior del horno.

En el enfriamiento rápido, la probeta se extrae del horno al finalizar el tiempo de permanencia a máxima temperatura y se enfría al ambiente en posición vertical, como se ha descrito en el apartado 3.3. El enfriamiento lento, por su parte, consiste en enfriar la probeta en el interior del horno en posición horizontal sobre el mismo refractario utilizado en la cocción.

Los resultados de curvatura, expansión post-cocción y tensiones residuales a las 3 temperaturas ensayadas $\left(1190^{\circ} \mathrm{C}, 1210^{\circ} \mathrm{C}\right.$ y $\left.1230^{\circ} \mathrm{C}\right)$, se presentan en la figura 4.77 a la figura 4.82 para el modelo 4 y en la figura 4.83 a la figura 4.88 para el modelo 7 .

La velocidad de enfriamiento apenas modifica la expansión post-cocción global de la pieza. Sin embargo, cabe recordar que el fenómeno de las curvaturas diferidas está más relacionado con una expansión diferencial (expansión diferente entre la parte inferior y superior de la pieza) que con la expansión global.

Las tensiones residuales disminuyen al reducir la velocidad de enfriamiento, siendo prácticamente nulas en piezas procesadas con enfriamiento lento. Los perfiles de tensión, cuando existen, son simétricos y se alcanzan mayores tensiones a la temperatura más alta, como consecuencia del mayor contenido de fase líquida de las piezas. En cualquier caso, para producir cambios de curvatura, las piezas deberían estar más tensionadas y presentar perfiles de tensión no simétricos.

En general, una disminución de la velocidad de enfriamiento también reduce la curvatura diferida.

Para explicar este fenómeno, cabe indicar que una velocidad de enfriamiento más rápida puede conducir a un mayor volumen especifico de la fase vítrea en el soporte y por lo tanto a una mayor sensibilidad a la humedad ambiente. De hecho, como se ha mencionado anteriormente (apartado 4.1.2.B), la expansión por humedad en cerámicas porosas se origina en la absorción de moléculas de agua en las fases hidratables de las piezas cocidas como la fase vítrea.

Por otra parte, en condiciones de laboratorio, el enfriamiento lento conduce a un mayor tiempo de permanencia de la pieza a temperaturas próximas a la temperatura máxima de cocción, conduciendo a un mayor grado de cocción del material que favorece la reducción de las curvaturas diferidas.

No obstante, la variación de la velocidad de enfriamiento realizada en el laboratorio es bastante acusada, por lo que esta variable no debe tener una repercusión importante dentro de las variaciones que pueden realizarse en los hornos industriales. 
4. Resultados y discusión

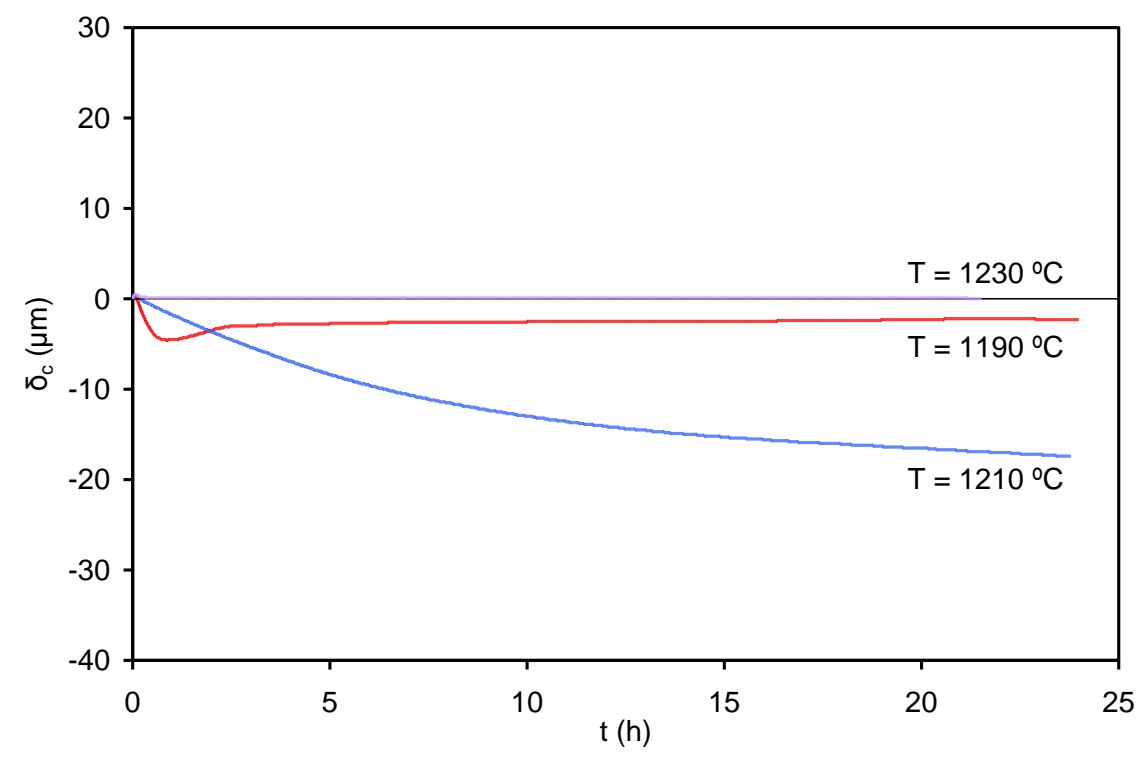

Figura 4.77. Curvatura diferida del modelo 4 con enfriamiento rápido.

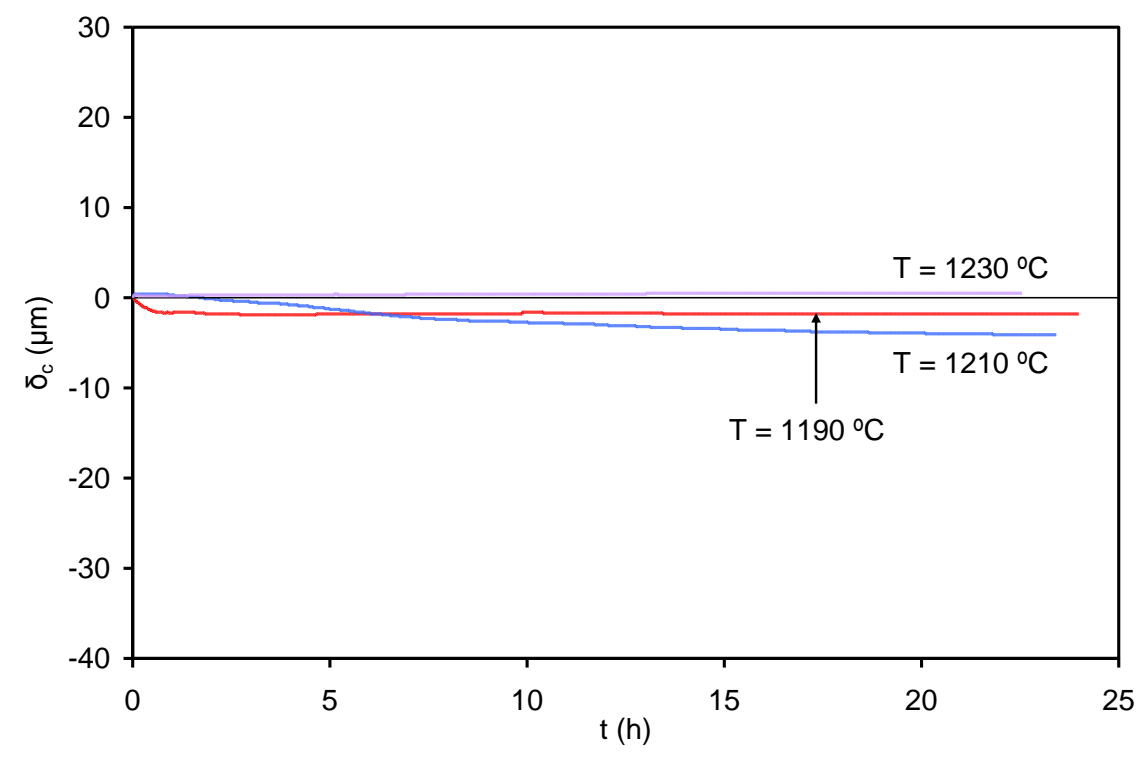

Figura 4.78. Curvatura diferida del modelo 4 con enfriamiento lento. 


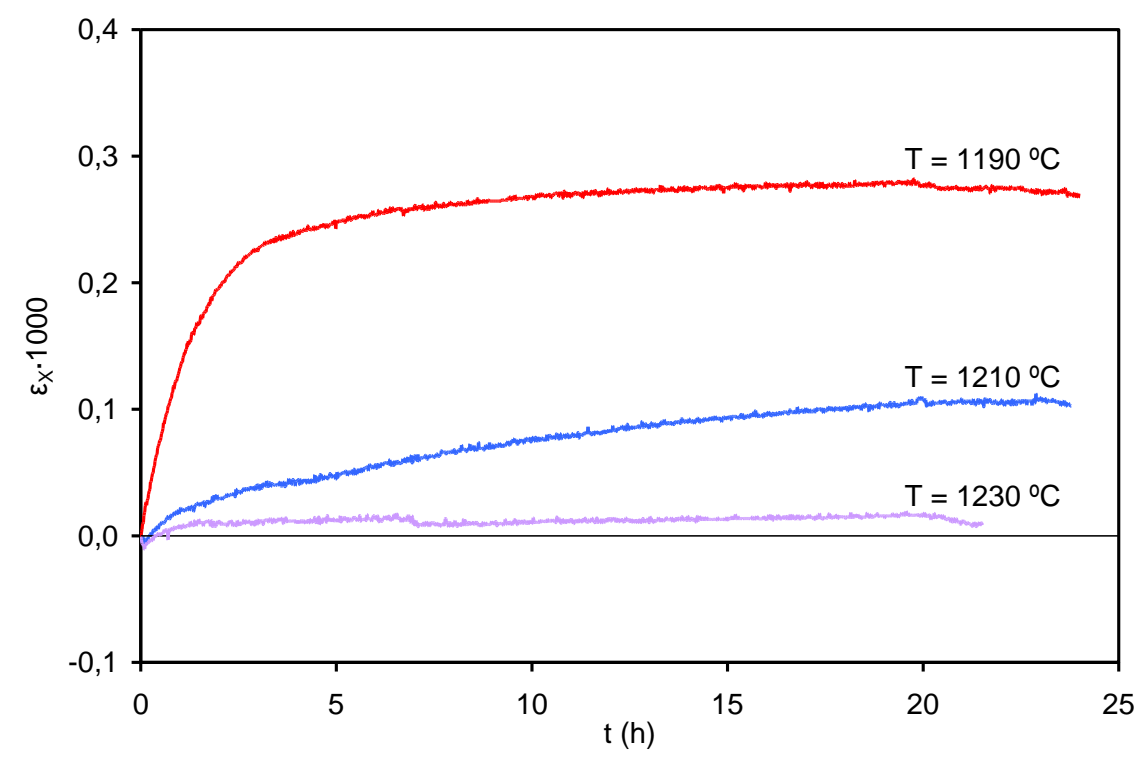

Figura 4.79. Expansión post-cocción del modelo 4 con enfriamiento rápido.

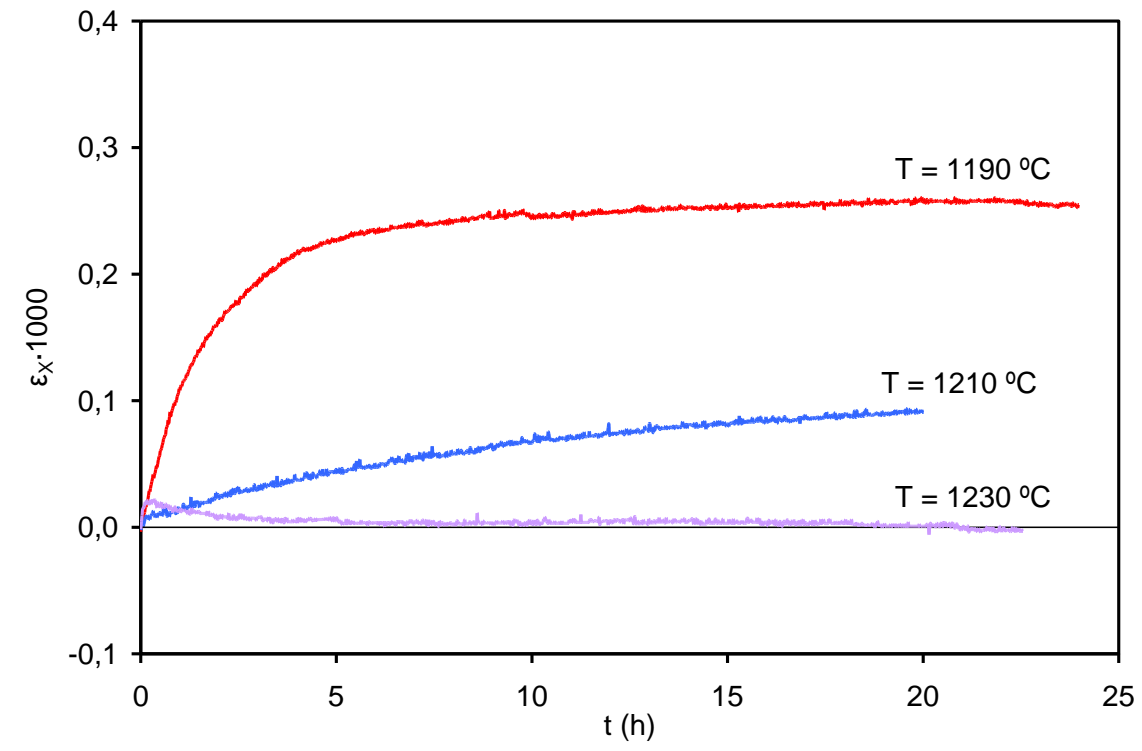

Figura 4.80. Expansión post-cocción del modelo 4 con enfriamiento lento. 


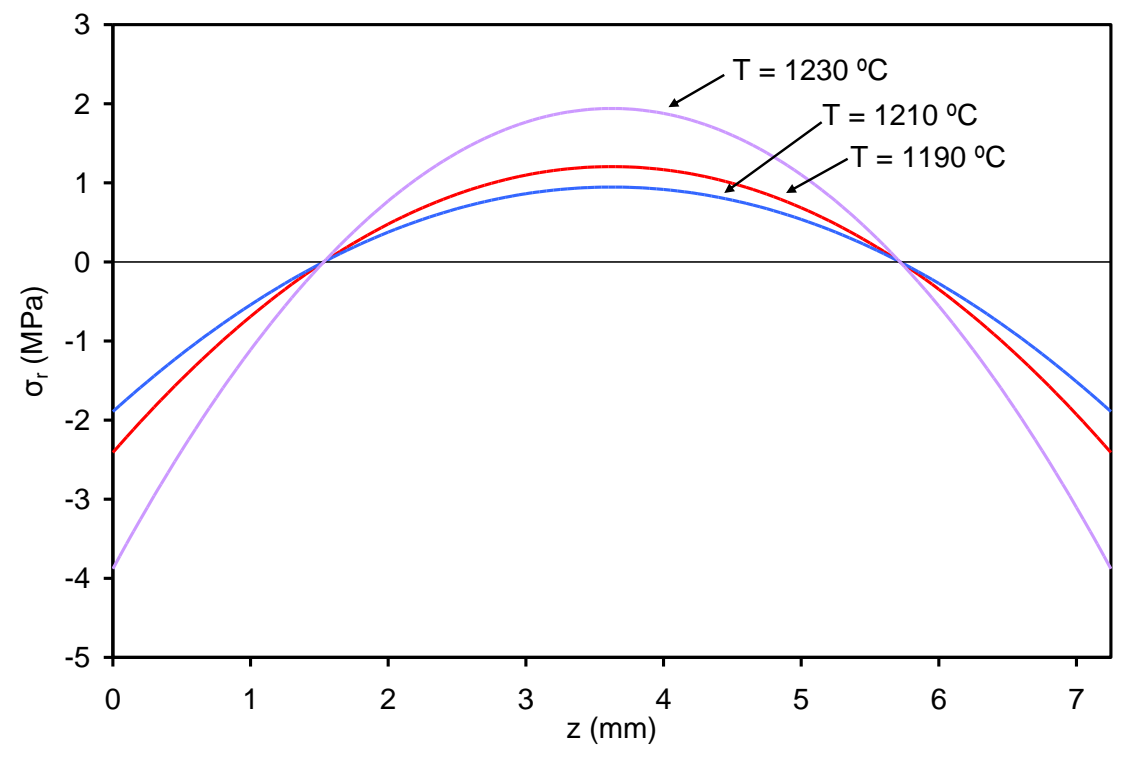

Figura 4.81. Tensiones residuales del modelo 4 con enfriamiento rápido.

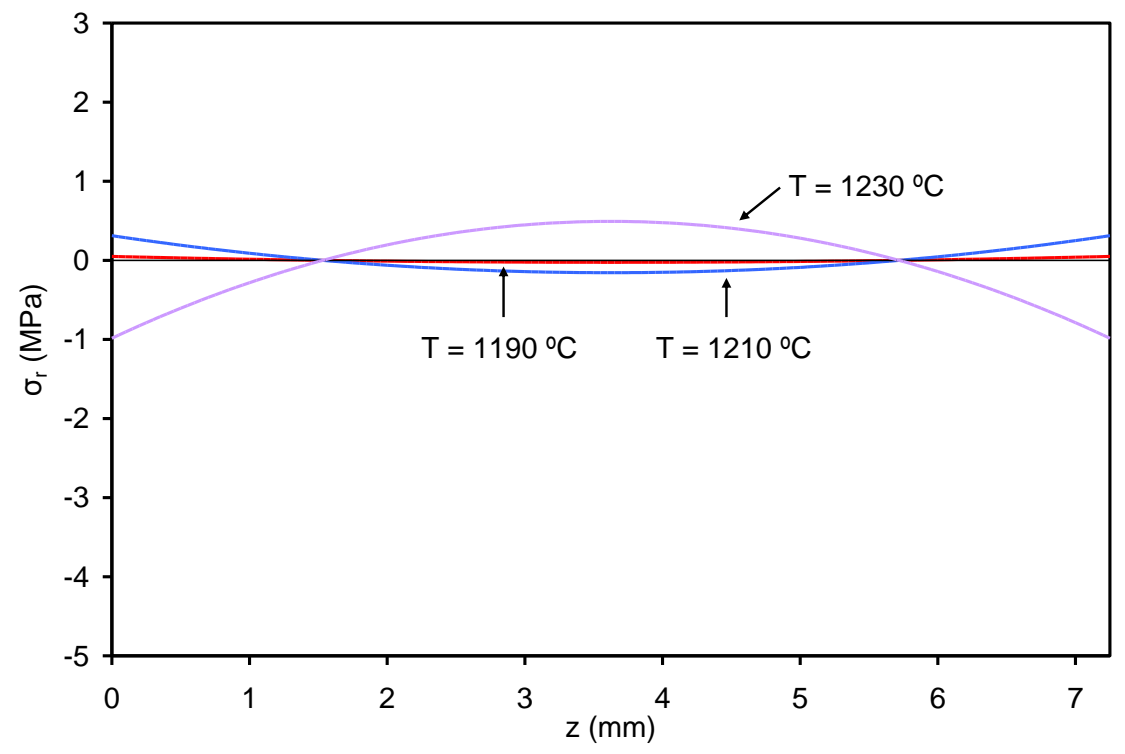

Figura 4.82. Tensiones residuales del modelo 4 con enfriamiento lento. 


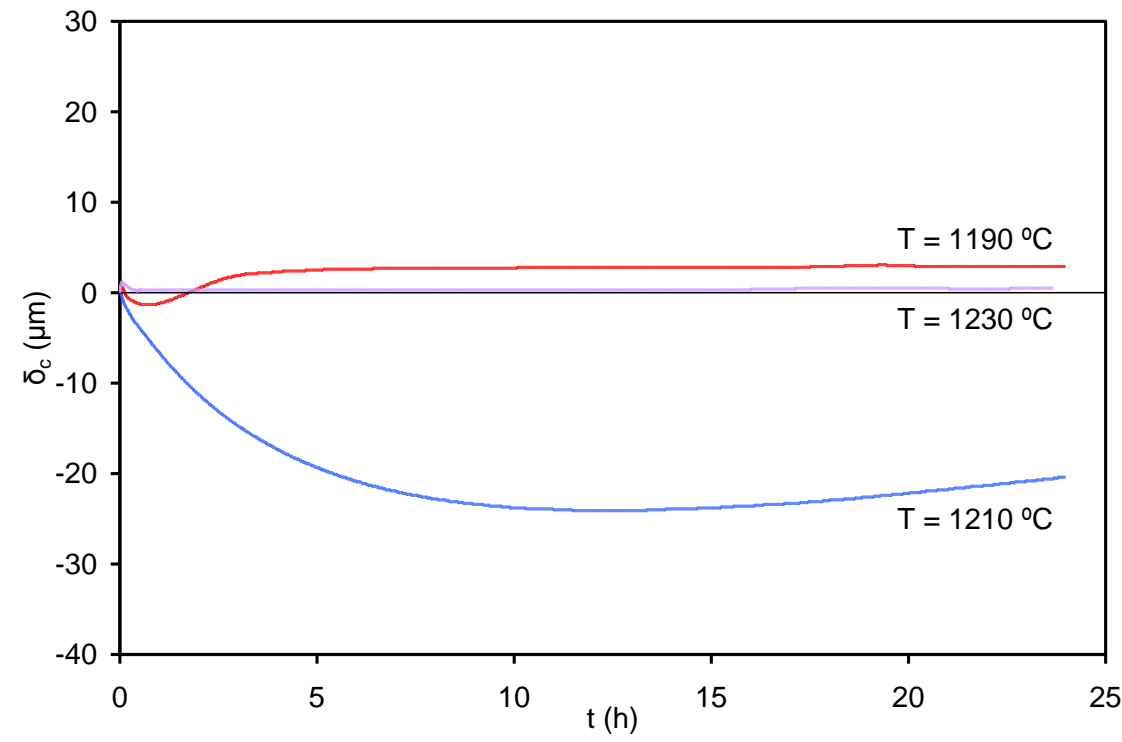

Figura 4.83. Curvatura diferida del modelo 7 con enfriamiento rápido.

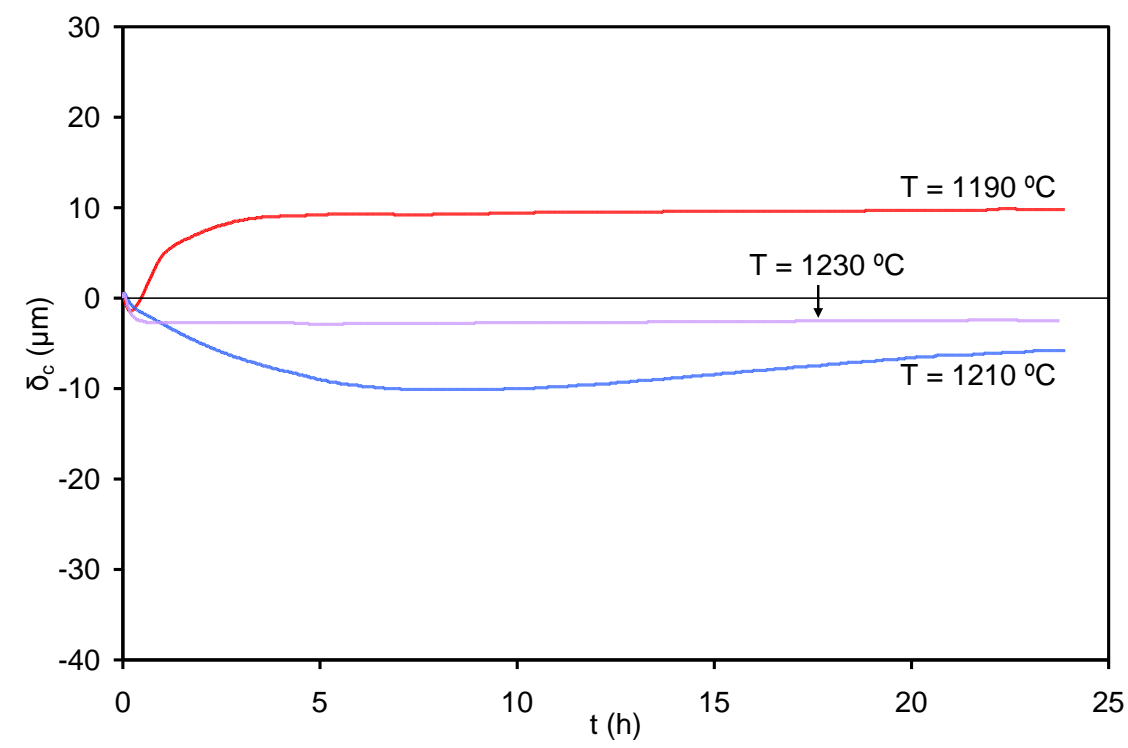

Figura 4.84. Curvatura diferida del modelo 7 con enfriamiento rápido lento. 
4. Resultados y discusión

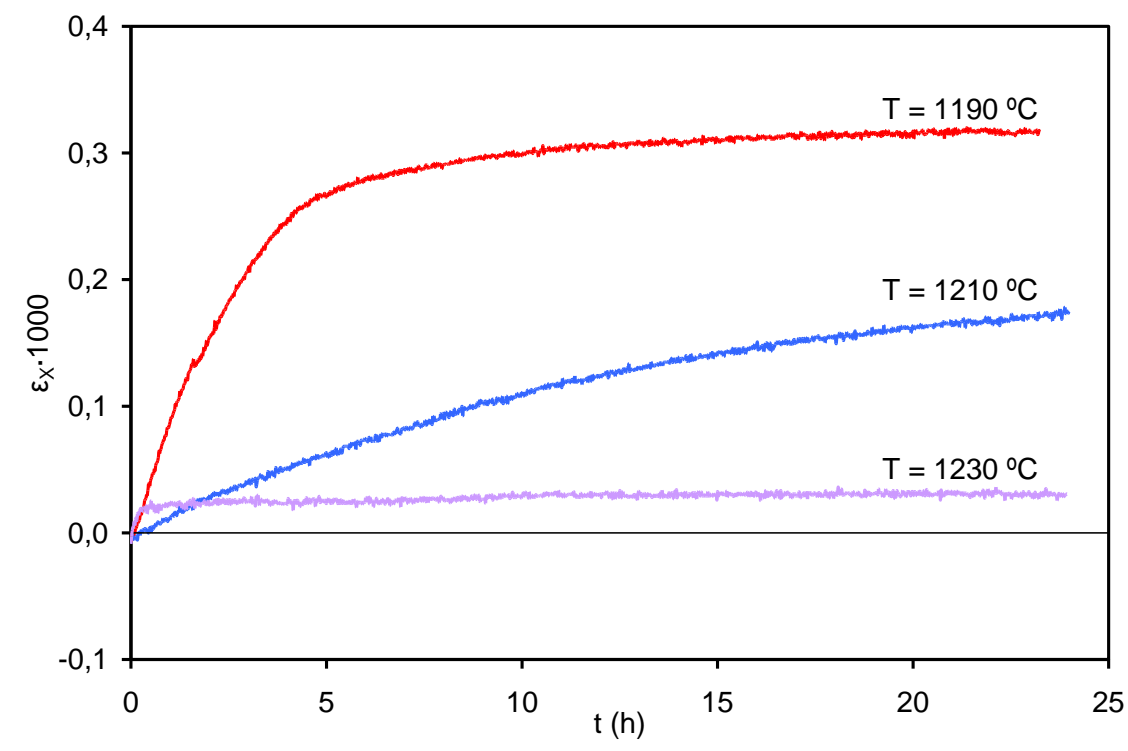

Figura 4.85. Expansión post-cocción del modelo 7 con enfriamiento rápido.

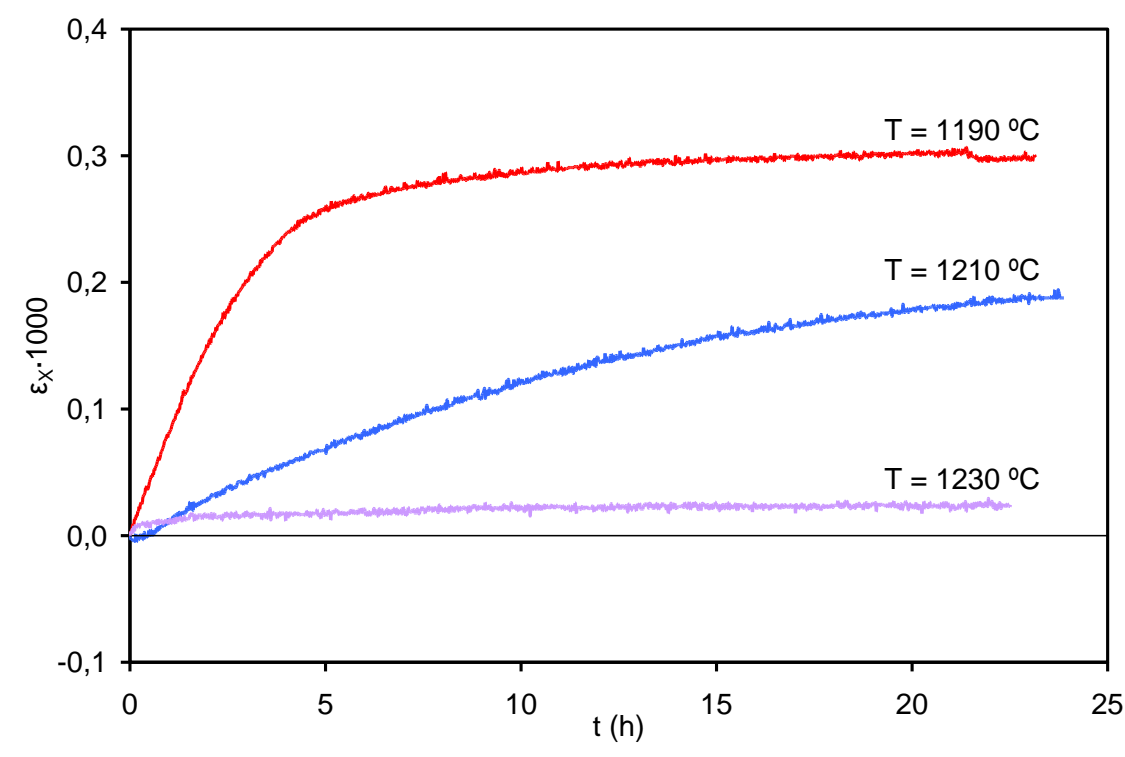

Figura 4.86. Expansión post-cocción del modelo 7 con enfriamiento lento. 


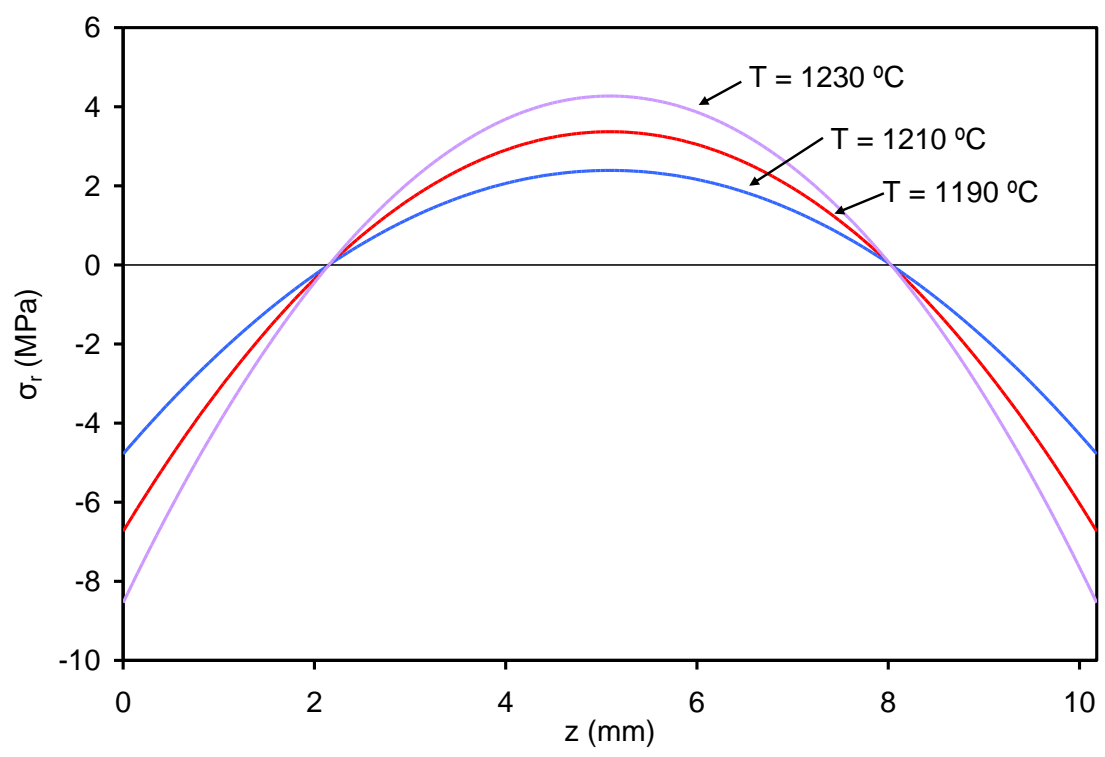

Figura 4.87. Tensiones residuales del modelo 7 con enfriamiento rápido.

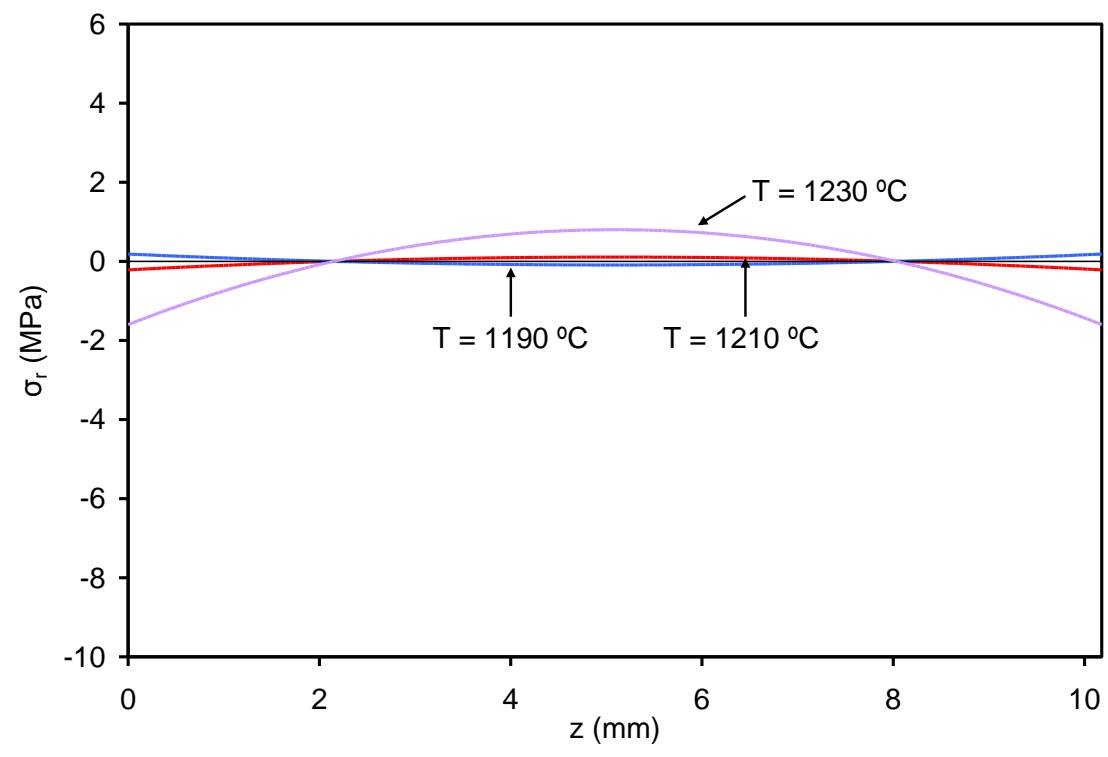

Figura 4.88. Tensiones residuales del modelo 7 con enfriamiento lento. 
Finalmente, destaca el distinto comportamiento del modelo 7 a temperatura baja $\left(1190^{\circ} \mathrm{C}\right)$ consistente en que la pieza presenta una mayor tendencia hacia la convexidad (flecha positiva) cuando el enfriamiento es lento. Con objeto de verificar esta medida, se realizaron cocciones a más temperaturas. Los cambios en curvatura experimentados para ambos enfriamientos se recogen en la figura 4.89 y la figura 4.90 .

Se confirma la notable influencia de la temperatura máxima de cocción, ya comentada en el apartado 4.3.2, de forma que variaciones pequeñas $\left(5^{\circ} \mathrm{C}\right)$ son suficientes para provocar grandes cambios de curvatura. A partir de estas gráficas se deduce que, para este modelo, la disminución de la velocidad de enfriamiento tiende a curvar las piezas de forma menos cóncava (como en el modelo 4) a temperaturas relativamente elevadas, y de forma más convexa para temperaturas muy inferiores a la de cocción del producto. 


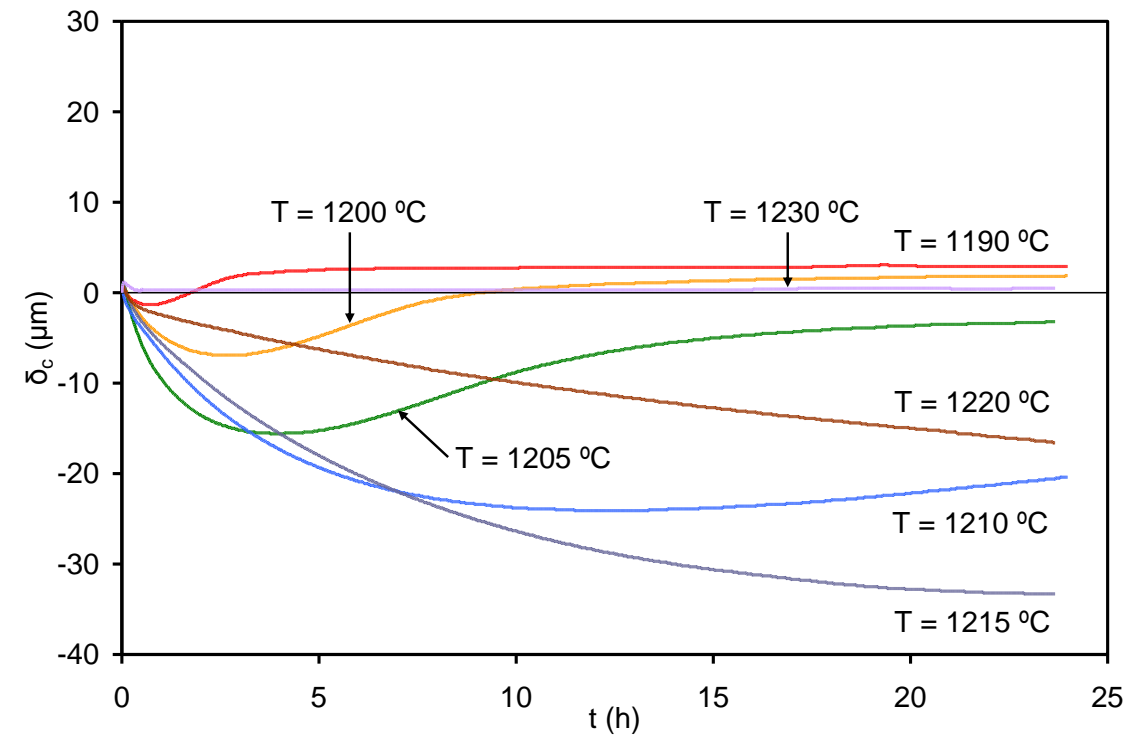

Figura 4.89. Curvatura diferida del modelo 7 cocido a más temperaturas con enfriamiento rápido.

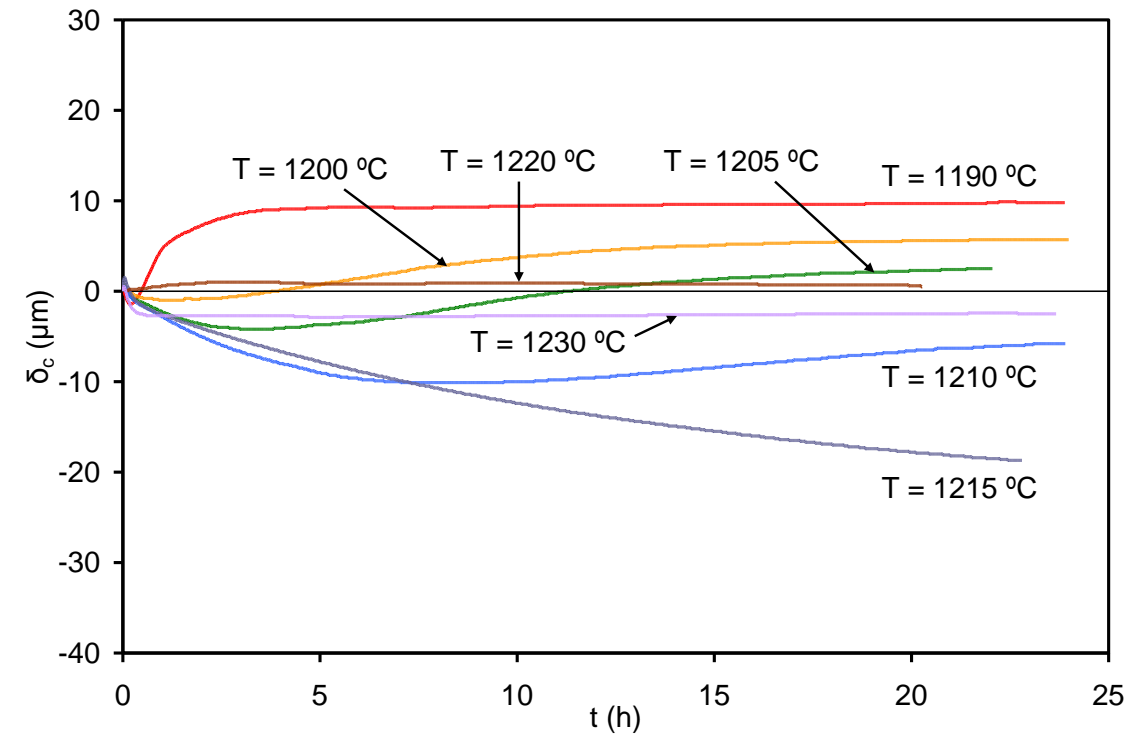

Figura 4.90. Curvatura diferida del modelo 7 cocido a más temperaturas con enfriamiento lento. 


\subsubsection{Relación entre variables}

Para finalizar, se han efectuado una serie de representaciones a fin de establecer correlaciones entre diferentes propiedades, independientemente de las condiciones de procesado (temperatura máxima de cocción, tamaño de partícula de la suspensión, tipo de enfriamiento, espesor del soporte, etc.).

Todos los resultados obtenidos a lo largo del estudio de variables apuntan a la existencia de una relación entre la expansión post-cocción y la absorción de agua. En la figura 4.91 se representa la expansión a las 24 horas frente a la absorción de agua a vacío a los 3 días en las diferentes condiciones ensayadas para los dos modelos. Se observa cómo efectivamente ambas variables están relacionadas.

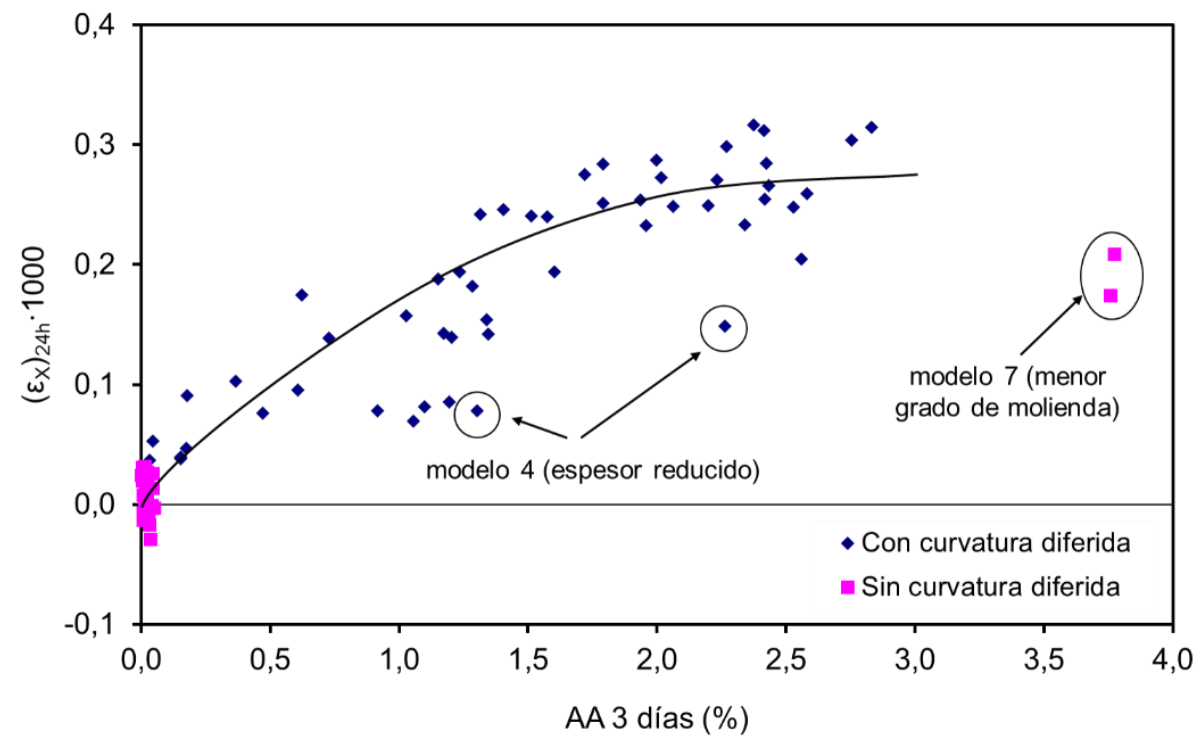

Figura 4.91. Relación entre la expansión a las 24 horas y la absorción de agua a los 3 días.

Analizando la figura 4.91 se constata que las piezas con absorción de agua nula o casi nula no presentan expansión ni, por tanto, curvatura diferida. Además, se observa que al aumentar la expansión a las 24 horas lo hace también la absorción de agua, aunque la relación no es lineal. Se observan 2 casos aparentemente anómalos en la curva. Ambos puntos corresponden a las probetas del modelo 7 conformadas a partir de un polvo con menor grado de molienda y cocidas a baja temperatura. Debe recordarse que a temperaturas bajas una parte de la expansión se produce con anterioridad al inicio de las medidas (en el interior del horno), por lo que los valores de expansión representados son inferiores a los reales. Asimismo, en estos casos, el cambio de curvatura tras la cocción es tan rápido que ocurre antes de empezar la medida, explicando que experimentalmente no se hayan observado curvaturas en diferido. 
La absorción de agua a vacío también permite estimar cualitativamente si la evolución de la curvatura con el tiempo será rápida o lenta. Así, las piezas con valores elevados de la absorción de agua van a mostrar una variación rápida de la curvatura con el tiempo. Esta relación se basa en el hecho de que las piezas con expansión alta (alta absorción de agua) también presentan una variación de la expansión con el tiempo elevada, lo que conduce a un cambio de la curvatura con el tiempo rápido.

En casos extremos, cuando el grado de cocción de la pieza es muy bajo (absorción superior al 3,5\%), la expansión es tan rápida que el valor medido es inferior al esperado y el cambio de curvatura se produce principalmente dentro del horno, con anterioridad a la realización de las medidas. No obstante, no es posible predecir la curvatura final a partir del valor de absorción de agua.

Si se representa el valor de expansión a las 24 horas frente a la densidad aparente en cocido, se obtienen la figura 4.92 y la figura 4.93 . Se representan por separado ambos modelos debido a la mayor densidad real del modelo 7 , que contiene circón.

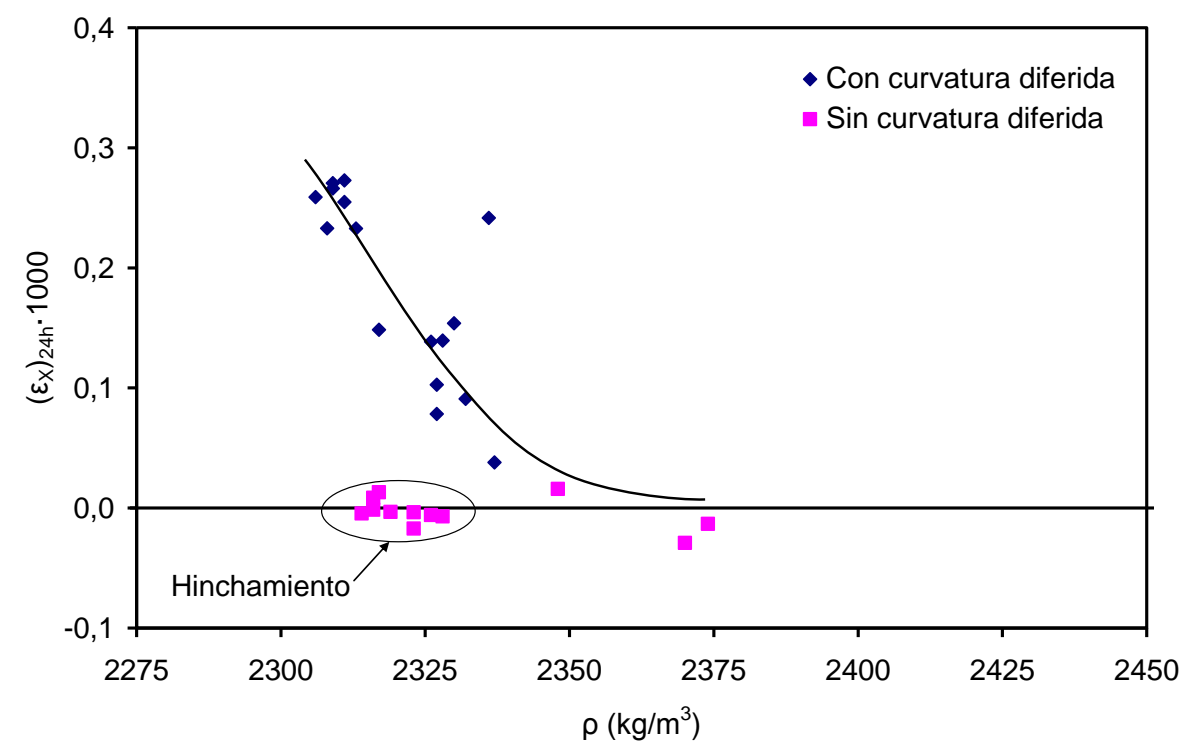

Figura 4.92. Relación entre la expansión a las 24 horas y la densidad aparente en cocido para el modelo 4.

Se observa que la expansión disminuye al aumentar la densidad en cocido hasta anularse cuando se alcanzan valores cercanos a los de máxima densificación. A partir de este momento, al aumentar la temperatura de cocción se produce un hinchamiento de la pieza sin que ello implique la aparición de los fenómenos de expansión post-cocción y curvatura diferida. El modelo 4 no presenta curvatura diferida cuando se alcanzan densidades superiores a 2,340 g/ $/ \mathrm{cm}^{3}$ mientras que el modelo 7 necesita alcanzar valores 
de $2,420 \mathrm{~g} / \mathrm{cm}^{3}$. Esta variable, fácilmente medible, podría utilizarse para conocer de forma aproximada si las piezas van a presentar curvatura diferida.

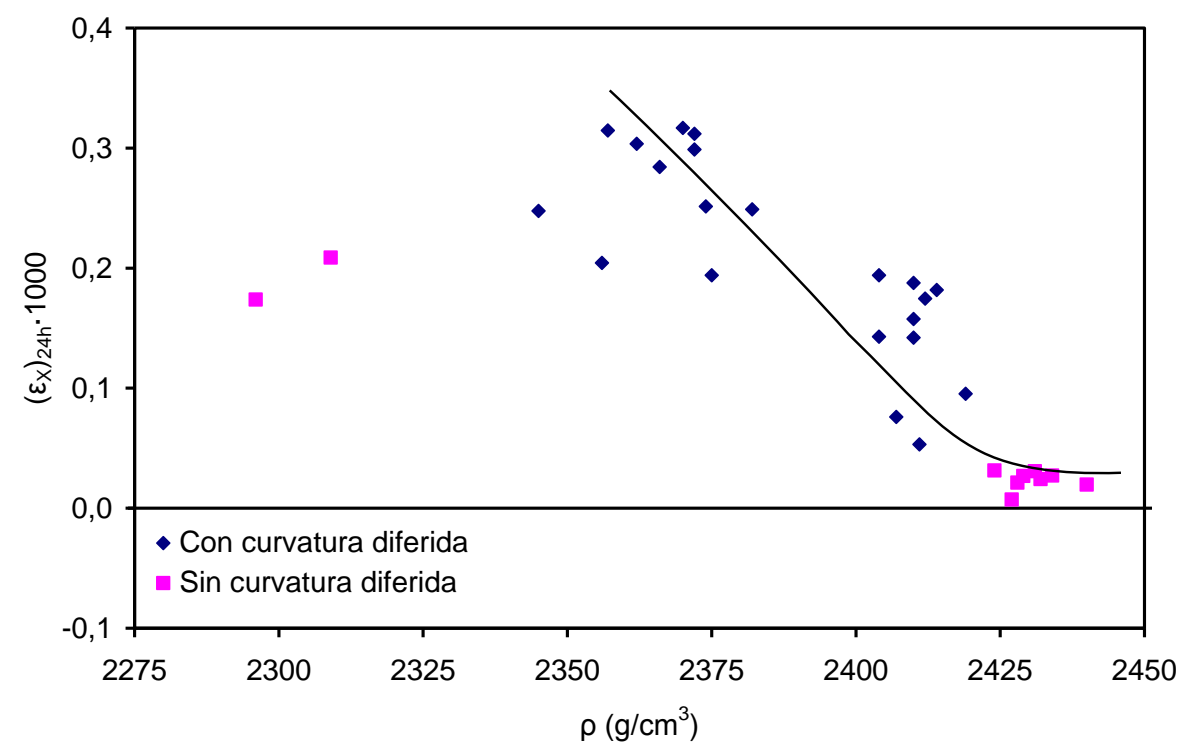

Figura 4.93. Relación entre la expansión a las 24 horas y la densidad aparente en cocido para el modelo 7.

\subsubsection{Conclusiones}

En esta fase del estudio se ha analizado, con piezas de laboratorio, la influencia que ejercen algunas variables de proceso sobre la curvatura diferida y se ha intentado justificar el comportamiento observado mediante la medida de otras propiedades (expansión post-cocción con el tiempo, densidad aparente en cocido, absorción de agua, penetración de azul de metileno y tensiones residuales). Se ha comprobado que prácticamente la totalidad de las variables seleccionadas, en mayor o menor medida, son susceptibles de modificar la curvatura diferida.

Las principales conclusiones que se extraen del trabajo realizado son las siguientes:

- En todos los ensayos realizados se observa que la curvatura diferida está íntimamente relacionada con la expansión que experimentan los soportes tras la cocción. De esta forma, las piezas sin expansión post-cocción no presentan curvatura diferida y aquellas en las que la cinética de expansión es elevada cambian rápidamente su curvatura con el tiempo.

- La expansión post-cocción está relacionada a su vez con la porosidad abierta de las piezas y con su densidad aparente, que evalúan el grado de cocción alcanzado. La temperatura para la cual se elimina la curvatura diferida puede conocerse de forma aproximada mediante la realización de un ensayo enérgico de absorción de agua a vacío o mediante la medida de la densidad aparente. 
- El aumento de la temperatura de cocción y/o del tiempo de permanencia a esta temperatura disminuye la curvatura diferida al aumentar el grado de cocción de la pieza. Ambas variables son muy efectivas para la solución del problema.

- El grado de molienda influye sobre la microestructura en crudo de la pieza, de forma que a medida que aumenta se obtienen piezas crudas con una distribución del tamaño de poro exenta de poros de tamaño elevado. Ello, junto a la mayor reactividad de la composición, acelera el proceso de sinterización, proporcionando piezas sin curvatura diferida a menor temperatura.

- El aumento del grado de molienda disminuye la temperatura de vitrificación y en menor medida la temperatura de máxima densificación. Ello permite obtener piezas sin curvatura diferida a temperaturas inferiores a la de hinchamiento. Esta variable es muy eficaz para eliminar los problemas de curvatura diferida sin aumentar la deformación piroplástica de la pieza.

- La densidad aparente en seco también influye sobre el proceso de sinterización. Un aumento de esta variable disminuye la temperatura para la que se elimina la curvatura diferida, aunque su efectividad no es tan alta como la observada para otras variables como la temperatura de cocción, tiempo de permanencia a máxima temperatura o grado de molienda.

- Los cambios en la velocidad de enfriamiento modifican la magnitud de las tensiones, pero el perfil de tensiones continúa siendo simétrico. A escala de laboratorio se ha observado que la disminución de la velocidad de enfriamiento es beneficiosa para minimizar el problema debido probablemente al mayor grado de cocción alcanzado al aumentar el tiempo en el que la pieza se encuentra a temperatura alta o a la disminución del volumen especifico de fase vítrea en el soporte que puede dificultar su hidratación. La modificación del enfriamiento en hornos industriales es limitada, lo que reduce la efectividad de esta variable para evitar la curvatura diferida.

- La presencia de esmalte aumenta notablemente la variación de la curvatura de la pieza tras la cocción, independientemente del espesor de la capa de esmalte. Este hecho debe de estar relacionado con el efecto impermeabilizante que ejerce el esmalte, el cual disminuye la cinética de expansión de la zona superior del soporte.

- La modificación del espesor de las piezas influye sobre aspectos térmicos y mecánicos de la misma, lo que dificulta el análisis de esta variable. En principio una reducción del espesor de las piezas aumenta su grado de cocción y las hace más deformables. Esta tendencia se ha observado en piezas esmaltadas, pero no en soportes sin esmaltar.

- Estos resultados facilitan el entendimiento del fenómeno de las curvaturas en diferido, ponen de manifiesto cuales deben de ser las acciones a emprender a nivel industrial para minimizar el problema y qué ensayos de control proporcionan la información más útil. Además, sientan la base 
necesaria para el desarrollo del modelo matemático, que debe basarse en la expansión del soporte y no en la existencia de tensiones residuales.

\subsection{MODELIZACIÓN DE LAS CURVATURAS EN DIFERIDO}

En esta fase, el objetivo es desarrollar un modelo matemático, lo más sencillo posible, que permita justificar la evolución de las curvaturas diferidas medidas en el apartado 4.3, estableciendo con ello el papel que juegan los diferentes factores (expansión, tensiones residuales, propiedades mecánicas, geometría, etc.).

El planteamiento que se ha seguido para desarrollar los modelos ha sido definir la ecuación (o ecuaciones) más sencilla posible que permitiera describir un determinado aspecto o característica de las curvaturas diferidas. Se han considerado preferibles los modelos simples frente a aquéllos que pudieran ser más precisos pero que, en cambio, requirieran la determinación de un mayor número de parámetros.

Cabe indicar también que en todos los modelos desarrollados se va a trabajar con diferencias de curvatura respecto a las condiciones de salida de la pieza del horno. Con este criterio la curvatura inicial (a la salida del horno) será siempre cero. Asimismo, hay que indicar que se ha seleccionado el criterio de signos de considerar positivas las curvaturas convexas y negativas las cóncavas.

A continuación, se pasan a describir los modelos desarrollados, con un nivel creciente de complejidad y de capacidad explicativa de las curvaturas diferidas.

\subsubsection{Modelo A: Modelo biproceso}

\section{A. Fundamento}

La evolución de la curvatura de las piezas de gres porcelánico sigue el mismo patrón en prácticamente todos los casos: la curvatura evoluciona hacia la concavidad y, posteriormente, invierte su sentido. Al final la pieza puede quedar casi plana o presentar una ligera curvatura.

Este comportamiento hace pensar en que puedan existir dos fenómenos antagónicos, uno que tiene tendencia a inducir curvaturas cóncavas y otro que produce curvaturas convexas. Además, estos fenómenos transcurren a diferente velocidad, siendo el primero el más rápido. Las expresiones matemáticas más sencillas que permiten describir cada uno de estos fenómenos son:

Ecuación 4.10

$$
\frac{\mathrm{d} \delta_{\mathrm{c} 1}}{\mathrm{dt}}=-\mathrm{k}_{1}\left(\mathrm{~A}_{1}-\delta_{\mathrm{c} 1}\right)
$$




\section{Ecuación 4.11}

$$
\frac{\mathrm{d} \delta_{\mathrm{c} 2}}{\mathrm{dt}}=-\mathrm{k}_{2}\left(\mathrm{~A}_{2}-\delta_{\mathrm{c} 2}\right)
$$

donde:

$A_{1}$ : flecha final que alcanzaría la pieza si sólo existiera el primer proceso (el que produce la curvatura cóncava).

$\mathrm{A}_{2}$ : flecha final que alcanzaría la pieza si sólo existiera el segundo proceso (el que produce la curvatura convexa).

La evolución de la flecha puede deducirse de las ecuaciones anteriores:

Ecuación 4.12

Ecuación 4.13

$$
\delta_{\mathrm{c}}=\delta_{\mathrm{c} 1}+\delta_{\mathrm{c} 2}
$$$$
\delta_{C}=A_{2}\left(1-e^{-t / \tau_{2}}\right)-A_{1}\left(1-e^{-t / \tau_{1}}\right)
$$

donde:

$$
\begin{array}{ll}
\tau_{1}: & \text { constante de tiempo del primer proceso. } \\
\tau_{2}: & \text { constante de tiempo del segundo proceso. }
\end{array}
$$

\section{B. Resultados}

En la figura 4.94 se muestra la evolución de la curvatura de una pieza de gres porcelánico el ajuste obtenido aplicando la ecuación 4.13. Como puede observarse, el modelo se ajusta muy bien a la curva experimental.

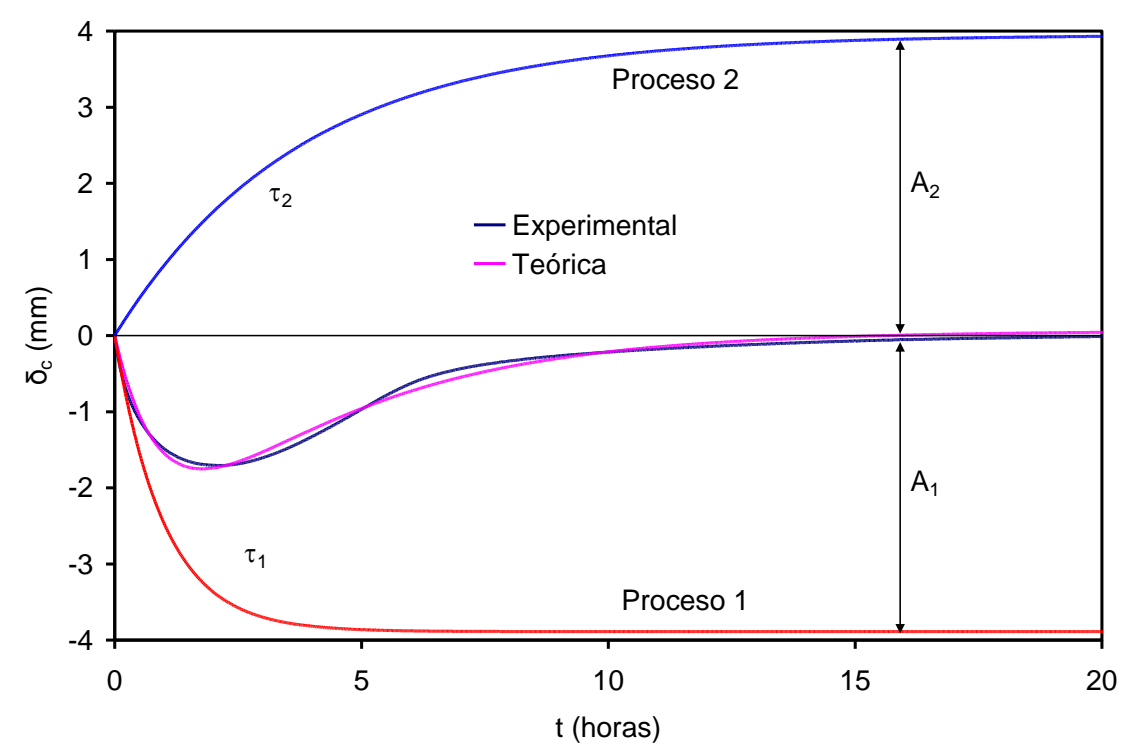

Figura 4.94. Evolución de la curvatura teórica y su descomposición en dos procesos. 
Sin embargo, el modelo presenta varias limitaciones:

- En ocasiones, diferentes combinaciones de $A_{1}$ y $A_{2}$ conducen a resultados similares de $\delta c$.

- Sólo permite ajustar resultados experimentales (no se puede usar para predecir el comportamiento de las piezas).

- Los parámetros no se correlacionan de forma clara con propiedades de los materiales tales como la expansión por humedad, la porosidad o las propiedades mecánicas.

\subsubsection{Modelo B: Expansión diferencial discontinua}

\section{A. Fundamento}

Teniendo en cuenta la relación observada entre expansión y curvaturas diferidas (las piezas que no presentan expansión tampoco tienen curvaturas diferidas), cabe pensar que la expansión de los soportes puede jugar un determinado papel. Suponiendo que la expansión se debe, en cierta medida, a la pequeña porosidad abierta que presenta la pieza, la superficie esmaltada no debería presentar ninguna expansión. De forma simplificada se podría plantear, por tanto, un modelo en el que la expansión progresara desde la superficie de la costilla hacia la cara vista (figura 4.95).
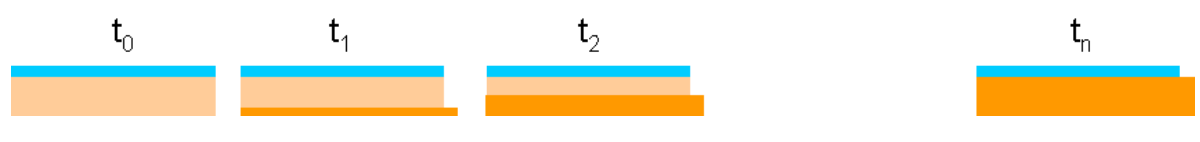

Figura 4.95. Expansión progresiva del soporte.

Además, también con el fin de simplificar, se puede considerar que la fracción de soporte que ha expandido lo ha hecho en una magnitud igual a $\varepsilon_{\mathrm{x}}$; es decir, un punto cualquiera del soporte, o bien no ha expandido o si lo ha hecho, ha sufrido una expansión igual a $\varepsilon_{X}$ que es constante en el tiempo. Por tanto, lo único que cambia con el tiempo es la fracción de soporte que ha expandido.

Para caracterizar el grado de avance de la expansión se puede definir el parámetro $\xi$ como:

Ecuación 4.14

$$
\xi=\frac{h_{1}}{h_{1}+h_{2}}
$$

donde:

$h_{1}$ : espesor de soporte que ha sufrido expansión.

$h_{2}$ : espesor de soporte que no ha sufrido expansión. 
La flecha de curvatura $(\delta c)$ se puede calcular a partir de:

$$
\text { Ecuación } 4.15 \quad \delta_{\mathrm{c}}=\frac{\mathrm{L}^{2} \kappa}{8}
$$

donde:

L: longitud de la pieza o probeta (dimensión a lo largo de la cual se mide la flecha).

$\kappa: \quad$ curvatura (inversa del radio de curvatura).

La curvatura $\kappa$ se calcula como:

$$
\text { Ecuación 4.16 } \quad \kappa=\frac{1}{h} \cdot \frac{6\left(1-2 z_{0}^{\prime}\right) \varepsilon_{\mathrm{X}}}{\left(1+\mathrm{h}_{2}^{\prime}+\mathrm{h}_{\mathrm{v}}^{\prime}\right)^{2} \mathrm{E}_{\mathrm{ef}}^{\prime}}
$$

donde:

$h: \quad$ espesor total $\left(h_{1}+h_{2}+h_{v}\right)$.

$\mathrm{Z}_{0}^{\prime}$ : posición adimensional de la fibra neutra $\left(\mathrm{z}_{0} / \mathrm{h}_{1}\right)$.

Z0: posición de la fibra neutra (medida desde la superficie de la costilla).

$\mathrm{h}_{2}$ : cociente $\mathrm{h}_{2} / \mathrm{h}_{1}$.

$h_{v}^{\prime}$ : cociente $h_{v} / h_{1}$.

$h_{v}$ : espesor del vidriado

E'ef: módulo de elasticidad efectivo adimensional.

La posición adimensional de la fibra neutra se puede calcular como:

Ecuación 4.17

$$
z_{0}^{\prime}=1+\frac{h_{2}^{\prime 2}+E_{v}^{\prime} h_{v}^{\prime}\left(2 h_{2}^{\prime}+h_{v}^{\prime}\right)-1}{2\left(h_{2}^{\prime}+E_{v}^{\prime} h_{v}^{\prime}+1\right)}
$$

donde:

$E^{\prime}$ : módulo de elasticidad adimensional del vidriado $\left(E_{v} / E_{1}\right)$

Ev: módulo de elasticidad del vidriado

El módulo de elasticidad efectivo adimensional viene dado por la expresión:

Ecuación 4.18

$$
E_{e f}^{\prime}=\frac{4}{\left(1+h_{2}^{\prime}+h_{v}^{\prime}\right)^{3}}\left[\begin{array}{l}
\left(1-E_{v}^{\prime}\right)\left(1+h_{2}^{\prime}-z_{0}^{\prime}\right)^{3}+ \\
+z_{0}^{\prime 3}+E_{v}^{\prime}\left(1+h_{2}^{\prime}+h_{v}^{\prime}-z_{0}^{\prime}\right)^{3}
\end{array}\right]
$$




\section{B. Resultados}

A partir de las ecuaciones anteriores, utilizando valores típicos para todas las propiedades (tabla 4.30) se obtiene la figura 4.96. El modelo predice un valor máximo de la curvatura de $-1,2 \mathrm{~mm}$, lo que es coherente con los valores medidos, por tanto, este modelo permite concluir que la expansión progresiva de los soportes podría ser la causa (o una de las causas) de las curvaturas diferidas.

Tabla 4.30. Parámetros del modelo B utilizados en la simulación.

\begin{tabular}{|l|c|}
\hline Propiedad & Valor \\
\hline Módulo elasticidad soporte $\left(\mathrm{E}_{1}=\mathrm{E}_{2}=\mathrm{E}_{\mathrm{s}}\right)$ & $40 \mathrm{GPa}$ \\
\hline Módulo elasticidad vidriado $\left(\mathrm{E}_{\mathrm{v}}\right)$ & $60 \mathrm{GPa}$ \\
\hline Espesor soporte $\left(\mathrm{h}_{\mathrm{s}}=\mathrm{h}_{1}+\mathrm{h}_{2}\right)$ & $9 \mathrm{~mm}$ \\
\hline Espesor esmalte $\left(\mathrm{h}_{\mathrm{v}}\right)$ & $200 \mu \mathrm{m}$ \\
\hline Longitud $(\mathrm{L})$ & $0,5 \mathrm{~m}$ \\
\hline Expansión soporte $(\varepsilon \mathrm{x})$ & $2,5 \cdot 10^{-3}$ \\
\hline
\end{tabular}

Se observa que, para $\xi=1$ (todo el soporte ha expandido), $\delta c \neq 0$; el valor de $\delta c$ en estas condiciones es la curvatura diferida asociada al acoplamiento entre soporte y esmalte. Si la capa de esmalte fuera muy delgada este valor sería cero.

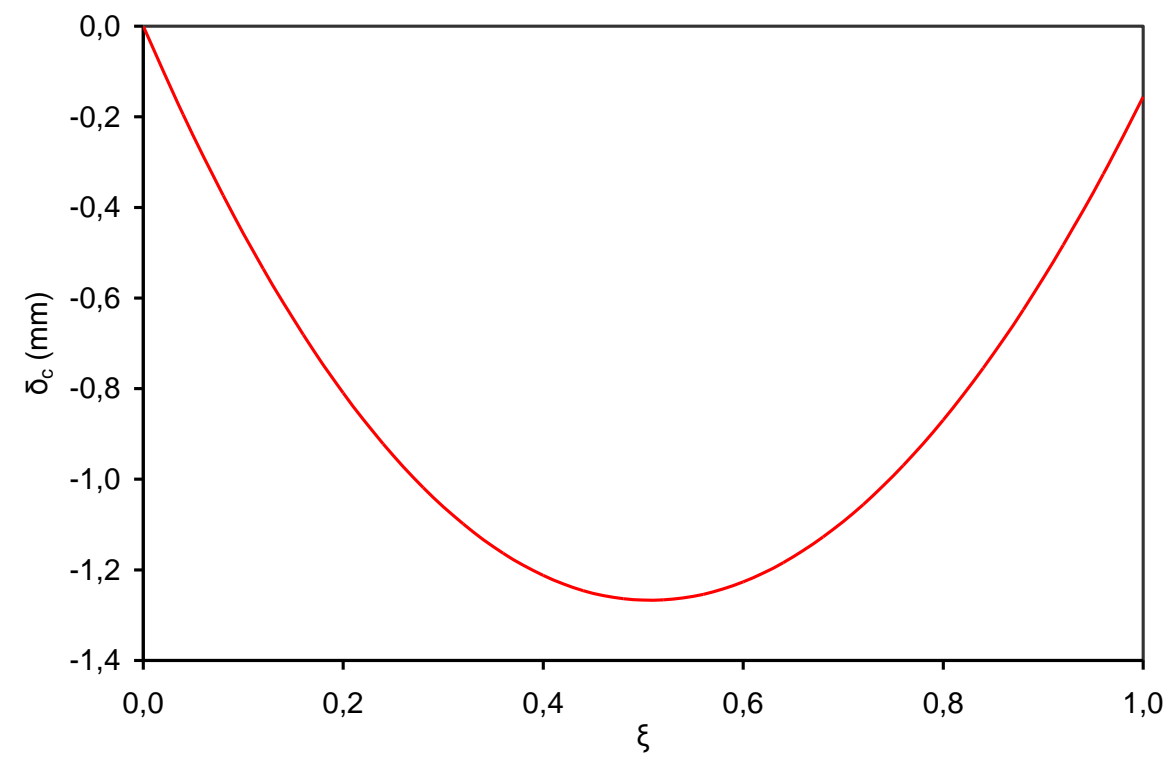

Figura 4.96. Evolución de la flecha de curvatura en función del parámetro adimensional $\xi$. 
El modelo B es muy sencillo, sin embargo, presenta una serie de inconvenientes:

1. No explica el comportamiento de piezas de gres porcelánico no esmaltado, para las cuales no existiría curvatura diferida debido a que la progresión de la expansión tiene lugar a partir de las dos superficies simultáneamente. El modelo requiere la presencia de una capa de esmalte.

2. La expresión que permite calcular la flecha está en función de la variable $\xi$. El objetivo es conocer cómo varía la flecha con el tiempo (t); por tanto, el modelo debería indicar cómo varía $\xi$ con t.

\subsubsection{Modelo C: Expansión diferencial asociada a un proceso difusional}

\section{A. Fundamento}

El modelo $B$ es muy simplista, ya que considera que existe una discontinuidad en la expansión (desde la superficie de la costilla hasta una distancia $h_{1}$ el soporte ha expandido, y desde ese punto hasta la cara vista la expansión es cero, existiendo un punto, entre las dos zonas, en que la expansión pasa bruscamente de $\varepsilon \times a$ 0). Es más razonable suponer que la expansión presenta una gradación desde la superficie de la costilla, donde sería máxima, hasta la cara vista (figura 4.97).

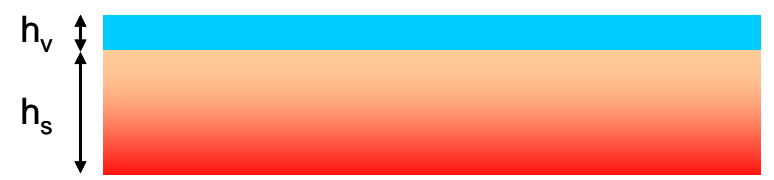

$$
\begin{aligned}
& E_{v}, \varepsilon_{x}=0 \\
& E_{s}, \varepsilon_{x}=\varepsilon_{X}(t, z)
\end{aligned}
$$

Figura 4.97. Expansión gradual del soporte desde la superficie de la costilla hasta la cara vista.

Hay que suponer que existe un factor que desencadena esta expansión (podría ser la humedad ambiente), y que progresa desde la superficie de la costilla hacia la cara vista. Se puede considerar, como hipótesis de trabajo, que este factor (que se va a denominar $c$ ), se difunde siguiendo una ley similar a la de Fick para la migración de la humedad durante el secado o a la de Fourier, que controla la transferencia de calor por conducción [Pakowski et al., 2006]

Esta ley establece que la variación de c con el tiempo y con la posición (distancia desde la superficie de la costilla) viene dada por la ecuación diferencial:

Ecuación 4.19

$$
\frac{\partial c}{\partial t}=D \frac{\partial^{2} c}{\partial z^{2}}
$$


donde:

D: coeficiente de difusividad.

z: posición de un punto de la pieza respecto a la superficie de la costilla.

La velocidad a la que se difunde $c$ depende exclusivamente de D. A medida que $\mathrm{D}$ es mayor, también es más rápida la cinética del proceso.

Para resolver la ecuación 4.19 es necesario definir las condiciones iniciales y de contorno. En el caso de piezas no esmaltadas, estas condiciones adoptan la forma:

Ecuación 4.20

$$
\begin{array}{ll}
\forall \mathrm{z} & \mathrm{t}=0 \rightarrow \mathrm{c}=0 \\
\mathrm{z}=0 \mathrm{t}>0 & \rightarrow \mathrm{c}=1 \\
\mathrm{z}=\mathrm{h} & \mathrm{t}>0 \rightarrow \mathrm{c}=1
\end{array}
$$

Para piezas esmaltadas, las ecuaciones se pueden escribir como:

Ecuación 4.21

$$
\begin{array}{ll}
\forall \mathrm{z} & \mathrm{t}=0 \rightarrow \mathrm{c}=0 \\
\mathrm{z}=0 & \mathrm{t}>0 \rightarrow \mathrm{c}=1 \\
\mathrm{z}=\mathrm{h} & \mathrm{t}>0 \rightarrow \mathrm{J}=-\mathrm{D} \frac{\mathrm{dc}}{\mathrm{dz}}=0
\end{array}
$$

donde:

$\mathrm{J}$ : densidad de flujo de c.

La ecuación 4.20 indica básicamente que c se propaga desde las dos superficies hacia el interior, mientras que la ecuación 4.21 implica que $c$ sólo se propaga desde la superficie de la costilla. Además, se supone que el cambio de la expansión en la superficie se produce de manera instantánea.

La ecuación 4.19, con las condiciones de la ecuación 4.20. se puede integrar analíticamente, obteniéndose:

Ecuación 4.22

$$
c=1-\frac{4}{\pi} \sum_{n=1}^{\infty} \frac{1}{(2 n-1)} e^{-4 B_{n}^{2 t^{\prime}}} \operatorname{sen} 2 B_{n} z^{\prime}
$$

Para piezas esmaltadas, de la ecuación 4.19 y la ecuación 4.21 se llega a:

Ecuación 4.23

$$
c=1-\frac{4}{\pi} \sum_{n=1}^{\infty} \frac{1}{(2 n-1)} e^{-B_{n}^{2 t^{\prime}}} \operatorname{sen} B_{n} z^{\prime}
$$

donde:

Ecuación 4.24

$$
\mathrm{t}^{\prime}=\frac{\mathrm{Dt}}{\mathrm{h}^{2}}
$$


Ecuación 4.25

$$
\mathrm{z}^{\prime}=\frac{\mathrm{z}}{\mathrm{h}}
$$

Ecuación 4.26

$$
B_{n}=\frac{(2 n-1) \pi}{2}
$$

Una vez obtenida la evolución de c con el tiempo y con la posición, es necesario relacionarla con la expansión. Para ello se propuso la siguiente relación lineal (es la expresión más sencilla que podría justificar la evolución de la curvatura observada).

\section{Ecuación 4.27}

$$
\varepsilon_{X}(\mathrm{t}, \xi)=c(\mathrm{t}, \xi) \cdot\left(\frac{1-\xi}{2} \varepsilon_{X}^{c o}+\frac{1+\xi}{2} \varepsilon_{X}^{c v}\right)
$$

donde:

$$
\begin{aligned}
\varepsilon_{X}^{c o} \text { : expansión máxima de la superficie de la costilla (la que se } & \\
& \text { alcanzaría después de un tiempo muy largo). } \\
\varepsilon_{X}^{c v} \text { : } & \text { expansión máxima de la cara vista (la que se alcanzaría después } \\
& \text { de un tiempo muy largo). }
\end{aligned}
$$

\section{B. Resultados}

A partir de las ecuaciones anteriores se calculó la evolución de la curvatura en función del tiempo, considerando que al aumentar la temperatura máxima de cocción el coeficiente de difusividad, D, se reducía (menor permeabilidad) y $\varepsilon_{\mathrm{X}}$ era inferior.

Se observa que, para piezas esmaltadas, la tendencia es cualitativamente correcta, y las curvas presentan un mínimo (figura 4.98). Sin embargo, al aplicar este modelo a piezas no esmaltadas, la curvatura es mucho mayor y no existe ningún mínimo (figura 4.99).

La razón de la inexistencia de un mínimo en piezas no esmaltadas se debe a que la difusividad es la misma en la zona de la costilla que en la cara vista, esto hace que los procesos de curvatura hacia la concavidad y hacia la convexidad se desarrollen a la misma velocidad. Por tanto, para poder reproducir la evolución de las curvaturas en piezas no esmaltadas es necesario que el coeficiente de difusividad sea diferente en la zona de la costilla y en la cara vista. 


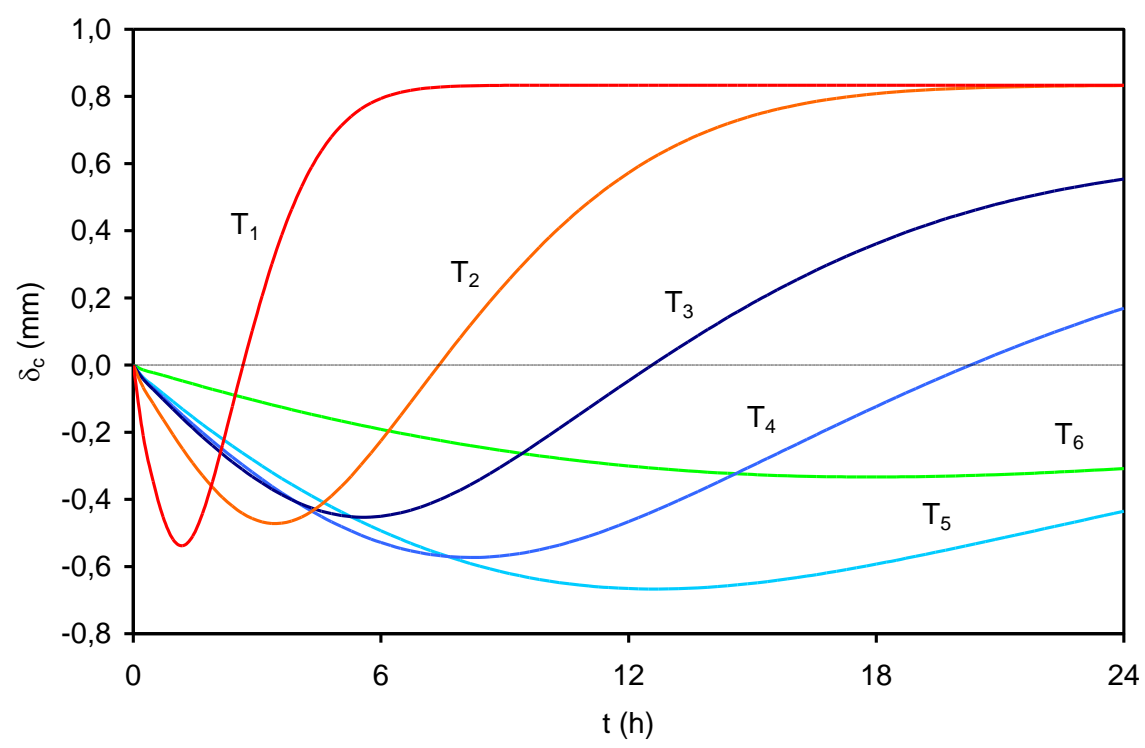

Figura 4.98. Piezas esmaltadas. Evolución cualitativa de la flecha de curvatura en función del tiempo para diferentes valores del coeficiente de difusividad y de la expansión del soporte (correspondientes a distintas temperaturas máximas de cocción: $\left.T_{1}<T_{2}<\ldots<T_{6}\right)$.

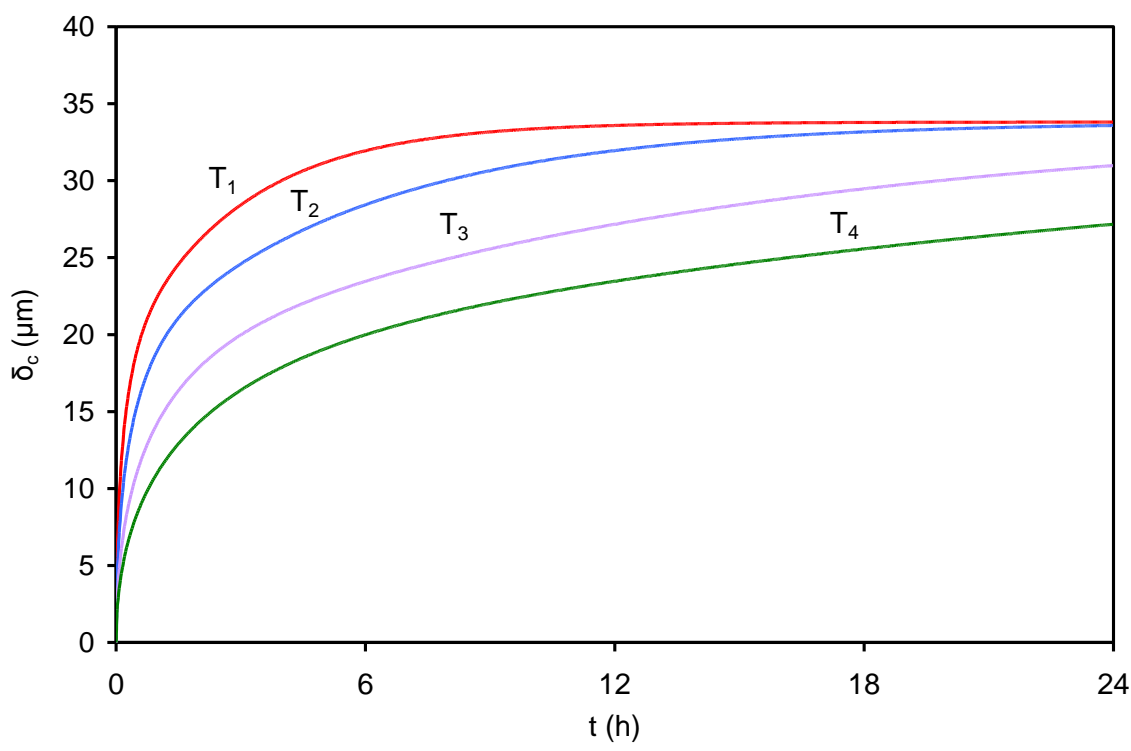

Figura 4.99. Piezas no esmaltadas. Evolución cualitativa de la flecha de curvatura en función del tiempo para diferentes valores del coeficiente de difusividad y de la expansión del soporte (correspondientes a temperaturas máximas de cocción distintas: $\left.T_{1}<T_{2}<T_{3}<T_{4}\right)$. 


\subsubsection{Modelo D: Expansión diferencial con difusividad variable}

\section{A. Fundamento}

El problema fundamental del modelo $C$ es que no permitía que la expansión del soporte se desarrollara a diferente velocidad en la superficie de la costilla y en la cara vista. La forma obvia de resolver este problema consiste en plantear un coeficiente de difusividad que sea función de la posición. El modelo más sencillo es una relación lineal entre la expansión y la posición:

\section{Ecuación 4.28}

$$
D(z)=D^{c o}\left(1-z^{\prime}\right)+D^{c v}\left(1-z^{\prime}\right)
$$

donde:

$\mathrm{D}^{\mathrm{CO}}$ : coeficiente de difusividad en la superficie de la costilla.

$\mathrm{DCV}^{\mathrm{C}}$ : coeficiente de difusividad en la cara vista.

Experimentalmente (apartado 4.3) se constató que la penetración de agua con azul de metileno podía ser diferente a través de la superficie de la costilla y de la cara vista (figura 4.100). Esto apoya la hipótesis de un coeficiente de difusividad variable, que podría deberse a la existencia de un grado de cocción diferente entre la superficie de la costilla y la cara vista.

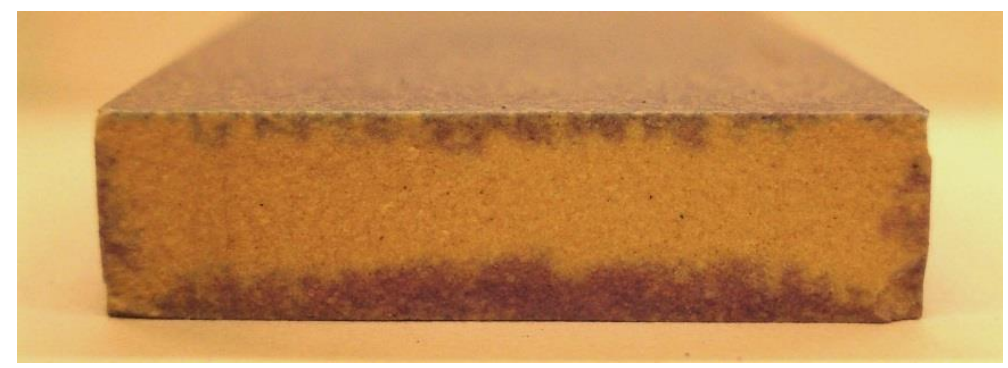

Figura 4.100. Penetración del azul de metileno después de un ensayo de absorción al vacío a tres días para el modelo 7 cocido a 1210 ㄷ.

Se podrían plantear ecuaciones más realistas que la ecuación 4.28; de hecho, cabe esperar que el centro de la pieza tenga un coeficiente de difusividad mayor que las superficies, debido a que la temperatura de cocción en este punto es menor. Sin embargo, emplear ecuaciones más complejas no haría sino incrementar el número de parámetros a determinar.

La ecuación de difusión cuando $D$ es variable adopta la forma:

$$
\text { Ecuación } 4.29 \quad \frac{\partial \mathrm{c}}{\partial \mathrm{t}}=\frac{\partial}{\partial \mathrm{z}}\left(\mathrm{D} \frac{\partial \mathrm{c}}{\partial \mathrm{z}}\right)
$$

que tiene que resolverse con las condiciones de contorno e iniciales definidas en la ecuación 4.20 y la ecuación 4.21. En este caso la resolución es compleja. 
Es necesario recurrir a un método numérico para resolver este problema (en el anexo 4 se muestran los detalles del cálculo). Para ello se ha desarrollado un programa informático usando Scilab.

El modelo requiere de 4 parámetros de ajuste $\left(\varepsilon_{X}^{c o}, \varepsilon_{X}^{c o}, \mathrm{D}^{\mathrm{CO}}, \mathrm{D}^{\mathrm{CV}}\right)$ que, además, son función de la temperatura.

\section{B. Efecto de los parámetros del modelo sobre la curvatura diferida}

Con el objeto de analizar el papel que ejercen los diferentes parámetros del modelo sobre las curvaturas diferidas, en las siguientes figuras se ha representado la variación de la curvatura diferida cuando se modifica alguno de los parámetros, manteniendo constantes todos los demás.

En la figura 4.101 se constata que a medida que aumenta la expansión de la costilla $\left(\varepsilon_{1}{ }^{\mathrm{CO}}<\ldots<\varepsilon \times 5 \mathrm{CO}\right)$, la curvatura se hace más cóncava (negativa). Si las expansiones de la superficie de la costilla y de la cara vista son iguales, la curvatura empieza siendo cóncava, pero finalmente se anula. Se observa también que la magnitud de la expansión tiene una pequeña influencia sobre el instante de tiempo en el que se alcanza el mínimo de curvatura.

Si se incrementa la expansión de la cara vista sucede lo contrario (figura 4.102). A medida que aumenta esta expansión $\left(\varepsilon \times 1 \mathrm{CV} \ldots<\varepsilon \times{ }_{5} \mathrm{CV}\right)$ la curvatura pasa a ser menos cóncava.

En cualquiera de los dos casos, la curvatura máxima es negativa (cóncava); ello es debido a que el coeficiente de difusividad de la superficie de la costilla es más elevado, por tanto, la zona que empieza a expandir en primer lugar es esta última, independientemente de si $\varepsilon x^{\mathrm{CO}}$ es mayor o menor que $\varepsilon x^{\mathrm{CV}}$. La diferencia $\varepsilon x^{C V}-\varepsilon x^{C O}$ influye en la curvatura final de la pieza (para tiempos largos).

En la figura 4.103 se presenta el efecto del coeficiente de difusividad de la superficie de la costilla $\left(\mathrm{D}^{\mathrm{CO}}\right)$. A medida que aumenta este coeficiente $\left(\mathrm{D}_{1} \mathrm{CO}_{<} \ldots<\mathrm{D}_{5} \mathrm{CO}\right)$ aumenta la diferencia de velocidad de expansión entre la superficie de la costilla y la cara vista (hay que recordar que $D^{\mathrm{CO}}>\mathrm{D}^{\mathrm{CV}}$ ) y, por tanto, aumenta la curvatura cóncava máxima. Además, al aumentar $\mathrm{D}^{\mathrm{CO}}$ la cinética es más rápida y se alcanza antes el mínimo.

En la figura 4.104 se muestra el efecto del incremento del coeficiente de difusividad de la cara vista. Al aumentar este coeficiente $\left(\mathrm{D}_{1} \mathrm{CV}_{<} \ldots<\mathrm{D}_{5} \mathrm{CV}\right)$ disminuye la diferencia de velocidad de expansión entre la superficie de la costilla y la cara vista (sucede lo contrario que al aumentar $\mathrm{D}^{\mathrm{CO}}$ ) y disminuye la curvatura cóncava máxima. También se observa que al aumentar $\mathrm{D}^{\mathrm{CV}}$ la cinética es más rápida y se alcanza antes el mínimo. 


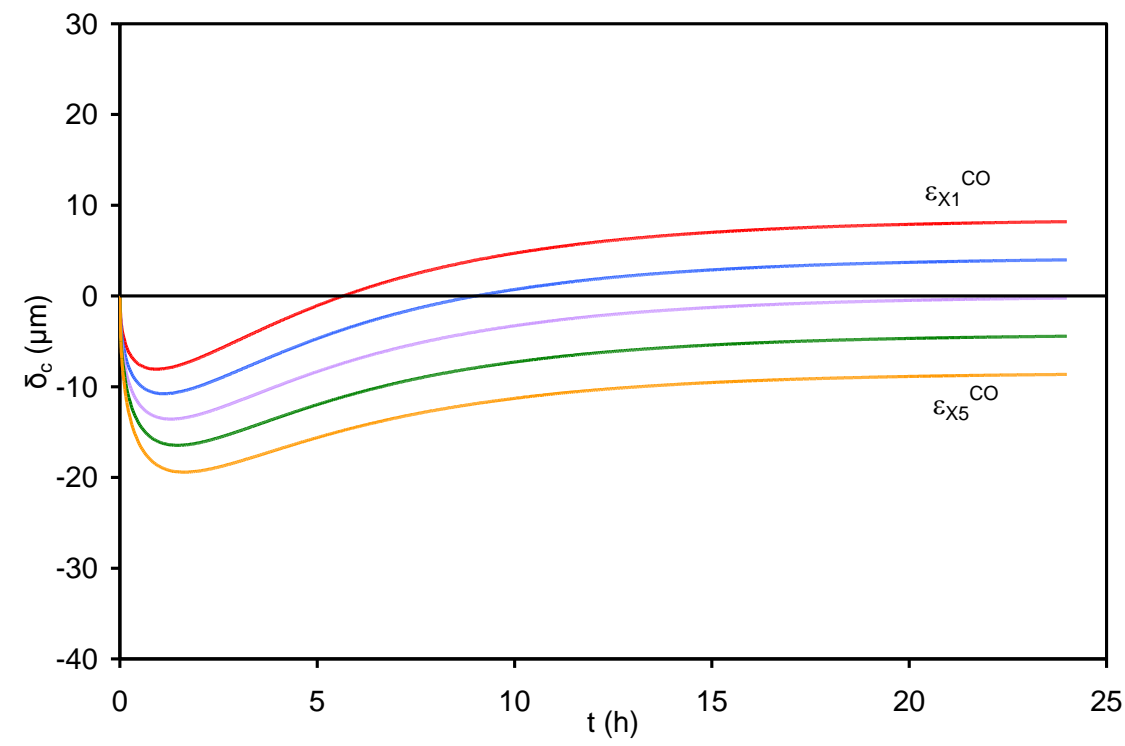

Figura 4.101. Influencia de la expansión de la superficie de la costilla sobre la curvatura diferida $\left(\varepsilon \times 1{ }^{c O}<\ldots<\varepsilon \times 550\right)$.

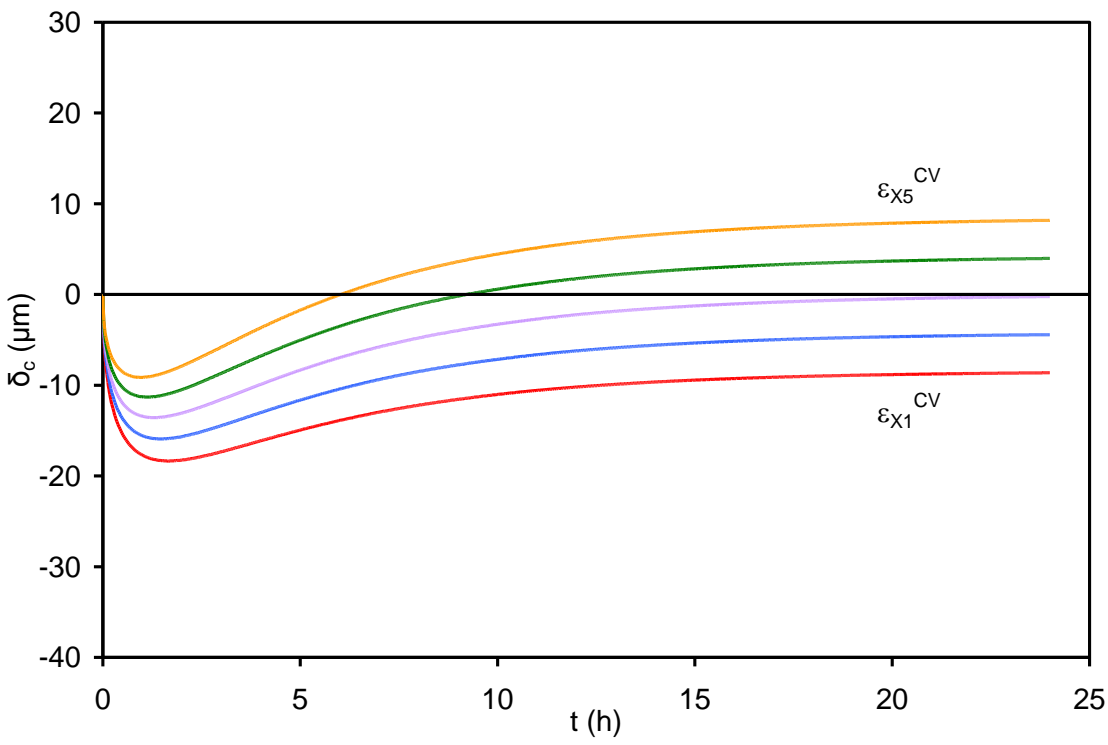

Figura 4.102. Influencia de la expansión de la superficie de la cara vista sobre la curvatura diferida $\left(\varepsilon \times 1{ }^{c V}<\ldots<\varepsilon \times 5^{c V}\right)$. 
4. Resultados y discusión

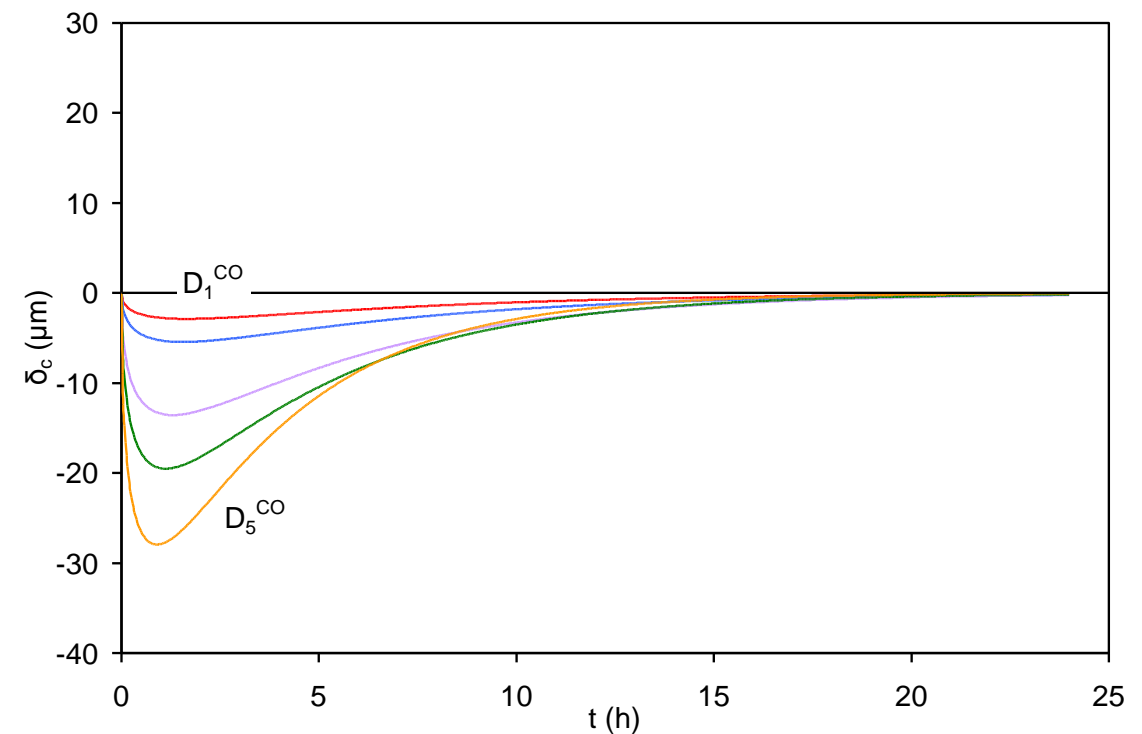

Figura 4.103. Influencia del coeficiente de difusividad de la superficie de la costilla sobre la curvatura diferida $\left(D_{1} C O_{<} \ldots<D_{5} C O\right)$.

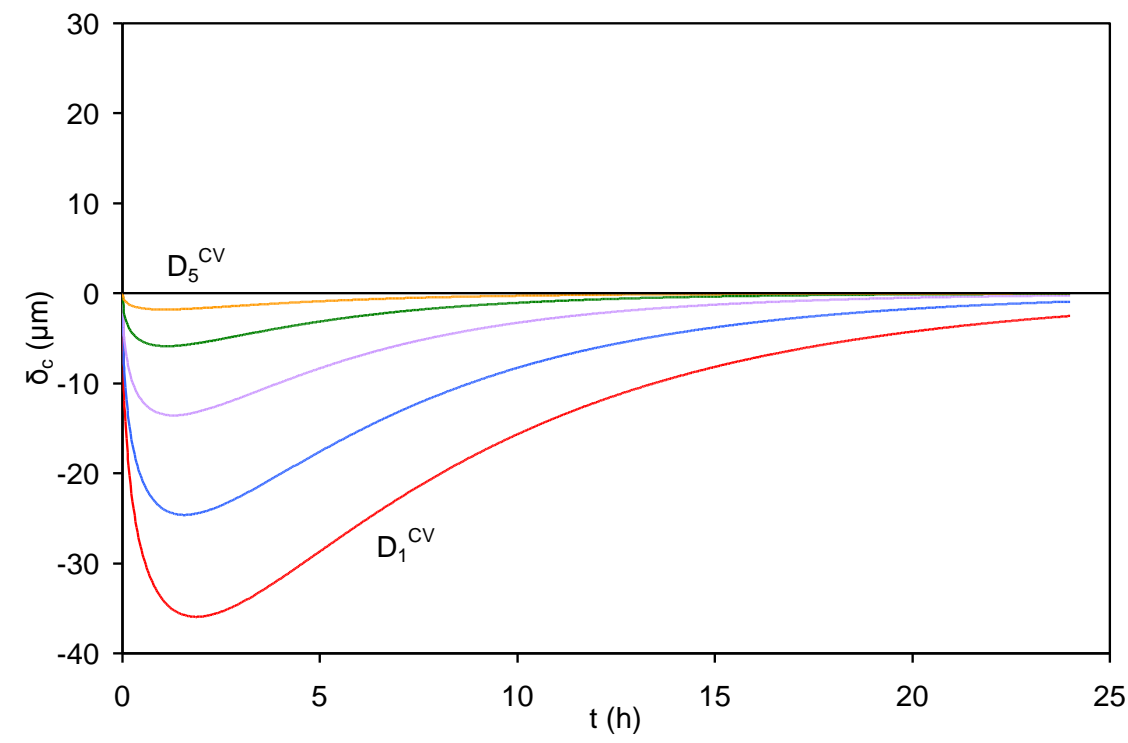

Figura 4.104. Influencia del coeficiente de difusividad de la cara vista sobre la curvatura diferida $\left(D_{1} c v_{1} \ldots<D_{5} c v\right)$. 


\section{Resultados}

En la figura 4.105 se comparan los valores de flecha de curvatura experimental y predicha utilizando el modelo $\mathrm{D}$, en el caso de piezas de gres porcelánico no esmaltadas obtenidas a partir de baldosas industriales crudas del modelo 7 cocidas en laboratorio a diferentes temperaturas máxima de cocción.

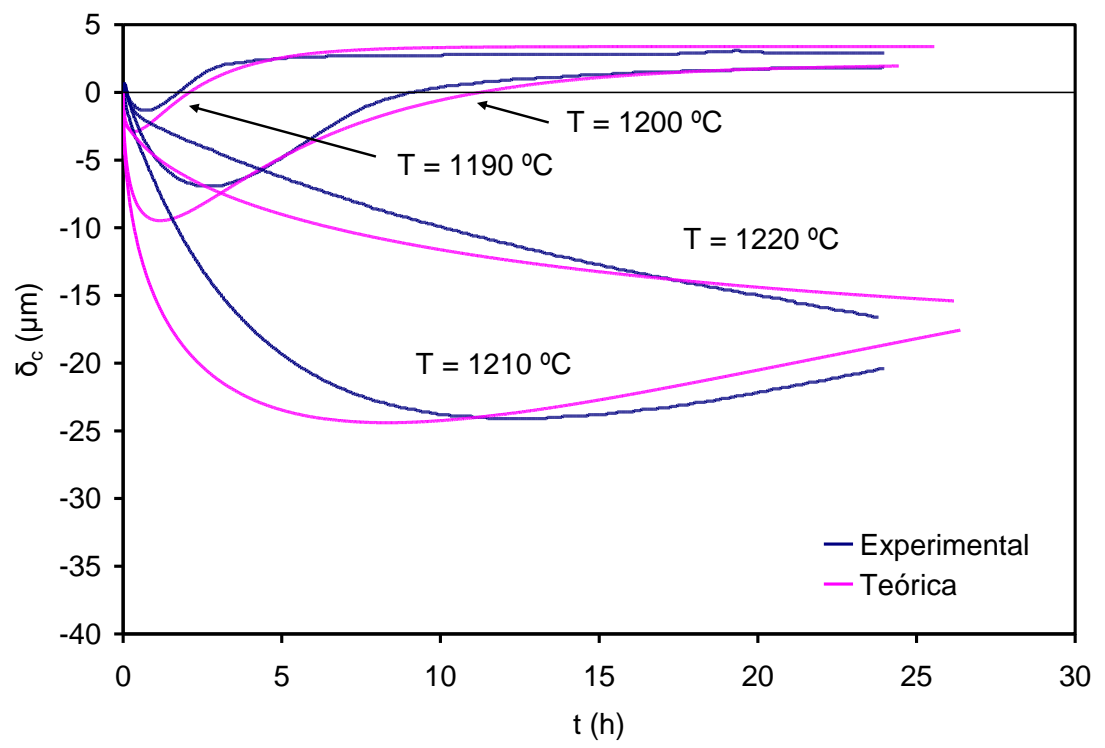

Figura 4.105. Comparación de la curvatura experimental y la predicha por el modelo $D$.

Se observa que el modelo predice los resultados de forma semicuantitativa (permite conocer tendencias y magnitud de la curvatura), pero los resultados no son exactos. Esto es debido a dos factores:

- El modelo es demasiado sencillo, en el sentido de que muchas de las ecuaciones empleadas (ecuación 4.27, ecuación 4.28 y ecuación 4.29) eran las expresiones matemáticas más simples que podían reproducir, en principio, el comportamiento observado.

- Se ha constatado que, en ocasiones, al repetir un ensayo se obtenían curvaturas diferidas significativamente diferentes. Esto indica que, en determinados intervalos de temperatura, las curvaturas diferidas son muy sensibles a las condiciones de ensayo (o a las condiciones de operación si se trata de una pieza procesada industrialmente). Esta podría ser la causa de que, en ocasiones, dos producciones del mismo modelo se comporten industrialmente de forma diferente. Un pequeño cambio en composición, grado de molienda, temperatura máxima de cocción, etc. puede conducir a grandes variaciones en las curvaturas diferidas.

El modelo dispone de 4 parámetros, tal como se ha indicado anteriormente: $\left(\varepsilon x^{C O}, \varepsilon x^{C V}, D^{C O}, D^{C V}\right)$ que, además, son función de la temperatura. En la figura 
4.106 se presenta el valor de la expansión de la superficie de la cara vista y de la costilla en función de la temperatura máxima de cocción utilizados en la figura 4.105.

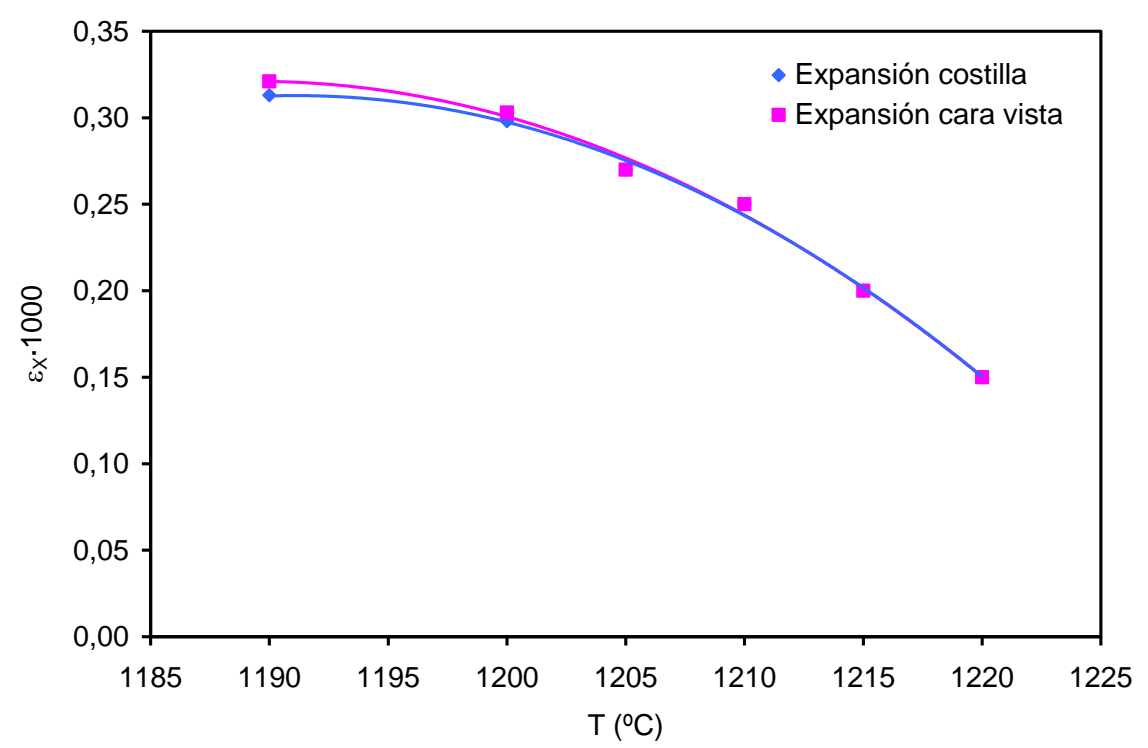

Figura 4.106. Expansión de la superficie de la costilla $\left(\varepsilon x^{c o}\right)$ y de la cara vista $\left(\varepsilon x^{c V}\right)$ en función de la temperatura máxima de cocción.

Se constata que la diferencia de expansión es muy pequeña, y se produce a bajas temperaturas. Esto significa que, por encima de $1200 \stackrel{\circ}{ } \mathrm{C}$, la curvatura diferida final de las piezas debería ser próxima a cero (hecho que han observado algunas de las empresas participantes en piezas industriales). Sin embargo, los datos experimentales de la figura 4.105 no permiten comprobar este resultado ya que a estas temperaturas la curvatura diferida es tan lenta que no se ha llegado a estabilizar después de las 24 horas que dura el ensayo.

También se observa que la expansión va reduciéndose a medida que aumenta la temperatura. Esto es debido, posiblemente, al mayor desarrollo de fases vítreas y al cerramiento de los poros.

En la figura 4.107 se indica la evolución del coeficiente de difusividad de la superficie de la costilla y de la cara vista en función de la temperatura. A medida que aumenta la temperatura, $D$ se reduce. Esto se debe a que al incrementarse la temperatura se reduce la porosidad abierta y, por tanto, la permeabilidad, que está directamente relacionada con $\mathrm{D}$. La reducción de $\mathrm{D}$ con la temperatura máxima de cocción es la causa de que las curvaturas diferidas sean progresivamente más lentas a medida que aumenta $T$.

El valor de $D$ en la superficie de la costilla es ligeramente más elevado (esta superficie es más permeable), lo que hace que la expansión en esta superficie progrese más rápidamente. Finalmente, este comportamiento se traduce en 
que las piezas curvan inicialmente de forma cóncava y, para tiempos largos, reducen su curvatura.

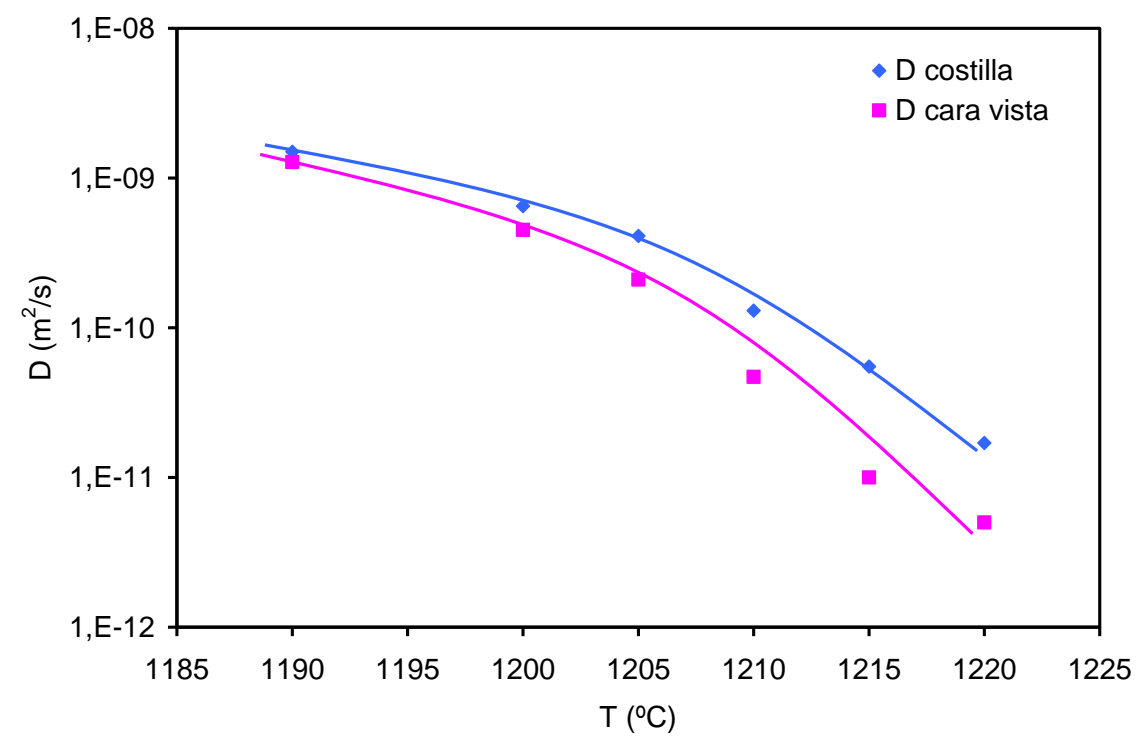

Figura 4.107. Coeficientes de difusividad de la costilla $\left(D^{C O}\right)$ y de la cara vista $\left(D^{c V}\right)$ en función de la temperatura máxima de cocción.

\subsubsection{Validación de las hipótesis del modelo}

El modelo matemático desarrollado está basado en las siguientes hipótesis:

- Existe una diferencia en la expansión final de la cara vista y de la costilla del soporte (expansión diferencial).

- Los coeficientes de difusividad son distintos en ambas caras del soporte, conduciendo a distintas cinéticas de expansión entre la cara vista y la costilla.

Es necesario comprobar experimentalmente la existencia de estas diferencias con el fin de validar los mecanismos propuestos para explicar las curvaturas en diferido.

Para ello se puso a punto un ensayo para medir la expansión diferencial, consistente en apilar y cocer conjuntamente dos probetas de soporte con el espesor reducido a la mitad. Al no poder enfriar las probetas en posición vertical, los ensayos de expansión diferencial se realizaron con las probetas en posición horizontal durante el enfriamiento, es decir con la costilla en contacto con el aislante y la cara vista al aire. A este tipo de enfriamiento se le denomina enfriamiento rápido asimétrico. Después del enfriamiento, se midió por separado la expansión de cada una de las mitades (cara vista y costilla). El procedimiento utilizado esta descrito con más detalle en el apartado 3.4.10. 
Para confirmar que el enfriamiento asimétrico no afecta significativamente a la expansión ni a la curvatura de la pieza, se cocieron probetas enteras con este tipo de enfriamiento a las 3 temperaturas de cocción y se midió la expansión post-cocción y la curvatura en diferido. Los resultados obtenidos (figura 4.108 y figura 4.109) indican que el enfriamiento rápido asimétrico conduce a curvaturas diferidas y expansiones del mismo orden de magnitud que el enfriamiento rápido estándar (figura 4.27 y figura 4.28).

Los ensayos de expansión diferencial se han llevado a cabo con el modelo 7 , realizando cocciones con enfriamiento rápido asimétrico a 3 temperaturas máximas de cocción $\left(1190^{\circ} \mathrm{C}, 1210^{\circ} \mathrm{C}\right.$ y $\left.1230^{\circ} \mathrm{C}\right)$, y con enfriamiento lento a la temperatura máxima de cocción intermedia (1210 ํㅡ). Los resultados obtenidos vienen recogidos de la figura 4.110 a la figura 4.113. Debe recordarse que una expansión diferencial negativa conduce a curvaturas cóncavas, mientras que un valor positivo promueve curvaturas convexas.

Al comparar las medidas de expansión diferencial con la evolución de la curvatura en diferido, se aprecia lo siguiente:

- Independientemente de las condiciones de cocción, existe una buena correlación entre la expansión diferencial y la curvatura en diferido. Las piezas evolucionan hacía curvaturas convexas cuando la expansión diferencial es positiva, y hacía curvaturas cóncavas cuando la expansión diferencial es negativa.

- A la temperatura más baja $(1190 \stackrel{\circ}{\circ})$, la expansión final de la cara vista es mayor que la de la costilla. Esto conduce a una curvatura final de la pieza más convexa que a la salida del horno. Además, se aprecia que las velocidades de expansión de la cara vista y de la costilla son similares, y que la expansión de ambas caras se ha estabilizado a cabo de 24 horas. Esta evolución explica la curvatura diferida medida sobre la probeta entera (figura 4.108).

- A la temperatura intermedia $\left(1210^{\circ} \mathrm{C}\right)$, independientemente del tipo de enfriamiento, la costilla presenta una expansión final mayor que la cara vista. Por lo tanto, la curvatura final de la probeta es más cóncava que la inicial. Asimismo, se aprecian diferencias significativas en la cinética de expansión de ambas caras, especialmente con enfriamiento rápido asimétrico (la cara vista presenta una expansión más lenta que la costilla) Como consecuencia de estas diferencias, las piezas tardan alrededor de 5 horas en alcanzar la curvatura mínima.

- El enfriamiento rápido conduce a mayores diferencias de expansión entre ambas caras que el enfriamiento lento, y por lo tanto a una curvatura final más acusada.

- A la temperatura de cocción más alta $(1230 \stackrel{\circ}{\circ})$ ), las expansiones de la cara vista y de la costilla son bajas y con valores casi idénticos. A esta temperatura, no existen ni expansión diferencial ni curvatura en diferido. 
4. Resultados y discusión

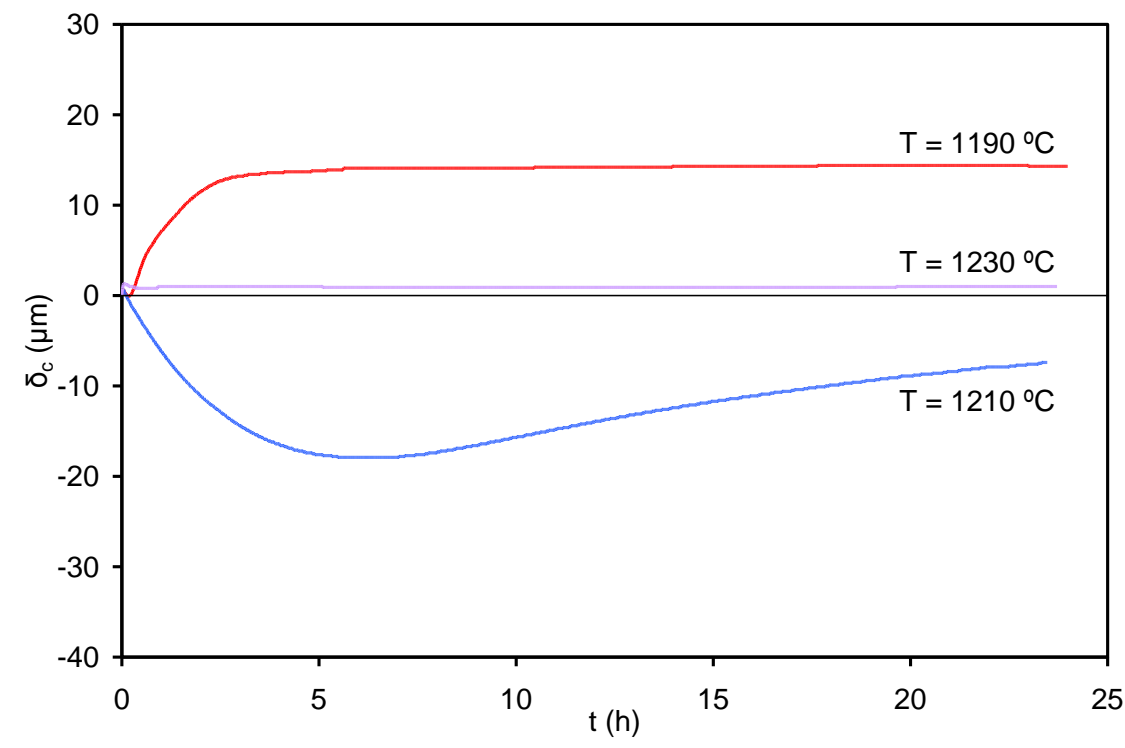

Figura 4.108. Curvatura diferida del modelo 7 con enfriamiento rápido asimétrico.

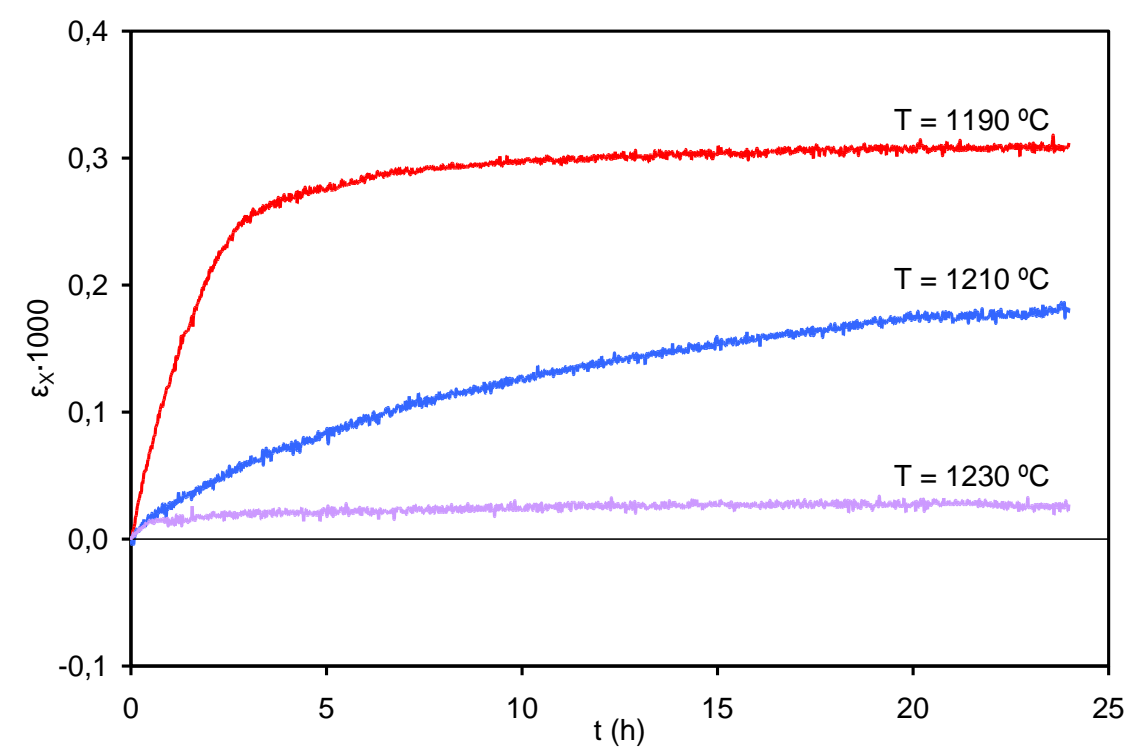

Figura 4.109. Expansión post-cocción del modelo 7 con enfriamiento rápido asimétrico. 


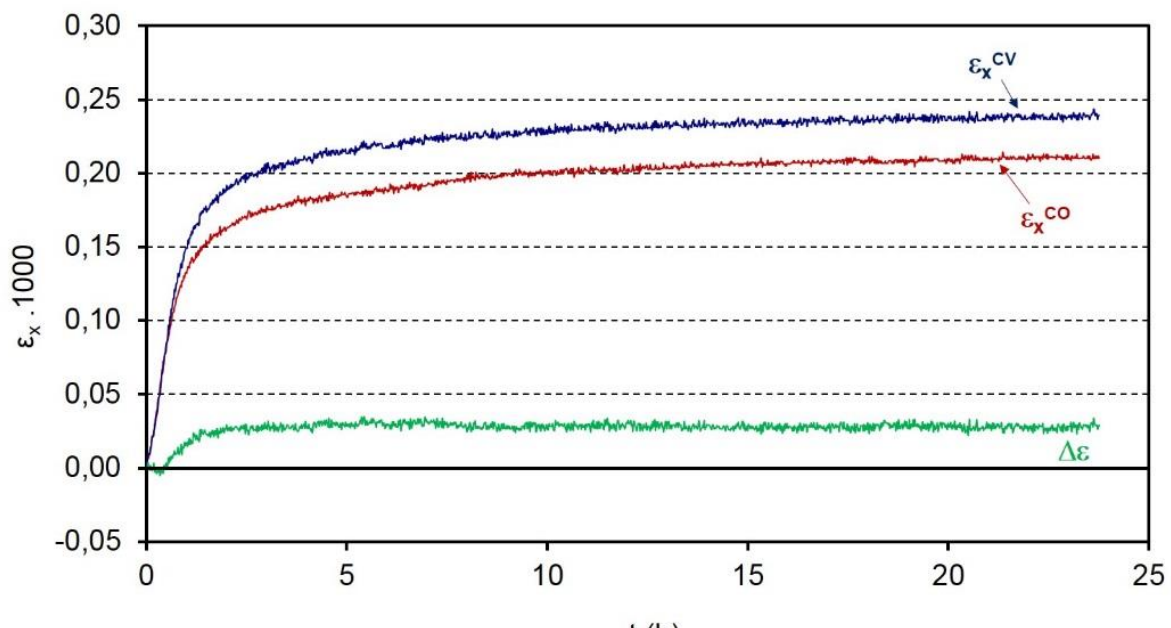

$\mathrm{t}(\mathrm{h})$

Figura 4.110. Expansión diferencial del modelo 7 cocido a $1190{ }^{\circ} \mathrm{C}$ con enfriamiento rápido asimétrico.

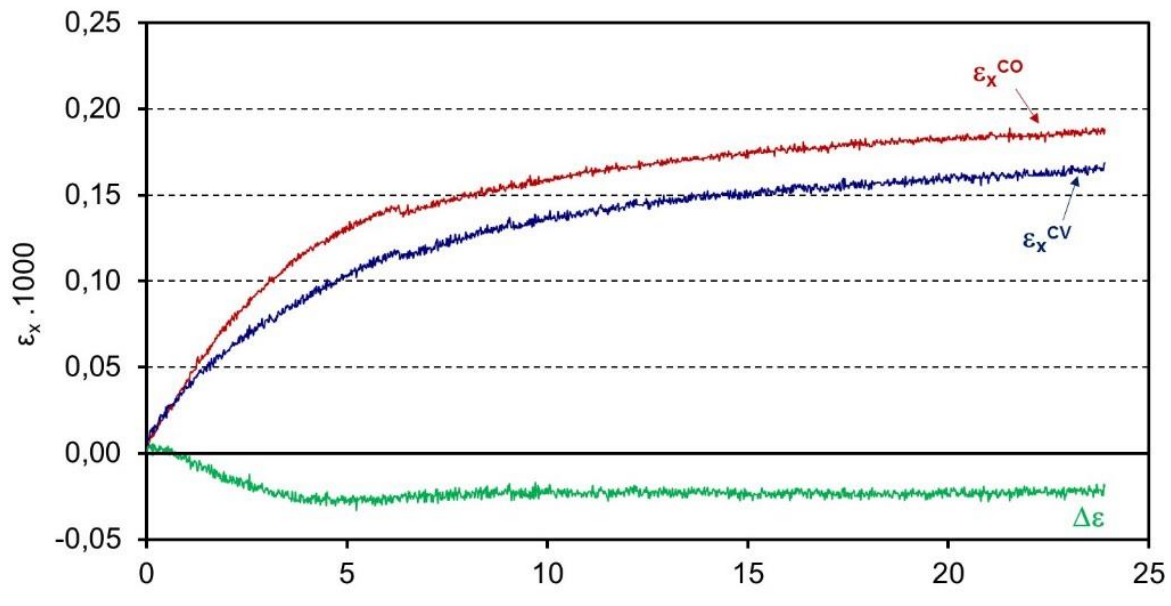

$\mathrm{t}(\mathrm{h})$

Figura 4.111. Expansión diferencial del modelo 7 cocido a 1210 o C con enfriamiento lento. 


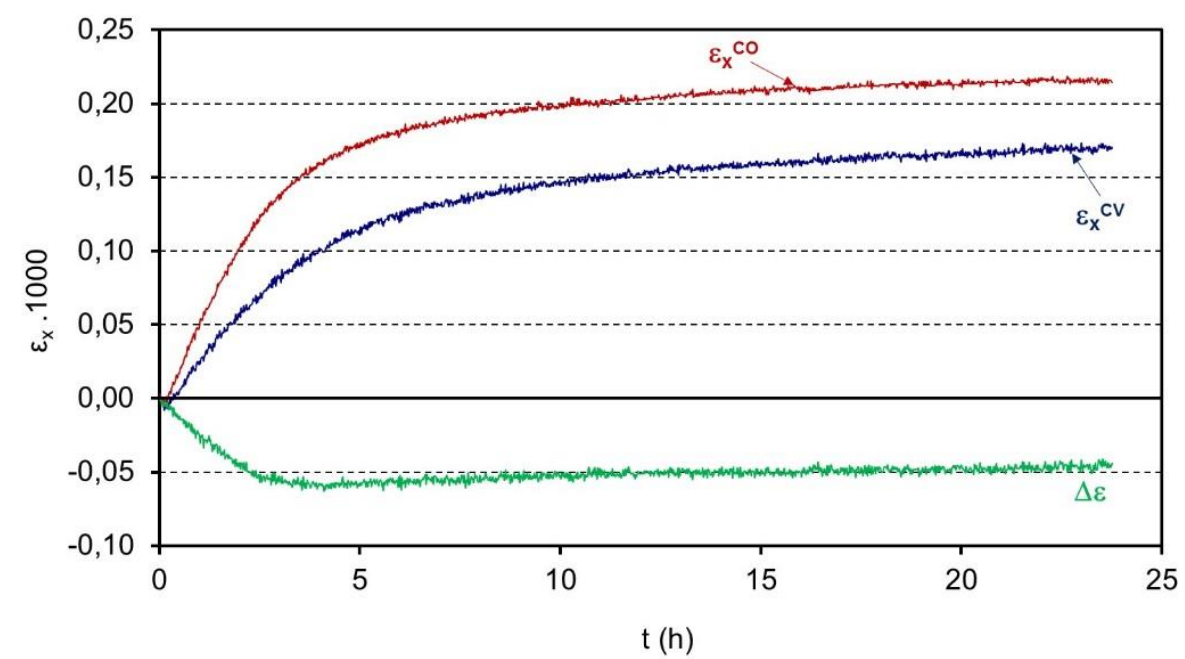

Figura 4.112. Expansión diferencial del modelo 7 cocido a $1210{ }^{\circ} \mathrm{C}$ con enfriamiento rápido asimétrico.

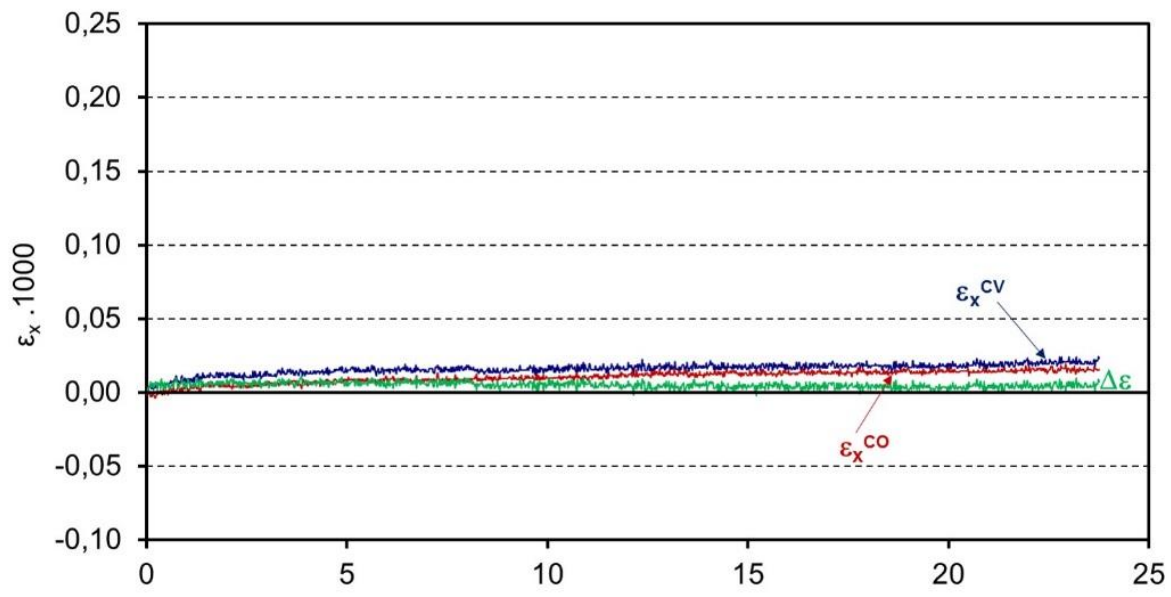

$t(h)$

Figura 4.113. Expansión diferencial del modelo 7 cocido a $1230 \stackrel{\circ}{\text { C con }}$ enfriamiento rápido asimétrico.

Los resultados experimentales confirman que los mecanismos propuestos en el desarrollo del modelo $\mathrm{D}$ explican el fenómeno de las curvaturas en diferido. La diferencia de expansión entre la cara vista y la costilla controla la curvatura final de la pieza, mientras que la diferencia en sus cinéticas de expansión conduce a la existencia de un mínimo en la curvatura diferida. 


\subsubsection{Conclusiones}

Se ha desarrollado una serie de modelos que predicen, con grado creciente de complejidad y aplicabilidad, las curvaturas diferidas. A la vista de los resultados obtenidos cabe concluir que:

- Se ha comprobado que el mecanismo de expansión diferencial de los soportes (diferente en la cara vista y en la superficie de la costilla) explica la evolución de las curvaturas en diferido. Los valores de expansión del soporte requeridos en el modelo son de la misma magnitud que los medidos experimentalmente.

- El mínimo de curvatura que aparece a un tiempo intermedio se debe al diferente coeficiente de difusividad (D) de la superficie de la costilla respecto a la cara vista. Sin embargo, la diferencia de $D$ entre estas dos superficies no tiene ninguna influencia en la curvatura final.

- La curvatura final que tienen las piezas es función de la diferencia de expansión de la cara vista respecto a la superficie de la costilla.

- La incorporación de una capa de esmalte influye en las curvaturas diferidas porque modifica la expansión del soporte próximo a la cara vista. El papel que juega el esmalte desde el punto de vista mecánico (por acoplamiento esmalte/soporte) es despreciable, aunque influye en el valor absoluto de la curvatura que tiene la pieza a la salida del horno.

- Los modelos consiguen explicar toda la tipología de comportamientos, pero a costa de incrementar el número de parámetros. No parece fácil que un fenómeno tan complejo como la curvatura diferida en gres porcelánico pueda explicarse con modelos sencillos. El elevado número de parámetros limita la utilización práctica de los modelos como herramienta predictiva, aunque no invalida su utilidad para explicar los fenómenos que puedan influir sobre las curvaturas diferidas.

En la tabla 4.31 se resumen las ventajas y las limitaciones de cada uno de los modelos desarrollados. 
Tabla 4.31. Ventajas y limitaciones de los diferentes modelos matemáticos propuestos.

\begin{tabular}{|c|c|c|}
\hline & Ventajas & Limitaciones \\
\hline Modelo A & $\begin{array}{l}\text { - Muy sencillo } \\
\text { conceptualmente. } \\
\text { - Aplicable a piezas } \\
\text { esmaltadas y no } \\
\text { esmaltadas. }\end{array}$ & $\begin{array}{l}\text { - Diferentes } \\
\text { combinaciones de } \\
\text { parámetros conducen a } \\
\text { valores de } \delta c \text { similares. } \\
\text { - Sólo permite ajustar } \\
\text { resultados } \\
\text { experimentales (no tiene } \\
\text { carácter predictivo). } \\
\text { - Parámetros con poco } \\
\text { significado físico. }\end{array}$ \\
\hline Modelo B & $\begin{array}{l}\text { - Modelo sencillo: sólo } \\
\text { dispone de un } \\
\text { parámetro de ajuste: } \varepsilon x \text {. } \\
\text { - Permite explicar el } \\
\text { efecto de la expansión } \\
\text { diferencial del soporte. }\end{array}$ & $\begin{array}{l}\text { - La cinética depende la } \\
\text { variable } \xi \text {, no del tiempo. } \\
\text { - Sólo aplicable a piezas } \\
\text { esmaltadas. }\end{array}$ \\
\hline Modelo C & $\begin{array}{l}\text { - Toma en consideración } \\
\text { la variación de } \delta c \\
\text { respecto al tiempo. } \\
\text { - Es un modelo } \\
\text { relativamente sencillo. } \\
\text { Contiene tres } \\
\text { parámetros: } \varepsilon_{X}{ }^{c o}, \varepsilon_{X}{ }^{c v} y \\
\text { D. }\end{array}$ & $\begin{array}{l}\text { - Sólo aplicable a piezas } \\
\text { esmaltadas. }\end{array}$ \\
\hline Modelo D & $\begin{array}{l}\text { - Considera que el } \\
\text { coeficiente de } \\
\text { difusividad D pueda ser } \\
\text { diferente en la superficie } \\
\text { de la costilla y en la cara } \\
\text { vista. } \\
\text { - Explica la curvatura } \\
\text { cóncava de la pieza y su } \\
\text { posterior reducción. }\end{array}$ & $\begin{array}{l}\text { - Es el modelo más } \\
\text { complejo. Contiene } 4 \\
\text { parámetros de ajuste que } \\
\text { son función de la } \\
\text { temperatura. } \\
\text { - La capacidad predictiva } \\
\text { del modelo se ve } \\
\text { reducida por el número } \\
\text { de parámetros y su } \\
\text { dependencia de la } \\
\text { temperatura. }\end{array}$ \\
\hline
\end{tabular}




\subsection{Propuesta de ensayos de control industrial}

Es necesario disponer de algún tipo de ensayo para determinar a nivel industrial si un tipo de pieza va a sufrir curvaturas en diferido. El método más evidente es medir directamente la evolución de la curvatura tras la cocción. Sin embargo, es un método relativamente complicado y bastante lento, por lo que resulta necesario encontrar ensayos alternativos más rápidos que permitan conocer con antelación si una pieza de gres porcelánico va a experimentar curvatura diferida cuando se procesa en determinadas condiciones.

\subsubsection{Posibles ensayos de control industrial}

La investigación realizada puso de manifiesto la relación que existe entre las curvaturas en diferido y otras propiedades del material como la expansión, el grado de cocción y la absorción de agua.

A la vista de estos resultados, se proponen los siguientes ensayos de control:

- Evolución de la expansión post-cocción durante 24 horas. Si no hay expansión, no hay curvatura en diferido.

- Medida de la expansión por humedad en autoclave. Debe ser prácticamente nula.

- Medida de la densidad aparente en cocido. Debe ser superior a un valor umbral.

- Determinación de la absorción de agua. Debe ser inferior a un valor umbral.

El método ideal debería de ser sencillo, rápido y preciso. Sin embargo, resulta difícil encontrar un ensayo que combine estas tres cualidades, como puede apreciarse en la tabla 4.32 .

Tabla 4.32. Características de los posibles ensayos de control.

\begin{tabular}{|l|c|c|c|}
\hline Método & Sencillez & Rapidez & Sensibilidad \\
\hline Curvatura en diferido & 0 & - & + \\
\hline Expansión post-cocción & - & - & + \\
\hline Expansión por humedad (autoclave) & 0 & 0 & + \\
\hline Densidad aparente en cocido & + & + & 0 \\
\hline Absorción de agua - ebullición & + & 0 & 0 \\
\hline Absorción de agua - vacío & + & - & + \\
\hline
\end{tabular}

- baja / 0 media / + alta 
No obstante, dos de los métodos propuestos destacan de los demás:

- A nivel de laboratorio, la medida de la absorción de agua a vacío permite determinar de forma muy sensible si una pieza va a sufrir curvaturas en diferido. Este ensayo es más sencillo que la medida directa de la curvatura o la determinación de la expansión post-cocción.

- En planta, la medida de la densidad aparente en cocido a la salida del horno puede permitir controlar de forma sencilla y rápida el grado de cocción de las baldosas, y por lo tanto determinar si van a sufrir curvaturas en diferido o no.

\subsubsection{Validación de los ensayos de control industrial propuestos}

Con el fin de validar los ensayos de control propuestos, se ensayaron varios modelos industriales de gres porcelánico suministrados por distintas empresas. Se realizaron dos series de ensayos, la primera con probetas cocidas a nivel de laboratorio y la segunda con piezas industriales.

\section{A. Validación a nivel de laboratorio}

A partir de piezas industriales esmaltadas crudas, se cortaron probetas de 150 x $30 \mathrm{~mm}$. Para cada modelo ensayado, estas probetas se cocieron como mínimo a tres temperaturas en intervalos de $20^{\circ} \mathrm{C}$. Las temperaturas se seleccionaron en función de los resultados obtenidos, siempre en torno a 1210 -C. Para cada probeta se determinaron la curvatura en diferido, la densidad aparente en cocido y la absorción de agua a vacío.

A continuación, se presentan los resultados obtenidos para los distintos modelos. En cada caso se muestran dos gráficas. La primera corresponde a la medida de la flecha realizada durante las 24 horas posteriores a la cocción. La segunda muestra la evolución de la absorción de agua a vacío a lo largo de 7 días. Además, se incluye una tabla con los valores de densidad aparente en cocido $(\rho)$ y de absorción de agua a vacío transcurridos 7 días $\left(\mathrm{AA}_{7}\right.$ días $)$ para cada temperatura máxima de cocción.

Todos los modelos ensayados muestran un comportamiento cualitativamente similar, el cual coincide con la evolución observada en las fases anteriores del trabajo tanto a nivel industrial (apartado 4.1) como a escala de laboratorio (apartado 4.3). Este comportamiento se caracteriza porque a baja temperatura la pieza evoluciona rápidamente hacia una curvatura cóncava (flecha negativa) hasta alcanzar un mínimo (máxima concavidad), a partir del cual la pieza evoluciona en sentido contrario más lentamente para adquirir, en la mayoría de los casos, una curvatura convexa (flecha positiva) a las 24 horas.

Los resultados también confirman que para todas las piezas existe una temperatura a la que no se observa curvatura diferida. Esta temperatura es diferente para cada uno de los modelos ensayados. 
a) Modelo 1

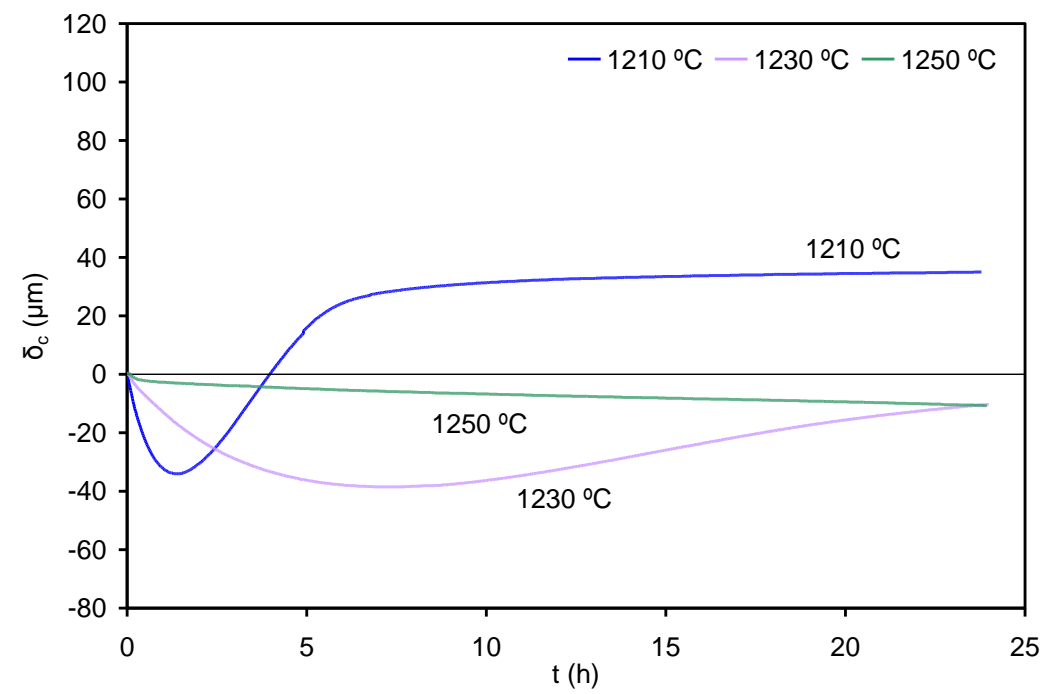

Figura 4.114. Evolución de la curvatura con el tiempo para el modelo 1.

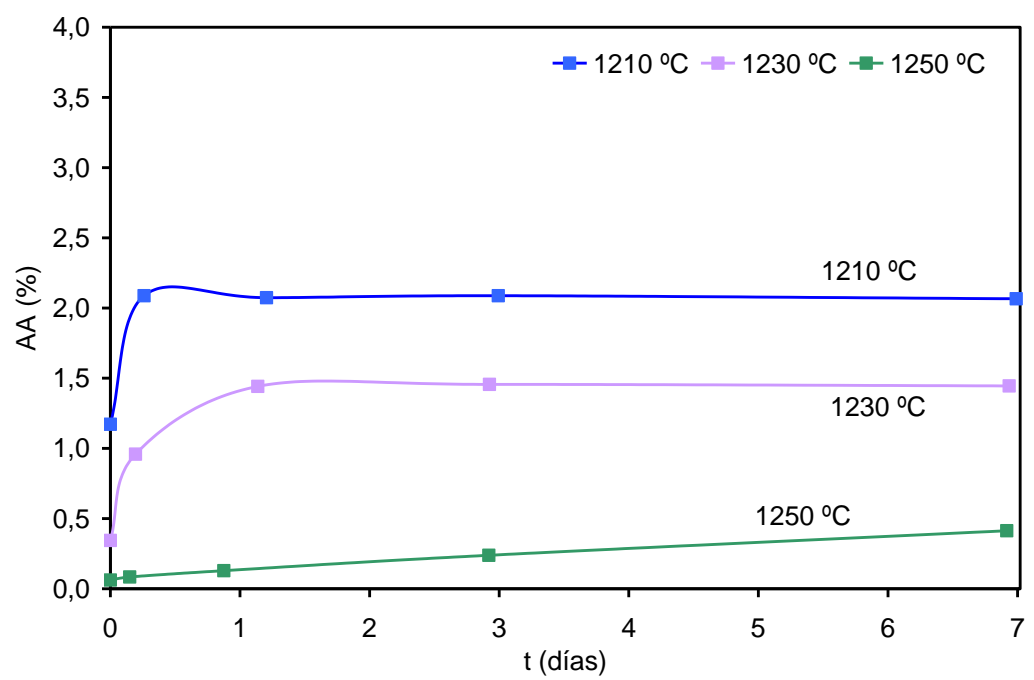

Figura 4.115. Evolución de la absorción de agua a vacío del modelo 1.

Tabla 4.33. Propiedades del modelo 1.

\begin{tabular}{|c|c|c|}
\hline $\mathbf{T}\left({ }^{\circ} \mathbf{C}\right)$ & $\mathbf{\rho ~ ( \mathbf { g } / \mathbf { c m } ^ { 3 } )}$ & $\mathbf{A A} \mathbf{7}$ dias $(\%)$ \\
\hline 1210 & 2,342 & 2,1 \\
\hline 1230 & 2,364 & 1,4 \\
\hline 1250 & 2,360 & 0,4 \\
\hline
\end{tabular}

160 
b) Modelo 2

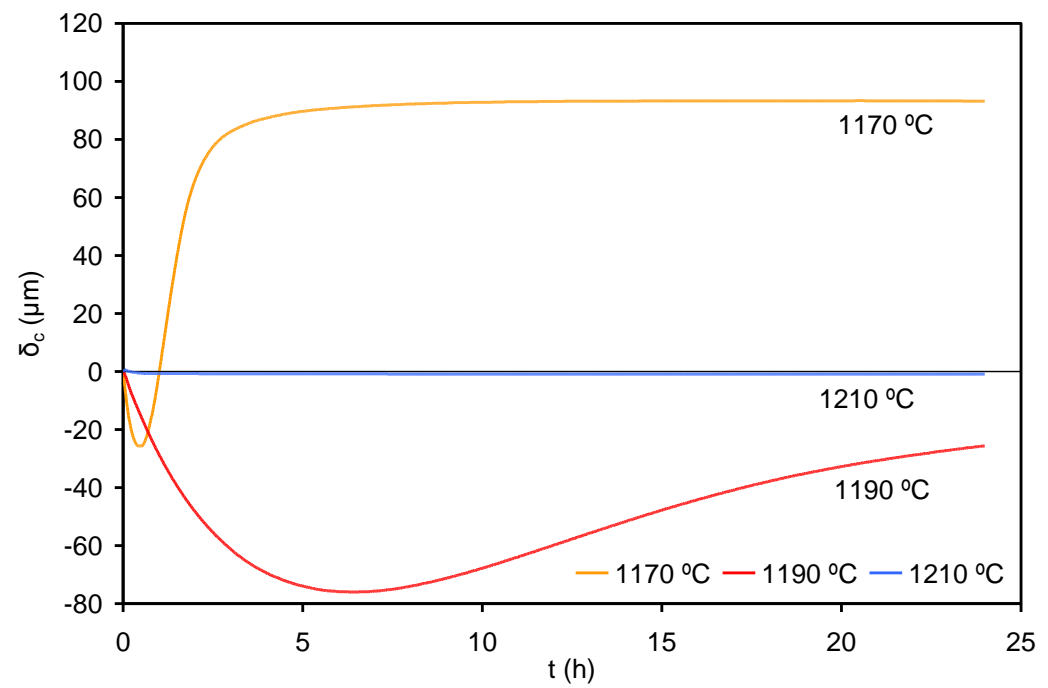

Figura 4.116. Evolución de la curvatura con el tiempo para el modelo 2.

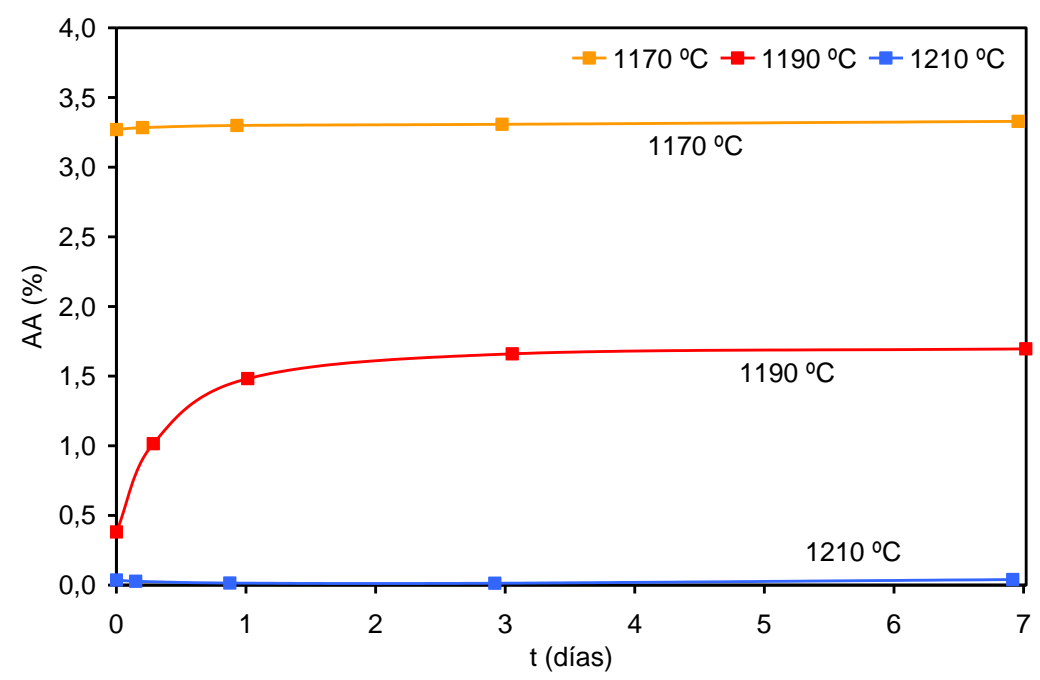

Figura 4.117. Evolución de la absorción de agua a vacío del modelo 2.

Tabla 4.34. Propiedades del modelo 2.

\begin{tabular}{|c|c|c|}
\hline $\mathbf{T}\left({ }^{\circ} \mathbf{C}\right)$ & $\mathbf{\rho ~ ( g / \mathbf { c m } ^ { 3 } )}$ & $\mathbf{A A}_{\mathbf{7}}$ dias $(\%)$ \\
\hline 1170 & 2,332 & 3,3 \\
\hline 1190 & 2,387 & 1,7 \\
\hline 1210 & 2,361 & 0,0 \\
\hline
\end{tabular}


4. Resultados y discusión

c) Modelo 3

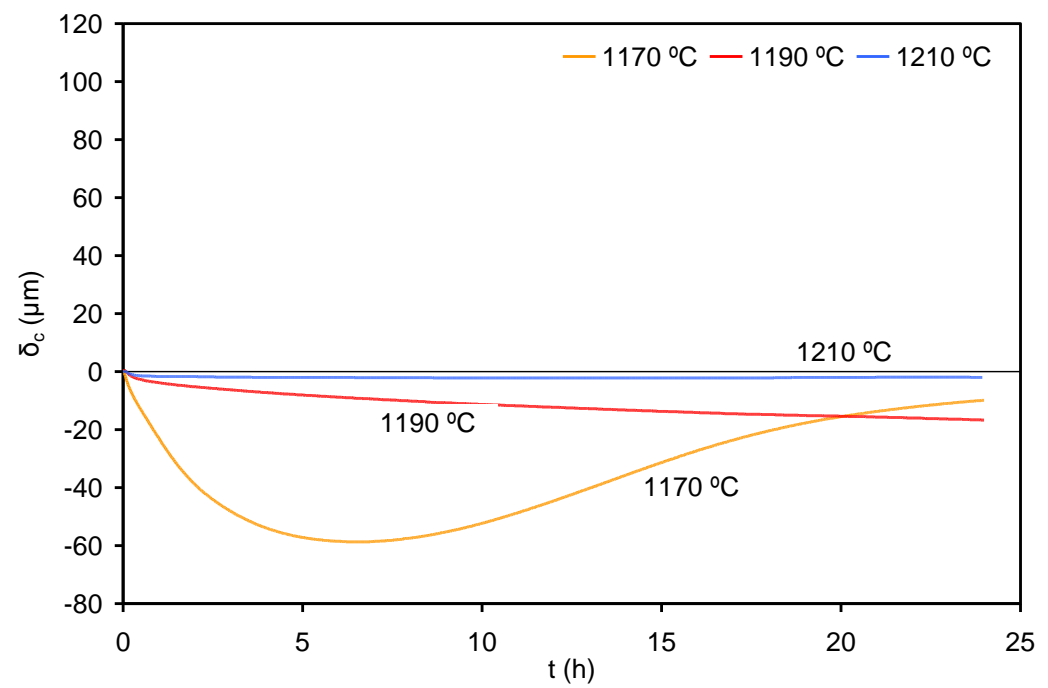

Figura 4.118. Evolución de la curvatura con el tiempo para el modelo 3.

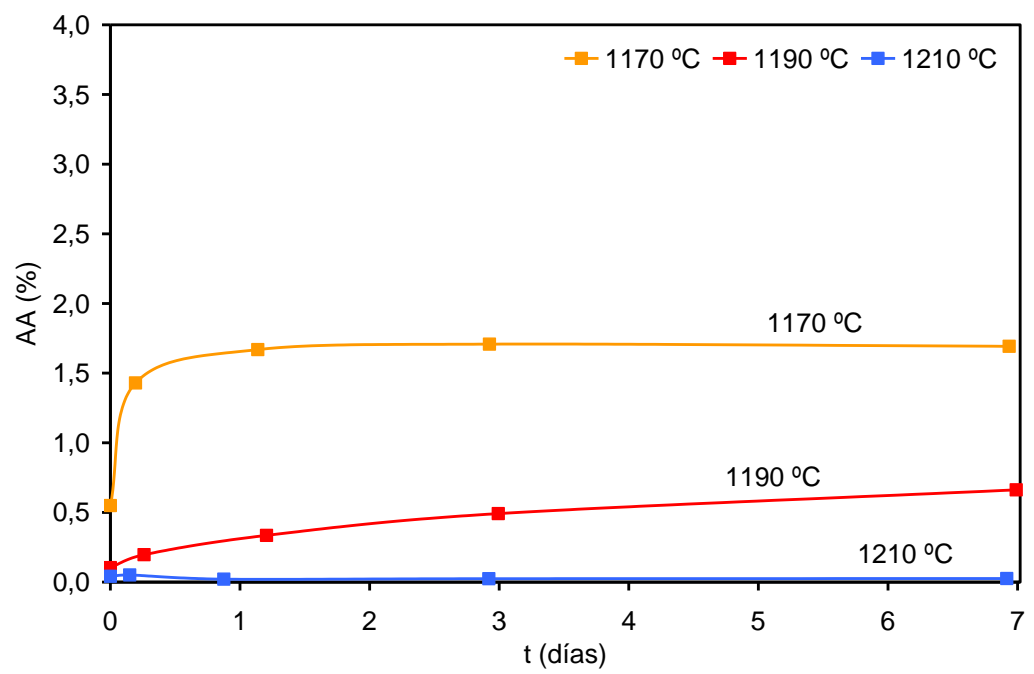

Figura 4.119. Evolución de la absorción de agua a vacío del modelo 3.

Tabla 4.35. Propiedades del modelo 3.

\begin{tabular}{|c|c|c|}
\hline $\mathbf{T}\left({ }^{\circ} \mathbf{C}\right)$ & $\mathbf{\rho ~ ( \mathbf { g } / \mathbf { c m } ^ { 3 } )}$ & $\mathbf{A A} \mathbf{7}$ días $(\%)$ \\
\hline 1170 & 2,380 & 1,7 \\
\hline 1190 & 2,383 & 0,7 \\
\hline 1210 & 2,349 & 0,0 \\
\hline
\end{tabular}


d) Modelo 4

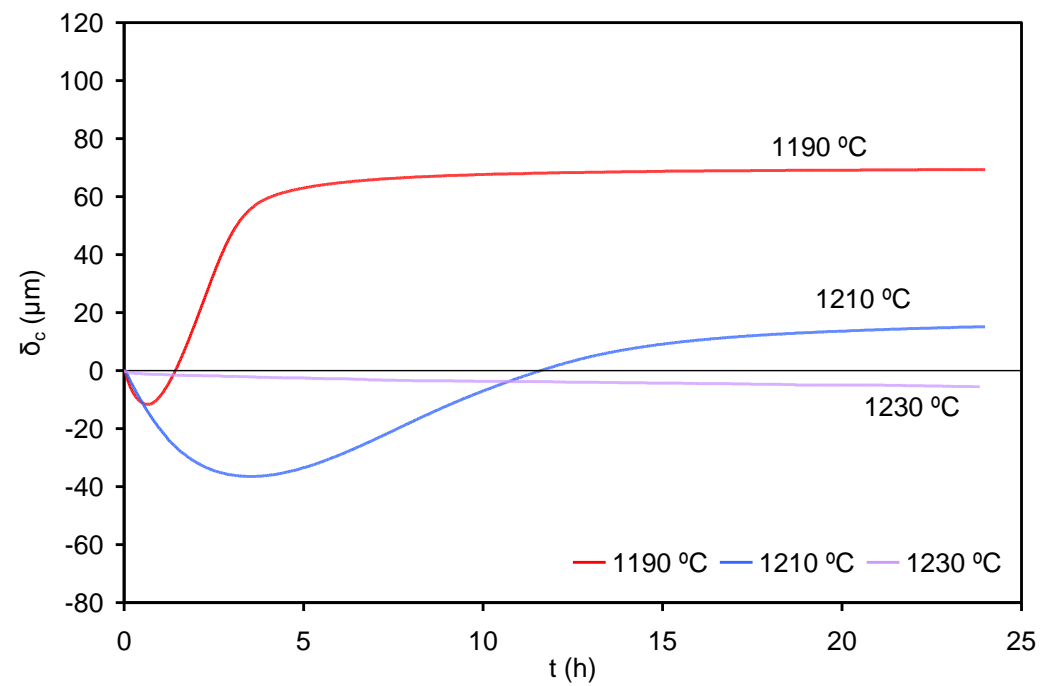

Figura 4.120. Evolución de la curvatura con el tiempo para el modelo 4.

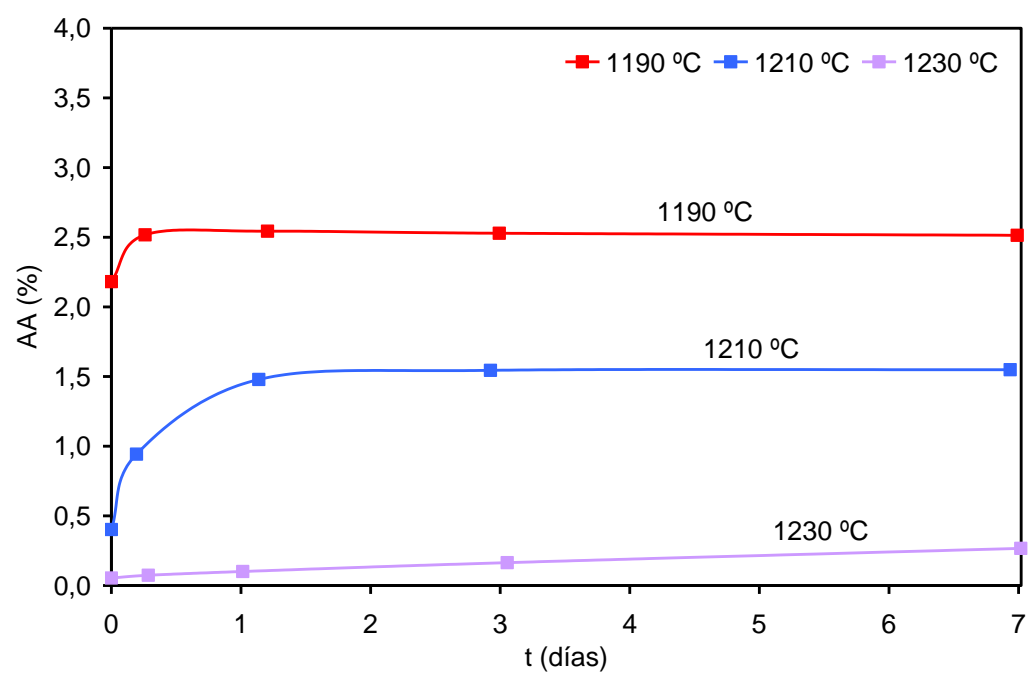

Figura 4.121. Evolución de la absorción de agua a vacío del modelo 4.

Tabla 4.36. Propiedades del modelo 4.

\begin{tabular}{|c|c|c|}
\hline $\mathbf{T}\left({ }^{\circ} \mathbf{C}\right)$ & $\boldsymbol{\rho}\left(\mathbf{g} / \mathbf{c m}^{3}\right)$ & $\mathbf{A A}_{\mathbf{7}}$ dias $(\%)$ \\
\hline 1190 & 2,307 & 2,5 \\
\hline 1210 & 2,334 & 1,5 \\
\hline 1230 & 2,326 & 0,3 \\
\hline
\end{tabular}


4. Resultados y discusión

e) Modelo 5

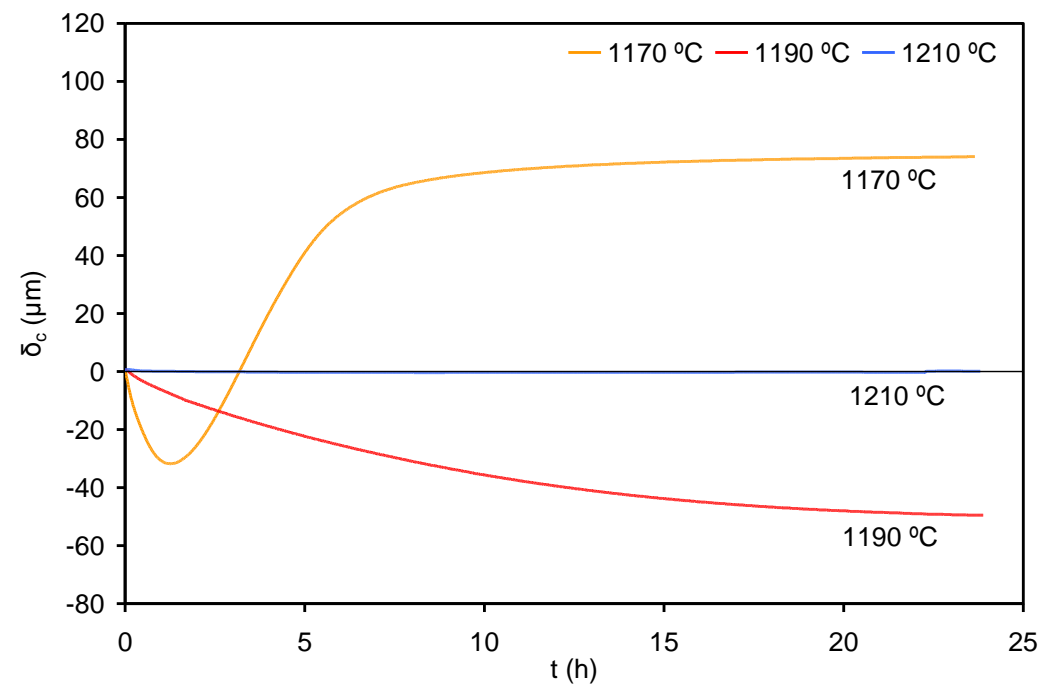

Figura 4.122. Evolución de la curvatura con el tiempo para el modelo 5.

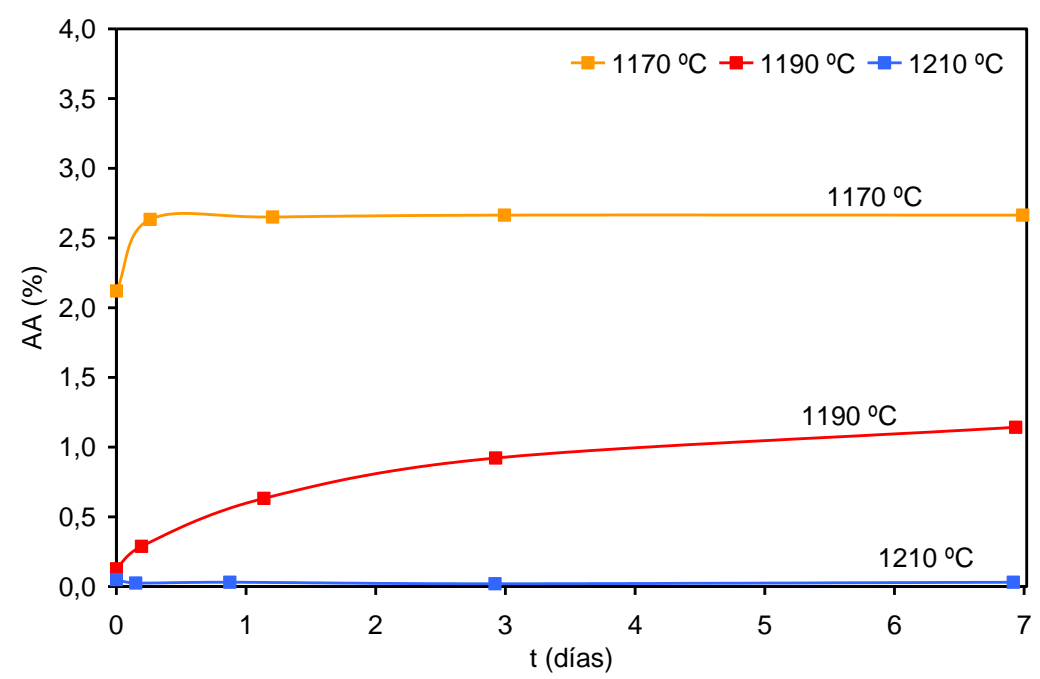

Figura 4.123. Evolución de la absorción de agua a vacío del modelo 5.

Tabla 4.37. Propiedades del modelo 5.

\begin{tabular}{|c|c|c|}
\hline $\mathbf{T}\left({ }^{\circ} \mathbf{C}\right)$ & $\mathbf{\rho ~ ( g / \mathbf { c m } ^ { 3 } )}$ & $\mathbf{A A} \mathbf{7}$ días $(\%)$ \\
\hline 1170 & 2,340 & 2,7 \\
\hline 1190 & 2,380 & 1,1 \\
\hline 1210 & 2,341 & 0,0 \\
\hline
\end{tabular}


f) Modelo 6

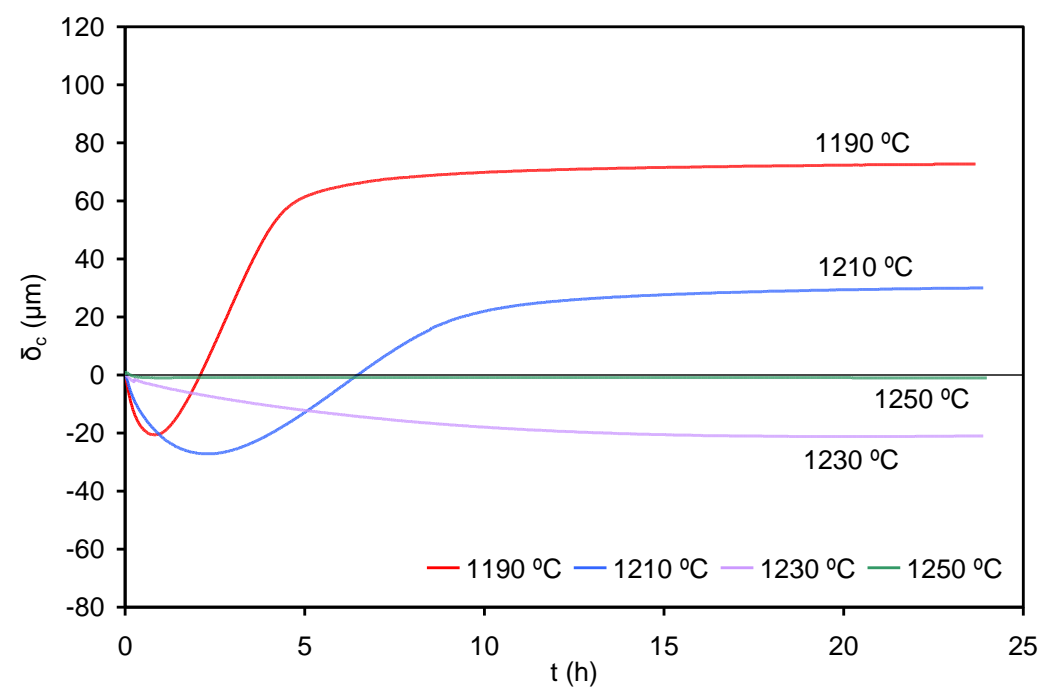

Figura 4.124. Evolución de la curvatura con el tiempo para el modelo 6.

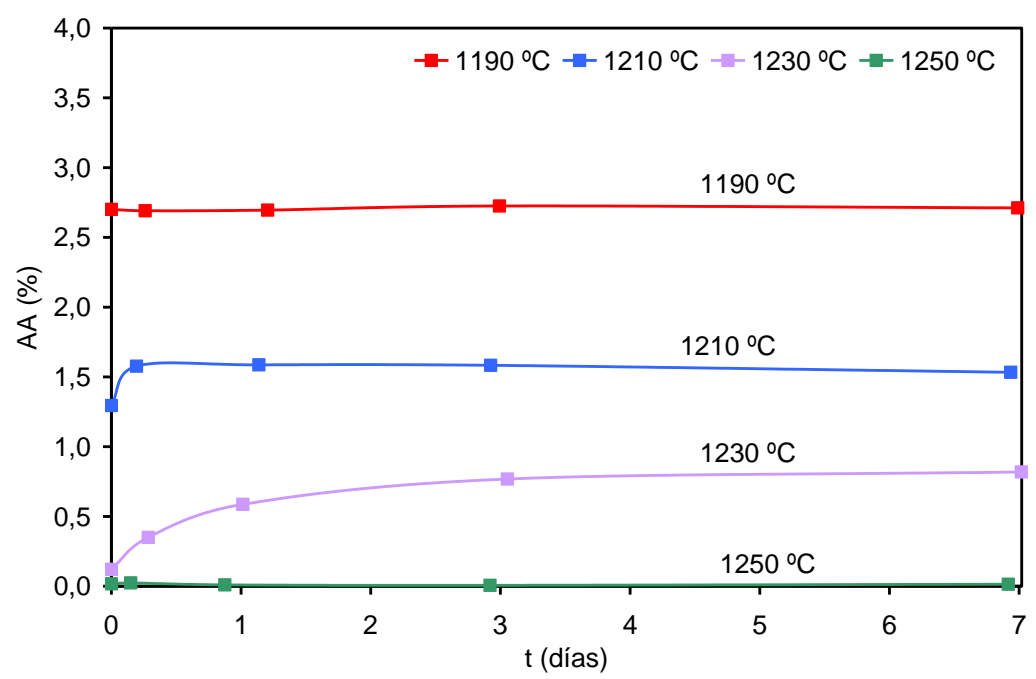

Figura 4.125. Evolución de la absorción de agua a vacío del modelo 6.

Tabla 4.38. Propiedades del modelo 6.

\begin{tabular}{|c|c|c|}
\hline $\mathrm{T}\left({ }^{\circ} \mathrm{C}\right)$ & $\rho\left(\mathrm{g} / \mathrm{cm}^{3}\right)$ & $\mathrm{AA}_{7}$ días $(\%)$ \\
\hline 1190 & 2,364 & 2,7 \\
\hline 1210 & 2,394 & 1,5 \\
\hline 1230 & 2,410 & 0,8 \\
\hline 1250 & 2,381 & 0,0 \\
\hline
\end{tabular}


4. Resultados y discusión

g) Modelo 7

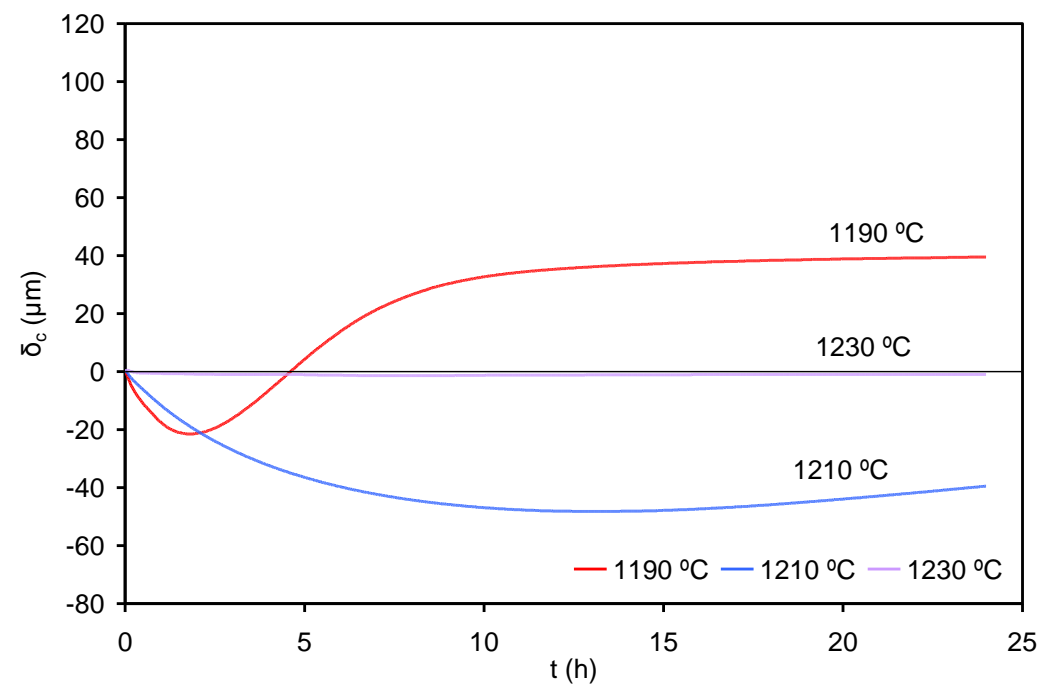

Figura 4.126. Evolución de la curvatura con el tiempo para el modelo 7.

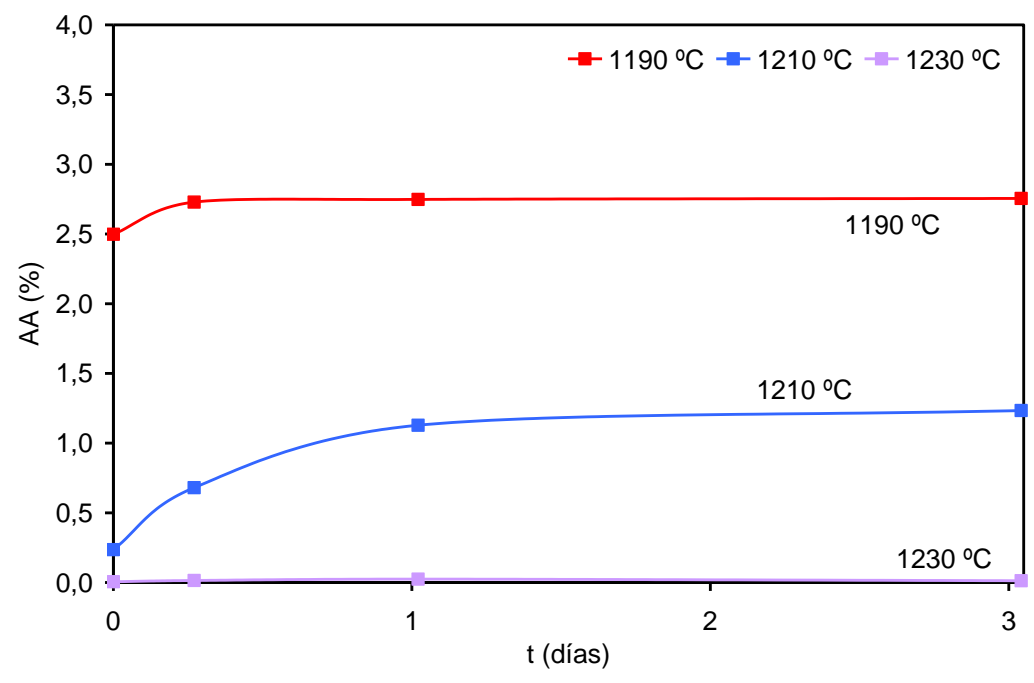

Figura 4.127. Evolución de la absorción de agua a vacío del modelo 7.

Tabla 4.39. Propiedades del modelo 7.

\begin{tabular}{|c|c|c|}
\hline $\mathbf{T}\left({ }^{\circ} \mathbf{C}\right)$ & $\mathbf{\rho ~ ( g / \mathbf { c m } ^ { 3 } )}$ & $\mathbf{A A}_{\mathbf{3}}$ dias $(\%)$ \\
\hline 1190 & 2,362 & 2,8 \\
\hline 1210 & 2,404 & 1,2 \\
\hline 1230 & 2,424 & 0,0 \\
\hline
\end{tabular}


h) $\underline{\text { Modelo } 8}$

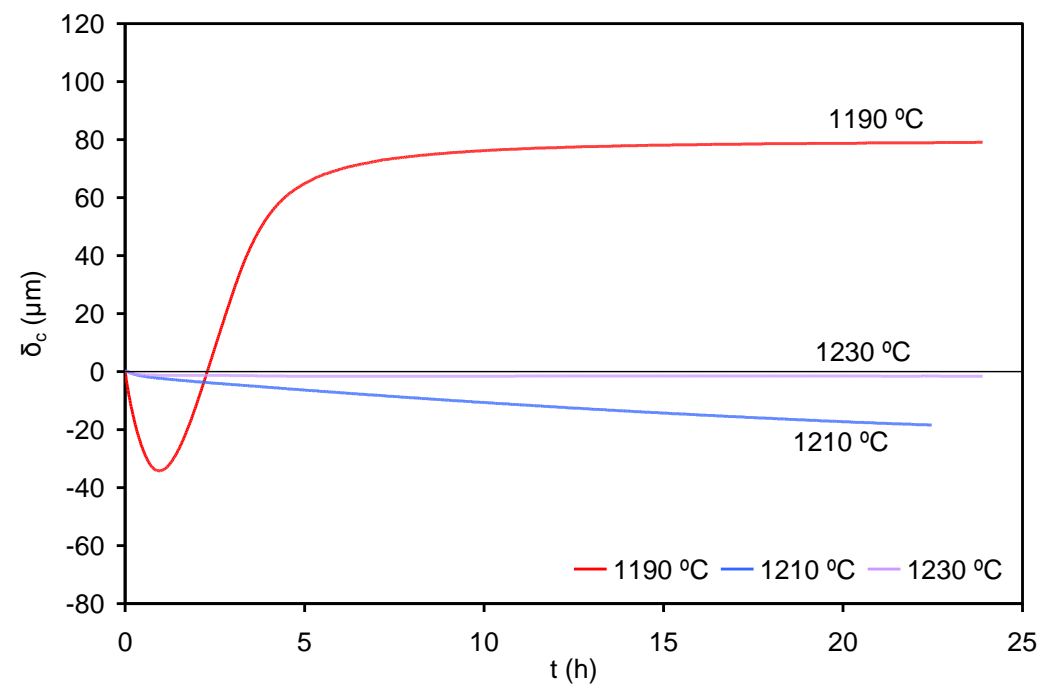

Figura 4.128. Evolución de la curvatura con el tiempo para el modelo 8.

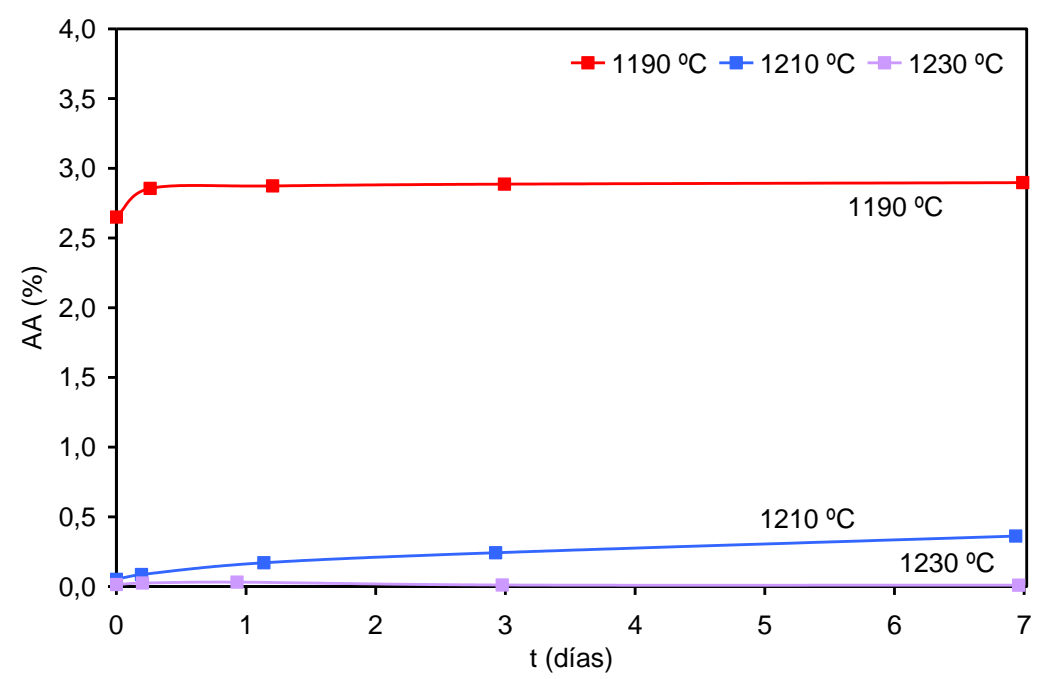

Figura 4.129. Evolución de la absorción de agua a vacío del modelo 8.

Tabla 4.40. Propiedades del modelo 8.

\begin{tabular}{|c|c|c|}
\hline $\mathbf{T}\left({ }^{\circ} \mathbf{C}\right)$ & $\mathbf{\rho ~ ( \mathbf { g } / \mathbf { c m } ^ { 3 } )}$ & $\mathbf{A A}_{\mathbf{7}}$ dias $(\%)$ \\
\hline 1190 & 2,314 & 2,9 \\
\hline 1210 & 2,347 & 0,4 \\
\hline 1230 & 2,263 & 0,0 \\
\hline
\end{tabular}


4. Resultados y discusión

i) Modelo 9

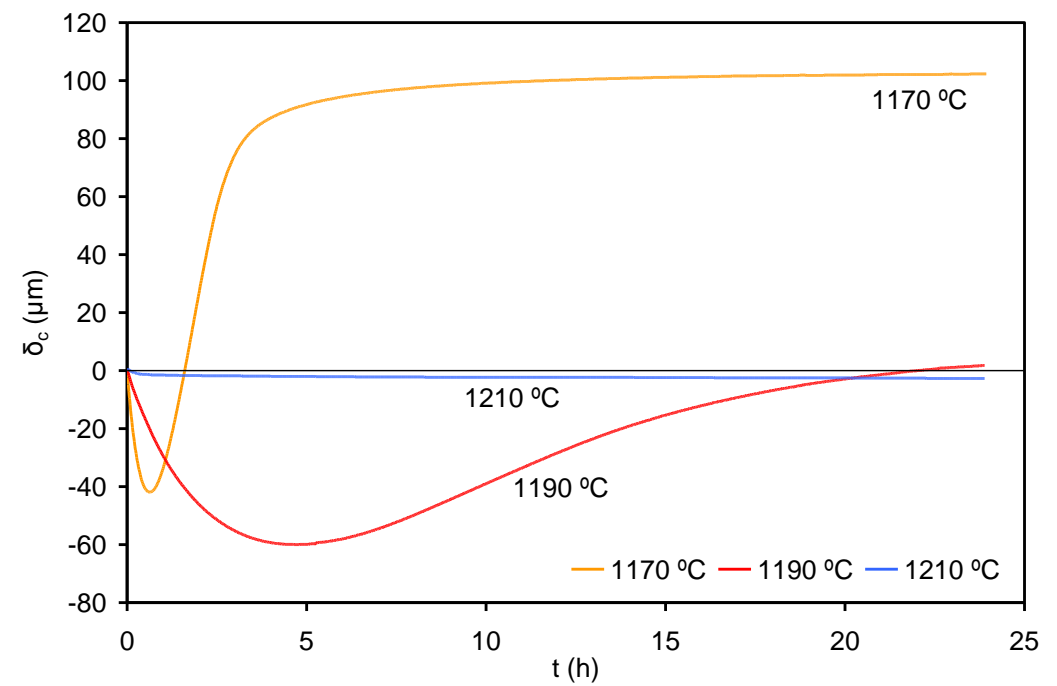

Figura 4.130. Evolución de la curvatura con el tiempo para el modelo 9.

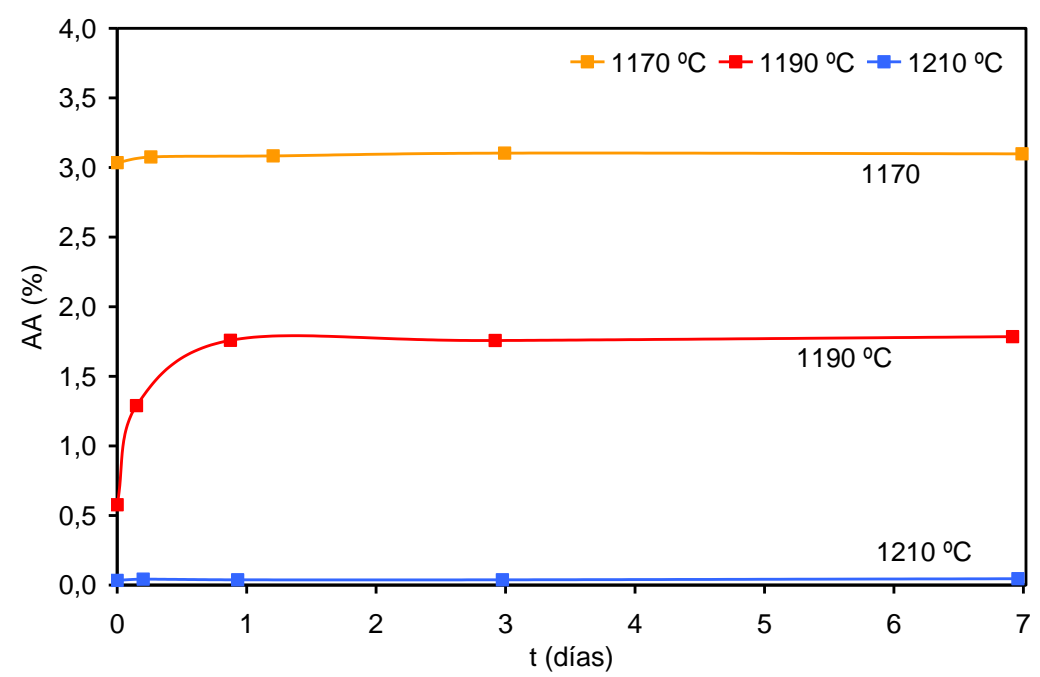

Figura 4.131. Evolución de la absorción de agua a vacío del modelo 9.

Tabla 4.41. Propiedades del modelo 9.

\begin{tabular}{|c|c|c|}
\hline $\mathbf{T}\left({ }^{\circ} \mathbf{C}\right)$ & $\mathbf{\rho ~ ( g / \mathbf { c m } ^ { 3 } )}$ & $\mathbf{A A} \mathbf{7}$ días $(\%)$ \\
\hline 1170 & 2,315 & 3,1 \\
\hline 1190 & 2,378 & 1,8 \\
\hline 1210 & 2,360 & 0,3 \\
\hline
\end{tabular}


j) Modelo 10

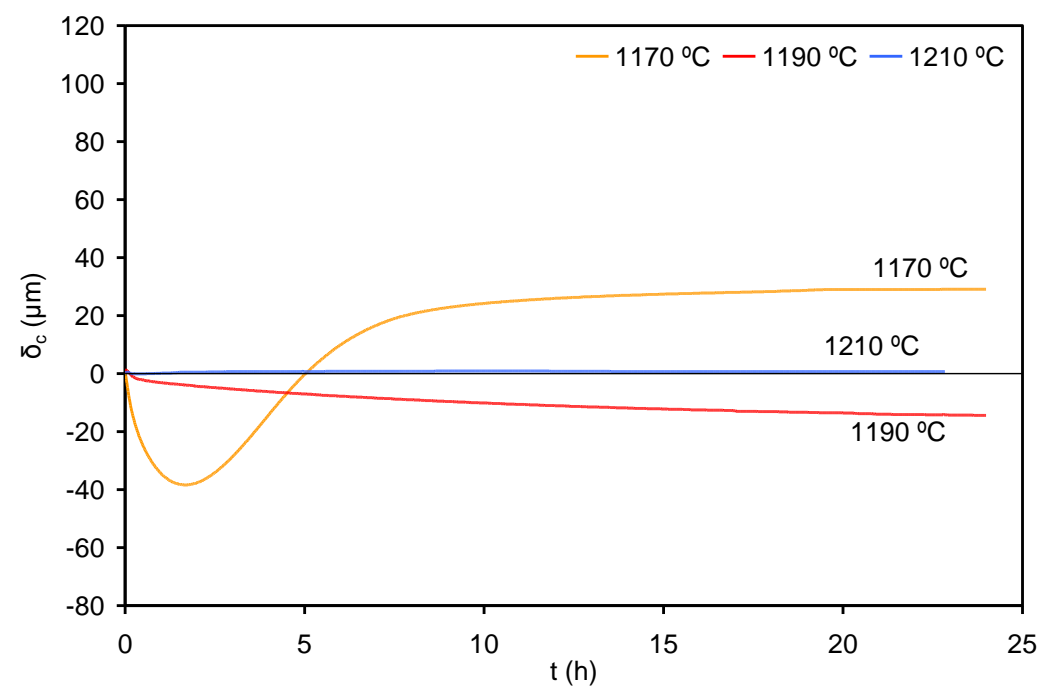

Figura 4.132. Evolución de la curvatura con el tiempo para el modelo 10.

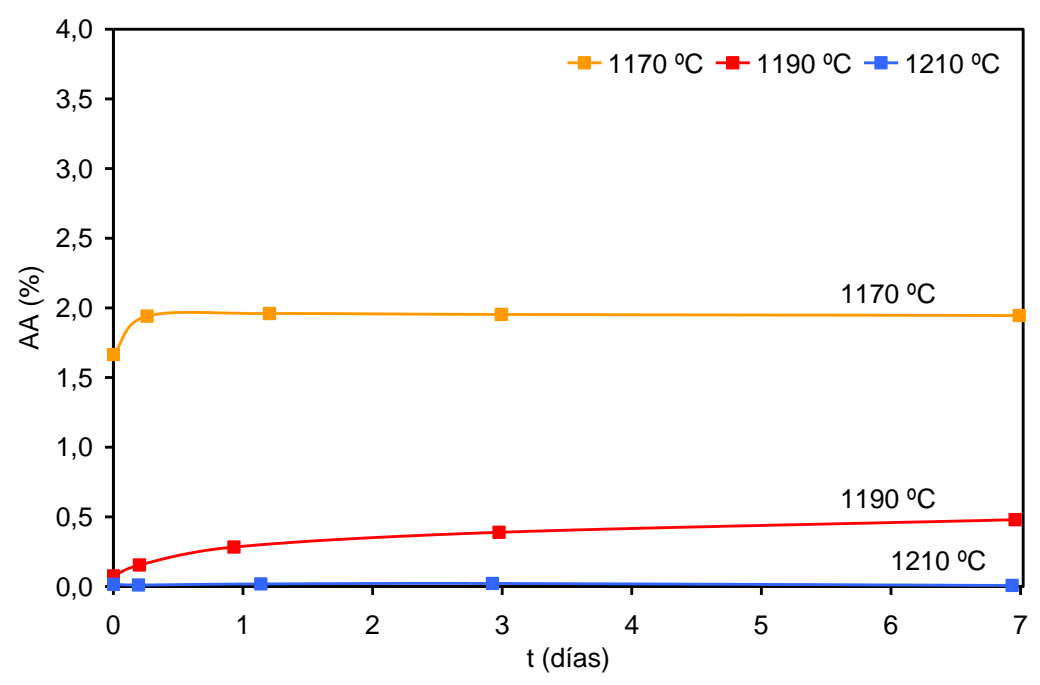

Figura 4.133. Evolución de la absorción de agua a vacío del modelo 10.

Tabla 4.42. Propiedades del modelo 10.

\begin{tabular}{|c|c|c|}
\hline $\mathbf{T}\left({ }^{\circ} \mathbf{C}\right)$ & $\boldsymbol{\rho}\left(\mathbf{g} / \mathbf{c m}^{3}\right)$ & $\mathbf{A A}_{\mathbf{7}}$ dias $(\%)$ \\
\hline 1170 & 2,368 & 1,9 \\
\hline 1190 & 2,386 & 0,5 \\
\hline 1210 & 2,361 & 0,0 \\
\hline
\end{tabular}


4. Resultados y discusión

k) Modelo 11

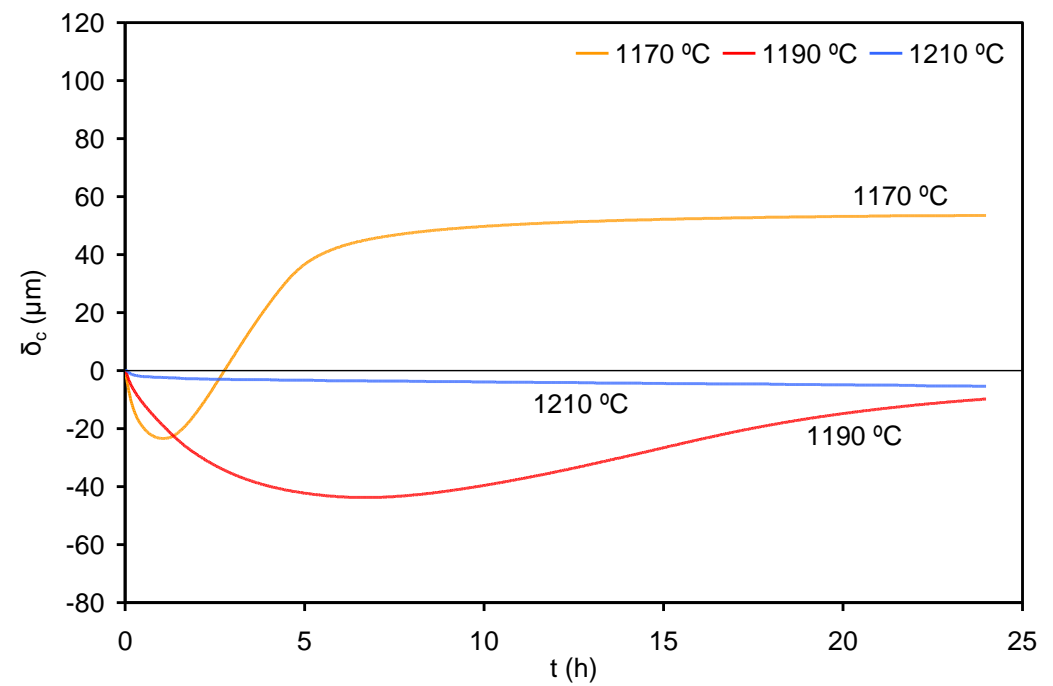

Figura 4.134. Evolución de la curvatura con el tiempo para el modelo 11.

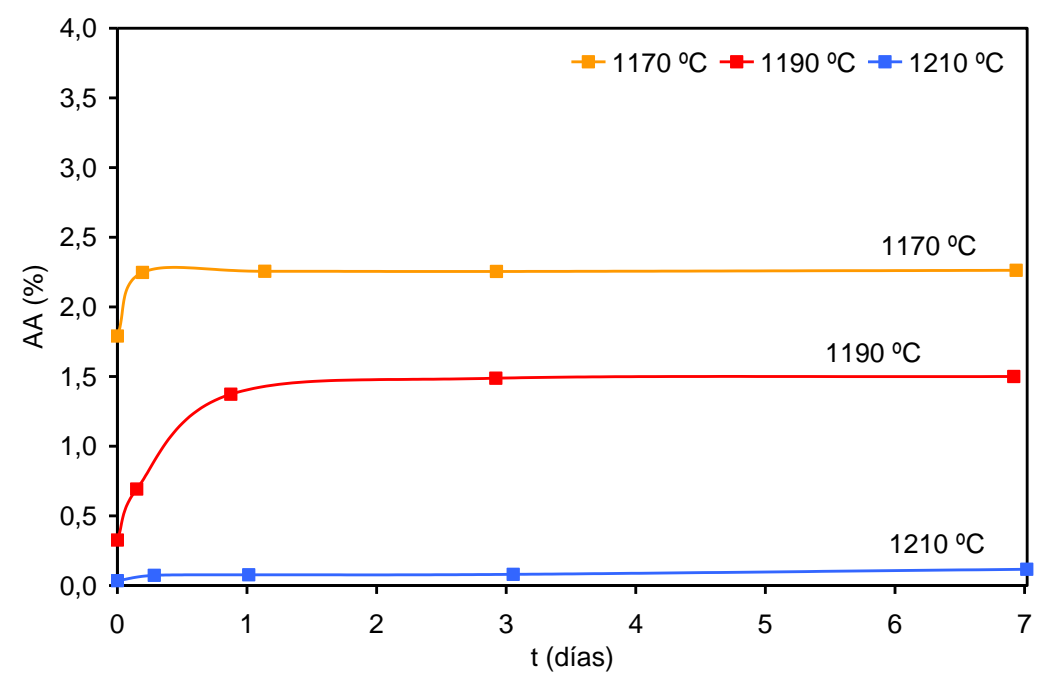

Figura 4.135. Evolución de la absorción de agua a vacío del modelo 11.

Tabla 4.43. Propiedades del modelo 11.

\begin{tabular}{|c|c|c|}
\hline $\mathbf{T}\left({ }^{\circ} \mathbf{C}\right)$ & $\mathbf{\rho ~ ( g / \mathbf { c m } ^ { 3 } )}$ & $\mathbf{A A}_{\mathbf{7}}$ dias $(\%)$ \\
\hline 1170 & 2,364 & 2,3 \\
\hline 1190 & 2,397 & 1,5 \\
\hline 1210 & 2,357 & 0,1 \\
\hline
\end{tabular}

170 
I) Modelo 12

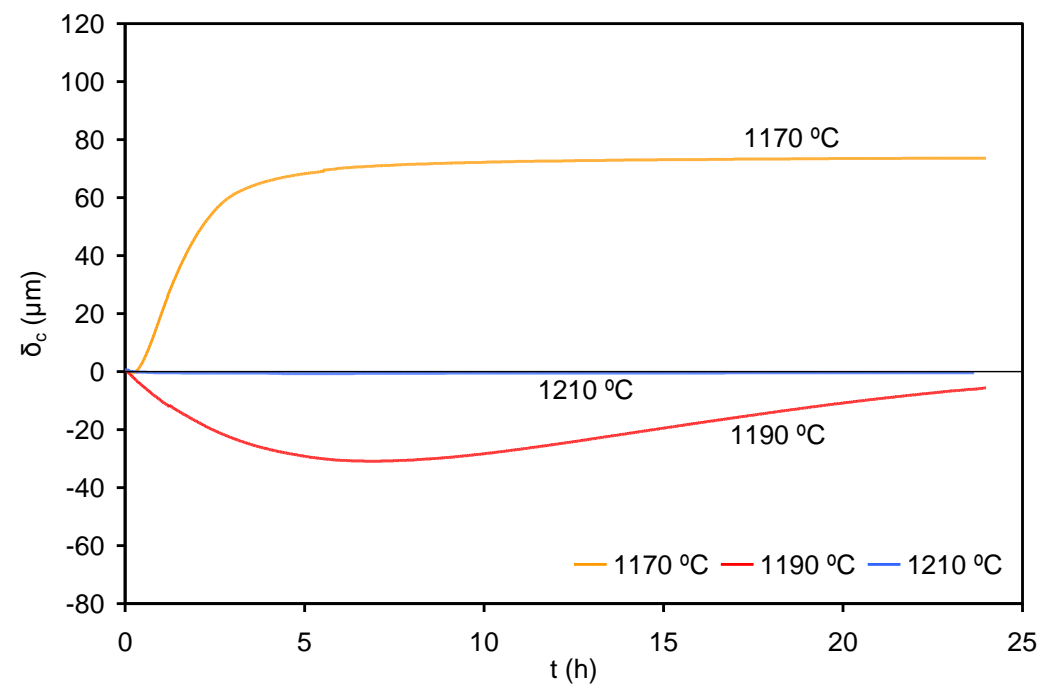

Figura 4.136. Evolución de la curvatura con el tiempo para el modelo 12.

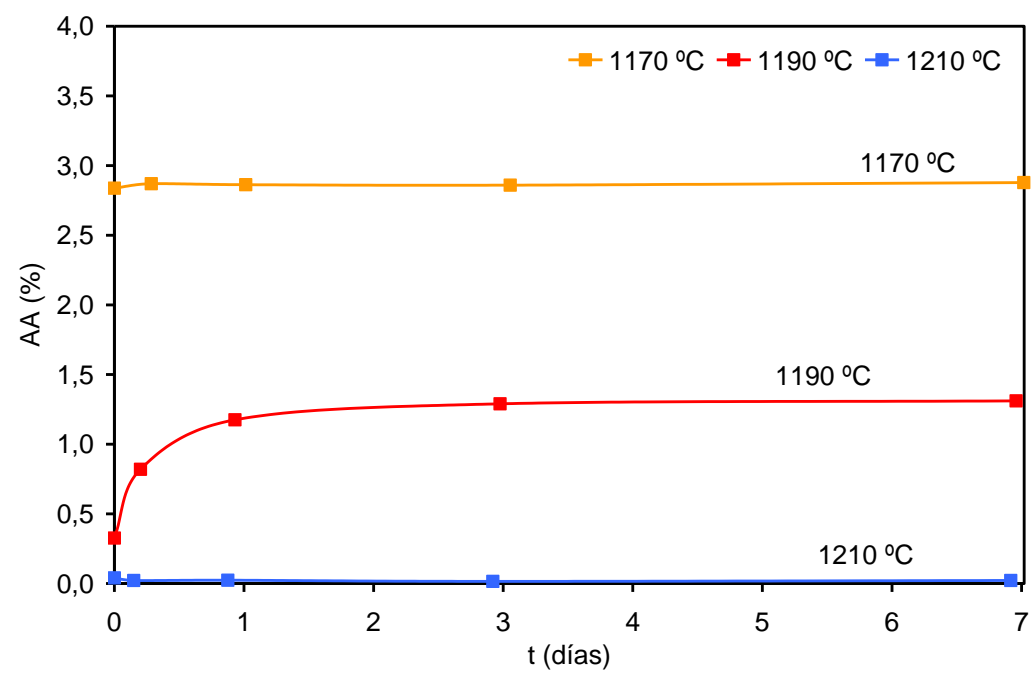

Figura 4.137. Evolución de la absorción de agua a vacío del modelo 12.

Tabla 4.44. Propiedades del modelo 12.

\begin{tabular}{|c|c|c|}
\hline $\mathbf{T}\left({ }^{\circ} \mathbf{C}\right)$ & $\boldsymbol{\rho}\left(\mathbf{g} / \mathbf{c m}^{\mathbf{3}}\right)$ & $\mathbf{A A} \mathbf{7}$ dias $(\%)$ \\
\hline 1170 & 2,347 & 2,9 \\
\hline 1190 & 2,386 & 1,3 \\
\hline 1210 & 2,378 & 0,0 \\
\hline
\end{tabular}


4. Resultados y discusión

m) Modelo 13

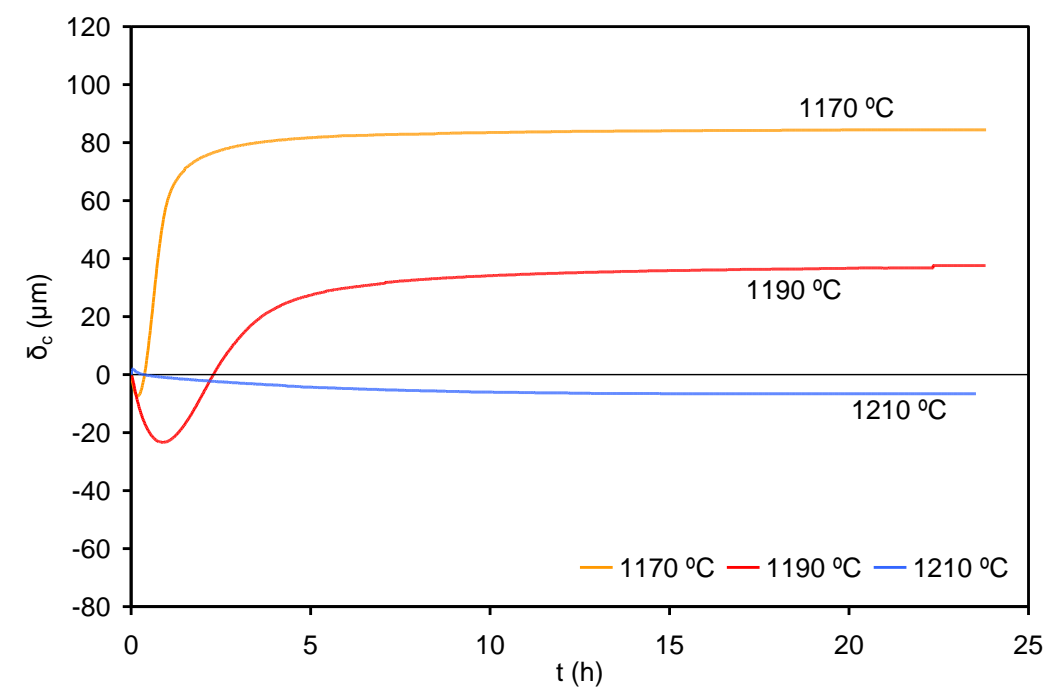

Figura 4.138. Evolución de la curvatura con el tiempo para el modelo 13.

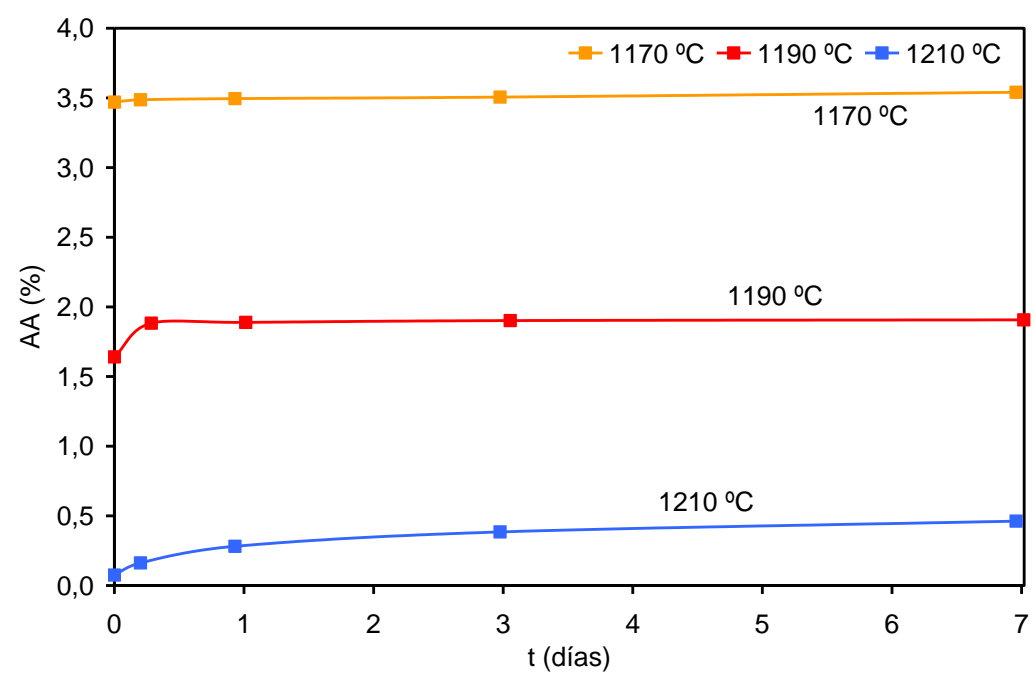

Figura 4.139. Evolución de la absorción de agua del modelo 13.

Tabla 4.45. Propiedades del modelo 13.

\begin{tabular}{|c|c|c|}
\hline $\mathbf{T}\left({ }^{\circ} \mathbf{C}\right)$ & $\boldsymbol{\rho}\left(\mathbf{g} / \mathbf{c m}^{3}\right)$ & $\mathbf{A A}_{\mathbf{7}}$ dias $(\%)$ \\
\hline 1170 & 2,313 & 3,5 \\
\hline 1190 & 2,362 & 1,9 \\
\hline 1210 & 2,365 & 0,5 \\
\hline
\end{tabular}


n) Modelo 14

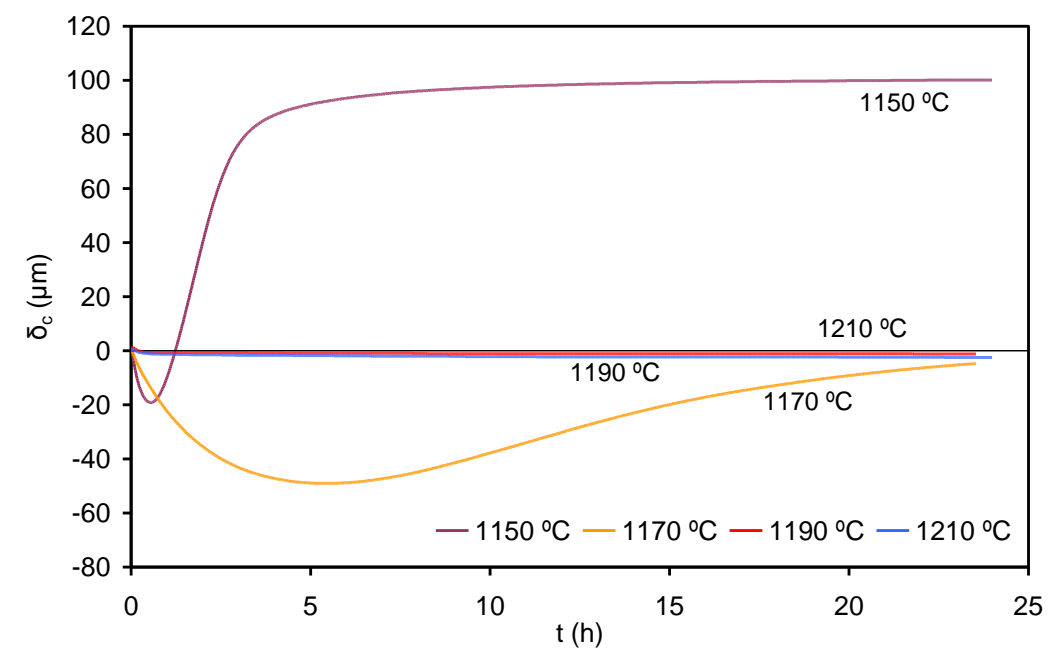

Figura 4.140. Evolución de la curvatura con el tiempo para el modelo 14.

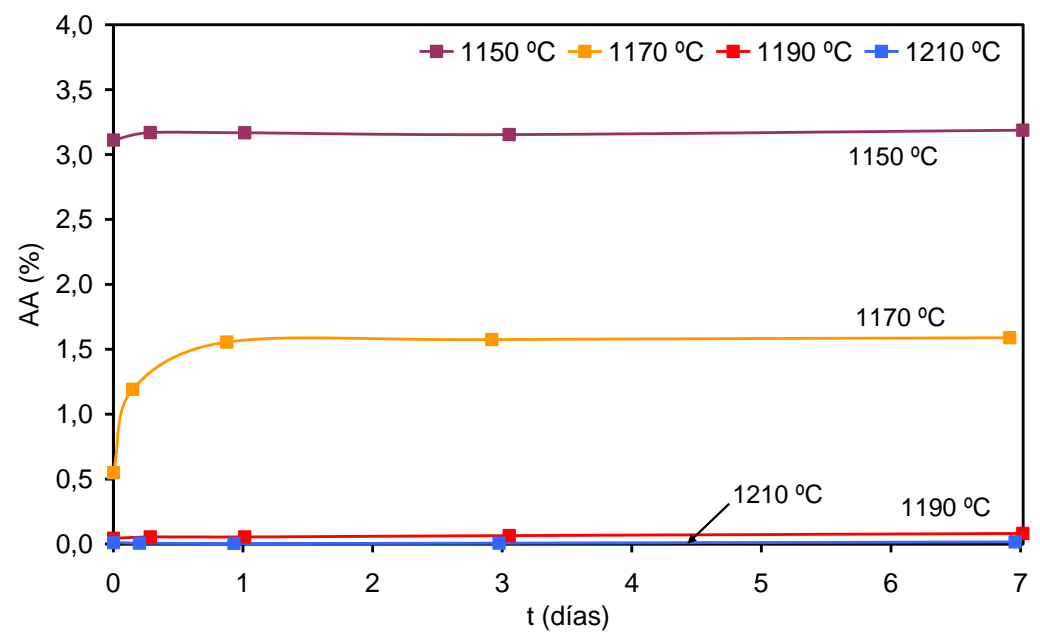

Figura 4.141. Evolución de la absorción de agua al vacío del modelo 14.

Tabla 4.46. Propiedades del modelo 14.

\begin{tabular}{|c|c|c|}
\hline $\mathbf{T}\left({ }^{\circ} \mathbf{C}\right)$ & $\mathbf{\rho ~ ( g / \mathbf { c m } ^ { 3 } )}$ & $\mathbf{A A}_{\mathbf{7}}$ dias $(\%)$ \\
\hline 1150 & 2,343 & 3,2 \\
\hline 1170 & 2,402 & 1,6 \\
\hline 1190 & 2,392 & 0,1 \\
\hline 1210 & 2,373 & 0,0 \\
\hline
\end{tabular}




\section{o) Conclusiones}

Los resultados de los ensayos de absorción de agua indican lo siguiente:

- En las condiciones ensayadas, no se producen variaciones importantes en la absorción de agua transcurridos más de 1 día. Como excepción se encuentran las piezas cocidas a temperaturas próximas a la de absorción de agua cero, para las cuales se observa un ligero aumento de la absorción de agua a vacío durante varios días. Sin embargo, estas piezas presentan una curvatura diferida muy baja.

- Al aumentar la temperatura de cocción, la absorción de agua se reduce y se ralentiza su aumento con el tiempo de permanencia en el baño. Si se incrementa suficientemente la temperatura, la absorción de agua se anula y no varía con el tiempo. Para temperaturas máximas de cocción muy bajas, la absorción de agua a vacío aumenta mientras que la curvatura ya es estable. Estas condiciones están muy lejos de las requeridas para alcanzar un bajo valor de absorción de agua necesario para baldosas de gres porcelánico.

- A medida que disminuye la variación de la absorción de agua con el tiempo también lo hace la curvatura.

- A las temperaturas para las cuales la absorción de agua a los 7 días es prácticamente nula $(<0,5 \%)$, no se aprecian curvaturas diferidas en las piezas, independientemente del modelo ensayado.

- La ausencia de curvatura diferida y nula absorción de agua se producen a distinta temperatura de cocción según el modelo.

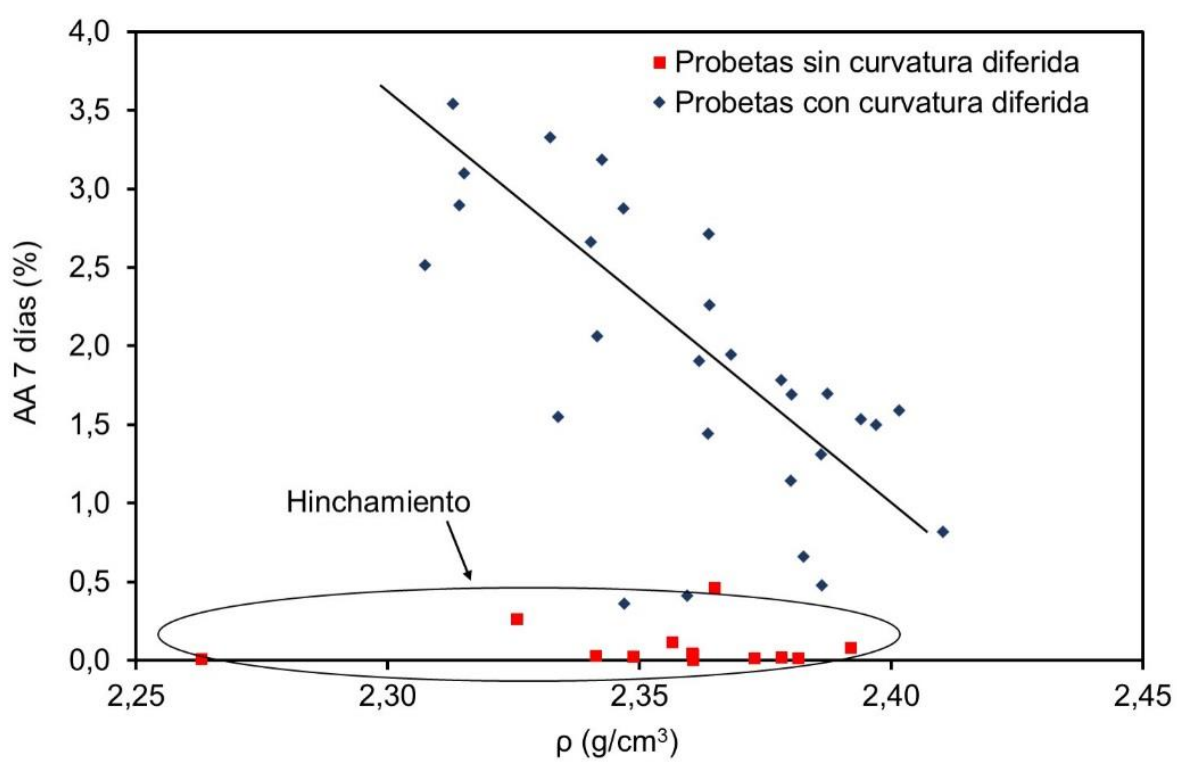

Figura 4.142. Relación entre la absorción de agua a vacío y la densidad aparente en cocido. 
Por su parte, la densidad aparente no sigue una tendencia monótona con el incremento de temperatura, sino que primero aumenta y luego disminuye. Ello es debido a que se realizan cocciones a temperaturas superiores a la de máxima densificación y se produce un hinchamiento de la pieza. La figura 4.142 muestra la relación entre densidad aparente en cocido y la absorción de agua a los 7 días. Se observa que la densidad aumenta conforme disminuye la absorción hasta que se produce el hinchamiento de la pieza $(A A<0,5 \%)$. A partir de ese momento, la densidad disminuye.

\section{B. Validación con baldosas industriales}

En esta segunda parte se caracterizaron baldosas de gres porcelánico industriales de algunos de los modelos anteriores. Las determinaciones realizadas fueron las siguientes:

- densidad aparente en cocido $\left(\rho_{\mathrm{ap}}\right)$,

- densidad real $\left(\rho_{\mathrm{R}}\right)$,

- absorción de agua (AA),

- expansión por humedad (EH).

La densidad aparente en cocido $\left(\rho_{\mathrm{ap}}\right)$ se determinó por inmersión en mercurio y la absorción de agua por el método de impregnación a vacío (AA). Al objeto de conocer si el aumento de la absorción de agua con el tiempo se debía a la penetración progresiva de agua en el interior de la pieza y, en caso afirmativo, por qué superficie penetraba el agua, se realizaron ensayos de absorción de agua a vacío añadiendo azul de metileno al agua utilizada. Una vez finalizado el ensayo (transcurridos los 7 días de permanencia en el baño) se cortaron las probetas y se observó su sección.

La expansión por humedad $(\mathrm{EH})$ se ha realizado siguiendo el método descrito en la norma ASTM C 370-88 "Standard test method for moisture expansion of fired whiteware products", que consiste en determinar la variación de longitud de las probetas ensayadas, después de un tratamiento en autoclave.

Se determinó también la porosidad total $(\varepsilon)$, al objeto de poder comparar composiciones con distinta densidad real $(\rho R)$, como aquéllas que contienen silicato de circonio. La expresión utilizada fue la siguiente:

$$
\text { Ecuación } 4.30 \quad \varepsilon=\left(1-\frac{\rho_{a p}}{\rho_{R}}\right) \cdot 100
$$

En la tabla 4.47 se muestran los valores de las diferentes propiedades determinadas.

El valor de la densidad real para todos los soportes osciló entre 2,54 y 2,56 $\mathrm{g} / \mathrm{cm}^{3}$, a excepción del soporte del modelo 6 para el cual se tomó un valor de $2,59 \mathrm{~g} / \mathrm{cm}^{3}$. 
Tabla 4.47. Características de las baldosas industriales ensayadas.

\begin{tabular}{|c|c|c|c|c|c|c|c|}
\hline Modelo & $\begin{array}{c}\text { AA } \\
(\%)\end{array}$ & $\begin{array}{c}\text { AA } 7 \text { días } \\
(\%)\end{array}$ & $\begin{array}{c}\rho_{\mathrm{ap}} \\
\left(\mathbf{g} / \mathbf{c m}^{3}\right)\end{array}$ & $\begin{array}{c}\boldsymbol{\rho}_{\mathbf{R}} \\
\left(\mathbf{g} / \mathbf{c m}^{3}\right)\end{array}$ & $\begin{array}{c}\boldsymbol{\varepsilon} \\
(\%)\end{array}$ & $\begin{array}{c}\text { EH } \\
(\%)\end{array}$ & $\begin{array}{c}\text { Curvatura } \\
\text { diferida }\end{array}$ \\
\hline 1 & 0,6 & 2,2 & 2,33 & 2,55 & 9 & 0,40 & Sí \\
\hline 2 & 0,2 & 1,3 & 2,37 & 2,55 & 7 & 0,20 & Sí \\
\hline 3 & 0,2 & 0,2 & 2,37 & 2,55 & 7 & 0,10 & No \\
\hline 4 & 0,8 & 2,3 & 2,31 & 2,54 & 9 & 0,20 & Sí \\
\hline 5 & 0,5 & 2,1 & 2,35 & 2,55 & 8 & 0,30 & Sí \\
\hline 6 & 0,2 & 1,3 & 2,40 & 2,59 & 7 & 0,30 & Sí \\
\hline 7 & 0,1 & 0,1 & 2,42 & 2,56 & 6 & 0,00 & No \\
\hline 8 & 0,5 & 2,1 & 2,33 & 2,55 & 9 & 0,20 & Sí \\
\hline 9 & 0,1 & 0,1 & 2,36 & 2,55 & 7 & 0,10 & No \\
\hline 10 & 0,1 & 0,1 & 2,38 & 2,55 & 7 & 0,00 & No \\
\hline 11 & 0,3 & 1,5 & 2,36 & 2,55 & 7 & 0,20 & Sí \\
\hline
\end{tabular}

En la figura 4.143 y en la figura 4.144 se muestran los valores de la densidad aparente y porosidad para los distintos modelos, diferenciando entre aquellos que presentan curvatura diferida y aquellos que no la presentan. Se observa lo siguiente:

- $\quad$ La densidad aparente de los modelos ensayados oscila entre 2,31 y 2,42 $\mathrm{g} / \mathrm{cm}^{3}$ y su porosidad entre 6 y $9 \%$.

- En general, los modelos con curvatura diferida presentan menores valores de la densidad aparente, aunque existe un intervalo de valores de esta característica en el que se posicionan modelos con ambos comportamientos (con y sin curvatura diferida).

- Esto mismo sucede cuando se representan los valores de porosidad, aunque en este caso el intervalo de valores de porosidad en el que se encuentran modelos con y sin curvatura diferida es más estrecho. Ello se debe principalmente a la diferente densidad real del modelo 6.

Estos resultados confirman que existe cierta relación entre la densidad aparente, la porosidad y la existencia de curvaturas diferidas. Sin embargo, el ensayo no es lo suficientemente sensible para discriminar la existencia o no de curvatura diferida cuando se comparan modelos fabricados con composiciones y variables de proceso distintas. 


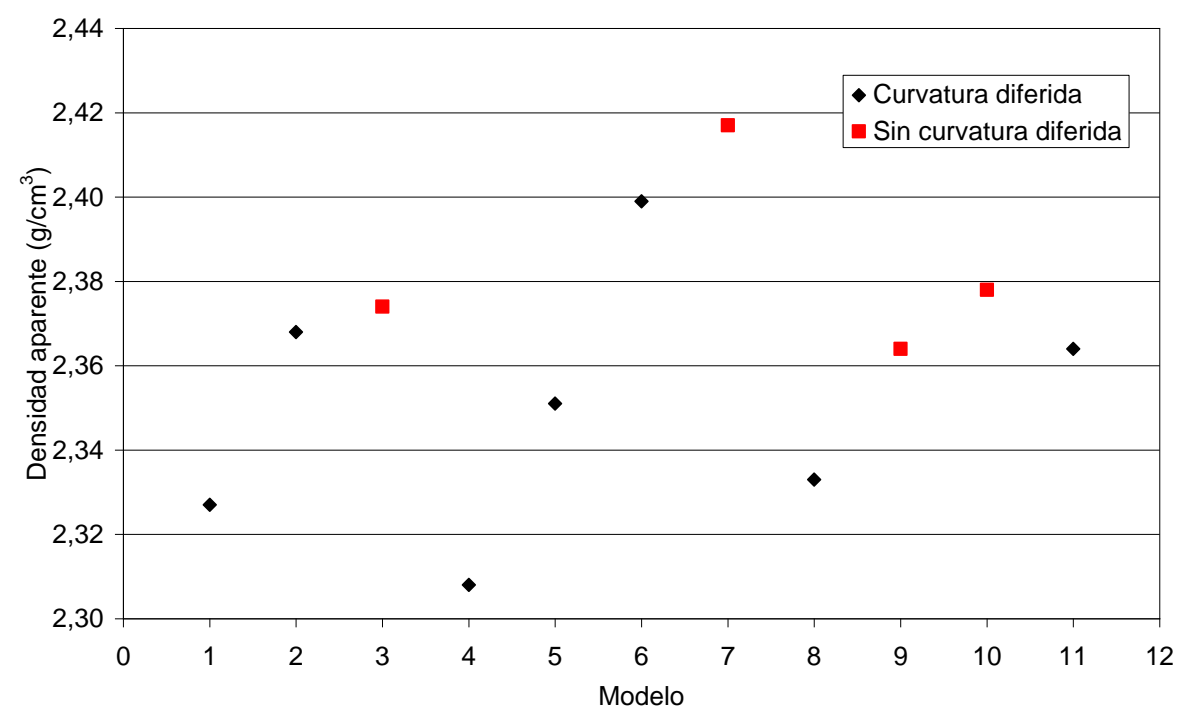

Figura 4.143. Densidad aparente de los modelos ensayados.

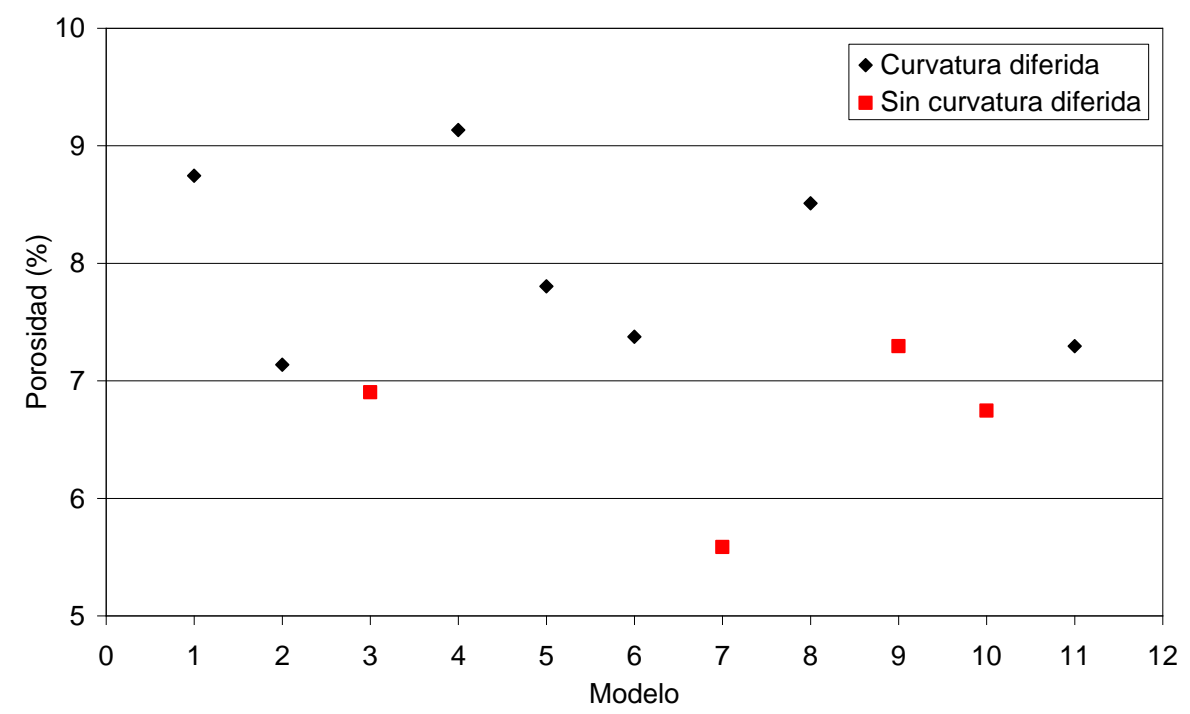

Figura 4.144. Porosidad total de los modelos ensayados.

En el caso de la expansión por humedad, los resultados están representados en la figura 4.145 distinguiendo entre los modelos con y sin curvatura diferida. Puede apreciarse que los modelos con bajos valores de la expansión por humedad (inferiores a 0,1\%) no presentan el citado comportamiento, mientras que aquellos con valores iguales o superiores al 0,2 \% sí que lo presentan. En este caso no existe solapamiento en los valores de expansión por humedad entre ambos comportamientos, aunque la diferencia de expansión por humedad entre los modelos con y sin curvatura diferida es pequeña. 


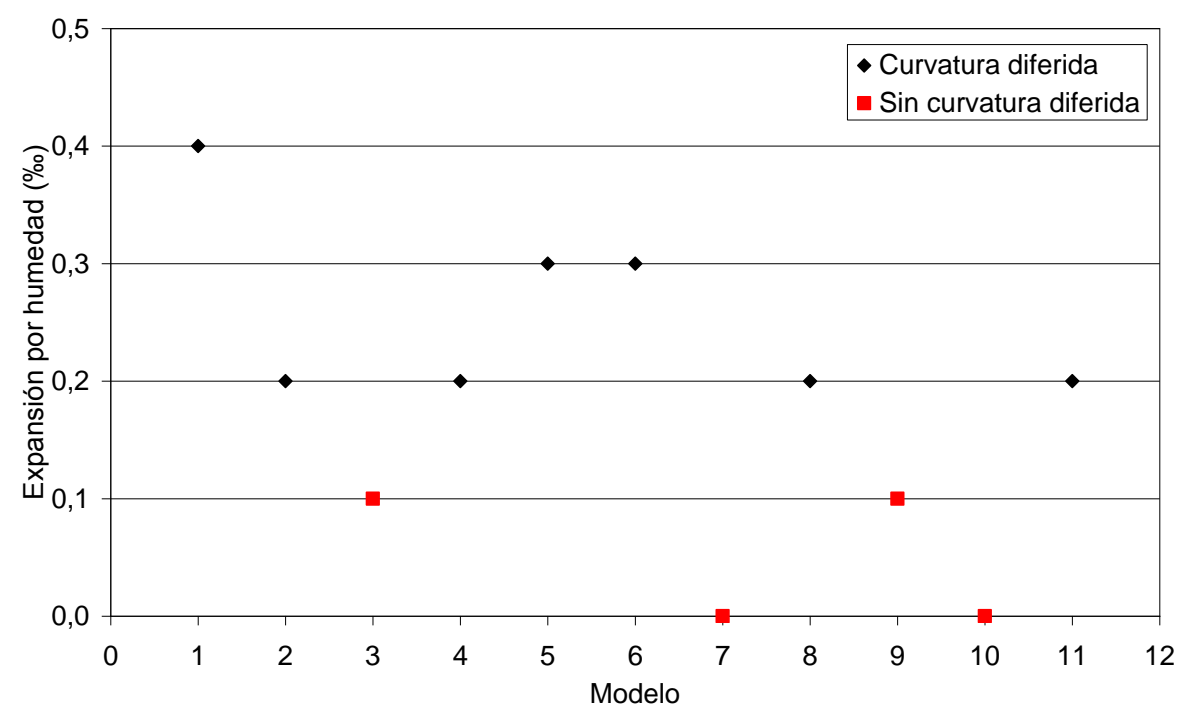

Figura 4.145. Expansión por humedad de los modelos.

En lo que respecta a la absorción de agua a vacío se aprecia que los modelos que presentan una baja absorción de agua ( $0,2 \%$ o inferior) y que además no aumenta con el tiempo de permanencia en el agua no presentan curvaturas diferidas (modelos 3, 7, 9 y 10). Por el contrario, aquéllos que presentan valores superiores de la absorción de agua también son aquéllos en los que esta característica aumenta al sumergir las piezas durante 7 días, presentando además curvatura diferida.

Debe destacarse la existencia de modelos con un bajo valor de absorción de agua $(0,2 \%)$, como los modelos 2 y 6 , los cuales presentan curvatura diferida. En este caso, experimentan un aumento de la absorción de agua con el tiempo, por lo que puede concluirse que para que una determinada baldosa no presente curvatura diferida es necesario que posea una baja absorción de agua y que además no aumente con el tiempo.

Como aspecto interesante, se encuentran los modelos 3 y 11. Ambas baldosas corresponden a un mismo modelo de dos fabricaciones diferentes. Los valores de absorción de agua son muy parecidos (0,2 y 0,3\%) sin embargo el modelo 3 no presenta curvatura diferida y el modelo 11 sí que la presenta. En este caso el ensayo de absorción de agua a los 7 días es capaz de discernir ambos comportamientos.

Una vez establecida la correlación entre la curvatura diferida y el valor de absorción de agua tras la impregnación y tras la permanencia de las piezas sumergidas durante 7 días, se planteó la posibilidad de reducir el tiempo de ensayo. Para ello se determinó la absorción de agua de las piezas a tiempos más cortos 1 y 3 días. En la figura 4.146 se muestran los resultados obtenidos. En esta figura, los valores de absorción de agua para tiempo cero corresponden a la medida tras la impregnación a vacío de las piezas. 


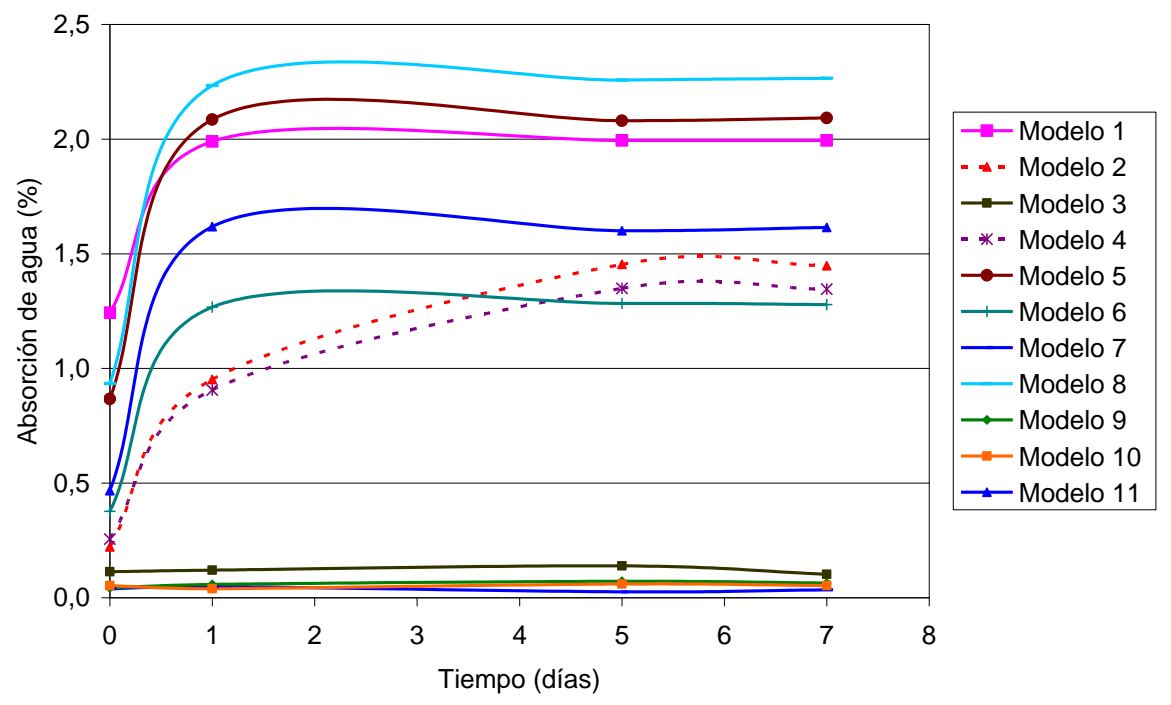

Figura 4.146. Evolución de la absorción de agua con el tiempo.

Se observa lo siguiente:

- Los modelos 3, 7, 9 y 10 presentan valores de absorción de agua muy bajos, los cuales permanecen estables con el tiempo. El resto de modelos presentan valores de la absorción de agua inicial más altos, y además aumentan apreciablemente con el tiempo.

- La absorción de agua se estabiliza para la mayoría de los modelos tras 1 día de permanencia en el baño. Como excepción se encuentran los modelos 2 y 4 para los cuales la estabilización se produce a los 5 días (aunque probablemente si se hubieran ensayado tiempos menores la absorción de agua se hubiera estabilizado con anterioridad a los 5 días).

- Existe una relación clara entre los valores de absorción de agua y la curvatura diferida. De este modo los modelos 3, 7, 9 y 10 que no presentan curvatura diferida poseen bajos valores de absorción de agua, los cuales son estables con el tiempo.

Como se indicó anteriormente, los ensayos de absorción de agua a vacío se realizaron añadiendo azul de metileno al agua utilizada. Una vez finalizado el ensayo (transcurridos los 7 días de permanencia en el baño) se cortaron las probetas y se observó su sección.

En la figura 4.147 se muestra el aspecto de la sección de las probetas correspondientes a los modelos 5 (con curvatura diferida) y 9 (sin curvatura diferida). Se observa que en el modelo 5 ha penetrado el azul de metileno mientras que en el modelo 9 no ha penetrado. Además, la penetración se produce por la cara inferior (costillas) de la pieza, lo que indica que, como era previsible, el esmalte actúa sellando la superficie. 


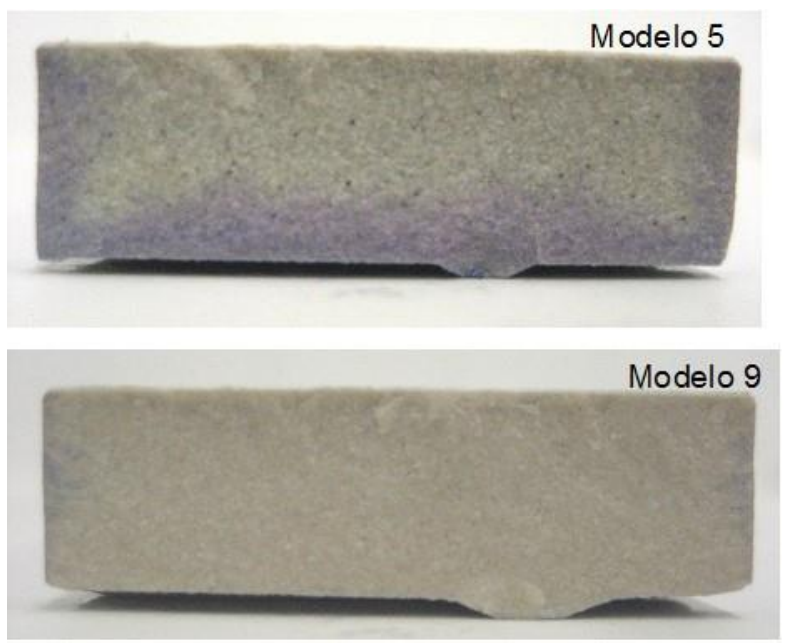

Figura 4.147. Penetración para los modelos 5 y 9.

En la figura 4.148 se muestra el aspecto de las probetas de los modelos 3 y 11 (mismo modelo de fabricaciones diferentes). También se observa que en el modelo 3 , sin curvatura diferida, no ha penetrado el azul de metileno, mientras que en el modelo 11 sí que ha penetrado.

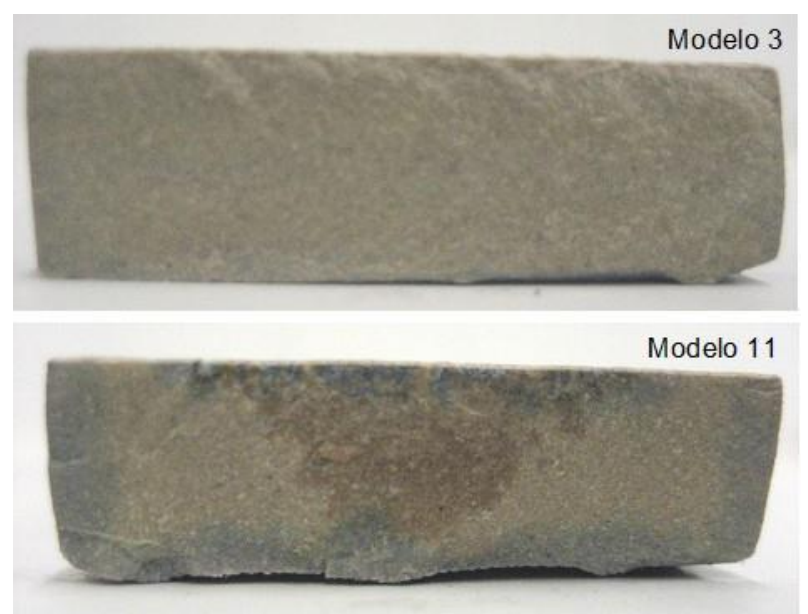

Figura 4.148. Penetración para los modelos 3 y 11.

Resultados similares se obtuvieron para el resto de los modelos ensayados, lo que permite concluir que el esmalte actúa impermeabilizando la superficie superior de las piezas y que el agua penetra en las piezas por la superficie inferior. La penetración alcanzada por el azul de metileno se representó frente a la absorción de agua ( $\mathrm{AA}_{7}$ días), obteniéndose la gráfica de la figura 4.149. Se observa cierta correlación entre ambas características, aunque con una elevada dispersión en los resultados debido probablemente a la dificultad de medir con exactitud la penetración del azul de metileno y a la diferente porosidad de las probetas ensayadas. 


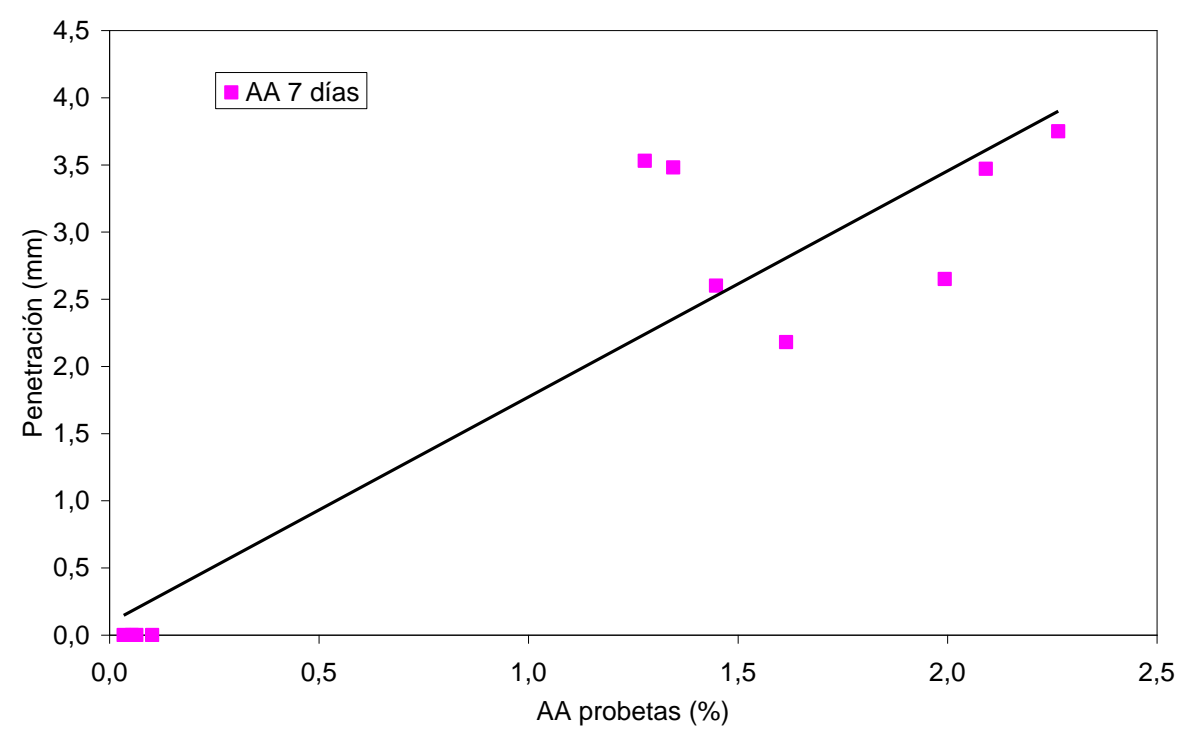

Figura 4.149. Relación entre la penetración y la absorción de agua a los 7 días.

Una de las cuestiones que se plantean es por qué el azul de metileno no penetra por el soporte y alcanza la superficie esmaltada. A fin de esclarecer el tema se realizó una serie de ensayos adicionales.

Se llevaron a cabo absorciones de agua en condiciones de vacío más enérgicas, con una presión de 50 mbar y un tiempo de permanencia de 2 horas, mientras que en el método de impregnación a vacío utilizado anteriormente se mantenían las probetas a 100 mbar durante 30 minutos. El ensayo se efectuó sobre probetas esmaltadas de dos modelos, cocidas en horno de laboratorio a distintas temperaturas. En la figura 4.150 y en la figura 4.151 se comparan los resultados obtenidos a las diferentes condiciones de vacío, en lo que se refiere a absorción y penetración.

Se desprende lo siguiente:

- La absorción de agua disminuye al incrementar la temperatura máxima de cocción para las dos condiciones de ensayo realizadas.

- En general, la absorción de agua aumenta cuando las condiciones de vacío se vuelven más enérgicas. Sin embargo se observan algunas excepciones. Para temperaturas elevadas $\left(1230^{\circ} \mathrm{C}\right)$ la absorción es prácticamente cero y no se modifica con las condiciones de vacío. Para temperaturas bajas $\left(1190^{\circ} \mathrm{C}\right)$ la absorción de agua es apreciable y para uno de los modelos no varía al incrementar el vacío. Ello puede deberse a que la estructura porosa se encuentra muy intercomunicada.

- La penetración prácticamente no varía con los cambios en el vacío como se muestra en la figura 4.152. Se trata por tanto de un parámetro muy poco sensible. 


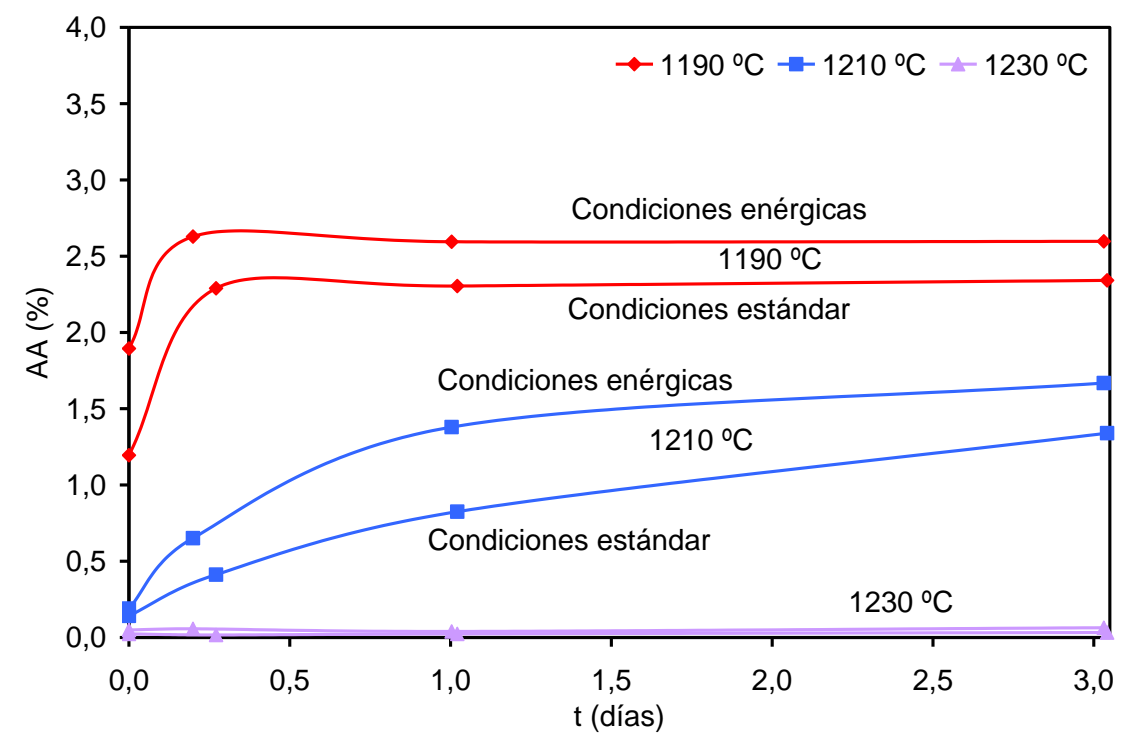

Figura 4.150. Evolución de la absorción de agua con el tiempo para el modelo 4 en distintas condiciones de ensayo.

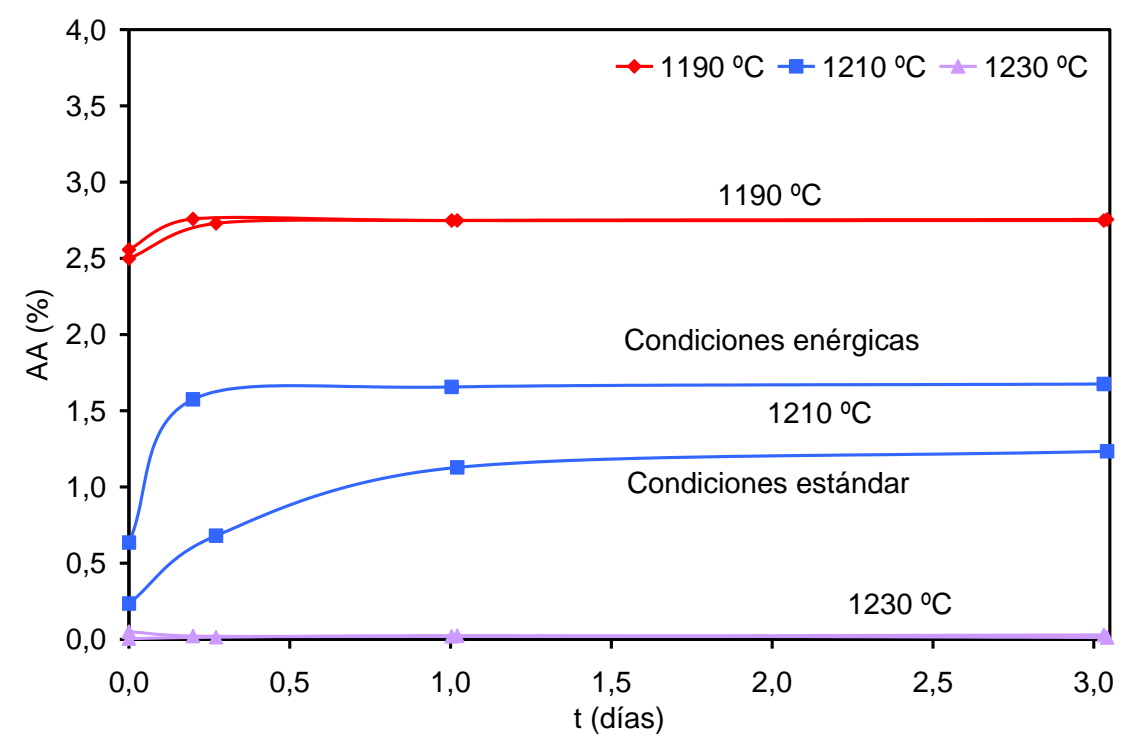

Figura 4.151. Evolución de la absorción de agua con el tiempo para el modelo 7 en distintas condiciones de ensayo. 


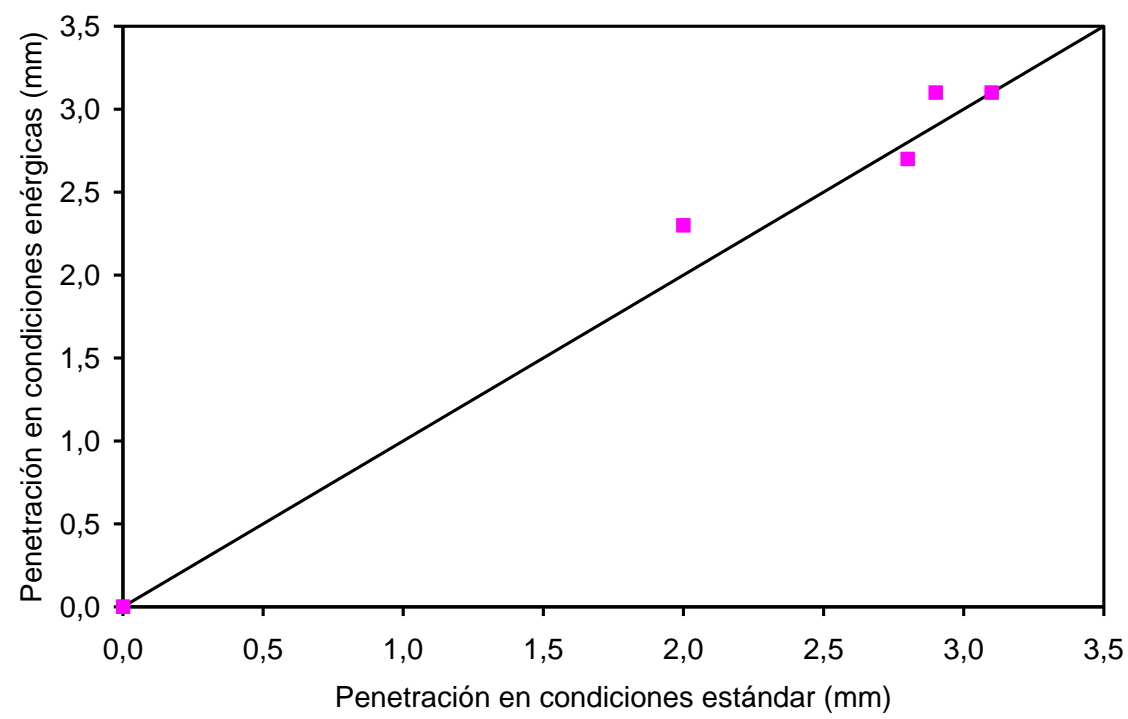

Figura 4.152. Relación entre las penetraciones del azul de metileno a diferentes condiciones de vacío.

Para finalizar se realizó un ensayo de absorción de agua por el método de impregnación a vacío en condiciones estándar sobre probetas esmaltadas a las cuales se les eliminó la parte inferior una vez cocidas, de tal modo que el espesor se redujo a la mitad.

Se seleccionaron probetas cocidas a una temperatura máxima de $1210^{\circ} \mathrm{C}$ de los dos modelos anteriores. Con este experimento se pretendía conocer si el hecho de que el azul de metileno no penetra hasta la zona superior de la pieza era debido a la inexistencia de porosidad interconectada en esta zona o a la presencia de aire que impide que el agua siga penetrando.

En la figura 4.153 se compara la evolución de la absorción con el tiempo de las probetas con el espesor reducido y sin reducir, mientras que en la figura 4.154 se muestra la sección de las piezas con el espesor reducido.

Se observa lo siguiente:

- La absorción de agua de las piezas de espesor reducido es superior, lo que parece indicar que la zona superior de la pieza presenta una mayor porosidad que la zona inferior.

Durante la cocción, existen diferencias de temperaturas entre la cara vista y la costilla. Efectivamente, la temperatura de la superficie superior, comparada con la de la superficie inferior, es mayor durante el calentamiento y menor durante el enfriamiento [Cantavella et al., 2006]. El hecho de que durante el calentamiento la superficie superior se encuentre a mayor temperatura que la inferior, y que suceda lo contrario durante el enfriamiento, se debe a que los rodillos del horno apantallan la transferencia de calor. Como consecuencia, la superficie inferior del horno reacciona térmicamente de forma más lenta que la superior, lo que podría explicar las diferencias observadas en la porosidad. 
- La absorción de agua de las piezas delgadas aumenta de forma más rápida respecto a las piezas estándar, lo que indica que la porosidad en esta zona también esta interconectada.

- La penetración no es en absoluto despreciable, lo que confirma la interconectividad de la porosidad, aunque tampoco se llega a alcanzar la superficie esmaltada.

Ello permite concluir que en la zona superior del soporte la porosidad también está interconectada y que el motivo por el que el azul de metileno no penetra hasta la superficie esmaltada se debe, con toda probabilidad, a la presencia de aire ocluido en el interior de los poros que no es capaz de eliminarse con el vacío.

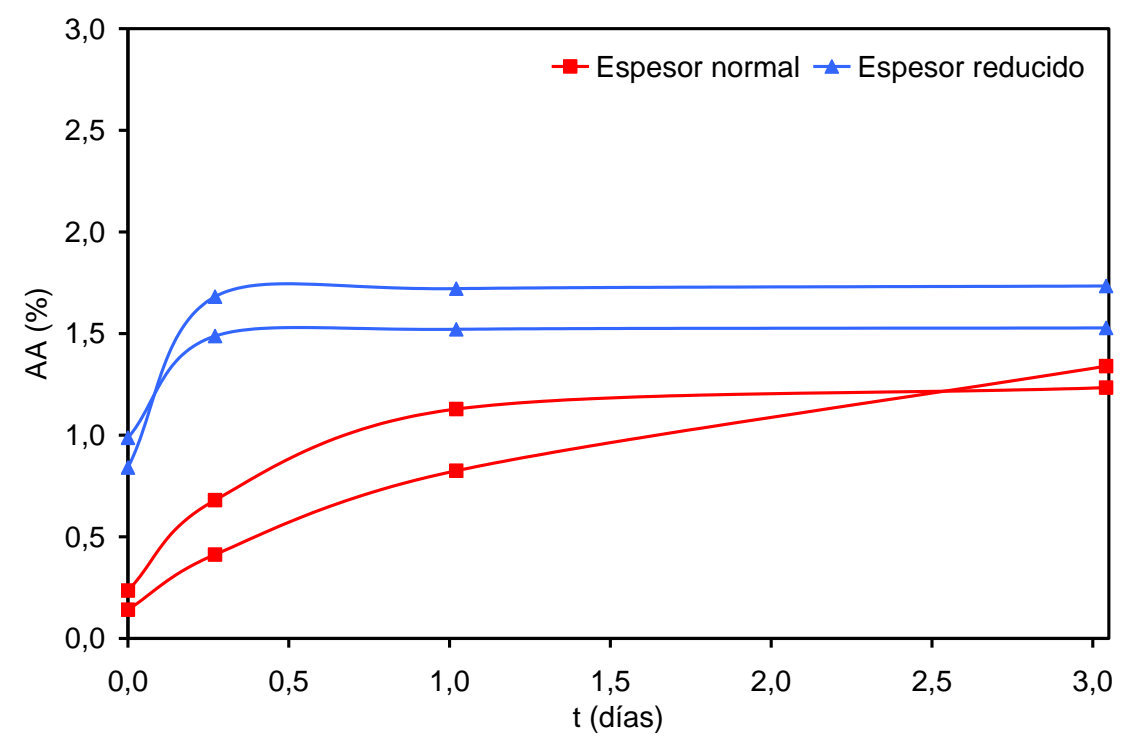

Figura 4.153. Evolución de la absorción de agua con el tiempo de las probetas cocidas a $1210^{\circ} \mathrm{C}$ con el espesor reducido y sin reducir.

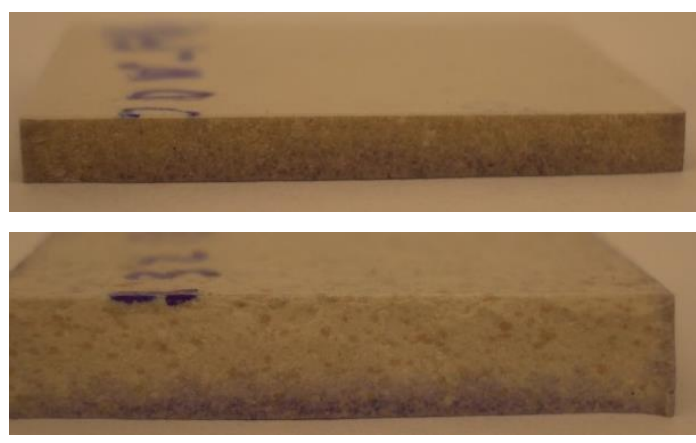

Figura 4.154. Penetración de las probetas con el espesor reducido. 
Para finalizar este apartado se ha representado la expansión por humedad frente a la porosidad total y absorción de agua a los 7 días de los modelos ensayados al objeto de conocer la existencia de alguna correlación entre estas variables.

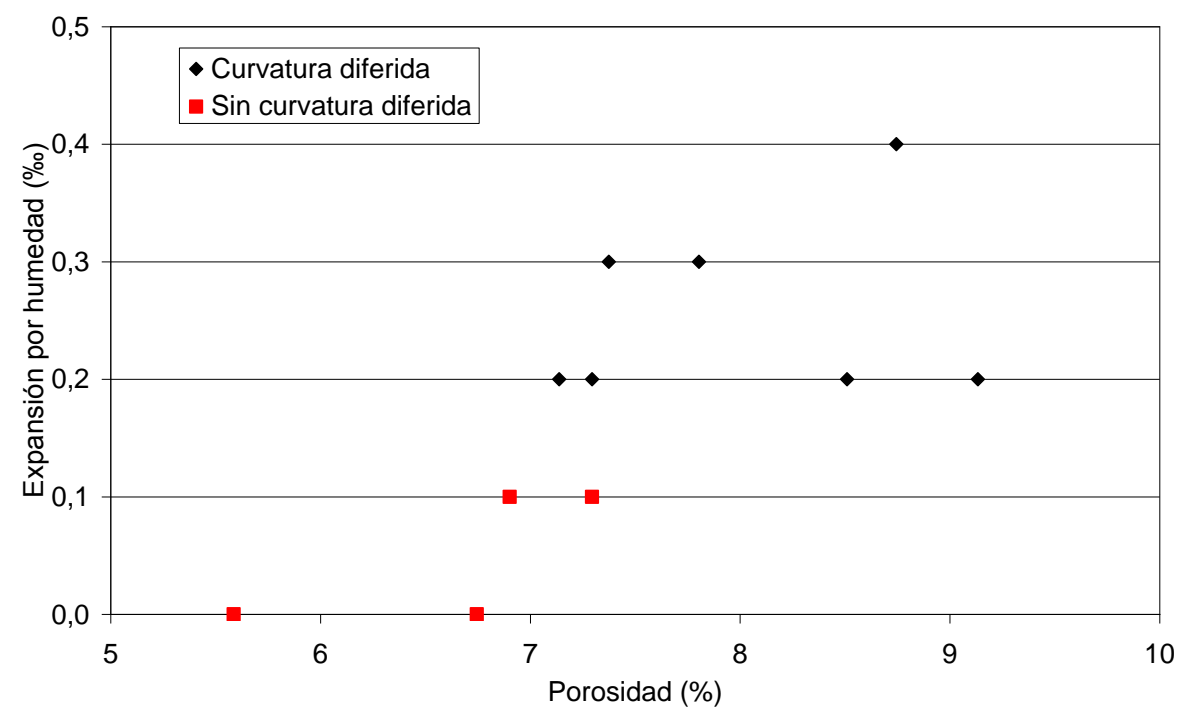

Figura 4.155. Relación expansión por humedad-porosidad de los distintos modelos.

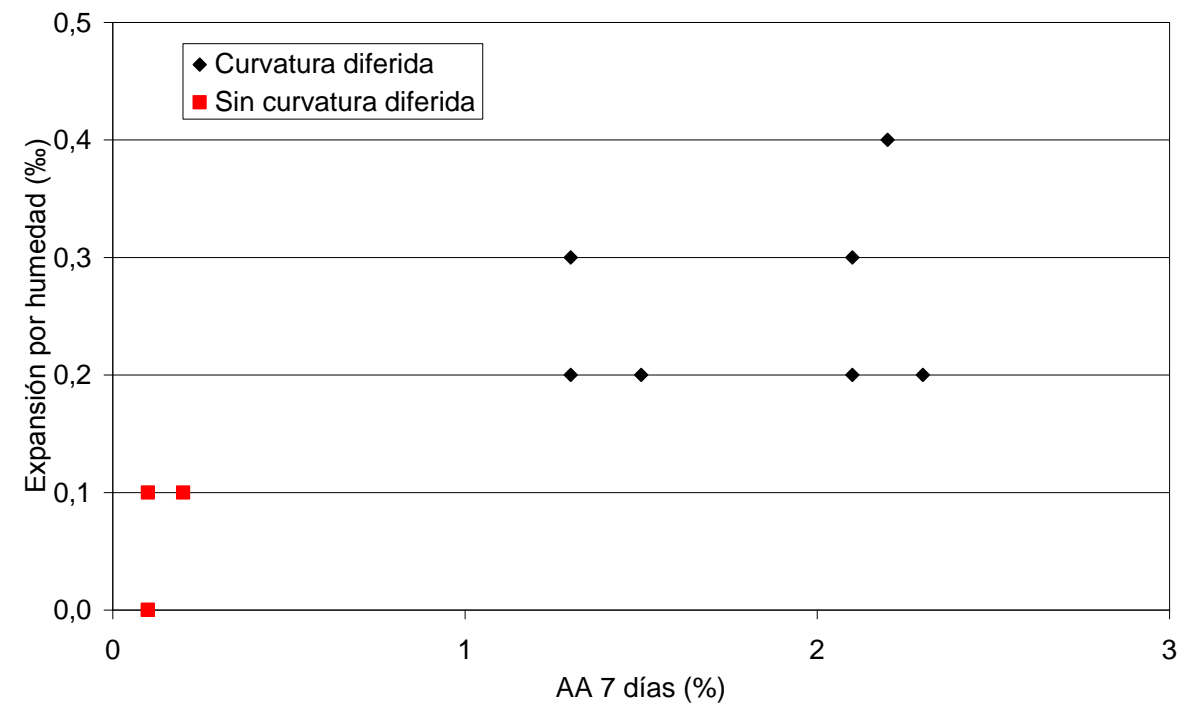

Figura 4.156. Relación expansión por humedad-absorción de agua a los 7 días de los distintos modelos.

En la figura 4.155 se observa que a medida que aumenta la porosidad de las baldosas también lo hace la expansión por humedad, aunque la dispersión de resultados es elevada. Cabe citar la existencia de baldosas con valores de 
porosidad en torno al $6 \%$ que presentan una nula expansión por humedad. Ello se debe a que se trata de modelos en los que la porosidad es cerrada y por lo tanto no accesible por el agua.

En la figura 4.156 se representa la expansión por humedad frente a la absorción de agua a los 7 días, observándose una mejor correlación entre ambas características.

\subsubsection{Conclusiones}

Para proponer y validar un ensayo de control industrial, se han ensayado un mayor número de baldosas, comprobando que en términos generales, los modelos con curvatura diferida son aquéllos que presentan una menor densidad aparente (mayor porosidad), mayor absorción de agua y mayor expansión por humedad tras su permanencia en el autoclave.

Los ensayos realizados confirman la relación entre la absorción de agua a vacío y las curvaturas en diferido:

- A medida que disminuye la variación de la absorción de agua con el tiempo también lo hace la curvatura.

- Las piezas que presentan una expansión de agua prácticamente nula, no presentan curvaturas en diferidos.

A la vista de estos resultados, la determinación de la absorción de agua a vacío aparece como un ensayo de control industrial muy efectivo. A nivel práctico es aconsejable realizar 2 medidas: la primera medida tras 30 minutos de permanencia en el baño, y la segunda transcurrido 6 horas. Si la primera medida es superior a $0,5 \%$, es muy probable que la pieza sufra curvaturas en diferido. En cambio, si la absorción de agua inicial es baja $(<0,5 \%)$ y no aumenta con el tiempo, las baldosas presentarán una curvatura estable tras su cocción. Es decir las piezas con curvatura diferida son aquellas que, además de presentar mayores valores de absorción de agua, experimentan un aumento de este parámetro con el tiempo.

La medida de la densidad aparente en cocido también puede utilizarse como método de control industrial al ser una técnica rápida y utilizada de forma rutinaria en la industria cerámica. En un principio es posible evitar la aparición de curvaturas diferidas manteniendo el valor de densidad aparente por encima de un valor umbral. Sin embargo, se ha comprobado que es un parámetro algo más difícil de utilizar ya que este valor umbral depende de la composición utilizada en el proceso, por lo que debe determinarse experimentalmente en cada una de las empresas y para cada tipo de composición de gres porcelánico. Además, en algunos casos se ha observado que es necesario cocer la pieza a una temperatura superior a la de máxima densificación para evitar las curvaturas en diferido.

Finalmente, la medida de la expansión por humedad en autoclave permite determinar de forma muy fiable si una pieza va a sufrir curvaturas en diferido. Sin embargo, es un ensayo más complicado de llevar a cabo en condiciones industriales que el de absorción de agua a vacío. 


\section{Capítulo 5. Conclusiones y recomendaciones}

CAPÍTULO 5. CONCLUSIONES Y RECOMENDACIONES......................... 187

5.1. ORIGEN DE LAS CURVATURAS EN DIFERIDO .................................... 189

5.2. APLICACIÓN INDUSTRIAL............................................................ 190

5.2.1. MEDIDAS PARA PREVENIR LAS CURVATURAS EN DIFERIDO........................... 190

5.2.2. ENSAYOS DE CONTROL INDUSTRIAL................................................. 191 
5. Conclusiones y recomendaciones 


\subsection{ORIGEN DE LAS CURVATURAS EN DIFERIDO}

Al empezar esta tesis doctoral, se plantearon dos hipótesis para explicar el fenómeno de curvaturas diferidas en baldosas de gres porcelánico (véase el apartado 4.1.2), tal y como se indica a continuación:

- Hipótesis 1: Relajación de tensiones residuales

Con el fin de confirmar o refutar esta primera hipótesis, se determinaron las tensiones residuales tanto de origen térmico como de acoplamiento esmalte/soporte para cuatro modelos industriales de gres porcelánico (véase el apartado 4.2.10). Estos modelos presentaban distintos comportamientos frente a las curvaturas en diferido: dos de ellos presentaban una curvatura estable después de su salida del horno mientras que los otros dos sufrían curvaturas diferidas.

Los resultados obtenidos indicaron que todos los modelos presentaban perfiles de tensiones residuales y valores de fluencia similares, independientemente de su comportamiento frente a las curvaturas en diferido.

Por lo tanto, se estableció que la relajación de las tensiones residuales no es la causa principal de las curvaturas en diferido en baldosas de gres porcelánico.

- Hipótesis 2: Expansión del soporte

Para validar esta segunda hipótesis, se midió la expansión post-cocción de los soportes de cuatro modelos industriales de gres porcelánico (véase el apartado 4.2.7).

Se comprobó que los dos soportes que sufrían curvaturas diferidas también expandían tras la cocción, mientras que los que no cambiaban de curvatura con el tiempo no presentaban expansión post-cocción.

Estos resultados confirmaron que existe una relación entre las curvaturas diferidas y la expansión de los soportes.

Sin embargo, al medir la evolución de la curvatura después de la salida del horno de varios modelos industriales de gres porcelánico, se comprobó que la curvatura suele mostrar primero una evolución hacia el sentido cóncavo para, después de transcurrido cierto tiempo, invertir esta tendencia (véase el apartado 4.1.1).

Este tipo de comportamiento no se puede explicar considerando una expansión homogénea del soporte como se ha comprobado al desarrollar modelos matemáticos que permiten reproducir el fenómeno de las curvaturas diferidas (véase el apartado 4.4).

Para explicar los resultados experimentales, es necesario que exista una diferencia (de magnitud y velocidad) en la expansión del soporte entre la cara vista y la cara posterior, tanto en productos esmaltados como no esmaltados. 
De hecho, el modelo matemático que mejor reproduce las curvaturas diferidas medidas experimentalmente se basa en las siguientes suposiciones:

1. Existe un gradiente en la expansión final a lo largo del espesor del soporte, a este fenómeno se le denominó expansión diferencial.

2. La cinética de expansión varía entre la cara vista y la cara posterior del soporte.

Finalmente, se puso ha puesto a punto un ensayo para confirmar la existencia de estas diferencias de expansión tanto en la magnitud como en velocidad (véase el apartado 4.4.5).

Los resultados experimentales obtenidos permitieron validar los mecanismos propuestos para explicar las curvaturas en diferido, es decir que las curvaturas diferidas en baldosas de gres porcelánico se deben a la existencia de una expansión diferencial de los soportes. Aunque el origen de esta expansión no ha sido aclarado en este trabajo, es posible que se deba, al menos parcialmente, a la difusión de humedad ambiental dentro del soporte.

\subsection{APLICACIÓN INDUSTRIAL}

La aplicación industrial de los resultados obtenidos en esta tesis tiene dos niveles y permite:

- Definir condiciones de proceso en las que se evitan las curvaturas en diferido.

- Establecer ensayos de control a la salida del horno para detectar si un lote de baldosas de gres porcelánico va a sufrir curvaturas en diferido.

\subsubsection{Medidas para prevenir las curvaturas en diferido}

El análisis a escala de laboratorio de la influencia de algunas de las variables de proceso sobre la curvatura diferida demuestra que la casi totalidad de las variables seleccionadas son susceptibles de modificar la curvatura diferida (véase el apartado 4.3.).

Considerando los resultados obtenidos y las limitaciones relacionadas con el proceso industrial, así como los requisitos de calidad del producto final, se recomienda adoptar una de las siguientes estrategias para evitar el fenómeno de curvaturas en diferido en piezas industriales:

1. Incrementar la temperatura máxima de cocción.

El aumento de la temperatura de cocción es muy efectivo para solucionar el problema de las curvaturas en diferido.

A mayor temperatura, se reducen las curvaturas en diferido como consecuencia de un mayor grado de cocción de las baldosas. Sin embargo, puede ser difícil adoptar esta estrategia en caso de las composiciones más refractarias. Además, un incremento excesivo de la temperatura de cocción puede conducir a deformaciones piroplásticas durante la cocción reduciendo la calidad del producto final. 
2. Aumentar el grado de molienda.

Se ha comprobado que esta variable es muy eficaz para eliminar los problemas de curvatura diferida sin aumentar la deformación piroplástica de la pieza.

De hecho, al aumentar el grado de molienda, se consigue evitar la formación de poros grandes en las piezas en crudo e incrementar la reactividad de la composición. Todo ello facilita la sinterización de las baldosas durante la cocción, conduciendo a la obtención de productos sin curvatura diferida a menor temperatura.

\subsubsection{Ensayos de control industrial}

Es necesario disponer de un ensayo de control industrial, que permita averiguar de formar sencilla, rápida y fiable si un lote de baldosas va a sufrir curvaturas en diferido.

Con el fin de recomendar una estrategia efectiva en entornos industriales, se realizó una serie de ensayos con 14 modelos industriales con distinto comportamiento frente a las curvaturas en diferido (véase el apartado 4.5).

En general, los modelos con curvatura diferida presentan una menor densidad aparente, una mayor absorción de agua y una mayor expansión por humedad tras su permanencia en autoclave. Asimismo, se confirmó la relación entre el aumento de la absorción de agua a vacío con el tiempo y las curvaturas en diferido, ya que la curvatura disminuye a medida que se reduce la variación de la absorción de agua con el tiempo. Además, las piezas que presentan una absorción de agua prácticamente nula y que no aumente con el tiempo, tampoco experimentan curvaturas en diferido.

Considerando los resultados obtenidos y los requisitos industriales se aconseja utilizar uno de los ensayos de control que se indican a continuación:

1. Determinación de la absorción de agua a vacío

La determinación de la absorción de agua a vacío aparece como un ensayo de control industrial muy efectivo.

De hecho, se ha comprobado que las piezas con curvatura diferida son aquellas que, además de presentar valores altos de absorción de agua, experimentan un aumento de este parámetro con el tiempo. Por lo tanto, se recomienda realizar una primera medida tras 30 minutos de permanencia en el baño, y otra transcurridas 6 horas. Si la primera medida es superior a $0,5 \%$, es muy probable que el lote correspondiente sufra curvaturas en diferido. En cambio, si la absorción de agua inicial es baja $(<0,5 \%)$ y no se incrementa con el tiempo, las baldosas no sufrirán curvaturas en diferido tras su cocción.

Se ha constatado que las baldosas con valores de absorción de agua inferiores al $0,2 \%$ no presentan curvaturas en diferido. 
2. Medida de la densidad aparente en cocido

La medida de la densidad aparente en cocido también es una buena opción para el control industrial debido a su rapidez y sencillez además de ser usada habitualmente en la industria cerámica.

Para evitar las curvaturas en diferido es necesario alcanzar un alto grado de cocción, es decir una densidad aparente en cocido elevada. A nivel industrial, es necesario determinar primero el valor umbral de densidad aparente por encima del cual las baldosas no sufren curvaturas en diferido, ya que este valor depende de la densidad real de la composición. Una vez determinado este valor, el uso de esta técnica es muy sencillo, rápido y eficaz para detectar lotes con problemas de curvaturas en diferido.

En general, las baldosas sin aditivos opacificantes con valores de densidad aparente superiores a $2380 \mathrm{~kg} / \mathrm{m}^{3}$ no experimentan curvaturas diferidas. 
6. Bibliografía

\section{Capítulo 6. Bibliografía}

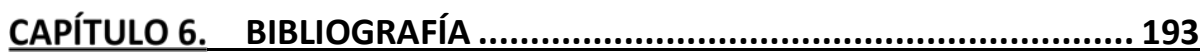

6.1. REFERENCIAS BIBLIOGRÁFICAS

195

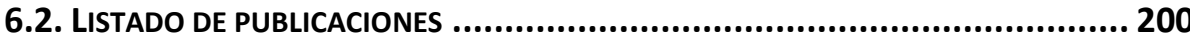

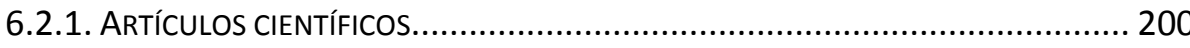

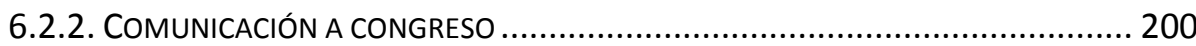


6. Bibliografía 


\subsection{REFERENCIAS BIBLIOGRÁFICAS}

Amorós et al., 1989

Amorós, J.L., Blasco, A., Carceller, J.V. y Sanz, V., 1989. Acuerdo esmalte-soporte (II): Expansión térmica de soportes y esmaltes cerámicos. Técnica Cerámica, 179, pp.644-657.

Amorós et al., 2007

Amorós, J.L., Orts, M.J., García-Ten, J., Gozalbo, A. y Sánchez, E., 2007. Effect of the green porous texture on porcelain tile properties. Journal of the European Ceramic Society, 27(5), pp.2295-2301.

Ashworth, 1969

Ashworth, D.R., 1969. A method of determining the bulk density of ceramics. J. Brit. Ceram. Soc., 6, p.70.

ASTM C 370-88

ASTM C 370 - 88(2012): 1988. Standard test method for moisture expansion of fired whiteware products.

Bernardin, 2006

Bernardin, A.M., Medeiros, D., da Silva, H.C. y Riella, H.G., 2006. La piroplasticidad del gres porcelánico. In Memorias del IX Congreso mundial de la calidad del azulejo y del pavimento cerámico, QUALICER. Cámara Oficial de Comercio, Industria y Navegación (pp. 207-213).

Cantavella, 1998

Cantavella Soler, V., 1998. Simulación de la deformación de baldosas cerámicas durante la cocción (Doctoral dissertation, PhD thesis).

Cantavella et al., 2006

Cantavella, V., Moreno, A., Mezquita, A., Llorens, D., Barberá, J. y Palanques, A., 2006. Distribución de temperaturas en el interior de una pieza durante la cocción industrial. In el IX Congreso Mundial de la Calidad del Azulejo y del Pavimento Cerámico-Qualicer.

Cantavella et al., 2009

Cantavella, V., Moreno, A., Mezquita, A., Jarque, J.C., Barberá, J. y Palanques, A., 2009. Evolution of Stresses and Curvatures in Porous Bodies during Cooling. Tile Brick Int., pp. 58-63. 


\section{CTL, 2009}

Guía de mejores técnicas disponibles para el sector de fabricación de baldosas cerámicas en la Comunitat Valenciana; 2009, Centro de Tecnologías Limpias (CTL) - Conselleria de Medi Ambient, Aigua, Urbanisme i Habitatge- Generalitat Valenciana), Valencia (España)

De Noni et al., 2007

De Noni Junior, A., Hotza, D., Cantavella, V. y Vilches, E.J.S., 2007. Influencia del enfriamiento de la etapa de cocción sobre las propiedades mecánicas del gres porcelánico. Boletín de la Sociedad Española de Cerámica y Vidrio, 46(4), pp.163-170.

De Noni et al., 2011

De Noni, A., Hotza, D., Soler, V.C. y Vilches, E.S., 2010. Influence of composition on mechanical behaviour of porcelain tile. Part II: Mechanical properties and microscopic residual stress. Materials Science and Engineering: A, 527(7), pp.1736-1743.

Dondi et al., 1999

Dondi, M., Ercolani, G., Melandri, C., Mingazzini, C. y Marsigli, M., 1999. The chemical composition of porcelain stoneware tiles and its influence on microstructural and mechanical properties. Interceram, 48(2), pp.7583.

Dondi et al., 2014

Dondi, M., Raimondo, M. and Zanelli, C., 2014. Clays and bodies for ceramic tiles: Reappraisal and technological classification. Applied Clay Science, 96, pp.91-109.

\section{Escardino et al., 1985}

Escardino, A., Amorós, J.L. y Negre, F.C., 1985. Defectos de planaridad en las piezas de pavimento gresificado motivados por deformación piroplástica. Influencia de las variables del proceso. Taulells, 3.

\section{Flórez et al., 2009}

Flórez, E.N., Díaz, J.I., Dulce, H.J., Peña, G. y Sanchez, J., 2009. Efecto de la resistencia a la helada en baldosas cerámicas esmaltadas. Suplemento de la Revista Latinoamericana de Metalurgia y Materiales, S1 (1), pp. 377-381.

García-Ten et al., 2004

García-Ten, J., Sánchez, E., Mallol, G., Jarque, J.C. y Arroyo, A., 2004. Influence of operating variables on spray-dried granule and resulting tile characteristics. In Key Engineering Materials (Vol. 264, pp. 1499-1502). Trans Tech Publications. 
Gualtieri, 2007

Gualtieri, A.F., 2007. Thermal Behavior of the Raw Materials Forming Porcelain Stoneware Mixtures by Combined Optical and In Situ X-Ray Dilatometry. Journal of the American Ceramic Society, 90(4), pp.12221231.

Harrison et al., 1964

Harrison, R y, Dinsdale. A.,1964. The effect of temperature and pressure on moisture expansion. Trans. Br. Ceram. Soc, 63, pp.63-75.

ISO 13006

ISO 13006: 2012. Ceramic tiles - Definitions, classification, characteristics and marking.

ITC, 1991

Defectos de fabricación de pavimentos y revestimientos cerámicos. 1991. Instituto de Tecnología Cerámica, Castellón (España).

ITC, 2002

Materias primas para la fabricación de soportes de baldosas cerámicas. 2002. Instituto de Tecnología Cerámica, Castellón (España).

IVE, 2011

Guía de la Baldosa Cerámica: el vademecum de la baldosa cerámica, para su clasificación, su elección, materiales de agarre y rejuntado, la redacción del proyecto, el control de la obra, el uso y el mantenimiento. 6a edición, 2011. Instituto Valenciano de la Edificación. Generalitat Valenciana, Valencia (España).

Manfredi et al., 1996

Manfredini, T., Romagnoli, M. y Rincón, J.M., 1996. Gres porcelánico: aplicaciones arquitectónicas, procesado y propiedades físico-mecánicas. Materiales de construcción, (242), pp.107-118.

Mari, 1982

Mari, E.A., 1982. Los vidrios: propiedades, tecnologías de fabricación y aplicaciones. Editorial Americalee.

Martín-Marquez et al., 2008

Martín-Márquez, J., Rincón, J.M. y Romero, M., 2008. Effect of firing temperature on sintering of porcelain stoneware tiles. Ceramics International, 34(8), pp.1867-1873. 
6. Bibliografía

Pakowski et al., 2006

Pakowski, Z. y Mujumdar, A.S, 2006. Basic process simulation and calculation in drying. En Handbook of industrial drying. CRC Press., pp. 53-80.

Prime, 1999

Prime, M.B., 1999. Residual stress measurement by successive extension of a slot: the crack compliance method. Applied Mechanics Reviews, 52(2), pp.75-96.

Quereda et al., 2012

Quereda, M.F., Saburit, A., Ten, F.G., Lorente, M.M., Gimeno, C. y Sánchez, A., 2012. Uso del flexímetro óptico para evaluar la tendencia a deformar durante la cocción de soportes y baldosas cerámicas. Técnica Cerámica, 398, pp. 190-192.

Raimondo et al., 2010

Raimondo, M., Dondi, M., Zanelli, C., Guarini, G., Gozzi, A., Marani, F. y Fossa, L., 2010. Processing and properties of large-sized ceramic slabs. Boletín de la Sociedad Española de Cerámica y Vidrio, 49(4), pp.289-295.

Sánchez et al., 2001

Sanchez, E., Orts, M.J., Garcia-Ten, J. y Cantavella, V., 2001. Porcelain tile composition effect on phase formation and end products. American Ceramic Society Bulletin, 80(6), pp.43-49.

Sánchez et al., 2006

Sánchez, E., García-Ten, J. y Regueiro, M., 2006. Materias para la industria cerámica española. Situación actual y perspectivas. Bol. Soc. Esp. Ceram, 45(1), pp.1-12.

Sánchez et al., 2010

Sánchez, E., García-Ten, J., Sanz, V. y Moreno, A., 2010. Porcelain tile: almost 30 years of steady scientific-technological evolution. Ceramics International, 36(3), pp.831-845.

Schurecht et al., 1929

Schurecht, H.G. y Pole, G.R., 1929. Effect of water in expanding ceramic bodies of different compositions. Journal of the American Ceramic Society, 12(9), pp.596-614.

Segadäes et al., 2003

Segadães, A.M., Carvalho, M.A. y Ferreira, H.C., 2003. Using phase diagrams to deal with moisture expansion. Ceramics international, 29(8), pp.947-954. 
Smith, 1955

Smith, A.N., 1955. Investigations on the moisture expansion of porous ceramic bodies. Trans. Brit. Ceram. Soc, 54(5), pp.300-18.

Stringer et al., 1970

Stringer, R.K. y Mckinnon, N.A., 1970 On a method of determining the bulk density of ceramics. J. Br. Ceram. Soc., 7 (1).

Tenorio Cavalcante et al., 2004

Tenorio Cavalcante, P., Dondi, M., Ercolani, G., Guarini, G., Melandri, C., Raimondo, M. y Almendra, E.R., 2004. The influence of microstructure on the performance of white porcelain stoneware. Ceramics international, 30(6), pp.953-963.

Timoshenko, 1925

Timoshenko, S., 1925. Analysis of bi-metal thermostats. JOSA, 11(3), pp.233-255.

UNE-EN 14411

UNE-EN 14411: 2013. Baldosas cerámicas. Definiciones, clasificación, características, evaluación de la conformidad y marcado.

UNE-EN ISO 10545-10

UNE-EN ISO 10545-10: 1997. Baldosas cerámicas. Parte 10: determinación de la dilatación por humedad.

Vasic, 1992

Vasic, R.M., 1992. Influence of pore-size distribution on frost resistance and moisture expansion of bricks. IMS Inst. Bull., 7(1), pp.15-18.

Zanelli, 2011

Zanelli, C., Raimondo, M., Guarini, G. y Dondi, M., 2011. The vitreous phase of porcelain stoneware: composition, evolution during sintering and physical properties. Journal of Non-Crystalline Solids, 357(16), pp.32513260. 


\subsection{LISTADO DE PUBLICACIONES}

\subsubsection{Artículos científicos}

Además, los resultados obtenidos en el marco de esta tesis doctoral han dado lugar a las siguientes publicaciones científicas, que vienen recopiladas en el anexo 5 de esta tesis:

- Bannier, E., García-Ten, J., Castellano, J. y Cantavella, V., 2013. Delayed curvature y residual stresses in porcelain tiles. Journal of the European Ceramic Society, 33(3), pp.493-501. (véase el anexo 5, p. 239)

- Cantavella, V., García-Ten, J., Sánchez, E., Bannier, E., Sánchez, J., Soler, C. y Sales, J., 2009. Curvaturas diferidas en gres porcelánico. Análisis y medida de los factores que intervienen. Cerámica Información, 359, pp. 95-109. (véase el anexo 5, p. 251)

- Cantavella, V., García -Ten, J., Sánchez, E., Bannier, E., Sánchez, J., Soler, C. y Sales, J., 2008. Delayed Curvatures in Porcelain Tiles. Analysis and measurement of influencing factors. Cfi Ber. DKG, 85(6), pp. 50-58. (véase el anexo 5, p. 269)

\subsubsection{Comunicaciones a congresos}

Como resultado de esta tesis doctoral, se ha realizado la siguiente comunicación a congreso:

- Cantavella, V., García-Ten, J., Sánchez, E., Bannier, E., Sánchez, J., Soler, C. y Sales, J Curvaturas diferidas en gres porcelánico. Análisis y medida de los factores que intervienen. (ponencia)

X QUALICER. Congreso mundial de la calidad del azulejo y del pavimento cerámico Castellón 10 - 13 Febrero 2008

En: Qualicer 2008: X Congreso mundial de la calidad del azulejo y del pavimento cerámico. Castellón: Cámara oficial de comercio, industria y navegación, 2008. pp. P.BC207-P.BC224. 


\section{ANEXOS}

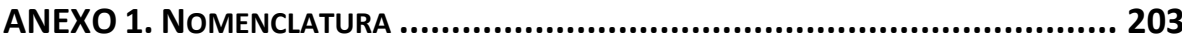

ANEXO 2. MEDIDA DE LAS TENSIONES RESIDUALES DE ACOPLAMIENTO ESMALTE-ENGOBE-SOPORTE

ANEXO 3. MEDIDA DE LAS TENSIONES RESIDUALES POR EL MÉTODO DE RELAJACIÓN DE LA DEFORMACIÓN POR CORTE INCREMENTAL.

ANEXO 4. RESOLUCIÓN DE LA ECUACIÓN DE DIFUSIÓN CON COEFICIENTE DE

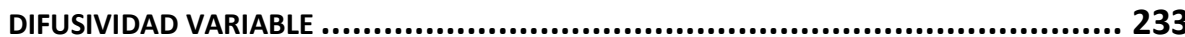

ANEXO 5. ARTÍCULOS PUBLICADOS .................................................. 237 
Anexos 


\section{Anexo 1. Nomenclatura}


Nomenclatura 
Nomenclatura

\begin{tabular}{|c|c|c|}
\hline \multicolumn{2}{|c|}{ Símbolos latinos } & \multirow{2}{*}{$\begin{array}{c}\begin{array}{c}\text { Apartado primera } \\
\text { aparición }\end{array} \\
4.4 .1\end{array}$} \\
\hline A1 & $\begin{array}{l}\text { flecha final que alcanzaría la pieza si sólo } \\
\text { existiera el primer proceso (el que produce la } \\
\text { curvatura convexa) en el modelo matemático } \mathrm{A}\end{array}$ & \\
\hline A2 & $\begin{array}{l}\text { flecha final que alcanzaría la pieza si sólo } \\
\text { existiera el segundo proceso (el que produce la } \\
\text { curvatura cóncava) en el modelo matemático A }\end{array}$ & 4.4.1. \\
\hline AA & absorción de agua & 3.4.7. \\
\hline $\mathrm{AA}_{3}$ días & $\begin{array}{l}\text { absorción de agua después de } 3 \text { días de } \\
\text { inmersión }\end{array}$ & 4.3.2. \\
\hline $\mathrm{AA}_{7 \text { días }}$ & $\begin{array}{l}\text { absorción de agua después de } 7 \text { días de } \\
\text { inmersión }\end{array}$ & 4.2.4. \\
\hline a & longitud aparente de una probeta curvada & 4.2.7. \\
\hline$a x$ & Constante adimensional & 4.2.7. \\
\hline$a_{n}$ & $\begin{array}{l}\text { Profundidad de la entalla en el ensayo de } \\
\text { medida de tensiones por corte incremental }\end{array}$ & 3.4.5. \\
\hline \multirow{2}{*}{ b } & anchura & 3.4.4. \\
\hline & constante adimensional & 4.2 .7$. \\
\hline bx & constante adimensional & 4.2.7. \\
\hline Cs & contracción del soporte & 1.2 .1 \\
\hline $\mathrm{Cv}$ & contracción del esmalte & 1.2 .1 \\
\hline CV & cara vista & 4.2 .8$. \\
\hline c & factor que desencadena la expansión & 4.4.3. \\
\hline D & coeficiente de difusividad del soporte & 4.4.3. \\
\hline $\mathrm{D}^{\mathrm{CO}}$ & $\begin{array}{l}\text { coeficiente de difusividad del soporte en la } \\
\text { superficie de la costilla }\end{array}$ & 4.4.4. \\
\hline $\mathrm{D}^{\mathrm{CV}}$ & $\begin{array}{l}\text { coeficiente de difusividad del soporte en la cara } \\
\text { vista }\end{array}$ & 4.4.4. \\
\hline \multirow[t]{2}{*}{ E } & $\begin{array}{l}\text { empuje de una probeta medida por inmersión } \\
\text { en mercurio }\end{array}$ & 3.4.1. \\
\hline & módulo de elasticidad & 3.4.4. \\
\hline$E^{\prime}$ & módulo de elasticidad adimensional $\left(E / E_{s}\right)$ & Anexo 2 \\
\hline$E_{\text {ef }}$ & módulo de elasticidad efectivo & 3.4.4. \\
\hline
\end{tabular}




\begin{tabular}{|c|c|c|}
\hline$E_{\text {ef }}^{\prime}$ & $\begin{array}{l}\text { módulo de elasticidad efectivo adimensional } \\
\left(E_{e f} / E_{s}\right)\end{array}$ & 4.4.2. \\
\hline$E_{e f, g}$ & $\begin{array}{l}\text { módulo de elasticidad efectivo de las probetas } \\
\text { formadas por } 2 \text { láminas (soporte }+ \text { engobe) }\end{array}$ & Anexo 2 \\
\hline$E^{\prime}$ ef,g & $\begin{array}{l}\text { módulo de elasticidad efectivo adimensional de } \\
\text { las probetas formadas por } 2 \text { láminas }\left(E_{e f, g} / E_{s}\right)\end{array}$ & Anexo 2 \\
\hline$E_{e f, g v}$ & $\begin{array}{l}\text { módulo de elasticidad efectivo de las probetas } \\
\text { formadas por } 3 \text { láminas (soporte }+ \text { engobe }+ \\
\text { vidriado) }\end{array}$ & Anexo 2 \\
\hline$E_{\text {eftgv }}^{\prime}$ & $\begin{array}{l}\text { módulo de elasticidad efectivo adimensional de } \\
\text { las probetas formadas por } 3 \text { láminas }\left(E_{e f, g v} / E_{s}\right)\end{array}$ & Anexo 2 \\
\hline$E_{g}$ & módulo de elasticidad del engobe & 4.2.8. \\
\hline E'g & $\begin{array}{l}\text { módulo de elasticidad adimensional del } \\
\text { engobe }\left(E_{g} / E_{s}\right)\end{array}$ & Anexo 2 \\
\hline $\mathrm{EH}$ & expansión por humedad & 4.5.2. \\
\hline$E_{s}$ & módulo de elasticidad del soporte & 4.2.8. \\
\hline $\mathrm{E}_{\mathrm{v}}$ & módulo de elasticidad del vidriado & 4.2 .8$. \\
\hline$E_{v}^{\prime}$ & $\begin{array}{l}\text { módulo de elasticidad adimensional del } \\
\text { vidriado }\left(\mathrm{E}_{\mathrm{v}} / \mathrm{E}_{\mathrm{s}}\right)\end{array}$ & 4.4.2. \\
\hline $\mathrm{F}$ & fuerza & 3.4.4. \\
\hline$F_{R}$ & carga de rotura & 3.4.4. \\
\hline $\mathrm{Fo}_{\mathrm{O}}$ & número de Fourier & Anexo 4 \\
\hline $\mathrm{GD}_{\mathrm{D}}$ & cizalla diferida & 4.2.9. \\
\hline$g$ & engobe & 3.4.4. \\
\hline $\mathrm{h}$ & espesor & 3.4.4. \\
\hline$h_{1}$ & $\begin{array}{l}\text { espesor de soporte que ha sufrido expansión } \\
\text { en el modelo matemático B }\end{array}$ & 4.4.2. \\
\hline $\mathrm{h}_{2}$ & \begin{tabular}{|l|l} 
espesor de soporte que no ha sufrido \\
expansión en el modelo matemático B
\end{tabular} & 4.4.2. \\
\hline$h_{2}$ & cociente $h_{2} / h_{1}$, en el modelo matemático $B$ & 4.4.2. \\
\hline $\mathrm{h}_{\mathrm{g}}$ & espesor del engobe & 4.2.8. \\
\hline $\mathrm{h}_{\mathrm{g}}$ & espesor adimensional del engobe $\left(h_{g} / h_{s}\right)$ & Anexo 2 \\
\hline$h_{s}$ & espesor del soporte $\left(h_{s}=h_{1}+h_{2}\right)$ & 4.2.8. \\
\hline$h_{v}$ & espesor del vidriado & 4.2.8. \\
\hline
\end{tabular}


Nomenclatura

\begin{tabular}{|c|c|c|}
\hline \multirow{2}{*}{ h'v } & cociente $h_{v} / h_{1}$ & 4.4.2. \\
\hline & espesor adimensional del esmalte $\left(h_{g} / h_{s}\right)$ & Anexo 2 \\
\hline i & $\begin{array}{l}\text { índice correspondiente a la longitud de la } \\
\text { entalla }\end{array}$ & Anexo 3 \\
\hline J & densidad de flujo de c & 4.4.3. \\
\hline k & $\begin{array}{l}\text { índice correspondiente al orden del polinomio } \\
\text { de Legendre }\end{array}$ & Anexo 3 \\
\hline $\mathrm{k}_{1}$ & constante & 4.4.1. \\
\hline $\mathrm{k}_{2}$ & constante & 4.4.1. \\
\hline $\mathrm{L}$ & longitud de una pieza o probeta & 4.2.7. \\
\hline M & momento & Anexo 2 \\
\hline $\mathrm{m}$ & masa & 3.4.1. \\
\hline $\mathrm{ma}$ & masa de agua absorbida por una pieza & 3.4.7. \\
\hline $\mathrm{m}_{\mathrm{s}}$ & masa de una pieza seca & 3.4.7. \\
\hline$P_{k}$ & polinomio de Legendre de grado $\mathrm{k}$ & 3.4.5. \\
\hline $\mathrm{R}$ & residuo a $40 \mu \mathrm{m}$ & 4.3.3. \\
\hline \multirow{2}{*}{ S } & separación entre apoyos & 3.4.4. \\
\hline & sumada de cuadrados & Anexo 3 \\
\hline S & soporte & 3.4.4. \\
\hline $\mathrm{T}$ & temperatura & 1.2.1. \\
\hline Ta & $\begin{array}{l}\text { temperatura de acoplamiento efectivo del } \\
\text { esmalte }\end{array}$ & 1.2.1. \\
\hline $\mathrm{T}_{\mathrm{amb}}$ & temperatura ambiente & 1.2.1. \\
\hline$T_{\max }$ & temperatura de máxima densificación & 4.3.3. \\
\hline $\mathrm{T}_{\mathrm{R}}$ & temperatura de reblandecimiento del esmalte & 4.2.6. \\
\hline$T_{v}$ & temperatura de vitrificación & 4.3.3. \\
\hline $\mathrm{t}$ & tiempo & 3.4.9. \\
\hline $\mathrm{v}$ & vidriado & 3.4.4. \\
\hline Z & $\begin{array}{l}\text { posición de un punto de la pieza respecto a la } \\
\text { superficie de la costilla }\end{array}$ & 4.2.10. \\
\hline$z^{\prime}$ & Posición adimensional (z//hs) & Anexo 2 \\
\hline$Z_{0}$ & posición de la fibra neutra & 4.4.2. \\
\hline
\end{tabular}




\begin{tabular}{|l|l|c|}
\hline$z_{0}{ }^{\prime}$ & posición adimensional de la fibra neutra $\left(z_{0} / h_{s}\right)$ & 4.4 .2$. \\
\hline$z_{a i}$ & $\begin{array}{l}\text { penetración del azul de metileno por la cara } \\
\text { inferior de la baldosa }\end{array}$ & 4.3 .1$. \\
\hline$z_{a s}$ & $\begin{array}{l}\text { penetración del azul de metileno por la cara } \\
\text { superior de la baldosa }\end{array}$ & 4.3 .1$. \\
\hline
\end{tabular}

\begin{tabular}{|c|c|c|}
\hline \multicolumn{2}{|c|}{ Símbolos griegos } & \multirow{2}{*}{$\begin{array}{c}\text { Apartado primera } \\
\text { aparición }\end{array}$} \\
\hline$\alpha$ & coeficiente de dilatación & \\
\hline$\Delta \varepsilon$ & expansión diferencial & 4.4 .5$. \\
\hline$\Delta \varepsilon_{\mathrm{fg}}$ & $\begin{array}{l}\text { diferencia de expansión entre el engobe y el } \\
\text { soporte }\end{array}$ & Anexo 2 \\
\hline$\Delta \varepsilon_{\mathrm{fv}}$ & $\begin{array}{l}\text { diferencia de expansión entre el vidriado y el } \\
\text { soporte }\end{array}$ & Anexo 2 \\
\hline$\delta c$ & flecha central de curvatura & 3.4.4. \\
\hline$\delta_{c 1}$ & $\begin{array}{l}\text { flecha debido al primer proceso en el modelo } \\
\text { matemático } \mathrm{A}\end{array}$ & 4.4.1. \\
\hline$\delta_{\mathrm{C} 2}$ & $\begin{array}{l}\text { flecha debido al segundo proceso en el modelo } \\
\text { matemático } \mathrm{A}\end{array}$ & 4.4.1. \\
\hline$\delta_{\mathrm{CDv}}$ & flecha asociada a la deformación viscosa & 4.2.9. \\
\hline \multirow{2}{*}{$\varepsilon$} & deformación & 4.2 .9$. \\
\hline & porosidad & 4.5 .2 \\
\hline$\varepsilon_{0}$ & elongación & Anexo 2 \\
\hline$\varepsilon_{c}$ & expansión debido a la curvatura & 4.2.7. \\
\hline$\varepsilon d$ & deformación elástica diferida & 4.2 .9 . \\
\hline$\varepsilon_{\mathrm{e}}$ & deformación elástica & 4.2.9. \\
\hline$\varepsilon f$ & deformación libre & Anexo 2 \\
\hline$\varepsilon$ flex & flexión & Anexo 3 \\
\hline$\varepsilon_{g}$ & deformación de la galga & 3.4 .5 \\
\hline Elong & elongación & Anexo 3 \\
\hline Eth & expansión térmica & 4.2.7. \\
\hline
\end{tabular}


Nomenclatura

\begin{tabular}{|c|c|c|}
\hline$\varepsilon_{\text {th0 }}$ & expansión térmica inicial & 4.2.7. \\
\hline$\varepsilon v$ & deformación viscosa & 4.2.9. \\
\hline$\varepsilon_{\mathrm{x}}$ & expansión del soporte & 3.4.9. \\
\hline$\varepsilon_{X}^{c o}$ & $\begin{array}{l}\text { expansión del soporte en la superficie de la } \\
\text { costilla }\end{array}$ & 4.4.3. \\
\hline$\varepsilon_{X}^{c v}$ & expansión del soporte en la cara vista & 4.4.3. \\
\hline$\gamma_{\mathrm{ij}}$ & $\begin{array}{l}\text { factores de calibrado (medida de las tensiones } \\
\text { residuales de origen térmico) }\end{array}$ & 3.4.5. \\
\hline$\kappa$ & curvatura & 4.4.2. \\
\hline$\kappa^{\prime}$ & Curvatura adimensional (кh) & Anexo 2 \\
\hline$\lambda_{\mathrm{k}}$ & $\begin{array}{l}\text { coeficiente del polinomio de Legendre de grado } \\
\text { k (medida de las tensiones residuales de } \\
\text { origen térmico) }\end{array}$ & 3.4.5. \\
\hline$\eta$ & viscosidad & 4.2 .9$. \\
\hline$\rho$ & densidad aparente en cocido & 3.4.1. \\
\hline$\rho_{\mathrm{ap}}$ & densidad aparente & 4.5 .2 \\
\hline$\rho_{\mathrm{R}}$ & densidad real & 4.5 .2 \\
\hline$\rho_{\text {seco }}$ & densidad aparente en seco & 4.3.4. \\
\hline$\rho_{\mathrm{Hg}}$ & densidad del mercurio & 3.4.1. \\
\hline$\sigma$ & tensión & 4.2 .9$. \\
\hline$\sigma^{\prime}$ & Tensión adimensional $(\sigma / E)$ & Anexo 3 \\
\hline$\sigma g$ & tensión en el engobe & Anexo 2 \\
\hline$\sigma \mathrm{m}:$ & tensión máxima aplicada & 4.2 .9$. \\
\hline$\sigma_{\mathrm{R}}$ & resistencia mecánica & 3.4.4. \\
\hline$\sigma_{\mathrm{R}, \mathrm{ef}}$ & resistencia mecánica efectiva & Anexo 2 \\
\hline$\sigma_{\mathrm{Rg}}$ & $\begin{array}{l}\text { resistencia mecánica de las probetas formadas } \\
\text { por } 2 \text { láminas (soporte + engobe) }\end{array}$ & Anexo 2 \\
\hline$\sigma_{\mathrm{Rg}}{ }^{\prime}$ & $\begin{array}{l}\text { resistencia mecánica adimensional de las } \\
\text { probetas formadas por } 2 \text { láminas }\left(\sigma_{\mathrm{Rg}} / \mathrm{E}_{\mathrm{s}}\right)\end{array}$ & Anexo 2 \\
\hline$\sigma_{\mathrm{RS}}$ & resistencia mecánica del soporte $\left(\sigma_{\mathrm{RS}} / \mathrm{E}_{\mathrm{s}}\right)$ & Anexo 2 \\
\hline
\end{tabular}




\begin{tabular}{|c|c|c|}
\hline$\sigma_{\mathrm{RS}}{ }^{\prime}$ & resistencia mecánica adimensional del soporte & Anexo 2 \\
\hline$\sigma_{\mathrm{Rv}}$ & $\begin{array}{l}\text { resistencia mecánica de las probetas formadas } \\
\text { por } 3 \text { láminas (soporte + engobe + esmalte) }\end{array}$ & Anexo 2 \\
\hline$\sigma_{\mathrm{Rv}}{ }^{\prime}$ & $\begin{array}{l}\text { resistencia mecánica efectiva de las probetas } \\
\text { formadas por } 3 \text { láminas }\left(\sigma_{\mathrm{Rv}} / \mathrm{E}_{\mathrm{s}}\right)\end{array}$ & Anexo 2 \\
\hline$\sigma_{r}$ & tensión residual & 3.4.5. \\
\hline$\sigma_{\mathrm{s}}$ & tensión en el soporte & Anexo 2 \\
\hline$\sigma_{v}$ & tensión en el esmalte & Anexo 2 \\
\hline$\tau_{1}$ & $\begin{array}{l}\text { constante de tiempo del primer proceso en el } \\
\text { modelo matemático } \mathrm{A}\end{array}$ & 4.4.1. \\
\hline$\tau_{2}$ & $\begin{array}{l}\text { constante de tiempo del segundo proceso en el } \\
\text { modelo matemático } A\end{array}$ & 4.4.1. \\
\hline$\tau$ & constante de tiempo & 4.2.9. \\
\hline$\tau \mathrm{D}$ & cociente entre viscosidad y cizalla diferida & 4.2.9. \\
\hline$\tau \mathrm{x}$ & constante de tiempo & 4.2.7. \\
\hline$\xi$ & $\begin{array}{l}\text { coordenada adimensional de posición, para el } \\
\text { cálculo de las tensiones residuales de origen } \\
\text { térmico }\end{array}$ & 3.4.5. \\
\hline$\zeta$ & $\begin{array}{l}\text { grado de avance de la expansión, en el modelo } \\
\text { matemático B }\end{array}$ & 4.4.2. \\
\hline
\end{tabular}




\section{Anexo 2. \\ Medida de las tensiones residuales de acoplamiento esmalte-engobe-soporte}


Medida de las tensiones residuales de acoplamiento esmalte-engobe-soporte 


\section{A2.1. Cálculo de LAS tensiones Residuales}

En este anexo se describe el procedimiento de medida de las tensiones residuales por acoplamiento esmalte-engobe-soporte. A partir de los ensayos de flexión en 3 puntos realizados (véase los capítulos 3 y 4) se calcularon:

- los módulos de elasticidad de las distintas capas que forman una baldosa (soporte, engobe y esmalte),

- las tensiones residuales de acople esmalte-soporte.

Para ello, fue necesario generalizar la ecuación de Timoshenko [Timoshenko, 1925] a sistemas elásticos de tres láminas. A continuación, se describen las ecuaciones obtenidas tras esta generalización.

La deformación total puede escribirse como suma de una deformación elástica $\left(\varepsilon_{e}\right)$ más una deformación libre $(\varepsilon f)$ :

$$
\text { Ecuación } 1 \quad \varepsilon=\varepsilon_{\mathrm{e}}+\varepsilon_{\mathrm{f}}
$$

La deformación total también puede expresarse como suma de dos contribuciones: una elongación ( $\left.\varepsilon_{0}\right)$ y una flexión, llegando a la ecuación 2.

$$
\text { Ecuación } 2 \quad \varepsilon=\varepsilon_{0}+\kappa\left(\mathrm{z}-\mathrm{z}_{0}\right)
$$

Donde $\kappa$ es la curvatura (inversa del radio de curvatura) y zo es la posición de la fibra neutra. El balance de fuerzas y momentos conduce a:

$$
\begin{array}{ll}
\text { Ecuación 3 } & \mathrm{F}=0=\mathrm{b} \int_{0}^{\mathrm{h}} \mathrm{E}\left(\kappa\left(\mathrm{z}-\mathrm{z}_{0}\right)-\varepsilon_{\mathrm{f}}+\varepsilon_{0}\right) \mathrm{dz} \\
\text { Ecuación } 4 & \mathrm{M}=0=\mathrm{b} \int_{0}^{\mathrm{h}} \mathrm{E}\left(\kappa\left(\mathrm{z}-\mathrm{z}_{0}\right)-\varepsilon_{\mathrm{f}}+\varepsilon_{0}\right)\left(\mathrm{z}-\mathrm{z}_{0}\right) \mathrm{dz}
\end{array}
$$

En una viga sin deformaciones libres $(\varepsilon f=0)$ y sometida exclusivamente a flexión $\left(\varepsilon_{0}=0\right)$, la posición de la fibra neutra se obtiene a partir de la ecuación 3:

\section{Ecuación 5}

$$
z_{0}^{\prime}=\frac{z_{0}}{h_{s}}=1+\frac{E_{g}^{\prime} h_{g}^{\prime 2}+E_{v}^{\prime} h_{v}^{\prime}\left(2 h_{g}^{\prime}+h_{v}^{\prime}\right)-1}{2\left(E_{g}^{\prime} h_{g}^{\prime}+E_{v}^{\prime} h_{v}^{\prime}+1\right)}
$$


A partir de la ecuación 3 , también es posible calcular la elongación $\left(\varepsilon_{0}\right)$; es decir la deformación correspondiente a una expansión homogénea y que, por lo tanto, no provoca ninguna curvatura:

$$
\text { Ecuación } 6 \quad \varepsilon_{0}=\frac{E_{g}^{\prime} h_{g}^{\prime} \Delta \varepsilon_{f g}+E_{v}^{\prime} h_{v}^{\prime} \Delta \varepsilon_{f v}}{1+E_{g}^{\prime} h_{g}^{\prime}+E_{v}^{\prime} h_{v}^{\prime}}
$$

Por otra parte, la curvatura adimensional $\left(\kappa=\kappa h_{s}\right)$ de la probeta puede deducirse de la ecuación 4, llegando a:

$$
\text { Ecuación 7 } \quad \kappa^{\prime}=\frac{6}{\left(1+h_{g}^{\prime}+h_{v}^{\prime}\right)^{3} E_{e f}^{\prime}}\left[\begin{array}{l}
-E_{g}^{\prime} \Delta \varepsilon_{\mathrm{fg}}\left(1-z_{0}^{\prime}\right)^{2}+ \\
\left(E_{g}^{\prime} \Delta \varepsilon_{\mathrm{fg}}-\mathrm{E}_{\mathrm{v}}^{\prime} \Delta \varepsilon_{\mathrm{fv}}\right)\left(1+\mathrm{h}_{\mathrm{g}}^{\prime}-\mathrm{z}_{0}^{\prime}\right)^{2}+ \\
\mathrm{E}_{\mathrm{v}}^{\prime} \Delta \varepsilon_{\mathrm{fv}}\left(1+\mathrm{h}_{\mathrm{g}}^{\prime}+\mathrm{h}_{\mathrm{v}}^{\prime}-\mathrm{z}_{0}^{\prime}\right)^{2}
\end{array}\right]
$$

Utilizando la ley de comportamiento elástico se pueden obtener las tensiones:

Ecuación 8

$$
\frac{\sigma}{\mathrm{E}_{\mathrm{s}}}=\sigma^{\prime}=\mathrm{E}^{\prime}\left(\kappa^{\prime}\left(\mathrm{z}^{\prime}-\mathrm{z}_{0}^{\prime}\right)-\varepsilon_{\mathrm{f}}+\varepsilon_{0}\right)
$$

A partir de la ecuación 8, se deducen las tensiones residuales en cada capa:

- Tensiones residuales en el soporte:

$$
\text { Ecuación } 9 \quad \sigma_{\mathrm{s}}^{\prime}=\kappa^{\prime}\left(\mathrm{z}^{\prime}-\mathrm{z}_{0}^{\prime}\right)+\varepsilon_{0}
$$

- Tensiones residuales en el engobe:

$$
\text { Ecuación } 10 \quad \sigma_{g}^{\prime}=E_{g}^{\prime}\left(\kappa^{\prime}\left(z^{\prime}-z_{0}^{\prime}\right)\right)+\varepsilon_{0}-\Delta \varepsilon_{f g}
$$

- Tensiones residuales en el esmalte:

$$
\text { Ecuación } 11 \quad \sigma_{v}^{\prime}=E_{v}^{\prime}\left(\kappa^{\prime}\left(z^{\prime}-z_{0}^{\prime}\right)\right)+\varepsilon_{0}-\Delta \varepsilon_{f v}
$$




\section{A2.2. CÁLCULO DE $\Delta \varepsilon_{\mathrm{fg}} \mathrm{Y} \Delta \varepsilon_{\mathrm{fv}}$}

El cálculo $\Delta \varepsilon_{\mathrm{fg}}$ y $\Delta \varepsilon_{\mathrm{fv}}$ se basa en la determinación de la resistencia mecánica de una pieza de soporte (s) soporte + engobe $(s+g)$ y soporte + engobe + vidriado $(s+g+v)$ con la cara vista hacia arriba. En ensayos en flexión en tres puntos y piezas homogéneras, la resistencia mecánica $\sigma_{\mathrm{R}}$ se puede calcular como:

Ecuación 12 $\quad \sigma_{\mathrm{R}}=\frac{3}{2} \frac{\mathrm{S}}{\mathrm{bh}^{2}} \mathrm{~F}_{\mathrm{R}}$

En el caso de piezas laminadas, la aplicación de la Ecuación 12 conduce a una resistencia mecánica efectiva:

Ecuación 13 $\quad \sigma_{\mathrm{R}, \mathrm{ef}}=\frac{3}{2} \frac{\mathrm{S}}{\mathrm{bh}^{2}} \mathrm{~F}_{\mathrm{R}}$

Esta resistencia mecánica es efectiva porque considera la pieza como homogénea. Es necesario hacer una corrección que tenga en cuenta que el soporte y las capas de aplicación pueden tener módulos de elasticidad diferentes. Esta corrección conduce a una resistencia mecánica "real" del soporte.

Ecuación 14 $\frac{\sigma_{\mathrm{R}, \mathrm{c}}}{\sigma_{\mathrm{R}, \mathrm{efc}}}=\frac{2 \mathrm{z}_{0 \mathrm{c}}^{\prime}}{\mathrm{E}_{\mathrm{efc}}^{\prime}\left(1+\mathrm{h}_{\mathrm{g}}^{\prime}+\mathrm{h}_{\mathrm{v}}^{\prime}\right)}$

Donde $\mathrm{c}$ puede ser $\mathrm{g}$ o $\mathrm{v}$.

A partir de la Ecuación 14 se puede plantear las siguientes ecuaciones:

Ecuación 15

$$
\frac{\sigma_{\mathrm{Rg}}-\sigma_{\mathrm{Rs}}}{\mathrm{E}_{\mathrm{s}}}=\kappa_{\mathrm{g}} \mathrm{h}_{\mathrm{s}} \mathrm{z}_{0 \mathrm{~g}}^{\prime}-\frac{\mathrm{E}_{\mathrm{g}}^{\prime} \mathrm{h}_{\mathrm{g}}^{\prime} \Delta \varepsilon_{\mathrm{fg}}}{1+\mathrm{E}_{\mathrm{g}}^{\prime} \mathrm{h}_{\mathrm{g}}^{\prime}}
$$


Medida de las tensiones residuales de acoplamiento esmalte-engobe-soporte

Ecuación 16 $\frac{\sigma_{\mathrm{Rv}}-\sigma_{\mathrm{Rs}}}{\mathrm{E}_{\mathrm{s}}}=\kappa_{\mathrm{v}} \mathrm{h}_{\mathrm{s}} \mathrm{z}_{0 \mathrm{v}}^{\prime}-\frac{\mathrm{E}_{\mathrm{g}}^{\prime} \mathrm{h}_{\mathrm{g}}^{\prime} \Delta \varepsilon_{\mathrm{fg}}+\mathrm{E}_{\mathrm{v}}^{\prime} \mathrm{h}_{\mathrm{v}}^{\prime} \Delta \varepsilon_{\mathrm{fv}}}{1+\mathrm{E}_{\mathrm{g}}^{\prime} \mathrm{h}_{\mathrm{g}}^{\prime}+\mathrm{E}_{\mathrm{v}}^{\prime} \mathrm{h}_{\mathrm{v}}^{\prime}}$

Utilizando las ecuaciones anteriores se puede calcular $\Delta \varepsilon$ fg y $\Delta \varepsilon_{\mathrm{fv}}$ explícitamente:

Ecuación $17 \Delta \varepsilon_{\mathrm{fg}}=\frac{\mathrm{E}_{\mathrm{ef}, \mathrm{g}}^{\prime}\left(1+\mathrm{h}_{\mathrm{g}}^{\prime}\right)^{2}\left(1+\mathrm{E}_{\mathrm{g}}^{\prime} \mathrm{h}_{\mathrm{g}}^{\prime}\right)\left(\sigma_{\mathrm{Rg}}^{\prime}-\sigma_{\mathrm{Rs}}^{\prime}\right)}{\mathrm{E}_{\mathrm{g}}^{\prime} \mathrm{h}_{\mathrm{g}}^{\prime}\left(6 \mathrm{z}_{0}^{\prime}-\mathrm{E}_{\mathrm{efg}}^{\prime}\left(1+\mathrm{h}_{\mathrm{g}}^{\prime}\right)^{2}\right)}$

\section{Ecuación 18}

$$
\Delta \varepsilon_{\mathrm{fv}}=\frac{(1-\mathrm{c})\left(1+\mathrm{E}_{g}^{\prime} h_{\mathrm{g}}^{\prime}+\mathrm{E}_{\mathrm{v}}^{\prime} \mathrm{h}_{\mathrm{v}}^{\prime}\right)\left(\sigma_{\mathrm{Rv}}^{\prime}-\sigma_{\mathrm{Rs}}^{\prime}\right)-\left(\mathrm{c}+\mathrm{h}_{\mathrm{g}}^{\prime}-\mathrm{E}_{\mathrm{v}}^{\prime} \mathrm{h}_{\mathrm{v}}^{\prime}\left(\mathrm{h}_{\mathrm{g}}^{\prime}+\mathrm{h}_{\mathrm{v}}^{\prime}\right)\right) \mathrm{E}_{\mathrm{g}}^{\prime} \mathrm{h}_{\mathrm{g}}^{\prime} \Delta \varepsilon_{\mathrm{fg}}}{\left(\mathrm{c}+\mathrm{h}_{\mathrm{g}}^{\prime}+\left(1+\mathrm{E}_{g}^{\prime} \mathrm{h}_{\mathrm{g}}^{\prime}\right)\left(\mathrm{h}_{\mathrm{g}}^{\prime}+\mathrm{h}_{\mathrm{v}}^{\prime}\right)\right) \mathrm{E}_{\mathrm{v}}^{\prime} \mathrm{h}_{\mathrm{v}}^{\prime}}
$$

Donde:

Ecuación $19 \quad \mathrm{c}=1+\mathrm{h}_{\mathrm{g}}^{\prime}-\frac{\mathrm{E}_{\mathrm{ef}, \mathrm{gv}}^{\prime}\left(1+\mathrm{h}_{\mathrm{g}}^{\prime}+\mathrm{h}_{\mathrm{v}}^{\prime}\right)^{3}}{6 \mathrm{z}_{0}^{\prime}}$ 


\section{Anexo 3. Medida de las tensiones residuales por el método de relajación de la deformación por corte incremental}


Método de relajación de la deformación por corte incremental 


\section{A3.1. SistemAS HOMOgÉNEOS}

\section{A3.1.1. Introducción}

\section{A. Descomposición de deformaciones}

La deformación total en un punto de un sólido debido a la deformación elástica $\left(\varepsilon_{e}\right)$ y libre $\left(\varepsilon_{f}\right)$ es:

\section{Ecuación 1}

$$
\varepsilon=\varepsilon_{\mathrm{e}}+\varepsilon_{\mathrm{f}}
$$

El cambio dimensional de una pieza paralelepipédica (viga) se puede expresar como suma de dos contribuciones: una elongación o cambio de longitud (Elong) y una flexión o cambio de curvatura $(\varepsilon$ flex $)$ :

Ecuación 2

$$
\varepsilon=\varepsilon_{\text {long }}+\varepsilon_{\text {flex }}=\varepsilon_{0}+\kappa\left(\mathrm{z}-\mathrm{z}_{0}\right)
$$

Ecuación 3

$$
\varepsilon=\varepsilon_{\text {long }}+\varepsilon_{\text {flex }}=\left(\varepsilon_{0}-\kappa z_{0}\right)+\kappa Z
$$

La ecuación 3 indica que el perfil de deformaciones es lineal, pero no permite calcular de forma separada $\varepsilon_{0}$ y zo.

De la ecuación 1 y la ecuación 2:

Ecuación 4

Ecuación 5

$$
\frac{\sigma}{\mathrm{E}}=\sigma^{\prime}=\varepsilon_{\mathrm{e}}=\kappa\left(\mathrm{z}-\mathrm{z}_{0}\right)+\varepsilon_{0}-\varepsilon_{\mathrm{f}}
$$

\section{B. Balance de fuerzas}

Considerando una única lámina homogénea, el balance de fuerzas es:

$$
\mathrm{F}=0=\mathrm{b} \int_{0}^{\mathrm{h}} \mathrm{E}\left(\kappa\left(\mathrm{z}-\mathrm{z}_{0}\right)+\varepsilon_{0}-\varepsilon_{\mathrm{f}}\right) \mathrm{dz}
$$

Ecuación 6

$$
\kappa \int_{0}^{\mathrm{h}}\left(\mathrm{z}-\mathrm{z}_{0}\right) \mathrm{dz}=\int_{0}^{\mathrm{h}}\left(\varepsilon_{\mathrm{f}}-\varepsilon_{0}\right) \mathrm{dz}
$$

Si se imagina una viga sin deformaciones libres $(\varepsilon f=0)$ y sometida exclusivamente a flexión $\left(\varepsilon_{0}=0\right)$ se tiene: 
Método de relajación de la deformación por corte incremental

$$
\begin{gathered}
\kappa \int_{0}^{\mathrm{h}}\left(\mathrm{z}-\mathrm{z}_{0}\right) \mathrm{dz}=0 \\
\mathrm{z}_{0}=\frac{\int_{0}^{\mathrm{h}} \mathrm{zdz}}{\int_{0}^{\mathrm{h}} \mathrm{dz}}=\frac{\mathrm{h}}{2}
\end{gathered}
$$

Si el material está sometido a otros esfuerzos $\left(\varepsilon \notin \neq 0, \varepsilon_{0} \neq 0\right)$, considerando la definición anterior de $z_{0}$ se obtiene, de la ecuación 6 :

Ecuación 8

$$
\varepsilon_{0}=\frac{1}{\mathrm{~h}} \int_{0}^{\mathrm{h}} \varepsilon_{\mathrm{f}} \mathrm{dz}
$$

\section{Balance de momentos}

La aplicación del balance de momentos conduce a:

$$
\mathrm{M}=0=\mathrm{b} \int_{0}^{\mathrm{h}} \mathrm{E}\left(\kappa\left(\mathrm{z}-\mathrm{z}_{0}\right)+\varepsilon_{0}-\varepsilon_{\mathrm{f}}\right)\left(\mathrm{z}-\mathrm{z}_{0}\right) \mathrm{dz}
$$

Y combinando las expresiones anteriores:

Ecuación 9

$$
\kappa=\frac{\int_{0}^{\mathrm{h}} \varepsilon_{\mathrm{f}}\left(\mathrm{z}-\mathrm{z}_{0}\right) \mathrm{dz}}{\int_{0}^{\mathrm{h}}\left(\mathrm{z}-\mathrm{z}_{0}\right)^{2} \mathrm{dz}}
$$

\section{A3.1.2. Uso de los polinomios de Legendre en sistemas homogéneos}

Llegados a este punto es útil expresar \&f como un desarrollo de polinomios de Legendre:

Ecuación 10

$$
\varepsilon_{\mathrm{f}}(\zeta)=\sum_{\mathrm{k}=0}^{\infty} \lambda_{\mathrm{k}} \mathrm{P}_{\mathrm{k}}(\zeta)
$$

Los primeros polinomios de Legendre son: 


$$
\begin{aligned}
& P_{0}(x)=1 \\
& P_{1}(x)=x
\end{aligned}
$$

Ecuación 11

$$
\begin{aligned}
& P_{2}(x)=\frac{3}{2} x^{2}-\frac{1}{2} \\
& P_{3}(x)=\frac{5}{2} x^{3}-\frac{3}{2} x
\end{aligned}
$$

Estos polinomios tienen la propiedad de ser ortogonales en el intervalo [-1,1]:

Ecuación 12

$$
\int_{-1}^{1} \mathrm{P}_{\mathrm{n}}(\zeta) \mathrm{P}_{\mathrm{m}}(\zeta) \mathrm{d} \zeta=\frac{2}{2 \mathrm{n}+1} \delta_{\mathrm{mn}}
$$

Definiendo $\zeta$ como:

Ecuación 13

$$
\zeta=\frac{2(\mathrm{z}-\mathrm{h} / 2)}{\mathrm{h}}=\frac{2}{\mathrm{~h}}\left(\mathrm{z}-\frac{\mathrm{h}}{2}\right)=\frac{2 \mathrm{z}}{\mathrm{h}}-1
$$

Ecuación 14

$$
\mathrm{d} \zeta=\frac{2}{\mathrm{~h}} \mathrm{dz}
$$

Ecuación 15

$$
\frac{2 \mathrm{z}}{\mathrm{h}}=1+\zeta \quad \rightarrow \quad \mathrm{z}=\frac{\mathrm{h}}{2}(1+\zeta)
$$

Ecuación 16

$$
\mathrm{z}-\mathrm{z}_{0}=\mathrm{z}-\frac{\mathrm{h}}{2}=\frac{\mathrm{h}}{2}(1+\zeta)-\frac{\mathrm{h}}{2}=\frac{\mathrm{h}}{2} \zeta
$$

\section{A. Cálculo de la elongación عo}

De la ecuación 8:

Ecuación 17

$$
\varepsilon_{0}=\frac{1}{2} \int_{-1}^{1} \varepsilon_{\mathrm{f}} \mathrm{d} \zeta
$$

De ecuación 17 y la ecuación 10:

Ecuación 18

$$
\varepsilon_{0}=\frac{1}{2} \sum_{\mathrm{k}=0}^{\infty} \lambda_{\mathrm{k}} \int_{-1}^{1} \mathrm{P}_{\mathrm{k}}(\zeta) \mathrm{d} \zeta
$$


Método de relajación de la deformación por corte incremental

Ecuación 19

$$
\varepsilon_{0}=\frac{1}{2} \sum_{\mathrm{k}=0}^{\infty} \lambda_{\mathrm{k}} \frac{2}{2 \mathrm{k}+1} \delta_{\mathrm{k} 0}=\frac{1}{2} \lambda_{0} 2
$$

Ecuación 20

$$
\varepsilon_{0}=\lambda_{0}
$$

\section{B. Cálculo de la curvatura $\kappa$}

Utilizando la variable $\zeta$ :

$$
\kappa=\frac{\left(\frac{\mathrm{h}}{2}\right)^{2} \int_{-1}^{1} \varepsilon_{\mathrm{f}} \zeta \mathrm{d} \zeta}{\left(\frac{\mathrm{h}}{2}\right)^{2} \frac{\mathrm{h}}{2} \int_{-1}^{1} \zeta^{2} \mathrm{~d} \zeta}
$$

Ecuación 21

$$
\kappa^{\prime}=3 \int_{-1}^{1} \varepsilon_{\mathrm{f}} \zeta \mathrm{d} \zeta
$$

$$
\begin{aligned}
& \kappa^{\prime}=3 \sum_{\mathrm{k}=0}^{\infty} \lambda_{\mathrm{k}} \int_{-1}^{1} \mathrm{P}_{\mathrm{k}}(\zeta) \zeta \mathrm{d} \zeta \\
& \kappa^{\prime}=3 \sum_{\mathrm{k}=0}^{\infty} \lambda_{\mathrm{k}} \frac{2}{2 \mathrm{k}+1} \delta_{\mathrm{k} 1}=3 \lambda_{1} \frac{2}{3}
\end{aligned}
$$

Ecuación 22

$$
\kappa^{\prime}=2 \lambda_{1}
$$

\section{Cálculo del perfil de tensiones}

De la ecuación 5 se tiene:

$$
\sigma^{\prime}=\kappa\left(z-z_{0}\right)+\varepsilon_{0}-\varepsilon_{\mathrm{f}}
$$

De la ecuación 16:

Ecuación 23

$$
\mathrm{z}-\mathrm{z}_{0}=\frac{\mathrm{h}}{2} \zeta
$$




$$
\sigma^{\prime}=\frac{1}{2} \kappa^{\prime} \zeta+\varepsilon_{0}-\varepsilon_{\mathrm{f}}
$$

De la ecuación 20:

\section{Ecuación 24}

$$
\begin{aligned}
& \varepsilon_{0}=\lambda_{0} \\
& \sigma^{\prime}=\lambda_{1} \zeta+\lambda_{0}-\varepsilon_{\mathrm{f}}
\end{aligned}
$$

De la ecuación 10:

$$
\begin{array}{r}
\sigma^{\prime}=\lambda_{0}+\lambda_{1} \zeta-\lambda_{0}-\lambda_{1} \zeta-\sum_{\mathrm{k}=2}^{\infty} \lambda_{\mathrm{k}} \mathrm{P}_{\mathrm{k}}(\zeta) \\
\sigma^{\prime}=-\sum_{\mathrm{k}=2}^{\infty} \lambda_{\mathrm{k}} \mathrm{P}_{\mathrm{k}}(\zeta)
\end{array}
$$

Ecuación 25

La ecuación 25 básicamente indica que para conocer las tensiones residuales hay que determinar los coeficientes $\lambda_{k}$.

\section{A3.1.3. Cálculo de los coeficientes $\lambda$}

\section{A. Expansión de la deformación libre}

Haciendo un desarrollo utilizando los polinomios de Legendre, la deformación libre se puede escribir como:

\section{Ecuación 26}

$$
\varepsilon_{\mathrm{f}}=\sum_{\mathrm{k}=0}^{\mathrm{n}_{\mathrm{p}}-1} \varepsilon_{\mathrm{f}, \mathrm{k}}=\sum_{\mathrm{k}=0}^{\mathrm{n}_{\mathrm{p}}-1} \lambda_{\mathrm{k}} \mathrm{P}_{\mathrm{k}}(\zeta)
$$

Se considera un corte de profundidad $a_{i}$ y un solo término en la descomposición de ef (polinomio k-ésimo). Este corte provocará una deformación en galga:

$$
\hat{\varepsilon}_{\mathrm{g}}\left(\mathrm{a}_{\mathrm{i}}, \mathrm{P}_{\mathrm{k}}\right)=\gamma_{\mathrm{ik}}
$$

Por el principio de superposición:

$$
\hat{\varepsilon}_{g, i}=\hat{\varepsilon}_{g}\left(a_{i}\right)=\hat{\varepsilon}_{g}\left(a_{i}, \varepsilon_{f}\right)=\hat{\varepsilon}_{g}\left(a_{i}, \sum_{k=0}^{n_{p}-1} \lambda_{k} P_{k}\right)=\sum_{k=0}^{n_{p}-1} \lambda_{k} \hat{\varepsilon}_{g}\left(a_{i}, P_{k}\right)
$$


Método de relajación de la deformación por corte incremental

Ecuación 27

$$
\hat{\varepsilon}_{\mathrm{g}, \mathrm{i}}=\hat{\varepsilon}_{\mathrm{g}}\left(\mathrm{a}_{\mathrm{i}}\right)=\sum_{\mathrm{k}=0}^{\mathrm{n}_{\mathrm{p}}-1} \lambda_{\mathrm{k}} \gamma_{\mathrm{ik}}
$$

O utilizando la notación de Einstein (suma para los índices repetidos):

Ecuación 28

$$
\hat{\varepsilon}_{\mathrm{g}, \mathrm{i}}=\hat{\varepsilon}_{\mathrm{g}}\left(\mathrm{a}_{\mathrm{i}}\right)=\gamma_{\mathrm{ik}} \lambda_{\mathrm{k}}
$$

Índices:

i: $\quad$ longitud de la entalla

k: orden del polinomio

B. Cálculo de los factores $\lambda_{k}$. Ensayos por una cara.

a) Mínimos cuadrados

Se define la suma de los cuadrados como:

$$
\mathrm{S}=\sum_{\mathrm{i}=1}^{\mathrm{n}_{\mathrm{C}}}\left(\varepsilon_{\mathrm{g}}\left(\mathrm{a}_{\mathrm{i}}\right)-\hat{\varepsilon}_{\mathrm{g}}\left(\mathrm{a}_{\mathrm{i}}\right)\right)^{2}
$$

Donde la suma está extendida a todas las profundidades del corte. De la ecuación 28 :

Ecuación 29

$$
\mathrm{S}=\sum_{\mathrm{i}=1}^{\mathrm{n}_{\mathrm{C}}}\left(\varepsilon_{\mathrm{g}, \mathrm{i}}-\gamma_{\mathrm{ik}} \lambda_{\mathrm{k}}\right)^{2}
$$

Aplicando la condición de mínimo:

$$
\frac{\partial S}{\partial \lambda_{i}}=0 \rightarrow[\gamma]^{\mathrm{T}}[\gamma]\{\lambda\}=[\gamma]^{\mathrm{T}}\left\{\varepsilon_{\mathrm{g}}\right\}
$$

Ecuación 30

$$
\{\lambda\}=\left([\gamma]^{\mathrm{T}}[\gamma]\right)^{-1}[\gamma]^{\mathrm{T}}\left\{\varepsilon_{\mathrm{g}}\right\}
$$

Donde las llaves indican que la variable es un vector y los corchetes una matriz. La ecuación 30, por tanto, permite calcular de manera explícita los valores de $\lambda_{k}$ 


\section{A3.2. SistemAS LAMINADOS}

En los sistemas laminados la pieza puede no ser homogénea. El caso habitual de sistema laminado es aquel en que se quiere tomar en consideración la presencia de soporte, engobe y vidriado.

En este apartado se va a seguir un razonamiento similar, en la medida de lo posible, al planteado en los sistemas homogéneos.

\section{A3.2.1. Introducción}

\section{A. Descomposición de deformaciones}

La ecuación 5 adopta ahora la forma:

Ecuación 31

$$
\frac{\sigma}{\mathrm{E}_{\mathrm{j}}}=\sigma^{\prime}=\varepsilon_{\mathrm{e}}=\kappa\left(\mathrm{z}-\mathrm{z}_{0}\right)+\varepsilon_{0}-\varepsilon_{\mathrm{f}}
$$

\section{B. Balance de fuerzas}

Considerando una barra formada por una serie de láminas, el balance de fuerzas es:

$$
\mathrm{F}=0=\mathrm{b} \int_{0}^{\mathrm{h}} \mathrm{E}\left(\kappa\left(\mathrm{z}-\mathrm{z}_{0}\right)+\varepsilon_{0}-\varepsilon_{\mathrm{f}}\right) \mathrm{dz}
$$

Lo que conduce a:

Ecuación 32

$$
\mathrm{z}_{0}=\frac{\int_{0}^{\mathrm{h}} \mathrm{Ezdz}}{\int_{0}^{\mathrm{h}} \mathrm{Edz}}
$$

Ecuación 33

$$
\varepsilon_{0}=\frac{\int_{0}^{\mathrm{h}} \mathrm{E} \varepsilon_{\mathrm{f}} \mathrm{dz}}{\int_{0}^{\mathrm{h}} \mathrm{Edz}}
$$

\section{Balance de momentos}

Del balance de momentos:

$$
M=0=b \int_{0}^{h} E\left(\kappa\left(z-z_{0}\right)+\varepsilon_{0}-\varepsilon_{f}\right)\left(z-z_{0}\right) d z
$$


A partir de la ecuación anterior se llega a:

Ecuación 34

$$
\kappa=\frac{\int_{0}^{h} E \varepsilon_{f}\left(z-z_{0}\right) d z}{\int_{0}^{h} E\left(z-z_{0}\right)^{2} d z}
$$

\section{A3.2.2. Uso de los polinomios de Legendre en sistemas laminados}

Llegados a este punto se expresará \&f como un desarrollo de polinomios de Legendre. Se define:

Ecuación 35

$$
\begin{aligned}
& \mathrm{H}_{0}=0 \\
& \mathrm{H}_{\mathrm{j}+1}=\mathrm{H}_{\mathrm{j}}+\mathrm{h}_{\mathrm{j}} ; \quad \mathrm{j}=0,1, \ldots, \mathrm{n}_{\mathrm{L}}-1
\end{aligned}
$$

Por tanto:

Ecuación 36

$$
\mathrm{h}_{\mathrm{j}}=\mathrm{H}_{\mathrm{j}+1}-\mathrm{H}_{\mathrm{j}}
$$

En el caso de sistemas laminados, la deformación libre en la lámina j-ésima se escribe como:

Ecuación 37

$$
\varepsilon_{\mathrm{f}, \mathrm{j}}\left(\zeta_{\mathrm{j}}\right)=\sum_{\mathrm{k}=0}^{\mathrm{n}} \lambda_{\mathrm{jk}} \mathrm{P}_{\mathrm{jk}}\left(\zeta_{\mathrm{j}}\right)
$$

Donde $\zeta_{\mathrm{j}}$ es:

Ecuación 38

$$
\zeta_{\mathrm{j}}=\frac{2\left(\mathrm{z}-\mathrm{H}_{\mathrm{j}}\right)}{\mathrm{h}_{\mathrm{j}}}-1
$$

$\mathrm{Y}$, análogamente:

Ecuación 39

$$
\zeta_{\mathrm{j} 0}=\frac{2\left(\mathrm{z}_{0}-\mathrm{H}_{\mathrm{j}}\right)}{\mathrm{h}_{\mathrm{j}}}-1
$$


Los polinomios $\mathrm{P}_{\mathrm{jk}}$ se definen dentro de cada lámina como:

Ecuación $40 \quad \mathrm{P}_{\mathrm{jk}}\left(\zeta_{\mathrm{j}}\right)=\left\{\begin{array}{ccc}0 & \mathrm{si} & \zeta_{\mathrm{j}}<-1 \\ \mathrm{P}_{\mathrm{k}}\left(\zeta_{\mathrm{j}}\right) & \mathrm{si} & -1 \leq \zeta_{\mathrm{j}} \leq 1 \\ 0 & \mathrm{si} & \zeta_{\mathrm{j}}>1\end{array}\right.$

A partir de la ecuación 38 se tiene:

Ecuación 41

$$
\mathrm{d} \zeta_{\mathrm{j}}=\frac{2}{\mathrm{~h}_{\mathrm{j}}} \mathrm{dz}
$$

Ecuación 42

$$
\frac{2\left(\mathrm{z}-\mathrm{H}_{\mathrm{j}}\right)}{\mathrm{h}_{\mathrm{j}}}=1+\zeta_{\mathrm{j}} \quad \rightarrow \quad \mathrm{z}=\mathrm{H}_{\mathrm{j}}+\frac{\mathrm{h}_{\mathrm{j}}}{2}\left(1+\zeta_{\mathrm{j}}\right)
$$

\section{Ecuación 43}

$$
\mathrm{z}-\mathrm{z}_{0}=\mathrm{H}_{\mathrm{j}}+\frac{\mathrm{h}_{\mathrm{j}}}{2}\left(1+\zeta_{\mathrm{j}}\right)-\mathrm{H}_{\mathrm{j}}-\frac{\mathrm{h}_{\mathrm{j}}}{2}\left(1+\zeta_{\mathrm{j} 0}\right)=\frac{\mathrm{h}_{\mathrm{j}}}{2}\left(\zeta_{\mathrm{j}}-\zeta_{\mathrm{j} 0}\right)
$$

\section{A. Cálculo de la posición de la fibra neutra}

De la ecuación 32:

Ecuación $44 \quad \mathrm{z}_{0}=\frac{\int_{0}^{\mathrm{h}} \mathrm{Ezdz}}{\int_{0}^{\mathrm{h}} \mathrm{Edz}}$

Y operando:

$$
\mathrm{z}_{0}=\frac{\frac{1}{2} \sum_{\mathrm{j}=0}^{\mathrm{n}_{\mathrm{L}}-1} \mathrm{E}_{\mathrm{j}} \mathrm{h}_{\mathrm{j}}\left(2 \mathrm{H}_{\mathrm{j}}+\mathrm{h}_{\mathrm{j}}\right)}{\sum_{\mathrm{j}=0}^{\mathrm{n}_{\mathrm{L}}-1} \mathrm{E}_{\mathrm{j}} \mathrm{h}_{\mathrm{j}}}
$$


Método de relajación de la deformación por corte incremental

\section{B. Cálculo de la elongación عo}

De ecuación 33:

Ecuación 45

$$
\varepsilon_{0}=\frac{\sum_{\mathrm{j}=0}^{\mathrm{n}_{\mathrm{L}}-1} \mathrm{E}_{\mathrm{j}} \mathrm{h}_{\mathrm{j}} \lambda_{\mathrm{j} 0}}{\sum_{\mathrm{j}=0}^{\mathrm{n}_{\mathrm{L}}-1} \mathrm{E}_{\mathrm{j}} \mathrm{h}_{\mathrm{j}}}
$$

\section{Cálculo de la curvatura $\kappa$}

De la ecuación 34:

Ecuación 46

$$
\kappa^{\prime}=\frac{2 \sum_{\mathrm{j}=0}^{\mathrm{n}_{\mathrm{L}}-1} \mathrm{E}_{\mathrm{j}} \mathrm{h}_{\mathrm{j}}^{\prime 2}\left(\lambda_{\mathrm{j} 1}-3 \lambda_{\mathrm{j} 0} \zeta_{\mathrm{j} 0}\right)}{\sum_{\mathrm{j}=0}^{\mathrm{n}_{\mathrm{L}}-1} \mathrm{E}_{\mathrm{j}} \mathrm{h}_{\mathrm{j}}^{\prime 3}\left(3 \zeta_{\mathrm{j} 0}^{2}+1\right)}
$$

\section{Cálculo del perfil de tensiones}

De la ecuación 31 y operando:

Ecuación 47

Ecuación 48

Ecuación 49

$$
\begin{aligned}
& \mu_{\mathrm{j} 0}=\lambda_{\mathrm{j} 0}-\varepsilon_{0}+\frac{1}{2} \kappa^{\prime} \mathrm{h}_{\mathrm{j}}^{\prime} \zeta_{\mathrm{j} 0} \\
& \mu_{\mathrm{j} 1}=\lambda_{\mathrm{j} 1}-\frac{1}{2} \kappa^{\prime} \mathrm{h}_{\mathrm{j}}^{\prime} \\
& \mu_{\mathrm{jk}}=\lambda_{\mathrm{jk}} \quad \mathrm{k} \geq 2
\end{aligned}
$$




\section{A3.2.3. Cálculo de la deformación libre}

\section{A. Expansión de la deformación libre}

En el caso de sistemas laminados, la deformación libre en la lámina j-ésima se puede escribir como:

$$
\varepsilon_{\mathrm{f}, \mathrm{j}}\left(\zeta_{\mathrm{j}}\right)=\sum_{\mathrm{k}=0}^{\mathrm{n}_{\mathrm{p}}-1} \lambda_{\mathrm{jk}} \mathrm{P}_{\mathrm{jk}}\left(\zeta_{\mathrm{j}}\right)
$$

y la deformación libre total será:

$$
\varepsilon_{\mathrm{f}}(\zeta)=\sum_{\mathrm{j}=0}^{\mathrm{n}_{\mathrm{L}}-1} \varepsilon_{\mathrm{f}, \mathrm{j}}\left(\zeta_{\mathrm{j}}\right)=\sum_{\mathrm{j}=0}^{\mathrm{n}_{\mathrm{L}}-1} \sum_{\mathrm{k}=0}^{\mathrm{n}_{\mathrm{p}}-1} \lambda_{\mathrm{jk}} \mathrm{P}_{\mathrm{jk}}\left(\zeta_{\mathrm{j}}\right)
$$

Si se considera un corte de profundidad $a_{i}$ y sólo un término en la descomposición de ef (lámina j-ésima y polinomio k-ésimo), la deformación provocada en la posición en que se encuentra la galga será:

$$
\hat{\varepsilon}_{\mathrm{g}}\left(\mathrm{a}_{\mathrm{i}}, \mathrm{P}_{\mathrm{jk}}\right)=\gamma_{\mathrm{ijk}}
$$

Por el principio de superposición:

$$
\begin{gathered}
\hat{\varepsilon}_{g, i}=\hat{\varepsilon}_{g}\left(a_{i}\right)=\hat{\varepsilon}_{g}\left(a_{i}, \varepsilon_{f}\right)=\hat{\varepsilon}_{g}\left(a_{i}, \sum_{j=0}^{n_{L}-1} \sum_{k=0}^{n_{p}-1} \lambda_{j k} P_{j k}\right)=\sum_{j=0}^{n_{L}-1} \sum_{k=0}^{n_{p}-1} \lambda_{j k} \hat{\varepsilon}_{g}\left(a_{i}, P_{j k}\right) \\
\text { Ecuación } 50 \\
\hat{\varepsilon}_{g, i}=\hat{\varepsilon}_{g}\left(a_{i}\right)=\sum_{j=0}^{n_{L}-1} \sum_{k=0}^{n_{p}-1} \lambda_{j k} \gamma_{i j k}
\end{gathered}
$$

Utilizando la notación de Einstein:

$$
\text { Ecuación } 51 \quad \hat{\varepsilon}_{\mathrm{g}, \mathrm{i}}=\hat{\varepsilon}_{\mathrm{g}}\left(\mathrm{a}_{\mathrm{i}}\right)=\gamma_{\mathrm{ijk}} \lambda_{\mathrm{jk}}
$$

Índices:

i: $\quad$ profundidad de la entalla $(\mathrm{i}=0,1, \ldots, \mathrm{nc}-1)$ 
Método de relajación de la deformación por corte incremental

$\mathrm{j}: \quad$ lámina $\left(\mathrm{j}=0,1, \ldots, \mathrm{nL}_{\mathrm{L}}-1\right)$

$\mathrm{k}$ : $\quad$ orden del polinomio $(\mathrm{k}=0,1, \ldots, \mathrm{np}-1)$

B. Cálculo de los factores $\lambda_{k}$. Ensayos realizados haciendo el corte por una cara

Se define la suma de los cuadrados:

$$
\mathrm{S}=\sum_{\mathrm{i}=1}^{\mathrm{n}_{\mathrm{C}}}\left(\varepsilon_{\mathrm{g}}\left(\mathrm{a}_{\mathrm{i}}\right)-\hat{\varepsilon}_{\mathrm{g}}\left(\mathrm{a}_{\mathrm{i}}\right)\right)^{2}
$$

De la ecuación 51:

Ecuación 52

$$
\mathrm{S}=\sum_{\mathrm{i}=1}^{\mathrm{n}_{\mathrm{C}}}\left(\varepsilon_{\mathrm{g}, \mathrm{i}}-\gamma_{\mathrm{ijk}} \lambda_{\mathrm{jk}}\right)^{2}
$$

Aplicando la condición de mínimo:

$$
\begin{aligned}
& \frac{\partial S}{\partial \lambda_{m n}}=0 \\
& -2 \sum_{i=1}^{n_{C}}\left(\varepsilon_{g, i}-\gamma_{i j k} \lambda_{j k}\right) \gamma_{i m n}=0 \\
& \sum_{i=1}^{n_{C}} \gamma_{i m n} \gamma_{i j k} \lambda_{j k}=\sum_{i=1}^{n_{C}} \gamma_{i m n} \varepsilon_{g, i}
\end{aligned}
$$

Ecuación 53

$$
\gamma_{\mathrm{imn}} \gamma_{\mathrm{ijk}} \lambda_{\mathrm{jk}}=\gamma_{\mathrm{imn}} \varepsilon_{\mathrm{g}, \mathrm{i}}
$$

Se trata de un sistema de $\mathrm{n}_{\mathrm{T}}=\mathrm{n}_{\llcorner} \mathrm{n}_{\mathrm{P}}$ ecuaciones con $\mathrm{n}_{\mathrm{T}}$ incógnitas.

C. Cálculo de los factores $\lambda_{k}$. Combinación de dos ensayos realizado el corte por cada una de las caras.

a) Uso de una galga

El mismo procedimiento de cálculo es aplicable en el caso de que se hagan dos ensayos, uno empezando la entalla por la parte superior y el otro 
haciéndola por la inferior. En este caso es necesario calcular $\lambda_{\mathrm{ijk}}$ y $\lambda_{\mathrm{ijk}}^{*}$ de forma independiente (utilizando el método de los elementos finitos).

De la ecuación 37:

$$
\varepsilon_{\mathrm{f}, \mathrm{j}}\left(\zeta_{\mathrm{j}}\right)=\sum_{\mathrm{k}=0}^{\mathrm{n}_{\mathrm{p}}-1} \lambda_{\mathrm{jk}} \mathrm{P}_{\mathrm{jk}}\left(\zeta_{\mathrm{j}}\right)
$$

A partir de la cual se puede establecer la ecuación:

\section{Ecuación 54}

$$
\varepsilon_{\mathrm{g}, \mathrm{i}}=\gamma_{\mathrm{ijk}} \lambda_{\mathrm{jk}}
$$

Si se hace el corte comenzando por la cara inferior:

$$
\varepsilon_{\mathrm{f}, \mathrm{j}}^{*}\left(\zeta_{\mathrm{j}}\right)=\sum_{\mathrm{k}=0}^{\mathrm{n}_{\mathrm{p}}-1} \lambda_{\mathrm{jk}}^{*} \mathrm{P}_{\mathrm{jk}}\left(\zeta_{\mathrm{j}}\right)
$$

A partir de la ecuación anterior se llegaría a:

Ecuación 55

$$
\varepsilon_{\mathrm{g}, \mathrm{i}}^{*}=\gamma_{\mathrm{ijk}}^{*} \lambda_{\mathrm{jk}}^{*}
$$

$\varepsilon_{\mathrm{f}, \mathrm{j}}^{*}\left(\zeta_{\mathrm{j}}\right)$ se puede relacionar con $\varepsilon_{\mathrm{f}, \mathrm{j}}\left(\zeta_{\mathrm{j}}\right)$ :

$$
\begin{aligned}
& \varepsilon_{f, j}^{*}\left(\zeta_{j}\right)=\varepsilon_{f, j^{*}}\left(-\zeta_{j^{*}}\right)=\sum_{k=0}^{n_{p}-1} \lambda_{j^{*}, k} P_{j^{*}, k}\left(-\zeta_{j^{*}}\right)=\sum_{k=0}^{n_{p}-1}(-1)^{k} \lambda_{j^{*}, \mathrm{k}} P_{j^{*}, \mathrm{k}}\left(\zeta_{j^{*}}\right) \\
& j^{*}=n_{L}-j-1
\end{aligned}
$$

Por tanto:

$$
\lambda_{\mathrm{jk}}^{*}=(-1)^{\mathrm{k}} \lambda_{\mathrm{j}^{*}, \mathrm{k}}
$$

\section{Ecuación 56}

$$
\lambda_{\mathrm{jk}}^{*}=(-1)^{\mathrm{k}} \lambda_{\mathrm{n}_{\mathrm{L}}-1, \mathrm{k}}
$$


Método de relajación de la deformación por corte incremental

$$
\left\{\begin{array}{c}
\varepsilon_{\mathrm{g}, 1} \\
\varepsilon_{\mathrm{g}, 2} \\
\cdots \\
\varepsilon_{\mathrm{g}, \mathrm{n}_{\mathrm{C}}} \\
\varepsilon_{\mathrm{g}, 1}^{*} \\
\varepsilon_{\mathrm{g}, 2}^{*} \\
\ldots \\
\varepsilon_{\mathrm{g}, \mathrm{n}_{\mathrm{C}}}^{*}
\end{array}\right\}=\left[\begin{array}{cccc}
\gamma_{100} & \gamma_{101} & \cdots & \gamma_{1, \mathrm{n}_{\mathrm{L}}-1, \mathrm{n}_{\mathrm{P}}-1} \\
\gamma_{200} & \gamma_{201} & \cdots & \gamma_{2, \mathrm{n}_{\mathrm{L}}-1, \mathrm{n}_{\mathrm{P}}-1} \\
\cdots & \cdots & \cdots & \cdots \\
\gamma_{\mathrm{n}_{\mathrm{C}} 00} & \gamma_{\mathrm{n}_{\mathrm{C}} 01} & \cdots & \gamma_{\mathrm{n}_{\mathrm{C}}, \mathrm{n}_{\mathrm{L}}-1, \mathrm{n}_{\mathrm{P}}-1} \\
\gamma_{1, \mathrm{n}_{\mathrm{L}}-1,0}^{*} & -\gamma_{1, \mathrm{n}_{\mathrm{L}}-1,1}^{*} & \cdots & (-1)^{\mathrm{n}_{\mathrm{P}}-1} \gamma_{1, \mathrm{n}_{\mathrm{L}}-1, \mathrm{n}_{\mathrm{P}}-1}^{*} \\
\gamma_{2, \mathrm{n}_{\mathrm{L}}-1,0}^{*} & -\gamma_{2, \mathrm{n}_{\mathrm{L}}-1,1}^{*} & \cdots & (-1)^{\mathrm{n}_{\mathrm{P}}-1} \gamma_{2, \mathrm{n}_{\mathrm{L}}-1, \mathrm{n}_{\mathrm{P}}-1}^{*} \\
\ldots & \cdots & \cdots & \ldots \\
\gamma_{\mathrm{n}_{\mathrm{C}}, \mathrm{n}_{\mathrm{L}}-1,0}^{*} & -\gamma_{\mathrm{n}_{\mathrm{C}}, \mathrm{n}_{\mathrm{L}}-1,1}^{*} & \cdots & (-1)^{\mathrm{n}_{\mathrm{P}}-1} \gamma_{\mathrm{n}_{\mathrm{C}}, \mathrm{n}_{\mathrm{L}}-1, \mathrm{n}_{\mathrm{P}}-1}^{*}
\end{array}\right]\left\{\begin{array}{c}
\lambda_{00} \\
\lambda_{01} \\
\cdots \\
\lambda_{\mathrm{n}_{\mathrm{L}}-1, \mathrm{n}_{\mathrm{P}}-1}
\end{array}\right\}
$$

\section{b) Uso de dos galgas}

Las ecuaciones del apartado anterior pueden extenderse al cálculo con dos galgas, obteniéndose:

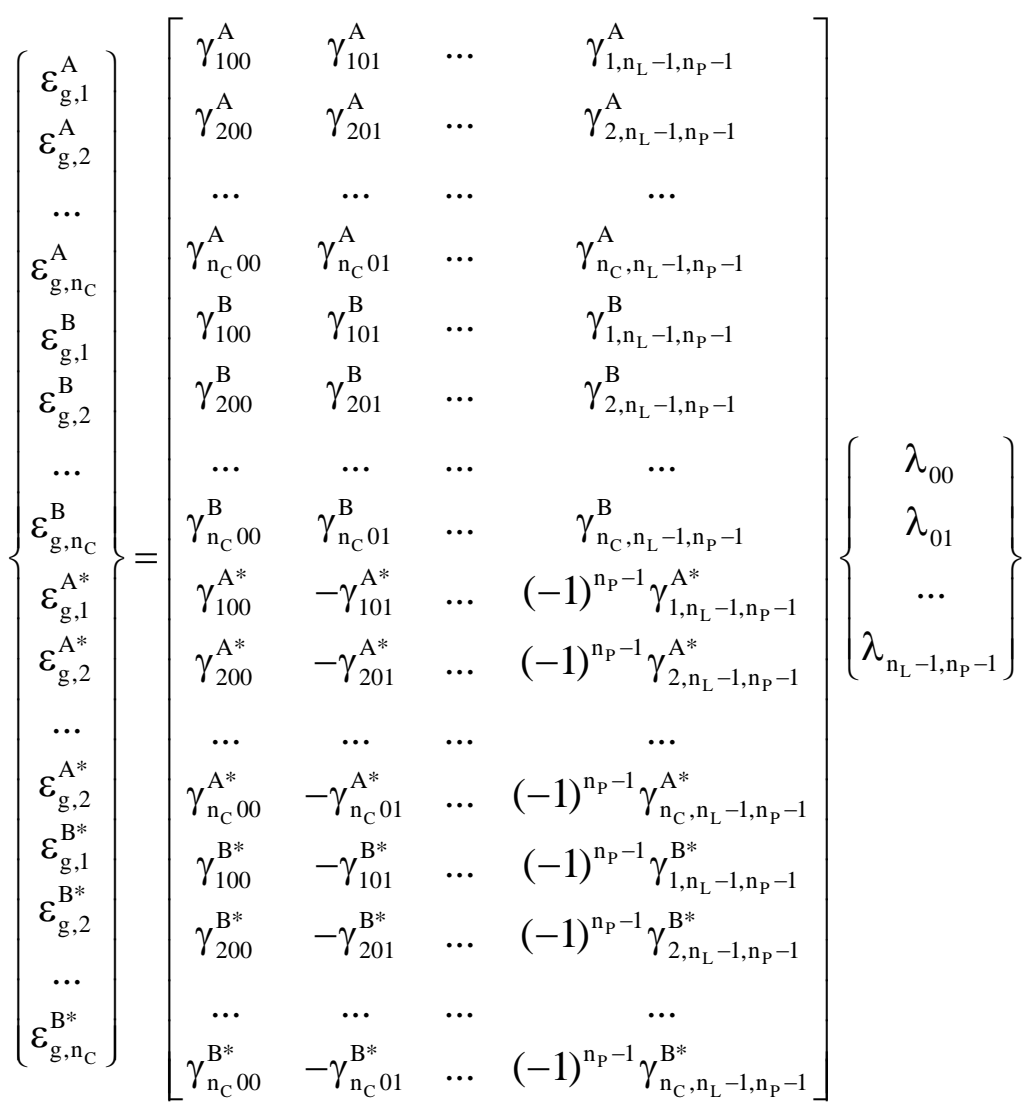




\section{Anexo 4. Resolución de la ecuación de difusión con coeficiente de difusividad variable}


Resolución de la ecuación de difusión con difusividad variable 
El modelo 3 plantea modelizar las curvaturas en diferido utilizando un coeficiente de difusividad que es una función lineal de la posición:

Ecuación 1

$$
D(z)=D^{c o}\left(1-z^{\prime}\right)+D^{c v}\left(1-z^{\prime}\right)
$$

Asimismo, la ecuación de difusión cuando $\mathrm{D}$ es variable adopta la forma:

Ecuación $2 \quad \frac{\partial \mathrm{c}}{\partial \mathrm{t}}=\frac{\partial}{\partial \mathrm{z}}\left(\mathrm{D} \frac{\partial \mathrm{c}}{\partial \mathrm{z}}\right)$

Para poder resolver la ecuación anterior es habitual realizar el siguiente cambio de variable:

Ecuación $3 \quad \mathrm{y}=\int_{0}^{\mathrm{z}} \frac{\mathrm{dz}}{\mathrm{D}(\mathrm{z})}$

Lo que permite escribir la ecuación de la difusión como:

Ecuación $4 \quad \frac{\partial \mathrm{c}}{\partial \mathrm{t}}=\mathrm{D}^{*} \frac{\partial^{2} \mathrm{c}}{\partial \mathrm{y}^{2}}$

donde:

Ecuación $5 \quad \mathrm{D}^{*}=\frac{1}{\mathrm{D}}$

A continuación, hay que aproximar las derivadas por cocientes de diferencias, lo que permite transformar la ecuación 4 en:

$$
\begin{aligned}
& \frac{\partial \mathrm{c}}{\partial \mathrm{t}} \approx \frac{\mathrm{c}_{\mathrm{i}}(\mathrm{t}+\Delta \mathrm{t})-\mathrm{c}_{\mathrm{i}}(\mathrm{t})}{\Delta \mathrm{t}}=\frac{\mathrm{c}_{\mathrm{i}}^{\prime}-\mathrm{c}_{\mathrm{i}}}{\Delta \mathrm{t}} \\
& \frac{\partial^{2} \mathrm{c}}{\partial \mathrm{y}^{2}} \approx \frac{\mathrm{c}_{\mathrm{i}-1}(\mathrm{t}+\Delta \mathrm{t})-2 \mathrm{c}_{\mathrm{i}}(\mathrm{t}+\Delta \mathrm{t})+\mathrm{c}_{\mathrm{i}+1}(\mathrm{t}+\Delta \mathrm{t})}{(\Delta \mathrm{y})^{2}}=\frac{\mathrm{c}_{\mathrm{i}-1}^{\prime}-2 \mathrm{c}_{\mathrm{i}}^{\prime}+\mathrm{c}_{\mathrm{i}+1}^{\prime}}{(\Delta \mathrm{y})^{2}} \\
& \mathrm{c}_{\mathrm{i}}^{\prime}-\mathrm{c}_{\mathrm{i}}=\frac{\mathrm{D}_{\mathrm{i}}^{*} \Delta \mathrm{t}}{\Delta \mathrm{y}^{2}}\left(\mathrm{c}_{\mathrm{i}-1}^{\prime}-2 \mathrm{c}_{\mathrm{i}}^{\prime}+\mathrm{c}_{\mathrm{i}+1}^{\prime}\right)
\end{aligned}
$$

Ecuación $6 \quad-\mathrm{Fo}_{i} \mathrm{c}_{\mathrm{i}-1}^{\prime}+\left(1+2 \mathrm{Fo}_{\mathrm{i}}\right) \mathrm{c}_{\mathrm{i}}^{\prime}-\mathrm{Fo}_{\mathrm{i}} \mathrm{c}_{\mathrm{i}+1}^{\prime}=\mathrm{c}_{\mathrm{i}} \quad 2 \leq \mathrm{i} \leq \mathrm{n}-2$ 
Resolución de la ecuación de difusión con difusividad variable

Donde se ha definido el número de Fourier como:

Ecuación $7 \quad \mathrm{Fo}_{\mathrm{i}}=\frac{\mathrm{D}_{\mathrm{i}}^{*} \Delta \mathrm{t}}{\Delta \mathrm{y}^{2}} \rightarrow \mathrm{Fo}_{\mathrm{i}}=\frac{\Delta \mathrm{t}}{\mathrm{D}_{\mathrm{i}} \Delta \mathrm{y}^{2}}$

En el caso de piezas no esmaltadas, las condiciones iniciales y de contorno adoptan la forma:

Ecuación 8

$$
\begin{aligned}
& \forall \mathrm{z} \quad \mathrm{t}=0 \rightarrow \mathrm{c}=0 \\
& \mathrm{z}=0 \mathrm{t}>0 \rightarrow \mathrm{c}=1 \\
& \mathrm{z}=\mathrm{h} \mathrm{t}>0 \rightarrow \mathrm{c}=1
\end{aligned}
$$

La aplicación de estas condiciones conduce a:

Ecuación $9 \quad\left(1+2 \mathrm{Fo}_{1}\right) \mathrm{c}_{1}^{\prime}-\mathrm{Fo}_{1} \mathrm{c}_{2}^{\prime}=\mathrm{c}_{1}+\mathrm{Fo}_{1} \quad \mathrm{i}=1$

Ecuación $10 \quad-\mathrm{Fo}_{\mathrm{n}-1} \mathrm{c}_{\mathrm{n}-2}^{\prime}+\left(1+2 \mathrm{Fo}_{\mathrm{n}-1}\right) \mathrm{c}_{\mathrm{n}-1}^{\prime}=\mathrm{c}_{\mathrm{n}-1}+\mathrm{Fo}_{\mathrm{n}-1} \quad \mathrm{i}=\mathrm{n}-1$

De la ecuación 7, la ecuación 9 y la ecuación 10:

\section{Ecuación 11}

$\left[\begin{array}{cccccc}1+2 \mathrm{Fo}_{1} & -\mathrm{Fo}_{1} & 0 & \ldots & 0 & 0 \\ -\mathrm{Fo}_{2} & 1+2 \mathrm{Fo}_{2} & -\mathrm{Fo}_{2} & \ldots & 0 & 0 \\ 0 & -\mathrm{Fo}_{3} & 1+2 \mathrm{Fo}_{3} & \ldots & 0 & 0 \\ \ldots & \ldots & \ldots & \ldots & \ldots & \ldots \\ 0 & 0 & 0 & \ldots & 1+2 \mathrm{Fo}_{n-2} & -\mathrm{Fo}_{n-2} \\ 0 & 0 & 0 & \ldots & -\mathrm{Fo}_{n-1} & 1+2 \mathrm{Fo}_{n-1}\end{array}\right]\left[\begin{array}{c}\mathrm{c}_{1}^{\prime} \\ \mathrm{c}_{2}^{\prime} \\ \mathrm{c}_{3}^{\prime} \\ \ldots \\ \mathrm{c}_{\mathrm{n}-2}^{\prime} \\ \mathrm{c}_{\mathrm{n}-1}^{\prime}\end{array}\right]=\left[\begin{array}{c}\mathrm{c}_{1}+\mathrm{Fo}_{1} \\ \mathrm{c}_{2} \\ \mathrm{c}_{3} \\ \ldots \\ \mathrm{c}_{n-2} \\ \mathrm{c}_{\mathrm{n}-1}+\mathrm{Fo}_{\mathrm{n}-1}\end{array}\right]$

La relación entre y y z se puede establecer a partir de la ecuación 3 y la ecuación 1, llegándose a:

Ecuación $12 \quad y=\frac{h}{D^{C V}-D^{C O}} \ln \left(1+\frac{D^{C V}-D^{C O}}{D^{C O}} \frac{z}{h}\right)$

La ecuación 11 se resolvió mediante un programa de ordenador escrito en Scilab. 


\section{Anexo 5. \\ Artículos científicos publicados}


Artículos científicos publicados 


\section{Artículo 1}

- Título: "Delayed curvature y residual stresses in porcelain tiles"

- Autores: Bannier, E., García-Ten, J., Castellano, J. y Cantavella, V.

- Revista: Journal of the European Ceramic Society 33(3), pp.493-501

- Año: 2013 
Artículos científicos publicados 


\title{
Delayed curvature and residual stresses in porcelain tiles
}

\author{
E. Bannier*, J. García-Ten, J. Castellano, V. Cantavella \\ Instituto de Tecnología Cerámica (ITC) - Asociación de Investigación de las Industrias Cerámicas (AICE), \\ Universitat Jaume I (UJI), Campus universitario Riu Sec. Av. Sos-Baynat, s/n. 12006 Castellón, Spain \\ Received 25 July 2012; received in revised form 20 September 2012; accepted 23 September 2012
}

Available online 27 October 2012

\begin{abstract}
Most industrial porcelain tiles suffer changes in their curvature after firing: such process is known as delayed curvature. One of the hypotheses used to explain this phenomenon is based on the relaxation of residual stresses by creep. In this study two types of industrial glazed porcelain tiles have been studied. One of them displayed delayed curvature after firing, whereas the other one presented a stable curvature. The main objective was to determine if the delayed curvatures were caused by the residual stresses generated during rapid industrial cooling. Both types of existing residual stresses (thermal stresses, caused by thermal gradients inside the tile during cooling, and body-glaze fit stresses, due to the thermal expansion mismatch between body and glaze) were measured, as well as related samples properties (elastic modulus, creep behaviour, thermal expansion). The results demonstrated that the residual stresses are not the main cause of the delayed curvature phenomenon. () 2012 Elsevier Ltd. All rights reserved.
\end{abstract}

Keywords: Traditional ceramics; Residual stress; Thermal expansion; Delayed curvature

\section{Introduction}

In the last years, the ceramic floor tile industry has evolved towards higher performance products such as porcelain stoneware, ${ }^{1}$ allowing the fabrication of larger tiles (up to $120 \mathrm{~cm} \times 120 \mathrm{~cm}$ ). This evolution of the product is associated with a greater technical complexity in both materials and process parameters, ${ }^{2-5}$ leading to the apparition of some manufacturing problems.

One of these problems is known as delayed curvature and corresponds to the modification of the tile curvature after firing, during periods of time of several days or even weeks. Although the delayed curvature is especially prejudicial in porcelain stoneware due to their large size, this problem is not specific of this kind of material; in fact, a similar phenomenon is widely observed in ceramic wall tiles, which are formed by a glazed porous body. ${ }^{6}$ In this kind of tiles, the curvature tends to a concave value with time before it stabilizes. Such behaviour can be explained by the expansion of the body, as a consequence of its high porosity (which is accessible by the environmental

\footnotetext{
* Corresponding author. Tel.: +34 96434 24 24; fax: +34 964342425 .

E-mail address: emilie.bannier@itc.uji.es (E. Bannier).
}

0955-2219/\$ - see front matter @ $\odot 2012$ Elsevier Ltd. All rights reserved. http://dx.doi.org/10.1016/j.jeurceramsoc.2012.09.018 moisture) and of the presence of phases with a tendency to expand when they are hydrated. ${ }^{7-9}$

In general, the phenomenon of delayed curvature has a negative effect on the quality of the end product. Indeed the tile curvature continues evolving after its sorting, and in many cases, it reaches values outside the commercial specifications. In order to solve this problem, the manufacturers usually modify the kiln thermal cycle in order to produce tiles with a given curvature after firing. Such curvature is designed so that the final tiles are as flat as possible when the final curvature is reached. This method gives quite good results for porous tiles, but it is not always effective in the case of porcelain stoneware as a consequence of the lack of reproducibility in the curvature evolution after firing. Therefore it is necessary to understand the origin of the delayed curvatures in that kind of material, as the mechanisms involved should be different than in the case of porous tiles.

In fact, porcelain tiles usually display a totally different behaviour: the curvature initially evolves in a direction (habitually towards concavity) and, after a certain time, this tendency is inverted. This change in the evolution of the curvature, together with the very low porosity of the porcelain stoneware (water absorption lower than $0.5 \%$ ) and its low content in hydratable phases, indicate that the causes of the delayed curvatures are much more complex in this material. 


\begin{tabular}{|c|c|}
\hline \multicolumn{2}{|c|}{ Nomenclature } \\
\hline E & Young's modulus $(\mathrm{Pa})$ \\
\hline$E^{\prime}$ & dimensionless Young's modulus $\left(E / E_{\mathrm{s}}\right)$ \\
\hline$E_{\mathrm{ef}}$ & effective Young's modulus (Pa) \\
\hline$E_{\mathrm{ef}}^{\prime}$ & $\begin{array}{l}\text { effective dimensionless Young's modulus } \\
\left(E_{\mathrm{ef}} / E_{\mathrm{s}}\right)\end{array}$ \\
\hline$E_{\text {ef }, \mathrm{g}}$ & $\begin{array}{l}\text { effective Young's modulus of the two-layer sam- } \\
\text { ple (body + engobe) }(\mathrm{Pa})\end{array}$ \\
\hline$E_{\text {ef,g }}^{\prime}$ & $\begin{array}{l}\text { effective dimensionless Young's modulus of the } \\
\text { two-layer sample }\left(E_{\mathrm{ef}, \mathrm{g}} / E_{\mathrm{s}}\right)\end{array}$ \\
\hline$E_{\text {ef,gv }}$ & $\begin{array}{l}\text { effective Young's modulus of the three-layer sam- } \\
\text { ple (body + engobe }+ \text { glaze) }(\mathrm{Pa})\end{array}$ \\
\hline$E_{\mathrm{ef}, \mathrm{gv}}^{\prime}$ & $\begin{array}{l}\text { effective dimensionless Young's modulus of the } \\
\text { three-layer sample }\left(E_{\mathrm{ef}, \mathrm{gv}} / E_{\mathrm{s}}\right)\end{array}$ \\
\hline$E_{\mathrm{x}}$ & $\begin{array}{l}\text { Young's modulus of the } x \text { layer }(x=s \text { : body, } x=g \text { : } \\
\text { engobe, } x=v \text { : glaze })(P a)\end{array}$ \\
\hline$E_{\mathrm{x}}^{\prime}$ & $\begin{array}{l}\text { dimensionless Young's modulus of the } \mathrm{x} \text { layer } \\
(\mathrm{x}=\mathrm{g} \text { : engobe, } \mathrm{x}=\mathrm{v} \text { : glaze })\left(E_{\mathrm{x}} / E_{\mathrm{s}}\right)\end{array}$ \\
\hline$F$ & $\operatorname{load}(\mathrm{N})$ \\
\hline$h$ & sample thickness $(\mathrm{m})$ \\
\hline$h_{\mathrm{x}}$ & $\begin{array}{l}\text { thickness of the } x \text { layer }(x=s \text { : body, } x=g \text { : engobe, } \\
x=v \text { : glaze }(m)\end{array}$ \\
\hline$h_{\mathrm{x}}^{\prime}$ & $\begin{array}{l}\text { dimensionless thickness of the } \mathrm{x} \text { layer }(\mathrm{x}=\mathrm{g} \text { : } \\
\text { engobe, } \mathrm{x}=\mathrm{v} \text { : glaze })\left(h_{\mathrm{x}} / h_{\mathrm{s}}\right)\end{array}$ \\
\hline$M$ & momentum $(\mathrm{N} \mathrm{m})$ \\
\hline$z$ & position $(\mathrm{m})$ \\
\hline$z^{\prime}$ & dimensionless position $\left(z / h_{\mathrm{s}}\right)$ \\
\hline$z_{0}$ & neutral axis position $(\mathrm{m})$ \\
\hline$z_{0}^{\prime}$ & dimensionless neutral axis position $\left(z_{0} / h_{\mathrm{s}}\right)$ \\
\hline$\varepsilon$ & total strain \\
\hline$\varepsilon_{\mathrm{e}}$ & elastic strain \\
\hline$\varepsilon_{\mathrm{f}}$ & free strain \\
\hline$\Delta \varepsilon_{\mathrm{fg}}$ & expansion mismatch between engobe and body \\
\hline$\Delta \varepsilon_{\mathrm{fv}}$ & expansion mismatch between glaze and body \\
\hline$\varepsilon_{0}$ & homogeneous sample expansion \\
\hline$\kappa$ & curvature $\left(\mathrm{m}^{-1}\right)$ \\
\hline$\kappa^{\prime}$ & dimensionless curvature $(\kappa h)$ \\
\hline$\sigma_{\mathrm{x}}$ & $\begin{array}{l}\text { stress in the } x \text { layer }(x=s \text { : body, } x=g \text { : engobe, } \\
x=v \text { : glaze })(P a)\end{array}$ \\
\hline$\sigma_{\mathrm{R}}$ & mechanical strength $(\mathrm{Pa})$ \\
\hline$\sigma_{\mathrm{R}, \mathrm{ef}}^{\prime}$ & effective mechanical strength $(\mathrm{Pa})$ \\
\hline$\sigma_{\mathrm{Rg}}$ & $\begin{array}{l}\text { mechanical strength of the two-layer sample } \\
\text { (body + engobe) }(\mathrm{Pa})\end{array}$ \\
\hline$\sigma_{\mathrm{Rg}}^{\prime}$ & $\begin{array}{l}\text { dimensionless mechanical strength of the two- } \\
\text { layer sample }\left(\sigma_{\mathrm{Rg}} / E_{\mathrm{s}}\right)\end{array}$ \\
\hline$\sigma_{\mathrm{Rs}}$ & body mechanical strength $(\mathrm{Pa})$ \\
\hline$\sigma_{\mathrm{Rs}}^{\prime}$ & dimensionless body mechanical strength $\left(\sigma_{\mathrm{Rs}} / E_{\mathrm{s}}\right)$ \\
\hline$\sigma_{\mathrm{Rv}}$ & $\begin{array}{l}\text { mechanical strength of the three-layer sample } \\
\text { (body + engobe + glaze) }(\mathrm{Pa})\end{array}$ \\
\hline$\sigma_{\mathrm{Rv}}^{\prime}$ & $\begin{array}{l}\text { dimensionless mechanical strength of the three- } \\
\text { layer sample }\left(\sigma_{\mathrm{Rv}} / E_{\mathrm{s}}\right)\end{array}$ \\
\hline
\end{tabular}

Characteristics of the porcelain tiles used in this study.

\begin{tabular}{lll}
\hline & Model A & Model B \\
\hline Dimension $(\mathrm{mm})$ & $450 \times 450$ & $460 \times 460$ \\
Body thickness $(\mathrm{mm})$ & 8.35 & 8.62 \\
Engobe thickness $(\mathrm{mm})$ & 0.09 & 0.15 \\
Glaze thickness $(\mathrm{mm})$ & 0.13 & 0.10 \\
Delayed curvature & Yes & No \\
\hline
\end{tabular}

During rapid industrial cooling of the porcelain tiles, residual tresses are generated as a consequence of the thermal expansion mismatch between the glaze and body, and of the thermal gradient generated inside the tile. ${ }^{10}$ Recently, some works have been published which suggest that the delayed curvatures in porcelain tiles are caused by those residual stresses. ${ }^{11,12}$ However, none of these studies actually verified the validity of this hypothesis. In the present work, the residual stresses have been measured for two types of industrial porcelain tiles which displayed different behaviours with regards to the delayed curvature phenomenon. The main objective was to determine the relation between residual stresses and delayed curvature.

\section{Materials and methods}

\subsection{Materials}

Two different industrial glazed porcelain tiles have been studied. Both samples were formed by 3 different layers: body, engobe and glaze, which will be referred hereafter by the letters $\mathrm{s}$ (body), g (engobe) and v (glaze).

The first tile (model A) exhibited delayed curvature after firing, whereas the second one (model B) presented a stable curvature with time. Some characteristics of both specimens are given in Table 1.

\subsection{Delayed curvature measurements}

The delayed curvature begins immediately after the firing step, and may last for several days. In order to quantify the magnitude and kinetics of this phenomenon, the central deflection of the tiles $\left(\delta_{\mathrm{C}}\right)$ was measured along both diagonals at different times after firing. ${ }^{11}$ The first measurement was done immediately at the exit of the industrial kiln and was taken as initial state. The evolution of the central deflection was then measured during 2 months. For each model (A and B), 5 different tiles fabricated at the same time were considered, and the results were averaged.

\subsection{Elastic properties determination}

The different layers that formed each sample (body, engobe and glaze) were mechanically characterized.

First, the mechanical strength and the Young's modulus of each body were determined by 3-point bending using a universal testing machine (Instron 4501, INSTRON, USA). For each model, 10 samples of $150 \mathrm{~mm} \times 20 \mathrm{~mm}$ were obtained from 
unglazed industrial bodies and tested at a constant displacement rate of $1 \mathrm{~mm} / \mathrm{min}$. The elastic modulus and the mechanical strength were obtained from the load/displacement curves and the maximum load, respectively.

In the case of engobes and glazes, the elastic moduli were evaluated using an indentation method. The tests were performed with a nanoindentation equipment (NanoTest, Micromaterials, UK), using a Berkovich indenter. For all samples, 20 measurements were carried out at a load rate of $100 \mathrm{mN} / \mathrm{s}$, with a maximum load of $1000 \mathrm{mN}$. The distance between 2 successive indentations was maintained constant at $500 \mu \mathrm{m}$. During all the process, the evolution of the indentation depth as a function of the applied load was registered, allowing the calculation of the sample indentation modulus. This method could not be used in the case of the bodies, as their high roughness led to highly dispersed results and thus to a greater uncertainty in the measurements.

\subsection{Creep behaviour characterization}

The creep behaviour of the bodies was determined by 3 point bending, applying a constant load corresponding to half of the mechanical strength of each material. ${ }^{11}$ Prismatic samples $(220 \mathrm{~mm} \times 20 \mathrm{~mm})$ were prepared from unglazed industrial bodies, and the distance between the 2 lower bearing rods was $180 \mathrm{~mm}$. The central deflection of the probe was measured during 5 days using a linear variable differential transformer (LVDT, Solartron Metrology, UK)

\subsection{Thermal expansion}

The thermal expansion was determined using an absolute dilatomer (EP-402, Netzsch, Germany) calibrated with a sapphire standard. The thermal cycle was completed at $5{ }^{\circ} \mathrm{C} / \mathrm{min}$ up to $800^{\circ} \mathrm{C}$ for bodies and engobes, and up to the softening temperature for glazes.

Samples of $30 \mathrm{~mm} \times 5 \mathrm{~mm} \times 5 \mathrm{~mm}$ were cut from unglazed industrial bodies. Engobes and glaze specimens were prepared from industrial slurries by drying them, pressing the resulting powder and firing the resulting samples in a laboratory kiln.

\subsection{Residual stresses determination}

During rapid industrial cooling of porcelain stoneware tiles, two types of residual stresses can be generated:

- thermal stresses, which are generated inside the bodies as a consequence of the existence of thermal gradients between the surface and the core of the tile during industrial cooling

- body-glaze fit stresses, which are caused by differences in the thermal expansions of the glaze, engobe and body. study.

Both types of residual stresses have been measured in this
2.6.1. Thermal residual stresses

The thermal stresses inside the bodies have been determined on unglazed samples, using the strain relaxation slotting method, also known as the crack-compliance method ${ }^{13,14}$ This destructive technique consists in releasing the residual stresses by performing a thin cut on the sample. As a consequence of this stress relaxation, the sample suffers a deformation that can be measured using a strain gauge fixed to its lower surface. During the test, the slot depth $\left(a_{\mathrm{i}}\right)$ is increased incrementally, measuring the strain at each step on a point close to the slot using the strain gauge $\left(\varepsilon_{\mathrm{i}}\right)$. The method has been successfully used to determine residual stress profile inside porcelain stoneware samples, demonstrating that the residual stresses can be calculated from the resulting $\varepsilon_{\mathrm{i}}\left(a_{\mathrm{i}}\right)$ curves. ${ }^{15}$

\subsubsection{Body-glaze fit stresses}

As a consequence of the thermal expansion mismatch between body and glaze, the glaze layer of a porcelain stoneware tile is usually submitted to compressive stresses. The existence of such residual stresses next to the sample surface changes the apparent mechanical strength measured by 3 -points bending, as illustrated by Fig. 1 .

During 3-point bending of a stress-free sample, a compressive stress is generated on the upper surface of the specimen as a consequence of the load application. Meanwhile, tensile stresses emerge on the lower surface. Failure takes place when the tensile stresses are higher then the mechanical strength, corresponding to certain load $\left(F_{2}\right)$.

Still, if the specimen already presents internal stresses, the failure will take place at a different load. Fig. 1 illustrates the case of a sample which initially displays compressive stresses next to its lower surface. In this case, the load applied during the 3-point bending first leads to the elimination of the compressive stresses and then to the formation of tensile stresses next to the lower surface. As a consequence the failure will occur at a higher applied load $\left(F_{3}\right)$ and the effective mechanical strength measured by 3-point bending will be higher than the real mechanical strength of the material. If the lower surface is in traction, the opposite phenomenon will take place leading to a lower failure load and thus to a lower apparent mechanical strength.

In order to determine the body-glaze fit stresses, three types of samples were tested: body, two-layer samples (body + engobe) and three-layer specimens (body + engobe + glaze). The two- and three-layer samples were prepared with standard and double thickness of the engobe and glaze layers respectively. The effective mechanical strength of all samples was determined by three-point bending, testing the specimens first with the glazed surface in compression and second with the glazed surface under traction. In the case of the body samples, the glazed surface corresponds to the one on which the engobe and glaze layers should have been applied. From the experimental results and considering the linear elastic law, the residual stresses found in each layer can be calculated by using a generalized form of Timoshenko equation ${ }^{16}$ which is valid for two-layer systems, as described hereafter in Appendix A. 


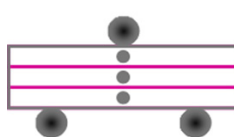

Without residual stresses

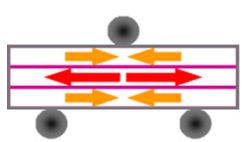

With residual stresses

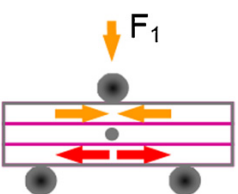

failure
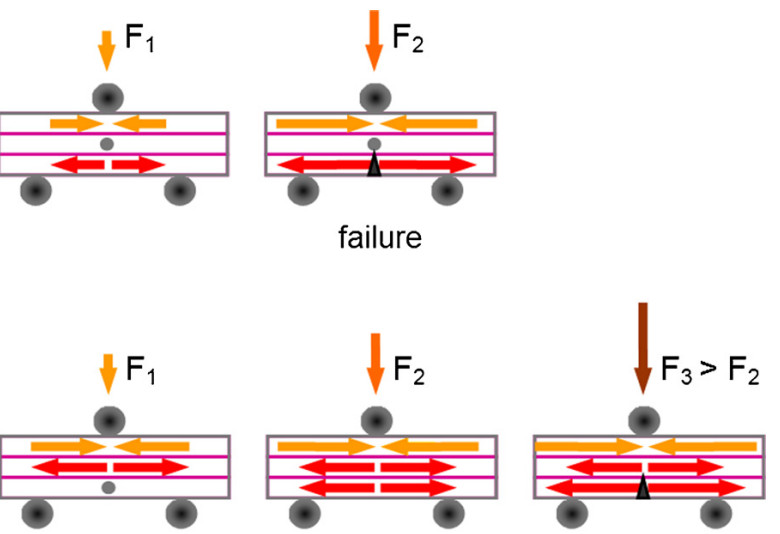

failure

Fig. 1. Change in the mechanical strength of a 3-point bending specimen as a consequence of the presence of residual stresses $\left(F_{1}<F_{2}<F_{3}\right)$.
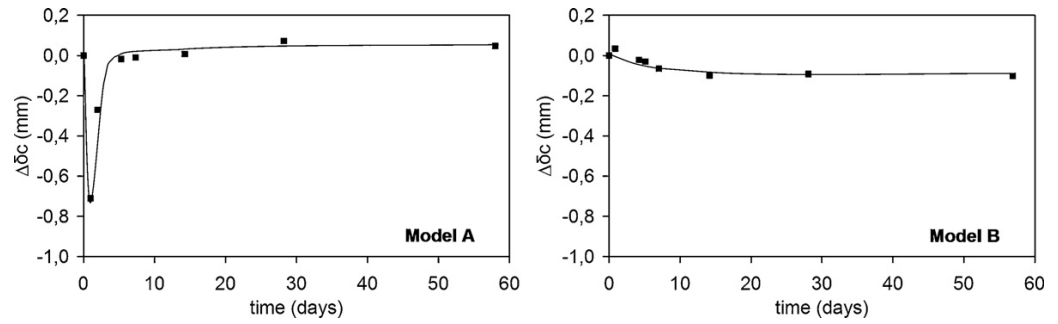

Fig. 2. Evolution of the curvature with time for both samples.

\section{Results}

\subsection{Curvature measurement}

The evolution of the central deflection was measured during 2 months and the results are given in Fig. 2 for both samples. By convention, a positive value corresponds to concave curvature, whereas a negative value indicates a convex deflection.

The curvature of model A first evolved rapidly to concave values, until it reached a minimum around 2 days after firing. Then, the curvature went back to convex values and finally stabilized about 5 days after firing. The measurements also confirmed that the curvature of model B did not significantly change with time.

\subsection{Elastic properties of bodies, engobes and glazes}

In order to calculate the residual stresses, it is necessary to know the elastic properties of the layers which form the porcelain stoneware tiles. The mechanical strengths and Young's moduli
Table 2

Mechanical strengths and elastic moduli of the bodies (3-point bending test).

\begin{tabular}{lll}
\hline & $\sigma_{\mathrm{RS}}(\mathrm{MPa})$ & $E_{\mathrm{s}}(\mathrm{GPa})$ \\
\hline Model A & $43 \pm 2$ & $34 \pm 1$ \\
Model B & $55 \pm 1$ & $40 \pm 1$ \\
\hline
\end{tabular}

of the bodies are given in Table 2. The body of model A displayed lower values of both properties.

Table 3 shows the results of the indentation tests. Within the experimental error, the models exhibited similar elastic moduli

Table 3

Elastic moduli of engobes $\left(E_{\mathrm{g}}\right)$ and glazes $\left(E_{\mathrm{v}}\right)$ (indentation method).

\begin{tabular}{lcc}
\hline & $E_{\mathrm{g}}(\mathrm{GPa})$ & $E_{\mathrm{v}}(\mathrm{GPa})$ \\
\hline Model A & $60 \pm 11$ & $75 \pm 6$ \\
Model B & $64 \pm 15$ & $78 \pm 8$ \\
\hline
\end{tabular}


Artículos científicos publicados

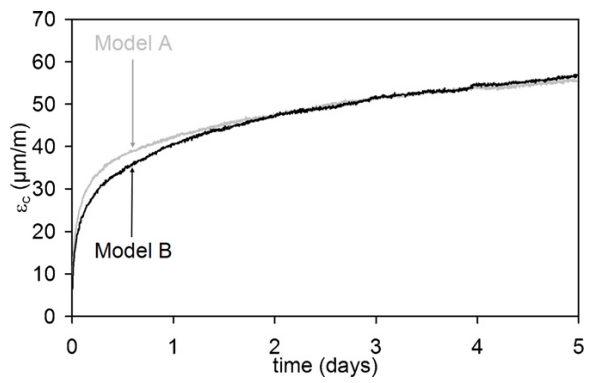

Fig. 3. Strain evolution $\left(\varepsilon_{\mathrm{c}}\right)$ during the creep tests.

for both engobe and glaze layers. Moreover, the glazes exhibited somehow higher Young's moduli than the engobes.

\subsection{Creep behaviour of the bodies}

The creep behaviour was characterized by 3-point bending as described before. The evolution of the central deflection was registered throughout 5 days. The results are given in Fig. 3.

The experimental curves can be divided in two well-defined parts: initially the strain rate decreased (primary creep) and then a constant slope was observed corresponding to a steadystate (secondary creep). Such behaviour is typical of viscoelastic materials.

Although no significant differences were found between the two specimens, it has to be pointed out that both samples presented a significant deformation under the application of the load. As a consequence, creep could provide a stress relaxation mechanism in porcelain tiles.

\subsection{Thermal expansion of bodies, engobes and glazes}

As mentioned before, the misfit between the thermal expansion of glaze and body may generate residual stresses inside the porcelain stoneware tile. In this part of the work, the thermal behaviour of the different layers forming the samples have been studied in order to estimate such misfit.

Table 4

\begin{tabular}{llll}
\multicolumn{2}{l}{ Coefficients of thermal expansion $(\alpha)$ of all the layers. } \\
\hline & $\begin{array}{l}\alpha_{50-300} \times 10^{6} \\
\left({ }^{\circ} \mathrm{C}^{-1}\right)\end{array}$ & $\begin{array}{l}\alpha_{300-500} \times 10^{6} \\
\left({ }^{\circ} \mathrm{C}^{-1}\right)\end{array}$ & $\begin{array}{l}\alpha_{500-650} \times 10^{6} \\
\left({ }^{\circ} \mathrm{C}^{-1}\right)\end{array}$ \\
\hline $\begin{array}{l}\text { Model A } \\
\text { Body }\end{array}$ & 6.3 & 8.1 & \\
$\begin{array}{l}\text { Engobe } \\
\text { Glaze }\end{array}$ & 7.4 & 8.7 & 9.7 \\
Model B & 6.3 & 6.5 & 11.4 \\
$\quad$ Body & 6.6 & 8.4 & 6.4 \\
Engobe & 8.4 & 10.3 & 9.7 \\
Glaze & 6.1 & 6.3 & 13.7 \\
\end{tabular}

Dilatometric curves are given in Fig. 4, whereas Table 4 contains the coefficients of thermal expansion (CTE) of the different materials.

These results confirmed the existence of a thermal expansion misfit between the layers of both porcelain stoneware tile specimens. However, the thermal behaviour of the layers of model A (which displayed delayed curvature) and model B (which presented a constant curvature with time) are highly similar, especially in the case of the bodies and glazes. The main differences are found in the engobe behaviour.

\subsection{Residual stresses}

3.5.1. Thermal residual stresses

Fig. 5 shows the stress profile obtained for both bodies. The experimental curves, giving the strain gauge measurements as a function of the slot depth, are also provided.

It can be observed that the surfaces of both samples are in compression whereas their cores display tensile stresses. The residual stresses measured are quite low, with maximum compression values around $-3 \mathrm{MPa}$, next to the unglazed surface (value of $z=0$ ), and maximum tensile stresses of about $1 \mathrm{MPa}$ in the centre of the sample. For both specimens, the compression was higher on the unglazed surface than on the glazed one.

As a consequence of the high cooling rate, the tiles are submitted to a significant thermal gradient along the body thickness during the first stage of the industrial cooling. Such gradient leads to a faster thermal contraction next to the sample surface than inside the tile, and generates a viscous flow which reduces the generation of stresses at high temperature. This process continues until the tiles reach a temperature at which the viscous flow is practically null. Since the tile inner temperature is higher than the superficial one, its contraction during cooling down to room temperature will also be greater Such difference causes the apparition of tensile stresses in the interior of the specimen and of compressive stresses next to its surfaces, as confirmed by the experimental stress profiles (Fig. 5).

As mentioned before, both residual stress profiles are slightly asymmetric. Such asymmetry can be explained by the different cooling rates experimented by the upper and lower surfaces within the industrial kiln. ${ }^{17}$

\subsubsection{Body/glaze fit stresses}

The effective 3-point bending mechanical strengths of the different specimens are given in Table 5. In the tests realized with the glazed surface down, this surface is in traction during the test; whereas in the tests done with the glazed surface up, it is the unglazed surface which is in traction. The engobe or glaze layers with double thickness are referred as $2 \mathrm{~g}$ and $2 \mathrm{v}$.

If the tests are conducted with the glazed surface up, there is no significant difference in the effective mechanical strength when the engobe and glaze layers are added. Such results indicate that the presence of these layers does not appreciably modify the stress profile next to the unglazed surface. On the contrary, the effective mechanical strength values are notably 
Artículos científicos publicados
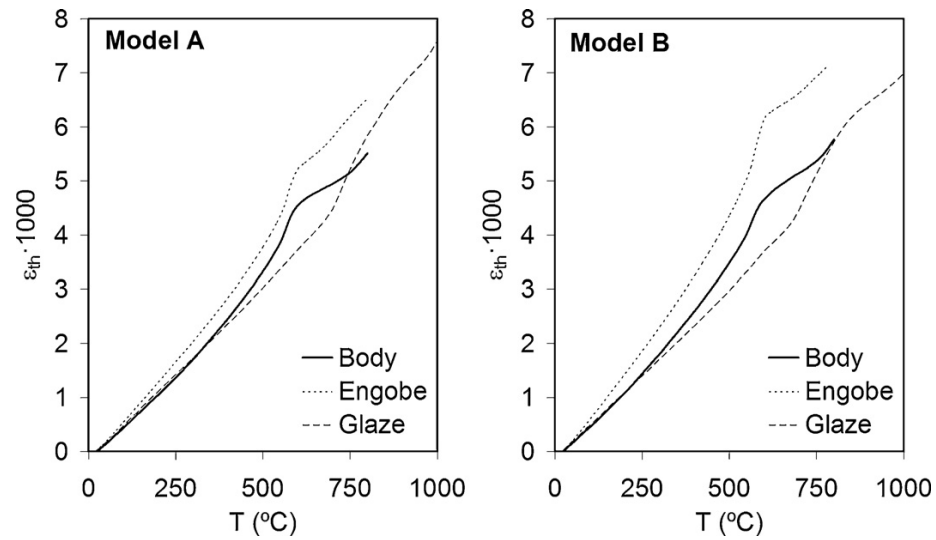

Fig. 4. Dilatometric curves of the layers that formed model A (with delayed curvature) and model B (without delayed curvature)
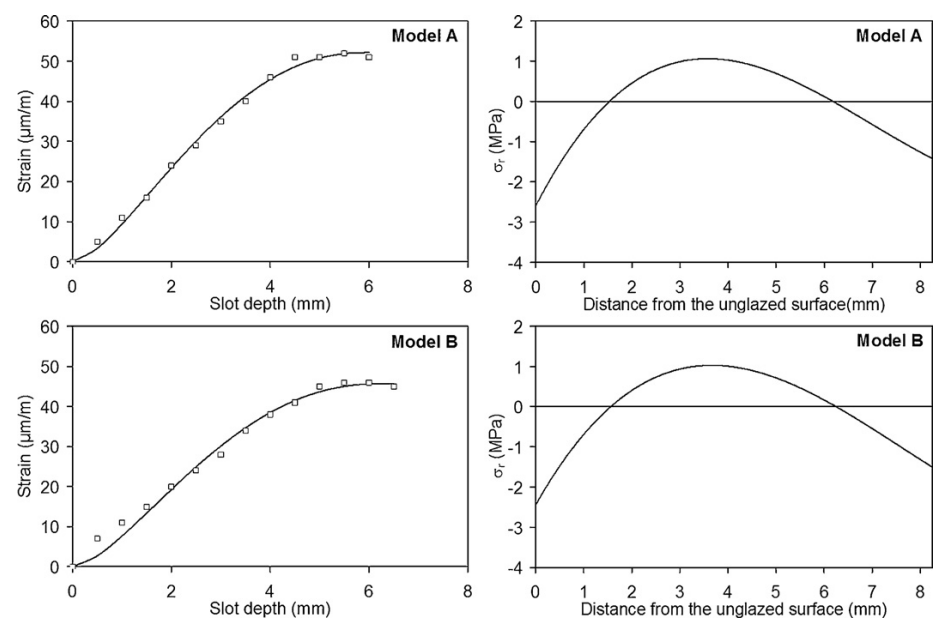

Fig. 5. Strain gauge deformation as a function of the slot depth (left) and thermal residual stresses profiles (right) for both models.

Table 5

Effective mechanical strengths (MPa)

\begin{tabular}{|c|c|c|c|c|c|c|c|c|c|c|}
\hline \multirow[b]{2}{*}{ Glazed surface position } & \multicolumn{2}{|l|}{$\mathrm{s}$} & \multicolumn{2}{|l|}{$s+g$} & \multicolumn{2}{|l|}{$s+2 g$} & \multicolumn{2}{|l|}{$s+g+v$} & \multicolumn{2}{|c|}{$s+g+2 v$} \\
\hline & Up & Down & Up & Down & Up & Down & Up & Down & Up & Down \\
\hline Model A & $43 \pm 1$ & $45 \pm 1$ & $44 \pm 2$ & $51 \pm 3$ & $45 \pm 1$ & $54 \pm 2$ & $49 \pm 1$ & $54 \pm 1$ & $46 \pm 2$ & $54 \pm 2$ \\
\hline Model B & $55 \pm 1$ & $56 \pm 1$ & $57 \pm 1$ & $31 \pm 1$ & $51 \pm 2$ & $23 \pm 1$ & $53 \pm 3$ & $46 \pm 1$ & $57 \pm 1$ & $49 \pm 2$ \\
\hline
\end{tabular}


Artículos científicos publicados

Table 6

Body-glaze fit residual stresses.

\begin{tabular}{lcr}
\hline & \multicolumn{2}{l}{$\sigma_{\text {res }}(\mathrm{MPa})$} \\
\cline { 3 - 3 } & $\mathrm{s}+2 \mathrm{~g}$ & $\mathrm{~s}+\mathrm{g}+2 \mathrm{v}$ \\
\hline Model A & & \\
$\quad$ Body (interface with the engobe) & -0.4 & 8.1 \\
Engobe & 4.6 & 12.9 \\
$\quad$ Glaze & - & -77.3 \\
Model B & & \\
$\quad$ Body (interface with the engobe) & -9.0 & 1.5 \\
Engobe & 63.3 & 73.7 \\
Glaze & - & -72.6 \\
\hline
\end{tabular}

influenced by the presence of engobe and glaze if the tests are realized with the glazed surface down.

Finally, it was found that both bodies displayed slightly higher apparent mechanical strength when there were tested with the glazed surface down. It might be partly attributed to the higher compressive stresses observed next to the unglazed surface in the thermal residual stresses profiles (Fig. 5).

The body/glaze fit stresses were calculated from the mechanical strength of the samples with double-thickness engobe or glaze layer. Indeed the single-thickness layers led to quite similar mechanical strength with respect to the body, and thus to a significant error in the residual stresses measurement. Table 6 shows the residual stresses obtained for each sample. A negative value corresponds to a compressive stress whereas a positive value indicates a tensile stress.

It can be appreciated that the stresses in the body at its interface with the engobe is always significantly lower than the stresses measured inside the engobe and glaze layers. In absolute value, these stresses are comparable to the thermal residual stresses measured before (Section 3.5.1). Furthermore it was found that the residual stresses in the body passed from compressive to tensile values when the glaze layer was added, whereas the engobe layer is always in traction independently of the presence of the glaze, with somehow higher tensile stresses in the three-layer specimens.

If the 2 models are compared, it can be seen that model $\mathrm{B}$ displayed much higher tensile stresses in the engobe than model A. Finally, the glaze layers are submitted to similar tensile stresses in both models.

The results are in agreement with the dilatometric curves obtained previously (Fig. 4). Actually, both engobes presented a higher dilatation than the body, with greater differences in the case of model B. On the contrary, both glazes displayed lower dilatation coefficients than the bodies. During cooling, if the 3 layers were completely free, the engobe would present the higher contraction and the glaze the lower one. Consequently, during the cooling of a two-layer specimen, the body limits the contraction of the engobe leading to a tensile stress inside the engobe and to compression in the body next to the interface, due to the reciprocal effect. When the glaze is added, it impedes the full contraction of the other two layers, leading to higher stresses in both engobe and body, and to the generation of significant compressive stresses inside the glaze layer.

\section{Discussion}

In this work, two types of porcelain tiles have been studied. It was found that both models presented a drastically different evolution of their curvature after firing. The curvature of mode A first evolved to significant convex value, before it got back to a concave deflection and stabilized. On the contrary, model B presented a stable curvature.

Moreover, the bodies of both samples presented a viscoelastic behaviour under the application of a constant load, proving the existence of a stress relaxation mechanism. This result is essential with regards to the delayed curvature phenomenon. Actually, the hypothesis considered to explain this phenomenon is based on the presence of residual stresses inside the tiles. However, these stresses need to be released by some mechanism, such as creep, in order to cause variation in the tile curvature. In addition to the existence of creep, the residual stress profile must be asymmetric. Indeed, a symmetrical profile means that the stresses are identical on the glazed and unglazed surface of the sample. Therefore, the tile will not tend to curve towards either of its sides.

The residual stresses generated during the industrial cooling of porcelain tiles can be classified in two types: thermal stresses, caused by thermal gradients inside the tile, and body-glaze fit stresses, due to the thermal expansion mismatch between body and glaze. Both types of stresses have been quantified.

With respect to the thermal residual stresses measured in this study, the following results should be highlighted:

- The stress profiles of both bodies were highly similar with compressive stresses at the sample surfaces and tensile ones inside the samples.

- The stresses were low, with values between -3 and $1 \mathrm{MPa}$

- The profiles were slightly asymmetric with higher stresse next to the upper surface.

As mentioned before, an unsymmetrical profile could lead to delayed curvature in the presence of creep. However, it is not possible to establish a direct relation between the experimental residual stress profiles and the delayed curvature phenomenon. Indeed, both models presented almost the same residual stress profile with an identical creep behaviour, but only model A displayed delayed curvature.

With respect to the body-glaze fit residual stresses, the main conclusions are:

- These stresses were quite high in the engobe and glaze layers. However, they were much lower in the body.

- The residual stresses found in the body as a consequence of the body-glaze fit were of the same order of magnitude than that those of thermal origin. 


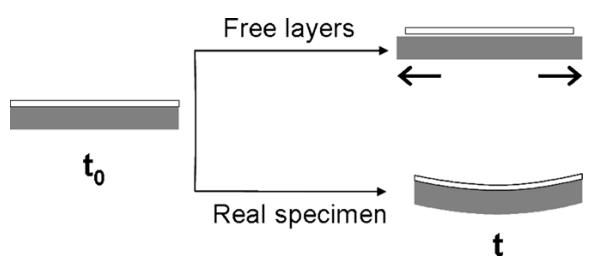

Fig. 6. Schematic representation of a delayed curvature caused by the body expansion.

- In the three-layer samples, the body of model A displayed slightly greater tensile stresses than model B.

As mentioned before, both samples presented radically different behaviour with respect to delayed curvatures. As a consequence, major differences should be found in the body-glaze fit residual stresses in order to justify such discrepancies. However, the body-fit residual stresses are comparable in both models. Moreover their values are pretty low. As a consequence, they are not the main cause of the delayed curvature.

From the results obtained in this work, it can be concluded that the residual stresses existing in the body, either from thermal origin or due to the body-glaze fit, do not cause the delayed curvature phenomenon. Further work is necessary in order to find out the origin of the delayed curvature. A possible explanation is based on the expansion of the tile body after firing, as illustrated in Fig. 6 in the case of a glazed sample.

Still, a homogenous body expansion does not explain why some unglazed porcelain stoneware tiles also suffer delayed curvature. However, the existence of an expansion mismatch between the glazed and unglazed surfaces of the tile could cause the delayed curvature in unglazed specimens. As no conclusive results exist to validate the existence of such differences, more investigation is necessary: first to quantify the body expansion in porcelain stoneware samples, and second to confirm the possible relation between body expansion and delayed curvature. In particular, a novel experimental procedure should be designed in order to measured separately the expansion of the upperand lower-parts of a porcelain tile and thus to verify the possible existence of an expansion mismatch between glazed and unglazed surfaces.

\section{Conclusions}

The main purpose of this study was to determine if residual stresses are at the origin of the delayed curvature phenomenon observed in most industrial porcelain tiles. To fulfil this objective, two different industrial glazed porcelain tiles were characterized: the first one displayed delayed curvature after firing, whereas the second one presented a stable curvature with time. Both samples were formed by 3 layers (body, engobe and glaze) which were mechanically characterized, showing comparable properties. It was found that both specimens displayed very similar residual stresses and creep behaviour, whereas only one of the materials presented delayed curvature. As a consequence, this work clearly refutes the hypothesis which suggests that the delayed curvatures are caused by the relaxation of the residual stresses that are generated during industrial cooling. Further investigation is necessary in order to understand the delayed curvature phenomenon in porcelain stoneware tiles.

\section{Acknowledgment}

This work has been supported by the Spanish Ministry of Science and Innovation (project BIA2009-10692).

\section{Appendix A.}

In this appendix, the generalization of Timoshenko equation ${ }^{16}$ used to calculate the residual stresses due to the thermal expansion mismatch in three-layer system is given, allowing the definition of the equations necessary to calculate the bodyfit residual stresses from the results of the 3-point bending tests described previously.

In general, the total sample strain can be expressed as the sum of an elastic deformation $\left(\varepsilon_{\mathrm{e}}\right)$ and a free deformation $\left(\varepsilon_{\mathrm{f}}\right)$.

$$
\varepsilon=\varepsilon_{\mathrm{e}}+\varepsilon_{\mathrm{f}}
$$

It can also be divided into a homogenous expansion part $\left(\varepsilon_{0}\right)$ and a flexion part, obtaining the following expression:

$\varepsilon=\varepsilon_{0}+\kappa\left(z-z_{0}\right)$

In addition, the force balance and momentum balance are defined by:

$F=0=b \int_{0}^{h} E\left(\kappa\left(z-z_{0}\right)-\varepsilon_{\mathrm{f}}+\varepsilon_{0}\right) d z$

$M=0=b \int_{0}^{h} E\left(\kappa\left(z-z_{0}\right)-\varepsilon_{\mathrm{f}}+\varepsilon_{0}\right)\left(z-z_{0}\right) d z$

The neutral axis position for a three-layer sample can be obtained from Eq. (3) by considering a sample without free deformation $\left(\varepsilon_{\mathrm{f}}=0\right)$, and submitted to pure bending $\left(\varepsilon_{0}=0\right)$ :

$z_{0}^{\prime}=\frac{z_{0}}{h_{\mathrm{s}}}=1+\frac{E_{\mathrm{g}}^{\prime} h_{\mathrm{g}}^{\prime 2}+E_{\mathrm{v}}^{\prime} h_{\mathrm{v}}^{\prime}\left(2 h_{\mathrm{g}}^{\prime}+h_{\mathrm{v}}^{\prime}\right)-1}{2\left(E_{\mathrm{g}}^{\prime} h_{\mathrm{g}}^{\prime}+E_{\mathrm{v}}^{\prime} h_{\mathrm{v}}^{\prime}+1\right)}$

From Eq. (3), it is also possible to calculate $\varepsilon_{0}$, which corresponds to a homogenous expansion and, though, does not cause any curvature:

$\varepsilon_{0}=\frac{E_{\mathrm{g}}^{\prime} h_{\mathrm{g}}^{\prime} \Delta \varepsilon_{\mathrm{fg}}+E_{\mathrm{v}}^{\prime} h_{\mathrm{v}}^{\prime} \Delta \varepsilon_{\mathrm{fv}}}{1+E_{\mathrm{g}}^{\prime} h_{\mathrm{g}}^{\prime}+E_{\mathrm{v}}^{\prime} h_{\mathrm{v}}^{\prime}}$

Moreover, the sample curvature can be deduced from Eq. (4):

$$
\begin{aligned}
\kappa^{\prime} & =\frac{6}{\left(1+h_{\mathrm{g}}^{\prime}+h_{\mathrm{v}}^{\prime}\right)^{3} E_{\mathrm{ef}}^{\prime}}\left[-E_{\mathrm{g}}^{\prime} \Delta \varepsilon_{\mathrm{fg}}\left(1-z_{0}^{\prime}\right)^{2}\right. \\
& +\left(E_{\mathrm{g}}^{\prime} \Delta \varepsilon_{\mathrm{fg}}-E_{\mathrm{v}}^{\prime} \Delta \varepsilon_{\mathrm{fv}}\right)\left(1+h_{\mathrm{g}}^{\prime}-z_{0}^{\prime}\right)^{2} \\
& \left.+E_{\mathrm{v}}^{\prime} \Delta \varepsilon_{\mathrm{fv}}\left(1+h_{\mathrm{g}}^{\prime}+h_{\mathrm{v}}^{\prime}-z_{0}^{\prime}\right)^{2}\right]
\end{aligned}
$$


where:

The elastic law indicates that the stress can be calculated from the strain and the Young's modulus:

$$
\sigma=E \varepsilon_{\mathrm{e}}=E\left(\kappa\left(z-z_{0}\right)-\varepsilon_{\mathrm{f}}+\varepsilon_{0}\right)
$$

Eq. (8) can also be written as:

$$
\frac{\sigma}{E_{\mathrm{s}}}=\sigma^{\prime}=E^{\prime}\left(\kappa^{\prime}\left(z^{\prime}-z_{0}^{\prime}\right)-\varepsilon_{\mathrm{f}}+\varepsilon_{0}\right)
$$

From Eq. (9), the residual stresses in the different layer can be deduced:

- Residual stress in the body

$$
\sigma_{\mathrm{s}}^{\prime}=\kappa^{\prime}\left(z^{\prime}-z_{0}^{\prime}\right)+\varepsilon_{0}
$$

- Residual stress in the engobe layer

$$
\sigma_{\mathrm{g}}^{\prime}=E_{g}\left(\kappa^{\prime}\left(z^{\prime}-z_{0}^{\prime}\right)+\varepsilon_{0}-\Delta \varepsilon_{\mathrm{fg}}\right.
$$

- Residual stress in the glaze layer

$$
\sigma_{\mathrm{v}}^{\prime}=E_{\mathrm{v}}^{\prime}\left(\kappa^{\prime}\left(z^{\prime}-z_{0}^{\prime}\right)+\varepsilon_{0}-\Delta \varepsilon_{\mathrm{fv}}\right.
$$

The expansion differences between the body and the other 2 layers can be obtained from the 3-point bending tests. If the unglazed surface of the sample is under traction, the momentum is given by:

$$
M=\frac{1}{12} b \kappa E_{\mathrm{s}} E_{\mathrm{ef}}^{\prime} h_{\mathrm{s}}^{3}\left(1+h_{\mathrm{g}}^{\prime}+h_{\mathrm{v}}^{\prime}\right)^{3}
$$

The real mechanical strength of the material is given by:

$$
\sigma_{\mathrm{R}}=E_{\mathrm{s}} \varepsilon_{z=0}=-E_{\mathrm{s}} \kappa z_{0}
$$

The effective mechanical strength (measured by 3-point bending) can be calculated from:

$$
\frac{\sigma_{\mathrm{R}}}{\sigma_{\mathrm{R}, \mathrm{ef}}}=\frac{2 z_{0}^{\prime}}{E_{\mathrm{ef}}^{\prime}\left(1+h_{\mathrm{g}}^{\prime}+h_{\mathrm{v}}^{\prime}\right)}
$$

If the unglazed surface is in compression, Eq. (13) is still valid by reversing the momentum sign, and the thermal expansion mismatch can be deduced:

$$
\Delta \varepsilon_{\mathrm{fg}}=\frac{E_{\mathrm{ef}, \mathrm{g}}^{\prime}\left(1+h_{\mathrm{g}}^{\prime}\right)^{2}\left(1+E_{\mathrm{g}}^{\prime} h_{\mathrm{g}}^{\prime}\right)\left(\sigma_{\mathrm{Rg}}^{\prime}-\sigma_{\mathrm{Rs}}^{\prime}\right)}{E_{\mathrm{g}}^{\prime} h_{\mathrm{g}}^{\prime}\left(6 z_{0}^{\prime}-E_{\mathrm{ef}, \mathrm{g}}^{\prime}\left(1+h_{\mathrm{g}}^{\prime}\right)^{2}\right)}
$$

$c=1+h_{\mathrm{g}}^{\prime}-\frac{E_{\mathrm{ef}, \mathrm{gv}}^{\prime}\left(1+h_{\mathrm{g}}^{\prime}+h_{\mathrm{v}}^{\prime}\right)^{3}}{6 z_{0}^{\prime}}$

\section{References}

Sánchez E, García-Ten J, Sanz V, Moreno A. Porcelain tile: almost 30 year of steady scientific-technological evolution. Ceram Int 2010;36:831-45.

2. Tenorio Cavalcante PM, Dondi M, Ercolani G, Guarini G, Melandri C, Raimondo M, et al. The influence of microstructure on the performance of

3. Tucci A, Esposito L, Malmusi L, Rambaldi E. New body mixes for porcelain stoneware tiles with improved mechanical characteristics. J Eur Ceram Soc 2007;27:1875-81

4. Martín-Márquez J, Ma Rincón J, Romero M. Effect of firing temperature on sintering of porcelain stoneware tiles. Ceram Int 2008;34:1867-73.

5. Celik H. Effect of spray-dried powder granularity on porcelain tile properties. J Ceram Process Res 2011;12(4):483-7.

6. Cantavella V, Moreno A, Mezquita A, Jarque JC, Barberá J, Palanques A Evolución de las tensiones y curvaturas en soportes porosos durante el enfriamiento. In: Proceedings of Qualicer 2008: X Congreso mundial de la calidad del azulejo y del pavimento cerámico. Castellón, Spain: Cámara Oficial de Comercio, Industria y Navegación; 2008. p. BC241-55.

7. Vasic RM. Influence of pore size distribution of frost resistance and moisture expansion of bricks. IMS Inst Bull 1192;7:15-8.

8. Segadaes AM, Carvalho MA, Ferreira HC. Using phase diagrams to deal with moisture expansion. Ceram Int 2003;29(8):947-54.

9. Smith AN. Investigations on the moisture expansion of porous ceramic bodies. Trans Br Ceram Soc 1955;54(5):300-18.

10. Cantavella V, Mezquita A, Moreno A, Silva G, Barberá J. Modelling of the generation of residual stresses of thermal origin in ceramic materials. the generation of residual stresses of thermal origin in ceramic materials.
In: Proceedings of 11th CIMTEC: international ceramics congress \& 4th forum on new materials. 2006.

forum on new materials. 2006 .
11. Cantavella V, García-Ten J, Sánchez E, Bannier E, Sánchez J, Soler C, Cantavella V, García-Ten J, Sánchez E, Bannier E, Sánchez J, Soler C,
et al. Delayed curvatures in porcelain tiles. Analysis and measurement of et al. Delayed curvatures in porcelain tiles. Analysis

12. Bresciani A, Spinelli B. Porcelain tile pyroplastic deformation during firing and post-firing variation in planarity. In: Proceedings of Qualicer 2012: XI Foro Global del Recubrimiento Cerámico. Castellón, Spain: Cámara Oficial de Comercio, Industria y Navegación; 2012.

13. Schajer GS. Relaxation methods for measuring residual stresses: techniques and opportunities. Exp Mech 2010;50:1117-27.

4. Prime MB. Residual stress measurement by successive extension of a slot: the crack compliance method. Appl Mech Rev 1999;52(2):75-96.

15. De Noni Jr A, Hotza D, Cantavella Soler V, Sanchez Vilches D. Influence of macroscopic residual stresses on the mechanical behavior and microstructure of porcelain tile. J Eur Ceram Soc 2008;28:2463-9.

16. Timoshenko S. Analysis of bi-metal thermostats. J Opt Soc Am 1925;11(3):233-55.

17. Enrique JE, Cantavella V, Moreno A, Negre F. Estimating inner temperature profile in firing tile. Am Ceram Soc Bull 1998;77(7):77-80. 
Artículos científicos publicados 


\section{Artículo 2}

- Título: "Curvaturas diferidas en gres porcelánico. Análisis y medida de los factores que intervienen"

- Autores: Cantavella, V., García-Ten, J., Sánchez, E., Bannier, E., Sánchez, J., Soler, C. y Sales, J.

- Revista: Cerámica Información, 359, pp. 95-109

- Año: 2009 
Artículos científicos publicados 


\section{Tecnología cerámica}

\section{Curvaturas diferidas en gres porcelánico. Análisis y medida de los factores que intervienen.}

V. Cantavella (1), J. Garcia-Ten (1), E. Sánchez (1), E. Bannier (1), J. Sánchez (2), C. Soler (2), I. Sales (2)

(1) Instituto de Tecnologia Cerámica (ITC). Asociación de Investigación de las Industrias Ceramicas (AICE)

Universitat Jaume l. Castellón. España.

(2) Taulell, S.A. Tau Cerámica, Castellón. España.

Resumen

Las baldosas de gres porcelánico, tanto esmaltado como no esmaltado, presentan un fenómeno conocido como "curvaturas diferidas", que consiste en el cambio de curvatura de las piezas después de su salida del horno. Este fenómeno resulta más problemático a medida que aumenta el tamaño de las baldosas.

En este trabajo se ha cuantificado la variación de la curvatura a lo largo del tiempo en piezas industriales de gres porcelánico esmaltado, observándose que la curvatura suele mostrar una evolución en un sentido (habitualmente hacia el sentido cóncavo o en barca) para, después de transcurrido cierto tiempo, invertir esta tendencia. Se ha parametrizado la cinética de este proceso considerando que existen dos mecanismos, simultáneos y antagónicos, con cinéticas diferentes.

Los análisis teóricos indican que sólo existen dos factores que pueden producir las curvaturas en diferido: las tensiones residuales y la expansión de los soportes. En ambos casos, es necesario que se den circunstancias adicionales para que aparezcan las curvaturas en diferido; así, por ejemplo, la presencia de tensiones residuales no es sinónimo de curvaturas en diferido, sino que es necesario un mecanismo adicional que permita la liberación progresiva de estas tensiones; este mecanismo recibe el nombre de fluencia. Además, se debe cumplir que el perfil de tensiones no sea simétrico respecto al plano central de la pieza.

En cuanto a la expansión de los soportes, también tienen que darse çondiciones especiales para que éstas puedan provocar curvaturas en diferido; en particular, es necesario que la expansión sea diferente por la cara vista y por la cara de costillas. Una expansión uniforme provocaría un ligero cambio dimensional, pero no una curvatura en diferido, ni siquiera en presencia de esmalte.

La medida de los factores que influyen en las curvaturas en diferido es compleja debido a que requiere el empleo de técnicas diferentes a las utilizadas habitualmente en la caracterización de baldosas cerámicas. Se han puesto a punto procedimientos para medir los diferentes factores que producen las curvaturas en diferido y se ha estudiado la influencia de algunas variables sobre ellos.

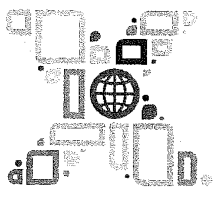

mir QuALCer'08

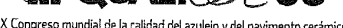

$10-13$ Febrero 2008 Castellón [Españãa] 


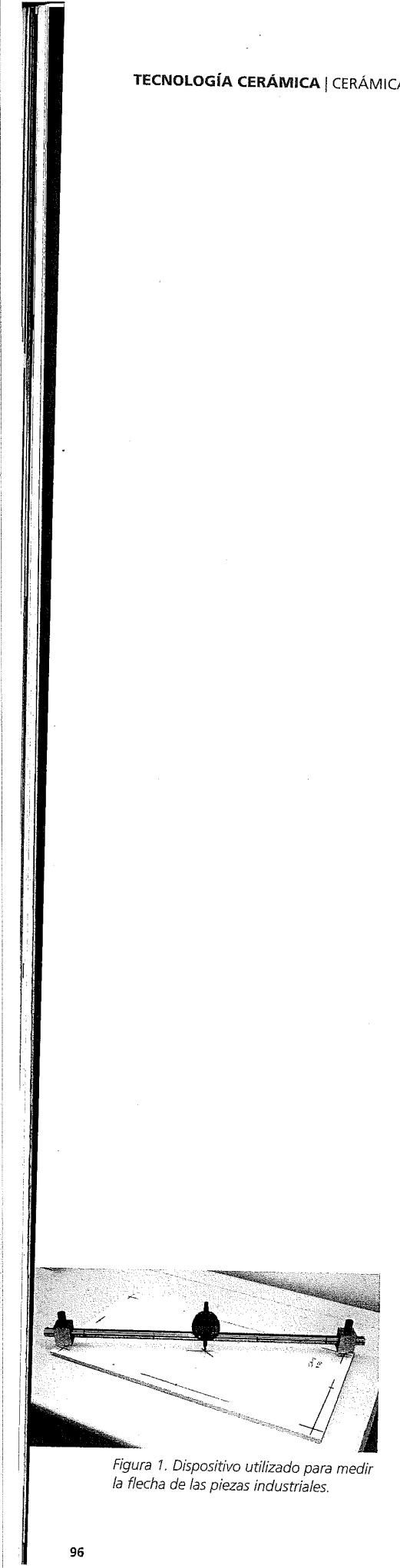

\section{Introducción}

Un significativo porcentaje de baldosas cerámicas, independientemente de su porosidad, presentan el fenómeno conocido como "curvaturas diferidas". Éste consiste en el cambio de curvatura de las piezas después de su salida del horno durante un periodo de tiempo que puede llegar a alcanzar varias semanas e incluso meses.

Aunque las curvaturas diferidas no son desconocidas en el sector cerámico, en la actualidad debido al aumento del tamaño de las baldosas que se fabrican pueden suponer un serio problema de fabricación. Así, la presencia de curvaturas diferidas origina problemas durante la fase de clasificación y sobre la calidad del producto final, por lo que es necesario conocer la curvatura final que alcanzará la baldosa al objeto de establecer con qué curvatura deben de salir del horno, así como los criterios para su clasificación.

Las curvaturas diferidas en las baldosas porosas o azulejos presentan una tendencia a la concavidad con el tiempo, posiblemente como consecuencia de la expansión que presentan los soportes debido a su elevada porosidad (que los hace accesibles por el agua) y a la presencia de fases que expanden al hidratarse $e^{[1,2]}$.

En gres porcelánico, tanto esmaltado como no esmaltado, este comportamiento es particularmente sorprendente, ya que la curvatura suele mostrar una evolución en un sentido (habitualmente hacia el sentido cóncavo) para, después de transcurrido cierto tiempo, invertir esta tendencia. El cambio en la evolución de la curvatura, unido a la muy baja porosidad de las baldosas de gres porcelánico (con absorciones de agua inferiores al $0,5 \%$ ) y a la baja proporción de fases hidratables presentes en las piezas cocidas indican que la causa de este comportamiento es mucho más compleja.

En este trabajo se estudian los factores que pueden intervenir sobre las curvaturas en diferido en piezas de gres porcelánico, tanto de forma directa como indirecta. Aunque queda mucho trabajo por realizar en el campo de las curvaturas diferidas, los resultados obtenidos permiten sentar las bases para su estudio sistemático.

\section{Medida de la evolución de la curvatura con el tiempo}

El primer paso en el estudio de las curvaturas diferidas en piezas de gres porcelánico fue la cuantificación de la magnitud y la cinética de las curvaturas diferidas.

Los ensayos consistieron en la medida de la flecha en el centro de la pieza $\left(\delta_{c}\right)$ a diferentes instantes, usando un reloj comparador colocado sobre un soporte con tres apoyos (figura 1). Dicha flecha se determinó para cada diagonal y se hizo un promedio. Es importante comenzar la realización de estas medidas inmediatamente después de la cocción en el horno industrial, dado que en estos momentos es cuando la evolución de la curvatura suele ser más rápida.

En la figura 2 se muestra la evolución de la curvatura con el tiempo durante un periodo de 13 días para baldosas de gres porcelánico esmaltado de 450 * $450 \mathrm{~mm}$ de un mismo modelo (Modelo-1) utilizando dos composiciones de soporte diferentes. Se puede observar que mientras que la curvatura de las piezas conformadas a partir del polvo 
atomizado 1 (Baldosa 1) salen del horno con una curvatura convexa $(0,22 \mathrm{~mm}$ de flecha) que prácticamente permanece invariable con el tiempo, la de la pieza obtenida a partir del polvo atomizado 2 (Baldosa 2) presenta una variación importante de la curvatura con el tiempo. Así, las piezas presentan una curvatura convexa de 0,24 mm a la salida del horno, que disminuye rápidamente y adquiere una curvatura cóncava a las 20 horas $\left(\delta_{c}=-0,06 \mathrm{~mm}\right)$. Pasado este tiempo, la curvatura de la pieza evoluciona más lentamente en sentido contrario hasta que se estabiliza prácticamente a los 8-10 días $\left(\delta_{c}=0,17 \mathrm{~mm}\right)$.

El comportamiento descrito es el que se observa habitualmente en las baldosas de gres porcelánico esmaltado, cambiando la magnitud de los valores de la flecha y la velocidad a la que ésta evoluciona en función de multitud de factores como el tipo de modelo, polvo atomizado, ciclo de cocción, temperatura máxima, condiciones ambientales, etc.

La evolución de la curvatura con el tiempo descrita anteriormente sugiere que la baldosa está sometida a dos fenómenos opuestos: uno rápido que tiende a disminuir la flecha y otro más lento que tiende a aumentarla. Así, puede decirse que la evolución global de la curvatura se debe a la suma de estos dos fenómenos. Matemáticamente esta descomposición puede hacerse de la forma siguiente:

EC. $1 \quad \delta_{c}=A_{1}\left(1-e^{-t / \tau_{1}}\right)+A_{2}\left(1-e^{-t / \tau_{2}}\right)$

Donde el término $A_{1}\left(1-\exp \left(-t / \tau_{1}\right)\right.$ corresponde al primer proceso y $A_{2}\left(1-\exp \left(-t / \tau_{2}\right)\right.$ al segundo. El parámetro $\tau$ es una constante de tiempo relacionada con la cinética del proceso, mientras que A indica la fecha de deformación que se alcanzará en cada uno de los procesos. En la figura 2 se representa esta ecuación para la Baldosa 2 (línea roja). Puede observarse que la ecuación propuesta describe adecuadamente el cambio de la fecha con el tiempo. La figura 3 ilustra la contribución de cada fenómeno en el proceso global.

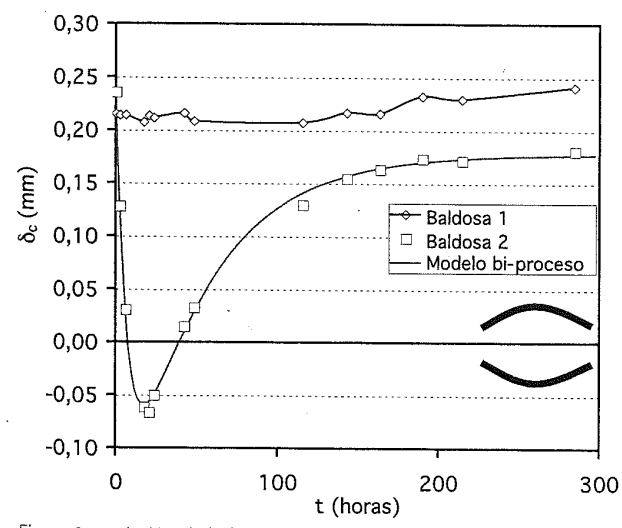

Figura 2. Evolución de la flecha de baldosas industriales. Modelo 1.

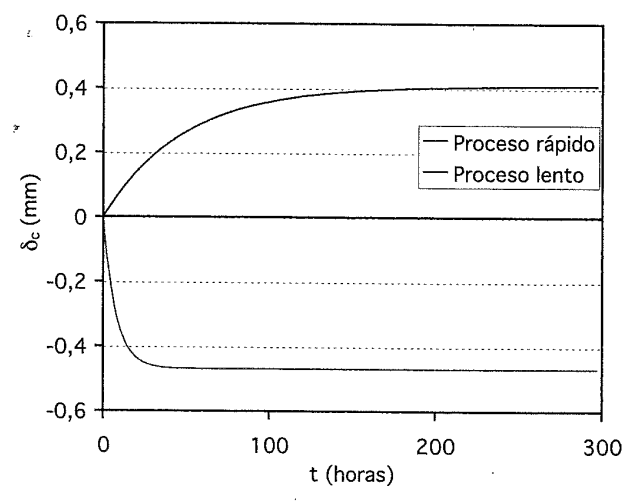

Figura 3. Contribución de los dos procesos. Modelo-1, Baldosa 2. 
Artículos científicos publicados

TECNOLOGÍA CERÁMICA | CERÁMICA INFORMACIÓN

La descomposición de la evolución de la curvatura en dos procesos no da una indicación acerca de las causas que lo originan; simplemente es una cuantificación y parametrización del proceso, que puede simplificar el análisis de la influencia que pueden tener las diferentes variables que intervienen.

\section{Factores que influyen sobre las curvaturas diferidas}

Los factores que influyen sobre las curvaturas en diferido de las baldosas se pueden agrupar en factores directos e indirectos. Los primeros se caracterizan por ser los causantes últimos de las curvaturas diferidas; los segundos pueden influir en las curvaturas en diferido bien porque actúen sobre algún factor directo, o bien porque modifiquen la evolución de la curvatura diferida (pero no la generan).

\subsection{Factores directos}

Para que una baldosa cocida modifique su curvatura con el tiempo es necesario que exista un cambio en las dimensiones de alguna de sus capas respecto a otras, como podría ser el caso de la expansión del soporte de una pieza esmaltada, o que se ejerza una fuerza sobre ella. Este último caso puede ocurrir cuando existe una relajación de las tensiones residuales presentes en la baldosa.

De este modo, básicamente existen dos factores que pueden causar las curvaturas diferidas: la expansión de los soportes y la relajación de las tensiones residuales. El resto de factores son indirectos.

\subsubsection{Expansión de los soportes}

En una pieza esmaltada, la expansión del soporte puede conducir a la aparición de curvaturas diferidas, tal como se muestra en la figura 4 . El mecanismo es muy similar al cambio de curvatura que se produce durante el enfriamiento dentro del horno, debido al acoplamiento entre las capas de esmalte y soporte como consecuencia de la diferencia de contracción entre ambas capas. En este caso la expansión del soporte conducirá a la obtención de una curvatura cóncava, suponiendo que la pieza inicialmente es plana y que el esmalte prácticamente no expande.

Una vez identificado uno de los factores que puede causar la curvatura diferida, es necesario verificar si los soportes de gres porcelánico expanden. Aunque es bien conocido que los soportes de los azulejos presentan una expansión por humedad apreciable, que puede llegar a producir problemas de cuarteo del esmalte en condiciones límite, esta

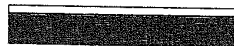

$\mathrm{t}=0$

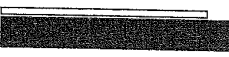

$t=t$

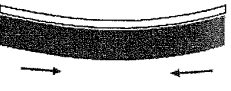

$\mathrm{t}=\mathrm{t}$

Vidriado

Soporte

Figura 4. Representación esquemática de la curvatura diferida originada por la expansión del soporte. 
propiedad no suele medirse en los soportes de gres porcelánico, debido a la inexistencia de defectos de cuarteo en estos productos y a su reducida porosidad.

\section{Procedimiento de medida}

La curvatura diferida se observa inmediatamente después de que las piezas han salido del horno, por lo que es necesario diseñar y poner a punto un procedimiento de ensayo que permita determinar cómo expansionan los soportes durante este periodo de tiempo. La principal dificultad que planteaba la realización de esta medida era la variación de temperatura durante el ensayo, lo que puede afectar de forma considerable a precisión de las medidas. Para solventar estas dificultades se construyó el dispositivo que se muestra en la figura 5, el cual es capaz de autocompensar los cambios de temperatura que sobre él induce la pieza caliente.

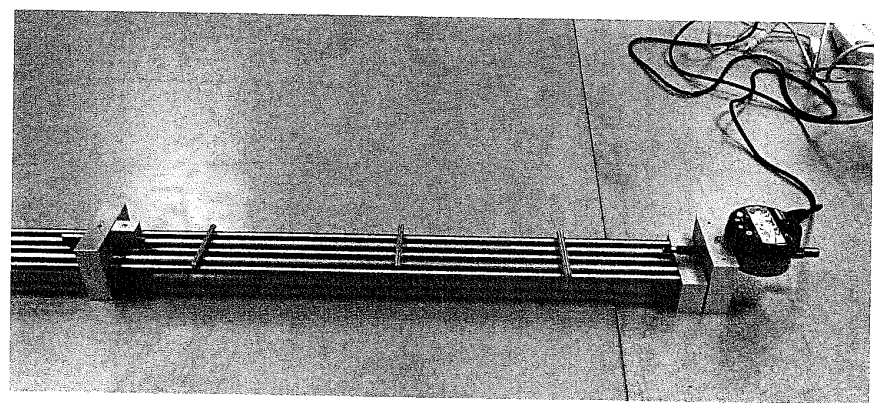

Figura 5. Dispositivo autocompensado en temperatura para medir la expansión del soporte.

\section{Resultados}

En la Figura 6 se muestra la evolución de la expansión de un soporte de gres porcelánico a la salida del horno industrial. Se observa que en los instantes iniciales la expansión es muy rápida, estabilizándose a partir de las 96 horas en un valor en torno a $0.18 \%$. Este resultado depende de la composición utilizada y de la temperatura máxima de cocción; sin embargo, se puede considerar representativo de este tipo de soportes. Con fines comparativos, cabe indicar que la

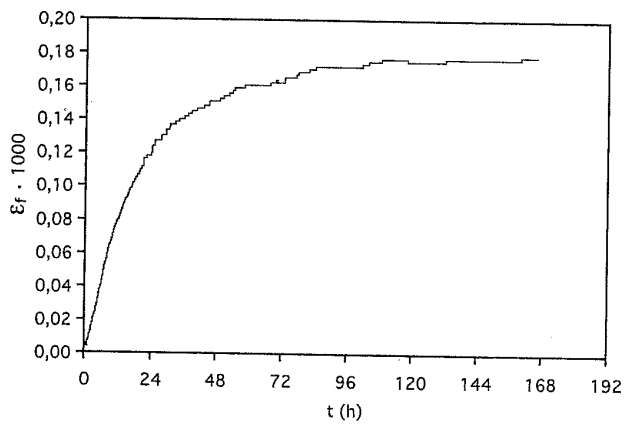

Figura 6. Evolución de la expansión de un soporte de gres porcelánico en función del tiempo.

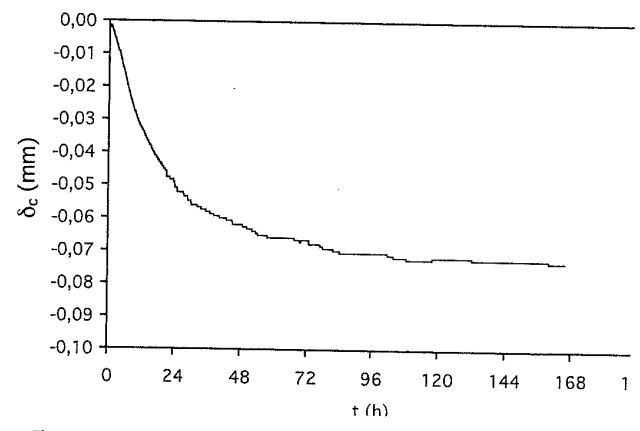

Figura 7. Curvatura diferida provocada por la expansión del soporte. 
Artículos científicos publicados

TECNOLOGÍA CERÁMICA | CERÁMICA INFORMACIÓN

expansión de los soportes de azulejo de cocción blanca suele estar alrededor de 0.35 $\%$, lo cual difiere sólo un factor 2 respecto al valor que presenta el gres porcelánico.

La expansión de los soportes, por sí sola, es insuficiente para explicar las curvaturas en diferido. Como se ha indicado anteriormente, es necesaria la presencia de otra capa que no se deforme. Este papel podría jugarlo la capa de esmalte en los productos esmaltados; sin embargo, hay baldosas de gres porcelánico no esmaltado que también presentan el problema de curvaturas diferidas. Por otra parte, el espesor de la capa de esmalte, en el caso de piezas de gres porcelánico suele ser pequeño (en torno a $100 \mu \mathrm{m})$, por lo que la curvatura generada también es pequeña. En la figura 7 se muestra el valor de la flecha de curvatura que presentará una baldosa de 410 x $410 \mathrm{~mm}$ calculada a partir de la expansión típica de un soporte de gres porcelánico, y considerando el acoplamiento con el esmalte. Como puede observarse, la expansión del soporte no es suficiente, en general, para explicar las curvaturas diferidas; aunque en algunos casos pueda jugar un cierto papel.

Anteriormente se ha considerado que la expansión del soporte es uniforme a lo largo de su espesor. Si existiera una diferencia entre la expansión del soporte entre la cara vista y su cara posterior, se podría justificar parte de la curvatura diferida, tanto en productos esmaltados como no esmaltados. Así, por ejemplo, una diferencia de $0,1 \%$ en la expansión de una pieza de tamaño $410 \times 410 \mathrm{~mm}$ podría provocar una curvatura diferida, expresada como flecha, de unos $0,3 \mathrm{~mm}$. No sólo eso, aun cuando la expansión total de ambas caras fuera la misma, una diferencia en la cinética de la expansión podría provocar cambios en el sentido de la curvatura similares a los observados en baldosas industriales. Aunque existen indicios que apuntan a la posible existencia de esta diferencia, todavía no existen resultados concluyentes sobre este punto.

\subsubsection{Relajación de tensiones residuales}

Una de las hipótesis utilizadas para explicar las curvaturas en diferido es la presencia de tensiones residuales en las baldosas. Si estas tensiones se relajan por algún procedimiento, como la fluencia, pueden conducir a variaciones en su curvatura.

Sin embargo, la existencia de un perfil de tensiones residuales no es sinómino de curvaturas diferidas. Es necesario, además, que este perfil sea asimétrico y que exista fluencia. Respecto a la asimetría del perfil, cabe indicar que un perfil simétrico significa que la tensión es la misma en la cara vista que en la cara posterior; por tanto, la pieza no tendrá tendencia a curvar hacia ninguno de los dos lados.

La existencia de tensiones residuales en las baldosas cerámicas puede deberse a dos causas: las originadas por el enfriamiento rápido de la pieza dentro del horno industrial, asociadas a los gradientes térmicos dentro de la pieza, y las producidas por el acoplamiento entre el soporte y el esmalte. Las primeras son las que se han medido en este trabajo, ya que habitualmente son de mayor magnitud que las originadas por el acoplamiento esmalte/soporte. Ello es debido a que el esmalte suele tener un espesor muy inferior al del soporte y a que el módulo de elasticidad del soporte es relativamente elevado comparado con el esmalte. 


\section{Procedimiento de medida}

Las tensiones residuales en el soporte originadas por gradientes térmicos se midieron utilizando el procedimiento denominado "relajación de la deformación por corte" (strain relaxation slotting method: SRSM). Este procedimiento consiste en pegar una galga en la parte inferior de la pieza sin esmalte (Figura 8) y, a continuación, hacer cortes de profundidad $\left(a_{1}\right)$ creciente desde la superficie superior, midiendo la deformación registrada por la galga $\left(\varepsilon_{\mathrm{g}}\right.$ ) (figura 9 ).

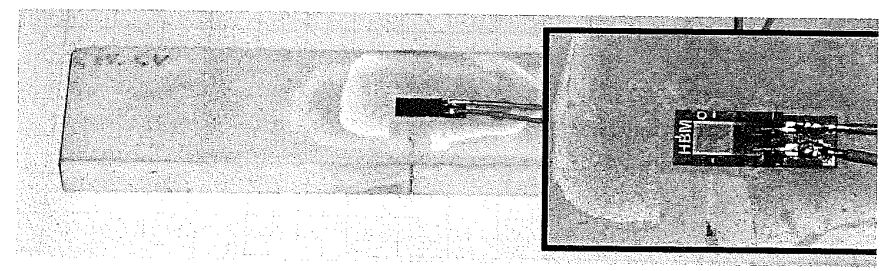

Figura 8. Ensayo de medida de las tensiones residuales y detalle de la galga.

Para poder calcular el perfil de tensiones residuales es necesario conocer la relación entre $\varepsilon_{\mathrm{g}}\left(\mathrm{a}_{\mathrm{i}}\right)$ y la tensión en cada punto del interior de la pieza. Esta relación viene determinada por unos factores de calibrado, que deben calcularse teóricamente para cada geometría mediante un método numérico (en este caso se utilizó el método de los elementos finitos). Finalmente, una vez conocidos los factores de calibrado es posible calcular el perfil de tensiones.

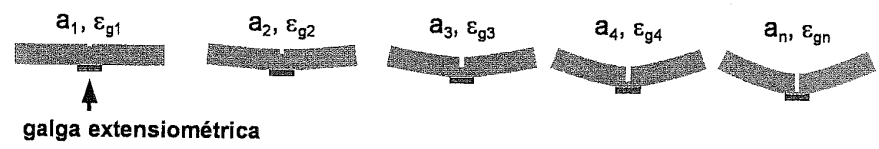

Figura 9. Representación esquemática del fundamento del método empleado para medir las tensiones residuales.

En ocasiones, con el objeto de mejorar la precisión del método se sitúan dos galgas extensiométricas, una en la superficie inferior, y otra en la superior, en un punto próximo a la zona de entalla (figura 10).

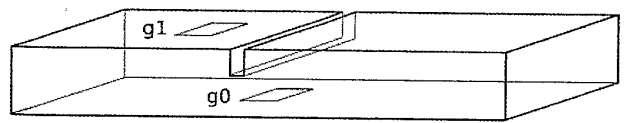

Figura 10. Ubicación de las galgas en la superficie inferior (g0) y superior $(g 1)$

\section{Resultados}

En la figura 11 se muestran los valores de deformación medida por ambas galgas (rombos y triángulos) y la curva de ajuste obtenida a partir del cálculo por elementos finitos. La pieza analizada fue una baldosa cocida en condiciones industriales. Se 
TECNOLOGIAA CERÁMICA | CERÁMICA INFORMACIÓN

observa que a medida que se incrementa la profundidad de la entalla (a), aumenta la deformación medida por las dos galgas. La galga superior es muy sensible al principio del corte (valores bajos de a), pero a medida que aumenta la profundidad de la entalla, esta galga rápidamente pierde sensibilidad y pasa a ser más relevante la galga inferior.

A partir de los datos de la figura 11 se determinaron los perfiles de tensiones residuales para dos modelos de gres porcelánico esmaltado (Modelo-1 y Modelo-2), que se muestran en la figura 12. El valor $\xi=-1$ corresponde a la superficie inferior y $\xi=+1$ a la superior (cara-vista). En ambos casos el perfil muestra tensiones negativas (compresión) en la superficie y positivas (tracción) en el centro. Este es el perfil típico que presenta un material templado.

El Modelo-1 tenía tensiones similares a las del Modelo-2 en la mitad inferior de la pieza, pero ligeramente mayores en la mitad superior; en promedio, podría afirmarse que el Modelo- 1 estaba ligeramente más tensionado que el Modelo-2, y su perfil era más simétrico. Experimentalmente se comprobó que el Modelo-1 no tenía tendencia a presentar problemas de curvaturas diferidas; mientras que el Modelo-2 sí los presentaba. Este resultado parece concordar con lo indicado anteriormente sobre la relación entre la simetría del perfil de tensiones y las curvaturas diferidas. En todo caso, para establecer conclusiones definitivas sería necesario profundizar en las medidas, analizando un mayor número de piezas y de modelos.

\section{Medida de la fluencia}

Las tensiones residuales, por sí solas, no provocan curvaturas diferidas, aunque sean altamente asimétricas. Es necesario que exista un mecanismo por el que la pieza pueda liberar estas tensiones. Este mecanismo se conoce como fluencia y, al igual que en el caso de las tensiones residuales, era necesario verificar si las piezas de gres porcelánico presentaban este comportamiento.

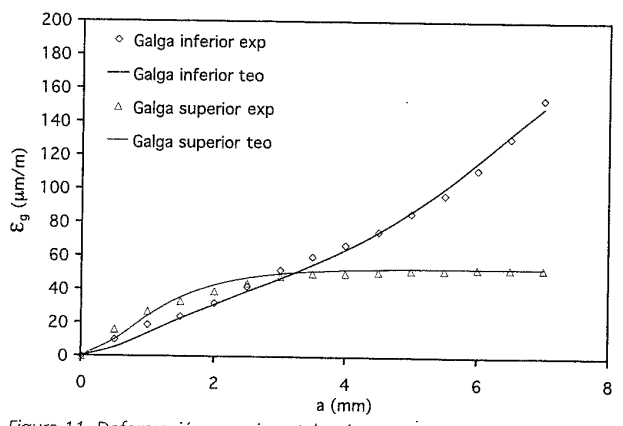

Figura 11. Deformación experimental y ajuste para una pieza de gres porcelánico.

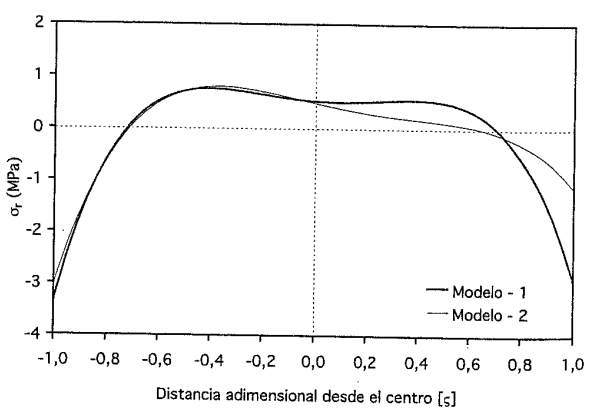

Figura 12. Perfil de tensiones residuales para el Modelo-1 y el Moldelo-2. 


\section{Procedimiento de medida}

Para medir la fluencia se utilizó el dispositivo mostrado en la figura 13. El dispositivo consta de un puente de flexión sobre el que se sitúa la probeta a analizar. A continuación se aplica una carga constante, mediante unas masas, y se registra la deformación de la probeta utilizando un medidor de desplazamiento (LVDT).

\section{Resultados}

La figura 14 muestra los resultados obtenidos. Se observa que la deformación no es cero, lo que indica que existe cierta fluencia. Además, se distinguen dos tramos: uno inicial, en el que la velocidad de deformación va disminuyendo (fluencia primaria), y un segundo en el que la pendiente es constante (fluencia secundaria). Este comportamiento puede modelizarse empleando el modelo viscoelástico mostrado en la figura 15. A partir de este modelo es posible establecer la siguiente relación entre la flecha y el tiempo:

$$
\text { EC. } 2 \quad \delta_{C}=\frac{S^{2} \sigma_{m}}{18 h \eta}\left(\tau_{D}\left(1-\mathrm{e}^{-t / \tau}\right)+t\right)
$$

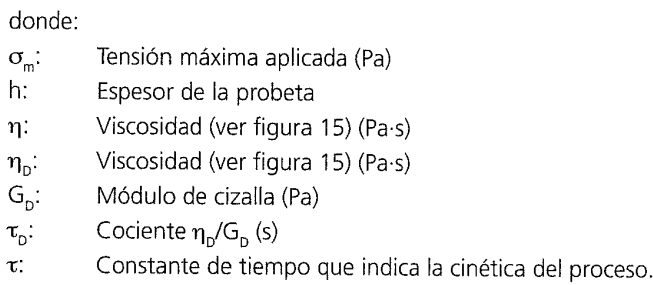

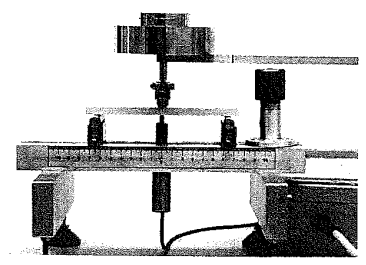

Figura 13. Dispositivo empleado para medir la fluencia.

El resultado de la aplicación de la ec. se muestra en la figura 14, comprobándose que ésta consigue reproducir correctamente los resultados experimentales.

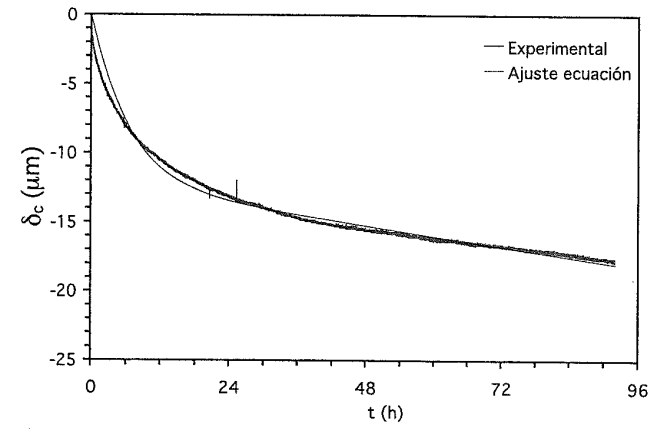

Figura 14. Deformación de una probeta de gres porcelánico bajo la aplicación de una carga.

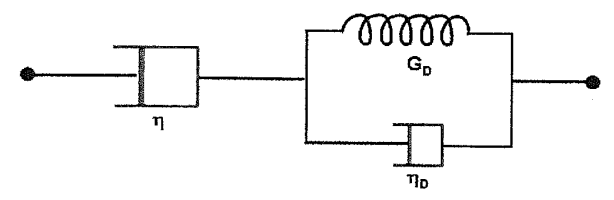

Figura 15. Modelo viscoelástico lineal empleado para modelizar la fluencia. 
Artículos científicos publicados

TECNOLOGIA CERÁMICA | CERÁMICA INFORMACIÓN

\subsection{Factores indirectos}

Las características de los materiales empleados en la fabricación de las baldosas de gres porcelánico (polvos atomizados, esmaltes, etc.) junto con variables de proceso utilizadas, definen las características de las baldosas cerámicas, como se observa en el esquema de la figura 16. Estos factores, aunque no son los responsables directos de las curvaturas diferidas, pueden ejercer en algunos casos, una enorme influencia sobre ellas. En este apartado analizan en primer lugar estos factores, para posteriormente mostrar algunos ejemplos de la influencia que ejercen tanto sobre la curvatura diferida como sobre los factores que la originan.
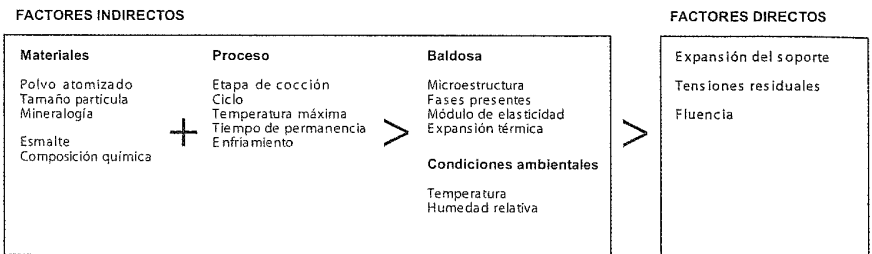

Figura 16. Factores que influyen sobre las curvaturas diferidas.

\subsubsection{Factores que afectan a la expansión del soporte}

La expansión por acción de la humedad de los soportes cerámicos es una característica conocida, existiendo en la normativa vigente procedimientos para su medida. Habitualmente, los valores de expansión por acción de la humedad en autoclave con ciclos de presión de vapor de 5 horas a 10 bares suelen oscilar entre el 0,6 y el 1,0\% para los soportes de azulejo, reduciéndose hasta valores inferiores al 0,3\% para baldosas de baja absorción de agua.

La expansión por humedad del los productos cerámicos porosos (loza y porcelana) ha sido ampliamente estudiada por su relación con los defectos de cuarteo del vidriado. Para estos productos el origen de la expansión por humedad de los soportes cerámicos es la adsorción química y física de moléculas de agua sobre las valencias libres existentes en las fases hidratables presentes en las piezas cocidas (fases vítreas y en especial fases amorfas provenientes de la deshidroxilación de los minerales arcillosos) ${ }^{[3]}$. Por ello, la expansión depende principalmente de la estructura porosa de la pieza (que define la mayor o menor accesibilidad por parte del agua) ${ }^{[1]}$ y de la naturaleza y contenido de fases presentes en la pieza cocida ${ }^{[2]}$. Estas características están muy influenciadas por la composición mineralógica de la composición utilizada, su tamaño de partícula y la cocción realizada ${ }^{[4]}$. Así, a medida que aumenta la fundencia de la composición del soporte y la temperatura de cocción o tiempo de permanencia, disminuye la expansión por humedad de estos soportes debido a la reducción de su porosidad y de su contenido en fases hidratables ${ }^{[5]}$

En el caso de los soportes de muy baja porosidad, como el gres porcelánico, no se han encontrado trabajos que aborden este tema, debido probablemente a la menor expansión y ausencia de defectos de cuarteo en estos productos. No obstante, y aunque el objetivo de este trabajo no fue determinar el motivo de la expansión que experimentan 
los soportes de gres porcelánico a la salida del horno (adsorción de humedad u otros) es probable que los factores que influyen sobre la expansión por humedad en soportes porosos también lo hagan en el caso de los soportes de gres porcelánico.

\subsubsection{Factores que afectan a las tensiones residuales}

Al alcanzar la temperatura máxima de cocción, las baldosas de gres porcelánico están formadas por una gran cantidad de fase líquida, cuarzo y albita residual y, en ocasiones, mullita ${ }^{[6]}$. En este estado, la pieza es capaz de relajar cualquier tensión que se ejerza sobre ella, ya que presenta una elevada deformabilidad. Es durante la fase de enfriamiento cuando se originan las tensiones residuales en las baldosas, ya sea por desajustes en el acoplamiento entre las capas de soporte y esmalte o por las contracciones diferenciales que surgen como consecuencia de la mayor velocidad de enfriamiento existente entre la periferia y el centro de la pieza. Así, puede decirse que los factores que determinan las tensiones residuales en las piezas de gres porcelánico son la expansión térmica y módulo de elasticidad del soporte y esmalte, sus espesores relativos y la velocidad de enfriamiento de la pieza.

Se ha observado que el aumento en el desajuste de la expansión térmica de ambas capas, así como el aumento en el espesor del esmalte incrementan las tensiones residuales. Asimismo, a medida que el enfriamiento es más rápido, aumenta el gradiente de temperatura en el interior de la baldosa ${ }^{[7]}$, lo que conduce a diferencias en la velocidad de contracción a lo largo de su sección. Ello causa un perfil de tensiones en el interior de la pieza que es más acusado a medida que aumenta la velocidad de enfriamiento [8]. Además, cuando la velocidad de enfriamiento no es igual por ambas superficies de la baldosas (situación habitual en los hornos de rodillos) el perfil de tensiones que se establece no es simétrico, como se verá más adelante.

\subsubsection{Factores que afectan a la fluencia}

Los factores que influyen sobre la fluenciá de las piezas de gres porcelánico deben asociarse a su microestructura. En la figura 17 se muestra la sección de una pieza de gres porcelánico observada por microscopía electrónica de barrido. Está formada por una matriz vitrea en la que se existen numerosos poros y microgrietas. Los poros presentes

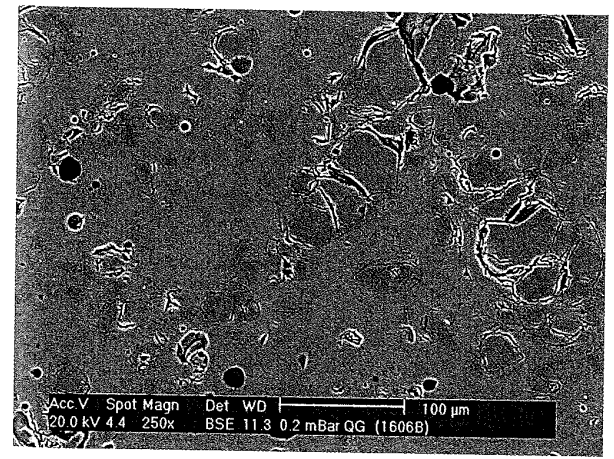

Figura 17. Sección transversal de una pieza de gres porcelánico.

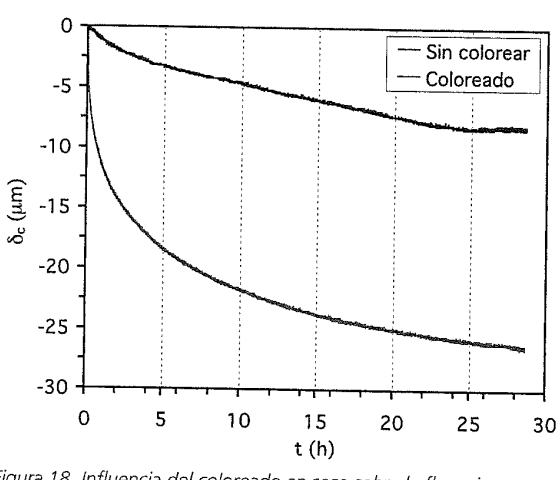

Figura 18. influencia del coloreado en seco sobre la fluencia. 
Artículos científicos publicados

TECNOLOGÍA CERÁMICA | CERÁMICA INFORMACIÓN

suelen presentar formas redondeadas y proceden de la descomposición de ciertas impurezas así como de la porosidad de elevado tamaño presente en la pieza cruda ${ }^{[9]}$. El origen de las microgrietas es variado, destacando los desajustes existentes entre las partículas de cuarzo residual y la matriz vítrea ${ }^{[8]}$ y las zonas de unión entre los gránulos del polvo atomizado que no se han deformado en su totalidad durante el prensado ${ }^{[10]}$

La fluencia en piezas de gres porcelánico está causada muy probablemente por el crecimiento de las microgrietas existentes en la pieza cuando ésta se encuentra sometida a un esfuerzo de tracción, por lo que los factores que las originan serán aquellos que determinen la fluencia en este tipo de baldosas. Se ha comprobado que un aumento en el contenido de cuarzo así como en el tamaño de partícula de éste origina una microestructura con una mayor cantidad de microgrietas, lo que probablemente aumentará la fluencia de las piezas. Esto mismo también puede suceder cuando el grado de molienda de la composición es insuficiente.

\subsubsection{Influencia del coloreado en seco sobre la fluencia}

Se han realizado ensayos de fluencia sobre probetas obtenidas a partir de baldosas industriales cocidas de gres porcelánico esmaltado cuya única diferencia era la utilización de un polvo atomizado coloreado en seco y sin colorear. Las probetas tenían unas dimensiones de $220 \times 20 \mathrm{~mm}$ y se mecanizaron para eliminar la "costilla". El espesor medio de estas probetas fue de $6,4 \mathrm{~mm}$ y la carga aplicada de $29 \mathrm{MPa}$.

En la figura 18 se observa que ambas probetas experimentan una deformación con el tiempo (fluencia), que es muy rápida al principio del ensayo y progresivamente se va estabilizando con el tiempo. Se aprecia que la pieza con pigmento presenta una deformación bastante superior a la pieza sin pigmento, lo que indica que la capacidad para deformar ante una tensión dada es muy superior para las piezas con pigmento.

Aunque en este trabajo no se ha estudiado el origen de esta diferencia, el motivo por el que la pieza coloreada presenta una fluencia superior puede relacionarse con la microestructura que presenta este tipo de baldosa, en la que las partículas de pigmento se concentran en determinadas zonas de la pieza (las zonas de contacto entre los gránulos del polvo atomizado) ${ }^{111}$. Estas zonas pueden actuar como defectos iniciadores de microgrietas cuando se utilizan elevados porcentajes de pigmento, cuyo crecimiento ante la aplicación de una determinada tensión podría ser el origen de la mayor fluencia observada.

A partir de estos resultados no puede concluirse directamente que las piezas coloreadas en seco vayan a presentar mayores problemas de curvaturas diferidas, dado que ello dependerá del resto de factores implicados. Tanto es así, que existen modelos coloreados en seco que no presentan curvaturas diferidas. Sin embargo, frente a la existencia de tensiones residuales asimétricas en las baldosas, y a igualdad de otros factores, aquellas baldosas que presenten una mayor fluencia tendrán más probabilidades de cambiar su curvatura con el tiempo.

\subsubsection{Influencia de la presencia de esmalte sobre la curvatura diferida}

En la figura 19 se muestra la evolución de la flecha con el tiempo para baldosas de gres porcelánico esmaltado, de $300 \times 600 \mathrm{~mm}$, con el soporte coloreado en seco con y sin 
la presencia de esmalte. Puede observarse que mientras que la baldosa con esmalte presenta una evolución de la curvatura cualitativamente similar a la mostrada en el apartado 2, el soporte sin esmalte sigue la evolución opuesta. Es interesante destacar que el tiempo para el que se observa la curvatura mínima en la pieza con esmalte ( 24 $\mathrm{h}, 0,37 \mathrm{~mm}$ ) prácticamente coincide con el tiempo para en que se detecta la máxima curvatura en el esmalte $(23 \mathrm{~h}, 1,02 \mathrm{~mm}$ )

Las causas de este comportamiento pueden deberse a la existencia de velocidades de expansión diferentes entre la cara-vista y la superficie posterior, dado que las baldosas se han cocido con el mismo ciclo y, por tanto, las tensiones residuales debidas al enfriamiento deben ser similares. Este mismo comportamiento también se observó en piezas de gres porcelánico no esmaltado, lo que parece indicar la enorme influencia que ejerce el esmalte sobre la evolución de la curvatura con el tiempo.

\subsubsection{Influencia de la fase de enfriamiento}

La fase de enfriamiento en los hornos industriales de rodillos se caracteriza por presentar un primer tramo de enfriamiento a elevada velocidad que se realiza mediante la inyección de aire a temperatura ambiente en el interior del horno. Este tipo de enfriamiento genera elevados gradientes de temperatura entre la superficie y el interior de la baldosa, lo que conduce a la existencia de tensiones residuales que pueden originar las curvaturas diferidas.

En este apartado se ha estudiado la influencia del enfriamiento sobre las tensiones residuales del soporte. Para ello se han utilizado probetas de $150 \times 30 \mathrm{~mm}$ obtenidas a partir de piezas industriales crudas de gres porcelánico esmaltado, que se han cocido en un horno eléctrico de laboratorio a $1200^{\circ} \mathrm{C}$ durante 6 minutos y se han enfriado fuera del horno ("quenching") de dos formas distintas:

- Enfriamiento simétrico: con la pieza vertical. Ambos lados de la pieza se enfriaban por igual.

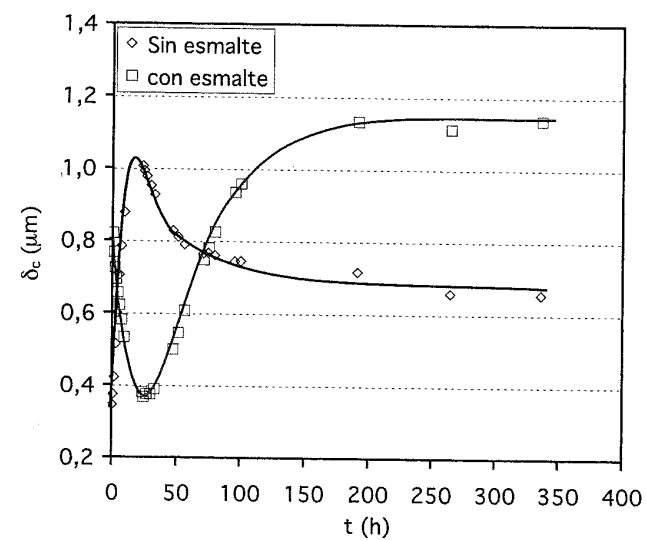

Figura 19. Evolución de la fecha de baldosas con y sin esmalte.

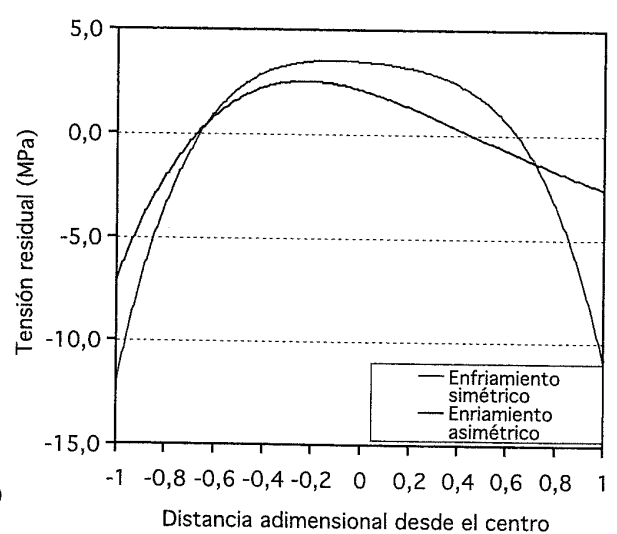

Figura 20. Perfil de tensiones residuales en función del tipo de enfriamiento. 
Artículos científicos publicados

TECNOLOGÍA CERÁMICA | CERÁMICA INFORMACIÓN

- Enfriamiento asimétrico: con la pieza horizontal sobre un refractario. En este caso el enfriamiento tiene lugar básicamente por la parte superior.

En la figura 20 se muestra el perfil de tensiones para las dos probetas enfriadas de forma diferente. Se observa que en ambos casos las dos superficies de las piezas se encuentran sometidas a una tensión de compresión, mientras que el interior de la pieza está traccionada, situación habitual en los materiales cerámicos. También se aprecia que el enfriamiento influye considerablemente sobre el perfil de tensiones. Así, cuando la probeta se enfría por igual por ambas caras (pieza enfriada en posición vertical) el perfil de tensiones es simétrico, mientras que la que ha sido enfriada en posición horizontal sobre refractario (enfriamiento asimétrico) tiene un perfil no simétrico. Estos resultados confirman que las diferencias en la velocidad de enfriamiento por la parte superior e inferior de la pieza pueden conducir a perfiles de tensiones asimétricos.

\section{Conclusiones}

En este trabajo se han estudiado los factores que pueden intervenir en las curvaturas en diferido de baldosas de gres porcelánico, obteniéndose las siguientes conclusiones:

- Se ha cuantificado la variación de la curvatura con el tiempo en piezas industriales observando que existe un cambio en su tendencia (cóncava-convexa). Ello implica que existen dos mecanismos, simultáneos y antagónicos, con cinéticas diferentes, que influyen sobre el proceso.

- Los análisis teóricos indican que sólo existen dos factores que pueden producir las curvaturas diferidas: la expansión de los soportes y las tensiones residuales. En ambos casos, es necesario que se den circunstancias adicionales para que aparezcan las curvaturas en diferido; así, es necesario que la expansión sea diferente por la cara vista y por la cara posterior. Una expansión uniforme provocaría un ligero cambio dimensional, pero no una curvatura en diferido significativa, ni siquiera en presencia de esmalte. En el caso de las tensiones residuales, el perfil de tensiones debe de ser asimétrico y tiene que existir un mecanismo que permita su liberación (fluencia).

- La medida de los factores que influyen en las curvaturas en diferido es compleja debido a que requiere el empleo de técnicas diferentes a las utilizadas habitualmente en la caracterización de baldosas cerámicas. Se han puesto a punto procedimientos para medir los diferentes factores que producen las curvaturas en diferido. Se ha diseñado un dispositivo auto compensado en temperatura para medir la expansión de los soportes; se ha aplicado en método denominado "relajación de deformación por corte" (Strain Relaxation Slotting Method -SRSM-) para medir las tensiones residuales en piezas de gres porcelánico y se han utilizado ensayos de flexión en 3 puntos con aplicación de una carga constante durante varios días con el fin de confirmar la presencia de fluencia en los soportes de gres porcelánico.

- Se ha comprobado que los soportes de gres porcelánico experimentan una expansión a su salida del horno. Estos soportes presentan, además, tensiones residuales y fluencia, lo que podría justificar la existencia de las curvaturas diferidas.

- Se han realizado experimentos modificando el tipo de polvo atomizado, eliminando el esmalte y modificando el enfriamiento. Estos experimentos han permitido disponer de una primera información acerca de la influencia de las características del material y del proceso de fabricación sobre la fluencia, tensiones residuales y curvatura diferida. 
- Aunque queda mucho trabajo por realizar en el campo de las curvaturas diferida, los resultados obtenidos permiten sentar las bases para su estudio sistemático.

\section{Bibliografía}

[1] VASIC, R.M. Influence of pore size distribution of frost resistance and moisture expansion of bricks. MS Instit. Bull. 7, 15-18, 1992.

[2] SEGADÄES, A.M.; CARVALHO, M.A.; FERREIRA, H.C. Using phase diagrams to deal with moisture expansion. Ceram. Int., 29 (8), 947-954, 2003.

[3] SMITH, A.N. Investigations on the moisture expansion of porous ceramic bodies. Trans. Br. Ceram. Soc., 54(5), 300-318, 1955.

[4] SCHURECHT, H.G.; POLE, G.R. Effect of water in expanding ceramic bodies of different compositions.. J. Am. Ceram. Soc., 12, 596-604, 1929.

[5] HARRISON, R.; DINSDALE. A. The effect of temperature and pressure on moisture expansion. Trans. Br. Ceram. Soc., 63, 63-75, 1964 .

[6] SANCHEZ, E.; ORTS, M.J.; GARCIA-TEN, 1.; CANTAVELLA, V.. Porcelain tile composition effect on phase formation and end products. Am. Ceram. Soc. bull., 80(6), 43-49, 2001

[7] CANTAVELlA, V.; MORENO, A.; MEZQUiTA, A.; LLORENS, D.; BARBERA, J.; PALANQUES, A. Distribución de temperaturas en el interior de una pieza durante la cocción industrial. En: Qualicer 2006 : IX Congreso mundial de la calidad del azulejo y del pavimento cerámico. Castellón: Cámara oficial de comercio, industria y navegación, 2006. pp. P.BC151-P.BC164.

[8] NONI JUNIOR, A. DE; HOTZA, D.; CANTAVELLA, V.; SANCHEZ, E.. Influencia del enfriamiento de etapa de cocción sobre las propiedades mecánicas del gres porcelánico. Bol. Soc. Esp. Ceram. Vidr. 46(4), 163-170, 2007

[9] AMORÓS, J.L.; ORTS, M.J.; GARCIA-TEN, J.; GOZALBO, A.; SÁNCHEZ, E.. Effect of green porous texture on porcelain tile properties. J. Eur. Ceram. Soc., 27, 2295-2301, 2007.

[10] GARCIA-TEN, J.; SANCHEZ, E.; MALLOL, G.; JARQUE, J.C.; ARROYO, A.. Influence of operating variables on spray-dried granule and resulting tile characteristics. Key Eng. Mater, 264-268, 1499$1502,2004$.

[11] GARCIA-TEN, J.; SANCHEZ, E.; QUEREDA, P.; SABURIT, A.; SÁNCHEZ, J.; SALES, J.; SOLER, C. Influencia del coloreado en seco en el comportamiento mecánico de piezas crudas de gres porcelánico. En: CARDA CASTELLÓ, J.B. Ciencia y tecnología de los materiales cerámicos y vítreos en el nuevo milenio: Libro de resúmenes de los trabajos presentados a la XLVI reunión anual de la Sociedad Española de Cerámica y Vidrio. Castellón: Faenza editrice ibérica, 2006. pp. 42 . ¥

Ponemos a su disposición nuestra experiencia para ayudarle en:

- Autoevaluación e implantación Modelo Europeo de Excelencia EFOM

- Asesoramiento ISO 9001, ISO 14001, OHSAS 18001

- Asesoramiento Legal Medioambiental

- Asesoramiento Tecnológico: Resolución de problemas productivos

- Disminución costes mala calidad

- Asesoramiento logística distribución, aprovisionamiento y almacenes

- Asesoramiento en proyectos de 1+D y deducciones fiscales

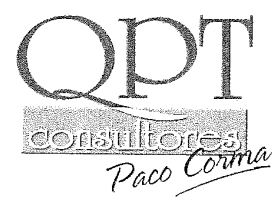

Rio Ebro 33, lzqda. $7^{\circ}-16$ 12540 Vila-real (Castellón-España) Tel/Fax: +34964536202 E-mail: qpteqpt-consulting.com www.-qpt-consulting.com
whall

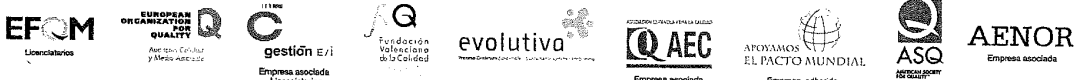


Artículos científicos publicados 


\section{Artículo 3}

- Título: "Delayed Curvatures in Porcelain Tiles. Analysis and measurement of influencing factors"

- Autores: Cantavella, V., García -Ten, J., Sánchez, E., Bannier, E., Sánchez, J., Soler, C. y Sales, J.

- Revista: Cfi Ber. DKG, 85(6), pp. 50-58

- Año: 2008 
Artículos científicos publicados 


\section{Process Enginineering}

\section{Y Cantavellat \\ E Sánctiez? \\ E. Bannier, \\ 1. Sánche \\ C. Soler
1. Sales? \\ Instituto de Te \\ Instituto de Tec- \\ (ITC). \\ Delayed Curvatures in Porcelain Tiles \\ Analysis and Measurement of Influencing Factors}

2 Taulell, SA Ta

Cerámica

(presented at

\section{Abstract}

Glazed and unglazed porcelain tiles exhibit a phenomenon known as 'delayed curvatures', which consist of the change in tile curvature after the tiles leave the kitn. This phenomenon becomes more problematic as tile size increases

In this study, the variation of curvastucly has been quar inctustrial gion was observed that thecurrar was obsene ally displays an evolution in one direction (customarily in a concave direction or vessel shape) which. after a certain time has elapsed reverses this trend The kinetics this process has been parameterised, assuming there are two simultane ous, opposing mechanisms, wihn different kinetics

Theoretical analyses indicate that only two factors can produce delayed curvatures: residual stresses and expansion of the tile body I both cases, additional circumstances need to occur for delayed curvatures to appear: thus for example the prence residual stresses is not synonymous with delayed curvaures, but an additional mechanism is needed that allows progressive release of these stresses, a mecha nism known as creep. In addition the condition that the stress profile is not symmetrical with respect to the centre plane of the tile also needs to be obeyed

in regard to the expansion of the bodies, special conditions must also occur for these to cause delayed curvatures. In particular, it is necessary for the expansion at the tile fart fac and at the rib face to be different Uniform expansion would cause a slight dimensional change but not delayed curvature not even in the presence of glaze

The measurement of the factors that influence delayed curvatures is complex because different techniques from those typically used in charac terising ceramic tiles are required

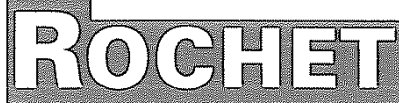

Z1 - B.P 25 - FO9101 PAMIERS cedex - France Tal. $33534013500-F a x 33534013501$ http://www brickcutter.com

E-Mail : arocheticouneur-rochet fr

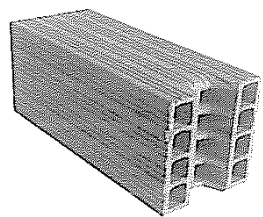

40 years in the ceramic industry

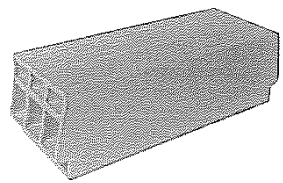

Five exits bricks cutter

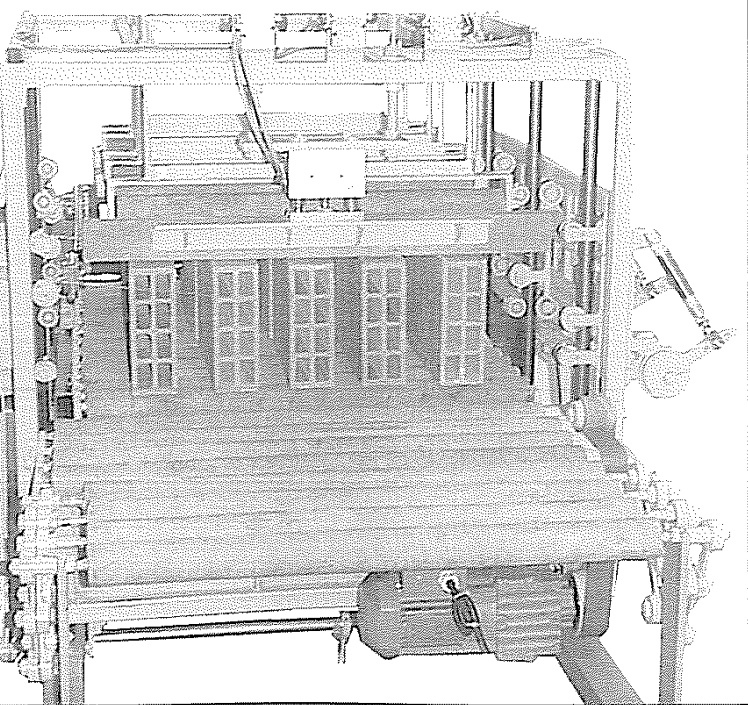

All types of cutters for bricks, thles, refiractories, avdanced ceramics 
Artículos científicos publicados

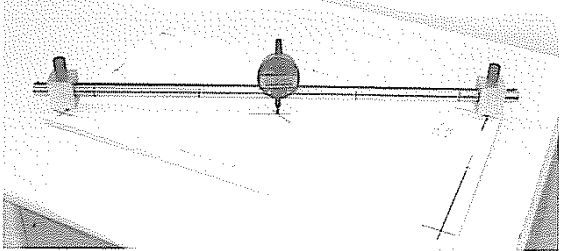

Fig. 1 Arrangement used to measure the deflection of industrial iles

Procedures have been fine-tuned to measure the different factors that give rise to clelayed curvatures, and the influence of certain variables on these lactors has been studied.

\section{Introduction}

A significant percentage of ceramics tiles, independently of their porosity, exhibit the phenomenon known as 'delayed curvatures' These consist of the change in tile curvature after the tile exits the kiln over a period of time that may take several weeks or even months

Although delayed curvatures are not unknown in the ceramic sector, they pose a serious manufacturing problem owing to the present larger tite sizes Thus, the presence of delayed curvatures leads to problems in the sorting stage and in final product quality, thus it is necessary to know the linal curvature that the tile witl develop in order to establish with what curvature the tile needs to leave the kiln, as well as the criteria for tile classification

The delayed curvatures in porous wall tiles or earthenware tiles display a trend towards concavity with time, possibly as a result of the expansion of the bodies due to their bigh porosity (which allows water to penetratel, and to the presence of phases that expand when the body hyctrates $[1,2]$ In both glazed and unglazed porcelain tile, such behaviour is particularly surprising, because the curvature displays an evolution in one direction (customarily in a concave direction) which, after a certain time, usuatly reverses direction The change in the evolution of the curvature, together with the very low porosity of porcelain tiles (water absorption below $0,5 \%$ ) and the low quantity of hyd ratable phases present in the fired tile, indicates that the cause of this behaysent in the fired tile, indic

In this study the factors that can influence delayed curvature in porcelain tiles, either directly or indirectly, have been examined. Although much work still remains to be done in the field of delayed curvatures, the results obtained lay the groundwork for a systematic study of delayed curvatures

\section{Measurement of the}

Evolution of Curvature with Time

The first step in the study of delayed curvatures in porcelain tile was the quantification of the magnitucle and kinetics of the delayed curvatures

The tests consisted of measuring the deflection in the centre of the piece $\left(\delta_{c}\right)$ at different moments, using a dial gauge set on a stand with three supports (Fig. 1) This deflection was determined for each diagonal and the results were then averaged. It is important to begin making these measurements immediately after firing in the inclustrial kiln, since that is when the curvature usually evolves fastest.

Fig 2 shows the evolution of curvature with time over a period of 13 days for the glazed porcelain tile of $450 \times 450 \mathrm{~mm}^{2}$ of the same model (Mode-1) using two different body com-

Cf/Ber DKG 85 (2008) No 6

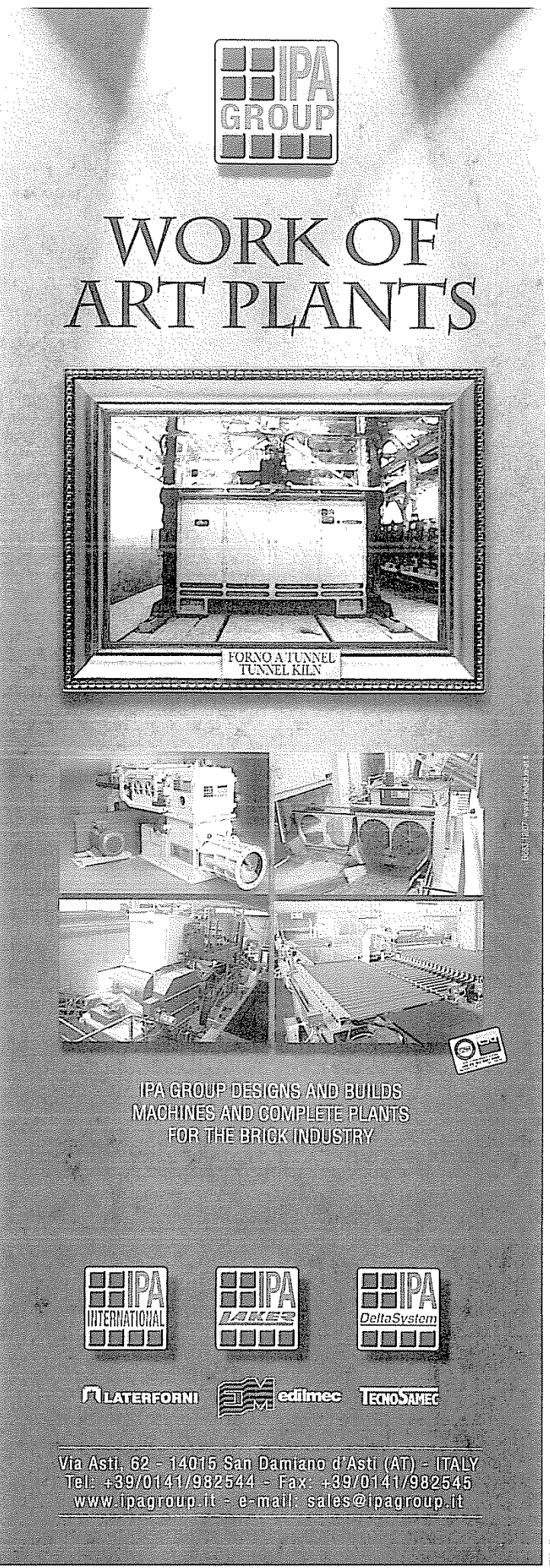




\section{Process Engineering}

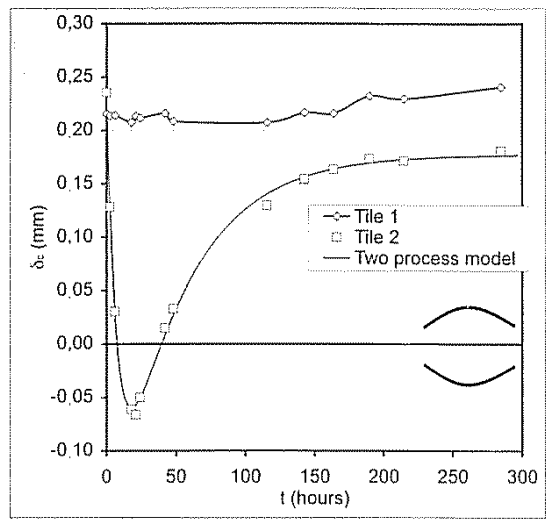

Fig 2 Evolution of deflection in industrial tiles (Modet 1 , Tile 2 )

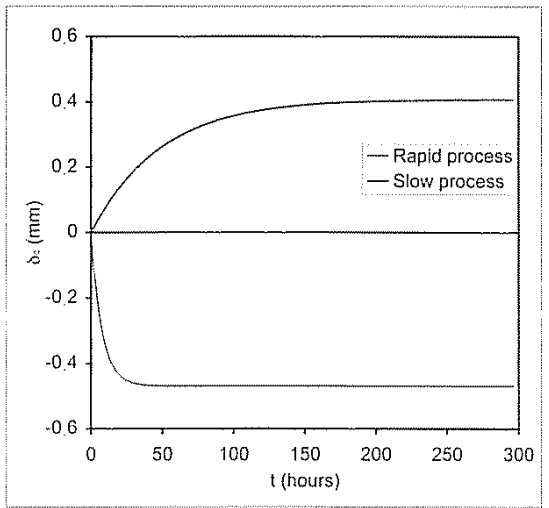

Fig 3 Contribution of both processes (Model 1. Tile 2)

positions It may be observed that whereas the pieces formed from spray-dried powder 1 (Tile 1) leave the kiln with a convex curvature $(0,22$ deflection), which practically remains invariable with time, the curvature of the piece obtained from

Fig $S$ Device that auto temperature for the measurement of body expansion

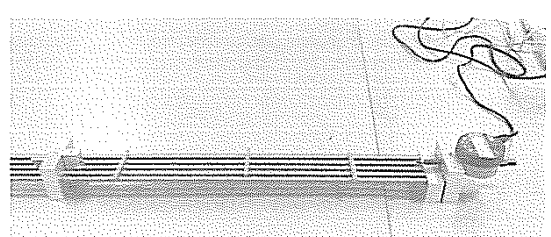

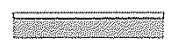

$t=0$

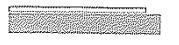

$t=1$

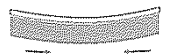

$\mathrm{t}=\mathrm{t}$

Tolaze

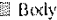

Fig 4 Schematic illustration of the delayed curvature produced by expansion of the

becomes a concave curvature after 20 hours $\left(\delta_{c}=-0,06 \mathrm{~mm}\right)$ After this time, the curvature of the piece evolves more slowly in the opposite direction until it practically stabilises after 810 days $\left(\delta_{c}=0,17 \mathrm{~mm}\right)$

The behaviour described is that typically observed in glazed porcelain tiles in which the magnitu of thes, in which the maznilude of the this evolves, change as a function of this evolves, change as a function of
a multitude of factors such as type of a multitude of factors such as type of cycle, peak temperature, environ mental conditions, etc

The foregoing evolution of curvature with time suggests that the tile is will time sugd at a rapid ope that phends na: a rapid one that tends to decrease the deilection and anothe slower one than tends to increase it Thus, the overall evolution of the curvature may be considered due to these two phenomena. Mathematically this decomposition can be writ. ten in the following form:

$D=A\left(1-e^{-2}\right)+A\left(1-w^{-\cdots}\right.$

Where the term $A_{1}\left(1-\exp \left|-1 / \tau_{1}\right|\right)$ cor responds to the first process and $A_{2}\left(1-\exp \left|-t / T_{2}\right|\right)$ to the second Para meter $T$ is a time constant related to process kinetics, whereas A indicates the strain deflection that will be reached in each process This equa tion is represented for Tile 2 (red line) in Fig 2 It may be observed that the proposed equation suitabl describes the change in deffection with time Fig 3 illustrates the con tribution of each phenomenon in the overali process

the overal process The decomposition of the processes does nol provide an indication of the originating causes; it is simply a quantification and parameterisation of th process, which may simplify the analysis of the influence that the dif ferent variables involved may have

Factors that Influence Delayed Curvatures

The factors that influence delayed curvatures in tiles may be divided into direct and indirest factors The former are characterised as being the ultimate causes of the delayed curvatures; the latter can affect the delayed curvatures either because they act on some direcl factor or because they modify the evolution of the delayed curvature (though they clo not generate it)

\section{Dired Factors}

To modify in a fired tile its curvature with time it is necessary to make some modifications, as it can occur by the expansion of the body of glazed like, or if a force is applied to the tile. This last case can take plac when relaxation occurs of the residual stresses present in the tile Thus there are basically two factors that can cause delayed curvatures: expansion of the bodies and relaxation of the residual stresses the remaining factors are indirecl Expansion of the Bodies In a glazed tile, the expansion of the body may lead to the appearance of delayed curvatures, as illustrated in Fig 4 The mechanism is very simila to the change in curvalure that occurs during cooling in the bith occurs do the cooling in the kith owing to the fit between the glaz and body layers as a result of the diference in shrinkage between both layers on this case, the expansion of the body will lead to a concave curvature, assuming that the piece is initialy flat and that the glaze pract cally does not expand

Once one of the factors that can cause the delayed curvature had been identified, it was necessary to verify whether porcelain tile bodie expanded Although it is well known that earthenware tile bodies display appreciable moisture expansion which may lead to problem of glaze crazing under limit condilions, property is usually not measured in porcelain tile bodies, owing to the inexistence of crazing defects in these products and to their low porosity

Measurement Procedure

Since delayed curvature needs to be observed starting immediately aiter the pieces leave the kiln, it was nec- 
Process Engineering

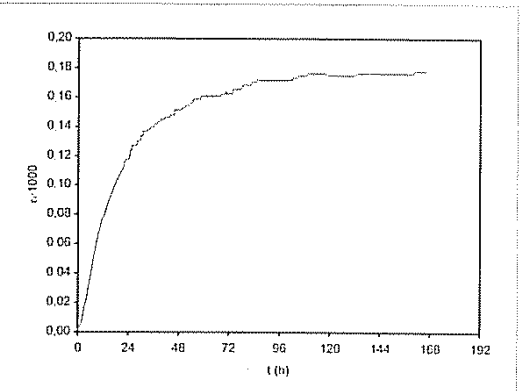

Fig. 6 Evolution of the expansion of a porcelain tile body as a

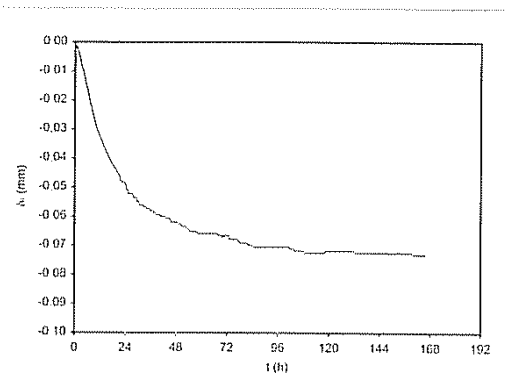

Fig 7 Delayed curvature caused by expansion of the body essary to design and fine-lune a tes procedure that would enable the determination of body expansion during this period of time The main difficulty posed in the performance of this measurement was the temperature variation during the test, which might consideribly aif which might considerably affect measurement accuracy. In order to address these difficulties a devic was built, shown in Fig 5 , which is able to offsel automatically the lemperature changes that the hot tile induces

Results

The evolution of the expansion of a porcelain tile body, starting when the tile exits the industrial kiln, is shown in Fig. 6. It may be observed that in the initial moments the expansion is very fast; then stabilises after 96 hours at a value of about $0,18 \%$. Though the result depends on the composition used and on the ped it may be considered representative for these cypes of bodies In comparison, the expansion of white-firing earthenware tile bodies usually lies at about $0,35 \%$, which only differs a factor of 2 with respect to that of porcelain tiles

The expansion of the bodies, of itself, is insulficient to explain the delayed curvatures As indicated previously, the presence of another layer that does not deform is required
This role could be played by the glaze layer in glazed products; how ever, there are also unglazed porcelain tiles that exhibit the problem or delayed curvatures. On the other hand the glaze coating on a porcein tile is usually thin (abour (im) which is why the resulting curvature is also small. Fig. 7 shows the curvature deflection that $410 \times 410 \mathrm{~mm}^{2}$ tile will display calct lated from the typical expansion of porcelain tile body, and considering the fit with the glaze It may be observed that the expansion of the explain the delayed curvatures, bough it can play a certain role in some cases.

In the foregoing, it has been assumed that the expansion of the body is uniform throughout the bicloness of the body If there was a difference between the expansion of bon at the lair face and a rear face, part of the delayed curvaure could be explained in both glazed and unglazed products Thus, for example, a difference of $0,1 \%$ in the expansion of $410 \times 410 \mathrm{~mm}^{2}$ size tile could cause delayed curvature expressed as a deflection, of about 0,3 mm Furugh the total expansion of both faces was the same, diference in the expansion kinetic could cause changes in the direction of the curvature similar to those observed in industrial tiles. Although there are indications that suggest this difference exists, there are no conclusive results yet on this point Pelaxation of Residual Stesses Relaxation of Residual Stresses One or the hypotheses used to explain delayed curvatures is the presence of residual stresses in the tiles. If these stresses are relaxed by some process, such as creep, they could lead to variations in tile curvature.

However, the existence of a residual stress profile is not synonymous with delayed curvatures. This profile also needs to be asymmetrical and there needs to be creep. In regard to profile asymmetry, it may be noted that

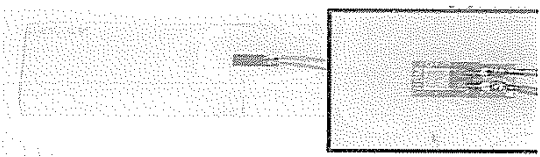

Fig. 8 Resictual stress measurement lest and detail of the gauge

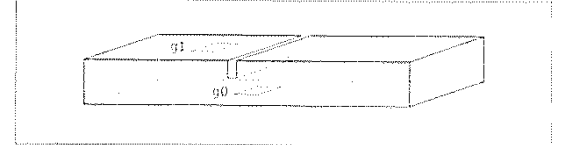

Fig 10

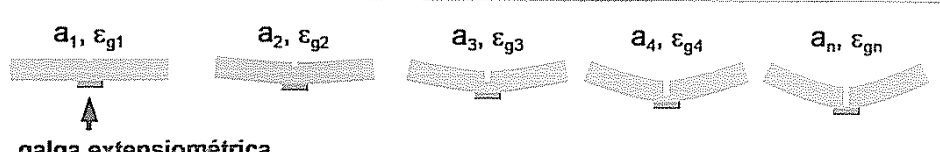

galga extensiométrica

Fig 9 Schematic illustration of the principle used to measure the residual stresses 


\section{Process Engimeering}

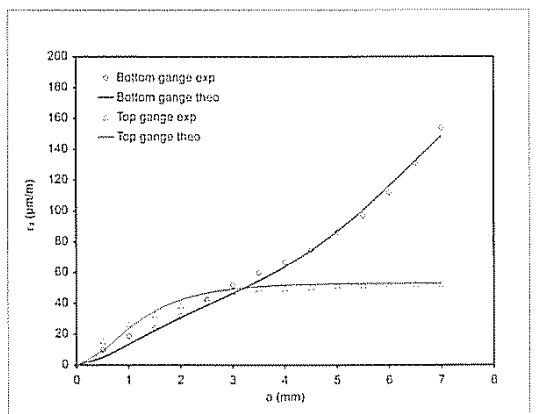

Fig 11 Experimental strain and fit for a porcelain tile

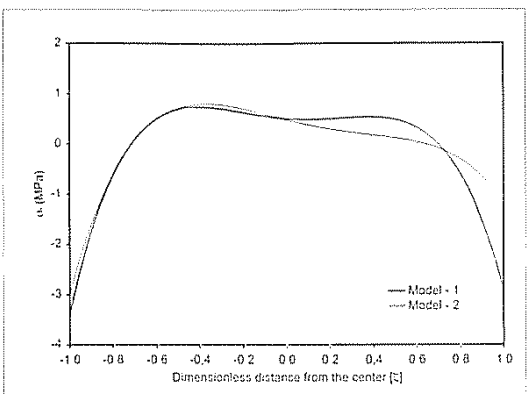

Fig. 12. Residual stress profles of Model-1 and Model-2 a symmetrical profile means that the stress is the same on the fair face as on the rear face, so that the piece will not tend to curve towards either of the two sides

The existence of residual stresses in ceramic tiles may be due to two ceramic tiles may be dised by causes. stresses caused by rapid cooling of the the in the industria kiln, associated with thermal grad-

Fig. 13
Device used to measure creep
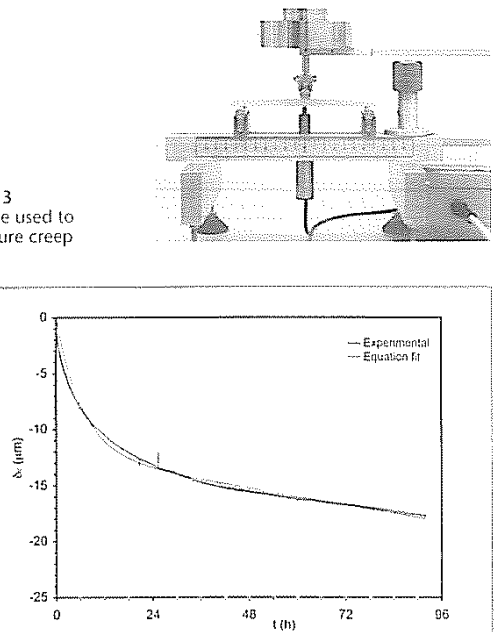

Fig. 14 Strain of a porcelain tile test piece uncler loading

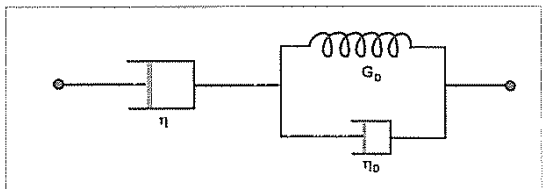

Fig. 15 Linear viscoelastic mociel used to motel creep ents in the piece, and stresses produced by the glaze/body fit The former have been measured in this study, since they are customarily of a greater magnitude than those stemming from the glaze fit That is ming from the glaze thit. That is hecause the glaze is usually much thinner than the body and because the body's modulus of elasticity is
relatively high compared with that refatively high
of the glaze. Residual Stress Measurement Measurement Procedure

The residual stresses in the body sternming from the thermal gradients were measured using the strain relaxation slouting method (SRSND) This method consists of fixing a This method consists of fixing a gauge to the bottom of the unglazed piece ( $\mathrm{Figl}$ 8), and then from the top surface, measuring the strain recorded by the gauge $\left(\epsilon_{0}\right)$ (Fig. 9)

In orcler to be able to calculate the residual stress profile it is necessary residual stress profile it is necessary to know the relation between $\epsilon_{s}\left(a_{i}\right)$ the piece. This relation is determined by certain calibration factors which need to be theoretically calculated for each geometry by a numerical method (in this case the finite ele. ment method was used) Finally, ment method was used) finally, once the calibration factors have been determined, it is poss
calculate the stress profile With a view to improving the accuracy of the method, two strain gauges are sometimes used, one on the bottom and the other on the top surface, located close to the notch area (Fig 10) area (Fig.

Results

Fig 11 shows the strain measure ment values of both gauges (rhom. buses and triangles) and the fitting curve obtained from the finite ele. mentcalculation the analysed piece was a tile fired under industrial conditions It may be observed that as hotch depth (a) increases, the strain measured by the two gauges increases. The top gauge is very sensitive at the beginning of the cut (low values of a) but as the notch depth increases, this gauge quickly loses its sensitivity and the bottom gauge becomes more relevant The data in Fig. 11 allowed the residual stress profiles of two models of glazed porcelain tite to be determined (Model I and Model 2), displayed in Fig 12 The value $\zeta=1$ corresponds to the bottom sur$\zeta=1$ corresponds to the bothom surface and $S=+1$ to the top suriace (fair face) In both cases the profile exhibits negative stresses (compression) at the surface and positive stresses (tension) in the centre This is the typical profile of a tempered material

Model 1 had stresses similar to those of Mode 2 in the bollom hall or piece, but es in the top half; generally speaking, it may be said that Model 1 was slightly more stressed than Model 2, and its profile was more symmetrical Experimentally it was verified that Model 1 did not tend to display any problems of delayed curvatures; problems of delayed curvatures; whers model 2 did curvas resti appears to agree with what has been indicated previously regarding the relation between stress profile symmetry and the delayed curvatures. In any event, in order to establish definitive conclusions it would be neces. sary to proceed futher with the measurements, analysing a greater number of tiles and models.

Creep Measurement

Residuat stresses, by themselves, do not cause delayed curvatures, ever when they are highly asymmetric II is necessary for there to be a mechanism that causes the tile to release

cii/Ber DKG 85 (2008) No 6 


\section{Process Engineering}

\section{Indirect Factor}

The characteristics of the material used in the manufacture of porcelain tiles (spray-dried powders, glazes etc ), logether with the process variables used, define cerarnic tile characteristics, as illustrated in the acteristics, as illustrated in the Although thes factors are not clirectly responsible for the clelayed curvatures, they can in some cases have an enormous influence on them This section analyses these factors first, and ther presents some examples of the influence they have on both delayed curvature and the faclors that originat delayed curvature

Factors that Affect Expansion of the Body

The expansion of ceramic bodies caused by humidity is a well-known characteristic, and methods are provided in the applicable standards to measure this The values of expan sion by humidity in an a with by humidity in an autoclave with water vapour pressure cycles or 5 at 10 bar, usually range from 0,6 to $1,0 \%$ for earthernware tile bodies, and drop to values below $0,3 \%$ for tiles with low wate absorption

The moisture expansion of porous ceramic products (earthenware and porcelain) has been widely studied owing to its relation to glaze crazing owing to its relation to glaze crazing defects In these products, moisture expansion of the ceramic bodies stems from the physical and chemical acisorption of water molecules on the free valencies existing in the hydratable phases (glassy phases and, in parlicular, arorphous phasan from clay minerar chous phases irome clay mineral dohydroxyla tion) present in the fired pieces [3] For this reason, expansion mainly depends on the porous structure of the piece (which defines its greater or lesser accessibility by water) [1] and on the nature and content of the phases present in the fired piece [2] These characteristics are highly influenced by the mineralogical composition of the composition used, its particle size and the firing schedule [4] Thus, as the fusibility of the body [A] Thus, as the fusiblity or the body composition and the ling temperan ture or residence time increase, the moisture expansion of these bodies decreases owing to their reduced porosity and hydratable phase content [5]

However, no studies have been found on mosture expansion in bodies with very rosity, such as porcelain tiles, probably because of the smaller expansion and absence of crazing in these products Although the objective of this study was not to determine the reason for the expansion of porcelain tile bodies after they left the kiln moisture adsorption or other rea(mons), the factors that in reainat iniluence moisture expansion in porous bodies are also likely to do so in the case of porcelain tile bodies.

actors that Affect Residual Stresses

When peak firing temperature is reached, the porcelain life is made up of a great quantity of lique up or a great quanity of liquici phase, quartz and residual albite, and sometimes mullite [6] In this state, the piece is able to relax any stress that is applied on it, since it is highty deformable $t h$ is during the cooling phase that residual stresses develop in the tiles, either because of a mismatch in the fit between the bocly and gaze layers, or bect the bilferend glaze layers, or because of the geresult of the greater cooling rate in the outer areas compared with the centre of the piece Thus, the factors that determine residual stresses in porcelain tiles are basically thermal expansion and modulus of elasticity of the

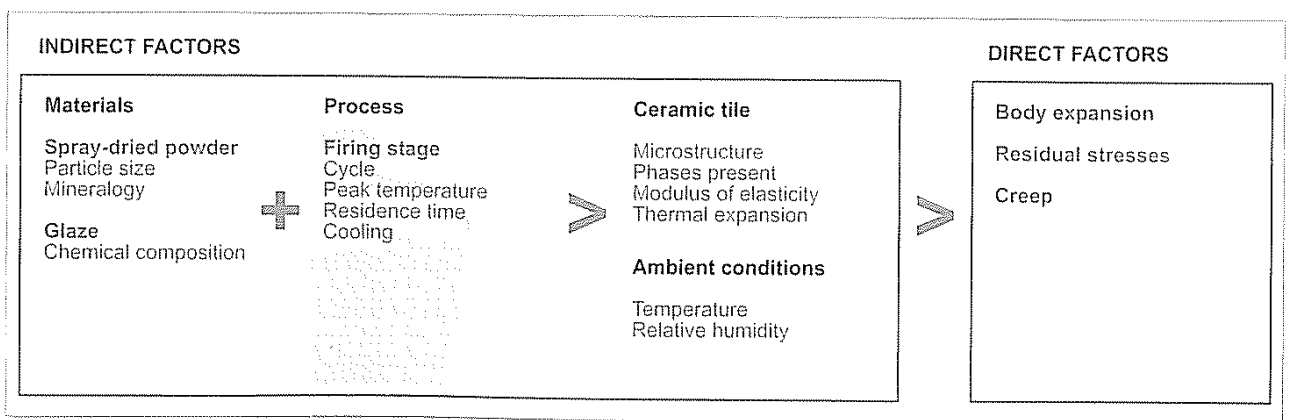

Fig 16 Factors that influence delayed curvatures 


\section{Process Engineering}
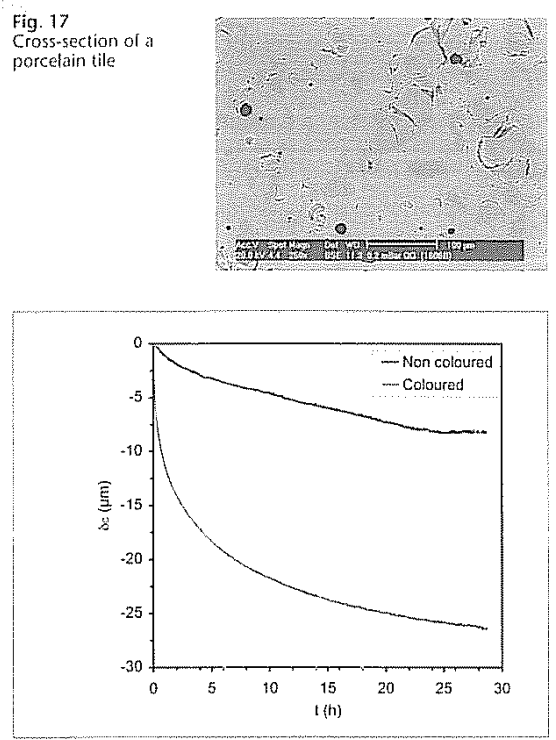

Fig 18 colouring on creap

body and the glaze, their relative thicknesses, and the tife cooling rate It has been observed that a greater mismatch of the thermal expansion of both layers, as well as a greater glaze thickness, raises residual stresses furthermore, when cooling is faster, the temperature gradien increases inside the tile [7], leading to different shrinkage rates through out the tile cross-section This pro duces a stress profile inside the piece duces a stress profle inside the piece that becomes more pronounced as the cooling rate increases [8]. In actition, when the cooling rate is not the same at both tile faces (the usual situation in roller kilas), the resulting stress profile is not symmetrical, as set out further below.
Factors that influence creep The factors that influence creep in porcelain tiles must be associated with the tile microstructure Fig 17 presents a cross-section of a porce lain tile observed by scanning electron microscopy (SEM) it consists of a glassy matrix contrining nur a glassy matix containing numerous pores and microcracks these pores decomposition of certain impurities as well as from large pores present in the green piece [9]. The origin of the microcracks varies, though they occur in particular as a result of the mismatches between the residual quartz particles and the glassy matrix [8], and the junctures of matrix [8], and the junctures sprayadried powder granules that
were not fuly deformed during pressing [10]

Creep in porcelain tile pieces is highly likely to be caused by growth of the existing microcracks in the tile when the tile is subjected to a tensile when the the is subjected to a tensile stress, so that the actors originating creep in these types of tiles it has creep in these types of tiles It has been verified that an increase in quartz content as well as in particle size produces a microstructure with a larger quantity of microcracks, which will probably increase tile creep. This can occur eg when the creep. This can occur eg when the milted

Influence of Dry Colouring on Creep

Creep tests were conducted on lest pieces cut from two types of industrial fired glazed porcelain tiles thes were fabricated using either The test pieces measured $220 \times 20$ $\mathrm{mm}^{2}$ and were machined to elimnate the rear rib. The average thick ness of these test pieces was $64 \mathrm{~mm}$ and the applied load was $29 \mathrm{MPa}$
Fig 18 shows that both cest pleces undergo strain (creep) with time, which is very rapid at the beginning of the test and progressively stabilis es with time It may be observed that the piece with pigment displays considerably larger strain than the non-pigmented piece indicating under given stress is much greater for the pigmented pieces

Although this study has not examined the origin of this difference, the reason that the coloured piece exhibits greater creep can be related to the microstructure of this type of tile, in which the particles are concentrated in centain areas of the plece (he contact areas between the spray-dried powder granules) [11] These regions can act as microcrack-initiating flaws when larger percentages of pigment are used, whose growth under the application of a particutar stress could originate the greater creep observed

The greater creep observed These resalts do not allow it to be direclly concluded that the drycoloured pieces will display greater problems in regard to delayed curvatures, since that depends on the other faclors involved Indeed, there are coloured models that exhibit no delayed curvatures However, with delayed curvathes However, with the existence of asymmetic residual stresses in the liles, and the other factors being equal, the tiles that present the grealest creep are more likely to change their curvature with time

Influence of the Presence of Glaze on Delayed Curvature 19 presents the evolution ge prents the evolution of the por glazed porcelain tiles, size $300 \times 600 \mathrm{~mm}$, with the dry-coloured body, with and without the presence of glaze. It shows that while the tile with the glaze displays a qualitalively similar

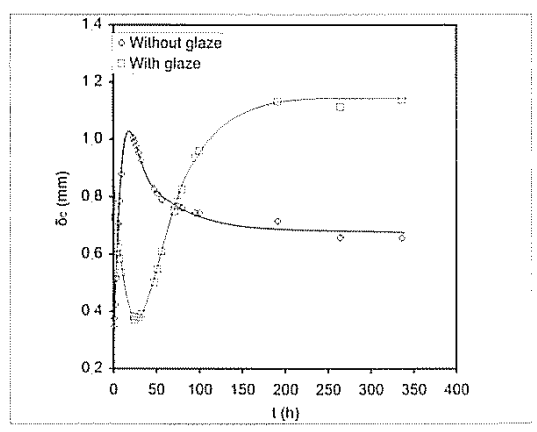

Fig 19 Evolution of tile deflection with and withoul glaze

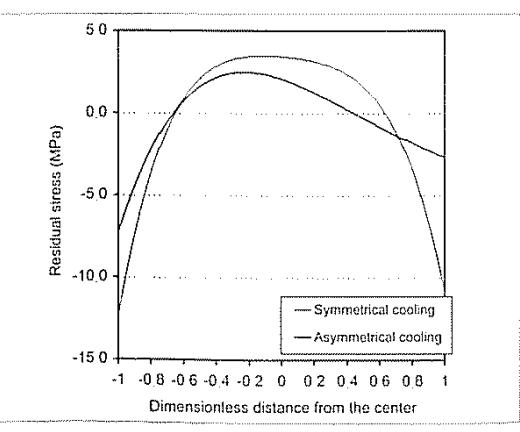

Fig. 20 Residual stress profile as a function of type of cooling 
curvature evolution to that shown in section 2 , the body without the glaze evolves in the opposite direction it should be noted that the time at which the minimum curvature in the glazed piece is observed $(24 \mathrm{~h}, 0,37$ $\mathrm{mm}^{2}$ ) practically concides with time at which the maximum curvature is detected in the tile without the glaze $\left(23 \mathrm{~h}, 1,02 \mathrm{~mm}^{2}\right)$

This behaviour may be due to the existence of different rates of expansion between the fair face and the rear surface, since the tiles have been fired with the same cycle and, therefore, the residual stresses caused by cooling should be similar

This same behaviour was atso observed in pieces of unglazed porcelain tiles, which seems 10 indicate the enormous influence of the glaze on the evolution of curvature with time

Influence of the Cooling Stage

The cooling stage in industrial roller kilns typically has a first rapid-cooling section by injection of air at ambient temperature into the kiln This type of cooling produces high temperature gradients between the surface and the inner part of the tile, which leads to residual stresses that can originate delayed curvatures

This part of the study examined the influence of cooling on residual stresses in the body. It was conducted using test pieces of $150 \times 30 \mathrm{~mm}^{2}$ cut from green industrial glazed porcelain tiles, which were fired in an electric laboratory kiln at $1200^{\circ} \mathrm{C}$ fot $6 \mathrm{~min}$ and cooled outside the kiln (air quenching) in two different ways:

- Symmetrical cooling: with the piece in a vertical posi tion. Both sides of the piece were identicatly cooled - Asymmetrical cooling: with the piece placed horizontally on a refractory slab In this case, cooling basically took place through the top

The stress profiles of the two test pieces cooled in difterent ways are shown in Fig. 20 It may be observed that in both cases the iwo surfaces of the pieces are subjected to a compressive stress, whereas the inside of the piece is under tension, which is the usual situation in ceramic materials Cooling is also observed to have considerable influence on the stress profile Thus, when the test piece is identically cooled at both faces (piec cooled in a vertical position), the stress profile is sym-

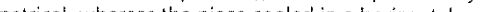
ion on refractory slab (asymmentic cooling) displays non-symmetrical profite. These results confirm that the differences in the cooling rate through the top and bottom of the piece can lead to asymmetrical stress profiles

\section{Conclusions}

This study has examined the factors that may influence delayed curvatures in porcelain tiles and allows the following conclusions to be drawn:

- The variation of curvature with time in industria porcelain tiles has been quantified, it being observed that there is a change in curvature trend (concave convex) This means that there are two simultaneous, opposing mechanisms, with different kinetics, which influence the process

- The theoretical analyses indicate that there are just wo factors that can cause the detayed curvatures: residual expansion of the bodies, and stresses. In both residual expansion of the bodies, and stresses. In both
cases, it is necessary for additional circumstances to be cases, it is necessary for additional circumstances to be present for delayed curvatures to appear; thus, expansion needs to be different at the fair face and at the rear face. Uniform expansion would cause a sligh dimensional change, but not significant delayed cur-

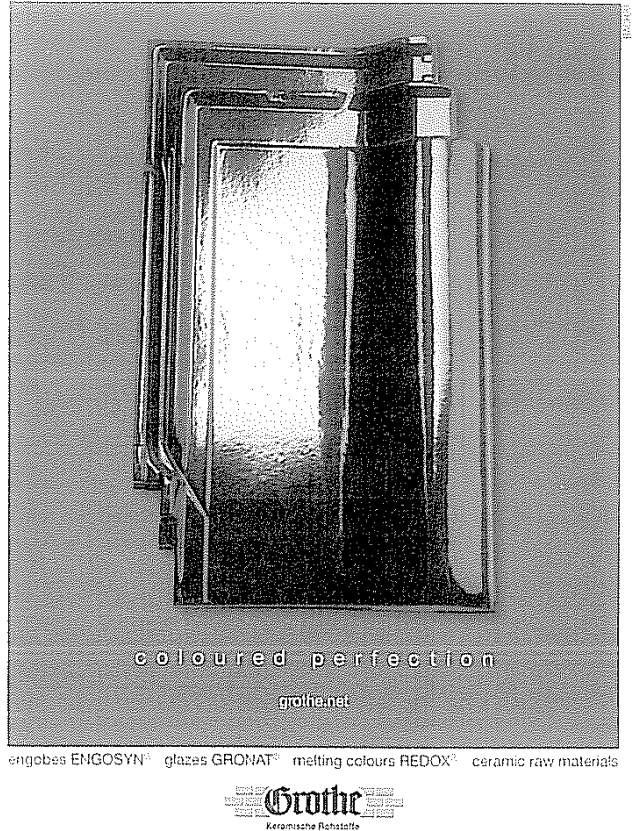

Grothe fohstoite GnbH \& Co KG Kreuzbreite 16 D-31675 Buckaburo T. $49-5722-9313.0 \quad F+49-5722-8533.60$

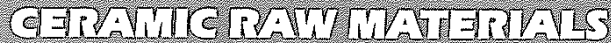

VOUEMTNIT

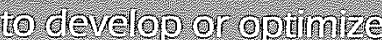

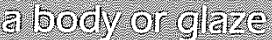

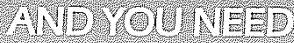

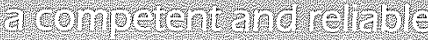

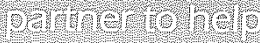

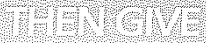

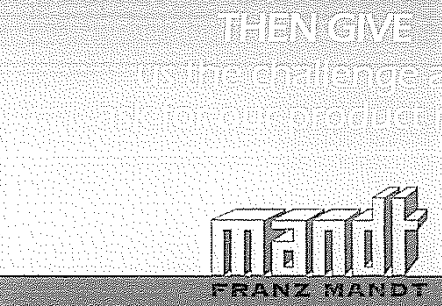

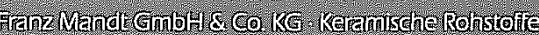

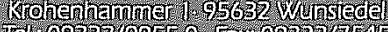

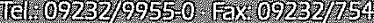

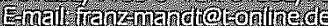

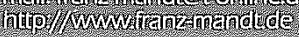




\section{Process Enginneering}

vature, not even in the presence of glaze in regard to the resiciual stresses, the stress profile needs to be asymmetrical and there needs to a mechanism that allows their release (creep).

- The measurement of the factors that influence delayed curvatures is complex because it usually requires use of other techniques than those typically employed in characterising ceramic tiles Procedures have been fine-tuned in the stucly to measure the different factors that produce delayed curvatures A device has been designed that automatically offsets temperaure for measuring the expa ture ror measury the expansion one bodies when the kiln; the strain relaxation slotting method (SRSM) has been applied to measure the residual stresses in porcelain tiles, and 3-point bend. ing tests with constant loading for

several days have been used to verify the presence of creep in porcelain tile bodies

- It has been verified that porcelain tile bodies undergo expansion when they exit the kiln These bodies also display residual stresses and creep, which could explain the existence of delayed curvatures nts have been conducted modifying the type of spray-dried powder, eliminating the glaze, and modifying the cooling. These experiments have provided initia information on the influence of the characteristics of the material and of the manufacturing process on creep, residuat stresses, and asses, and

- Though much remains to be done in the field of delayed curvatures the results obtained lay the groundwork for a systematic study of delayed curvatures

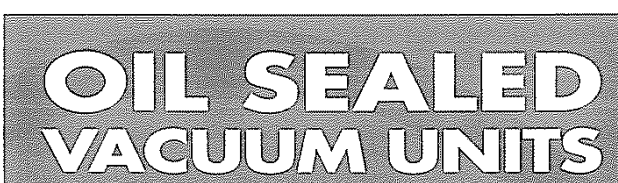

FOR THE BRICK AND THLE INDUSTRY

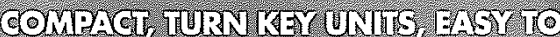
INSNI IDEAL FOR TGE VACUVM

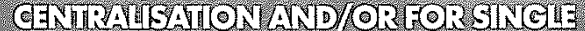

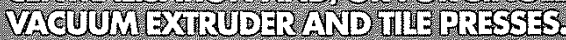

o hilith ohtol consient vecuutu degree o No need of coding wates o Redvored maintenothae

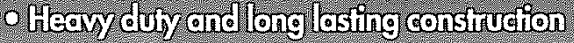

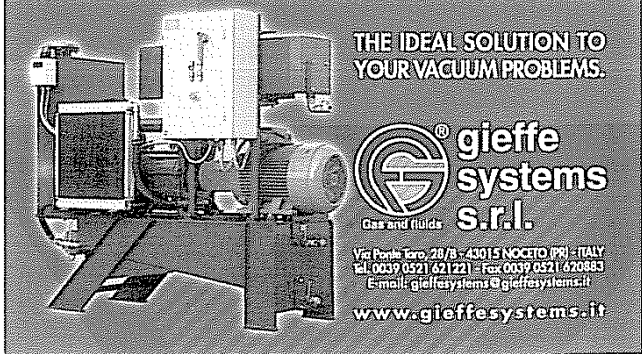

\section{Literature}

(1) Vasic, R.M : Influence of pore size dis tribution of trost resistance and mois. Eure expansion of trich $7(1992), 15.18$

12 Segades, A M. Carnalho, MA: Fer reira, H.C: Using phase diagrams to deal with moisture expansion Ceran int., 29 (2003) [8]. 947-954

(3) Smith AN: Investigations on the moisture expansion of porous ceramic bodies Trans. Br Ceran Soc, 5 (1055) [5] 300.318

14 Schutrecht, HG; Pole, $\mathrm{CR}$ : Elfect water in expanding ceramic bodies of Am Coram $56-604$

15) Harrison, R: Dinsdale $A$ : The effect of temperature and pressure on moistur Expansion Trans (1964). 63.75

(b) Sanchez, E; Orts, M.l; Garciaten, 1 Cantavela vor Porcelain ne compos-

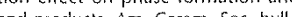
$80(2001)[6] 43-49$

[7] Cantavella V-Moreno A; Mezquita

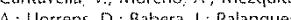
A. Temperature distibution ing cerami tile ruring fring in Qualicer 2006: Ix Would Congress on Cealce Tite Quality Caslellon Cimma oficial de comercio, industria y navegación 2006 pp PBC151-PBC164

(8) Noni funior A DE; Holza. D: CanLiwella, $Y$; Sinchez E Influencia de enfriamiento de la etapa de tocción sobre las propiedades mecanicas del gres porcelatico. Bor Soc Esp. Cer am Vidr, $46(2007) \mid 4] 163-170$

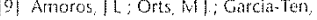
Gozalto, A; Sanchez. E: Elfect of graen porous texture on porcelain til propertes. I. Eur. Ceram so $27(2007) 2295-2301$

flol Garcia-Ten, I; Sanchez, E: Mallo o larçueE, |C: Arroyo. A Imfluence o operating variables on spray-dried granule and resulting tile characteris tics Key Eng War (2004) 264.268

111 Garcia-Ten L: Sanchez, E: Quereda P. Saburit A; Sanchez, I; Sales. 1 Soler, $C$ : Influencia del coloreado en seco en el comportamiento mecánico de piezas crudas de gres porcetánico En: CARDA CASTELLÓ I.B Ciencia y tecnologia de los materiales cerámi. libro resumenes de los trabios Lidof de resimenes de los trabajos presentadas a la XIV retinion anua Vidrio Casteltón Faenza Editric bérica $2006 \mathrm{pp}+2$ 